Florida International University FIU Digital Commons

\title{
What Makes Online Grocers Work? A Case Study Analysis of Factors Contributing to Online Grocery Store Profitability
}

William D. Lucky, Jr.

Florida International University

DOI: $10.25148 /$ etd.FI10022529

Follow this and additional works at: https://digitalcommons.fiu.edu/etd

Part of the E-Commerce Commons

\section{Recommended Citation}

Lucky, Jr., William D., "What Makes Online Grocers Work? A Case Study Analysis of Factors Contributing to Online Grocery Store Profitability" (2008). FIU Electronic Theses and Dissertations. 194.

https://digitalcommons.fiu.edu/etd/194 


\section{FLORIDA INTERNATIONAL UNIVERSITY}

Miami, Florida

\section{WHAT MAKES ONLINE GROCERS WORK？A CASE STUDY ANALYSIS OF FACTORS CONTRIBUTING TO ONLINE GROCERY STORE PROFITABILITY}

A dissertation submitted in partial fulfillment of the

requirements for the degree of DOCTOR OF PHILOSOPHY

in

BUSINESS ADMINISTRATION

by

William David Lucky, Jr.

2008 
To: Dean Joyce Elam

College of Business Administration

This dissertation, written by William David Lucky, Jr., and entitled What Makes Online Grocers Work? A Case Study Analysis of Factors Contributing to Online Grocery Store Profitability, having been approved in respect to style and intellectual content, is referred to you for judgment.

We have read this dissertation and recommend that it be approved.

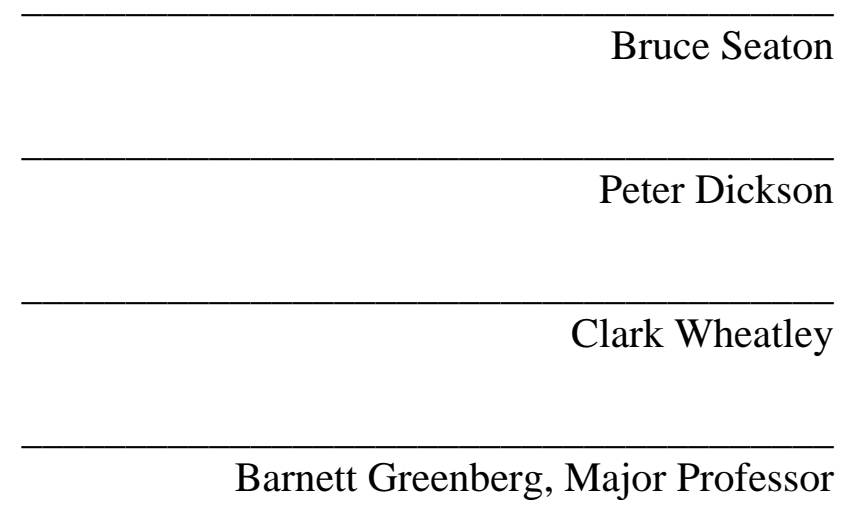

Date of Defense: January 25, 2008

The dissertation of William David Lucky, Jr. is approved.

Dean Joyce Elam

College of Business Administration

Dean George Walker

University Graduate School

Florida International University, 2008 
(C) Copyright 2008 by William David Lucky, Jr.

All rights reserved. 


\section{DEDICATION}

I dedicate this dissertation to my parents Dr. William D. Lucky, Sr. and Dr. Luretha F. Lucky who stood as pillars of excellence for me both academically and morally. I also dedicate this dissertation to my sister, Ameera L. Lucky and her children Jaylon and Nyeemah, for providing encouragement to see this project to the end. I would also like to dedicate this work to Barbara A. Lucky, the mother of my children, for her patience and support while I completed the degree. Lastly, I would like to dedicate this dissertation to my children William. D. Lucky, III and Janiah M. Lucky for providing the reasons to keep me going in life. Thanks to all. 


\section{ACKNOWLEDGMENTS}

I would like to express my deep gratitude to the members of my committee for helping me complete this endeavor. Your tireless support helped shape me into a better scholar. I would like to thank Dr. Peter Dickson for his guidance in helping to focus my research, providing a swift kick when necessary, and to exposing me to other lines of inquiry in the marketing discipline. Dr. Bruce Seaton was also very influential in shaping my project and his open-mindedness and endless optimism helped to sooth his frank, pointed, but necessary critiques. To Dr. Clark Wheatley, I would like to say thank you for providing guidance and insight as my project took shape. Finally, I would like to thank my major professor Dr. Barnett Greenberg for his endless patience and guidance while the research evolved. I know I have tested your patience like no other but you have always stayed positive and upbeat. You helped me learn how to stay focused and how to look at complex topics. The fact that you never lost confidence in me means more to me than you will ever know - thank you.

I would also like to thank the rest of the business faculty and especially the marketing faculty that have helped to shape my education. To Mrs. Hilda Aguiar and the rest of the Marketing Department staff, I would like to express my gratitude for helping me transverse the minefield of paperwork at each stage. 


\section{ABSTRACT OF THE DISSERTATION \\ WHAT MAKES ONLINE GROCERS WORK? A CASE STUDY ANALYSIS OF \\ FACTORS CONTRIBUTING TO ONLINE GROCERY STORE PROFITABILITY \\ by \\ William David Lucky, Jr.}

Florida International University, 2008

Miami, Florida

\section{Professor Barnett Greenberg, Major Professor}

This research examined the factors contributing to the performance of online grocers prior to, and following, the 2000 dot.com collapse. The primary goals were to assess the relationship between a company's business model(s) and its performance in the online grocery channel and to determine if there were other company and/or market related factors that could account for company performance.

To assess the primary goals, a case based theory building process was utilized. A three-way cross-case analysis comprising Peapod, GroceryWorks, and Tesco examined the common profit components, the structural category (e.g., pure-play, partnership, and hybrid) profit components, and the idiosyncratic profit components related to each specific company.

Based on the analysis, it was determined that online grocery store business models could be represented at three distinct, but hierarchically, related levels. The first level was termed the core model and represented the basic profit structure that all online grocers needed in order to conduct operations. The next model level was termed the structural model and represented the profit structure associated with the specific business 
model configuration (i.e., pure-play, partnership, hybrid). The last model level was termed the augmented model and represented the company's business model when idiosyncratic profit components were included. In relation to the five company related factors, scalability, rate of expansion, and the automation level were potential candidates for helping to explain online grocer performance. In addition, all the market structure related factors were deemed possible candidates for helping to explain online grocer performance.

The study concluded by positing an alternative hypothesis concerning the performance of online grocers. Prior to this study, the prevailing wisdom was that the business models were the primary cause of online grocer performance. However, based on the core model analysis, it was hypothesized that the customer relationship activities (i.e., advertising, promotions, and loyalty program tie-ins) were the real drivers of online grocer performance. 


\section{TABLE OF CONTENTS}

CHAPTER

PAGE

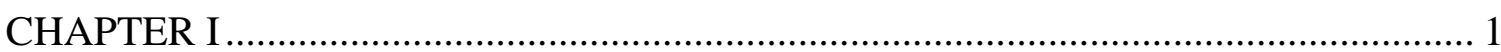

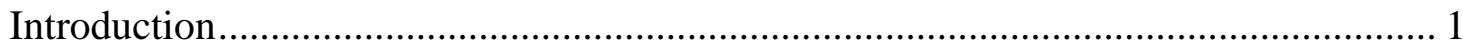

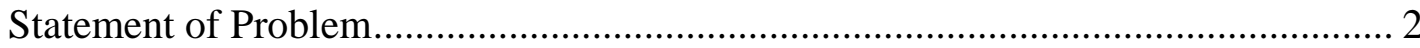

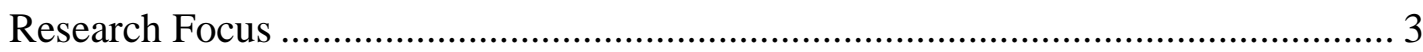

Purpose of Study ........................................................................................... 5

Research Questions....................................................................................... 5

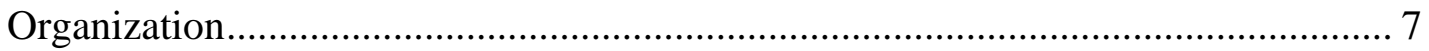

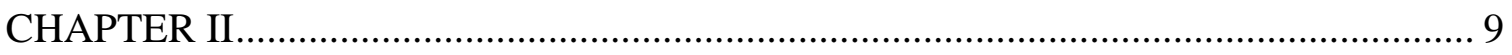

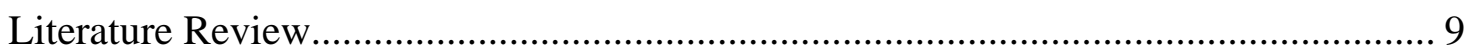

Small Town General Stores, Rural Area Country Stores, and Public Markets .......... 9

The Emergence of the Grocery Store....................................................................... 12

From Independent Grocery Stores to Grocery Chain Stores ...................................... 13

The Evolution of the Supermarket............................................................................ 17

From the Supermarkets to the Supercenters .............................................................. 19

From Brick-and-Mortar to Click-and-Mortar ............................................................ 21

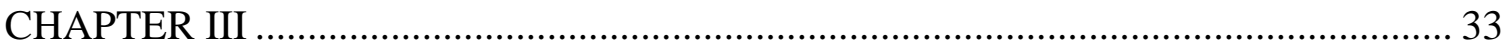

Building Theory from Case Analysis ........................................................................... 33

The Research Question and Construct Definition ..................................................... 35

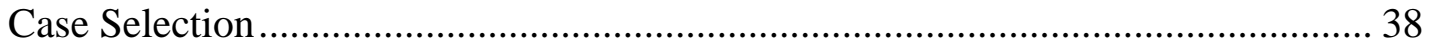

Developing Research Instruments and Protocols ..................................................... 43

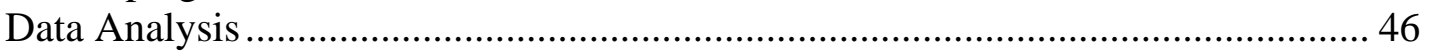

Within-Case Data Analysis.............................................................................. 46

Cross-Case Data Analysis............................................................................... 47

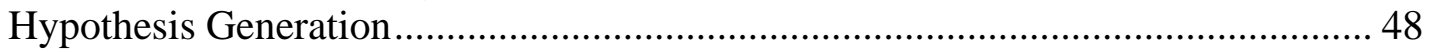

Enfolding Literature .......................................................................................... 50

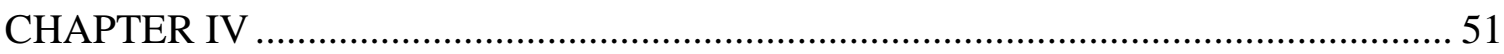

Delineating Online Grocery Store Business Models .................................................... 51

Amount of Physical Assets .................................................................................. 51

Method of Order Fulfillment ……………............................................................. 53

Method of delivery ............................................................................................ 56

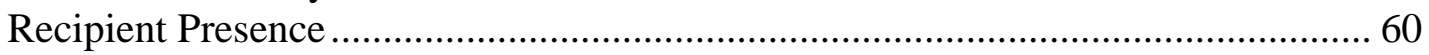

Receptacle Method........................................................................................... 62

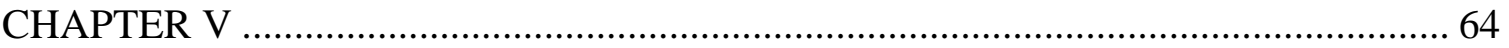

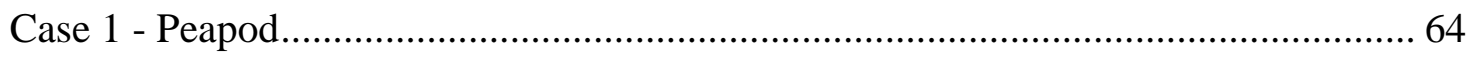

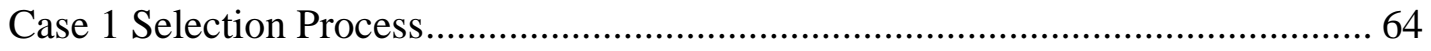

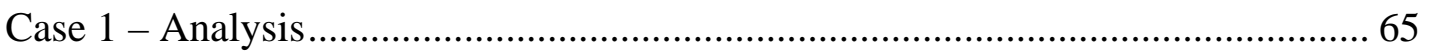

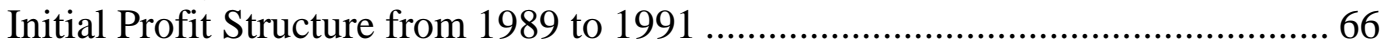


Profit Structure Analysis for Peapod: Profit Structure from 1989 to 1991.......... 68

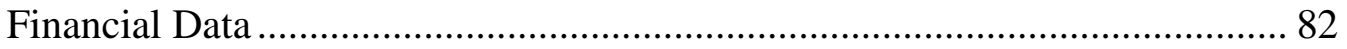

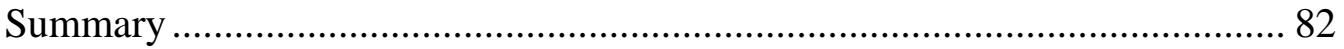

Peapod Profit Structure from 1992 - 1996 .......................................................... 84

Financial Data ....................................................................................... 100

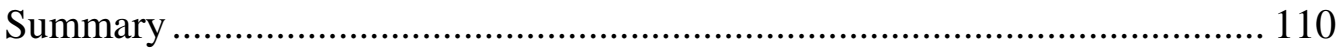

Peapod's Profit Structure from 1997 - 1999 ..................................................... 114

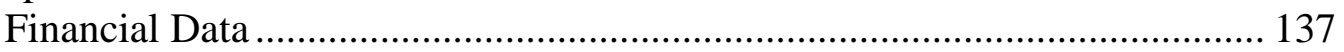

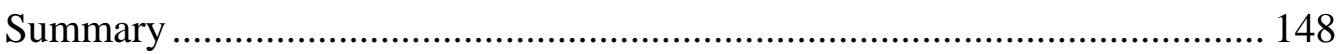

Peapod's Profit Structure from 2000 - 2006 ....................................................... 150

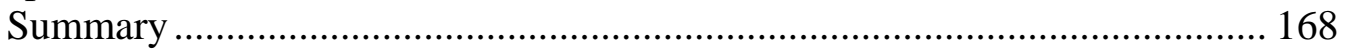

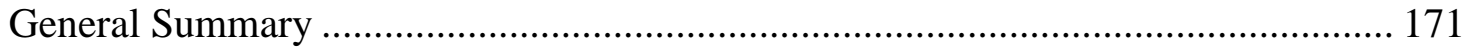

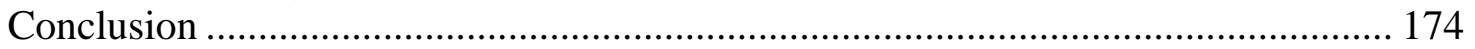

Verification of Peapod Results ................................................................................ 186

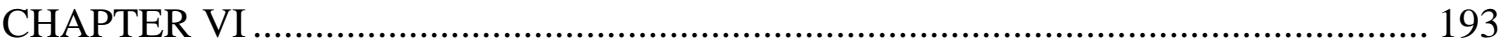

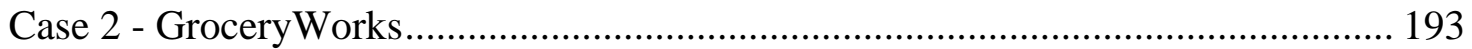

Case 2 Selection Process...................................................................................... 193

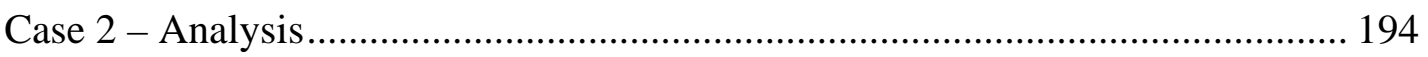

Initial Profit Structure from January 1999 - March 2000.................................. 194

Profit Structure Analysis for GroceryWorks: January 1999 to March 2000 .... 195

Financial data .......................................................................................... 214

Profit Structure Summary from January 1999 - March 2000.......................... 214

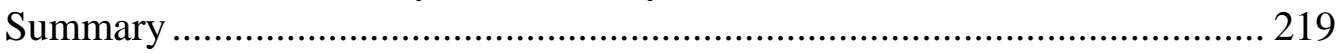

GroceryWorks Profit Structure for April 2000 - March 2001 ............................ 221

Profit Structure Analysis for GroceryWorks: April 2000 - March 2001 ............ 229

Profit Structure Summary from April 2000 - March 2001.............................. 240

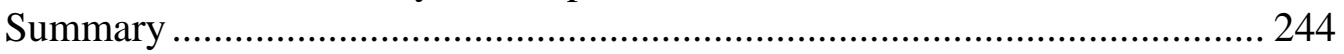

Profit Structure from April 2001 - December 2006 .......................................... 247

Profit Structure Analysis for GroceryWorks: April 2001 to December 2006. .. 250

Profit Structure Summary from April 2001 - December 2006........................ 268

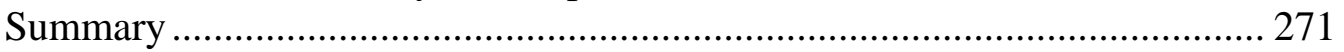

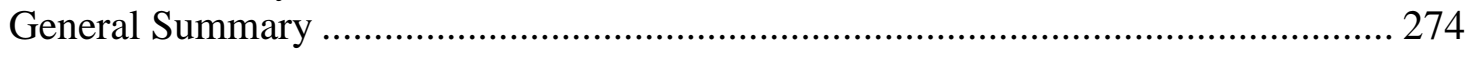

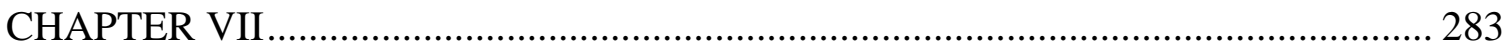

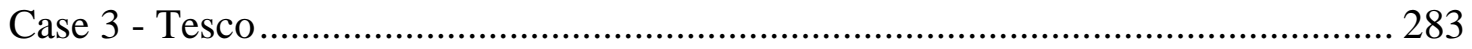

Case 3 Selection Process................................................................................... 283

Case 3 - Analysis......................................................................................... 284

Initial Profit Structure Components: January 1995 to December 1996 .............. 284

Initial Profit Structure Analysis for Tesco: January 1995 to December 1996... 285

Profit Structure Summary from January 1995 - December 1996.................... 298

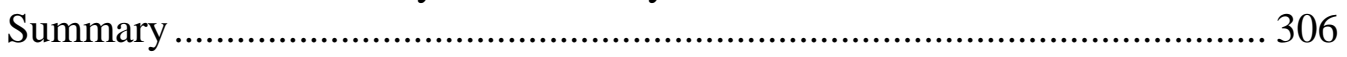

Tesco's Profit Structure from January 1997 to December 1998.......................... 307

Profit Structure Analysis from January 1997 to December 1998........................ 311

Profit Structure Summary from January 1997 - December 1998..................... 326 


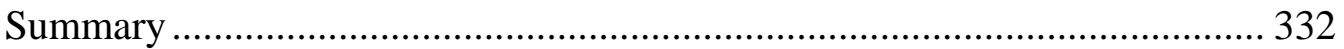

Tesco’s Profit Structure from January 1999 to December 2004.......................... 334

Tesco's Profit Structure Analysis from January 1999 to December 2004........... 340

Profit Structure Summary from January 1999 - December 2004..................... 389

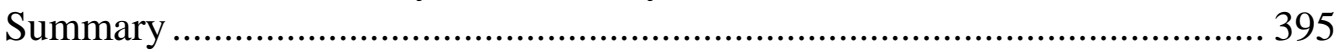

Profit Structure Components: January 2005 to December 2006 ........................ 400

Tesco's Profit Structure Analysis from January 2005 to December 2006.......... 406

Profit Structure Summary from January 2005 to December 2006 .................. 416

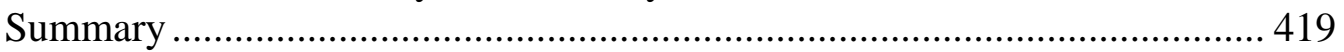

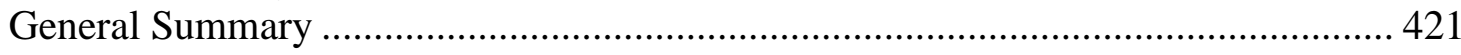

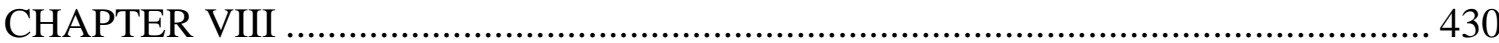

Between Case Analysis.......................................................................................... 430

Business Model Synopses................................................................................... 432

Case 1: Peapod............................................................................................ 432

Peapod's Model Dynamics ........................................................................ 436

Comments Concerning the Model .................................................................. 444

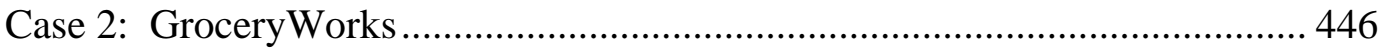

GroceryWorks Model Dynamics ................................................................. 448

Comments Concerning the Model ................................................................ 454

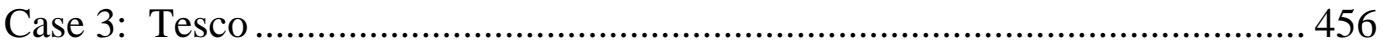

Tesco's Model Dynamics ....................................................................... 458

Comments Concerning the Model .................................................................. 463

Between Case Analysis Comparisons................................................................... 465

Rules for Making Model Comparisons............................................................. 466

Profit Structure Analysis Between Peapod, GroceryWorks, and Tesco ................... 470

Profit Structure Alignment............................................................................ 470

Discussion of Online Model Levels..................................................................... 471

Core Model Analysis …………………................................................................. 487

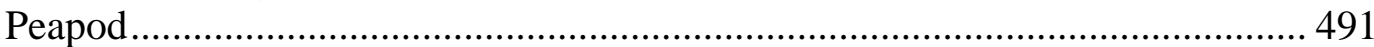

GroceryWorks ..................................................................................... 494

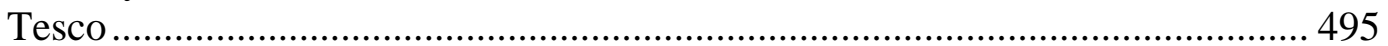

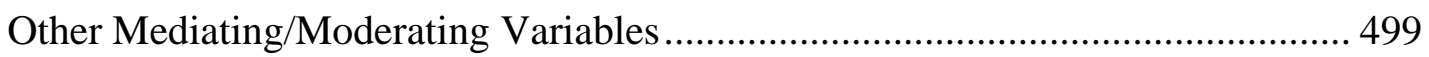

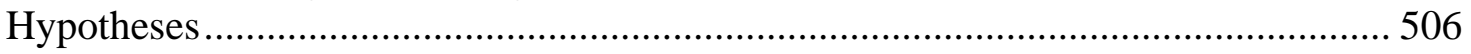

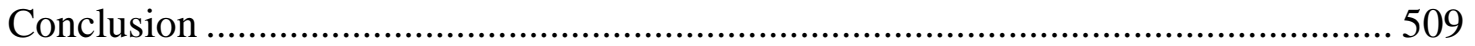

Limitations and Future Research .......................................................................... 513

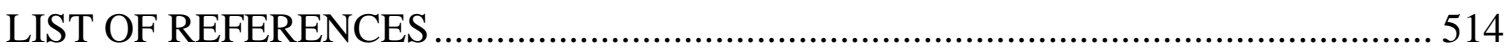

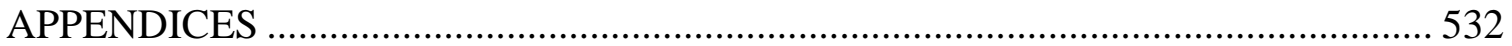

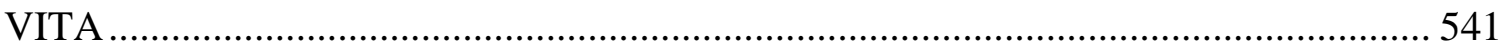




\section{LIST OF TABLES}

TABLE

PAGE

1. Factors of Online Grocery Store Business Models 52

2. Peapod's Profit Structure Components: 1989 - 1991

3. Other Mediating/Moderating Factors for Peapod: 1989 - 1991

4. Peapod's Profit Structure Components: $1992-1996$

5. Other Mediating/Moderating Factors for Peapod: 1992 - 1996

6. Peapod's Profit Structure Components: $1997-1999 \quad 121$

7. Other Mediating/Moderating Factors for Peapod: 1997 - 1999

8. Peapod's Profit Structure Components: $2000-2006$

9. Other Mediating/Moderating Factors: $2000-2006$

10. Peapod's Actual Profit Structure: 1989 - 2006

11. GroceryWorks Profit Structure Components: January 1999 March 2000

12. Other Mediating/Moderating Factors for GroceryWorks:

January 1999 - March 2000

13. Other Mediating/Moderating Factors for GroceryWorks:

April 2000 - March 2001

14. GroceryWorks Profit Structure Components: April 2000 March 2001

15. GroceryWorks Profit Structure Components: April 2001 December 2006

16. Other Mediating/Moderating Factors for GroceryWorks: April 2001 December 2006

17. Tesco’s Profit Structure Components: January 1995 - December 1996 
18. Other Mediating/Moderating Factors for Tesco: January 1995 December 1996

19. Tesco’s Profit Structure Components: January 1997 - December 1998

20. Other Mediating/Moderating Factors for Tesco: January 1997 December 1998

21. Tesco’s Profit Structure Components: January 1999 - December 2004

22. Other Mediating/Moderating Factors for Tesco: January 1999 December 2004

23. Tesco’s Profit Structure Components: January 2005 - December 2006

24. Other Mediating/Moderating Factors for Tesco: January 2005 December 2006

25. Peapod’s Profit Structure Components

26. GroceryWorks Profit Structure Components

27. Tesco’s Profit Structure Components

28. Common and Idiosyncratic Revenue Components for Peapod, GroceryWorks, and Tesco

29. Common and Idiosyncratic Front-End Costs Components for Peapod, GroceryWorks, and Tesco

30. Common and Idiosyncratic Back-End Cost Components for Peapod, GroceryWorks, and Tesco

31. Other Mediating/Moderating Factors for Peapod, GroceryWorks, and Tesco 


\section{LIST OF FIGURES}

FIGURE

PAGE

1. General Categories of Online Grocery Store Models

2. Peapod's Back-End Cost Components and Performance Drivers: $1989-1991$

3. Peapod's Performance Drivers and Performance Drivers: 1989 - 1991

4. Peapod's Revenue Components and Performance Drivers: 1989 - 1991

5. Peapod's Front-End Cost Components and Performance Drivers: 1989 - 1991

6. Peapod's Revenue Components and Performance Drivers: 1992 - 1996

7. Peapod's Back-End Cost Components and Performance Drivers: 1992 - 1996

8. Peapod's Front-End Cost Components and Performance Driver: $1992-1996$

9. Peapod’s Performance Drivers and Performance Drivers: 1992 - 1996

10. Peapod's System Development and Maintenance Costs: 1992 - 1996

11. Peapod’s Marketing and Selling Expenses: 1992 - 1996

12. Peapod's General and Administrative Costs: 1992 - 1996

13. Peapod's Grocery Costs: $1992-1996$

14. Peapod's Grocery Operations Costs: 1992 - 1996

15. Peapod's Combined Cost Components: 1992 - 1996

16. Peapod's Member and Retailer Services: 1992 - 1996

17. Peapod's Interactive Marketing Services: 1992 - 1996

18. Peapod’s Grocery Sales: $1992-1996$ 
19. Peapod's Cash Provided From Financing Operations: $1992-1996$

20. Peapod's Revenue Components (Grocery Sales, Interactive Marketing Services, and Member Retailer Services): 1992- 1996

21. Peapod's Revenue Components and Cash Provided from Financing Operations: 1992- 1996

22. Comparison Between Peapod's Total Revenue and Total Cost: $1992-1996$

23. Comparison Between Peapod's Total Revenue and Total Cost with Cash from Financing Operations Combined: 1992 - 1996

24. Peapod's Back-End Cost Components and Performance Drivers: $1997-1999$

25. Peapod's Performance Drivers and Performance Drivers: 1997 - 1999

27. Peapod's System Development and Maintenance Costs: 1997 - 1999

28. Peapod's Marketing and Selling Expenses: 1997 - 1999

31. Peapod's Grocery Operations: $1997-1999$

32. Peapod's Combined Cost Components: 1997 - 1999

33. Peapod's Member and Retailer Services: 1997 - 1999

34. Peapod's Interactive Marketing Services: 1997 - 1999

35. Peapod's Grocery Sales: 1997 - 1999

36. Peapod's Cash Provided from Financing Operations: 1997 - 1999

37. Peapod's Combined Revenue Components: 1997 - 1999

38. Peapod's Combined Revenue Components and Cash Provided from Financing Operations: 1997 - 1999 
39. Comparison Between Peapod's Total Revenue and Total Cost:

$1997-1999$

40. Peapod's Total Cost and Total Revenue with Cash from Financing

Operations: $1997-1999$

41. Peapod's Total revenue and Total Cost: $1992-1999$

42. Factors Mentioned by Retail Analyst

43. GroceryWorks Back-End Cost Components and Performance Drivers:

January 1999 - March 2000

44. GroceryWorks Performance Drivers and Performance Drivers:

January 1999 - March 2000

45. GroceryWorks Revenue Components and Performance Drivers:

January 1999 - March 2000

46. GroceryWorks Front-End Costs and Performance Drivers:

January 1999 - March 2000

47. GroceryWorks Front-End Costs and Performance Drivers:

April 2000 - March 2001

48. GroceryWorks Revenue Components and Performance Drivers:

April 2000 - March 2001

49. GroceryWorks Back-End Cost Components and Performance

Drivers: April 2001 - December 2006

255

50. GroceryWorks Revenue Components and Performance Drivers:

April 2001 - December 2006

264

51. Tesco's Back-End Cost Components and Performance Drivers:

January 1995 - December 1996

52. Tesco's Front-End Cost Components and Performance Drivers:

January 1995 - December 1996

53. Tesco's Performance Drivers and Revenue Components:

January 1995 - December 1996

54. Tesco's Performance Drivers and Performance Drivers:

January 1995 - December 1996 
55. Tesco's Front-End Cost Components and Performance Drivers: January 1997 - December 1998

56. Tesco's Performance Drivers and Performance Drivers:

January 1997 - December 1998

57. Tesco's Back-End Cost Components and Performance Drivers: January 1997 - December 1998

58. Tesco's Performance Drivers and Revenue Components:

January 1997 - December 1998

59. Tesco's Front-End Cost Components and Performance Drivers: January 1999 - December 2004

60. Tesco's Back-End Cost Components and Performance Drivers: January 1999 - December 2004

61. Tesco's Performance Drivers and Performance Drivers: January 1999 - December 2004

62. Tesco's Performance Drivers and Revenue Components: January 1999 - December 2004

63. Tesco's Back-End Cost Components and Performance Drivers: January 2005 - December 2006

64. Tesco's Front-End Cost Components and Performance Drivers: January 2005 - December 2006

65. Tesco's Performance Drivers and Revenue Components: January 2005 - December 2006

66. Tesco's Performance Drivers and Performance Drivers: January 2005 - December 2006

67. Peapod's Front-End Cost Components and Performance Drivers

68. Peapod's Performance Drivers and Performance Drivers 438

69. Peapod's Back-End Cost Components and Performance Drivers 439

70. Peapod's Revenue Components and Performance Drivers 440

71. GroceryWorks Front-End Costs and Performance Drivers 
72. GroceryWorks Performance Drivers and Performance Drivers

73. GroceryWorks Back-End Cost Components and Performance Drivers

74. GroceryWorks Revenue Components and Performance Drivers

75. Tesco's Front-End Cost Components and Performance Drivers

76. Tesco’s Performance Drivers and Performance Drivers

77. Tesco’s Back-End Cost Components and Performance Drivers

78. Tesco’s Performance Drivers and Revenue Components

79. Graphical Representation of Rule 1

80. Graphical Representation of Rule 2

81. Graphical Representation of Rule 3

82. Online Grocery Channel Model Levels

83. Core Online Grocery Home Delivery Model

84. Core Online Grocery Home Delivery Model with Website Generated Demand 


\section{Chapter I}

Introduction

Food distribution in the United States has a long history dating back 200 years. Over this period distribution channels have changed dramatically. These changes have included: (1) changes in the manufacturing of food products; (2) changes in the distribution of food products; (3) changes in food retail formats; and (4) changes in food retail delivery methods. Within the grocery industry, food manufacturing has progressed from the simple growing and selling of crops and livestock to the manufacturing of consumer packaged goods. In terms of distribution, the grocery industry has expanded from general stores, where the shopkeeper performed the tasks of warehousing, wholesaling, and retailing, to the modern extended channel structure where these functions are performed by specialized agents. From the retail perspective, there has been an evolution from general and rural stores to modern supermarkets and supercenters. Further, consumer order fulfillment has changed from full service, in which the customers had their orders filled by a clerk in the store, to self-service where the customers are required to select their own groceries. Lastly, there have been changes in the method for delivering groceries to the final customer. These include the progression from having customers come to the store and pick-up their groceries, to having the store pick, package and deliver the groceries to the customer's home.

It is the use of the home delivery channel that is of interest here. This channel has been used on at least four different occasions throughout the evolution of the grocery industry. What has changed over the years is the reason for utilizing the channel. For 
instance, the home delivery channel has been used as a means for service differentiation for competitive gain, as a service component for competitive parity, as a barrier to competition, as a service component weapon, and as a service component profit center. It is obvious that the home delivery of groceries is not a new service concept in the grocery industry (Kamarainen 2001, 2003). What has changed in recent years is the desire by some grocery retailers to again view the home delivery channel as a profit center and promote this service to a broader market through an electronic medium. In fact, some of these grocery retailers are attempting to fundamentally change the grocery industry by altering the channel structure in order to accommodate the new medium (Friedman 2000; Allen and Fjermestad 2001; Park and Regan 2003).

\section{$\underline{\text { Statement of Problem }}$}

The recent desire by grocery retailers to operate in the online home delivery channel may be centered in the need for growth in a mature industry characterized by traditionally low margins. Thus, while growth of the grocery industry in general is projected to be slow, the home delivery of groceries is one of the fastest growing areas in e-commerce (Rowland 2001; Kamarainen 2003; Keh and Shieh 2003). Despite this apparent opportunity the methods employed for tapping into that potential have not been entirely successful. During the late 1980s and throughout the 1990s, partnerships and pure-play online (Internet) grocers emerged to take advantage of the online channel. Early entrants, such as Peapod, Streamline, NetGrocer, and Webvan made promises that included access to a large selection of groceries, lower costs, and fast and flexible delivery. However, in the first half of 2000, the dot.com bubble burst and most of these 
pure-play dot.com grocery companies either went bankrupt, merged with other pure-plays in order to survive, or were bought out by brick-and-mortar (BAM) grocery retailers looking to establish their own home delivery channels (Hays, Keskinocak, and de Lopez 2004). As a result, some industry watchers began to challenge the validity of partnership and pure-play business models supporting the online (Internet) grocery home delivery channel (Morganosky and Cude 2002; Chen 2003).

With the collapse of the initial online channel, many of the traditional BAM supermarkets began to develop and operate their own online channels. However, none of these independent supermarkets and supermarket chains has been able to demonstrate that the online channel can be profitable. In actuality, many of these operations have since closed their 'virtual' doors. Again, industry analysts and watchers commented that perhaps the business models were to blame for the poor performance of these companies. It was also possible that there are structural factors associated with the online channel that had a more pronounced impact on determining company profitability, regardless of the business model selected. The high casualty rate of companies operating in the online grocery home delivery channel raises the question of what caused all the failures? In addition, for those companies that managed to survive in the channel, what has allowed them to do so?

\section{$\underline{\text { Research Focus }}$}

Although the early partnerships and pure-play grocers did not weather the competitive storm, their demise should not be seen as a total failure of their business models. Instead it should be viewed as a necessary first step in the evolution of the 
online grocery home delivery channel. Specifically, the emergence of partnerships and pure-play grocers marked the birth of the online grocery channel; and, as with all initial endeavors, there were bound to be certain setbacks, especially when given the technological novelty of the channel. Where and when these setbacks occurred was unforeseeable as were the actions taken by these companies in light of these setbacks.

The companies currently operating in the online channel gained their experience and expertise as a direct result of the demise of the original partnerships and pure-plays. Much of the groundwork and initial investment in the channel's development was made by these initial entrants. Most grocery industry analysts and watchers believed that the demise of these companies was the result of their business models. However, it is also possible that the demise of these early online grocers may have had as much to do with structural factors associated with the industry as it did with their business models.

Although partnerships and pure-play companies may have gone through bankruptcy or reorganization, it does not mean that certain key aspects of their operations were not successful. Perhaps certain aspects of these companies were actually operating successfully or, at least moving in the direction of operating successfully. If this was the case what factors were responsible for their success? Given that these initial entrants used several different business models, was their outcome truly a function of their business models or were there other factors that were responsible?

After the demise of several online grocers, many BAM grocers acquired or developed the capacity to conduct business through the online channel. To date, none of these BAM grocers have reported profits from operations and many have since ceased online operations. This dismal record begs the question: Can they be successful? Like 
partnerships and pure-plays, BAM grocers have used a variety of business models. Given this fact, was their performance truly a function of their business models, or are other factors responsible for their outcome?

\section{Purpose of Study}

To date, there has not been a systematic investigation of what led to the dismal outcome of many online grocery home delivery initiatives. According to many analysts and industry watchers, success or failure in the online channel was a function of the business models that these companies were using. Whether the specific business models used by online grocers were the root cause of company performance is one of the main focuses of this research. To investigate this issue, this dissertation utilized a case based theory building process. The goal was to assess the relationship between a company's business model(s) and the performance of that company in the online channel. Another goal was to determine if there are other factors, besides the business model, that could account for company success in the online channel.

\section{$\underline{\text { Research Questions }}$}

Is the performance of grocers operating in the online channel a function of the business models that they have used? In order to answer this primary question, there were corollary questions that needed to be answered as well. These questions include:

(2) What business models are available for use in the online grocery channel?

(3) How do companies operating in the online grocery channel define success?

(4) How do companies operating in the online grocery channel measure success? 
(5) If success is measured in terms of profitability, what are the various components of a company's cost structure in relation to the online channel?

(6) If success is measured in terms of profitability, what are the various components of a company's revenue structure in relation to the online channel?

(7) How has the company's profit structure impacted company success/failure?

(8) What is the relationship between the various profit structure components and company success/failure?

(9) Are there structural factors within the industry that may be responsible for the success/failure of companies in the online grocery channel?

(10) Are any online grocery retailers successful?

(11) If there are successful online grocery retailers, what distinguishes them from those online grocery retailers that are not successful?

These questions represent the crux of issues that this research aimed to look at.

Hence, the primary focus of this research was to examine whether or not the business models used by companies in the online grocery industry are solely responsible for their performance. Towards this end, it was necessary to provide a method for delineating the possible business models used in the online grocery home delivery channel and discuss the advantages and disadvantages associated with key aspects of these models. From there, an analysis was conducted to determine why some companies have been successful while others have not. In order to examine this issue, the case study method was used. The case study method was selected in order to gain a deeper and richer understanding of the dynamics of the emerging online grocery home delivery 
channel. The focus of the analysis was to gain insight into factors affecting the success of companies in this channel by looking at certain key companies. The goal was to isolate those key company factors and market characteristics that may have a significant impact on online grocery store success.

\section{Organization}

Chapter II provides the reader with a discussion of the evolution of the grocery industry in the United States. The chapter begins with the emergence of the small town stores and progresses to the emergence of online grocery retailers. The discussion centers on those points in the grocery industry's history where the home delivery of groceries has been utilized and the circumstances that have prompted its utilization.

Chapter III is a discussion of theory building from case analyses and its application to the online grocery industry. The steps necessary to conduct a case study analysis are described, and examples of how those steps are applicable to analyzing the online grocery home delivery channel are provided.

Chapter IV is a discussion of the factors used to delineate the various online grocery store business models. Five main factors are discussed along with the pros and cons of each factor. The chapter concludes by positing a list of possible models that can be derived from the five factors.

Chapters V, VI, and VII analyze Peapod, GroceryWorks, and Tesco, respectively. Each chapter provides a discussion of the process used to select each case. The analysis provided in each chapter assesses the specific company from its inception to December 2006, and provides an opportunity to see how that company's business model changed 
over time. To aid in the analysis, each chapter divides the company's history into sections, with each section focusing on the profit structure of the company during that specific time period. For a detailed understanding of the development of each company's profit structure, the entire case analysis should be read. For a brief but substantive overview of this process, each company’s profit structure summary and summary sections can be read. For a very general overview of each company the general summary section should be read.

Chapter VIII provided the cross-case analysis between all three online grocers. Included is a synopsis of each company's business model, a discussion of that model's dynamics, and comments concerning each company’s operationalization of the models. Rules for comparing case data are stated, followed by a discussion of online grocery model levels and their relation to the cases analyzed. Following these sections, other possible mediating/moderating variables are examined. Finally, hypotheses emanating from the case analyses are stated. 


\section{Chapter II}

\section{Literature Review}

The grocery industry in the United States has existed for over 200 years. It dates back to the small town and rural stores that supplied the early settlers and to the public markets that served America's first cities. The home delivery of groceries, on the other hand, has a much shorter history dating back about 100 years to the first general stores. During the growth phase of the modern supermarket, the grocery home delivery service all but vanished. However, by the early 1990s it seemed that the service was poised to make a comeback. This comeback was initially lead by partnership and pure-plays and is being further initiated by the traditional BAM grocers. What is presented next is a history of the grocery industry in the United States centered on the practice of grocery home delivery.

\section{$\underline{\text { Small Town General Stores, Rural Area Country Stores, and Public Markets }}$}

In America's early years, the general store and the country store served as the primary locations for the residents of small towns and rural areas to purchase their food products. In small towns, the general store was the dominant food retailer while in rural areas the country store dominated the food retail business (Jones 1936; Zimmerman 1955). These general and country stores tended to be non-departmentalized retailers carrying several lines of merchandise such as hardware, dry goods, and groceries. The two types of stores were the dominant retail forms during this time because the populations in the areas they served were not large enough to support public markets. 
The small general and country stores enjoyed success throughout the eighteenth century during which time technological developments helped them to prosper and grow. Two of the main developments that aided this growth were railroad transportation and the mass production of food products. As railroad transportation increased, the population of towns also increased resulting in the general and country stores taking on greater importance within those towns and rural communities that they served (Jones 1936; Stoffle 1972; Mayo 1993).

The advancements in transportation and mass production, which spurred the growth and prosperity of the general stores, were the very means by which the storekeeper system was replaced. By the end of the eighteenth century, the general stores began to lose their dominance to public markets which dominated grocery retailing during the eighteenth and nineteenth century. These public markets were successful in bringing the general stores to the brink of extinction. However, the increase in population actually saved the general store by allowing them to evolve. Specifically, as town populations grew, more shops opened that specialized in specific products and some storekeepers themselves began to specialize in the grocery trade (Jones 1936). The shift from general store to grocery store initiated the spark that would eventually consume the public markets. In addition, the public markets also faced a problem when the tenets of mass production and distribution were applied to food distribution. This brought about the development of the warehousing and wholesale distribution forms.

During the nineteenth century the main locations for food retail were public market places. In order to support one of these marketplaces, the town in which it was located had to be a certain size and the location itself had to meet the needs of both 
buyers and sellers. As populations in the small towns grew, food retail became more important and the marketplaces began to change. As the general stores began to specialize in food products other merchants began to specialize in areas such as general merchandising, butchery, and farm products (Seth and Randall 1999).

Due to the advent of the rail transportation system, the public markets themselves underwent change. Wholesalers became more prevalent due to the need to warehouse a growing number of food products being delivered by rail. With the development of the wholesale sector, the food distribution channel was beginning to evolve (Mayo 1993).

As the size of city populations continued to increase, the cities began to become overcrowded forcing many of the urban dwellers to move to the suburbs. As urban flight increased, the general stores and small grocery stores followed the population leading to a decentralization of the food retail industry. By establishing themselves in the suburban communities, the small grocers attracted the local residence who would have gone into the urban center to do their shopping at the public markets.

As the smaller stores began to compete with the marketplaces, the marketplaces made changes that allowed them to become more efficient. Specifically, the marketplace managers began applying management and marketing techniques, such as cost reduction processes, budgeting, financing, and sales promotions. Although these modernization efforts produced better efficiency and profitability, the public markets still faced an economic problem. The primary source of this agitation was the changing nature of American business in general, and food retailing in particular. That is, within the food retailing industry, the competition that the public markets faced from the grocery stores and wholesalers was steadily increasing (Mayo 1993). 


\section{The Emergence of the Grocery Store}

As populations moved to the suburbs it was more difficult for them to commute to the urban market centers to shop. At the same time, grocery stores were moving into the suburban markets where it was difficult for the public markets to follow. Because they were smaller, suburban grocery stores did not need the heavy traffic that the public markets relied on (Mayo 1993). This shift in the population from urban to suburban areas marked the beginning of the downfall of the public market.

In addition to the urban flight problem, some grocery stores were offering customers a service that public market stall merchants were unable to match. Specifically, some grocery stores offered home delivery service to their customers. With their decentralized location near suburban residential areas, the suburban grocery stores were able to provide this service much easier and cheaper than the public market stall merchants. The cost efficiencies were directly related to transportation overhead costs. Thus, for the suburban grocery store owners, home delivery of groceries was a way to differentiate their service offering from that of the public market stall merchants. The basis of the differentiation stemmed from a comparative difference between transportation costs for the public market stall merchants and the suburban grocery store owners. Home delivery was also used as a method for the suburban grocery store owners to differentiate themselves from one another. Given the size of the population, customer loyalty was necessary to stay in business. Delivering groceries to the homes of customers within a certain radius increased the probability that customers would continue to frequent the store that provided the service. 
Besides the urban flight problem and the development of home delivery service, the food retailing landscape began to change as well. The small merchants and grocers could not handle the increased amount of food being imported into the city. As a result, a wholesaling system began to emerge. As the wholesale channel grew, the stall merchants began to lose their dominance over the grocery stores.

\section{From Independent Grocery Stores to Grocery Chain Stores}

By the late nineteenth century, independent grocery stores had replaced the public marketplaces as the dominant grocery retail format. One of the primary concerns of the independent storekeepers was increasing their profit margins. Due to price competition from other grocers, raising prices was not a feasible long term solution. The other alternative was to reduce overhead costs. The push to reduce overhead costs was the main catalyst behind the move towards the grocery chain store (GCS) system. The reasoning was that if storekeepers could purchase large quantities of products, they could reduce the unit cost of their inventory which would lead to reduced overhead costs (Beckman and Nolen 1976).

In order to reap the benefits of bulk buying a high level of inventory turnover in the stores was necessary (Lebhar 1963). This required a paradigm shift in grocery retail from selling small quantities of products with high markups, to selling large quantities of products with low markups (Lebhar 1963). This shift resulted in a reduction in net profit per sale but an increase in net profit on volume. From a management perspective, the shift made stores more efficient because they were more profitable per square foot of selling space (Mayo 1993). 
With the shift in selling and purchasing tactics, grocery storekeepers found price competition to be the norm. As a result, service became the fundamental component for differentiation. Specifically, home delivery of groceries in the urban centers (i.e., cities) became a necessary component of business (Beckman and Nolen 1976). Those storekeepers who owned more than one store had a tremendous advantage in this area. For an independent storekeeper to offer home delivery he would need a horse, delivery wagon, and a driver to make deliveries. For storekeepers with more than one location (i.e., chain store operators) this requirement was less costly because they did not need a horse, wagon, and driver at each location, especially if their stores were located in close proximity to one another. In this situation, the chain stores could take orders from each store located in close proximity allowing them to broaden the order taking and delivery radius. Deliveries could then be made using a single delivery wagon/truck. The cost of operating a delivery service for the grocery chain store operator could be allocated to several stores which reduced the overhead cost of delivery for any one particular store. Also, the likelihood of a stockout could be reduced because products could be shifted from one store to another with minimal costs involved.

To present a unified front to the public, these chain stores used logos and/or symbols on their stores and delivery wagons, which served as a means of brand differentiation. Thus, as in the suburban markets, the home delivery of groceries in the urban centers was used as a means of service differentiation. The difference was that it was now being utilized by the chain stores as a weapon against the independent store owners. For the grocery chain stores, the costs of home delivery could be allocated to all the store locations, thus reducing the overall impact of delivery costs on any one store. 
For the independent store owners, this was not the case. By offering home delivery service, they were forced to accept lower profit margins since they had to incur the cost of home delivery without the ability to spread the cost over several store units.

During this same period, grocers in the suburban markets were already engaged in the home delivery of groceries. These grocers tended to be independent, but there were also a few grocery chains participating (Lebhar 1963). However, these grocers lacked the means to adequately cater to the growing number of suburban residents who could benefit from home delivery service. This market gap was exploited by a wave of home delivery companies (Mayo 1993).

The new grocery home delivery companies took a different approach to providing customers with home delivery. Instead of waiting for the customers to call to place an order and then making arrangements to deliver their groceries, the home delivery companies went on the offensive by purchasing wagons (and eventually trucks) to carry food items to suburban neighborhoods. Thus, they called on the customer instead of having the customer call on them. Due to the size of the delivery wagons/trucks, and the handling needs for certain products, these wagons/trucks only offered a few products that the salesman could sell competitively against the local grocery store (Mayo 1993). To distinguish themselves from the grocery stores, home delivery companies used product differentiation by offering products that were not always available in the grocery store or offering them before they were available in the grocery store (Mayo 1993). In order to increase customer loyalty, some of the larger home delivery companies offered their own branded products. 
These companies operated by having the delivery salesman go by the customer's house every two weeks on the same day and time. When the delivery salesman arrived, customers would receive the products that they ordered during the previous delivery (Wright 1958). These home deliveries resulted in a larger total grocery bill, but to the suburban residents, the cost was worth the convenience. Hence, for certain segments of the suburban population home delivery was seen as a convenience service.

Although the convenience of having groceries delivered played a role in the success of the home delivery companies, it was the utilization of promotional schemes, such as product premiums, that attracted households to home delivery (Wright 1958). During this time the grocery stores offered customers trading stamps that could be exchanged for premium gifts. The catch was to have the customers purchase enough items in order to accumulate enough trading stamps to redeem their gifts. However, the home delivery companies took a reverse approach to the premium exchange. Their objective was to have the consumer experience a psychological debt as a result of receiving a premium gift (Wright 1958; Mayo 1993). Specifically, before the customer had accumulated enough points through food purchases, the customer was allowed to take possession of a premium item. These salesmen then kept a running tab of how many stamps/points the product recipients needed to collect before they had paid off the premium item (Wright 1958). These salesmen would then return to the customer's home every two weeks to provide food products and deduct a certain number of points based on the level of purchase. This use of premiums allowed the home delivery salesman to get through the front door and to return on a recurring basis, which allowed them to build a customer base (Mayo 1993). 


\section{The Evolution of the Supermarket}

From the 1910s to the 1920s the grocery chain stores became more efficient than their independent storekeeper counterparts and literally put many of them out of business (Zimmerman 1955). The increase in efficiency was the result of better business management. Specifically, the chain stores developed a corporate type structure that utilized special departments dedicated to analyzing specific subsections of the business such as meats, produce, and dry groceries.

With the increased efficiency of the grocery chain stores, the independent grocers and wholesalers realized that they could no longer ignore the gains of the GCSs. As a result, they organized into affiliations in order to purchase food products in bulk from the food producers. These affiliations took the forms of retail cooperatives, wholesalersponsored groups, and sponsored syndicates (Zimmerman 1955; Ryant 1973; Beckman and Nolen 1976). In retail cooperatives, the independent grocers joined together to do cooperative buying and selling while the wholesale-sponsored groups aligned in order to engage in bulk buying (Cassady and Jones 1949). Regardless of the type of cooperative, the goal was to gain access to the economic benefits that accrued from volume buying and selling (Mayo 1993).

By the 1930s, the majority of grocery stores in America were either part of a GCS or were affiliated independents (Zimmerman 1955; Lebhar 1963). This transformation in the retail landscape caused the concentration of store ownership to fall into the hands of a small group of corporate owners. The expansion of the GCSs and the development of independent grocer cooperatives were two significant events that would lead to the evolution of the supermarket (Zimmerman 1955; Mayo 1993). Two other significant 
events were the proliferation of the automobile and the invention and proliferation of the refrigerator (Alexis 1962).

With the proliferation of the automobile and refrigerator, the seeds were sown for the emergence of the supermarket. The first prototype supermarkets appeared on the west coast of America during the 1920s (Zimmerman 1955; Mayo 1993; Zwiebach 2005). Some of the early supermarket pioneers were Ralph’s Grocery Company and Alpha Beta Food Market (Zimmerman 1955; Mayo 1993). By the 1930s, this new grocery store format had made its way to the east coast of the United States.

During the early 1930s, when the supermarket model was developing, the GCS did not see the new grocery retail format as a threat (Zimmerman 1955; Lebhar 1963; Deutsch 1999). However, by the mid-1930s, the supermarket format had made its presence known and the GCS realized that the new retail format was not a passing phase but a true competitor (Zimmerman 1955; Mayo 1993). Not only were GCS affected by the success of the supermarket model, affiliated independents (AI), non-affiliated independents (NAI), and wholesalers were also affected. For the NAI grocers and nonaffiliated wholesalers, the competition from the supermarkets hurt them the most because they had already been seriously wounded by the rise of the GCS (Zimmerman 1955). The GCS also began to feel the presence of the supermarkets when it became clear that a single supermarket could do the same volume of business as ten to twenty chain stores and do it with lower overhead costs (Beckman and Nolen 1976; Mayo 1993).

The rise of grocery stores continued through the 1930s and became the primary place for households to do their shopping. By the mid- to late-1930s many of the GCS began to convert to the supermarket format by consolidating and closing many of their 
store locations (Zimmerman 1955; Mayo 1993). As the supermarket format continued to take shape many of the independents and GCSs were still offering the home delivery of groceries as a convenience service. The service was necessary in order for independents and GCSs to differentiate themselves at a time when customer patronage was critical for survival.

As the GCSs moved to volume selling, they also switched to cash-and-carry low service formats. This meant the elimination of services in order to reduce overhead costs. As a result, home delivery by many of the GCSs was abandoned. Due to cost pressures it was not long before the AIs also abandoned the grocery home delivery service. With the trend towards larger supermarkets that offered more products to the customer, and the ease with which customers could reach a grocery store/supermarket, there was no longer any incentive to offer home delivery of groceries.

From the Supermarkets to the Supercenters

During the 1940s, the supermarket had proved to be more efficient for consumer grocery shopping. In many urban communities, it replaced the NIGs, wholesalers, and some AIs. In addition, after realizing the efficiency and sales potential of this retail format, GCSs consolidated many of their older and unprofitable stores and opened supermarkets (Zimmerman 1955; Lebhar 1963). By the 1950s, the urban market had become saturated with supermarkets making the suburban market the primary place for expansion opportunities. However, construction of a supermarket was expensive so only large and well financed competitors were able to compete for suburban market share (Mayo 1993). 
As the supermarket format took hold in the suburban markets, it began to replace many of the local neighborhood stores. Some of these stores were GCSs while others were independently owned. At the time, many of the independent grocery stores were offering home delivery as a way to compete with GCSs. Not many of the GCSs offered this service because it added to their overhead. Thus, the service was provided by these independents as a form of service differentiation. Once the supermarkets entered the suburban market, those that were owned by GCSs already knew that the home delivery of groceries was unprofitable and did not offer the service. Those urban supermarkets that were independent followed the lead of the GCSs when entering the suburban market and did not offer home delivery service.

By the 1960s, the supermarkets were a significant force in the grocery retail industry (Brady and Davis 1993). During the period from 1950 to 1960, management had developed successful techniques for store location and operations. By the 1960s the suburban market was saturated and there was a sharp reduction in store expansion. Supermarkets continued to dominate grocery retail during the 1970s which was evident by the fact that in 1971, the supermarket represented about 18 percent of all grocery stores, but accounted for 75 percent of total retail grocery sales volume (Mayo 1993).

During this period, warehouse clubs began to emerge, providing stern competition for the supermarkets (Brady and Davis 1993; Morganosky 1997). To respond to the threat the supermarkets created superstores and then hypermarkets. Although the hypermarkets were massive grocery retail outlets, the format never became a dominant force in the U.S. grocery retail industry. However, by the 1990s, an evolutionary offshoot of that retail format emerged and took the U.S. grocery retail industry by storm. 
This new grocery retail format was known as the supercenter. The supercenters offered a full line grocery store in the same location as a traditional retail outlet (Morganosky 1997). In the 2000s, the supercenter format continues to increase in popularity and proliferation.

\section{From Brick-and-Mortar to Click-and-Mortar}

During the 1990s, supercenters continued consolidating their hold on the grocery retail industry. Many grocery industry experts argued that supercenters posed a serious threat to traditional supermarket retailing. From a competitive standpoint, the supermarket chains were more fearful of the supercenter format than they were of the warehouse club format (Morganosky 1997; Kaufman 1998; Frankel, Goldsby, and Whipple 2002). To protect themselves from the advances of the supercenters, the affiliated independent supermarkets and the supermarket chains concluded that growth was their best weapon. The growth was achieved through mergers and acquisitions, with much of the consolidation occurring at the expense of the smaller grocery chains as they became the focus of attention of the larger supermarket chains (Silcock, Clarke, Clarke, and Wrigley 1999). Several mergers occurred that shifted the ownership in the grocery industry into the hands of an ever smaller, but financially larger, group of grocery conglomerates (Wrigley 2001; Balto 2001). During the late 1990s, the Federal Trade Commission (FTC) put regulatory brakes on the merger process and, by the end of the 1990s, the merger momentum had slowed to a crawl. As a result of consolidation, and the subsequent anti-merger rulings by the FTC, growth through acquisition was significantly curtailed leaving few opportunities for independent supermarkets and 
supermarket chains to continue growing. This meant that grocery retailers could no longer use mergers as a means of increasing their share of the U.S. grocery market. Add to this the success of the supercenters, and the result was a significant level of competition for market share in the grocery retail sector (Park and Park 2000). To get around the FTC regulatory barrier, these grocery chains began to look to other areas for expansion. Since the FTC had virtually closed the door on expansion through acquisition, the supermarket chains decided to continue their growth by dominating the different channels of food retail.

During the early part of the 1990s, one such grocery retail channel had already begun to take shape. It was spurred by changes in consumer values, the dynamics of the consumers' life-styles, and the advent of the Internet (Park and Park 2000). Specifically, given their work environments, many consumers found themselves routinely pressed for time. These time-sensitive (or time-starved) consumers voiced their desire for time saving devices and services. They placed a high value on products and services that allowed them to free up some time and they were willing to pay extra for these products and services (Liebeck 1996a; Park and Park 2000; Morganosky and Cude 2000). Given these realities, some forward looking entrepreneurs realized that the development of an alternative way for these consumers to shop for their groceries would provide them with the value that they were seeking. Thus, when the Internet became commercially available, the online grocery home delivery retail channel emerged. This channel allowed customers to place orders for groceries via the Internet and then have them delivered to their homes. It was assumed that this retail channel would also appeal to those consumers who disliked the shopping experience in general (Park and Park 2000; 
Morganosky and Cude 2000), consumers whose life-style revolved around technology (Liebeck 1996b), and consumers who liked to shop, but were limited in their ability to get to the store (Park and Park 2000; Morganosky and Cude 2000). The notion to target these consumers, however, was actually conceived before the Internet became available for public use. These attempts came in the form of partnerships between traditional brick-and-mortar grocery retailers and newly formed pure-plays which were grocery stores operating solely for home delivery (Lewis 1996).

One of the earliest participants in this effort was a company called Peapod, which began operations in Chicago in 1990. Peapod operated as a partnership where it served as the delivery arm for a traditional BAM grocery retailer. The service worked by allowing customers to place orders either electronically or by calling or faxing them to the store. Once Peapod received the order, the company would dispatch professional shoppers to a local store to pick the groceries from that store's shelves and then package them for delivery (Wallace 1994). Once the customer’s order had been picked and packaged, Peapod personnel would then deliver it to the customer's home. In this scenario, Peapod did not actually own the inventory. Instead, the company purchased it from the local grocer and then delivered it to the customer's home. In this regard, Peapod's primary goal was to offer their retail partner a new channel format. Based on the method of operation, Peapod's business model was a partnership between a traditional brick-and-mortar grocer that provided the inventory, and Peapod, which provided the picking, packing, and delivery service (Lewis 1996). Although it did not begin as an online grocer, in 1996, when the Internet became commercially available, Peapod began to take orders over the Internet with little changes to its service. 
Another company that participated in attempts at reviving the grocery home delivery channel was Streamline. Streamline began operations in 1993 in Westwood, Massachusetts and conducted business much the same as Peapod. Specifically, customers placed orders by telephone, fax or computer and their orders were delivered to their homes. One of the main differences in the Streamline model was that the groceries were delivered to temperature-controlled storage units installed in a secure location at the customer's property (Chamis 1999; Giblen 2000). Thus, deliveries could be made without the need for the customer to be home. Another difference in Streamline’s business model was that the company filled orders from a 56,000-square-foot warehouse. Further, Streamline delivered the orders to homes on a specific date following a predetermined route. This meant that determining the costs associated with delivery was much easier. Peapod, on the other hand, made delivers on demand so there was no fixed predetermined route which made Peapod's delivery system more complex in terms of the number of deliveries per route and the costs associated with each specific delivery route (Springer 2000). In essence, the Streamline model was more of a replenishment model because the company would delivered a certain basket of goods to the customer's home every so many weeks. Like Peapod, Streamline began to take orders online in 1996 once the Internet became commercially viable.

NetGrocer, based in North Brunswick, New York, was founded in 1995, and began making home deliveries in 1997. It was one of the first pure-plays organized to take advantage of the Internet. Like Streamline, NetGrocer used its own warehouse for inventory storage and order fulfillment. However, unlike Peapod and Streamline, NetGrocer's only delivered non-perishable goods and used Federal Express to make 
deliveries (Blair 1997; Liebeck 1997). Since Federal Express delivered all over the United States, NetGrocer's service was available all over the continental United States. NetGrocer's product selection was limited to 25,000 SKUs indicating that its business model was more geared towards replenishment of staples than traditional grocery shopping.

Webvan was one of the last pure-play entrants into the online grocery delivery market. It was based in Foster City, California and began operations in the San Francisco area in 1999. Like Peapod, Streamline, and Netgrocer, Webvan's service entailed taking orders over the Internet and delivering those orders to customers' homes. Webvan's service had certain operational similarities with those of the other online grocers, but there were also operational and strategic differences that distinguished its business model from that of the other online grocers. For example, like Streamline and NetGrocer, Webvan picked and packaged customer orders from a warehouse distribution center. The difference was the size of the distribution center and its technological sophistication. Specifically, Webvan's distribution center was a colossal 330,000 square foot unit that was highly automated requiring about half the number of employees that an equally sized non-automated distribution center needed. This allowed Webvan to offer 35,000 SKUs, including both non-perishable and perishable grocery items. This far exceeded the number of SKUs being offered by other online grocers (Howell 2000). In addition, the size of the distribution center gave Webvan the capability of servicing a 40 square mile area which was larger than the service area being covered by other online grocers from their distribution locations. Webvan's extensive reach was possible because it used a hub-and-spoke system that had around a dozen substations served by the distribution 
center and a fleet of delivery vans operating from each substation. This automated distribution center was the prototype for a series of 15 to 20 similar distribution centers that were to be built in major metropolitan areas (Howell 2000). In essence, Webvan’s business model was based on delivering groceries from highly automated distribution centers offering a selection of products similar to that of a conventional BAM supermarket (Massingill 1999). Its business model also called for rapid expansion in order to dominate the online grocery channel. It was this part of Webvan's business models that gained the attention of the supermarket chains. If Webvan and/or the other online grocers were successful at delivering groceries directly to customers' homes, in a manner that was convenient for the customer and profitable for the company, this would further erode the market share of the supermarket chains in the grocery retail industry.

Given this concern, most supermarket chains entered the online market with caution with most of their online efforts taking the form of partnerships (Lewis 1996). The decision for the supermarket chains to enter the online realm represented a tremendous commitment and revision of established business practices (Park and Park 2000). Many of these retailers were frightened by the possibility that their investments in their distribution channel infrastructure would become obsolete as the online channel developed (Lee 1996). That is, many of these independent supermarkets and supermarket chains had invested tens of millions of dollars in order to improve their distribution channels with the aim of becoming more efficient. By increasing efficiency, these supermarkets would be able to reduce costs and increase their profit margins. This meant that the investment in their distribution channel had a projected rate of return. If the online channel was to actually live up to its billing, these independent supermarkets and 
supermarket chains might be forced to abandon their investments. Moreover, these affiliated independent supermarkets and supermarket chains also feared that it might be necessary to invest large amounts of capital in order to gain the core competencies necessary to conduct business in the online channel. Thus, the decision to establish an online channel came with considerable costs that would have long-term repercussions on company profitability.

As a result, during the formative years of the online grocery channel's development, many of the affiliated supermarkets and supermarket chains were ambivalent to the channel. Many of them did not consider the fledgling Internet as a viable vehicle for the establishment of a new channel while others considered the online channel as a possibility in the future (Dorgan 1996). Part of the reason that some grocery retailers considered the online channel a future potential may have been due to the fact that in its infancy, the Internet was mainly a text-based system and was not very user friendly. Once graphic technology was developed and introduced, it would make the Internet more amenable to the grocery industry which relied heavily on visual presentation of inventory. Nonetheless, despite these drawbacks, there were some entrepreneurs who did see the Internet as a viable channel for selling groceries.

Due to initial resistance to embrace the online channel by the affiliated independents and supermarket chains, there existed a void in the market that was exploited by several visionary entrepreneurs. By the mid-1990s, these industry newcomers, known as partnerships and pure-plays, had made themselves known in the grocery retail industry. There was considerable fanfare with some commentators noting that they had the potential to reshape the grocery retail industry. By the late 1990s and 
early 2000s, the online grocery channel had become one of the fastest growing channels for food retail. Estimates concerning the channels growth varied by analysis and expert, with projections ranging from 0.02 percent to 40 percent of total grocery sales.

Regardless of the estimates, what was important was that this retail format was predicted to be the fastest growing grocery retail segment over the coming years.

By the early 2000s, it became clear that the online channel would not live up to its billing. Most, if not all, of the online grocers had not made a profit and several of the early entrants ran out of money and were forced to close their 'virtual' doors. Given the high cash burn rate of online grocers, some industry experts believed that in order for them to continue operations, they would need continual infusions of cash (Martyka 2000). This infusion did not materialize and in early 2000 the dot.com bubble burst, collapsing the fledgling online grocery channel. This collapse was primarily due to the fact that investors were no longer willing to invest money in companies that were neither profitable nor showed signs of becoming profitable in the near future. The collapse meant that many pure-plays and partnerships were dissolved or terminated. As a result, a void in the online grocery channel once again developed.

Although many initial online grocery channel participants did not survive, they were successful in laying the foundation for, and raising the awareness of, the online channel. For the supermarket chains, these initial forays allowed them the necessary time to determine whether or not the online channel was truly a potential threat to their domination of the grocery retail market. Based on the financial performance of many of these initial online grocers, it was clear, at least for the time being, that the online channel was incapable of being operated as a profit center. Therefore, it was unlikely to be a 
serious threat to the supermarket chains market share. Nonetheless, the channel showed enough promise to be considered for further development for other reasons. Specifically, what some supermarket chains saw in the online channel was a way of strengthening their existing brands and keeping their customers happy by adding what amounted to a value added channel component to their service offerings.

Due to their controlled participation in the online channel's development, when the void in the channel materialized, traditional BAM supermarket chains were in a position to make significant inroads into the channel. In order for them to take advantage of the void, the affiliated independent supermarkets and supermarket chains needed to acquire the core capabilities to function in the online channel. To do this, many of them either acquired the delivery company that they had been partnered with, merged with a failing pure-play online grocer, or developed their own online channel. For example, in the Boston market, Peapod had a partnership with Stop \& Shop, a subsidiary of Royal Ahold, the Dutch grocery retail conglomerate. During the collapse of the online market in early 2000, Peapod ran into financial problems and was on the verge of insolvency. Ahold subsequently purchased a controlling interest in Peapod, thereby, making Peapod Ahold's online subsidiary. Likewise, in early 2000, GroceryWorks, a pure-play Internet grocer also ran into financial difficulty. Safeway, a United States supermarket chain, acquired a controlling interest in GroceryWorks thus saving it from the brink of disaster. Albertsons and Publix, on the other hand, felt that it was in their best interest to develop their online channels from scratch. Hence, although the affiliated independent supermarkets and the supermarket chains were cognizant of the potential of the online channel, in the end, none of the initial entrants in the channel succeeded in developing a 
business model that was successful. This fact was very salient for the supermarket chains since not even the partnerships, in which many of them were participants, were successful.

In developing their business models, independent supermarkets and the supermarket chains were not building their operations from scratch. They had a rudimentary template left behind by the partnerships and pure-plays. That is, these supermarkets were drawing on lessons gleaned from the failed business models of the initial online channel entrants. One of the main lessons learned was that it was better to start modestly in a few markets and develop momentum, as opposed to being ambitious and starting in several markets at once. Also, it was good practice to avoid building large central distribution centers. In addition, it was imperative that there be a steady flow of capital, especially in the formative years, in order to establish a firm foothold in the online channel.

Based on these lessons, the supermarket chains turned their attention to developing business models for the online channel that they hoped would be more successful than those of their predecessors. What they brought to the table were large, deep pockets filled with the necessary capital to finance online channel operations. In addition, these supermarket chains were also able to use their size to gain cost advantages from bulk buying. Further, with their established distribution channels the supermarket chains were able to provide logistics coordination, and a network of stores that could be used as distribution centers. Hence, from an operational perspective, it seemed that the supermarket chains were in a better position to make the online channel successful. Nonetheless, for some supermarket chains, this proved not to be the case. 
Given the efficiencies and advantages that these supermarket chains had, to date none have been able to fully unlock the potential of the online channel. Just as their predecessors, some supermarket chains believed that the online channel could be run as a profit center. Some developed business models that relied on dedicated central distribution centers, while others used their stores as warehouses and distribution centers. In both cases, neither model has proven to be financially successful. For instance, in 2001 Publix establish an online division called PublixDirect to take advantage of the online channel. Its model used a central distribution center and a fleet of trucks to make home deliveries. Even with the sophistication of its operation, by 2003 the company had suspended operations for PublixDirect stating that too few customers had signed up for the service. Similarly, in 2002 Albertsons developed its online channel but instead of using a dedicated distribution center, the company opted to fill customer orders from local store shelves and deliver them using its own fleet. In 2006, company ownership changed and the new owners promptly terminated the online service in several markets. Although company spokespersons declined to discuss the underpinnings of their decision, experts close to the company cited the fact that Albertsons online delivery service was losing money and showed no sign of becoming profitable (Chandler 2006). Thus, even with superior capitalization and significant synergies, major supermarket chains have been unable to find a business model that is profitable for the online channel.

In sum, the home delivery of groceries, which was all but dead during the 1960s, 1970s, and 1980s, was resurrected in the 1990s in the form of an online home delivery channel. With the demise of many of the original partnerships and pure-plays, the supermarket chains considered the online channel worthy of their attention. Although the 
grocery home delivery service has reemerged, it is not clear whether it can be provided profitably and, if so, under what conditions. Besides the advantages and synergies that the supermarket chains had, the question is - do they have the right business model formulas to be successful in the online channel? Given the rash of failures of companies operating in the online home delivery channel, many analysts and industry watchers believe that those companies failed primarily as a result of their business models. Thus, whether or not the business model was the sole reason for the demise of many of the online grocery home delivery initiatives is one of the central questions that this dissertation aimed to address. 


\section{Chapter III}

\section{Building Theory from Case Analysis}

Over the last two decades, there has been a growing debate in marketing's academic arena concerning the application of qualitative methodology (Goulding 1998). Some researchers feel that qualitative research is disreputable research and, as such, do not want to be associated with it (Catterall 1998). Within the marketing research literature, the primary focus has been on quantitative research methods (de Ruyter and Scholl 1998). This traditional emphasis of marketing research, focused on objectivity, measurement, and the use of surveys and experiments as the primary vehicle for the creation of knowledge and theory, is now being challenged (Catterall 1998; Goulding 1998; Riege 2003). A growing number of researchers in marketing now contend that qualitative research methodologies, that provide insight and reveal meaning, are better suited for theory building. de Ruyter and Scholl (1998) contend that there has been an increase in the number of qualitative research projects that has gone largely unnoticed, and it can be expected that the interest and use of qualitative research methods will steadily increase in the decade ahead.

Qualitative research as a methodology covers a plurality of research paradigms (positivist, interpretive and critical), within which there are many research methods, research processes, and techniques. Several forms of qualitative research methods have been used in the area of Marketing. These include, but are not limited to, ethnography (Sherry 1990; Schouten and McAlexander 1995; Arnould 2001; Shoham 2004; Girod 2005), phenomenology (Thompson, Pollio and Locander 1994; Cherrier 2004; Harrison 
and Waite 2005; Thomas and Peters 2006), semiotics (Durgee 1986; Sherry and Camargo 1987; Hackley 1998; Gillespie and Morrison 2001; Harvey and Evans 2001; Bode 2005), grounded theory (Goulding 1998; Noble and Mokwa 1999; Bunker 2000; Golicic, Davis, McCarthy and Mentzer 2002; Geiger and Turley 2003; Hausman and Haytko 2003; Ashill, Frederikson, and Davies 2003; Schmidt and Pioch 2005; Mallalieu and Palan 2006), critical relativism (Anderson 1986; Hunt 1990), introspection (Wallendorf and Brucks 1993; Gould 1995), hermeneutics (O’Shaughnessy and Holbrook 1988; Gummesson 2003), and case studies (Tyler, McGirr, and Stanley 1998; Berghman, Matthyssens and Vandenbempt 2006). This last type of qualitative methodology, the case study, has gained more of a following over the last decade. Although it has not reached prominence in North America, the method is widely used in Europe (Voss, Tsikriktsis, and Fronhlich 2002) where it has been the basis for masters and $\mathrm{PhD}$ research theses (Perry 1998).

From a methodological standpoint, case studies have been a powerful way to gain new insight on issues and develop new theory concerning those issues (de Ruyter 1998; Wacker 1998). This form of research is well suited for examining the how and why questions surrounding an issue (Yin 1994; Voss et al. 2002) especially when there is little known about the issue in question (Weischedel, Matear, and Deans 2005; Goulding 1998). Thus, the case method is ideal for early, exploratory investigations in which the variables and their relationships are as yet unknown and the phenomenon in question is not at all understood. Given the relative immaturity of the online grocery channel, the case study method of analysis provided a mechanism for exploring issues concerning this channel's development, the various business models used by companies operating in the 
channel, whether the companies operating in the channel were doing so successfully, and the key drivers affecting company success/failure.

In order to conduct a rigorous case analysis, there are some general steps that needed to be followed (Eisenhardt 1989; Perry 1998; Voss et al. 2003). Although different researchers have used different terminology in describing these steps, there is a significant level of overlap between the various processes. What is presented next is a synthesis of these steps that borrows terminology from different authors. The goal is to retain the essence of the process while enumerating the basic steps of the case based theory building process in relation to the factors contributing to the success/failure of online channel initiatives.

\section{The Research Question and Construct Definition}

An initial definition of the constructs to be used and a general statement of the research question, in its broadest terms, are important for theory building from case studies (Eisenhardt 1989; Voss, Tsikriktsis, and Fronhlich 2002). By articulating the research question at such a broad level, the researcher is compelled to contemplate the constructs, as well as their definitions, that are to be used in the analysis (Voss et al. 2002). This process helps to shape the initial research design by laying out a general articulation of the constructs to be studied and the relationships between them. This articulation or framework can be in graphical or narrative form or a combination of the two (Miles and Huberman 1994). The idea is to force the researcher to think critically and selectively about the constructs to be included in the study (Eisenhardt 1989). Although this step is critical in establishing the initial parameters of the analysis, “. . . it is 
equally important to realize that both are tentative in the case study type of research design ... [because no] . . construct is guaranteed a place in the resultant theory, no matter how well it is measured” (Eisenhardt 1989, p.536). Therefore, it is possible that the research question and the initial constructs may change during the analysis as a result of data collection (Eisenhardt 1989; Voss et al. 2002). It should be noted that in some situations, the research question may stem from the conceptual framework while in other situations it may precede the development of the conceptual framework (Voss et al. 2002).

Using the case study method, a sizable amount of information can be amassed. Therefore, one reason for developing the constructs and research question(s) at the beginning is to help specify the types of companies to be studied and the type of data that should be collected for the analysis (Eisenhardt 1989; Voss et al. 2002). Further, since this is a theory building process, the researcher(s) conducting the case analysis should begin with the idea that there is no underlying theory and no hypotheses to test (Eisenhardt 1989). This is not to say that there should be no theoretical considerations of construct definitions stemming from previous research (Eisenhardt 1989; Wacker 1998; Perry 1998); but, that the importance of the constructs and their relationships to one another be allowed to distill as the analysis progresses (Eisenhardt 1989).

For analysis of the online grocery industry, it was decided to state the research questions first and then systematically derive the conceptual framework. Thus, the broad research question was stated as: Is the success/failure of partnerships, pure-plays, and hybrid online grocery stores a function of the business models that they were using or were there other factors responsible? To answer this question several corollary questions 
need to be answered. These questions included: (2) What were the possible types of business models that could be used in the online grocery industry? (3) What specific types of business models were being used in the online grocery industry? (4) How did companies operating in the online grocery industry define success/failure? (5) How did companies operating in the online grocery industry measure success/failure? (6) If success/failure was measured in terms of profitability, what were the various components of a company's cost structure? (7) If success was measured in terms of profitability, what were the various components of a company's revenue structure? (8) How had the company's profit structure impacted company success/failure? (9) What was the relationship between the various profit structure components and company success/failure? (10) Were there structural factors with in the industry that may have been responsible for the success/failure of companies in the online grocery channel? (11) Were any online grocery retailers successful? and (12) If there are online grocery retailers that were successful, what distinguishes them from other online grocery retailers that were unsuccessful?

Stating the research questions this broadly allowed for analyzing the online channel on a time line which could be viewed as the channel's evolutionary progression. Conceptualizing the online grocery channel as an evolutionary process allowed for the opportunity to define major phases that the channel had passed through. This enhanced the understanding of how different business models, and their associated cost and revenue structures, had come into play and the effects they had on company success/failure. In order to gain insight into these questions, it was necessary to select a 
set of companies to serve as the basis for the case based theory building process. The following section describes that process.

\section{$\underline{\text { Case Selection }}$}

The selection of cases to be used in the theory building process is an important step (Eisenhardt 1989). In certain regards, case based theory building is quite similar to that of traditional hypothesis testing research in that both require that there be an underlying population from which to draw a sample. However, it is the sample selection process that distinguishes the two methods. In traditional hypothesis-testing methodology, the generalizability of a pre-established theory is tested by subjecting that theory to an analysis conducted on a randomly selected sample. In this scenario, the random nature of the sample is a key criterion for assessing the viability of the hypotheses. However, in the case based theory building process, there is no specific theory to be tested and, therefore, no hypotheses to subject to the falsification process. The idea is to allow the research to be guided from a general to a more specific research question (Eisenhardt 1989; Wacker 1998). As the research question begins to solidify, it becomes possible to develop testable hypotheses. Hence, the random selection of a specific firm/company to analyze may not be desirable because the selection process may need to be guided by specific factors that require the selection of specific firms (Eisenhardt 1989; Stake 1994; Yin 1994; Perry 1998; Voss et al. 2002). Thus, within certain industries, one may find that in relation to the topic under study, there may be only a few firms that are feasible for selection (Eisenhardt 1989). If the sample selection was done randomly then these firms may not be included in the analysis and key insight 
related to the topic may be missed. As a result, it makes sense to select those cases that allow for the analysis of the chosen topic (Patton 1990). This means that the selection of a random sample may not be necessary or desirable (Eisenhardt 1989; Perry 1998; Voss et al. 2002). Therefore, the selection of cases, used for the theory building process for the online grocery industry was done purposefully not randomly.

When selecting cases for the theory building process, the cases should be selected in order to either (1) allow for the prediction of similar results (i.e., a literal replication) or (2) produce contrary results but for predictable reasons (i.e., a theoretical replication) (Yin 1994; Perry 1998; Voss et al. 2002). For the online grocery industry, it was prudent to use both selection criteria. That is, in order to examine whether the business models used by online grocers were responsible for the success/failure of those companies, those online grocers that had been going concerns from the channels inception were deemed the best candidates. This made it possible to examine how the variables associated with different business models had impacted company success/failure. Thus, initially cases were selected that allowed the researcher to gain insight concerning the different constructs and variables, and their relationship to company success/failure in the online channel.

Once the initial conceptual framework (i.e., model) has been put forward, information from additional sources can be collected and/or additional cases can be selected and analyzed to ascertain the degree of internal validity and reliability of the framework. The inclusion of information from additional sources may be necessary in order to verify the initial findings, provide an explanation for the initial findings, provide a context in which to interpret the initial findings, or to refute the initial findings. It 
should be noted that there is no requirement that additional information be collected. The only rule is that the researcher(s) provided an explanation for the inclusion of the additional information. In the present study, while analyzing the case data, it was necessary to collect additional information twice in order to verify the emergent relationships. The method for collecting the additional information is provided in the next section.

If no additional information is necessary, and a second case is analyzed, if the initial framework holds, then this is considered a literal replication. At this point, the case selection process can move to the selection of cases that should produce contrary results. In relation to the online grocery channel, it seemed intuitive to select companies that ceased being going concerns. This would allow the researcher to examine the relationship between the underlying variables associated with the defunct company's business model and that company's withdraw from the channel. Since the company ceased operations, the framework should allow for this prediction. If the framework successfully predicts that the company should withdraw from the channel, a theoretical replication would have been established.

A critical question to be answered in deciding on a sample is how many cases to select. As it currently stands there are no precise guidelines for determining this number (Romano 1989; Patton 1990). According to Romano (1989), this decision is usually left up to the researcher while Lincoln and Guba (1985) contend that case sampling should continue until the point of redundancy. Although there is no agreed upon method for determining the number of cases that need to be sampled in the theory building process, researchers, using their experience as a guide, have recommended between four and ten 
cases (Eisenhardt 1989; Perry 1998). According to Perry (1998) some researchers have advocated as few as two cases be utilized. Hedges (1985) suggested a maximum of 12 cases while Miles and Huberman (1994) note that more than 15 cases can make the research unmanageable. Given the various view points, there seems to be a weak agreement on a range for case selection with two to four as the minimum and 12 to 15 as the maximum number (Perry 1998). To assess whether a company's business model was responsible for that company's success/failure in the online channel, in the present study, a sample of three companies was selected. In order to develop the initial set of constructs and variables (i.e., conceptual framework) the analysis of one company, from its inception to the present, was conducted. Once the conceptual framework was developed the other cases were used to verify and refine the framework (Perry 1998).

Generally speaking the fewer the number of cases to be analyzed, the greater the opportunity for the researcher to provide depth from the analysis (Voss et al. 2002). A single in-depth case is usually reserved for longitudinal study because it allows the researcher to examine the constructs and their relationships over time. Specifically, the researcher can rely on historical data, which allows for the observation of the sequential and temporal relationship of events. This makes it possible to tease out cause and effect relationships between the constructs and variables of interest. Using historical data also makes it possible for the researcher to select cases that reflect either the presence or absence of the phenomenon under consideration (Voss et al. 2002).

The single case longitudinal study, however, is not without its problems. One of the main problems concerns post-rationalization, which is the interpretation of phenomena in a different manner than it would have been interpreted at the actual time of 
the phenomena (Voss et al. 2002). Another problem facing researchers that conduct longitudinal analyses concerns access. In order to gain a full understanding of certain phenomena, and the variables driving the phenomena, it may be necessary to be allowed access to sensitive or proprietary information and/or data. Those in control or possession of this information may not wish to allow the researcher access to it. Consequently, the resulting theory from the single case study may be incomplete. Hence, the fewer the number of cases analyzed, the less generalizable the finding and the greater the threat of researcher bias (Voss et al. 2002). On the other hand, the greater the number of cases analyzed, the more general and less in-depth the research findings. Thus, regardless of the actual number of cases to be analyzed, there are benefits and limitations that need to be considered.

Further, it is also necessary to build in controls which help to define the population. These controls are the factors that must be present/absent in order for a case to be included in the population. By building these controls into the construction of the population, the researcher is in the position to be able to hold certain factors constant while allowing others to vary as they naturally would (Meredith 1998; Voss et al. 2002). The factors being held constant can be considered blocking variables. It should be noted that the number of control variables may change during the theory building process. Specifically, as the analysis progresses, the researcher may determine that an initial control variable is insignificant and may subsequently remove it as a population criterion. On the other hand, the researcher may find that a previously unused or unknown variable is significant for delineating the population and it may be added as a population criterion. In relation to the online grocery industry, the control variable served as a moderating 
variable that helped to explain how, under different conditions, the relationships between the variables of interest change. For the current study, a geographic control was initially selected and used to separate companies in the online grocery industry into those in the United States and those in the United Kingdom.

\section{Developing Research Instruments and Protocols}

Good research protocol is necessary to enhance the rigor of the case based theory building process (Yin 1994). The protocol contains the research instrument(s) that are used in the data collection process, as well as the procedures and guiding rules to be followed for using the research instruments (Perry 1998). In addition, it also specifies from whom, and/or from where, different types of information or data are to be collected. In general, the central component of the research protocol is the set of questions that are used in interviews. The protocol should summarize the subject to be covered during the interview, state as specific as possible the questions to be asked, and indicate, in as much detail as possible, the type of data required (Voss et al. 2002). If several cases are used in the theory building process, the protocol becomes important because it acts as a guideline for collecting the information/data and as a boundary for determining what type of data is to be collected. Thus, the protocol helps to increase the reliability and validity of the case data being collected (Perry 1998).

Although the interview protocol serves as the guiding rules for conducting interviews, there are certain instances when it is necessary to alter the protocol. These alterations manifest as adjustments to the data collection instrument such as the addition of questions to the interview protocol or the additions of questions to a questionnaire. 
From a case based theory building process, these adjustments allow the researcher to probe emergent themes or to capitalize on special circumstances that may be present in a certain situation. For theory building research, these adjustments or alterations are allowed because the researcher is attempting to gain as much insight as possible from each case. Thus, altering the interview protocol has the potential to allow the researcher to better ground the theory and/or to provide new theoretical insight (Eisenhardt 1989). Nonetheless, this does not mean that the researcher should make changes haphazardly. Changes to the research protocol should be made in a controlled manner in order to take advantage of a unique situation.

In case study theory building research, there are usually multiple data sources for the researcher to use. These include structured and unstructured interviews, personal observations, informal conversations, attendance at meetings, surveys, and archival sources (e.g., company minutes, 10-k reports, and other company documents) (Eisenhardt 1989; Voss et al. 2002). Although many case studies rely on the collection of primary (e.g., interview) data, it is not necessary for this type of data to be used in order to conduct a case study. "An excellent case can be written using secondary data and information, rather than going to the company and interviewing top managers. Using secondary sources such as news releases, annual reports, industry surveys, magazine articles, and the Internet can be advantageous [for case study research]” (David 2003, p. 37). In relation to the online grocery channel, secondary sources were used to develop the initial conceptual framework. This framework specified the variables and components of interest, provide definitions for those variables and components, and describe the relationship between the variable, components, and company success. 
In the event that it is necessary to conduct interviews, the researcher needs to answer the critical question concerning the number of respondents to be contacted. This decision hinges on a determination of who might possess the information being sought. If one person can reliably answer a set of questions, then the researcher should focus attention on determining who that key person might be. However, if no one person possesses, in entirety, the information or data being sought, the researcher should determine the set of individuals who collectively have that information and interview each of them (Voss et al. 2002). Once the key informants have been identified, collecting this information can be accomplished either through telephone, live interviews, or through written questionnaires.

Also, although the terms qualitative research and case study are usually considered synonymous, there does exist the need, and desirability, for quantitative data to be included (Eisenhardt 1989; Wacker 1998; Voss et al. 2002). The inclusion, or generation, of quantitative data is sometimes necessary in order to highlight certain patterns (de Ruyter et al. 1998; Woodside and Wilson 2003). For example, with quantitative data, statistical relationships that are not readily observable to the researcher at the time of the analysis may be revealed. Using qualitative data techniques, the researcher may gain an understanding of the rationale or theory underlying the relationship uncovered via the quantitative analysis (Eisenhardt 1989). Hence, using multiple secondary sources, both quantitative and qualitative, can provide a significant amount of data on which to build theory. Just as in hypothesis testing research, the triangulation made possible from these various data sources increases the reliability and validity of the constructs and provides for stronger substantiation for the resultant 
hypotheses (Eisenhardt 1989). This, in turn, allows for a much richer assessment and understanding of the phenomenon involved. In relation to the collection of case data for the online grocery channel, newspaper articles (i.e., business press articles) and archival sources such as company prospectuses, $10-\mathrm{K}$ reports, and annual reports were the primary sources of data. Interviews were also used to help verify emergent results and to provide a context for interpreting the data.

\section{$\underline{\text { Data Analysis }}$}

Once the case study data has been collected, the theory building process then moves to the data analysis phase. This is generally a two step process, but in certain situations, it reduces to a single step process. If the theory is being developed from a single case study, the data analysis stage will be strictly a within case process. However, if two or more case studies form the basis of the data, then the first step will be a withincase analysis while the second step will be a cross case analysis (Eisenhardt 1989; Patton 1990; Perry 1998; Voss et al. 2002). For the analysis of the online grocery home delivery channel, both methods were utilized.

\section{Within-Case Data Analysis}

At the very foundation of the theory building process is the analysis of the data. There is no standard format for the within case data analysis process. One part of the process is simply the pure description of the situation which becomes the foundation on which theory is developed. With a longitudinal case study, one can construct an analysis based on the sequence of events. A pragmatic starting point can be simply to construct 
some type of display for the data to see if there are discernable relationships between the variables. A display is a visual method for presenting the data in a systematic manner so that the researcher can look for patterns. The actual representation of a display may be a simple array, an event listing, a critical incident chart, time-ordered matrices, or taxonomies (Miles and Huberman 1994; Voss et al. 2002). There are probably as many ways to construct a display as there are researchers. Regardless of the method chosen by the researcher to display the data, the ultimate goal is for the researcher to become intimately familiar with each case as a stand alone entity before generalizing across cases. For the online grocery industry, looking at each company from its inception to the present was considered a longitudinal analysis. As a result, listing the events from year to year was the method used for developing the display used to determine the variables of interest and the relationships between them.

\section{Cross-Case Data Analysis}

Once the within-case analysis is complete, the researcher must guard against the tendency to over generalize the results. Due to the fact that people are generally poor processors of information (Eisenhardt 1989), cross-case analysis is designed to protect the researcher from jumping to conclusions prematurely, and perhaps falsely, based on limited data or personal biases. Thus, the aim of cross-case analysis is to strengthen the internal validity of the findings and to increase their generalizability. This is accomplished by triangulation or the use of multiple data sources.

Just as with a within-case analysis, there are a number of methods for conducting cross-case analyses. Perhaps the simplest and most effective is to construct an array or 
display. Once this is done, the researcher can pick a group, category, or dimension and search within the resultant sub-samples for similarities or differences (Eisenhardt 1989; Voss et al. 2002). In a similar vein, the researcher can select pairs of cases and then look for similarities and differences between them (Voss et al. 2002) or the researcher could divide the data in terms of data type and look for similarities and differences (Eisenhardt 1989). If the case data are well-coded and quantified, continuous measures or data ordered in sequence can be developed. It may then be possible to express the data in graphical form or, if the data are organized in terms of continuous measures, it may be possible to conduct statistical analyses (Miles and Huberman 1994). In the end, the ultimate goal of cross-case analysis is to force the researcher to go beyond initial impression formed via the within-case analysis. For the three companies selected a threeway cross-case analysis was conducted. This allowed for the examination of common factors, factors related to the structural category (e.g., pure-play, partnership, and hybrid), and factors related to a specific company and the impact of these factors on company success/failure.

\section{Hypothesis Generation}

Case study analyses can be used for both hypothesis testing and theory development. In hypothesis testing framework, the researcher has some initial hypotheses which are then tested using the case study data. In the theory building framework, the idea is to shape and develop new hypotheses from the case study data (Eisenhardt 1989; Voss et al. 2002). The process of theory building generally has four steps which include definition of the variables, delineation of the domain, articulation of 
the relationships (model building), and theory prediction and empirical support (Wacker 1998). In case study theory building, each of these steps may involve an iterative process. That is, from an initial case, the researcher may develop and define a set of constructs and variables that are potentially related to the phenomenon of interest. At the same time, a tentative model of the relationship between the variables themselves and the phenomenon of interest is developed. From this model, the researcher then develops propositions or hypotheses. The resulting model and propositions/hypotheses are then compared to the data stemming from a second case. Analysis of the second case may then lead to the reconceptualization of the domain, the variables, their relationships, and/or even the propositions/hypotheses themselves (Eisenhardt 1989). This iterative process continues until there is a close fit between the theory and the case study data. At this point, the hypotheses are well grounded in the data and it is then possible to develop an empirical test for the theory.

Eisenhardt (1989) relates this iterative process to the development of a single construct measure based on multiple indicators in hypothesis testing research. Using multiple sources of data, the researcher builds measures for each construct. These measures should discriminate one construct from the other, and as such, establish construct validity. The difference between hypothesis testing research and theory building research is that in theory building research the constructs, their definitions, and their measurements emerge from the analysis process instead of being specified a priori. Based on the three cases analyzed in this study several hypotheses were posited. 


\section{Enfolding Literature}

In the theory building process it is important to determine how the emergent concepts, theory, or hypotheses relate to existing literature and theory. Researchers should refrain from the notion that what they are examining has not been studied before (Eisenhardt 1989; Voss et al. 2002). In reviewing the emergent theory, the researcher should ask what is the theory similar to, what is it in conflict with, and why. This may entail looking across a broad spectrum of literature.

Literature that expresses similar findings is noteworthy because it ties together underlying similarities in phenomena in areas that may otherwise not be associated with one another. On the other hand, literature that conflicts with the emergent theory provides the researcher with an opportunity to delve deeper into an issue in order to clarify the conflict.

Even in the traditional hypothesis testing research paradigm, there is usually an attempt to link the research findings to the general literature in order to strengthen them. In theory building research, linking the emergent theory to the existing literature becomes critical because it strengthens its internal validity and the generalizability.

Having expressed the main tenants of the case based theory building process used in this study, the focus now turns to assessing the different types of possible business

models that companies operating in the online grocery channel could use. The following section lists the factors that were used in this study to delineate the possible business models. 


\section{Chapter IV}

\section{Delineating Online Grocery Store Business Models}

One aim of this study was to ascertain the different possible types of business models that could be used by companies operating in the online channel. In order to delineate these various online grocery store business models, five key factors were taken into consideration. These factors included: (1) the amount of physical assets involved (Hays, Keskinocak and de Lopez 2004), (2) the method of order fulfillment, (3) the method of delivery (Copacino 1996), (4) recipient presence, and (5) the receptacle method (Kamarainen 2001; Punakivi, Yrjola, and Holmstrom 2001; Yrjola 2001) (see Table 1).

\section{$\underline{\text { Amount of Physical Assets }}$}

One key factor for categorizing the various online grocery store business models is the amount of physical assets involved. Physical assets here refer to the actual level of investment in, and/or ownership of, physical locations, including property and structures, for stocking and selling product inventory to the public. It does not refer to the level of investment in product inventory or the amount of inventory owned. Taking the amount of physical assets into consideration, the different business models can be represented on a continuum of increasing physical asset concentration. At one extreme are organizational formats with the least amount of physical asset concentration (e.g., pureplays) while at the other extreme are organizational formats with the greatest amount of physical asset concentration (e.g., pure brick-and-mortars) (Chen 2003). 
Table 1

Factors of Online Grocery Store Business Models

1. Asset Concentration

1. Pure-Play

2. Partnership Between Pure-Play and Brick-and-Mortar

3. Brick-and-Mortar

2. Order Fulfillment

1. Picking From Local Store Shelves

2. Picking From a Fulfillment Center Located in a Store

3. Picking From a Dedicated Central Fulfillment Center

3. Delivery Method

1. Having the Customer Pick Groceries Up From the Store

2. Having the Customer Pick Groceries Up From a Local Pickup Point

3. Having Groceries Delivered by a Third Party

4. Delivering the Groceries to the Customer's Home by Grocer

4. Consumer Presence

1. Attended

2. Unattended

5. Type of Receptacle

1. Reception Box

2. Delivery Box

Based on this factor, four general forms of grocery stores were identified. These included pure-plays, BAMs, click-and-mortars, and pure-play/brick-and-mortar partnerships. However, given that the focus of this comparison was on the online grocery channel, only the pure-plays, click-and-mortar (i.e., hybrid), and the pure-play/brick-andmortar partnership models were considered. The decision to exclude the brick-andmortar format was intuitive because the model did not have an online component. Excluding this format from the analysis results in the classification presented by Hays, Keskinocak and de Lopez (2004), which groups the various online grocery business models into the categories of (1) pure-play online, (2) a brick-and-mortar company 
selling online, or (3) a partnership/merger between a pure-play online and a brick-andmortar company (see Figure 1).

Figure 1: General Categories of Online Grocery Store Models

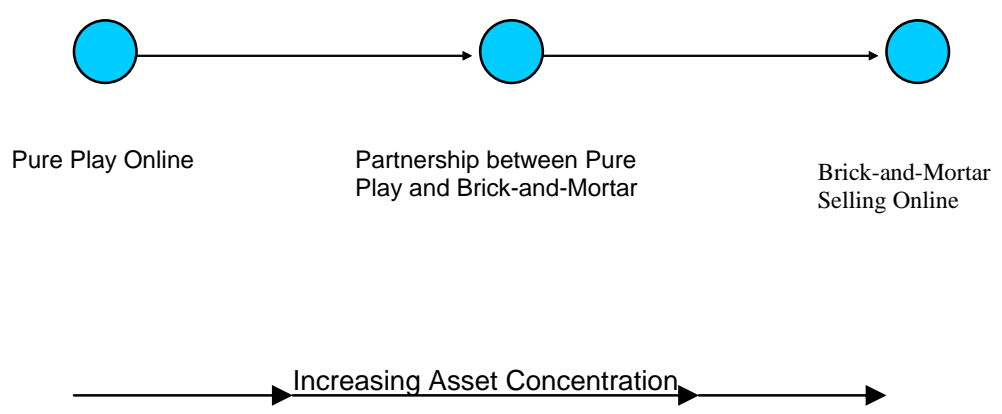

\section{Method of Order Fulfillment}

When assessing online grocery store business models, another significant factor to take into consideration was the method of order fulfillment used (de Koster 2002). The three main methods for filling customer orders include: (1) picking from a local store shelf (Hays et al. 2004; Doukidis et al. 2001; Ogawara, Chen, and Zhang 2003), (2) picking from a fulfillment center located in a local store (Hays et al 2004; Doukidis et al. 2001; de Koster 2002), or (3) picking from a dedicated central distribution center (Hays et al. 2004; Doukidis et al. 2001) (see Table 1).

Picking orders from local stores shelves allows the company to leverage its current physical assets. Once an order is placed, it is sent to the closest store where it is then filled. Employees use either hand held devices or devices attached to special shopping carts to guide them through the store to the proper location where they pick the 
products on the customer's shopping list. An advantage of this fulfillment method is that it is simple to set up with minimal costs (Hays et al. 2004; Yrjola 2003). Further, it allows a company to enter the online grocery channel quickly without having to develop a new distribution system and it does not require the building of costly facilities (Hays et al. 2004; Kamarainen et al. 2001). Also, the distance from the store to the consumer is shorter, which may result in a shorter time between placing and receiving an order. This increases the service level the company can offer the customer.

There are disadvantages with this fulfillment method as well. One of the main disadvantages is that this method is not scalable (Hays et al. 2004). Specifically, there comes a point when inefficiency sets in because the volume of orders being processed causes heavy in-store traffic as the pickers and general store patrons move around the aisles and jockey for positions in checkout lines. Further, when operating at or near capacity, this method may cause stockouts on store shelves for fast moving products. In addition, this order fulfillment method is very labor intensive and becomes costly as the volume of orders increases due to needing to have pickers and delivery personnel at each location (Kamarainen et al. 2001; Hays et al. 2004).

Picking from dedicated fulfillment centers (or warerooms) located within stores is a way of leveraging the current assets of the store while seeking some of the benefits associated with warehouse fulfillment. What separates this type of fulfillment method from that of the in-store fulfillment method is the manner in which the inventory is arranged. These fulfillment centers are organized to increase picking efficiency by arranging the inventory into zones based on the demand for the product (Kamarainen et al. 2001). However, once an order is received, it is filled in a similar fashion as it would 
be in the in-store fulfillment method. One of the primary advantages of this picking method is that it is less costly to modify an existing store than to build a large automated warehouse fulfillment and distribution center (Hays et al. 2004). In comparison to the instore fulfillment method, warerooms are easier to scale as order volume increases. Also, transportation costs are similar to the in-store fulfillment method but are lower than those of the central warehouse fulfillment method. Further, there is the advantage of shared costs between the store and the dedicated fulfillment unit (Hays et al 2004).

A primary disadvantage with this fulfillment method is that as order volume grows, it is not as scalable as a central warehouse fulfillment center (Hays et al. 2004). Moreover, there is the difficulty in keeping track of the inventory in both the store and the local dedicated fulfillment center. In addition, there still remains the cost associated with the labor for the fulfillment and delivery components because it is necessary to have delivery vehicles and personnel at each local fulfillment center.

Stand alone fulfillment centers are usually warehouses that are detached from the store and do not deal directly with the customer. They can range in size from 30,000 to 340,000 square feet and have varying levels of automation ranging from minimal to full automation. In addition to their size, these fulfillment centers tend to have different temperature zones to keep the various types of inventory fresh and contamination free (Hays et al. 2004). In comparison to the wareroom fulfillment centers, dedicated warehouse fulfillment centers can be 40 times larger and have an inventory capacity similar to a large supermarket. Most of these types of facilities are highly automated using conveyor belts and carrying bins to assemble orders (Hays et al. 2004). 
The warehouse fulfillment facility has advantages and disadvantages associated with it. In terms of advantages, it allows for centralized inventorying which provides better inventory tracking, higher turnover rates, and lower inventory costs. The order picking and packing can be automated, thereby lowering the labor costs (Kamarainen et al. 2001). It is also more efficient and scalable for large volumes of orders, but to take advantage of its scalability, capacity utilization must be high and cannot vary significantly over time (Hays et al. 2004; Kamarainen 2003).

In terms of the disadvantages, there is a high initial cost of between 20 and 35 million to build one of these large highly automated facilities, while a less automated facility costs between $\$ 4$ and $\$ 6$ million (Kamarainen et al. 2001). In addition, there is also the cost associated with acquiring, implementing, and maintaining inventory management and routing hardware and software. Moreover, the cost of making deliveries can be high because these facilities tend to be located in remote places that are a considerable distance from the customer base (Hays et al. 2004).

\section{Method of delivery}

A third factor to take into consideration when delineating online grocery store business models was the method of delivery. For many of these companies this was a major component of their service (de Koster 2002). For the online grocer, there are generally three main options for delivering groceries to the customer which include: (1) having the consumer pick the groceries up from the store (Hays et al. 2004; Kamarainen 2001), (2) have the customer pickup the groceries from a local pickup point (Hays et al. 2004; Kamarainen 2001; Doukidis et al. 2001; Copacino 1996), and (3) delivering the 
groceries to the consumer’s home (Hays et al. 2004; Punakivi 2001; Kamarainen 2001;

Doukidis et al. 2001; Park and Regan 2000; Copacino 1996) (see Table 1).

Having the consumers pickup their groceries from the store provides them with the least level of service. However, for those customers constantly on the move or those who are unsure about their daily schedules, this may be a desirable option (Hays et al. 2004). These customers benefit from being able to reduce their shopping time and are freed from a delivery time window. For those consumers not on the go with flexible schedules, they lose the benefit of having their groceries delivered while gaining the burden and cost of having to still make a trip to the grocery store. From the online grocer's perspective, this is a very cost effective method because there are no delivery costs associated with it. There is a cost for either outsourcing the order taking function or for acquiring the hardware and software necessary to perform the order taking function internally. In addition, there is also the cost of holding the customers' orders until they can pick them up. Thus, customer orders must be kept in a dedicated location so they are ready when the customers arrive and those items that are temperature sensitive must be stored in an area that will allow them to remain fresh and uncontaminated. Moreover, the opportunity cost associated with making this dedicated area available must also be considered.

Another delivery option is to have the customers pick their groceries up from a local pickup point. In this scenario, the online grocer and the customer agree on a location where the groceries will be delivered by the grocer and picked up by the consumer. This method increases the service level by allowing customers to take possession of their orders in locations other than the store itself. Using this delivery 
method, a truck carrying from 20 to 500 customer orders would arrive at an agreed on location where it would then wait for a designated period of time. During this period, customers arrive and take possession of their orders. For individuals who are constantly on the move, this may be of great utility for them especially if the pickup location is convenient for them to reach. A primary concern with this delivery method is determining how to select the delivery locations. This decision needs to take into consideration the actual level of service the company wants to provide, in accordance with the cost associated with providing that service level. The more locations that the company uses, the greater the service level for the customer, and the greater the delivery cost for the company. Likewise, the longer the wait time for the company at the chosen location, the greater the labor cost to the company. In addition, there is the opportunity cost associated with the idle wait time for the delivery personnel and the truck.

The last delivery method, and the one most associated with online grocers, is home delivery. For this method of delivery, there are two options: (1) having a third party deliver the groceries to the customer's home or (2) having the store itself deliver the groceries to the customer's home. Relying on a third party to deliver the groceries reduces the service level offered and makes the delivery service less flexible. For instance, deliveries can only be made when the third party deliverer is open for operation which may be early in the morning, during normal work hours, or late at night. Also, there may be specific time slots available for making deliveries, which may make it difficult for customers to plan their schedules around. Further, the third party delivery companies may not operate on certain days (e.g., holidays) which may impact a customer's decision to purchase online. There are, however, some benefits associated 
with using a third party delivery company. From a customer perspective, these delivery companies may offer a flat delivery fee based on the weight, not on the dollar amount, of the products purchased. For the grocer, having a third party to deliver the customers' groceries results in lower delivery costs especially in terms of personnel, fuel, and vehicle maintenance costs.

The second method for home delivery requires the online grocer to deliver the groceries itself. With this method, the online grocer assumes all the costs associated with delivering customers' orders to their homes. As with the other delivery methods, the company must determine the customer service level it want to provide. This entails making decisions concerning the number of delivery days, operating time during the day, and the time window for actual delivery (Hays et al. 2004). The more days during the week that the company decides to conduct delivery operations, the greater the service level for the consumer, but the more costly it is for the company in terms of operational and delivery costs. Operational costs increase because there must be personnel to pick and load the orders for delivery while from the delivery perspective, there must be personnel to actually make the deliveries. These operational and delivery costs are tempered by the hours of operation. In terms of the customer service level, the longer the hours of operation, the more likely the customer will be able to select a time window that is suitable to him/her. Therefore, the more hours during the day that the company dedicates to the delivery function the more costly the function becomes.

Factoring in the delivery time window increases the complexity of the delivery costs component. Again, from a customer service level perspective, the narrower the delivery window, the greater the benefit to the customers in terms of the amount of time 
they must wait to receive their orders. However, for the company, the narrower the delivery window, the less efficient and more costly the delivery function may become. Efficiency may decline because in order to comply with a narrow delivery time window, the company may have to dispatch delivery vehicles that have suboptimal order volumes. Thus, more deliveries will have to be made to the same general location in order to satisfy the delivery time window. Also, traffic conditions need to be taken into consideration since it is difficult to make on time deliveries when the delivery vehicles are stuck in traffic. These factors, when taken together, drive up the company's labor and fuel costs and increase the wear on its delivery vehicles. Thus, when determining the customer service level for the delivery function, the online grocer needs to take into consideration the cost structure associated with that level of service.

\section{$\underline{\text { Recipient Presence }}$}

If the company chooses to have the customer pick up the groceries from a local pickup point, or if the company chooses to actually deliver the groceries to the consumer's home, then the customer's presence becomes another factor to be considered (Doukidis et al. 2001; Kamarainen 2001; Campbell and Savelsbergh 2005). The presence of the consumer at the point of delivery can be classified according to the criteria: (1) attended and (2) unattended. When the customers are at home to receive their groceries, or must be present at a local delivery point to take possession of their groceries, the method of reception is termed 'attended'. When the customers are not at home to receive their groceries, or they can take possession of their groceries at a local 
pickup point without the company's delivery personnel present, the method of reception is termed 'unattended' (see Table 1).

When an online grocer uses an attended reception method, there are certain advantages and disadvantages associated with it. The main advantage is an increase in customer satisfaction resulting from the time savings that the customers experience by not having to commute to the grocery store to do their own shopping. Another advantage is that the customers can take possession of their groceries at a time and place that is convenient for them. Further, attended delivery makes it possible for the customers to assess the accuracy of the order. From the company's perspective, attended delivery allows the company to put a human face on its service thus shortening the perceived distance between the customer and the store.

When the online grocer uses unattended reception, there is also an increase in the customers' satisfaction stemming from the time they save by not having to commute to the grocery store to do their shopping. Moreover, there is the added benefit of allowing the customers to free themselves altogether from the delivery time window. Thus, the customers can take possession of their groceries at a time that is convenient for them. For the time-pressed customer this is a significant benefit. From the company's perspective, unattended reception increases the efficiency of the delivery function by allowing the company to make deliveries at times that benefit it. Further, it also allows the company to maximize the number of deliveries made on a single run by optimizing the number of orders per delivery vehicle.

The main disadvantage for both methods of reception is that they each result in an increase in the cost structure for the company by requiring it to develop and maintain a 
delivery channel. These costs may include the buying or leasing of a fleet of vehicles for making deliveries and the hiring of employees to actually make the deliveries. The key issues related to the delivery function concern keeping certain groceries cold and others frozen. Thus, the development of the cold chain is critical. This problem is compounded when unattended reception is considered. As a result, to develop the cold chain, a company would need to spend a significant amount of money on either the development or the purchase of equipment designed to facilitate delivery of temperature sensitive goods. These functions could be outsourced to a third party but, in so doing, the company may lose the ability to monitor and regulate the service which can affect customer satisfaction levels.

\section{$\underline{\text { Receptacle Method }}$}

If an online grocer decides to use an unattended delivery method, the type of receptacle used for storing the groceries becomes the fifth factor to consider (Doukidis et al. 2001). For unattended grocery delivery, there are two types of receptacles: (1) reception boxes and (2) delivery boxes. A reception box is a stand alone unit (similar to a refrigerator) that is installed in the customer's home (usually the garage, basement or car port) and has different temperature compartments for storing the various types of groceries. A delivery box is an insulated box that attaches securely to a holding unit which is bolted to the wall or ground outside the customer's home (Punakivi 2001). It tends to be smaller than a reception box and instead of having an autonomous power supply for cooling certain compartments it uses dry ice, or some equivalent, to accomplish that task (see Table 1). If the company is responsible for providing the 
reception boxes, this form of unattended delivery is the most costly method of home delivery. When choosing this method, the company must consider the time horizon for its investment. It may be several years before the company makes a profit even if it has an efficient delivery system. The delivery box is more economical than the reception box, but it too has a significant upfront cost associated with developing the units, purchasing enough for pickup and delivery, and installing and maintaining the holding units.

Combining these five factors resulted in the expanded list of possible online grocery store business models presented in Appendixes 1, 2, and 3. The choices made for each of the five factors has a significant bearing on a company's operational efficiency, overall cost and revenue structure, and the level of service that can be offered to the customer. Given these various business models, the question turned to which model(s) was (were) better suited for operating successfully in the online grocery channel? In order to make this assessment, it was necessary to determine the key drivers of online grocery store profitability. To do this, an initial company was selected for analysis and its profit structure was examined. The process for selecting the first company is discussed in the next section. 


\section{Chapter V}

\section{Case 1 - Peapod}

\section{$\underline{\text { Case } 1 \text { Selection Process }}$}

The main research question guiding this study was whether or not an online grocer's success/failure was a function of its business models. One of the secondary research question alluded to whether profitability could be used as a measure of success. In an attempt to understand whether online grocery stores were moving in the direction of becoming profitable, it was necessary to determine the components of profitability. In accordance with case based theory building, for insight into a particular phenomenon it may be necessary to select a sample in a purposeful fashion. That is, in relation to the topic under study, there may only be a handful of companies feasible for study. Therefore, in order to build a conceptual framework for online grocery store profitability, an initial company was selected and its profit structure was examined.

To be selected for analysis, a company had to have been a going concern from the inception of the online grocery channel. With the collapse of many online grocers during the late 1990s and early 2000s, this criterion was quite stringent. The contention was that the profit structure for these companies would be in its simplest form during the formative years of the online channels development. As a result, it would be easier to construct a rudimentary conceptual framework for examining the components of a company’s profit structure. It was further assumed that the profit structure of this company would change and become more complex as it matured with the channel. Thus, it would be possible to assess the changes in the profit structure, the interaction of new determinants with those already present in the structure, and, ultimately, the impact these 
changes had on company profit. Based on this criterion, the first company selected was Peapod.

Peapod was one of the first online grocers and, from its inception the company underwent several changes to its business model, which resulted in changes to its profit structure. Thus, Peapod served as a prime candidate for determining the different components associated with online grocer profitability. By examining the published material on Peapod, a rudimentary framework of its profit structure was compiled. As Peapod changed its business model, the framework was altered to reflect the inclusion of new, or the removal of old, profit structure components. Hence, each time Peapod changed business models, the framework was updated to reflect the changes. What is presented next is the analysis and discussion of Peapod's profit structure from its inception to 2006.

\section{Case 1 - Analysis}

This section presents the analysis of Peapod's profit structure. According to the case based theory building methodology, once the case study data have been collected they then needs to be analyzed. Since the objective was to begin the theory building process utilizing a single company, data analysis at this point was strictly a within-case analysis. Although there is no specific standard format for conducting a within-case analysis of data, a critical step in the process is the pure description of the situation. For Peapod, this information was gathered from published sources on a year to year basis and arranged sequentially to reflect the business activities of the company. Thus, the analysis of Peapod's data was similar to that of a longitudinal analysis, which is based on the 
analysis of the sequence of events. Once the Peapod data were organized into a sequential format, they were scrutinized to determine the components of the company's profit structure. Specifically, the data were analyzed serially from year to year with the intentions of listing those components that were deemed important to the company's profit structure. Because Peapod changed business models several times, altering its profit structure each time, it was necessary to group together certain years in order to assess the impact of those changes on the business model. What is presented next is a narrative of Peapod's business activities concentrating on factors related to the company’s profit structure.

\section{Initial Profit Structure from 1989 to 1991}

Peapod was founded in 1989 by Andrew and Thomas Parkinson, and became the first U. S. online grocery retailer. The two brothers spent six months developing the prototype software necessary for online grocery shopping. The first major cost that the company incurred was the development of its prototype ordering software. The expertise for developing and maintaining the software was internalized since it was done by one of the company founders. Although the company had been established it did not have an official place of business. To rectify that problem, Andrew Parkinson arranged a deal with the Technology Innovation Center (TIC), an incubator operated in affiliation with Northwestern University (Salay 2003). There the company leased 225 square feet of space for $\$ 400.00$ dollars per month. By working with TIC Peapod did not have to worry about capital expenditures associated with leasing land and facilities or purchasing 
land and building facilities. During this first year, the company also received its first source of seed capital in the amount of $\$ 60,000.00$ dollars.

To begin servicing its customers, Peapod negotiated a partnership deal with Jewel-Osco to acquire the necessary grocery inventory (Peapod, S-1, 1997; Salay 2003). In this arrangement, once customers purchased their groceries from Peapod, Peapod would then purchase them from Jewel at retail price. This method of inventory acquisition was very costly for Peapod. However, Peapod did not have to worry about the costs associated with holding and replenishing the inventory. Looking at the listing of the various business models, based on its partnership with Jewel-Osco and its method for picking groceries, Peapod was operating using model $6 \mathrm{~b}$ under the partnership category (see Appendix 1).

Once the inventory deal was completed, Peapod began providing its service to a small test market of 400 households in Evanston, Illinois. When customers placed a complete order, Peapod dispatched its professional shoppers to a local Jewel-Osco grocer to pick and package the groceries. This was a labor intensive activity, but given the scale of business operations, the costs were manageable at the time. Once the customer's order was filled it was delivered to the customer's home (Rewick 1998). Peapod's primary goal was to offer its retail partner a new channel format and build awareness for the brand (Peapod, S-1, 1997, p. 3). According to Andrew Parkinson, "[o]ur concept, from the beginning, was to work with retailers, providing them with a service cheaper than they could provide it to themselves" (Mathews 1997, p. 38). In the beginning, deliveries were made with the help of employees, family members, and friends of the founders using 
their own personal vehicles. Hence, the cost associated with the delivery function was minimized. Thus, fuel costs were the main delivery function cost incurred.

Profit Structure Analysis for Peapod: Profit Structure from 1989 to 1991

Investment Capital

1. The only source of capital was investment capital - IC(1) (see Table 2).

\section{Cost Components}

2. Initially, Peapod had three sources of costs: development of software - CC(1), 'software maintenance' - CC(11) and the leased space from TIC - CC(2). These costs were directly related to total cost (see Table 2).

3. Based on the method of inventory acquisition Peapod incurred an additional cost. This was the inventory acquisition inventory acquisition - CC(3) cost and was directly related to total cost (see Table 2).

4. In order to provide fulfillment operations Peapod incurred picking costs - CC(4), packing and assembly costs - CC(5), and fuel costs - CC(6). These costs were directly related to total cost (see Table 2).

\section{Performance Drivers}

5. Inventory acquisition - CC(3) was determined by the number of orders received and the number of items per order. Thus, the performance drivers 'number of orders' - $\mathrm{PD}(3)$ and 'items per order' - $\mathrm{PD}(13)$ were related to the cost component 'inventory costs' - CC(3) (see Figure 2).

6. The fuel cost was a variable cost driven by the number of orders delivered, the number of vehicles used for delivery, and the number of delivery attempts. Thus, the fuel cost was determined by the performance drivers 'number of orders delivered' - PD(9), 'number of vehicles used' - PD(15), and 'number of delivery attempts' - $\mathrm{PD}(14)$ in conjunction with the cost component 'fuel cost' - CC(6) (see Figure 2). (As delivery activity increases the fuel cost increased as well. 
However, this relationship may not be linear due to gains in efficiency from the routing and optimization process).

7. The 'picking costs' - CC(4) and the 'packing and assembly costs' - CC(5) had both fixed and variable components. The fixed component stemmed from the hiring and training of employees and related directly to total cost. For picking costs, the variable component represented the bulk of the cost and was based on how long it took the employees to pick the items, how many orders the employee needs to fill, the number of items needed for each order, and the number of items in inventory. Thus, the picking cost was determined by the performance drivers 'picking speed' - PD(5), 'number of orders' - PD(3), 'items per order' - PD(13), and 'number of lines picked' - $\mathrm{PD}(16)$ in conjunction with the cost component 'picking cost' - CC(4) (see Figure 2).

8. For the packing and assembly cost, the bulk of this cost was also variable in nature and was determined by the number of items in an order and the number of orders. Thus, the impact of packing and assembly costs on total costs was determined by the performance drivers 'items per order' - PD(13) and 'number of orders' - $\mathrm{PD}(3)$ in conjunction with the cost component 'packing/assembly costs' - CC(5) (see Figure 2).

9. Given that the picking and assembly functions were handled by employees, these employees were susceptible to fatigue and tedium. As a result, their picking speed fluctuated. As the picking speed fluctuated, it was reasonable to assume that picking accuracy and assembly accuracy would fluctuate as well. Hence, the performance driver 'picking speed' -PD(5) had an impact on the performance drivers 'picking accuracy' PD(6) and ‘assembly accuracy' - PD(7) (see Figure 3).

During the initial startup phase, Peapod conducted its own local branding and customer acquisition activities by putting fliers on phone poles and bulletin boards in local areas (Mathew 1997). Due to the company's limited amount of working capital, the branding and customer acquisition costs were significant. However, it was not long before the company began to co-brand with its retail partner in order to gain customer 
Table 2

Peapod's Profit Structure Components: 1989 to 1991

\begin{tabular}{|c|c|c|c|}
\hline $\begin{array}{l}\text { Sources of Operating } \\
\text { Capital }\end{array}$ & Front-End Cost Components & $\begin{array}{l}\text { Back-End Cost } \\
\text { Components }\end{array}$ & Performance Drivers \\
\hline Investment Capital & Order Taking Costs & Capital Expenditures & Customer Patronage Drivers \\
\hline \multirow[t]{2}{*}{ 1. Investment Capital } & 1. Website Related & 2. Capital Expend. & 1. Number of Orders (PD3) \\
\hline & 1a. Design Cost & 2a. Facilities Costs & 2. Items per Order (PD13) \\
\hline Fees & In-House (CC1) & Lease Costs (CC2) & 3. Number of New Customers (PD1) \\
\hline 1. Installation/Packaging (RC2) & 1b. Maintenance Costs & & $\begin{array}{l}\text { 4. Number of Repeat Customers } \\
\text { (PD2) }\end{array}$ \\
\hline \multirow[t]{2}{*}{$\begin{array}{l}\text { 2. Subscription/Membership } \\
\text { (RC3) }\end{array}$} & In-House (CC11) & Inventory Expense & $\begin{array}{l}\text { 5. Number of Membership Renewals } \\
\text { (PD4) }\end{array}$ \\
\hline & & 3. Inventory Costs & \\
\hline Delivery Revenue & Customer Relationship Costs & 3а. Acquisition Cost (CC3) & Delivery Service Drivers \\
\hline \multirow[t]{2}{*}{ 1. Core Delivery Fee (RC4) } & 7. Customer Awareness & & 6. Number of Orders Delivered (PD9) \\
\hline & 7a. Done Alone (CC7) & Fulfillment Expenses & 7. Number of Vehicles Used (PD15) \\
\hline Inventory Sales & 7b. Partnership (CC9) & 4. Picking Costs & $\begin{array}{l}\text { 8. Number of Delivery Attempts } \\
\text { (PD14) }\end{array}$ \\
\hline \multirow[t]{9}{*}{$\begin{array}{l}\text { 1. Grocery Inventory Sales (RC } \\
\text { 12) }\end{array}$} & 8. Customer Acquisition Costs & 4a. Human Capital (CC4) & \\
\hline & 8a. Done Alone (CC8) & 5. Packing/Assembly Costs & Operational Service Drivers \\
\hline & 8b. Partnership (CC10) & 5a. Human Capital (CC5) & 9. Fulfillment Performance \\
\hline & & 6. Delivery Costs & 9a. Picking Speed (PD5) \\
\hline & General And Administrative & 6a. Fuel Costs (CC6) & $\begin{array}{l}\text { 9b. Number of Lines Picked } \\
\text { (PD16) }\end{array}$ \\
\hline & 10. General and Admin. (CC17) & & 9c. Picking Accuracy (PD6) \\
\hline & $\begin{array}{l}\text { 11. Other Costs and Expenses } \\
\text { (CC18) }\end{array}$ & & 9d. Assembly Accuracy (PD7) \\
\hline & & & \\
\hline & & & \\
\hline
\end{tabular}


Figure 2: Peapod’s Back-End Cost Components and Performance Drivers: 1989 - 1991

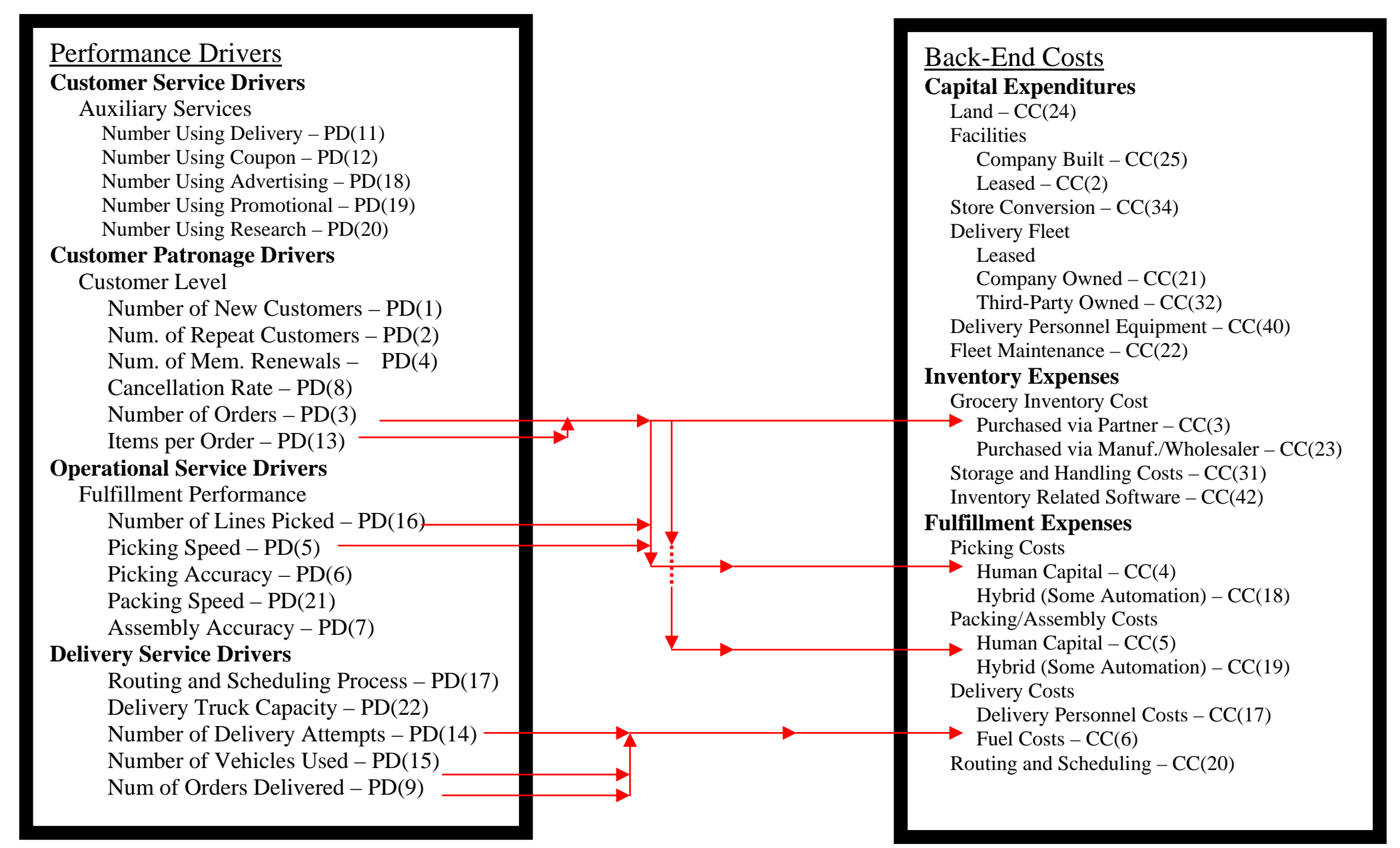


support for the service. In essence, Peapod changed its focus from trying to acquire customers on its own to leveraging the customer base of its partners. By co-branding the company was attempting to transfer the trustworthiness associated with the Jewel brand to itself. The decision to co-brand was also a cost cutting move that allowed Peapod to save money on awareness/recognition and acquisition activities.

Peapod received additional revenue based on its fee structure. In order to receive their service, Peapod customers had to pay a \$25.00 dollar installation fee, a \$30 dollar annual membership fee, a five dollar software packaging fee, and a five dollar delivery service fee (Salay 2003). Apparently, in order to strengthen brand loyalty, Peapod required customers to pay stiff up front fees for the service. This was to ensure that customers who joined the service had an incentive to continue using it. Further, Peapod also received revenue from selling the grocery inventory.

In order for Peapod to operate efficiently, the company needed to have a corporate staff, and personnel in the accounting, marketing, and human resource functions. In addition, during the natural course of business, the company incurred deprecation expenses and amortization costs.

\section{Revenue Components}

10. Peapod's revenue came from installation and packaging fees - RC(2), membership fees - RC(3), core delivery service fees - RC(4) and 'grocery inventory sales' - RC(12) (see Table 2).

\section{Cost Components}

11. In order to engage in branding and customer acquisition activities, the company incurred additional costs. These costs were 'customer awareness’ - CC(7) and ‘customer acquisition’- CC(8) and both 
Figure 3

Peapod's Performance Drivers and Performance Drivers: 1989 -1991

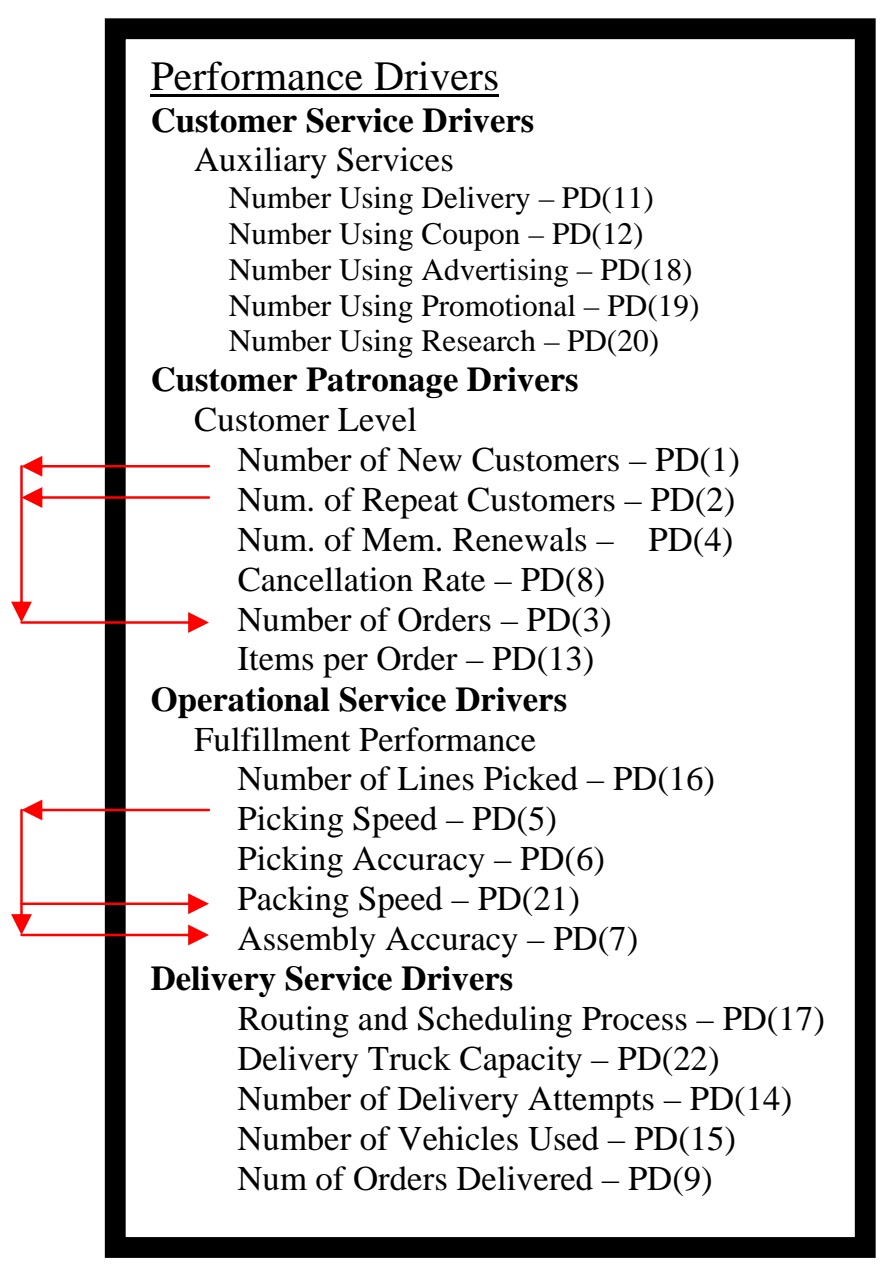


were directly related to total cost. However, these costs proved to be prohibitive for Peapod and they negotiated a deal with Jewel to conduct co-branding activities. Hence, Peapod's costs shifted from branding by themselves to branding in partnership with Jewel. This meant moving from 'customer awareness cost' - CC(7) to 'customer awareness cost' - CC(9) and from 'customer acquisition costs' $\mathrm{CC}(8)$ to 'customer acquisition cost' - CC(10). This shift resulted in cost savings for the company (see Table 2).

12. Peapod incurred routine day-to-day costs associated with the general administration of the company. These costs were incorporated under the heading general and administrative costs. The cost component 'general admin. costs' - CC(25) was directly related to total cost. In addition, Peapod also incurred costs associated with depreciation and amortization. These costs and expenses were incorporated under the heading of 'other costs and expenses' - CC(26) (see Table 2).

Performance Drivers

13. Since 'customer awareness cost' - CC(9) and 'customer acquisition cost' - CC(10) costs were designed to stimulate brand awareness and prompt customer trial they were linked to the performance drivers 'number of new customers' - PD(1) and 'number of repeat customers' - PD(2) (see Figure 5).

14. The actual amount of revenue generated from installation and packaging fees was determined by the number of new customers signing up for Peapod's service. Since this was a one time fee it only affected new customers. This revenue was generated by the performance driver 'number of new customers' - $\mathrm{PD}(1)$ in conjunction with the revenue component 'packaging/installation' - RC(2) (see Figure 4).

15. The revenue generated from membership and subscription fees was determined by the number of new customers signing up for Peapod's service and the number of customers who renewed their membership. This fee had to be paid by each new member and periodically by all other customers wanting to continue using the service after their current membership had lapsed. Thus, the revenue generated from membership/subscription fees was determined by the performance drivers 'number of new customers' - $\mathrm{PD}(1)$ and 'number of membership renewals' - $\mathrm{PD}(4)$ in conjunction with the revenue component ‘subscription/membership fees' - RC(3) (see Figure 4). 
16. The core delivery revenue was determined by the number of customer orders delivered and the fee assessed for each order delivered. Therefore, the portion of total revenue generated from core delivery services was determined by the performance driver 'number of orders delivered' - $\mathrm{PD}(9)$ in conjunction with 'core delivery fee' - RC(4) (see Figure 4).

17. Grocery inventory sales were determined by the numbers of orders and the number of items per order. This was represented by the link between the performance drivers 'number of orders' - $\mathrm{PD}(3)$ and 'items per order' - $\mathrm{PD}(13)$ in conjunction with the revenue component 'grocery inventory sales' - RC(12) (see Figure 4).

18. The performance driver 'number of orders' - PD(3) was determined by the number of new customers and the number of repeat customers. (The assumption was that new customers would order at least once). Thus, this performance driver was determined by the other performance drivers 'number of new customers' - PD(1) and 'number of repeat customers' - PD(2) (see Figure 3). (It should be noted that the 'number of orders' - $\mathrm{PD}(3)$ and the 'number of orders delivered' $\mathrm{PD}(9)$ represent their net amounts, and should be corrected for order cancellations. Here order cancellation represents the termination of delivery for a specific order placed by a new or repeat customer. On the other hand, the performance driver 'cancellation rate' - $\mathrm{PD}(8)$ refers to a new or repeat customer terminating their service relationship with the company. Therefore, one is order specific and the other is customer specific).

During Peapod's formative years, there were other factors that affected the company's profit structure. These factors were broadly grouped into company related factors and market structure related factors. The company related factors included scalability, method of delivery, the rate of expansion, automation level, and employee/management commitment. Scalability relates to the extent to which the capacity for picking, packing, and assembling customer orders could be increased in a cost effective manner. For the purpose of this study, the fulfillment function was 
Figure 4

Peapod's Revenue Components and Performance Drivers: 1989 -1991

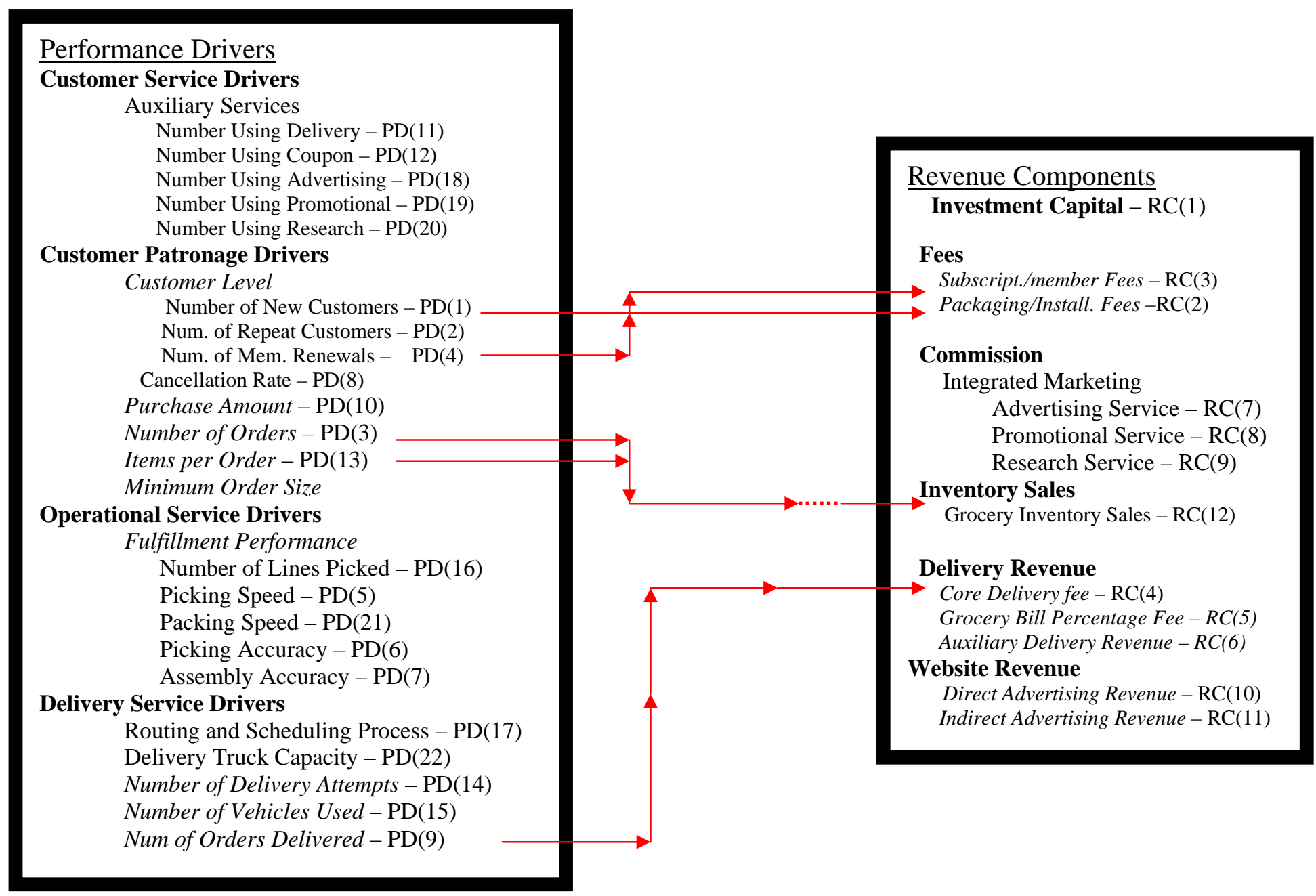


Figure 5

Peapod's Front-End Cost Components and Performance Drivers: 1989 -1991

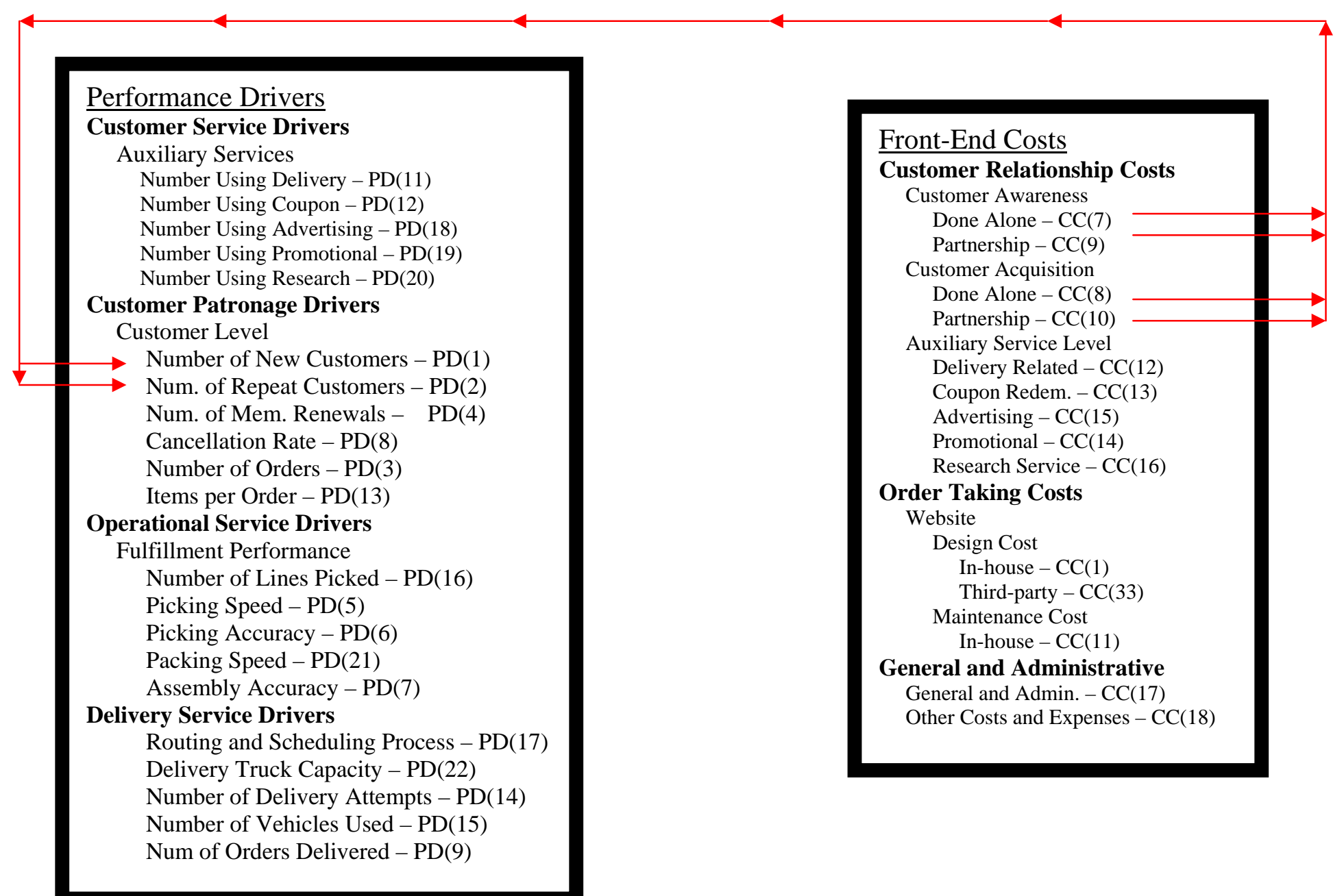


assessed based on the extent of its scalability which ranged from low to high. Peapod's initial model was a pure in-store model which meant that the number of orders that could be handled within a store was limited and once that capacity was reached, increasing it past that point would result in inefficiency. Although the in-store picking method was the least scalable, it was the easiest to implement in terms of time and capital requirements. Given Peapod's initial financial status, it is understandable why this method was selected (see Appendix 1).

Table 3

Other Mediating/Moderating Factors for Peapod: 1989 - 1991

\begin{tabular}{|c|c|}
\hline & $1989-1991$ \\
\hline Company Related Factors & \\
\hline Scalability (Picking Location) & \\
\hline $\begin{array}{c}\text { High } \\
\text { Medium Dedicated Warehouse } \\
\text { Large Dedicated Warehouse }\end{array}$ & \\
\hline $\begin{array}{c}\text { Moderate } \\
\text { Wareroom (Hybrid) } \\
\text { Small Dedicated Warehouse }\end{array}$ & \\
\hline $\begin{array}{c}\text { Low } \\
\text { In-Store }\end{array}$ & $\mathrm{X}$ \\
\hline & \\
\hline Method of Delivery & \\
\hline Store Pickup & \\
\hline Local Pickup & $\mathrm{X}$ \\
\hline Home Delivery & \\
\hline & $\mathrm{X}$ \\
\hline Company Rate of Expansion & \\
\hline Slow & \\
\hline Moderate & \\
\hline Fast & \\
\hline & $\mathrm{X}$ \\
\hline Automation Level & \\
\hline High & \\
\hline Moderate & \\
\hline Low & \\
\hline
\end{tabular}


Table 3 (Cont'd)

Other Mediating/Moderating Factors for Peapod: 1989 - 1991

\begin{tabular}{|c|c|}
\hline \multicolumn{2}{|l|}{ Company Related Factors (Cont'd) } \\
\hline Employee/Management Commitment & \\
\hline High & $\mathrm{X}$ \\
\hline \multicolumn{2}{|l|}{ Moderate } \\
\hline \multicolumn{2}{|l|}{ Low } \\
\hline \multicolumn{2}{|l|}{ Market Structure Factors } \\
\hline Connectivity & NA \\
\hline \multicolumn{2}{|l|}{ Internet Structure } \\
\hline \multicolumn{2}{|l|}{ High } \\
\hline \multicolumn{2}{|l|}{ Moderate } \\
\hline \multicolumn{2}{|l|}{ Low } \\
\hline Internet Penetration & NA \\
\hline \multicolumn{2}{|l|}{ High } \\
\hline \multicolumn{2}{|l|}{ Moderate } \\
\hline \multicolumn{2}{|l|}{ Low } \\
\hline Internet Access & NA \\
\hline \multicolumn{2}{|l|}{ High } \\
\hline \multicolumn{2}{|l|}{ Moderate } \\
\hline \multicolumn{2}{|l|}{ Low } \\
\hline Cost of Internet Service & NA \\
\hline \multicolumn{2}{|l|}{ High } \\
\hline \multicolumn{2}{|l|}{ Moderate } \\
\hline \multicolumn{2}{|l|}{ Low } \\
\hline \multicolumn{2}{|l|}{ Population Structure } \\
\hline \multicolumn{2}{|l|}{ Population Size } \\
\hline \multicolumn{2}{|l|}{ Population Density } \\
\hline \multicolumn{2}{|l|}{ Geographic Location } \\
\hline \multicolumn{2}{|l|}{ Continental } \\
\hline North America & $\mathrm{X}$ \\
\hline South America & \\
\hline Europe & \\
\hline Asia & \\
\hline
\end{tabular}


Table 3 (Cont'd)

Other Mediating/Moderating Factors for Peapod: 1989 - 1991

\begin{tabular}{|c|l|}
\hline & $1989-1991$ \\
\hline Market Structure Factors (Cont'd) & \\
\hline Country & \\
\hline United States & $\mathrm{X}$ \\
\hline United Kingdom & \\
\hline Japan & \\
\hline & \\
\hline County/Parish & \\
\hline Urban & $\mathrm{X}$ \\
\hline Suburban & \\
\hline Rural &
\end{tabular}

Another factor to take into consideration was the method of delivery. How the company chooses to deliver the customer's groceries had a significant bearing on the company's cost structure. In the formative years, attended home delivery was Peapod's chosen method of delivery. This was a costly method for delivering groceries because it required the company to incur most, if not all, the cost associated with transporting the groceries to the customer's home. It did, however, result in higher customer satisfaction in terms of delivery options (see Table 3).

Further, the company's rate of expansion was also a necessary factor to consider when analyzing the profit structure. In general, the faster the rate of expansion, the greater the impact on the company cost structure. This is due to the higher costs associated with acquiring facilities, inventory, delivery means, and the human capital necessary to conduct operations in multiple locations. Since Peapod did not utilize its own facilities, these costs were largely composed of inventory acquisition and labor costs. As a result, Peapod's expenses were mostly variable in nature. Thus, using their current model, each time Peapod entered a new market, the company had to enter into a 
partnership with a local BAM grocer and then hire and train several employees to perform the fulfillment functions. Due to the variable nature of this model, as the number of customers increased the costs associated with servicing those customers also increased. This situation was then repeated for each market that the company entered. Thus, a fast growth rate would compound this problem resulting in a volatile cost structure that would require a longer time horizon for the company to break even. Initially, Peapod only operated in one market which meant that it had a slow rate of expansion (see Table 3).

At the time of Peapod's founding, it did not rely on any automation. Therefore, there were no gains in efficiency originating in the fulfillment functions. Foregoing automation allowed Peapod to save capital that would have gone to purchasing and running an automated system. Employee and management commitment was also important to the company's profitability and survival. Without the sacrifices of the employees, especially in the beginning, Peapod may not have been able to meet its delivery obligations. Also, Peapod's management was dedicated to seeing the company survive and prosper. There were no apparent conflicting motives at work that may have undermined company operations (see Table 3).

The market structure factors included the level of connectivity, population structure, and geographical location. Connectivity was concerned with the ability of the online grocer's customers to access the Internet in order to place orders and communicate with the company. There were four subfactors associated with connectivity which included Internet structure, Internet penetration, Internet access, and cost of Internet service. Internet structure related to the Internet infrastructure present in an area, including the phone lines, fiber optics, and land lines (i.e., DSL). These sub-factors were 
assessed as low, medium, and high (see Table 3). It is unlikely that without a sizable group of potential customers with access to computers, that Peapod would have been able to survive

Population structure refers to the size and density of an area in terms of the population. This factor is directly related to the cost structure because the more disperse the population the greater the cost associated with delivering the groceries to the consumer. Assessing the population structure brings the geographical location into the discussion. Geographical location was assessed at the continental level and the country level (see Table 3). Together the population structure and the geographical location interact to determine the number of households within a specific market in general, and the number within the service area in particular. At this stage of the analysis it was uncertain what impact these factors had on the profit structure of online grocers but it seemed plausible that they may have had some impact.

\section{Financial Data}

No information concerning the financial performance of Peapod could be located for the period between 1989 and 1991. Aside from the information concerning investment capital, no revenue or costs sources could be located. Therefore, there was no financial analysis to present for Peapod's performance during the period 1989 to 1991.

\section{Summary}

Assessing Peapod's profit structure during the first few years revealed that the company was burdened by a significant cost structure (see Table 2). Specifically, the method for inventory acquisition was extremely costly because Peapod was buying the 
inventory from its retail partners at their retail price. Moreover, the fulfillment expenses were also considerable because the picking, packing, and assembly functions were done by employees, which drove up the labor costs. Further, since software design was internalized, the company needed employees who could handle this function which increased the labor costs still further. Lastly, customer awareness and customer acquisition activities were also very costly. However, the company was able to reduce these costs by co-branding with its retail partners.

In terms of revenue, Peapod's core service was the delivery of groceries to customer homes. It was the company's goal to make a profit by providing this service for a fee. However, in looking at the method of inventory acquisition, Peapod was unable to generate a significant profit margin on sales because the company was providing the customer with the groceries at retail price. Therefore, the only sources of income for the company were generated from subscription fees, packaging and installation fees, and core delivery fees. Investment capital served as another source of funding for Peapod. Given Peapod's customer base during this time period, there was no way the company could support its activities by relying solely on revenue. Moreover, investment capital was scarce during these initial years because investors did not understand Peapod's business model. The culmination of this deep cost pit and shallow capital stream resulted in losses for the first few years for Peapod.

Again, since there were no financial data found for Peapod between the years 1989 and 1991, it was not possible to provide an analysis of the actual profit structure components. Thus, support for the increasing cost structure comes from published sources in the business press. 


\section{$\underline{\text { Peapod Profit Structure from } 1992 \text { - } 1996}$}

During this time period Peapod reorganized into Peapod LP, a limited partnership, and continued focusing on building its customer base. Peapod continued developing its ordering software and began looking closely at its operating processes. During 1992, with the help of TIC, the company was able to secure an additional \$35,000.00 in investment capital (Salay 2003). The company also changed its pricing strategy to include a fee representing four to five percent of the total grocery bill. This was done in order to increase the margin on each delivery thus reducing the number of deliveries needed for breakeven.

In 1993, Peapod expanded geographically into the San Francisco area in partnership with Oakland, California based supermarket giant Safeway, Inc. This represented slow but significant expansion. To get their service operational, Peapod hired 35 employees who worked out of a single San Francisco Safeway store. According to Peapod's co-founder and executive vice-president at the time, Tom Parkinson, the company entered the San Francisco market while still expanding in the Chicago market in order to demonstrate to investors that the company could manage more than one city at a time. This was important to Peapod because the company was seeking additional capital through a private placement (Crown 1993). In order to facilitate the expansion Peapod had to improve its ordering software so it could support multi-area operations. Thus, there was a continuing cost for the internal development and maintenance of the ordering software.

In the San Francisco market, customers were able to select from over 10,000 different items (SKU's). In addition, using the computer software customers were able to 
develop up to 25 personalized shopping lists. For an extra fee, Peapod would also allow customers to request their processed film, prescription drugs, stamps, and/or commuter/bus passes. It is unclear whether or not there was a significant cost associated with the implementation of this service. If these extra items could be acquired in the same general location as the grocery items then the cost of this service would be negligible. In this instance the margin for these services should help to increase profit. Furthermore, Peapod provided an additional service to its customers by allowing all Safeway and manufacturers coupons to be accepted with the value credited to the customers' next purchase. In addition, the company also had a 90 minute time window for making deliveries. From Peapod's perspective, the 90 minute delivery window was costly to maintain. Specifically, there were times when the company had to dispatch delivery vehicles that were only half full during times that were not conducive to delivery efficiency (e.g., during high traffic). This made the delivery process inefficient for the company. Hence, Peapod needed to strike some sort of balance between customer service and operational efficiency.

Profit Structure Analysis for Peapod: Profit Structure from 1992 to 1996

Revenue Components

19. Peapod began to charge a percentage fee based on the total amount of the grocery bill. This revenue source was the 'grocery bill percentage fee' - RC(5) (see Table 4).

20. Increasing the service offerings was designed to allow Peapod's service to appeal to a wider segment of the market. By adding these 
Table 4

Peapod's Profit Structure Components: 1992 - 1996

\begin{tabular}{|c|c|c|c|}
\hline Sources of Operating Capital & Front-End Cost Components & $\begin{array}{l}\text { Back-End Cost } \\
\text { Components }\end{array}$ & Performance Drivers \\
\hline Investment Capital & Order Taking Costs & Capital Expenditures & Customer Service Drivers \\
\hline \multirow{2}{*}{ 1. Investment Capital } & 1. Website Related & 2. Capital Expend. & 11. Number Using Delivery (PD11) \\
\hline & 1a. Design Cost & 2a. Facilities & 12. Number Using Advertising (PD18) \\
\hline Fees & In-House (CC1) & Leased (CC2) & 13. Number Using Promotional (PD19) \\
\hline 1. Installation/Packaging (RC2) & 1b. Maintenance Cost & & 14. Number Using Research (PD20) \\
\hline \multirow[t]{2}{*}{ 2. Subscription/Membership (RC3) } & In-House (CC11) & Inventory Expense & \\
\hline & & 3. Inventory Costs & Customer Patronage Drivers \\
\hline Delivery Revenue & Customer Relationship Costs & 3a. Acquisition Cost (CC3) & 1. Number of Orders (PD3) \\
\hline 1. Core Delivery Fee (RC4) & 7. Customer Awareness & & 2. Items per Order (PD13) \\
\hline $\begin{array}{l}\text { 2. Grocery Bill Percentage Fee } \\
\text { (RC5) }\end{array}$ & 7a. Done Alone (CC7) & Fulfillment Expenses & 3. Number of New Customers (PD1) \\
\hline \multirow[t]{2}{*}{$\begin{array}{l}\text { 3. Auxiliary Delivery Revenue } \\
\text { (RC6) }\end{array}$} & 7b. Partnership (CC9) & 4. Picking Costs & 4. Number of Repeat Customers (PD2) \\
\hline & 8. Customer Acquisition Costs & 4a. Human Capital (CC4) & $\begin{array}{l}\text { 5. Number of Membership Renewals } \\
\text { (PD4) }\end{array}$ \\
\hline Commission & 8a. Done Alone (CC8) & 5. Packing/Assembly Costs & 6. Purchase Amount (PD10) \\
\hline 1. Integrated Marketing & 8b. Partnership (CC10) & 5a. Human Capital (CC5) & \\
\hline 1a. Advertising Service (RC7) & & 6. Delivery Costs & Delivery Service Drivers \\
\hline 1b. Promotional Service (RC8) & Auxiliary Services & 6a. Fuel Costs (CC6) & 7. Number of Orders Delivered (PD9) \\
\hline \multirow[t]{2}{*}{ 1c. Research Service (RC9) } & 9. Auxiliary Service Level & & 8. Number of Vehicles Used (PD15) \\
\hline & 9a. Delivery Related (CC12) & & 9. Number of Delivery Attempts (PD14) \\
\hline Inventory Sales & 9b. Coupon Redemption (CC13) & & \\
\hline \multirow[t]{7}{*}{ 1. Grocery Inventory Sales (RC 12) } & 9c. Promotional (CC14) & & Operational Service Drivers \\
\hline & 9d. Advertising (CC15) & & 10. Fulfillment Performance \\
\hline & 9e. Research (CC16) & & 10a. Picking Speed (PD5) \\
\hline & & & 10b. Number of Lines Picked (PD16) \\
\hline & General And Administrative & & 10c. Picking Accuracy (PD6) \\
\hline & 10. General and Admin. (CC17) & & 10d. Assembly Accuracy (PD7) \\
\hline & 11. Other Costs and Expenses (CC18) & & \\
\hline
\end{tabular}


services, Peapod gained another revenue source. This was represented by the revenue component 'auxiliary delivery revenue' - RC(6) (see Table 4).

\section{Cost Components}

21. Peapod increased the service level that it was offering by allowing customers to request their processed film, prescription drugs, stamps, and/or commuter/bus passes as part of their delivery. Increasing the service offerings was designed to allow Peapod's service to appeal to a wider segment of the market. By adding these services, the company incurred additional costs represented by the auxiliary cost component 'delivery related' - CC(12) (see Table 4).

22. The decision to accept Safeway and other product manufacturer's coupons further demonstrated that Peapod was attempting to improve its service offering. To provide this service, Peapod incurred an additional cost. This cost was represented by the front-end cost component 'coupon redemption' - CC(13) (see Table 4). It was not clear whether Peapod received any extra compensation from Safeway or the package goods manufacturers for these services so no revenue generation is discussed.

\section{Performance Drivers}

23. The revenue generated from the grocery bill percentage fee was derived by linking the performance drivers 'purchase amount' $\mathrm{PD}(10)$ and 'number of orders' - PD(3) to the revenue component 'grocery bill percentage fee' - RC(5) (see Figure 6). Since this fee was assessed on each order, it was a major component of Peapod's revenue stream.

24. The more product lines that employees had to pick from, the more costly it became for Peapod due to the increase in the time it took to pick the customer's order. The number of orders and the number of items per order also impacted the picking cost. Hence, the performance drivers 'number of lines picked' - $\mathrm{PD}(16)$, 'number of orders' - PD(3), 'items per order' - PD(13), and 'picking speed' $\mathrm{PD}(5)$ were linked to the cost component 'picking costs' - CC(4) (see Figure 7).

25. The amount of revenue generated by the auxiliary delivery services was determined by the performance driver 'number using delivery' $\mathrm{PD}(11)$ in conjunction with the revenue component 'auxiliary delivery revenue' - RC(6) (see Figure 6). 
Figure 6

Peapod's Revenue Components and Performance Drivers: 1992 - 1996

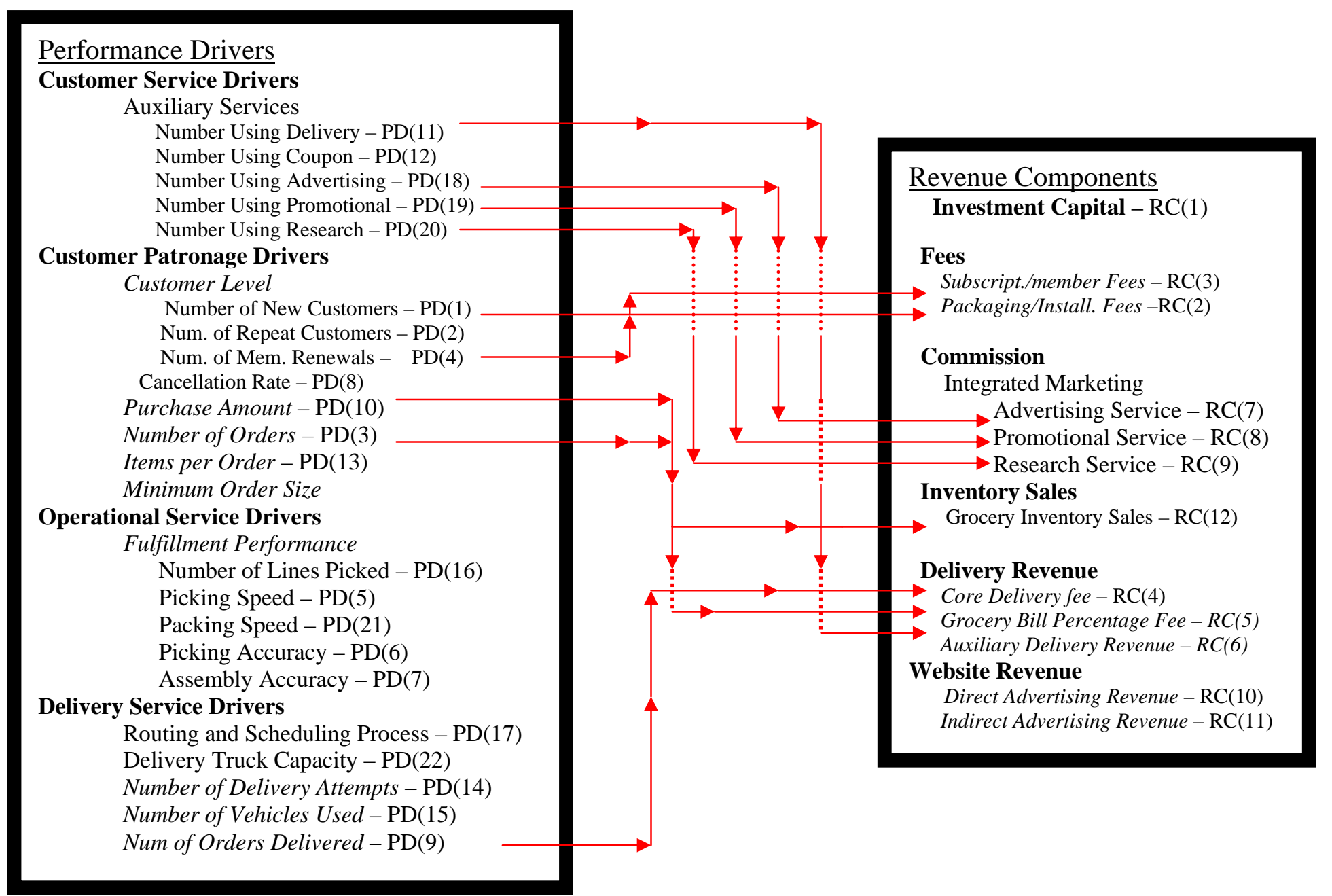


Figure 7

Peapod's Back-End Cost Components and Performance Drivers: 1992 - 1996

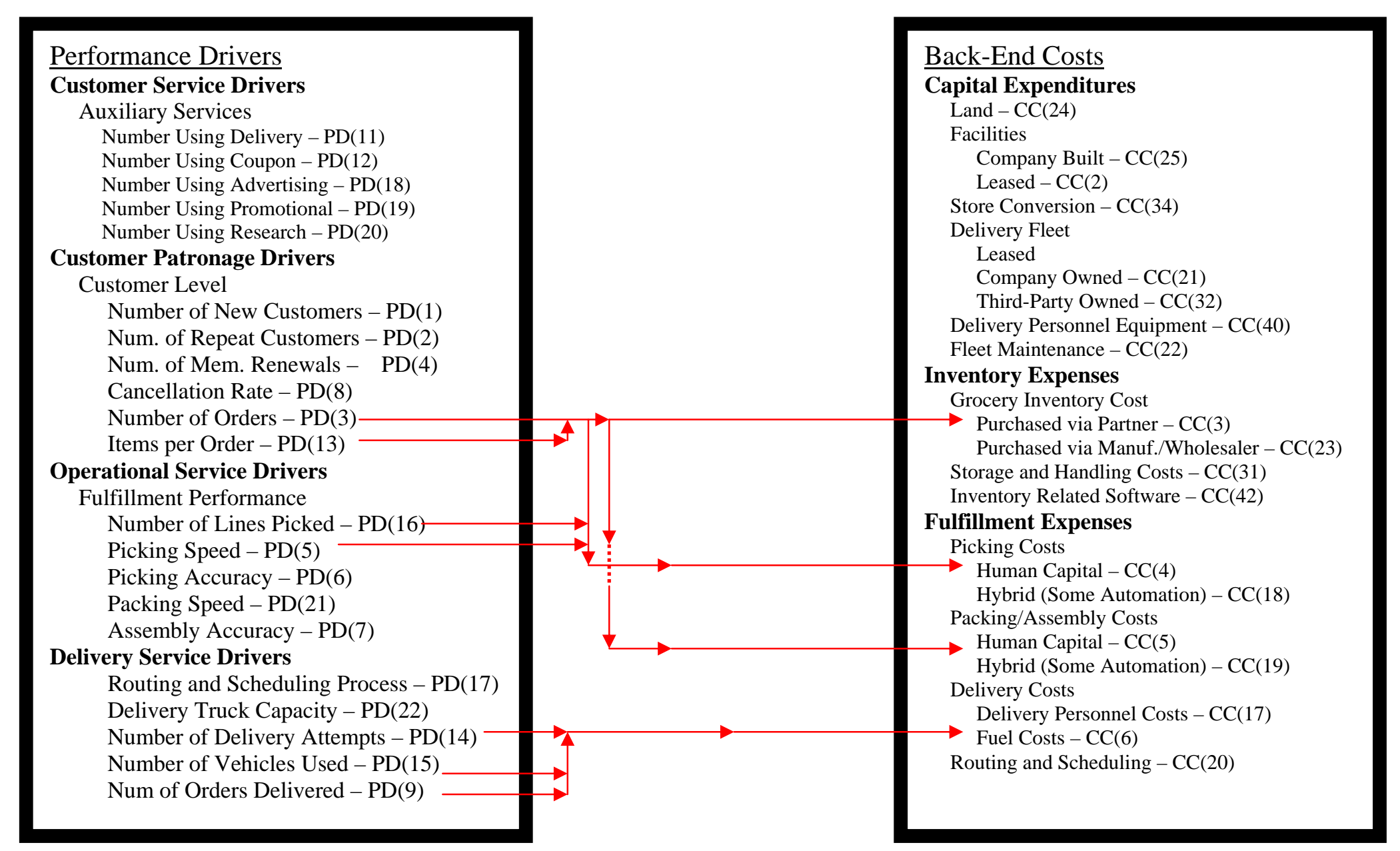


Figure 8

Peapod's Front-End Cost Components and Performance Driver: 1992 - 1996

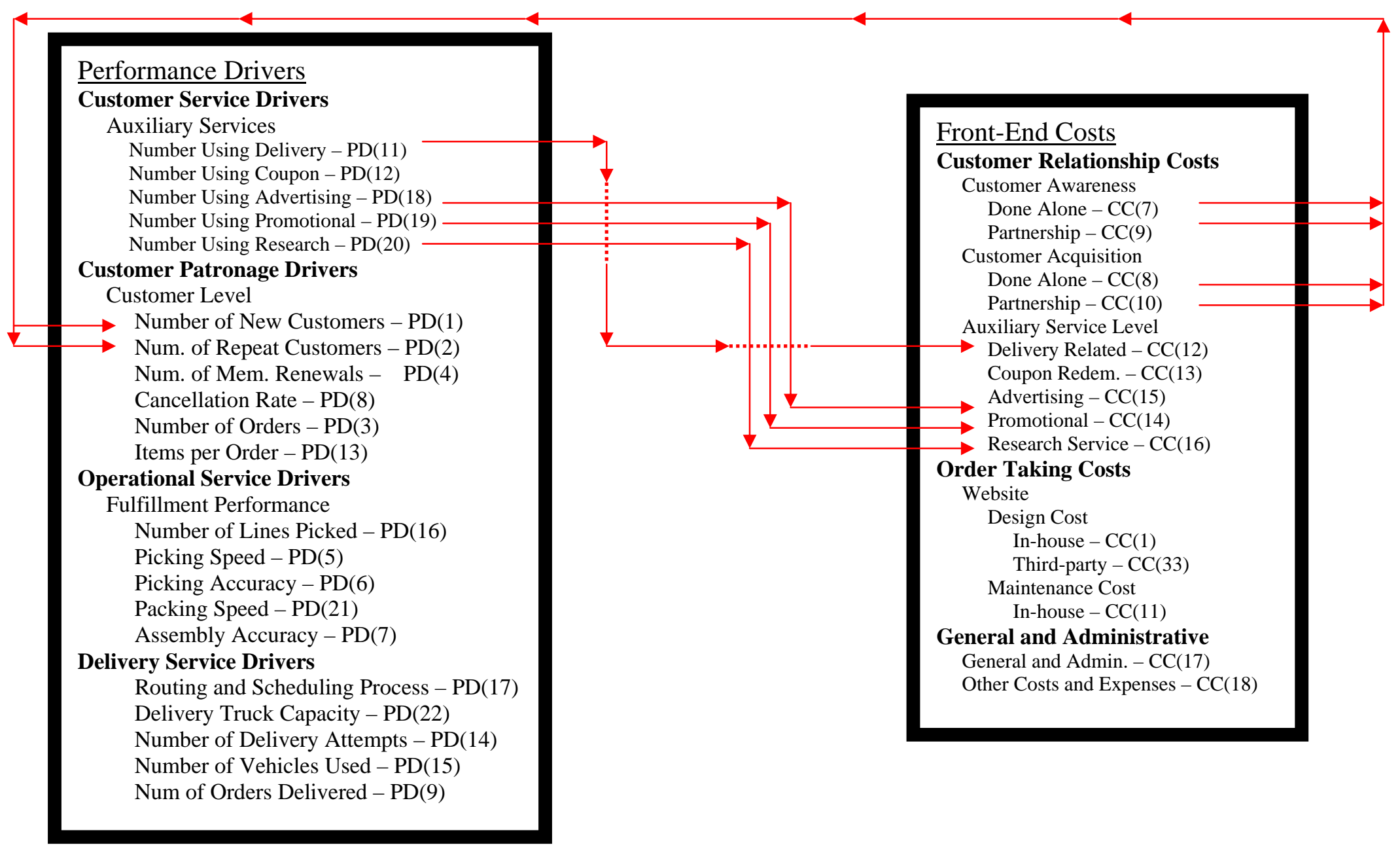


26. The cost associated with the auxiliary delivery service was determined by the performance driver 'number using delivery' $\mathrm{PD}(11)$ in conjunction with the cost component 'delivery related' CC(12) (see Figure 8). Whether or not these auxiliary delivery services make a positive contribution to the company's profit structure depends on the margins that the company can extract.

Other Mediating/Moderating Factors

27. The decision to expand operations indicated that the company had a slow rate of expansion (see Table 5).

TABLE 5

Other Mediating/Moderating Factors for Peapod: 1992 - 1996

\begin{tabular}{|c|l|l|}
\hline & $\begin{array}{l}1989- \\
1991\end{array}$ & $\begin{array}{l}1992- \\
1996\end{array}$ \\
\hline Company Related Factors & & \\
\hline Scalability (Picking Location) & & \\
\hline $\begin{array}{c}\text { High } \begin{array}{l}\text { Medium Dedicated Warehouse } \\
\text { Large Dedicated Warehouse }\end{array} \\
\text { Moderate } \\
\text { Wareroom (Hybrid) } \\
\text { Small Dedicated Warehouse }\end{array}$ & & \\
\hline $\begin{array}{c}\text { Low } \\
\text { In-Store }\end{array}$ & & \\
\hline X & \\
\hline Method of Delivery & & \\
\hline Store Pickup & & \\
\hline Local Pickup & & \\
\hline Home Delivery & & \\
\hline & $\mathrm{X}$ & \\
\hline Company Rate of Expansion & & \\
\hline Slow & $\mathrm{X}$ & \\
\hline Moderate & & \\
\hline Fast & & \\
\hline
\end{tabular}


TABLE 5 (Cont'd)

Other Mediating/Moderating Factors for Peapod: 1992 - 1996

\begin{tabular}{|c|c|c|}
\hline & $\begin{array}{l}1989- \\
1991\end{array}$ & $\begin{array}{l}1992- \\
1996\end{array}$ \\
\hline \multicolumn{3}{|c|}{ Company Related Factors (Cont'd) } \\
\hline \multicolumn{3}{|c|}{ Automation Level } \\
\hline High & $\mathrm{X}$ & \\
\hline \multicolumn{3}{|l|}{ Moderate } \\
\hline Low & $\mathrm{X}$ & \\
\hline \multicolumn{3}{|c|}{ Employee/Management Commitment } \\
\hline High & $\mathrm{X}$ & \\
\hline \multicolumn{3}{|l|}{ Moderate } \\
\hline \multicolumn{3}{|l|}{ Low } \\
\hline \multicolumn{3}{|l|}{ Market Structure Factors } \\
\hline Connectivity & NA & \\
\hline \multicolumn{3}{|l|}{ Internet Structure } \\
\hline \multicolumn{3}{|l|}{ High } \\
\hline \multicolumn{3}{|l|}{ Moderate } \\
\hline \multicolumn{3}{|l|}{ Low } \\
\hline Internet Penetration & NA & \\
\hline \multicolumn{3}{|l|}{ High } \\
\hline \multicolumn{3}{|l|}{ Moderate } \\
\hline \multicolumn{3}{|l|}{ Low } \\
\hline Internet Access & NA & \\
\hline \multicolumn{3}{|l|}{ High } \\
\hline \multicolumn{3}{|l|}{ Moderate } \\
\hline \multicolumn{3}{|l|}{ Low } \\
\hline Cost of Internet Service & NA & \\
\hline \multicolumn{3}{|l|}{ High } \\
\hline \multicolumn{3}{|l|}{ Moderate } \\
\hline \multicolumn{3}{|l|}{ Low } \\
\hline \multicolumn{3}{|l|}{ Population Structure } \\
\hline \multicolumn{3}{|l|}{ Population Size } \\
\hline Population Density & & \\
\hline
\end{tabular}


TABLE 5 (Cont'd)

Other Mediating/Moderating Factors for Peapod: 1992 - 1996

\begin{tabular}{|c|l|l|}
\hline & $\begin{array}{l}1989- \\
1991\end{array}$ & $\begin{array}{l}1992- \\
1996\end{array}$ \\
\hline Market Structure Factors (Cont'd) & & \\
\hline Geographic Location & & \\
\hline Continental & & \\
\hline North America & & \\
\hline South America & & \\
\hline Europe & & \\
\hline Asia & & \\
\hline & & \\
\hline Country & & \\
\hline United States & & \\
\hline United Kingdom & & \\
\hline Japan & & \\
\hline & & \\
\hline County/Parish & & \\
\hline Urban & & \\
\hline Suburban & $\mathrm{X}$ & \\
\hline Rural & & \\
\hline
\end{tabular}

In 1994, Ameritech acquired a minority stake in Peapod with the idea of developing a version of Peapod's service for the interactive television market. The deal gave Peapod access to new technology, but more importantly it gave the company some much needed capital. The funding was used to expand the operation by opening six new fulfillment centers with its retail partners.

Although Peapod continued to expand, the company had not turned a profit in any of the markets it was already operating in. During this expansion the company continued to operate under the same business model. The expansion effort itself signified that Peapod's growth strategy had switched to a moderate one. The objective of this strategy was to spread the high fixed costs over a large enough customer base to generate a profit 
without the need to raise rates or cut customer services. The two main problems with this strategy were that the company was not generating enough revenue to fuel its own growth, and thus had to rely on investment capital for growth financing. Secondly, the variable costs were a more serious problem than the fixed costs were. Since the company entered new markets in partnership with established grocery retailers, their actual fixed costs were low. However, with each new market that Peapod entered, it had to acquire the means to pick, pack and deliver groceries to its customers. The variable cost associated with these functions at each location was a significant portion of the overall cost structure. Thus, the growth strategy that the company had decided on was a major contributor to the ballooning costs. This resulted from the fact that the majority of the company's employees were employed in the picking, packing, and delivery areas. Hence, the company's labor bill was a significant portion of the total cost component. In September 1995, Peapod released its new ordering software, Version 4.0, which allowed the company to begin executing and selling its interactive marketing services. The software development and maintenance costs associated with bringing this software to market were another significant expenditure for the company. The majority of the cost was associated with the development personnel. This proprietary software was capable of implementing any marketing or promotional event desired by a consumer package goods company (CPG). This new revenue component for Peapod was possible because the company's membership database contained extensive information about the shopping behavior and preferences of its members. Thus, Peapod was able to provide the CPGs with an advertising, promotional, and market research service. As a result, Peapod was able to gain another source of revenue. Although the new software version had the 
potential to provide the company with revenue, the cost of developing the software was significant. Peapod's decision to internalize the software development function increased the cost component which contributed to the company's inability to turn a profit.

Coinciding with the release of the new software, and in conjunction with Jewel, Peapod embarked on its first broad-based radio and newspaper media campaign in the Chicago market. This resulted in a 63 percent increase in the company’s membership base from 4,600 in 1994 to 12,500 in 1995. In addition, the number of orders increased by 76 percent from 70,300 in 1994 to 124,100 in 1995 (Peapod, S-1, 1997). Therefore, the customer awareness and acquisition expenses were paying off for the company in the form of increased membership and total orders. In turn, this was having a positive impact on the company's revenue. Moreover, the company also began advertising on its website allowing it to generate another revenue source.

Investment Capital

28. During the year, Peapod received additional investment capital that it used to continue its market expansion. This was represented by the revenue component 'investment capital' - IC(1) (see Table 4).

Revenue Components

29. The Version 4.0 software also allowed Peapod the opportunity to generate additional revenue. This revenue came from the integrated marketing services the company was able to offer participating consumer package goods companies. This new revenue stream was represented by the integrated marketing revenue components 'advertising service' - RC(7), 'promotional service' - RC(8), and 'research service' - RC(9) (see Table 4).

\section{Cost Components}

30. The development and release of Peapod's Version 4.0 software required incurring both design and maintenance costs. This was 
represented by the website related cost components 'design' - CC(1) and 'maintenance' - CC(11) (see Table 4).

31. The co-branding strategy that Peapod was using required the company to commit capital to the awareness and acquisition campaign. This resulted in an increase in total cost stemming from an increase in the cost components 'customer awareness partnership' - CC(9) and ‘customer acquisition partnership’ - CC(10) (see Table 4).

\section{Performance Drivers}

32. The actual amount of revenue that Peapod received from its integrated marketing activities was determined by the number of CPG companies using the advertising, promotional, and research capabilities. This relationship was represented by the links between the auxiliary service performance drivers 'number using advertising' - PD(18), 'number using promotional' - $\mathrm{PD}(19)$, and 'number using research' - $\mathrm{PD}(20)$ in conjunction with the integrated marketing revenue components 'advertising service' - RC(7), 'promotional service' - RC(8), and 'research service’ - RC(9) (see Figure 6).

33. The co-branding activities resulted in an increase in membership and the number of orders. Thus, the customer relationship cost components 'customer awareness partnership' - CC(9) and 'customer acquisition partnership' - CC(10) were linked to the customer patronage performance drivers 'number of new customers' - $\mathrm{PD}(1)$ and 'number of repeat customers' - PD(2) (see Figure 8).

34. The increase in the number of orders resulted from an increase in the number of new customers and the number of repeat customers. Therefore, the customer patronage performance drivers 'number of new customers' PD(1) and 'number of repeat customers' - PD(2) was linked to the customer patronage performance driver 'number of orders' - PD(3) (see Figure 9).

\section{Other Mediating/Moderating Factors}

35. The decision by Peapod to establish operations in six new markets demonstrated that the company had progressed to a moderate rate of expansion (see Table 5). 
Figure 9

Peapod’s Performance Drivers and Performance Drivers: 1992 - 1996

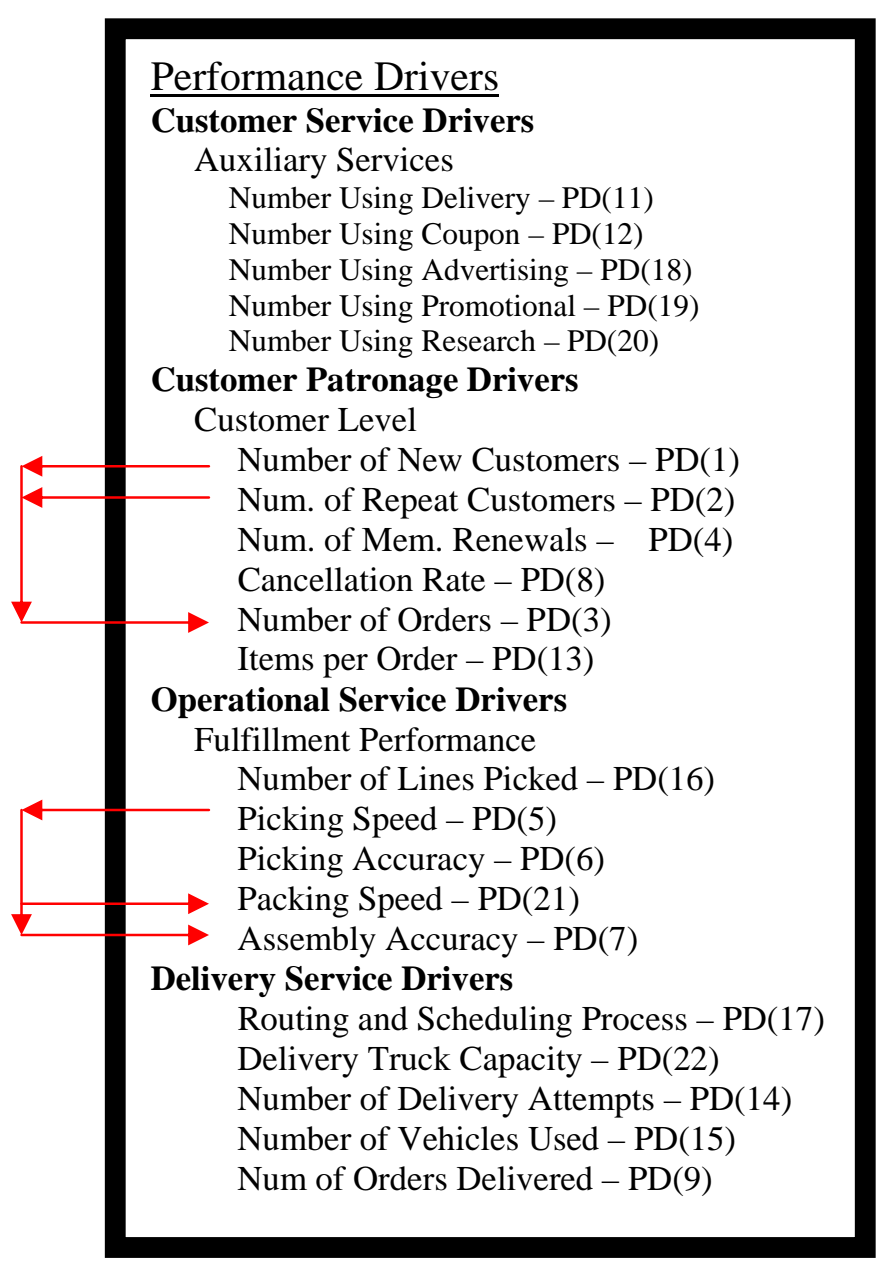


In 1996, Peapod began to take orders over the Internet and for the first half of the year, membership continued to grow. During this period the company expanded into the Columbus and Boston markets, which brought the total number of fulfillment centers to 27 (Peapod, S-1, 1997). Again this indicated a moderate expansion strategy. Further, Peapod realized that a significant portion of its expenses were tied to its fulfillment activities (Cross 1996). Hence, the initial strategy of expanding to dilute fixed costs was failing since the variable costs associated with fulfillment were the real cost drivers.

The advertising campaign that was started in September 1995 was continued through December 1996. During this period marketing and selling expenses increased by 159.9 percent from $\$ 1,533,000$ to $\$ 3,984,000$. Besides the amount directly related to acquisition programs, a portion of this cost was attributed to increased spending necessary to support two new market openings and expanded geographic coverage in Chicago and San Francisco/San Jose. These activities resulted in the number of orders increasing to 201,100 while the number of members increased to approximately 33,300 (Peapod, S-1, 1997).

Also during 1996, system development and maintenance expenses, which included new product development and the maintenance and enhancement of existing systems, increased $54.7 \%$ from $\$ 964,000$ to $\$ 1,492,000$. This increase resulted primarily from higher staffing and associated expenses required to support Peapod's growth. Again, it seemed that by internalizing the software development and maintenance functions, Peapod was substantially increasing the cost component of its profit structure. The fulfillment and software development and maintenance cost accounted for a significant proportion of Peapod's cost structure (Peapod, S-1, 1997). 
During the year Peapod received $\$ 17.25$ million in a private equity placement. The funds were earmarked to enhance its online service, aggressively expand its core business service, and enhance its interactive marketing service. One enhancement added was an Internet e-mail feature. Given the newness of the Internet, this was a significant feature to have at the time. From the company's perspective this did not seem to be costly and it likely enhanced the consumers' overall satisfaction with the service by increasing their satisfaction with the website design and function. Peapod also received revenue from its core delivery services and from its interactive marketing service.

Investment Capital

36. Peapod received an additional 17.25 million in private equity financing. This was represented by the investment component ‘investment capital' - IC(1) (see Table 4).

\section{Cost Components}

37. In order to continue providing the integrated marketing processes to the CPG companies, Peapod incurred expenses associated with the various components. This was represented by the auxiliary service cost components 'promotional'- CC(14), 'advertising' - CC(15), and 'research’ - CC(16) (see Table 4).

\section{Performance Drivers}

38. The actual cost associated with the integrated marketing processes (i.e., advertising, promotional, and research services) was based on the number of CPG companies utilizing the services. Therefore, the performance drivers ‘number using advertising' - PD(18), 'number using promotional' - PD(19), and 'number using research' - $\mathrm{PD}(20)$ were linked to their respective cost components 'advertising' CC(15), 'promotional' - CC(14), and 'research' - CC(16) (see Figure 8). 


\section{Other Mediating/Moderating Factors}

39. With the equity financing that Peapod received during the year the company was able to enter two new markets thereby continuing its moderated expansion strategy (see Table 5).

\section{Financial Data}

During 1992 Peapod reorganized into Peapod LP. As the company continued to expand its profit structure continued to change. Those revenue and cost components that were present in the formative years were still part of Peapod's profit structure. However, the expansion resulted in the addition of new cost and revenue components (see Table 4).

In terms of Peapod's cost structure, it was composed of front-end and back-end costs. The front-end costs include order taking, customer relationship, and general and administrative costs. The back-end costs were composed of capital expenditures, inventory expenses, and fulfillment expenses (see Table 4).

One of the main front-end cost components that Peapod had was associated with the development of its ordering software. Initially the software was designed to operate from a single location, but to facilitate its expansion Peapod had to make improvement in order to support multiple locations. This resulted in an increase in the software development and maintenance costs. In 1995, Peapod released version 4.0 of its software which allowed the company to offer interactive marketing services. The bulk of the cost associated with the software's development was attributed to the development personnel. In 1996, Peapod migrated its service to the Internet. This resulted in significant costs for software development and hardware acquisition. These increases were due mainly to higher staffing and associated expenses. For Peapod, the order taking function was accounted for under the heading 'system development and maintenance (SD\&M) (see 
Table 4). Figure 10 depicts the increase in system development and maintenance expenses during the period between 1992 and 1996 (Peapod, S-1, 1997). Peapod’s decision to internalize the software development function contributed to the company's inability to turn a profit.

Figure 10

Peapod’s System Development and Maintenance Costs: 1992 - 1996

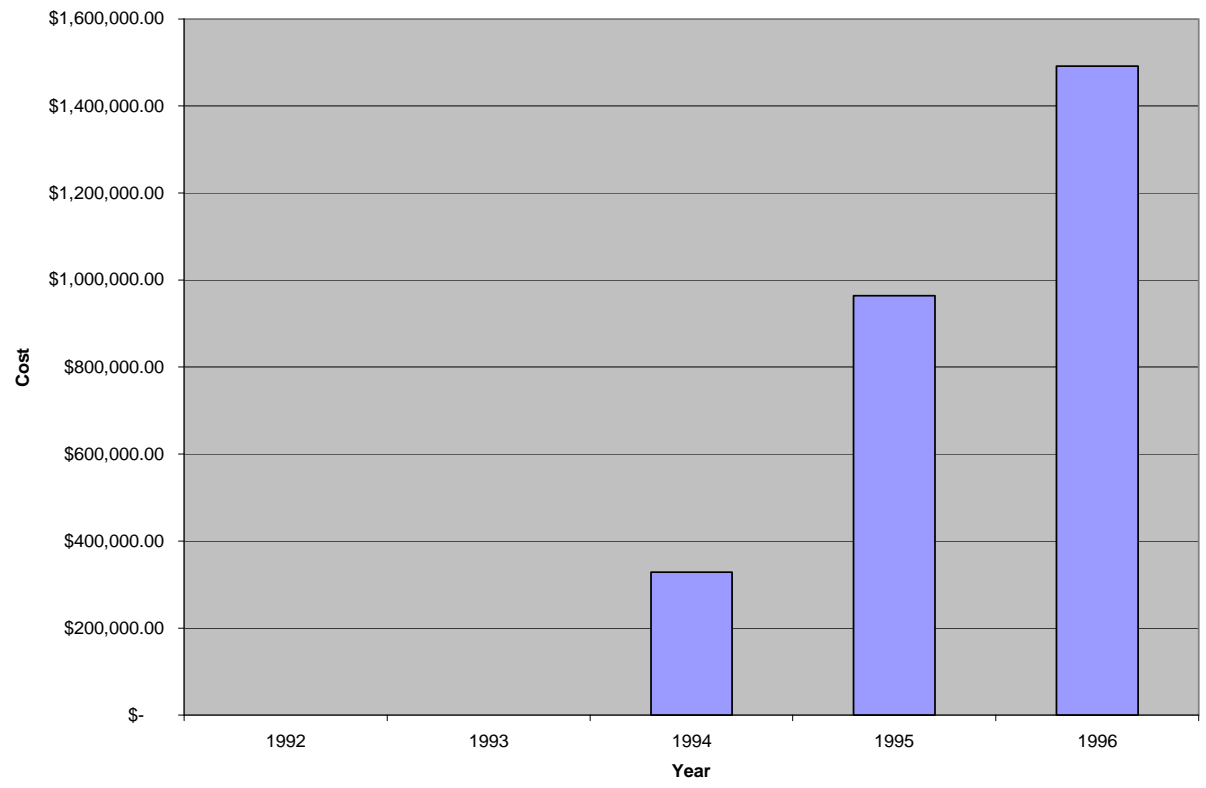

Another main front-end cost component for Peapod was the customer relationship costs. A significant portion of these costs were being shouldered by Peapod's retail partners but Peapod still had to pay a portion. Peapod categorized these customer relationship costs as 'marketing and selling' costs. The marketing and selling costs also included the costs associated with interactive marketing services (see Table 4). Figure 11 depicts the increase in the marketing and selling costs for Peapod during the period 1992 through 1996 (Peapod, S-1, 1997). 
Figure 11

Peapod's Marketing and Selling Expenses: 1992 - 1996

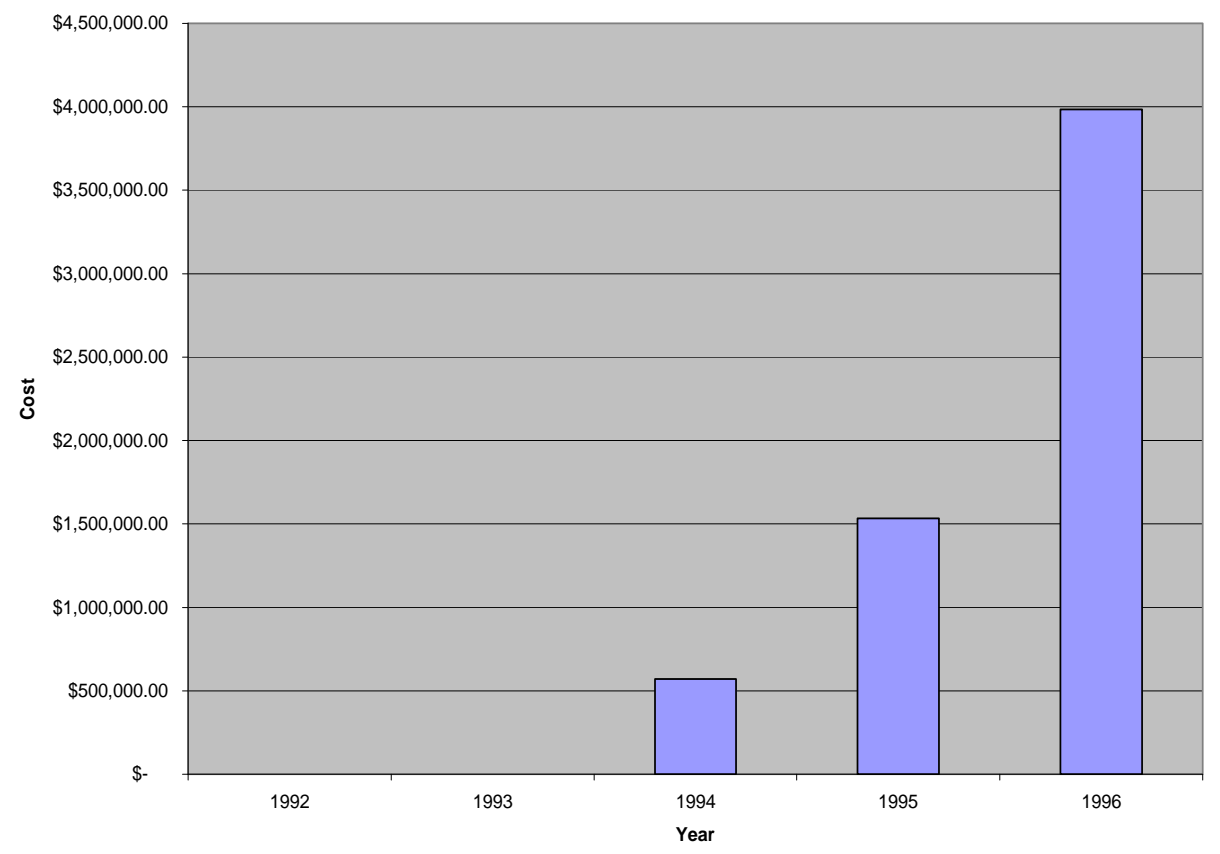

Each time that Peapod entered a new market, it had to develop the administrative infrastructure necessary to conduct business. These administrative costs financed the hiring of corporate staff, accounts, marketers, and human resource personnel. Peapod classified these costs as 'general and administrative costs' (see Table 4). Figure 12 shows the increase in this cost during the period between 1992 and 1996 (Peapod, S-1, 1997).

Given the business model that Peapod operated under, a significant back-end cost component was the cost of inventory acquisition. Since Peapod was purchasing its inventory from its retail partners at their retail prices, there were no volume discounts. Further, because Peapod was buying its inventory at retail price, the grocery sales and inventory acquisition costs were the same. Peapod categorized the inventory acquisition 
Figure 12

Peapod's General and Administrative Costs: 1992 - 1996

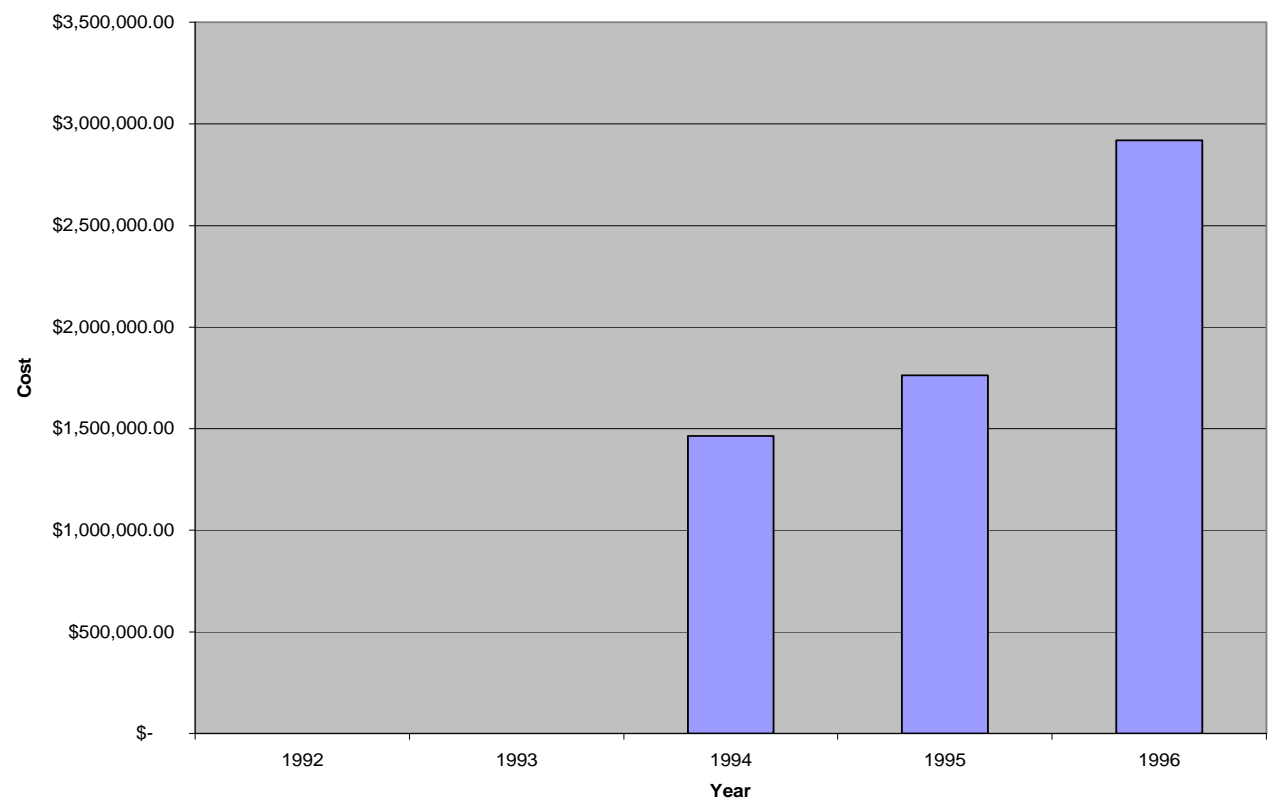

costs as 'grocery costs' (see Table 4). Figure 13 shows the increase in this cost for the period between 1992 through 1996 (Peapod, S-1, 1997).

Two other back-end costs that Peapod had to contend with were capital expenditures and fulfillment expenses. Capital expenditures represent the costs associated with purchasing land, and/or purchasing/renting facilities. Fulfillment expenses represent the costs associated with the picking, packing, and delivery functions. For Peapod, both of these back-end cost categories were accounted for under the heading 'grocery operations'. Under this heading were also the costs associated with the auxiliary service levels. These costs appear in Table 4 as front-end costs under the category of customer relationship costs. Peapod, however, included these costs under the heading 'grocery operations'. Figure 14 depicts the increase in grocery operations costs between the period 1992 to 1996. 
Figure 13

Peapod's Grocery Costs: 1992 - 1996

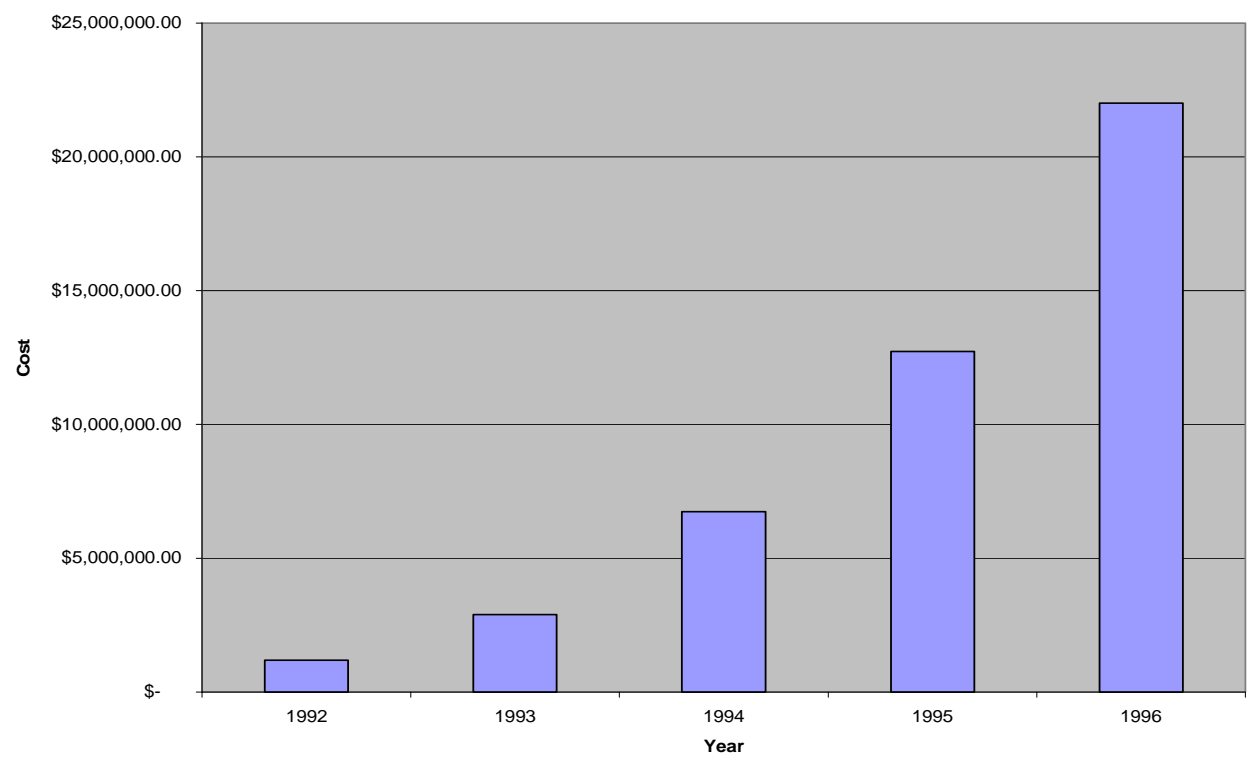

Figure 14

Peapod’s Grocery Operations Costs: 1992 - 1996

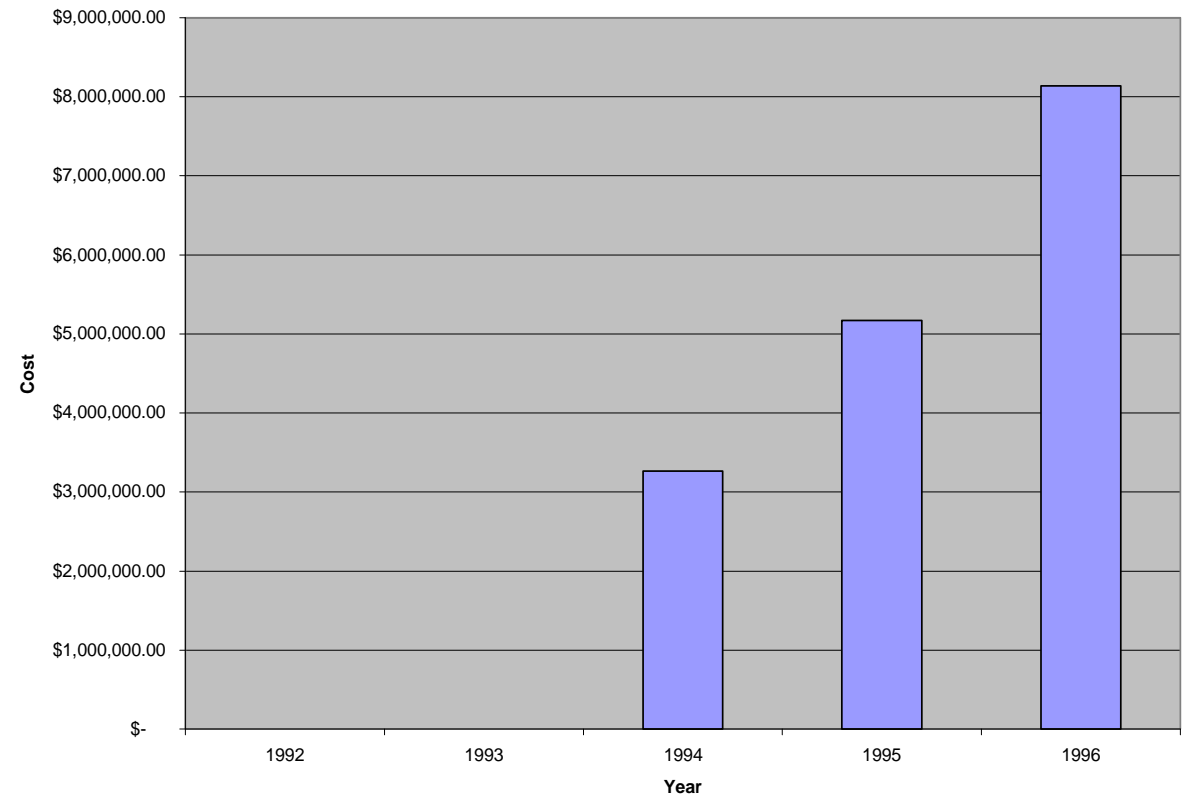


Lastly, Figure 15 displays the combined cost structure for Peapod during the period between 1992 and 1996 (Peapod, S-1, 1997). From this graph, it is apparent that the majority of Peapod's costs were associated with inventory acquisition and grocery operations. For Peapod, the most significant portion of the grocery operations costs was the fulfillment costs. Thus, the majority of Peapod's costs were associated with either purchasing inventory or picking, packing and delivering customer orders.

Figure 15

Peapod's Combined Cost Components: 1992 - 1996

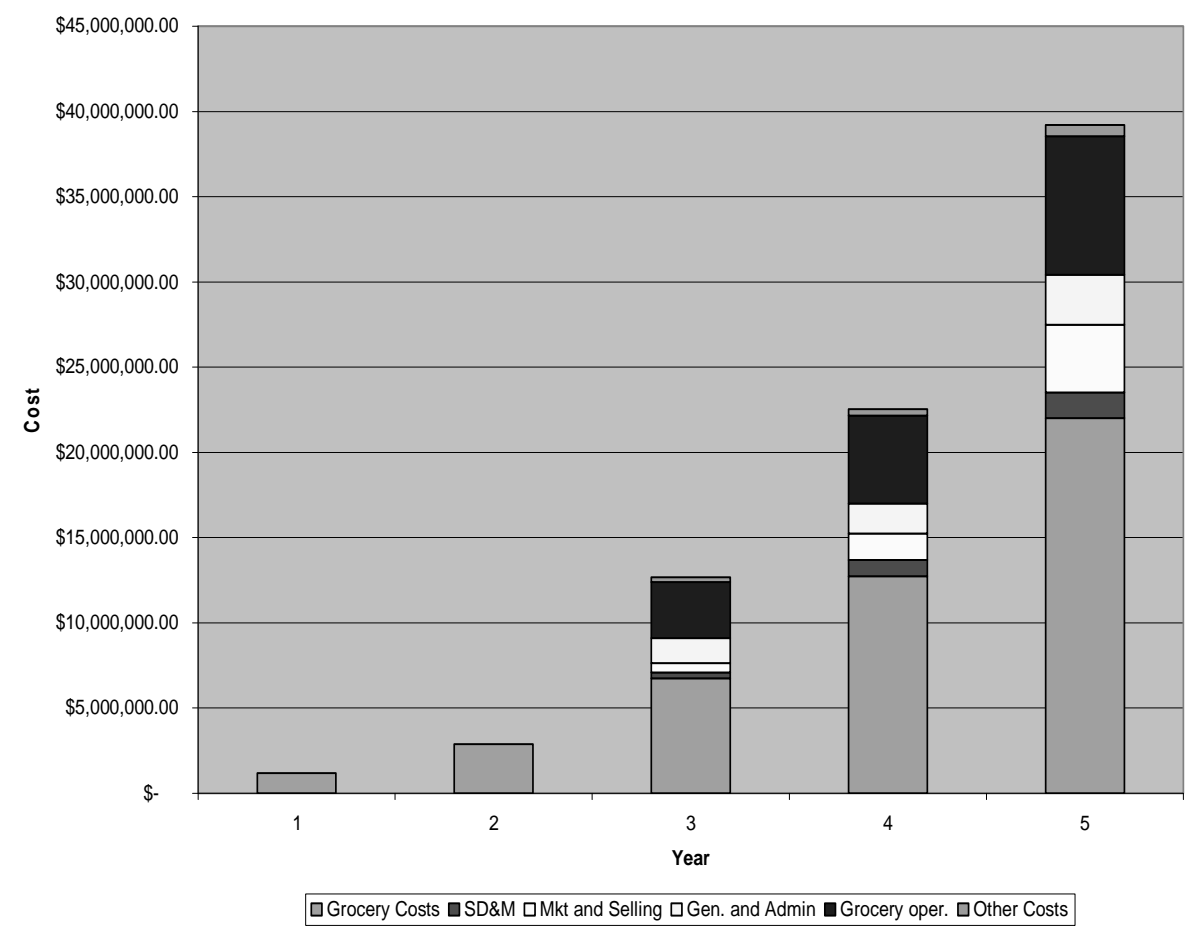

In terms of Peapod's revenue stream, it was composed of fees, commissions, and delivery revenue. For Peapod, delivery revenue and fees were combined and represented as the category 'member and retailer services' (see Table 4). Figure 16 displays the increase in 'member and retailer services’ during the period between 1992 and 1996. 
During 1996 this figure doubled as a result of the advertising and marketing campaign that began in late 1995. The revenue from commissions is represented by the category ‘interactive marketing services’ (see Table 4). Figure 17 displays the increase in this revenue component during the period between 1992 and 1996. (No financial data concerning the interactive marketing service was found prior to 1995). The revenue

Figure 16

Peapod's Member and Retailer Services: 1992 - 1996

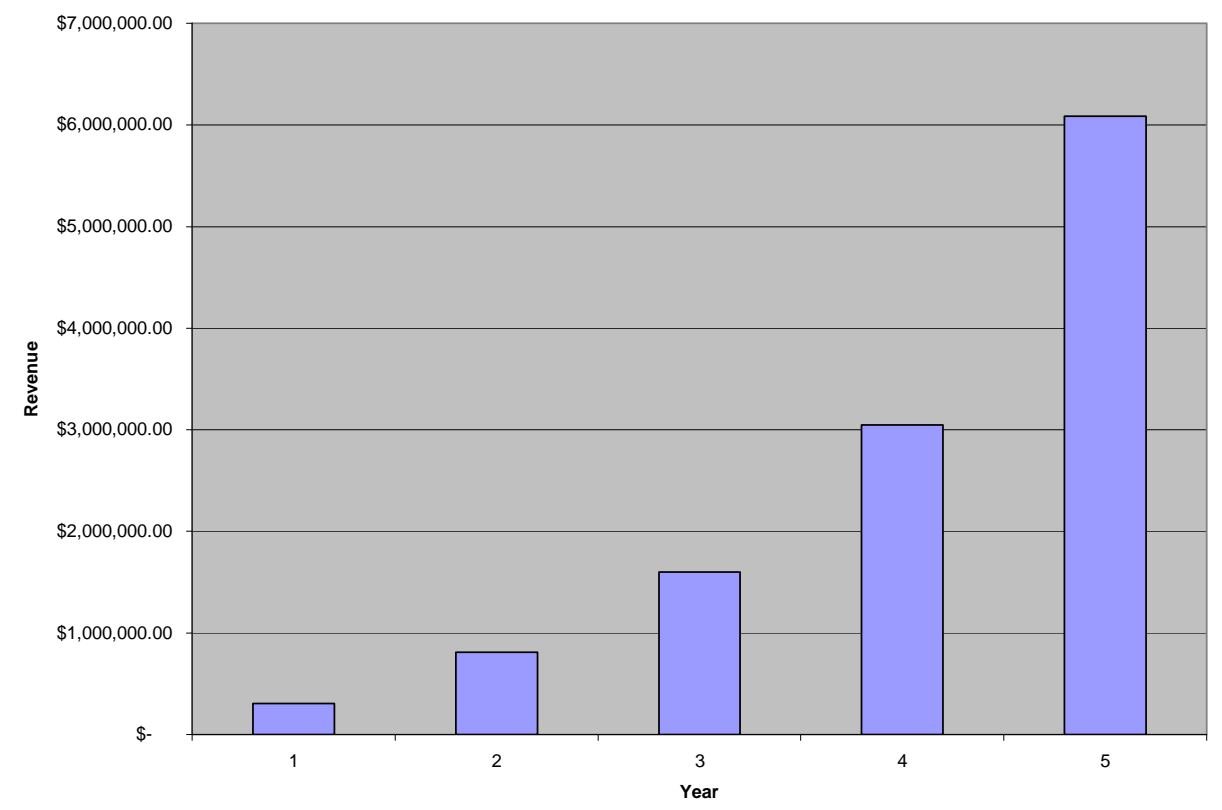

from the sale of inventory (i.e., groceries) is represented by the category 'grocery sales' (see Table 4). Figure 18 shows the increase in this revenue component during the period 1992 to 1996. Peapod also received capital from investors. The investment capital was represented by the category 'cash provided from financing operations'. Figure 19 displays the changes in this component during the period 1992 to 1996 (Peapod, S-1, 1997). 
Figure 17

Peapod's Interactive Marketing Services: 1992 - 1996

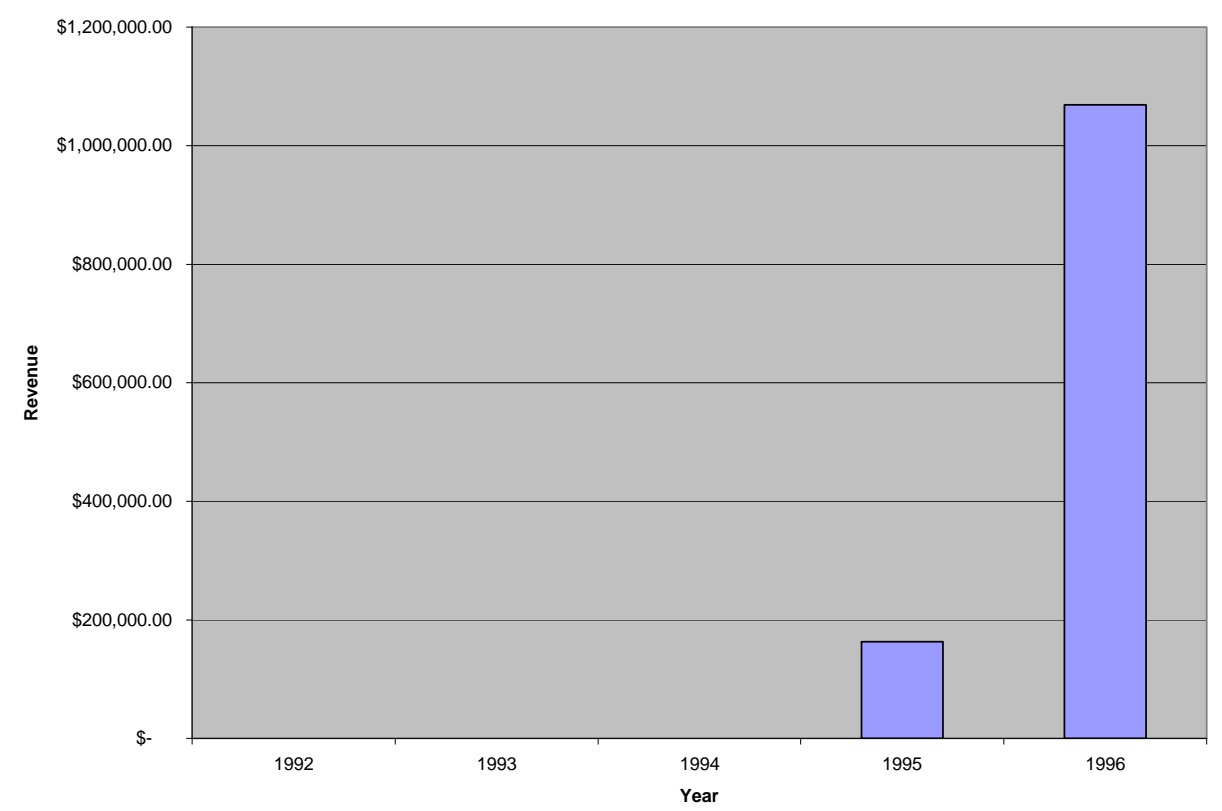

Figure 18

Peapod's Grocery Sales: 1992 - 1996

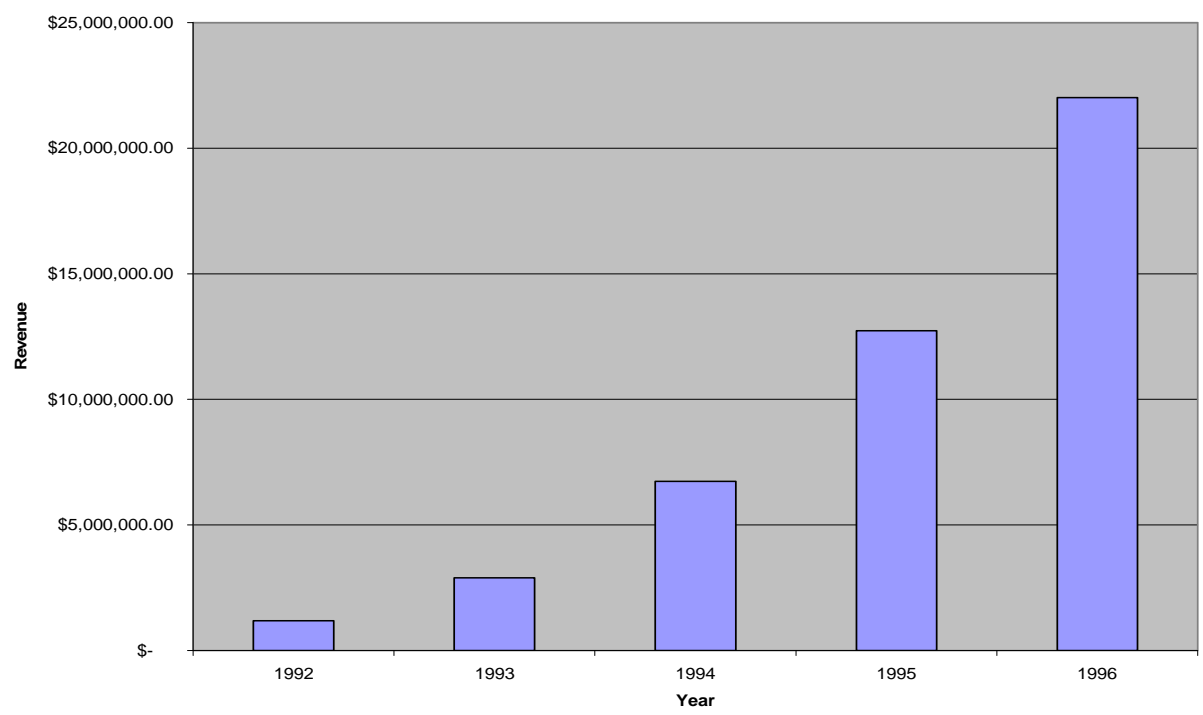


Figure 19

Peapod's Cash Provided From Financing Operations: 1992 - 1996

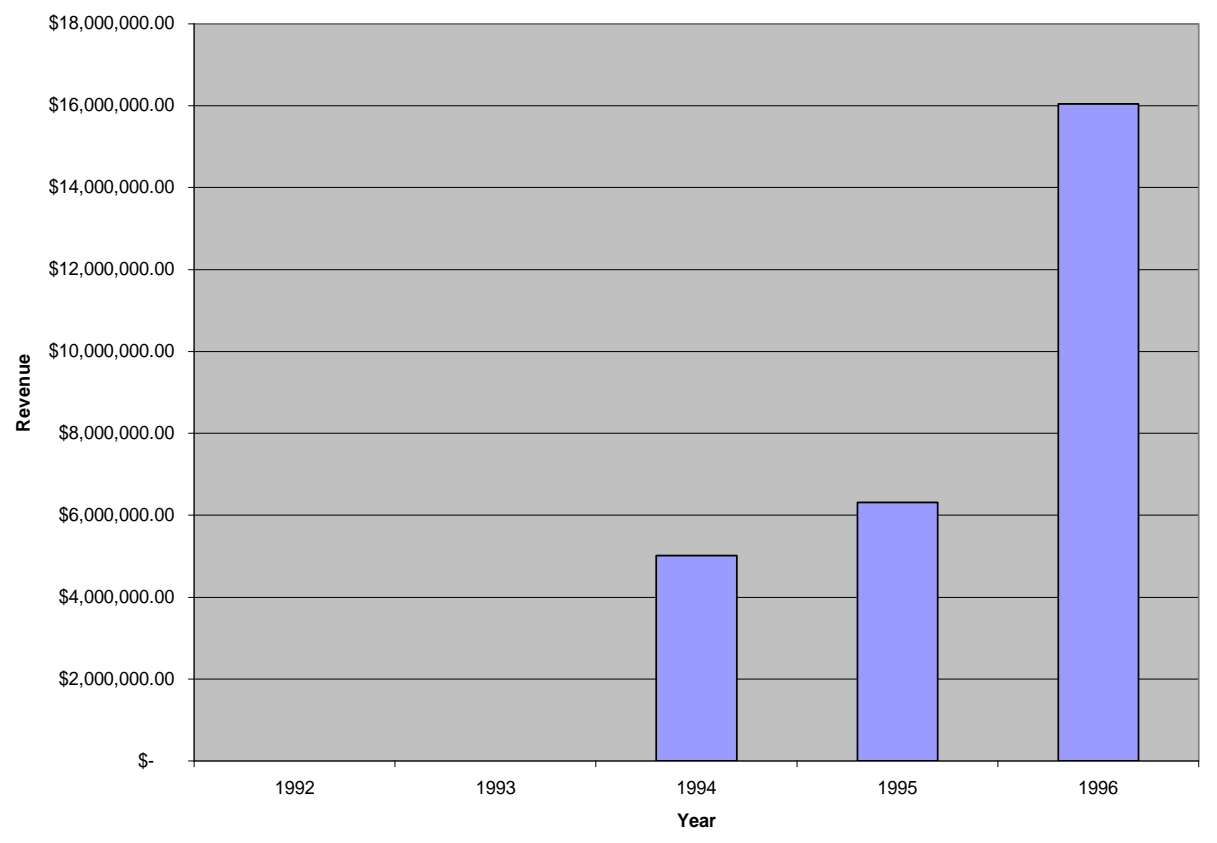

Figure 20 displays Peapod's combined revenue structure for the period between 1992 and 1996. The graph shows that the majority of Peapod's revenue was generated from the sale of groceries. Since the cost of groceries and the revenue from grocery sales were the same under the company’s operationalization of partnership model 6b (see Appendix 1), these two components offset one another. Taking this into consideration, the graph indicates that Peapod was generating very little revenue from the delivery and interactive marketing fees. Figure 21 displays the combined revenue with the inclusion of cash from financing operations. From this graph, it is clear that a significant portion of operating capital was provided by the company’s financing activities. Figure 22 depicts the relationship between total revenue and total cost for Peapod during the period between 1992 and 1996. The graph clearly shows that Peapod's cost structure was out pacing its revenue structure resulting in an operating loss. However, when the cash 
Figure 20

Peapod's Revenue Components (Grocery Sales, Interactive Marketing Services, and Member Retailer Services): 1992- 1996

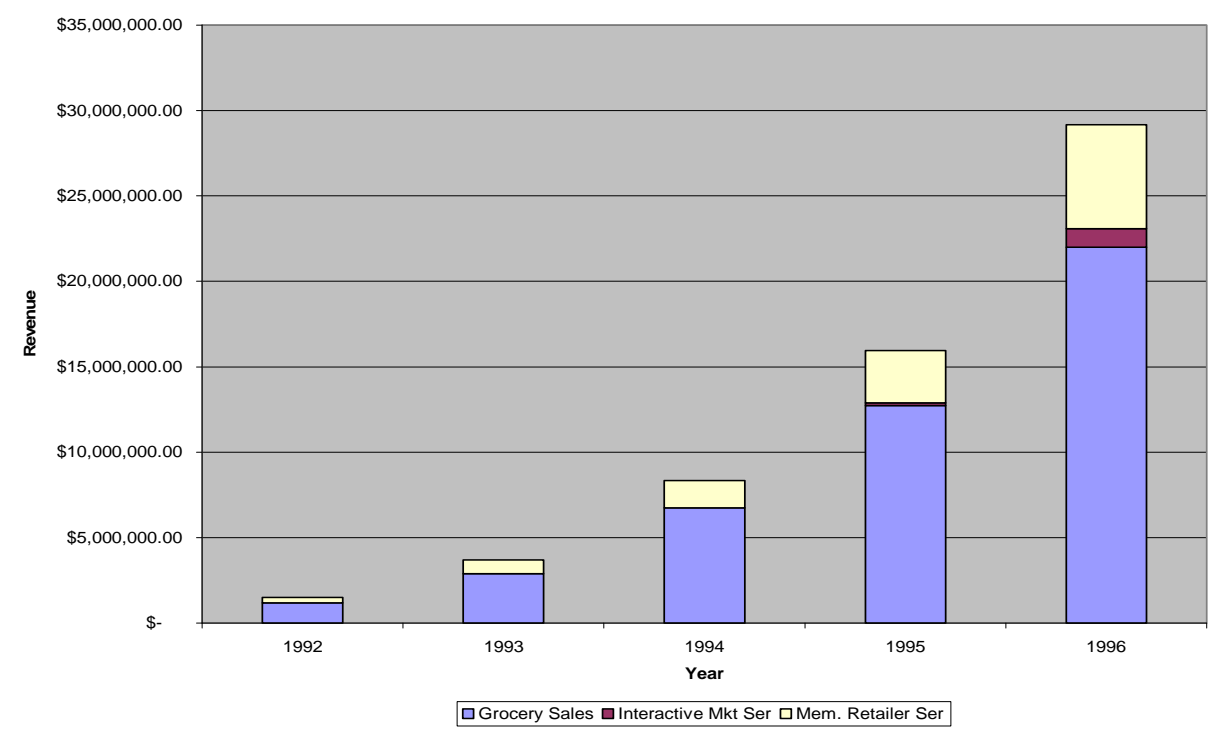

Figure 21

Peapod's Revenue Components and Cash Provided from Financing Operations: 19921996

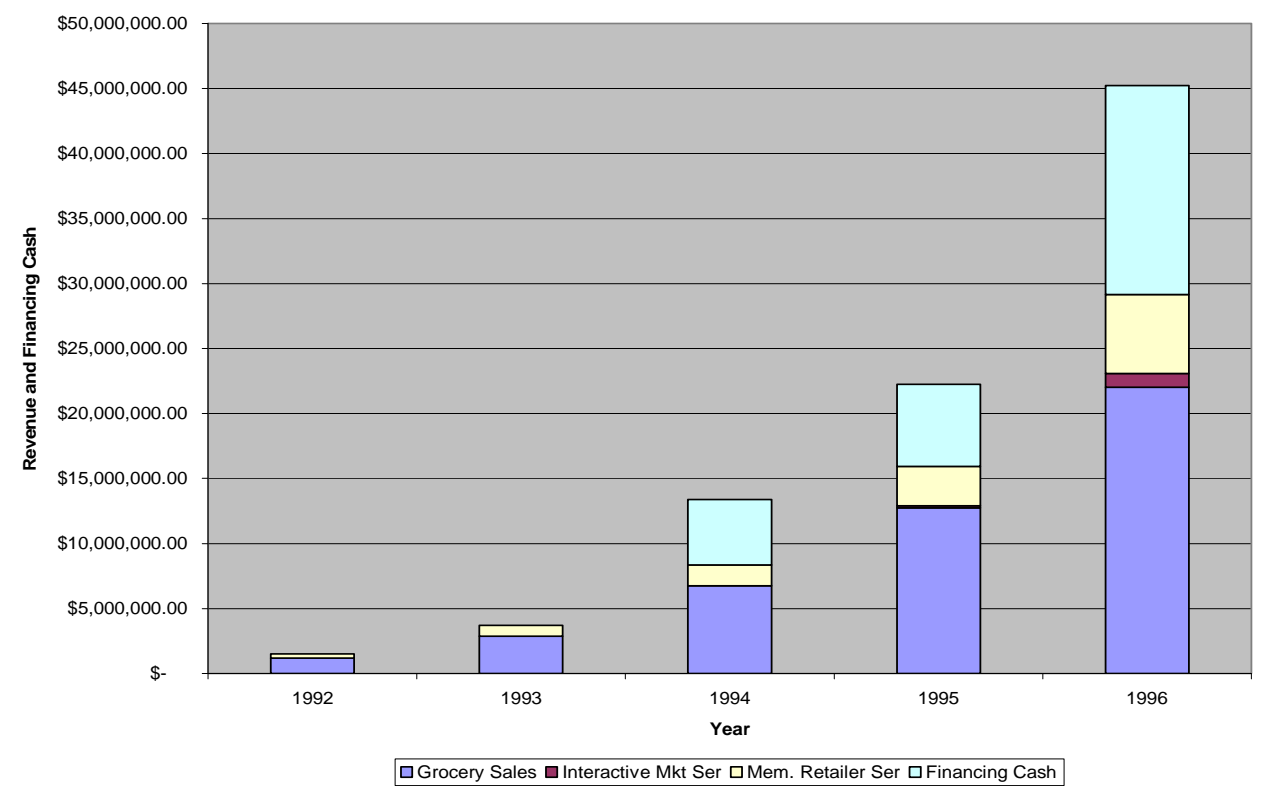


Figure 22

Comparison Between Peapod’s Total Revenue and Total Cost: 1992 - 1996

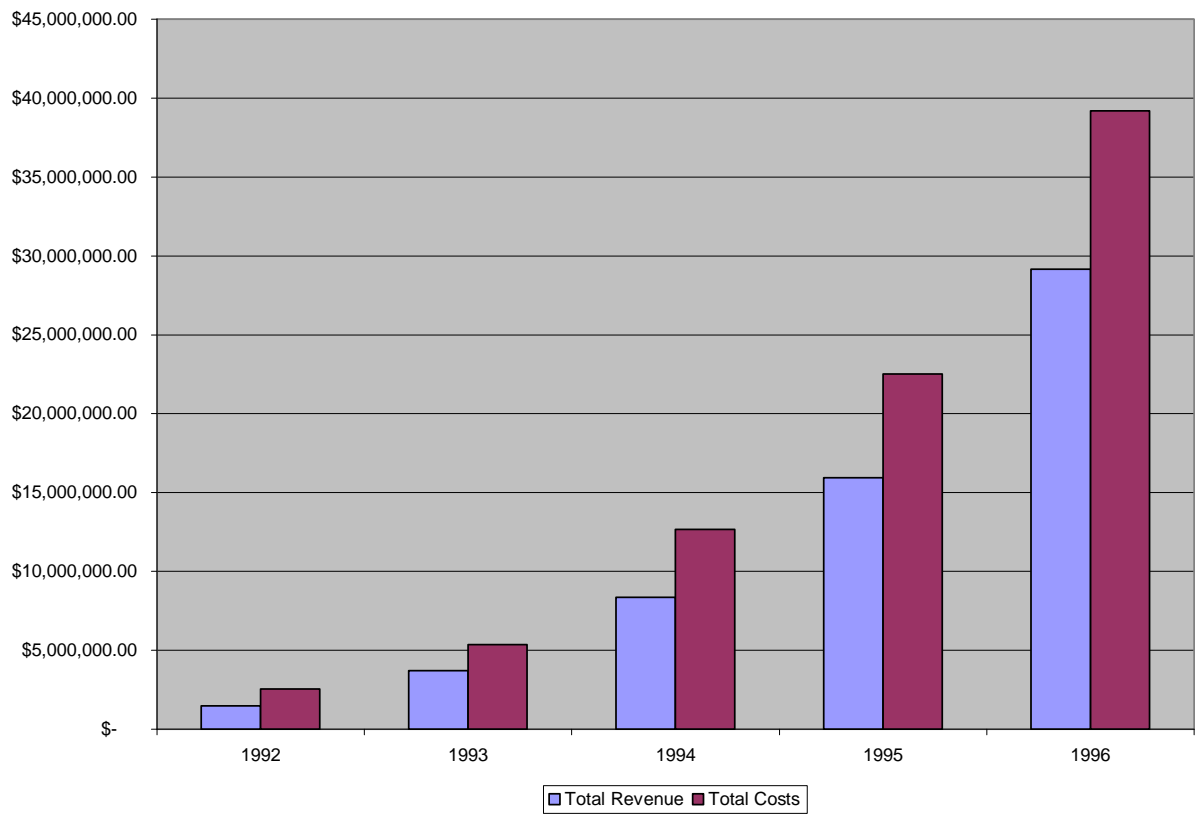

provided from financing operations was combined with total revenue, Peapod had enough capital to cover its total costs (see Figure 23) (Peapod, S-1, 1997). This demonstrated that without the capital generated from financing activities, Peapod would not have been able to survive.

\section{Summary}

During the period between 1992 and 1996 Peapod embarked on an expansion program. In 1993, the company entered the San Francisco area in partnership with Safeway, Inc., and by 1994, the company had expanded its operation to 13 locations. In 1996, Peapod again expanded into the Columbus and Boston markets. This brought the total number of locations for Peapod's service to 27. During this period Peapod had a moderate growth strategy. According to Andrew Parkinson, one of Peapod's cofounders, accelerated growth was part of the strategy. The logic was that if the company 
Figure 23

Comparison Between Peapod's Total Revenue and Total Cost with Cash from Financing Operations Combined: 1992 - 1996

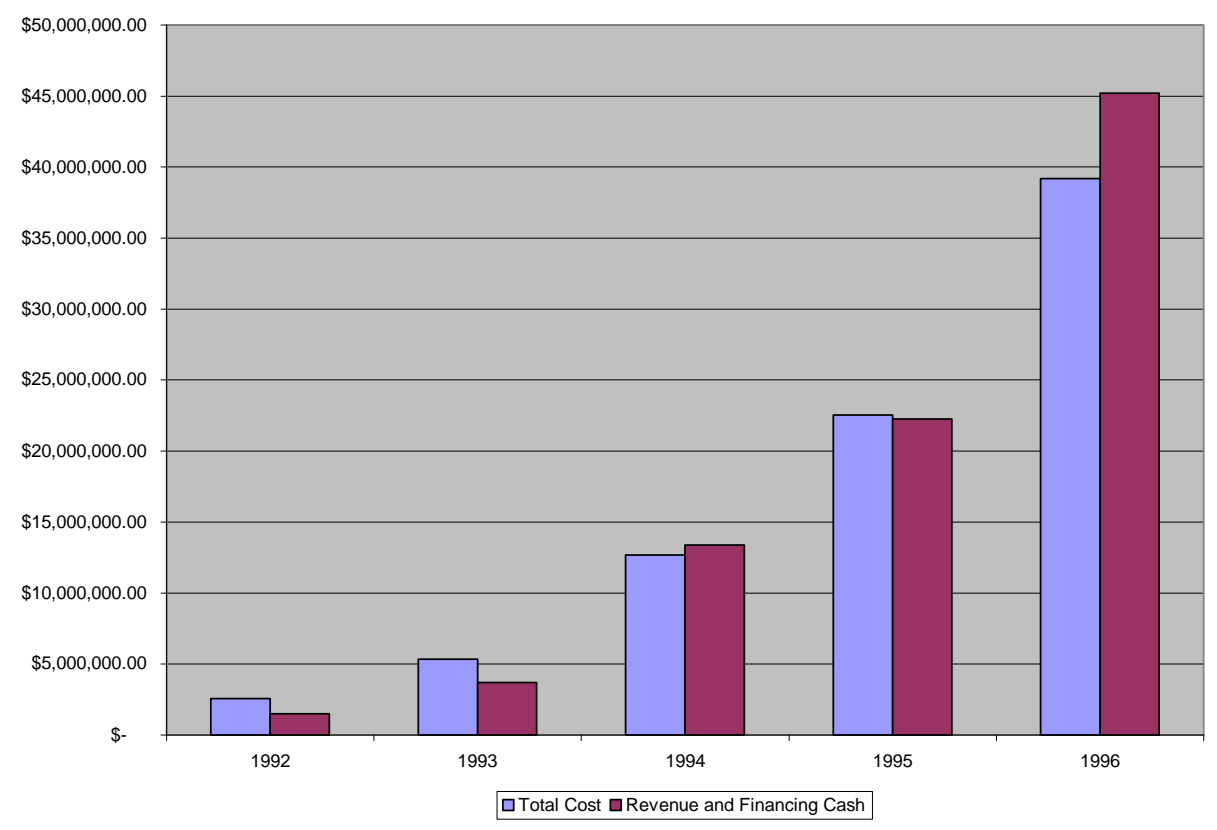

was able to spread its high fixed costs over a large enough customer base, it would eventually turn a profit without the need to raise rates or cut customer services.

However, there were two main problems with this strategy. First, Peapod was not generating enough revenue to fuel its own growth, and thus needed to rely on investment capital. Figure 22 shows the comparison between Peapod's costs and revenue components. From this figure it is clear that Peapod's costs were rising faster that its revenues. Thus, a major problem with Peapod's strategy was that Peapod was not generating enough revenue to fuel its own growth. However, once the cash provided from financing operations was included, Peapod was able to cover its total costs (see Figure 21). Hence, the cash from financing operation provided the necessary capital to fund Peapod's growth. 
Secondly, the variable costs were a more serious problem than the fixed costs. Since the company entered new markets in partnership with established grocery retailers, its actual fixed costs were low. However, with each new market that Peapod entered, it had to acquire the means to pick, pack and deliver groceries to its customers. This duplication of grocery operations caused the variable cost to became a significant portion of the company's overall cost structure. This is evident by the rise in grocery operations costs after 1993 when Peapod expanded into the San Francisco market (see Figure 13). Therefore, the growth strategy had a major impact on Peapod's cost structure.

Since Peapod's founding, the company had always relied on its proprietary software for the order taking function. To some extent this served as a barrier to entry for other companies, but it came with a high price. Specifically, when the company first expanded, the software had to be updated in order to handle multiple locations. This required Peapod to spend scarce resources. Then between 1994 and 1995 Peapod developed its Version 4.0 software. During this period the software development costs increased $193.4 \%$ from $\$ 329,000$ to $\$ 964,000$. The increase was mainly due to an increase in the number of employees needed to maintain the current systems and write the code for the Version 4.0 software. Therefore, due to the proprietary nature of Peapod's ordering software, the company incurred sizable costs in its system development and maintenance expenses (see Figure 10).

In early 1992 Peapod changed its pricing strategy by initiating a four to five percent fee on the total grocery bill. When faced with rising delivery costs, Peapod decided that it was necessary to include a percentage fee on each order in an attempt to 
generate additional revenue. Thus, Peapod began to realize that it had to increase its profit margins if it was ever going to break even.

Also during the period from 1992 to 1996 Peapod increased the level of service that it offered its customers. For an extra fee, Peapod allowed customers to request their processed film, prescription drugs, stamps, and commuter passes be delivered along with the groceries. Further, they allowed online shoppers to use both Safeway's and the product manufacturer's coupons with the value of the coupon being credited to the customer's next purchase. The Version 4.0 software allowed customers to compile up to 25 personalized shopping lists which allowed them to save time by reducing the amount of time it took to compile a shopping list. Moreover, the Version 4.0 software also allowed Peapod to increase the level of service that it offered to its business customers. Specifically, the software allowed Peapod to provide interactive marketing services to its retail partners and the consumer package goods companies (CPG). Lastly, the 90 minute delivery time window was designed to reduce the time customers had to wait for their deliveries. This particular service enhancement was expensive for Peapod because in order to meet this requirement Peapod sometimes need to dispatch delivery vehicles that were half full at time of the day when traffic was at its worst. These factors made the delivery process inefficient and ultimately quite expensive to maintain. Based on the services that Peapod was beginning to offer its customers, it was clear that the company was committed to increasing the customer service level. It was believed that by increasing the service level the service would appeal to a broader customer base. However, these services came with costs that added to the company's cost structure. 
Hence, between 1992 and 1996 Peapod underwent an expansion period. This expansion increased the cost structure of the company and was mainly attributed to the costs of grocery (i.e., fulfillment) operations being conducted in multiple locations. Further, during this time period Peapod's total costs out paced its total revenue. However, once the cash provided from financing operations was included, Peapod had the necessary capital to finance its operation. So, without the infusion of investment capital Peapod would not have been able to continue operating.

\section{Peapod's Profit Structure from $1997-1999$}

By early 1997, Peapod had incorporated in Delaware. During this time, the Chicago market began to provide a positive contribution to overall company operations. This was seen as a positive development and allowed Peapod to have a successful IPO of 4,000,000 shares giving the company a $\$ 58,120,040$ infusion of capital (Peapod, $10 \mathrm{~K}$, 1997). Also during this period, the company expanded into Atlanta, Georgia and Houston, Dallas, and Austin, Texas. As Peapod entered these new markets, it added a variation to the partnership model. In its original (i.e., full service) approach, Peapod employees handled all the picking, packing, assembly, and delivery functions for the retail partner. This was model 6b under the partnership heading in Appendix 1. However, once it entered the Houston, Dallas, and Austin markets, Peapod trained its retail partner's employees to do the picking, packing, assembly, and delivery functions while Peapod's employees maintained store level management responsibility over these functions (William Blair \& Company, October 3, 1997). The actual deliveries were still 
done using the Peapod fleet, but the drivers were the employees of the retail partner. This arrangement is represented by model 6a under the partnership heading in Appendix 1 .

Peapod's expansion into the four new markets was part of the company's stated business strategy which was “... to increase revenues and realize economies by aggressively expanding into new metropolitan markets and increasing penetration in existing markets” (Peapod, S-1, 1997, p. 4). Thus, Peapod acknowledged that its expansion strategy had moved from moderate to aggressive (or fast). As a result, the company experienced a significant increase in its inventory and labor expenses. Since Peapod did not lease or own its own fulfillment centers it had to have employees at each fulfillment site (i.e., at each retail partner's store). Most of the employees engaged in the fulfillment process were part-time employees. As a result, Peapod suffered a significant amount of turnover for these positions which led to an increase in the general and administrative costs associated with finding, hiring, and training part-time employees. This resulted in a significant amount of operating expenses which prompted the company to begin focusing on ways to reduce or eliminate certain cost components. One area in particular was the fulfillment component of its operation. As Peapod made changes to its fulfillment process, its business model began to evolve. One of the main reasons for the decision to make changes to its fulfillment processes was to reduce the cost associated with the high turnover rate of employees engaged in the picking and packing functions at the various store locations. It was unclear whether this change was part of Peapods original strategy or became part of the company's strategy after fulfillment costs became prohibitive. What was certain was that the decision to make adjustments to the fulfillment process operations was done in an attempt to reduce costs. 
By working closely with its retail partners Peapod was able to begin changing its business model to one that included more centralized order fulfillment. However, instead of building and operating its own stand alone central distribution centers, the company decided to develop local fulfillment centers attached to, or located within, its retail partners’ stores. In fact, Andrew Parkinson, noted that Peapod’s business model was “... evolutionary because as consumer volume increases, new formats can evolve ... [which] ... should allow Peapod eventually to pick product orders through a fulfillment center, rather than directly from retailer's shelves” (Amato-McCoy 1997, p. 61). Besides helping to increase efficiency, and reduce costs, these fulfillment centers were constructed to help alleviate the burden that Peapod's operations had on its retail partners' store operations. Specifically, Peapod's sales volume would sometimes cause stockouts, which became a customer service problem for the retail partner (Purpura 1997; Amato-McCoy 1998).

In addition to building dedicated wareroom fulfillment centers, Peapod also developed warehousing and routing technologies designed to increase the efficiency of order fulfillment. For example, Peapod developed hand-held scanning technology for the order picking and packing functions that were designed to increase the speed at which orders could be assembled (Peapod, S-1, 1997). The hand-held devices included the ability to transmit customer comments and product substitution information, entered on the website, directly to the pickers. Thus, the likelihood of consumer dissatisfaction, as a result of mispicking, was reduced. All these improvements were undertaken in order to reduce costs, improve quality, and enhance volume scalability (Rewick 1998).

With the help of its retail partners, Peapod was able to begin redesigning its online channel. Instead of having its fulfillment centers spread over several areas it 
began to centralize them. Peapod's management figured that by moving to a wareroom fulfillment model the company could save their customers $\$ 5$ to $\$ 10$ dollars per order and save the company 20 to 30 percent of the cost of filling orders from supermarkets shelves.

The decision to construct these dedicated fulfillment centers marked the point where Peapod's business model began to move towards that of an actual pure-play model. However, because Peapod did not actually own the wareroom facilities, it was still operating as a de facto partnership. By utilizing the wareroom facilities, Peapod was using business models 13a and 13b (see Appendix 1). According to Andrew Parkinson, "Our whole model has always been an evolutionary model. Picking out of the store is not the most effective way to pick, but it was the most effective way to build volume. The retailer has the brand name; they have the merchandising expertise; and they have a shopper base. We really wanted, and still want, to work with them, even if we are picking out of a warehouse" (Mathews 1997, p. 38).

During the year, Peapod also made changes to its delivery format by offering a drive through pick-up option in its Houston, Dallas, Austin, and Boston markets. The company felt that it would enable Peapod's members to eliminate their delivery costs while allowing the company more flexibility in scheduling deliveries. Initially customers revealed that they did not like this option but Peapod decided that it would continue to test the concept in current and future markets (Peapod, S-1, 1997). Again, this demonstrated Peapod's willingness to try various business models. In this situation, the company was experimenting with models 1 and 8 under the partnership category. 
Also during the year, the company released its software Version 5.0. One new feature of this software was the inclusion of audio and animation functions (Riedman 1997). Peapod was hoping that these enhancements would attract more advertising revenue. Further, the new software allowed Peapod to link to other advertisers' websites. The company was hoping to generate additional revenue by steering web traffic to other sites for a fee (Riedman 1997). Although the company was making improvements to the software with the intent of increasing revenue, the costs associated with maintaining the network's hardware and software increased to the point where it represented a significant percentage of costs.

In terms of customer acquisition, one of Peapod's primary objectives was to increase its customer base. To do so, the company conducted price elasticity tests to determine the relationship between its costs and fee structures and their membership levels (William Blair \& Company 1997b). In a test conducted in Boston, Peapod reduced prices and order volume tripled (Smith Barney 1997c). In another test conducted in Columbus, Ohio the company switched to a three tier system. Tier one allowed customers to pay an $\$ 11.95$ flat fee for the service, with no percentage charge or monthly fee. This was aimed at customers who occasionally used the online shopping service. The second tier was aimed at consumers who used the service more regularly. It required a $\$ 4.95$ monthly membership fee, plus a $\$ 6.95$ charge for delivery, with no percentage charge. The last tier was aimed at customers who were heavy users of the service and required them to pay a flat fee of $\$ 24.95$ per month, with no delivery fees, and no percentage charge, with a minimum order of $\$ 60$ (Frees 1997). According to Lynn Flannery, then director of member acquisition for Peapod, Columbus was the only city 
where Peapod was using the three-tiered option. Flannery cited low subscriber rates as the reason for the change.

In order to build brand equity, Peapod aggressively marketed its services through promotions and advertising. A major part of Peapod's marketing activities were conducted through cooperative marketing efforts with most of its grocery retail partners. According to Peapod, the extent and effectiveness of these cooperative marketing efforts were important to Peapod's success in any given market (Peapod, S-1, 1997). For example, in Chicago the partnership with Jewel increased Peapod's membership in that market by $233 \%$ and increased order volume by $148 \%$. It is not prudent to equate all the increase to an advertising campaign, but a portion of this increase can be attributed to the marketing effort. Peapod also began offering free gifts and service discounts to select members in an attempt to increase member usage and grocery order size. Company officials also expressed plans to implement loyalty programs in an attempt to increase member acquisition, current member usage, grocery order size, and member retention (Peapod, S-1, 1997).

By December 31, 1997, Peapod offered its online grocery home delivery service in eight markets and filled and delivered customers orders from 52 fulfillment centers covering 6,488,000 households. During this period, the number of members grew from 33,300 to 43,000 while total orders for the year were 396,600 compared to 201,100 in 1996. The increase was mainly due to the initiation of operations in four new markets while the remainder was due to deeper penetration in its current markets. By opening new markets, the variable costs associated with fulfillment operations continued to increase. In addition, marketing and selling expenses rose by 64 percent over 1996 
levels. The increase resulted primarily from the additional marketing staff needed to support the growth in interactive marketing services and other marketing initiatives, as well as the continued use of aggressive member acquisition programs during the year. As the company included more services the cost of providing those services increased to where it represented a significant percentage of cost. System development and maintenance expenses increased due to the development of the Version 5.0 end-user software.

Profit Structure Analysis for Peapod: Profit Structure from 1997 to 1999 Investment Capital

40. With a successful IPO of 4,000,000 shares, Peapod was able to raise $\$ 58,120,000$ in equity financing. This was represented by the investment capital component 'investment capital' - IC(1) (see Table $6)$.

Revenue Components

41. The development of the Version 5.0 software allowed Peapod to receive direct revenue for advertising on its site. Further, by providing links to advertiser's sites, Peapod also received indirect revenue from these companies. This was represented by the revenue components 'website direct advertising revenue' - RC(10) and 'website indirect advertising revenue' $-\mathrm{RC}(11)$. Peapod also received revenue from the sale of its grocery inventory. This was represented by 'grocery inventory sales' - RC(12) (see Table 6).

Cost Components

42. For each new market that Peapod entered, the company incurred costs associated with the hiring and training of part-time employees. Once operation in these new markets began, Peapod also generated costs associated with the fulfillment and delivery functions. This was 
Table 6

Peapod's Profit Structure Components: 1997 - 1999

\begin{tabular}{|c|c|c|c|}
\hline $\begin{array}{l}\text { Sources of Operating } \\
\text { Capital }\end{array}$ & Front-End Cost Components & $\begin{array}{l}\text { Back-End Cost } \\
\text { Components }\end{array}$ & Performance Drivers \\
\hline Investment Capital & Order Taking Costs & Capital Expenditures & Customer Service Drivers \\
\hline \multirow[t]{2}{*}{ 1. Investment Capital (IC1) } & 1. Website Related & 2. Capital Expend. & 11. Number Using Delivery (PD11) \\
\hline & 1a. Design Cost & 2a. Facilities & 12. Number Using Advertising (PD18) \\
\hline Fees & In-House (CC1) & Leased (CC2) & 13. Number Using Promotional (PD19) \\
\hline 1. Installation/Packaging (RC2) & 1b. Maintenance Cost & 8. Delivery Fleet & 14. Number Using Research (PD20) \\
\hline \multirow[t]{2}{*}{ 2. Subscription/Membership (RC3) } & In-House (CC11) & 8a. Company Owned (CC21) & \\
\hline & & 9. Fleet Maintenance (CC22) & Customer Patronage Drivers \\
\hline Delivery Revenue & Customer Relationship Costs & & 1. Number of Orders (PD3) \\
\hline 1. Core Delivery Fee (RC4) & 7. Customer Awareness & Inventory Expense & 2. Items per Order (PD13) \\
\hline 2. Grocery Bill Percentage Fee (RC5) & 7a. Done Alone (CC7) & 3. Inventory Costs & 3. Number of New Customers (PD1) \\
\hline \multirow[t]{2}{*}{ 3. Auxiliary Delivery Revenue (RC6) } & 7b. Partnership (CC9) & $\begin{array}{l}\text { 3a. Acquisition via Partner Cost } \\
\text { (CC3) }\end{array}$ & 4. Number of Repeat Customers (PD2) \\
\hline & 8. Customer Acquisition Costs & $\begin{array}{c}\text { 3b. Acquisition via } \\
\text { Manuf./Wholesaler (CC23) }\end{array}$ & $\begin{array}{l}\text { 5. Number of Membership Renewals } \\
\text { (PD4) }\end{array}$ \\
\hline Commission & 8a. Done Alone (CC8) & & 6. Purchase Amount (PD10) \\
\hline 1. Integrated Marketing & 8b. Partnership (CC10) & Fulfillment Expenses & 16. Cancellation Rate (PD8) \\
\hline 1a. Advertising Service (RC7) & & 4. Picking Costs & \\
\hline 1b. Promotional Service (RC8) & Auxiliary Services & 4a. Human Capital (CC4) & Delivery Service Drivers \\
\hline \multirow[t]{2}{*}{ 1c. Research Service (RC9) } & 9. Auxiliary Service Level & $\begin{array}{l}\text { 4b. Hybrid (Some } \\
\text { Automation) (CC18) }\end{array}$ & 7. Number of Orders Delivered (PD9) \\
\hline & 9a. Delivery Related (CC12) & 5. Packing/Assembly Costs & 8. Number of Vehicles Used (PD15) \\
\hline Inventory Sales & 9b. Coupon Redemption (CC13) & 5a. Human Capital (CC5) & 9. Number of Delivery Attempts (PD14) \\
\hline \multirow[t]{2}{*}{ 1. Grocery Inventory Sales (RC12) } & 9c. Promotional (CC14) & 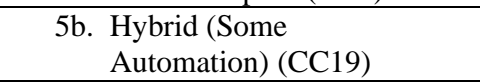 & 15. Delivery Truck Capacity (PD22) \\
\hline & 9d. Advertising (CC15) & 6. Delivery Costs & \\
\hline Advertising Revenue & 9e. Research (CC16) & 6a. Fuel Costs (CC6) & Operational Service Drivers \\
\hline $\begin{array}{l}\text { 1. Website Direct Advertising } \\
\text { Revenue (RC10) }\end{array}$ & & 7. Routing and Scheduling (CC20) & 8. Fulfillment Performance \\
\hline \multirow[t]{4}{*}{$\begin{array}{l}\text { 2. Website Indirect Advertising } \\
\text { Revenue (RC11) }\end{array}$} & General And Administrative & & 8a. Picking Speed (PD5) \\
\hline & 10. General and Admin. (CC17) & & 8b. Number of Lines Picked (PD16) \\
\hline & 11. Other Costs and Expenses (CC18) & & 8c. Picking Accuracy (PD6) \\
\hline & & & 8d. Assembly Accuracy (PD7) \\
\hline
\end{tabular}


represented by the cost components 'picking costs' - CC(4), 'packing/assembly costs' - CC(5), and 'delivery costs' - CC(6) (see Table 6).

43. With each new market that Peapod entered, the company needed to make arrangements with a brick-and-mortar grocer to acquire inventory. Thus, Peapod incurred costs associated with inventory acquisition. This was represented by the inventory expense 'inventory acquisition' - CC(3) (see Table 6).

44. With the development of the new hand-held scanners, Peapod began to automate its picking and packing functions. The costs associated with the automation were related to the fulfillment expenses. This was represented by the cost components 'picking costs hybrid' - CC(18) and 'packing/assembly costs hybrid' - CC(19). In addition, Peapod also incurred costs associated with the development of routing technology. This was represented by the cost component 'routing and scheduling' - CC(20) (see Table 6).

45. The development and release of Peapod's Version 5.0 software resulted in website related costs. This was represented by the cost components 'website design' - CC(1) and 'website maintenance' CC(11) (see Table 6).

46. The cost associated with advertising and promoting Peapod's services was represented by the front-end cost components 'customer awareness partnership' - CC(9), 'customer acquisition partnership' CC(10) (see Table 6).

47. In order for Peapod to function as a going concern, the company incurred general and administrative costs and other costs and expenses. These costs increased each time that Peapod entered a new market and were represented by the cost components 'general and admin.' CC(17) and 'other costs and expenses' - CC(18) (see Table 6).

Performance Drivers

48. Peapod incurred picking, packing, and delivery costs for each market that the company entered. These costs varied based on the level of turnover and the number of customers utilizing the service. Delivery costs were driven by the number of orders delivered, the number of vehicles used, the number of delivery attempts, and delivery truck capacity. Hence, 'delivery truck capacity' - PD(22), 'number of delivery attempts' - $\mathrm{PD}(14)$, 'number of vehicles used' - $\mathrm{PD}(15)$, and 
number of orders delivered' - $\mathrm{PD}(9)$ were linked to 'delivery personnel costs' - CC(17) and 'fuel costs' - CC(6). Packing costs were determined by the number of orders, items per order, and packing speed. Thus, 'number of orders' - PD(3), 'items per order' - PD(13) and 'packing speed' - $\mathrm{PD}(21)$ were linked to the cost component 'packing assembly costs' - CC(5). Picking costs were determined by the number of orders, the number of items per order, the number of lines picked, and the picking speed. Therefore, 'number of orders' $\mathrm{PD}(3)$, 'items per order' - PD(13), 'number of lines picked' - PD(16), and 'picking speed' - $\mathrm{PD}(5)$ were linked to the cost component 'picking cost' - CC(4) (see Figure 24).

49. Peapod's development of routing technologies was designed to improve the efficiency of the delivery process. Thus, the performance driver 'routing and scheduling process' - $\mathrm{PD}(17)$ was linked to the performance drivers 'delivery truck capacity' - $\mathrm{PD}(22)$, 'number of delivery attempts' - PD(14), and 'number of vehicles used' - PD(15) (see Figure 25).

50. The number of orders delivered was determined in part by the number of orders. This was represented by the link between the performance driver 'number of orders' - $\mathrm{PD}(3)$ and the other performance driver 'number of orders delivered' - PD(9) (see Figure 25).

51. Peapod's use of the hand-held scanners increased the picking speed, packing speed, picking accuracy and assembly accuracy. Therefore, the 'picking cost hybrid' - CC(18) and 'packing/assembly hybrid' $\mathrm{CC}(19)$ are linked to the performance drivers 'picking speed' - $\mathrm{PD}(5)$, 'packing speed' - PD(21), 'picking accuracy' - PD(6), and 'assembly accuracy’ - PD(7) (see Figure 24).

52. Based on price elasticity tests, Peapod determined that delivery fees were associated with customer trial and order volume. As a result, revenue components 'core delivery fee' - RC(4) and 'grocery bill percentage fee' - RC(5) were linked directly to the performance drivers 'number of new customers' - $\mathrm{PD}(1)$ and 'number of repeat customers' - PD(2) (see Figure 26).

Other Mediating/Moderating Factors

53. Peapods expansion into four new markets demonstrated that the company had moved from a moderate to an aggressive (or fast) growth strategy. This was also evident by the company's stated business strategy (see Table 7). 
Figure 24

Peapod's Back-End Cost Components and Performance Drivers: 1997 - 1999

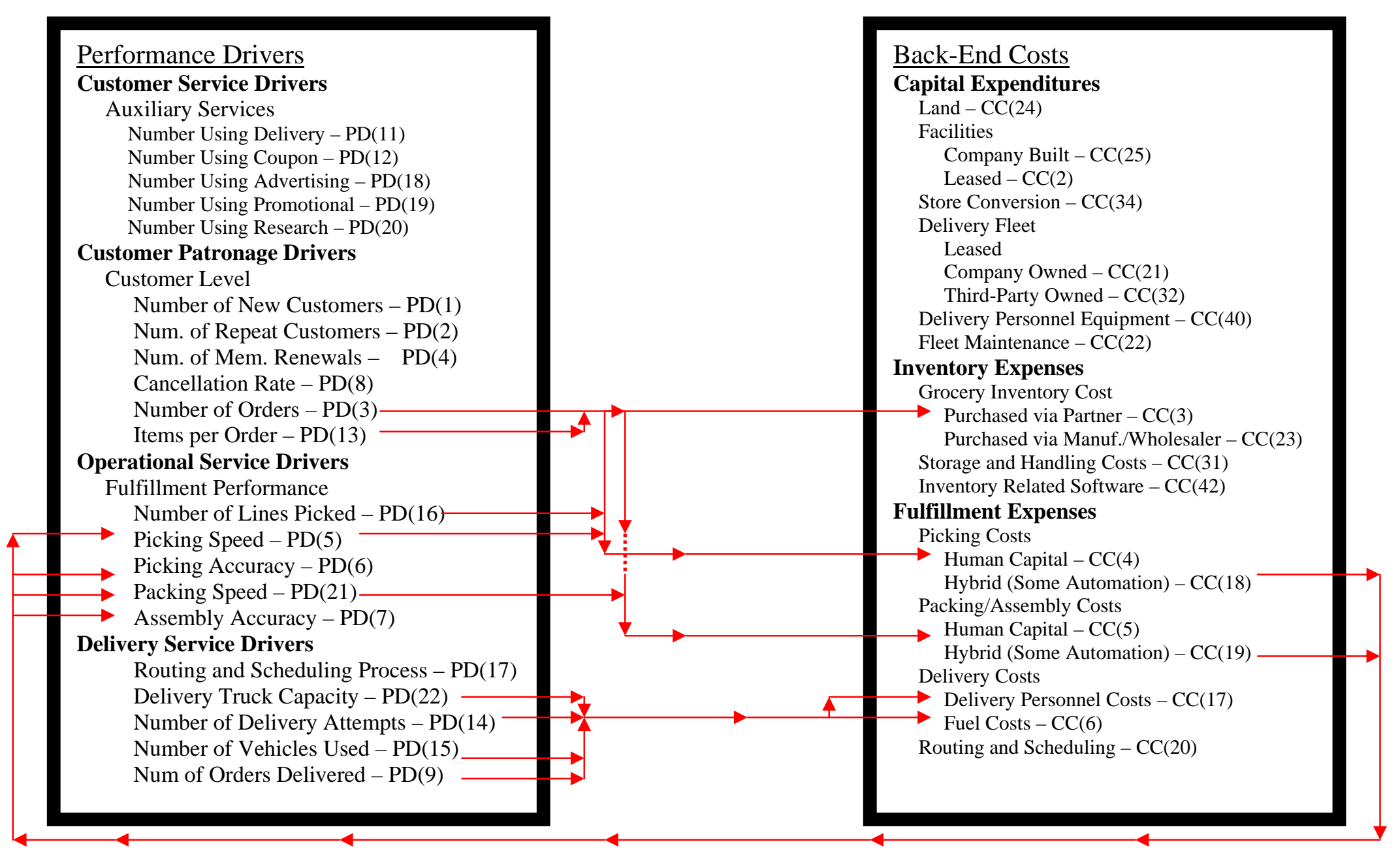


Figure 25

Peapod's Performance Drivers and Performance Drivers: 1997 - 1999

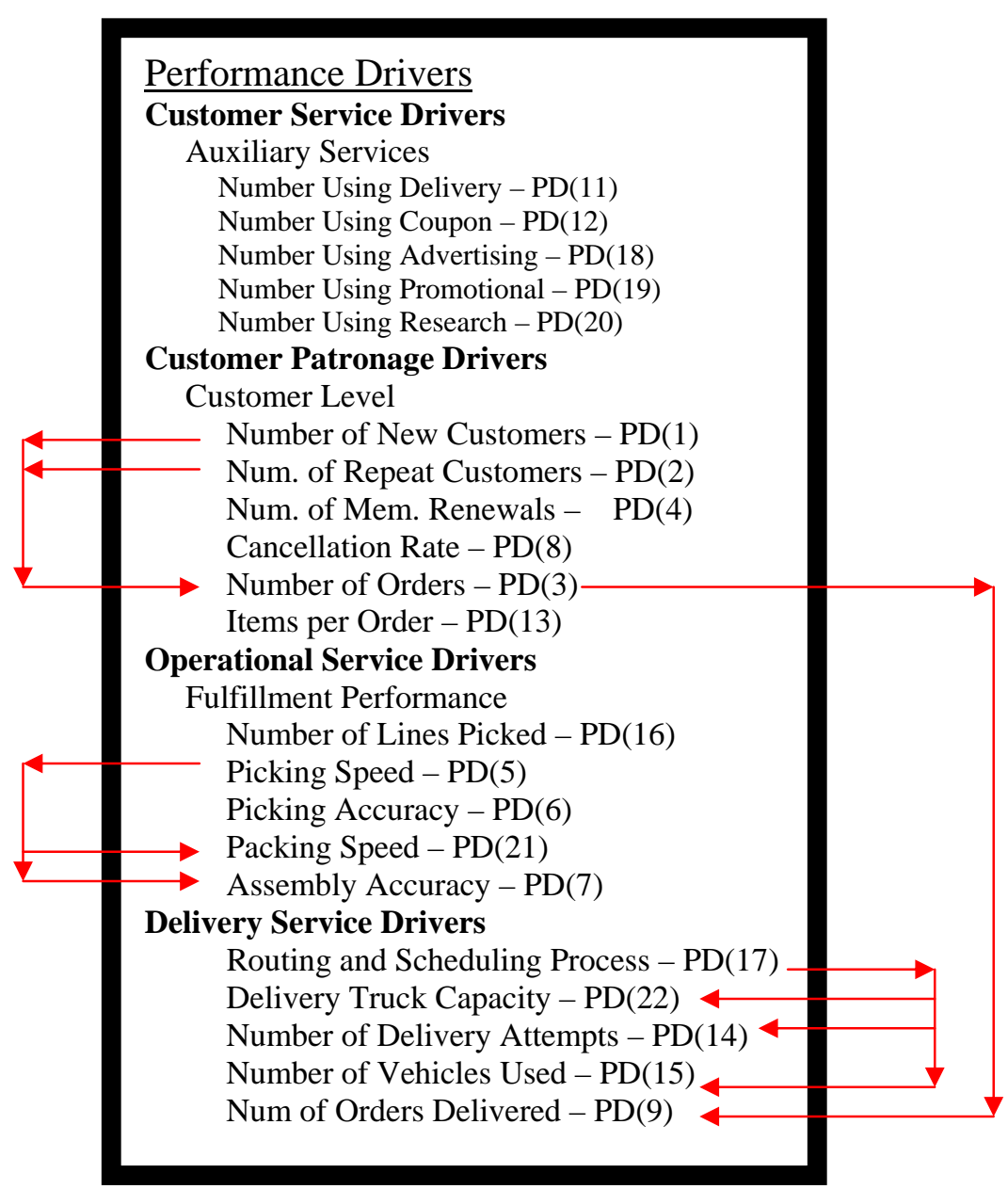


Figure 26

Peapod's Revenue Components and Performance Drivers: 1997 - 1999

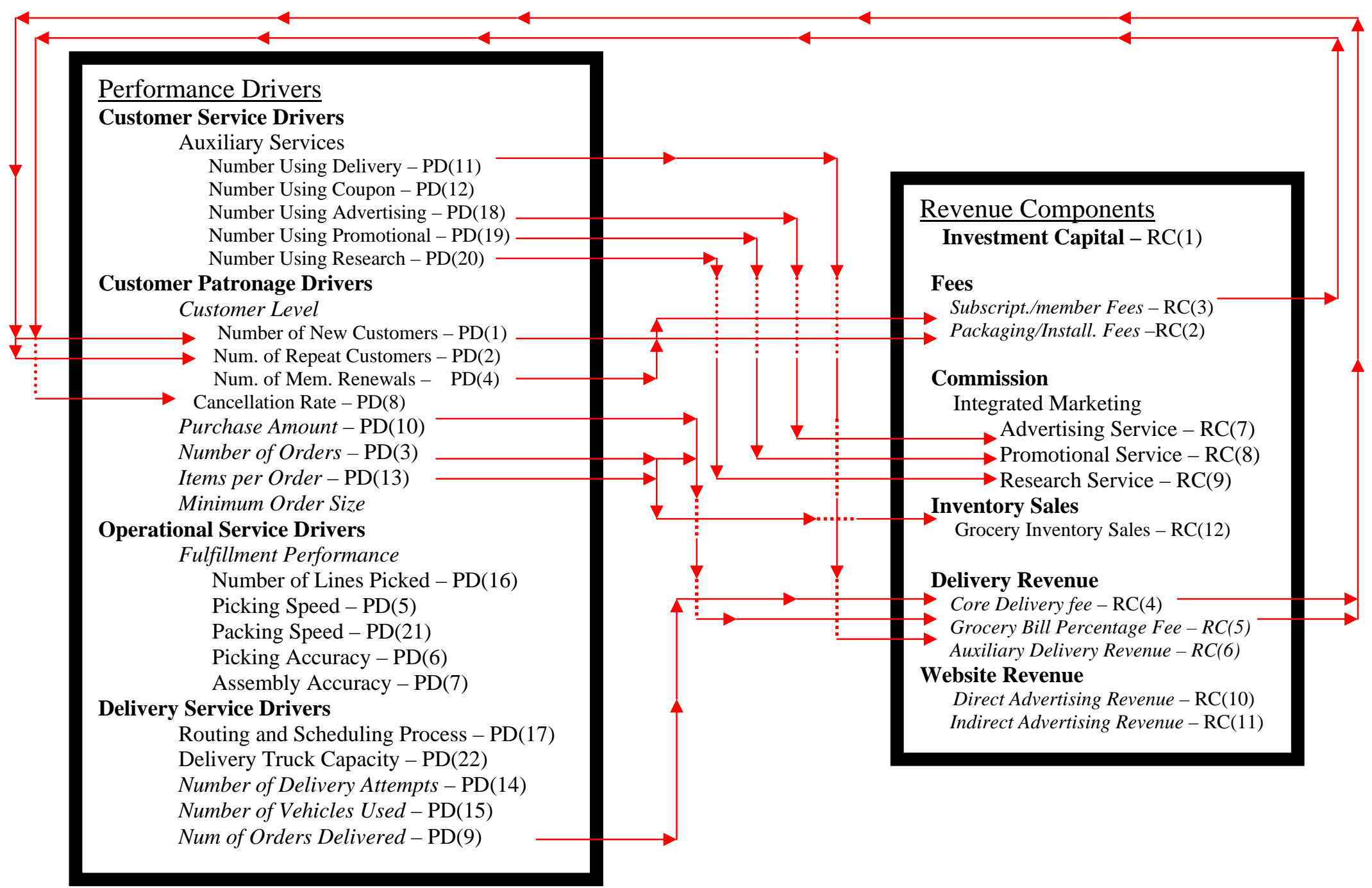


Table 7

Other Mediating/Moderating Factors for Peapod: 1997 - 1999

$\begin{array}{lll}1989- & 1992- & 1997- \\ 1991 & 1996 & 1999\end{array}$

Company Related Factors

Scalability (Picking Location)

High

Medium Dedicated

Warehouse

Large Dedicated Warehouse

Moderate

Wareroom (Hybrid)

$\mathrm{X}$

Small Dedicated Warehouse

Low

In-Store

X $\quad \mathrm{X}$

Method of Delivery

Store Pickup

Local Pickup

Home Delivery

X $\quad X$

Company Rate of Expansion

Slow

X

Moderate

Fast

X

X

Automation Level

High

Moderate

X $\quad \mathrm{X}$

Low

Employee/Management

Commitment

High

X $\quad$ X $\quad X$

Moderate

Low 
Table 7 (Cont'd)

Other Mediating/Moderating Factors for Peapod: 1997 - 1999

$$
\begin{array}{lll}
1989- & 1992- & 1997- \\
1991 & 1996 & 1999
\end{array}
$$

Market Structure Factors

Connectivity

Internet Structure

High

Moderate

Low

Internet Penetration

High

Moderate

Low

Internet Access

High

Moderate

Low

Cost of Internet Service

High

Moderate

Low

Population Structure

Population Size

Population Density

Geographical Location

Continental

North America

X $\quad$ X $\quad$ X

South America

Europe

Asia 
Table 7 (Cont'd)

Other Mediating/Moderating Factors for Peapod: 1997 - 1999

$\begin{array}{llll} & 1989- & 1992- & 1997- \\ & 1991 & 1996 & 1999 \\ \text { Country } & & & \\ \quad \text { United States } & \mathrm{X} & \mathrm{X} & \mathrm{X} \\ \quad \text { United Kingdom } & & & \\ \text { Japan } & & & \\ \text { County/Parish } & & & \\ \quad \begin{array}{l}\text { Urban } \\ \text { Suburban }\end{array} & & \\ \text { Rural } & \mathrm{X} & \mathrm{X} & \mathrm{X}\end{array}$

54. Peapod's decision to begin using centralized distribution (i.e., warerooms) centers was undertaken to reduce costs, improve quality, and enhance volume scalability. Construction of warerooms was also designed to alleviate the impact that Peapod's business had on its grocery retail partners. By building these warerooms, Peapod moved from low scalability to moderate scalability (see Table 7).

During March of 1998 Peapod closed its service in the Atlanta market because its retail partner, Bruno's, was sold. This move was precipitated by the fact that Atlanta had a sprawling population that made home delivery a very expensive service (Bond 1998).

Thus, for the home delivery of groceries an urban market was more conducive in terms of delivery related costs. In 1997 Peapod began testing a dedicated warehouse fulfillment model. Results showed that converting to a wareroom model could reduce picking times by more than 40 percent and reduce incidents of stockouts by two-thirds (Smith Barney 1997c). This would result in a decrease in picking, packing and assembly costs, and an increase in picking speed, picking accuracy, and assembly accuracy. According to 
Andrew Parkinson a secondary reason for moving to the wareroom model was that the company had reached scale with the in-store model.

The decision to experiment with the wareroom format signaled a change in Peapod's strategic focus. In a March 1998 interview with Progressive Grocer, Andrew Parkinson stated before the online grocery industry entered its growth cycle, there were still some pieces of Peapod's business model that needed to be addressed. These issues concerned inventory, fulfillment, quality, and price (Mathews 1998). In the interview Parkinson stated, “[a]t Peapod, we're going to be going into warehouse-fulfillment models operated in conjunction with retailers in several markets. We can do that because we have volume. By changing models, we can actually lower our cost, pick more efficiently and lower our overall overhead" (Mathews 1998, p.24). Thus, Parkinson subscribed to the idea that you have to invest in building an infrastructure that will allow you to lower costs even if, in the short run, that investment prevents you from making money. Parkinson admitted that the fulfillment model was a better model for filling orders by noting that he would be ". . .the first to admit [Peapod] reached scale with an in-store model that's not the most efficient model for picking.” (Mathews 1998).

Once Peapod decided to build the three proposed fulfillment centers, it announced that it would be relying on Exel Logistics for consultation and planning (Amato-McCoy 1998). Exel helped Peapod with site location analyses, routing optimization, facilities and operating process design, and consultation regarding technology requirements for materials handling and inventory management (Harrington 1998). Excel was in negotiation to acquire and operate one of Peapod's warehouses sometime during the following year. Exel had been consulting with Peapod for about a year before signing this 
agreement. The alliance marked a departure in Peapod's approach to managing its distribution channel (Saccomano 1998). The new fulfillment management systems used a combination of commercially available and internally developed applications. These systems were housed in the company's fulfillment centers and provided logistics support for ordering, picking, and vehicle routing. The centralized customer support systems coordinated call center operations, customer billing and electronic payment processing (Peapod, 10-K, 1998).

The fulfillment centers resembled a conventional grocery store with an added staging area for inventorying orders. Once an order was received, a Peapod 'shopper' would pick the order from the shelf and place it in paper shopping bags, using plastic bags for produce. The bags were then placed inside delivery containers called totes that could hold two shopping bags. The totes could be lined with foam and used to store frozen and refrigerated items by adding a dry-ice puck to a section. That section was then used to store the frozen items for up to 48 hours in outside temperatures of 104 degrees Fahrenheit. The adjacent sections of the tote served as a refrigeration unit and keep items cold, but not frozen, from the residual cold of the ice pucks (Sciacca 1999b). In terms of efficiency, the company estimated that it took about 20 minutes to pick an order from the wareroom fulfillment center which was approximately half the time it took to pick the same order from store shelves.

These new warehouse fulfillment centers allowed Peapod to use its new handheld scanning technology and the new transportation routing system which facilitated the cross-docking of perishable products to ensure freshness. Due to these new efficiencies, the company was able to reduce its delivery fees by half. According to Peapod's own 
research, once the delivery cost exceeded $\$ 10$ some customers would not try the service. Therefore, Peapod's decision to move to a dedicated wareroom model helped in reducing costs and also helped increase customer trial (Salomon Smith Barney 1998a; Peapod, 10K, 1998). In addition, the company also contemplated the elimination of monthly subscription fees noting that their elimination significantly increased the yield on membership drives and also lowered the cancellation rate (William Blair \& Company 1997c).

Another area where costs were critical was in the delivery of groceries. Peapod's current model required someone to be home to receive the delivery. However, the option of unattended delivery became viable with the development of technology that allowed the company to insulate and refrigerate its delivery totes. According to a company spokesperson Peapod's new tote technology was designed to give the company the flexibility necessary to make unattended home deliveries (Sciacca 1999). Peapod began considering unattended delivery when the company experimented with early morning delivery using the new totes. This was the company's first step towards unattended delivery and marked another permutation in its business model. It was unclear whether it was going to use this technology with the in-store picking model or with the local fulfillment (i.e., wareroom) model, but if it did it would have been using models $7 \mathrm{~b}$ and 14b respectively under the partnership category (see Appendix 1). The use of these new delivery methods resulted in greater customer satisfaction because the customer was free of the delivery schedule. For Peapod, the use of unattended delivery allowed for greater flexibility in the delivery function which resulted in lower delivery costs. 
In 1999 Peapod launched a nation wide service called 'Peapod Packages' (Peapod, 10K, 1998; Salomon Smith Barney 1998a). The service was being launched as a defensive move in an attempt to match a similar service offered by Netgrocer, one of Peapod's competitors. According to the company, the service was designed to build brand recognition before the company expanded its full service into new markets. The service allowed consumers to purchase, and have delivered, dry groceries and household products without having to use Peapod's dedicated software (Liebeck 1998). Once consumers select their basket of goods, they were shipped by United Parcel Service's (UPS) ground shipping at a flat cost of $\$ 7.95$ per order. What was interesting is that by using UPS, a third-party logistics provider, Peapod was actually experimenting with business model 11 under the partnership heading (see Appendix 1). With this model, the ordering, picking, and packing functions were done by Peapod while the actual delivery was handled by UPS.

Peapod's strategy during 1999 was to demonstrate that the new wareroom fulfillment center model could be profitable. The year began with the consolidation of a number of in-store fulfillment centers into the wareroom format. Although this format allowed Peapod to gain efficiencies in terms of picking and restocking, the efficiencies came with a significant reduction in the amount of inventory carried. Picking from its retail partners' stores allowed Peapod access to anywhere from 20,000 to 30,000 inventory items. In its warerooms, however, Peapod only stocked between 9000 to 12,000 products. These products included dry grocery goods, frozen and dairy products, and time sensitive perishable products including produce, meat and prepared foods (Sciacca 1999). This did not worry Peapod's management because they noted that the 
SKUs in the fulfillment center represented 90 to 95 percent of what the company's members wanted. This seems to be in contrast to what most grocery retailers believe. Most grocers believe that the more inventory that can be offered to the customer the higher the customer satisfaction level. This stems from the idea that with large inventories the customers will likely find what they are looking for or at least some substitute. The effect of the inventory reduction was directly related to the inventory holding costs. This reduction may have affected consumer satisfaction in relation to product selection. If this was the case then the decline in satisfaction may have had an effect on repeat orders and cancellation rates.

During 1999 Peapod also ended its relationship with Safeway and announced that it would be obtaining high quality products directly from wholesalers and specialty providers. Besides wanting to switch to a dedicated fulfillment center to gain efficiency, Peapod cited Safeway's lack of aggressive marketing as a reason for terminating the partnership. According to Andrew Parkinson, chief executive officer for Peapod, he had nothing but respect for the former retail partner, but "[i]n Safeway's case, they never got behind the [home-shopping] program like Jewel/Osco did [in Chicago]," (Sciacca 1999c). The decision to switch to a dedicated fulfillment model was also designed to reduce the inventory acquisition costs since the company would not have to pay retail price for its inventory. It was hoped that the savings would lead to reduced customer fees, which would spur repeat purchases and initial customer trials. To make deliveries from its new warehouse location Peapod purchased a fleet of box trucks.

The opening of its third dedicated fulfillment center solidified Peapod's new distribution strategy. In areas where the company did not have warehouses or significant 
volume, it continued to use the store picking model. To boost brand awareness and sales in the San Francisco area, Peapod decided to embark on an aggressive marketing campaign.

Since Peapod's inception, it had always operated in the red. The internally generated cash flow was always well short of its operating costs. The reality of this situation was significant because one of Peapod's stated business goals was to demonstrate that its business model could break even. However, during October, the company reported that its current cash and portfolio of marketable securities was insufficient to fund operations and capital requirements for the next year (Peapod, 10-Q, 1999). As a result, the company was actively evaluating financing opportunities (Woods 1999). Peapod officials attempted to soften the news by stating that they had in excess of \$15 million in cash and marketable securities at their disposal, which the company claimed was sufficient to fund operations into the third quarter of 2000. Peapod also divulged that it was in discussions with a number of potential investors that had expressed interest in the company. Moreover, the company acknowledged that it had retained the services of the investment banking firm Wasserstein Perella to help the company obtain additional financing and possibly a buyer (Woods 1999; Peapod, 10-K, 2000).

During November 1999, Peapod announced that Drayton McLane Jr., the former vice chairman of Wal-Mart had made an investment in the company and joined the board. Peapod also forged a partnership with Drayton’s company, the McLane Group, which specialized in distribution management and logistics. During this time Peapod announced that the McLane Group would be responsible for coordinating distribution for 
the central distribution centers. With the help of the McLane Group, Peapod was looking to increase efficiency in its distribution operations. According to John A. Caltagirone, chief logistics and operations officer for Peapod at the time, this move would result in another $15 \%$ to $20 \%$ improvement in productivity, primarily in the areas of receiving, stocking, packing and shipping. Again, this represented a move by Peapod to eliminate costs from its supply chain by utilizing software that was less costly than proprietary software and, in terms of time, easier to implement. Thus, switching to third-party software technology was an attempt to reduce the impact of system development and maintenance on the cost structure.

\section{Cost Components}

55. Peapod's decision to acquire inventory from wholesalers was designed to reduce overall inventory costs. This switch was initially made in one market, which meant that Peapod was still reliant on its grocery retail partners to supply it with inventory in other markets. This was represented by the cost component 'purchased via manuf./wholesaler' - CC(23). The continued inventory acquisition from retail partners was represented by the cost component 'purchased via partner' CC(3) (see Table 6).

56. In order to make deliveries from their dedicated fulfillment centers (i.e., warerooms), Peapod purchased a fleet of box delivery trucks. This was represented by the cost component 'delivery fleet company owned' - CC(21) (see Table 6).

57. With the purchase of the delivery fleet, Peapod also incurred costs associated with maintenance and upkeep of the delivery fleet. This cost was represented by the cost component 'fleet maintenance' CC(22) (see Table 6).

\section{Performance Drivers}

58. Based on Peapod's internal research, the elimination of monthly subscription fees increased the yield on membership drives and 
lowered the cancellation rate. These relationships were represented by the links between the revenue component 'subscrip./member fees' $\mathrm{RC}(3)$ and the performance drivers 'number of new customers - PD(1) and 'cancellation rate' - PD(8) (see Figure 26).

\section{Other Mediating/Moderating Factors}

59. Once Peapod began to incorporate new technology into their picking, packing, and delivery functions, the company moved from a low to a moderate automation level (see Table 7).

Financial Data

In 1997, Peapod was incorporated in Delaware. During the period between 1997 and 1999 Peapod's profit structure did not change substantially in relation to its revenue and cost components. However, geographic expansion into new markets plus enhancements to the fulfillment functions resulted in changes for certain cost and revenue components.

During this period, Peapod's cost structure consisted of front-end and back-end costs. The front-end costs include order taking costs, customer relationship costs, and general and administrative costs. The back-end costs include capital expenditures, inventory expenses, and fulfillment expenses (see Table 6).

During 1997 Peapod released its Version 5.0 software which included components that enabled audio and animation on its website. The cost associated with developing this software was primarily associated with the development personnel. These costs were a significant component of the cost structure due to the proprietary nature of the software. However, this changed in 1999 when Peapod and the McLane Group attempted to increase efficiency in the distribution area by implementing new third-party vendor routing and scheduling software. Up to this point all of Peapods 
software was developed in-house. This represented a move by the company to eliminate a sizable portion of the software development costs by utilizing software that was cheaper and easier to implement. There were still costs associated with the purchase and implementation of the third-party software; however, these costs were less than those associated with the design and implementation of proprietary software. Thus, switching to third-party software technology was an attempt to reduce the impact that system development and maintenance costs were having on the company's cost structure. During the period from 1997 to 1999 there were no other major changes to the order taking software. Figure 27 shows the increase in system development and maintenance expenses during the period between 1997 and 1999.

In order to build brand equity, Peapod aggressively marketed its service through advertising and promotions. A major part of this advertising campaign was conducted

Figure 27

Peapod’s System Development and Maintenance Costs: 1997 - 1999

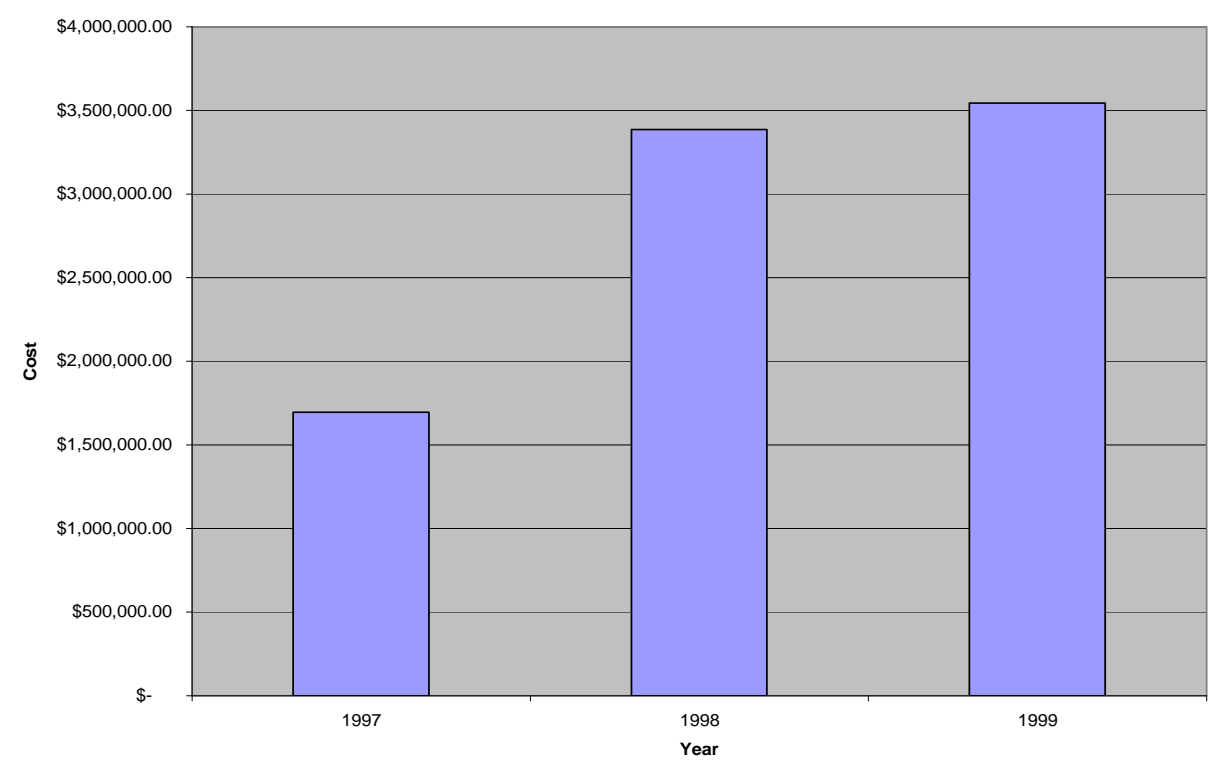


through cooperative relationships with Peapod's retail partners. For example, In 1997 Peapod and Jewel collaborated in the Chicago market and membership increased by $233 \%$ and order volume increased by $148 \%$. This marketing effort resulted in a $64 \%$ increase in customer relationship costs over 1996 levels. Figure 28 displays the increases in this cost for Peapod during the period between 1997 and 1999.

In order for Peapod to conduct business the company had to incur general and administrative costs. Each time the company entered a new market or established a new fulfillment center it incurred general and administrative costs (see Table 6). Figure 29 depicts the increase in this cost during the period between 1997 and 1999.

Figure 28

Peapod's Marketing and Selling Expenses: 1997 - 1999

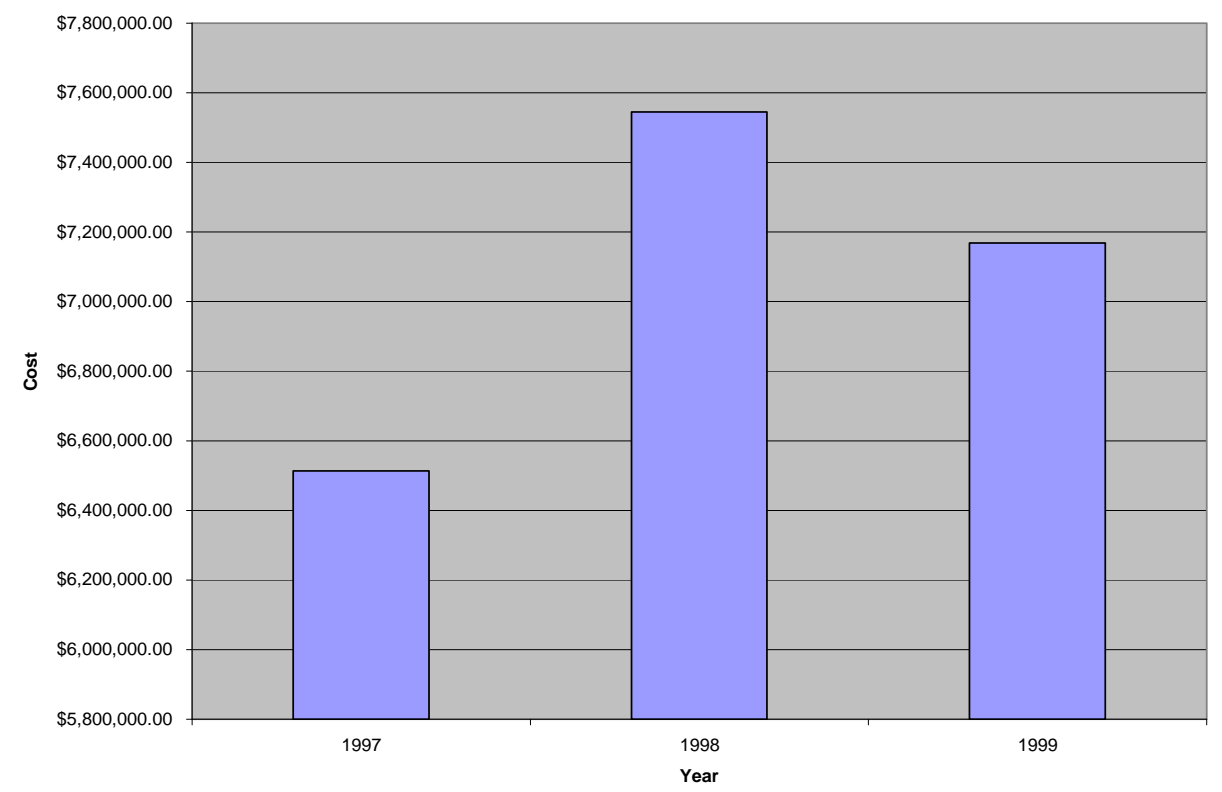

In relation to Peapod's back-end costs, inventory acquisition was a significant component. Peapod's business model required that the company purchase inventory from its retail partners at their retail prices. This proved to be an expensive way of 
Figure 29

Peapod's General and Administrative Expenses: 1997 - 1999

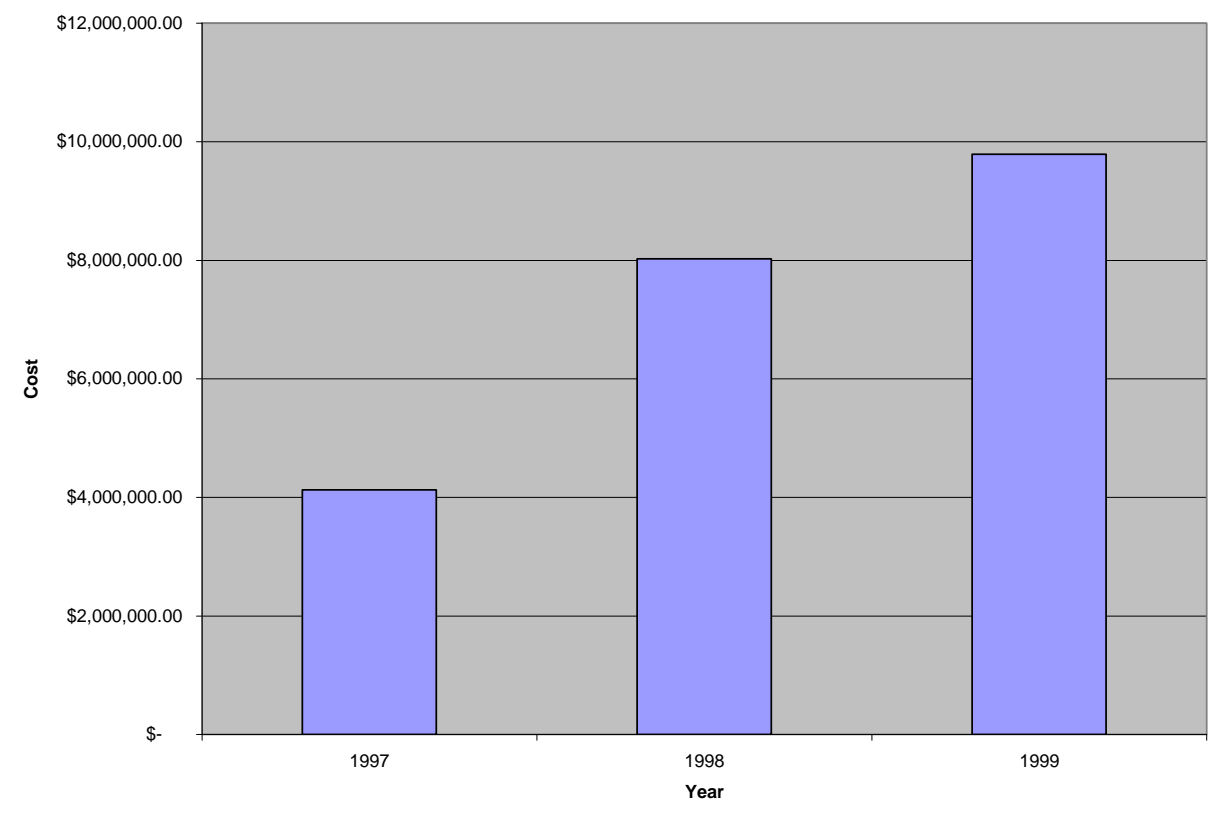

Figure 30

Peapod's Grocery Costs: 1997 - 1999

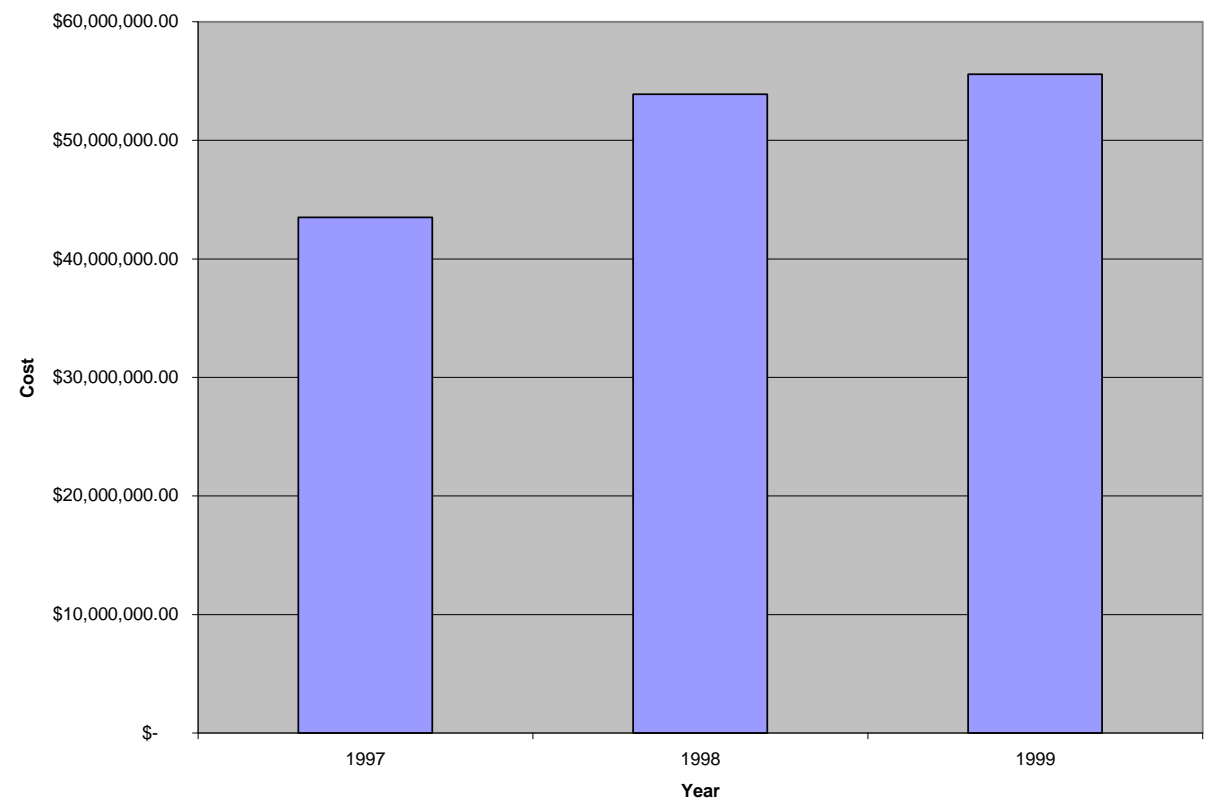


acquiring inventory. In an attempt to reduce the impact of this cost, Peapod ended its inventory agreement with Safeway and began acquiring products directly from wholesalers and specialty providers. Figure 30 displays the increase in this cost for the period between 1997 and 1999.

Capital expenditures and fulfillment expenses were two other back-end costs for Peapod. Capital expenditures represented costs associated with either: (1) purchasing land, equipment, or facilities or, (2) renting equipment and/or facilities. Prior to 1999 Peapod leased most of the equipment and facilities that it used. In 1999 the company purchased a fleet of box trucks to use at its dedicated fulfillment centers. Fulfillment expenses represented the costs associated with the picking, packing, and delivery functions. Using the in-store picking model, Peapod had to have employees at each location in order to conduct fulfillment activities. Most of those employed in the fulfillment function were part-time employees. Since Peapod had a high employee turnover rate the company had increased costs associated with finding, hiring, and training new employees. As a result, Peapod decided to make changes to the fulfillment function by switching to business models that included wareroom fulfillment centers. This allowed the company to consolidate several store-picking fulfillment centers, which helped to reduce the costs associated with fulfillment personnel.

To increase efficiency in the fulfillment function, Peapod developed new technology aimed at reducing costs, improving quality, and enhancing scalability. For Peapod, the capital expenditures and the fulfillment expenses were accounted for under the heading of grocery operation. This category also encompasses costs associated with the auxiliary service level. Figure 31 depicts the change in grocery operations cost for 
the period between 1997 and 1999. Figure 32 displays the combined front- and back-end costs for Peapod during the period. From this graph it was clear that Peapod's main costs were inventory acquisition costs, fulfillment and delivery costs, and general and administrative costs.

Figure 31

Peapod’s Grocery Operations: 1997 -1999

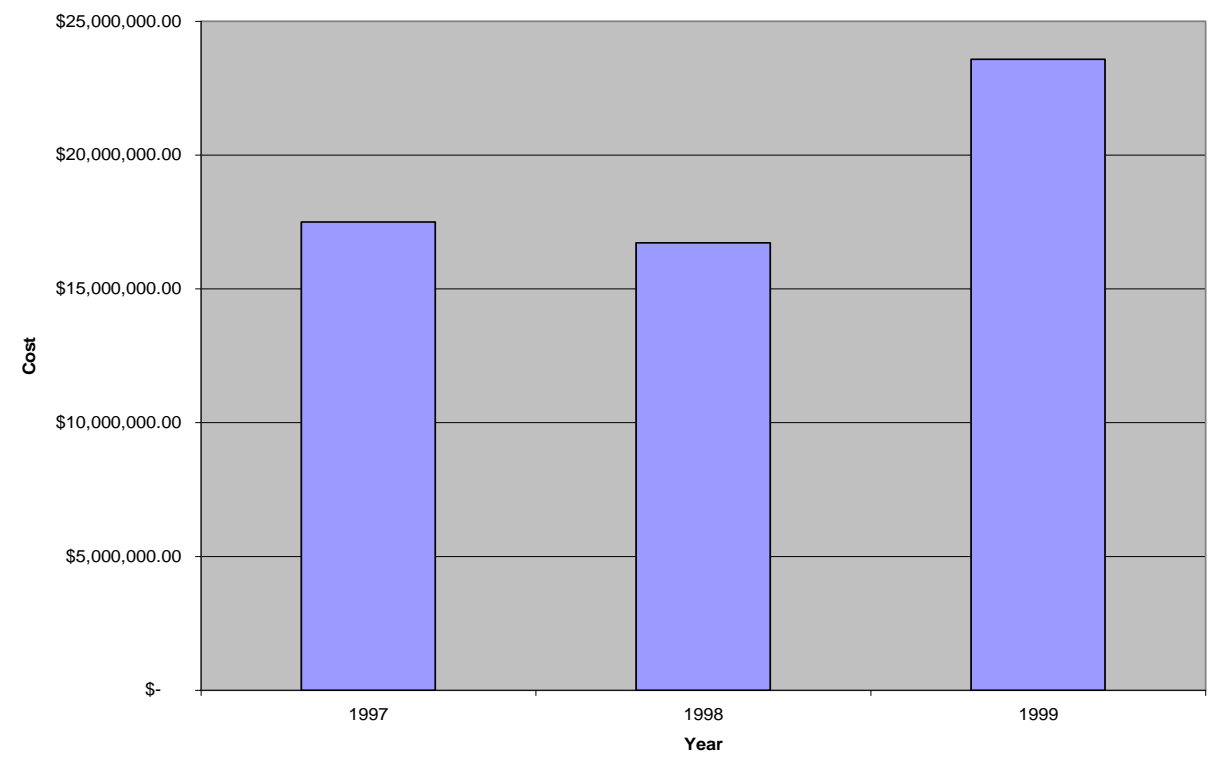

In terms of Peapod's revenue stream, it is composed of fees, commissions, delivery revenue, inventory sales, and website related revenue. For Peapod, delivery revenue and fees were combined and represented as the category 'member and retailer services'. Figure 33 displays the changes in 'member and retailer services' during the period between 1997 and 1999. The graph shows that member and retailer services decreased in 1998 and 1999. The decrease was partially due to the revenue lost as Peapod exited the Atlanta market. 
Figure 32

Peapod's Combined Cost Components: 1997 - 1999

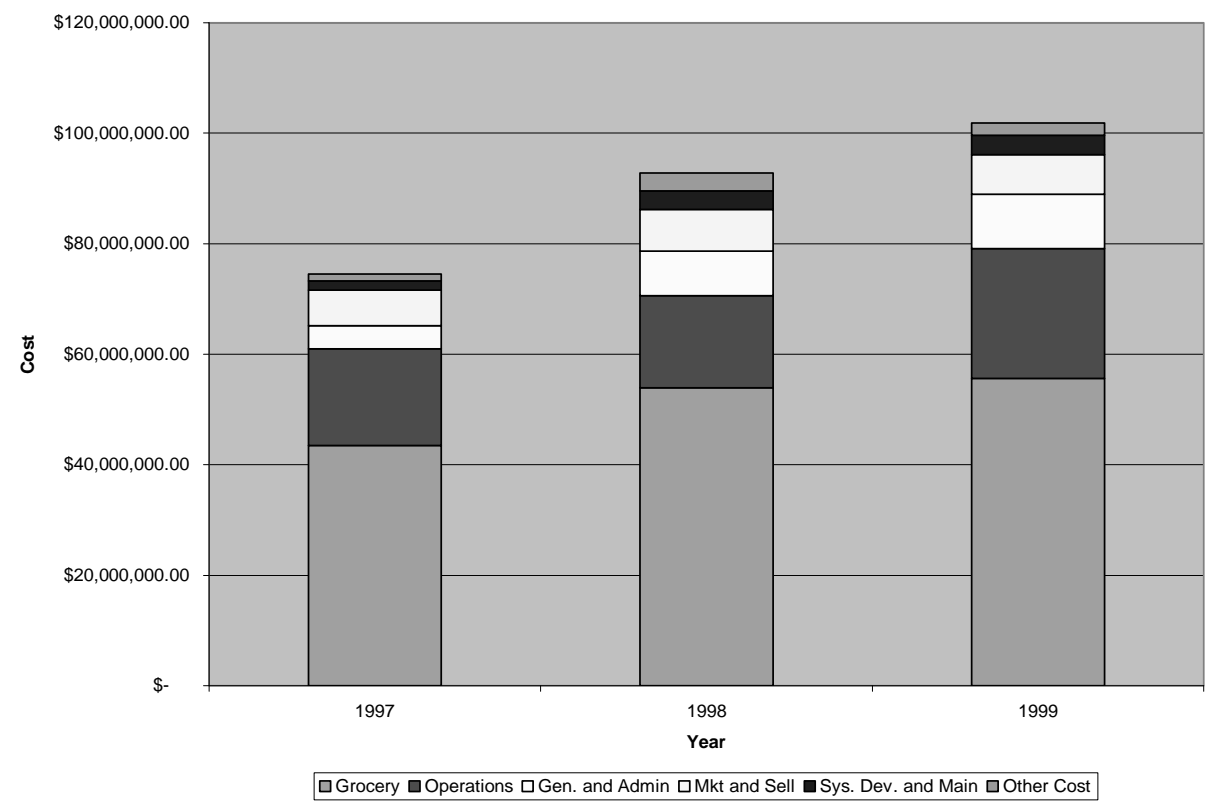

Figure 33

Peapod’s Member and Retailer Services: 1997 - 1999

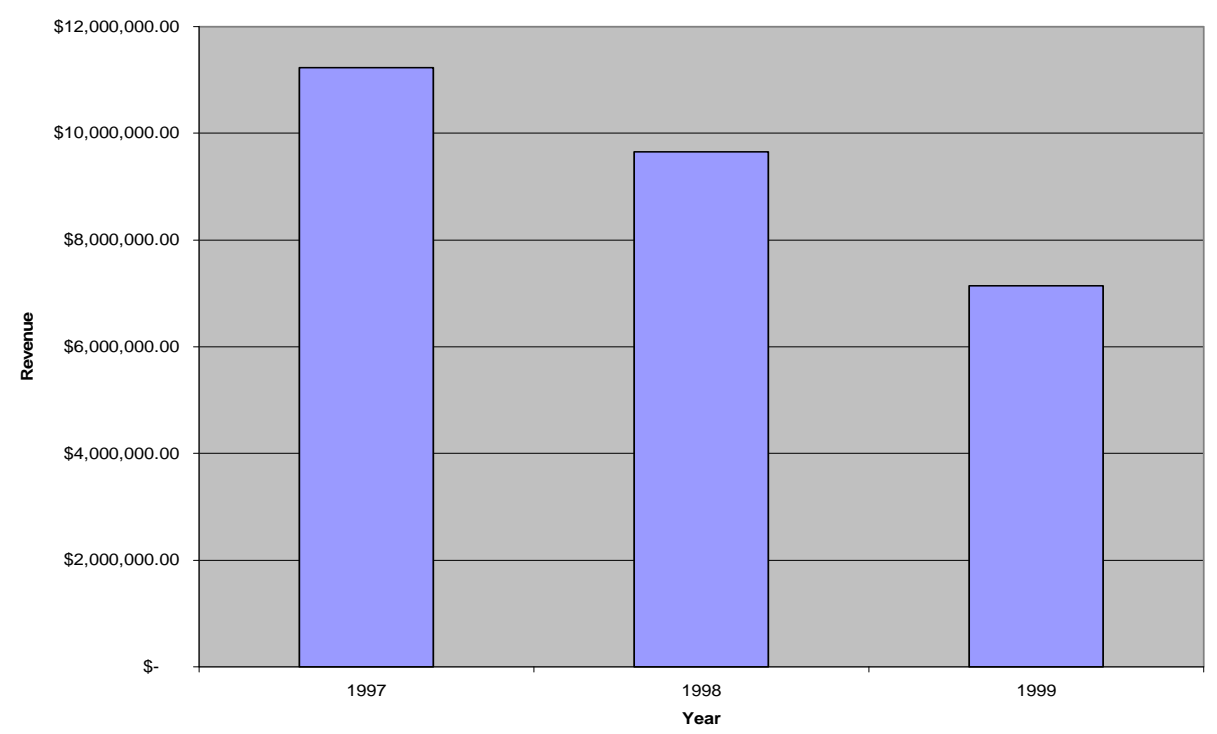


The revenue from commissions was represented by the category 'interactive marketing services'. Peapod also includes the revenue associated with advertising on its website in this category. Figure 34 displays the changes in this revenue component during the period between 1997 and 1999. The revenue from the sale of inventory (groceries) is represented by the category 'grocery sales'. Figure 35 shows the increase in this revenue component during the period. The investment capital was represented by the category 'cash provided from financing operations'. Figure 36 shows the financing activities for Peapod during the period.

Figure 34

Peapod's Interactive Marketing Services: 1997 - 1999

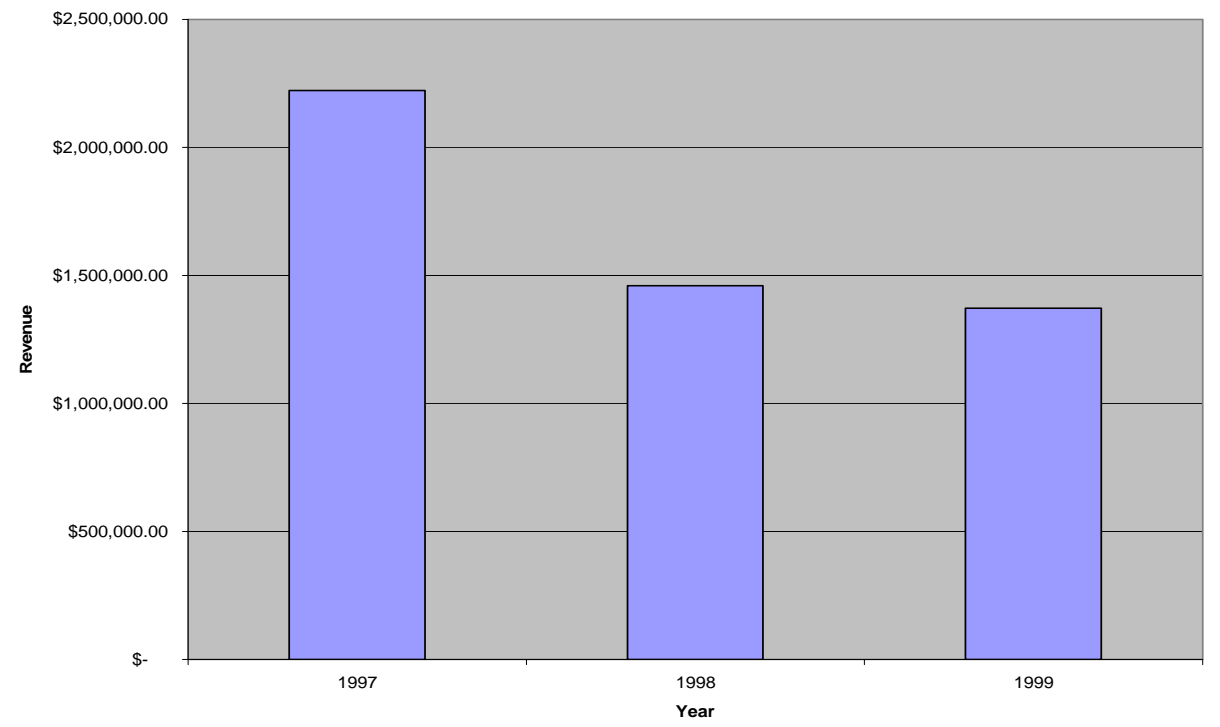

Figure 37 displays Peapod's combined revenue structure for the period between 1997 and 1999. Looking at the graph it is clear that the majority of Peapod's revenue came from the sale of grocery inventory. Very little of Peapod's revenue came from its core delivery function. Figure 38 displays Peapod's combined capital when the cash 
provided from financing operations was included. Lastly, Figure 39 depicts the relationship between total revenue and total cost for Peapod during the period. Based on

Figure 35

Peapod's Grocery Sales: 1997 - 1999

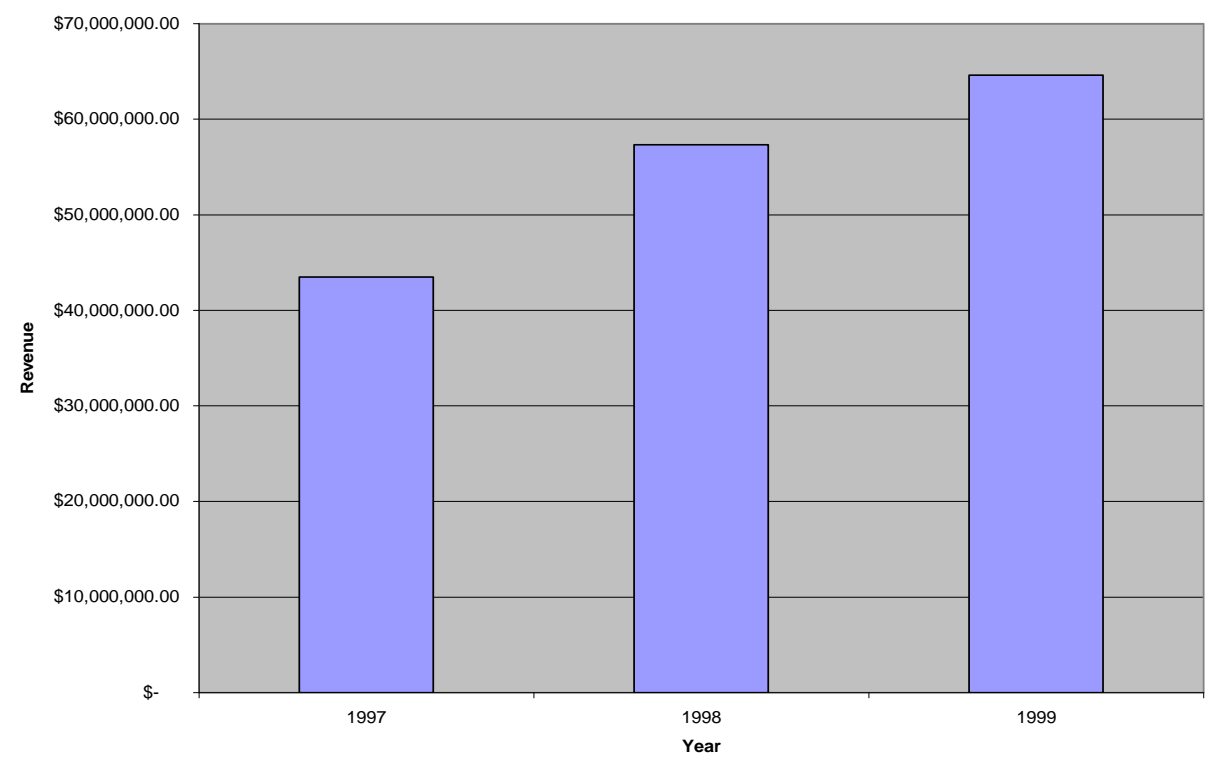

Figure 36

Peapod's Cash Provided from Financing Operations: 1997 - 1999

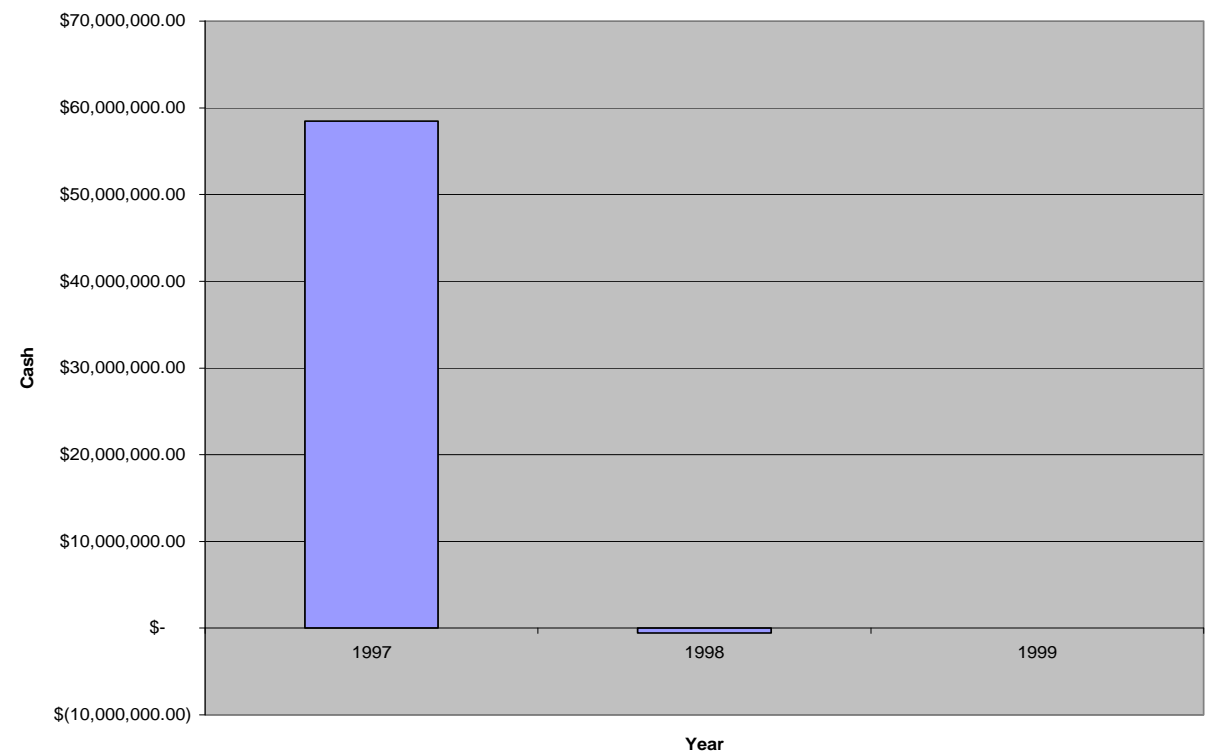


this graph, it is evident that Peapod's cost structure was still far out pacing its revenue structure. This meant that Peapod was continuing to operate at a financial loss. When the cash from financing operations was combined with total revenue, Peapod had enough capital to cover total costs in 1997 but in 1998 and 1999 total costs were greater than total revenue and cash combined (see Figure 40). However it was assumed that some of the capital collected in 1997 would be used in 1998 and 1999 to smooth the discrepancy between total revenue and total costs.

Figure 37

Peapod's Combined Revenue Components: 1997 - 1999

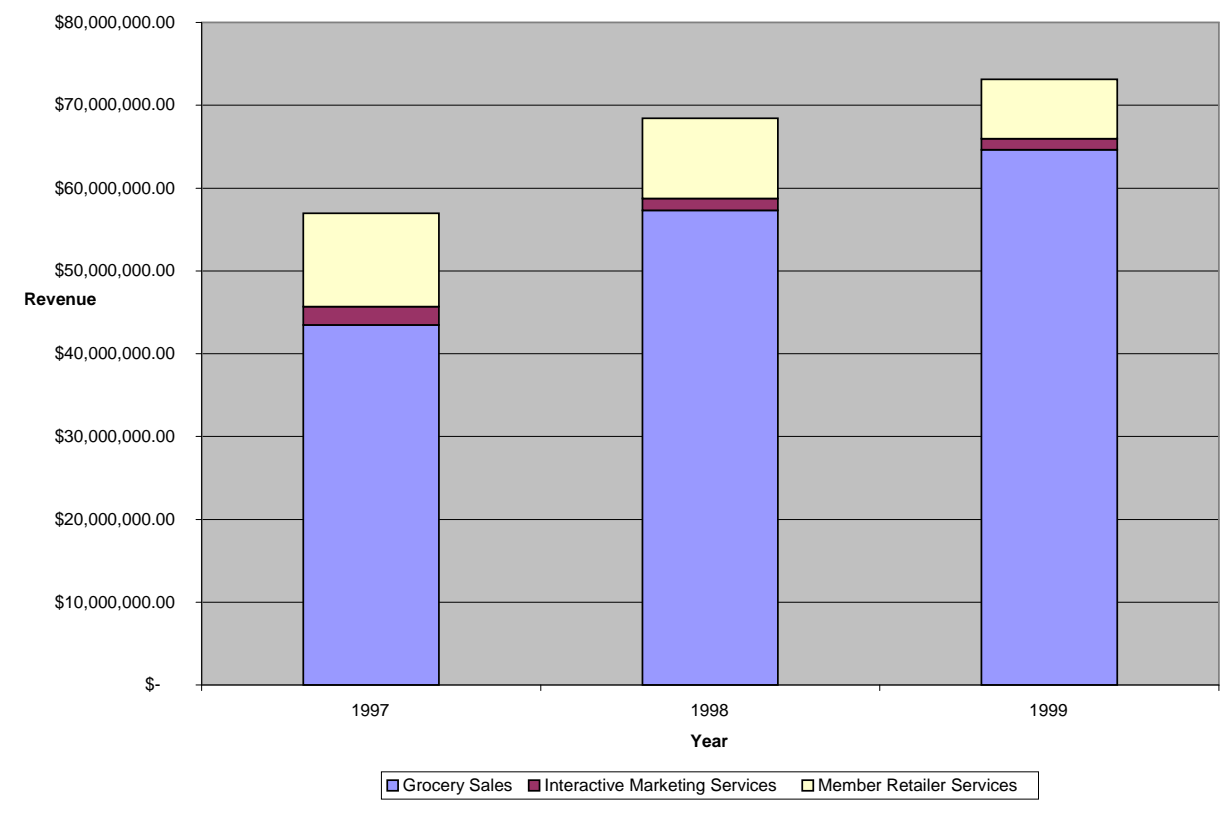


Figure 38

Peapod's Combined Revenue Components and Cash Provided from Financing Operations: $1997-1999$

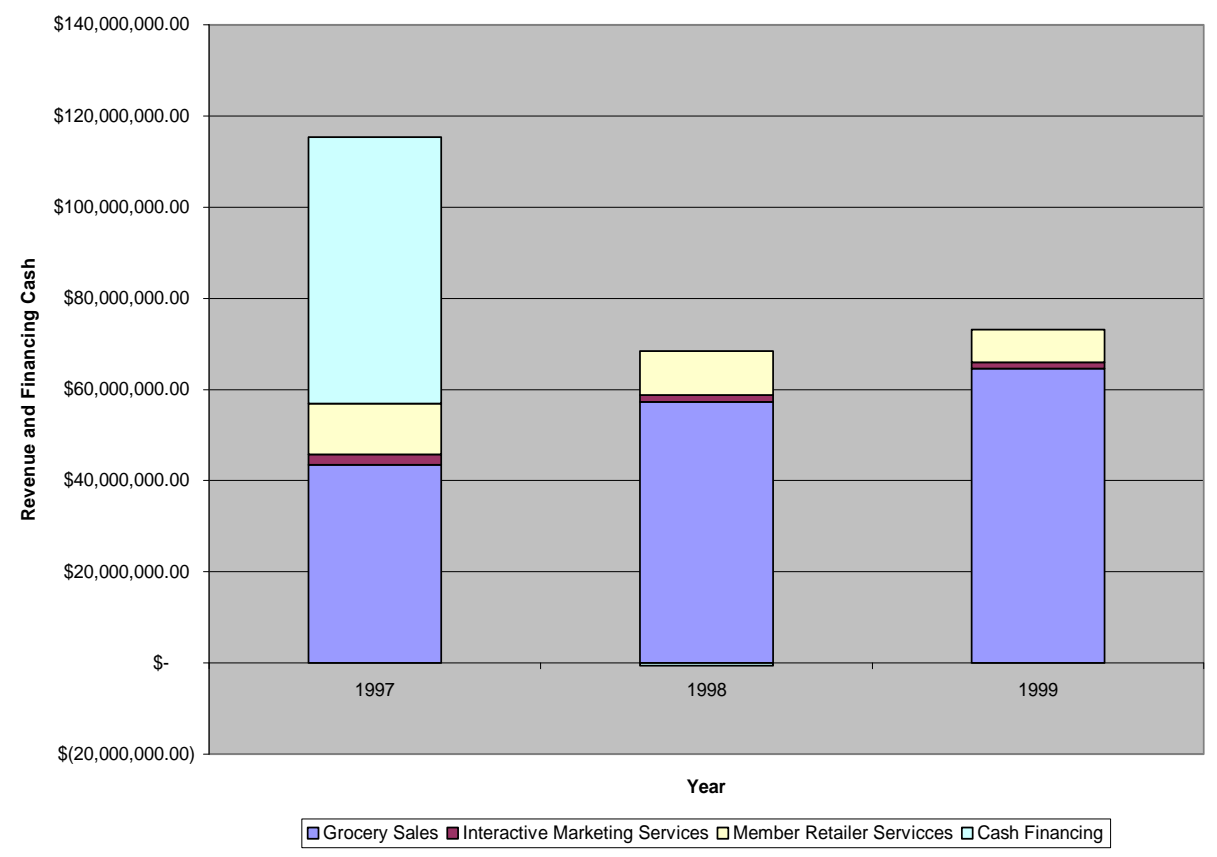

Figure 39

Comparison Between Peapod's Total Revenue and Total Cost: 1997 -1999

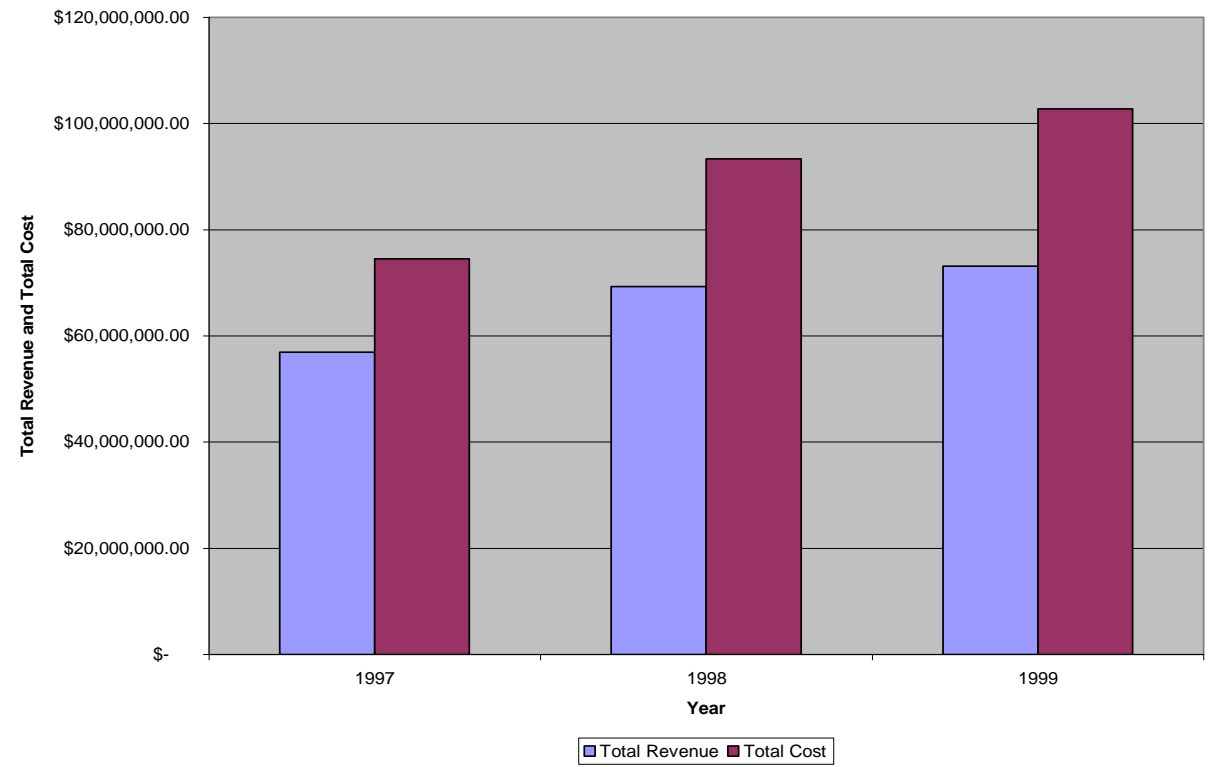


Figure 40

Peapod's Total Cost and Total Revenue with Cash from Financing Operations: 1997 1999

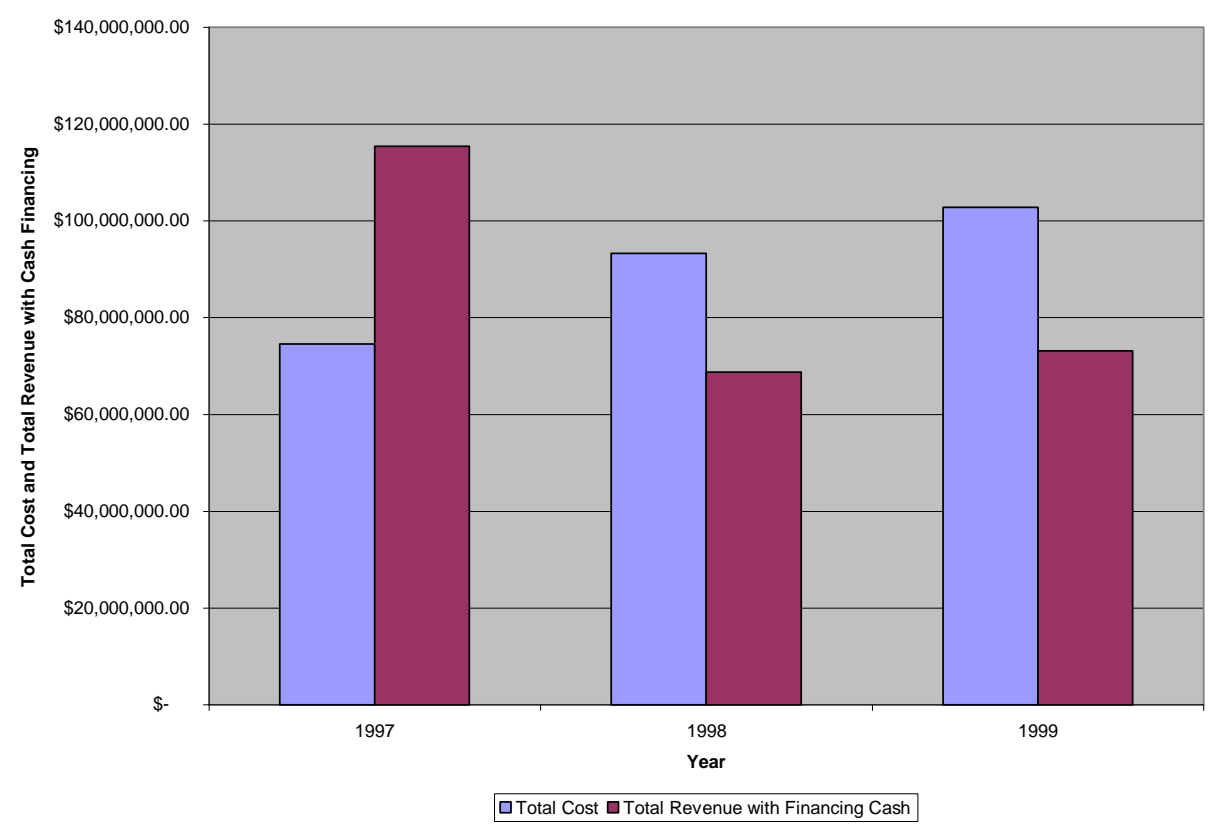

\section{Summary}

During 1997 Peapod expanded into the Houston, Atlanta, Dallas, and Austin markets and opened 25 new fulfillment centers bringing the total number of fulfillment centers to 52. The expansion coincided with the company's stated business strategy, which was to aggressively expand into new metropolitan markets and increase penetration in existing markets. No other expansion activities occurred during the period (Peapod, 10K, 1997).

During this period Peapod also began making changes to the fulfillment side of its business. One of the main reasons for these changes was to try to reduce the employee labor costs associated with this function. By working with its retail partners Peapod began incorporating dedicated fulfillment centers, known as warerooms, into its channel 
structure. This allowed Peapod to reduce the number of in-store fulfillment locations it was operating from. According to Peapod's management, the new warerooms saved the company 20 to 30 percent of the costs associated with filling orders from supermarket shelves. The warerooms also allowed the company to increase its volume scalability. To lower its inventory purchasing costs, Peapod began purchasing inventory from wholesalers and specialty providers. This allowed the company to increase its profit margin on inventory.

Also during this period Peapod developed new warehousing and routing technology. The warehousing technology consisted of hand-held scanners designed to increase the speed at which orders could be assembled while reducing the number of mispicks. These changes were designed to reduce costs and improve the quality of the delivery service. The new routing technology consisted of a transportation routing system that facilitated the cross-docking of perishable products. During this period Peapod also began providing unattended delivery using insulated delivery totes. By placing a dry-ice puck into these totes it was possible to keep food fresh for a longer period of time.

To increase demand for its service, Peapod increased the level of service that it offered its customers. For example, in 1997 the company announced that it would implement a loyalty program in an attempt to increase member acquisition, current member usage, grocery order size, and member retention. In 1998, Peapod began offering unattended home delivery. Further, in 1999 Peapod launched a nation wide service called 'Peapod Packages' which allowed customers to order food products from Peapod and have them sent anywhere UPS delivered. 
$\underline{\text { Peapod's Profit Structure from } 2000 \text { - } 2006}$

The year 2000 got off to a good start with sales figures from the fourth quarter of 1999 up with the efficiencies from the fulfillment centers increasing margins by 25 percent. The company continued consolidating its store based fulfillment centers into warerooms. These new facilities would be between 100,000 and 125,000 square feet. In early 2000, under the guidance of the McLane Group, Peapod was planning to open a 117,000 square foot centralized fulfillment center in Dallas, Texas. Peapod also intended to expand its facilities in the New York area and proceeded with plans to build centralized fulfillment centers in Austin and Houston, Texas (Springer 2000). Given its ambitious plans, it was obvious that Peapod was attempting to sever the partnerships between itself and its brick-and-mortar retail partners. In this regards, Peapod was attempting to take the final steps towards becoming a true pure-play.

Things were going well for Peapod because in February, the Company announced it had letters of intent stating that Apollo Management, L.P., The Yucaipa Companies, Pequot Capital Management, Inc., GRP II, L.P., and Group Rallye, would invest an aggregate of \$120 million for equity in Peapod (Kelsey 2000). The infusion of this new equity financing would help strengthen the company's financial position and aid in its stated strategy of rapid growth. However, during March, Peapod experienced a shakeup in its upper management when CEO Bill Malloy resigned due to health reasons. This occurred right at the time the company was in negotiations for the \$120 million dollar capital infusion. As a result of Mr. Malloy’s resignation, the investment group balked, and removed the deal from the table (Hobson 2000). With about \$3 million in cash left in reserve, Peapod's stock price began to plummet. 
In March, Peapod's retail partner Stop \& Shop Co. announced that in April it would formally launch its own online grocery delivery service in Connecticut. This new service was seen as an outgrowth of its partnership with Peapod. The venture called for Stop \& Shop to control all aspects of the operation and to use an in-store fulfillment model (Reidy 2000). With this move by Stop \& Shop, many felt that the partnership between it and Peapod would soon be over. According to industry analysts, Stop \& Shop's venture had the potential to break even quickly because it already had an infrastructure of stores to fill orders from. Further, Stop \& Shop was in a unique position because it was able to learn from Peapod over their four year partnership and use that knowledge to refine its business model (Reidy 2000). To gain efficiencies from the picking and packing functions, Stop \& Shop could convert its mezzanine areas into minifulfillment centers and operate them at a fraction of the cost it would take to build and operate a stand alone facility (Reidy 2000).

Things got even worse for Peapod during March when a class action lawsuit was filed against the company. The basis for the suit stemmed from conflicting claims made by Peapod. In their November 1999 SEC 10-Q filing, Peapod warned that it may not have enough money to cover its operating expenses for the coming year. Then on November 8, 1999 the company issued a statement saying that it had more than $\$ 15$ million in cash and marketable securities to cover operating expenses through the third quarter of 2000 (Kelsey 2000b). With this revelation there was little hope for a successful stock issue, and given the unwillingness of venture capitalists to invest in Peapod, the prospects for the company looked dim. With just $\$ 3$ million in reserves, 
Peapod's financial advisers, Wasserstein Perrella \& Co., were directed to pursue alternatives sources of funding or a possible sale of the company.

Given the low stock price, there were not many offers for Peapod right away, but by April Peapod was in merger talks with an unnamed backer (Springer 2000). That backer turned out to be Royal Ahold, the Dutch supermarket group, which offered Peapod \$20 million in revolving credit to stabilize its cash crisis and agreed to purchase $\$ 73$ million in convertible securities. Once the securities were converted Ahold would own 51 percent of Peapod (Peapod, 10-K, 2001). From a business model perspective, this marked the end of Peapod's partnership model and its move towards becoming a pure-play model and the beginning of its evolution as the online arm of a click-andmortar business.

What was interesting about the deal was that Stop \& Shop, which had recently decided to enter the online grocery business, was a subsidiary of Ahold. Thus, with the purchase of Peapod, Ahold was able to leapfrog in the online grocery industry by acquiring technology that was anywhere from 18 to 21 months ahead of its own. In addition, it gained the managerial capacity to operate in the U.S. online grocery market. According to the deal, Peapod provided the online technical expertise, Web interface and marketing expertise while Ahold provided mezzanine space that served as wareroom fulfillment centers. In May, Marc van Gelder became Peapod's new president and chief executive officer. Van Gelder was previously senior vice-president of supply chain management and logistics at Stop \& Shop, the New England subsidiary of Royal Ahold. This was seen as a necessary first step in smoothing the consolidation between the companies. 
Although Ahold had acquired 51 percent of Peapod, the terms of the deal where such that Peapod remained a stand-alone company and Ahold supplied it with goods, services, and fulfillment center space. Thus, with this strategic relationship Peapod received a supply and service agreement that allowed it to leverage Ahold's purchasing power and acquire goods at a lower price. In addition, Peapod was also able to leverage the brand equity of the local Ahold subsidiaries through co-branding and co-marketing (Peapod, 10-K, 2001). Peapod believed that by co-branding and co-marketing, the company was able to overcome several of the obstacles that customers encountered when trying a new service from an unknown retailer. Moreover, the merger allowed Peapod to purchase media in a more cost effective manner (Peapod, 10-K, 2001).

By August 2000 Peapod was already seeing benefits from the alliance with Ahold. In the Chicago market Peapod was able to change its pricing structure to offer free delivery on orders in excess of $\$ 75$. To increase its service appeal and brand recognition the company began providing customers with an unattended delivery option. Customers could have their orders delivered to a designated and secure location such as a back yard, a back porch or a special room in a building. The deliveries were made using the company's new innovative, tamper-resistant totes which were designed to keep groceries fresh by using insulated temperature controlled compartments. This seemed like a defensive move by Peapod since its competitors had similar service offerings. Nonetheless, the unattended delivery option marked the beginning of Peapod's evolution to business models 7a, 7b, 14a, and 14b under the hybrid category (see Appendix 3).

By September 2000, as a result of Peapod's alliance with Ahold, the company had to break certain agreements with other grocery chains that had served as fulfillment 
centers. This caused the company to pull out of the Columbus, Houston, Austin and Dallas markets (Peapod, 10-K, 2001). This was Peapod's new strategy which was to concentrate on areas where Ahold had a significant presence. This allowed Peapod to expand into Southern Connecticut and Washington, D.C. where Ahold owned retail outlets. By leveraging Ahold's BAM network of grocery stores, Peapod reduced the marketing costs associated with local brand building while at the same time increased its inventory buying power. Further, Peapod agreed to buy Streamline’s Washington distribution center and its Chicago assets, including its customer base, for \$12 million. By purchasing these dedicated central distribution centers Peapod began utilizing business models 20, and 21a under the hybrid category.

Also during the year, Peapod tested the viability of store pickups as an alternative to home delivery on a limited basis in Chicago and Boston. Interviews with consumers, revealed that they did not feel there was much of a convenience aspect or a real time savings if they had to go to the store to pick up their orders themselves. Even though the initial response to this service was not enthusiastic, the company had plans to extend the test on a larger scale (Zwiebach 2001b). Peapod's decision to test a store pickup alternative signifies that the company was using business models 1 and 8 under the hybrid category (see Appendix 3).

Profit Structure Analysis for Peapod: Profit Structure from 2000 to 2006 Investment Capital

60. Royal Ahold’s decision to acquire Peapod provided Peapod with $\$ 20$ million in revolving credit. This was represented by the investment capital component 'investment capital' - IC(1) (see Table 8). 


\section{Cost Components}

61. Establishing local fulfillment centers was done in conjunction with Peapod's grocery retail partners. Hence the costs associated with the physical construction of these fulfillment centers was offset by the retail partner. Peapod did incur the costs associated with the picking, packing, and delivery functions. These were represented by the cost components 'picking costs human capital' - CC(4), 'packing costs human capital' - CC(5), 'delivery personnel costs' - CC(17) and 'fuel costs' - CC(6) (see Table 8).

62. Once Peapod was a subsidiary of Royal Ahold, it received a supply and service agreement from them. As a result, Peapod was able to lower its inventory acquisition costs by leveraging Ahold's buying power. This was represented by the inventory cost components 'purchased via partner' - CC(3) and 'purchased via manuf./wholesaler - CC(23) (see Table 8).

The co-branding and co-marketing activities between Peapod and Ahold were represented by the cost components 'customer awareness partnership' - CC(9) and ‘customer acquisition partnership' - CC(10) (see Table 8).

63. Peapod's decision to buy the dedicated central fulfillment/distribution centers from Streamline required the company to spend \$12 million dollars. For this cost, Peapod acquired the fulfillment facility and the land that it was located on. This purchase was represented by the capital expenditure cost components 'land' - CC(24) and 'facilities company purchased/Built’ - CC(25) (see Table 8).

\section{Other Mediating/Moderating Factors}

64. By moving towards local fulfillment (i.e., warerooms) facilities, Peapod was moving towards becoming a true pure-play online grocer. The decision to construct centralized fulfillment/distribution center meant that Peapod was changing its scalability level from low to moderate (see Table 9). 
Table 8

Peapod's Profit Structure Components: 2000 - 2006

\section{Sources of Operating Capital}

\section{Investment Capital}

1. Investment Capital (IC1)

\section{Delivery Revenue}

1. Core Delivery Fee (RC4)

2. Grocery Bill Percentage Fee (RC5)

3. Auxiliary Delivery Revenue (RC6)

\section{Fees}

1. Installation/Packaging (RC2)

2. Subscription/Membership (RC3)

\section{Commission}

1. Integrated Marketing

\section{Front End Costs}

\section{Order Taking Costs}

1. Website Related

1a. Design

In-house (CC1)

1b. Maintenance

In-house (CC11)

Customer Relationship Costs

7. Customer Awareness

7a. Done Alone (CC7)

7b. Partnership (CC9)

8. Customer Acquisition

Costs

8a. Done Alone (CC8)

8b. Partnership (CC10)

\section{Back End Costs}

\section{Capital Expenditures}

1. Land (CC24)

2. Facilities

2a. Leased (CC2)

2b. Company Purchased /Built (CC25)

8. Delivery Fleet

8a. Company Owned (CC21)

9. Fleet Maintenance (CC22)

Fulfillment Expenses

4. Picking Costs (F,V)

4a. Human Capital (CC4)

4b. Hybrid (Some Automation) (CC18)

5. Packing/Assembly Costs (F,V)

5a. Human Capital (CC5)

5b. Hybrid (Some

Automation) (CC19)

\section{Performance Drivers}

\section{Customer Service Drivers}

11. Number Using Delivery (PD11)

12. Number Using Advertising (PD18)

13. Number Using Promotional (PD19)

14. Number Using Research (PD20)

\section{Customer Patronage Drivers}

1. Number of Orders (PD3)

2. Items per Order (PD13)

3. Number of New Customers (PD1)

4. Number of Repeat Customers (PD2)

5. Number of Membership Renewals (PD4)

6. Purchase Amount (PD10)

16. Cancellation Rate (PD8)
1b. Promotional Service (RC8)
Auxiliary Services
1c. Research Service (RC9)
9. Auxiliary Service Level

\section{Delivery Service Drivers}

7. Number of Orders Delivered (PD9) 
Table 8 (Cont'd)

Peapod's Profit Structure Components: 2000 - 2006

\section{Sources of Operating}

\section{Capital}

1. Direct Advertising Revenue

(RC10)

2. Indirect Advertising Revenue

(RC11)

\section{Inventory Sales}

1. Grocery Inventory Sales (RC12)

\section{Front End Costs}

Auxiliary Services (Cont'd)

9a. Delivery Related (CC12)

9b. Coupon Redemption (CC13)

9c. Promotional (CC14)

9d. Advertising (CC15)

9e. Research (CC16)

\section{General And Administrative}

10. General and Admin. (CC17)

11. Other Costs and Expenses

(CC18)

\section{Back End Costs}

Fulfillment Expenses (Cont’d)

\section{Performance Drivers}

Delivery Service Drivers (Cont'd)

6a. Fuel Costs (CC6)

8. Number of Vehicles Used (PD15)

9. Number of Delivery Attempts (PD14)

6b. Delivery Personnel Costs (CC17)

15. Delivery Truck Capacity (PD22)

13. Routing and Scheduling

(CC20)

\section{Inventory Expenses}

3. Inventory Acquisition Cost

3a. Purchased via Partner

(CC3)

3b. Purchased via

Manuf./Wholesaler (CC23)
Operational Service Drivers

8. Fulfillment Performance 8a. Picking Speed (PD5)

8b. Number of Lines Picked (PD16)

8c. Picking Accuracy (PD6)

8d. Assembly Accuracy (PD7) 
65. As a result of Peapod's merger with Ahold, Peapod exited markets where Ahold did not have a presence and entered new markets where Ahold did have a presence. This represented a change in Peapod's growth rate from fast to moderate (see Table 9).

66. Peapod's decision to allow customers in Chicago and Boston to pick up their completed orders from the store represents Peapod's willingness to utilize different business models. This was represented by the category ‘store pickup’ under the method of delivery in Table 9.

Table 9

Other Mediating/Moderating Factors: 2000 - 2006

Company Related Factors

$\begin{array}{llll}1989- & 1992- & 1997- & 2000- \\ 1991 & 1996 & 1999 & 2006\end{array}$

Scalability (Picking Location)

High

Medium Dedicated

Warehouse

Large Dedicated Warehouse

Moderate

Wareroom (Hybrid)

X $\quad \mathrm{X}$

Small Dedicated Warehouse

Low

In-Store $\quad$ X $\quad$ X

Method of Delivery

Store Pickup

$\begin{array}{lll} & X \\ X & X & X\end{array}$

Home Delivery

Company Rate of Expansion

Slow

$\mathrm{X}$

Moderate

$\mathrm{X}$

$\mathrm{X}$

Fast 
Table 9 (Cont'd)

Other Mediating/Moderating Factors: 2000 - 2006

$$
\begin{array}{llll}
1989- & 1992- & 1997- & 2000- \\
1991 & 1996 & 1999 & 2006
\end{array}
$$

Automation Level

High

Moderate

Low

$\begin{array}{llll} & & X & X\end{array}$

Employee/Management

Commitment

High

$\begin{array}{llll}X & X & X & X\end{array}$

Moderate

Low

Market Structure Factors

Connectivity

Internet Structure

High

Moderate

Low

Internet Penetration

High

Moderate

Low

Internet Access

High

Moderate

Low

Cost of Internet Service
High
Moderate

Low 
Table 9 (Cont'd)

Other Mediating/Moderating Factors: 2000 - 2006

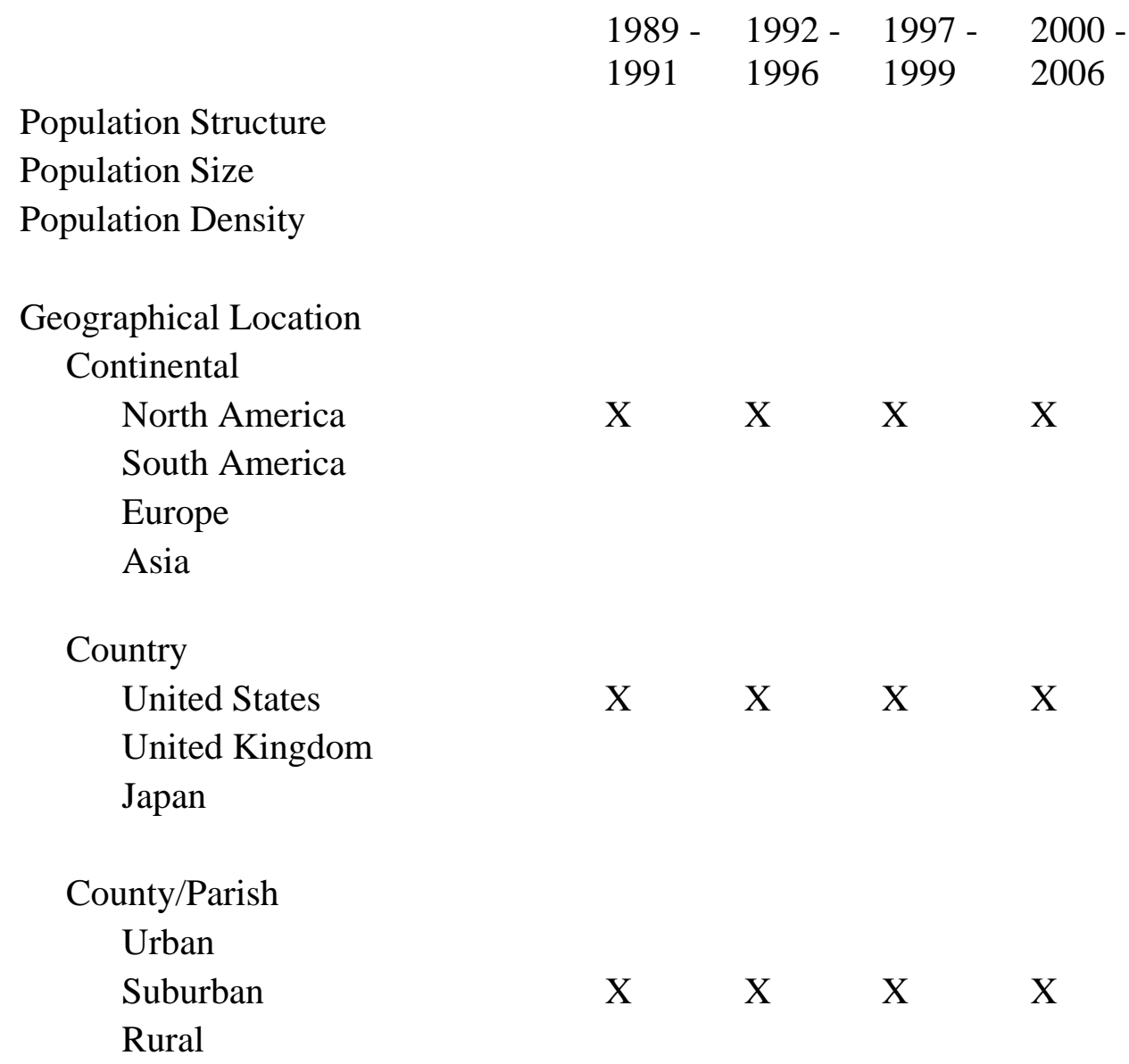

In January 2001 Peapod teamed with Giant Foods, another Royal Ahold subsidiary, and expanded its service into the Washington, D.C. area. This signaled the company's strategy to target the east coast where Royal Ahold had a significant presence and strong brand recognition. The addition of Peapod's service to the Giant Foods brand allowed Giant to offer an additional service to its customers. By teaming with Giant Peapod was actually leveraging the Giant brand. The idea was to transfer the trust that consumer had in Giant to Peapod. This allowed Peapod to shift capital away from advertising and brand building and into providing better service for its customers. 
In February 2001, Peapod exited the San Francisco market to save money and as a strategic move since Ahold did not have stores in the area (Merrefield 2001). According to Marc van Gelder, Peapod president and chief executive officer at the time, the San Fransciso market was not a strategic one for the company. At the time, Peapod was projecting that it would become profitable in the Chicago market, but overall the company was still losing money. According to van Gelder the average size of an order in the Chicago area was more than $\$ 125$ giving the company about a 32\% gross margin on orders (Ghitelman 2001). These numbers reflected the efficiencies Peapod gained from its partnerships with Ahold. According to van Gelder, by the summer, the company was due to show a profit in the Chicago market before marketing costs were considered. Company wide Peapod was predicting that it would be profitable by 2003. Even with these new numbers, the company, as a whole, was projected to be 50 million in the red.

Apparently, a main factor in the move towards profitability was the company's focus on transportation costs. During its 1999-2000 transition to three large dedicated centralized fulfillment centers, the company incorporated new technologies that allowed it to smooth out the routing process. Specifically, during the ordering process, the new software prompted consumers to choose a delivery time when the delivery truck was already planned to be in their neighborhood. Peapod also offered discounts to customers willing to state a six-hour window rather than the usual two-hour time-slot. This allowed delivery trucks to carry 16 as opposed to 10 orders per delivery run (Edgecliffe-Johnson 2001). Thus, Peapod was purposely shifting delivery demand to specific times in order to force the capacity it needed to offset the delivery costs. 
One possible reason for Peapod's success in the Chicago market stemmed from the fact that many of its rivals in that market had ceased operations allowing Peapod to benefit from the residual transfer of clientele. In addition, Peapod implemented a new pricing strategy with a minimum order amount of $\$ 50$ and a graduated scale up to $\$ 100$ at which point the delivery was free (Helet 2001). The graduated delivery fee was designed to cover delivery costs by having customers either pay more for smaller orders or having them make larger orders for free delivery. With a $\$ 50$ minimum, customers in all Peapod's markets paid a delivery fee of $\$ 9.95$ for orders up to $\$ 75$; $\$ 4.95$ for orders of $\$ 75$ to $\$ 100$ in Chicago, Long Island and Connecticut; and \$5 for orders over \$75 in Washington. Thus the delivery service was being viewed as a convenience service. In addition, the joint marketing and co-branding began paying off with stronger customer demand than the company had forecasted. Since Peapod did not have to invest capital in local brand building, the company looked for ways to increase its service level. One way was to capitalize on Ahold's 15 million customers using its loyalty programs which carried information about the buying habits of each customer. By integrating this information into Peapod's systems, loyalty members could choose to access online shopping lists compiled from what they normally bought in-store. This procedure reduced the time it took for customers to compile their shopping lists (Edgecliffe-Johnson 2001). Also, Peapod could target these customers with e-coupons, allowing them access to the same services that in-store customers received. Again, this demonstrated Peapod's focus on customer service.

Also during this period, Peapod was able to secure \$30 million from Ahold, which allowed the company to continue operations for the year. In order to keep 
Peapod's cash outlay at a minimum, Ahold suspended interest and dividend payments so the company could apply the extra capital to its cost structure. In March 2001, three months ahead of schedule, the company achieved its first-ever operating profit in the Chicago market. This milestone was attributed to the improvements in operating efficiencies. Specifically, gross profit per order increased $\$ 14.00$, to more than $\$ 45$ per order, as a result of higher product margins and an increased average order size. At the same time, operating costs were reduced by $\$ 10.00$ per order as a result of the proprietary routing technology. The company also announced that it was making "considerable progress" toward achieving operating profitability in the Long Island, N.Y., and Connecticut markets (Anonymous 2001b).

In May 2001, the company ended Peapod Packages, its nation wide delivery service, in order to save money and focus on its five current markets. This again demonstrated that the strategy was to focus resources in areas where Ahold had a significant presence. In July, Ahold announced it would acquire the remaining public shares of Peapod for an estimated $\$ 35$ million. This was prompted by the fact that investors had turned sour towards Internet grocers which made it difficult for Peapod to acquire enough private financing. Once the buyout was complete, Peapod no longer had to worry about financing. As a result, the company focused on continuing its geographic expansion on the East Coast while reducing its marketing costs by capitalizing on the brand equity of each of Ahold's grocery store chains. By bringing Peapod into the Ahold family, Ahold signaled that it believed the online grocery channel had significant potential. 
With the demise of WebVan in July, many analysts questioned whether selling groceries online would ever be profitable without the backing of an established BAM grocer. According to van Gelder, due to the demise of WebVan and HomeGrocer, Peapod contemplated eliminating free delivery altogether. Peapod maintained that customers must pay for the value added service of having their groceries delivered. Thus with no price competition, more of the actual cost of the delivery service was being passed on to the customer. By August, Peapod announced that it would be expanding its service into the northeastern and southeastern Washington, D. C. areas and into northeastern Prince George County, Maryland, by September. All the orders for Peapod by Giant would be picked, packed and delivered from the company's central fulfillment center located in Gaitherburg, Maryland.

Once Peapod went private it no longer disclosed financial information so there was little information available about the internal workings of the company after 2001. From 2002 forward, much of the information on Peapod had to be extracted from the business news and published reports on the company.

Given that Peapod no longer had to seek financing, it was able to concentrate on brand building and service enhancing activities. The company undertook a new advertising campaign to increase brand awareness in the five markets it was operating in. Apparently, the demise of WebVan caused many people to assume that Peapod was either out of business or going out of business. According to van Gelder, chief executive of Peapod, "[o]ne of our biggest challenges is awareness ... People think we went out of business, too” (Tribune Business News 2002). Peapod’s new advertising campaign included radio, print, and billboard advertising. Specifically, the company sponsored 
traffic and news updates on some radio stations, produced free-standing inserts distributed in local newspapers, and used actual billboards and the sides of buses.

Although many of Peapod's original competitors had ceased operations, the online grocery channel had moved into the second phase of its evolutionary cycle, which was marked by the entrance of the brick-and-mortar grocers. Since these grocery chains already had strong brands, there was no need to conduct brand building activities so advertising turned to awareness of the service. According to some industry watchers, when it comes to selling groceries online, companies should not bother unless they have a recognizable BAM grocery store name.

In September the company claimed that it was ahead of schedule towards reaching its profitability goals in the Boston market. This was partly due to the fact that all the major competition in that market had exited. Also, the company was able to leverage Stop \& Shop’s 30 percent market share (Lerner 2002). In October, van Gelder reported that Peapod had a 35 percent growth rate and was generating incremental sales as opposed to cannibalizing existing brick-and-mortar sales for Ahold. He also noted that Peapod was profitable in four out of the five markets that the company operated in and had an average order size of $\$ 135$.

In October the company announced that it would be expanding its service to the Providence, Rhode Island market. From Peapod's perspective, this was a good move because most of the people in the market were city dwellers and did not have direct access to cars. It was assumed that they would be happy to pay $\$ 10$ for the delivery service. 
In April 2003, Peapod by Stop \& Shop began service to the Hartford, Connecticut market and in May it expanded service to the Lake Geneva, Wisconsin market (Business Wire, 2003). In November, in its Chicago market, Peapod launched a new service known as 'Chicago's Best'. This was an aisle on the website that allowed online shoppers to choose foods from a variety of popular Chicago restaurants. This demonstrated Peapod's strategy of providing more service to its online customers while focusing on higher margin products. Peapod's continued expansion demonstrated Ahold's strategy of expanding on the East coast of the United States into areas where it already had BAM store recognition and customer loyalty. This also demonstrated that Ahold was focused on proving Peapod's service as a convenience. The addition of the 'Chicago's Best' selection to the delivery service showed that Peapod was focusing on enhancing the service to appeal to a broader customer bases.

\section{Costs Components}

67. For each market that Peapod entered, the company needed to hire enough personnel to pick, pack, and deliver customer orders. This was represented by the cost components 'picking costs human capital' CC(4) and 'picking costs hybrid' - CC(18). Further, the 'packing/assembly costs human capital' - CC(5) and 'packing/assembly costs hybrid' - CC(19) were also related to total cost (see Table 8).

68. The decision to offer the Chicago's Best delivery service was an attempt to provide the customer with a higher level of service. To provide this service Peapod incurred costs associated with pickup and delivery of takeout orders. This cost was represented by the auxiliary service level cost component 'delivery related' - CC(12) (see Table 8).

Other Mediating/Moderating Factors

69. Peapod's announcement that it was expanding its service into the northeastern and southeastern Washington, D. C. areas, as well as into 
northeastern Prince George County, Maryland, signified the company's commitment to moderate expansion. Further, the decision by Peapod to expand into the Providence, Rhode Island market also demonstrated the company was following a moderate expansion rate. In addition, Peapod's expansion into the Hartford, Connecticut and Lake Geneva, Wisconsin market was also in line with a moderate expansion rate (see Table 9).

By 2004 Peapod was operating in five markets using two different fulfillment methods. In its Chicago and Washington, D. C. markets, it used a dedicated warehouse while in smaller markets, it used "warerooms" which were located on the second floor of select Ahold's subsidiary stores. By using two different methods, Peapod was in a position to determine which method was the best. According to Thomas Parkinson, cofounder of the company, the two models were fairly similar. From an economic perspective transportation was less expensive when delivering from warerooms because delivery personnel did not have to drive as far, but the picking cost were more expensive because the company needed more warerooms to cover an area. For the warehouses, the picking and packing was cheaper, but the transportation was more expensive. Both seemed to be about the same in terms of the bottom line.

The company planned to continue searching for ways to increase the number of orders per truck and for ways to keep the vehicle routes as compact as possible. To accomplish this Peapod provided customers with incentives for accepting delivery at less desirable times. Hence, the more flexible the customer was in terms of delivery time the lower Peapod's delivery costs were. In addition to truck density and delivery time flexibility, Peapod also made adjustments to its service based on population density and demographics. In low-density areas deliveries could be made twice a week, while in 
densely populated areas deliveries could be made seven days a week. The density also affected Peapod's decision to offer unattended delivery. If a customer's home or business was located in an area designated as an unattended area, when the customers logged on to the website the unattended option would be displayed. These decisions concerning the delivery service indicate that Peapod was adjusting the service level, looking for the right balance between convenience and cost for its online home delivery service.

\section{Summary}

In 2000, Peapod's decision to continue consolidating its in-store based fulfillment centers into wareroom fulfillment centers represented the company's effort to reduce its labor costs by improving the performance of the picking and packing areas. During this period the company announced plans to expand into the New York market. On the surface it seemed that things were going well for Peapod. However, this changed when the company acknowledged that it had a cash shortage problem and might not be able to sustain operations for the last quarter of the year. This imbalance between Peapod's cost and revenue structures almost forced the company into insolvency. However, before that point was reached, Peapod was rescued by Ahold which initially bought a 51 percent interest in the company and provided it with a \$20 million dollar infusion of credit giving the company the necessary financial cushion to continue operations.

The merger also allowed Peapod to reduce certain costs. According to the terms of the deal, Peapod remained a stand-alone unit while Ahold supplied it with goods, services, and fulfillment center space. Through this arrangement, Peapod was able to 
leverage Ahold's purchasing power and acquire inventory from Ahold at lower rates than the company could get on its own. In addition, the co-branding and co-marketing allowed Peapod to leverage the brand equity of Ahold's grocery subsidiaries. Since Ahold was supplying the space for the warerooms, Peapod did not incur any significant costs associated with establishing these facilities. Hence, Peapod was able to increase its efficiency without having to actually pay for it. Moreover, the acquisition of Streamline's state-of-the-art dedicated distribution center in Washington allowed the company to move away from the in-store fulfillment models.

By the end of August 2000, Peapod was already capitalizing on the efficiencies gained through its merger with Ahold. With its financial future secure, Peapod turned to improving the service that it was offering. In 2000, as a result this efficiency gain, Peapod was able to reduce and even eliminate delivery fees in certain markets. This resulted in an increase in customer acquisition and repeat customer patronage and a decrease in the cancellation rate. This was in line with research the company had indicating that reducing or eliminating delivery fees resulted in increases in customer trial and membership drives. In addition, by expanding the unattended home delivery option the company made it easier for customers in certain areas to receive their groceries. Moreover, they also began to provide an in-store pickup alternative and, in 2001, began offering Ahold's loyalty customers e-coupons. In 2003 the company added the 'Chicago's Best' aisle to its website which provided customers in the Chicago market the ability to order prepared foods from some of Chicago's popular food restaurants. In an attempt to stimulate customer demand and reduce the costs associated with the fulfillment and delivery functions, Peapod operated under various business models. By altering its 
business model, and thus the level of service it was offering, Peapod was trying to have the service appeal to a wider customer base.

Also during the 2000 to 2006 period, Peapod was concerned with expanding its service into new markets. In 2000 the company expanded into the Southern Connecticut and Washington, D.C. area and in 2003 it expanded into the Lake Geneva Wisconsin market. Peapod's expansion activities were based on its strategy of targeting areas where an Ahold subsidiary already had a presence. This helped to reduce the costs associated with creating brand awareness and, because the consumer was familiar with the store brand, it helped to increase the yields on membership drives by reducing the consumer's decision inertia.

In March 2001, Peapod achieved its first operating profit in the Chicago market. Much of the credit for this milestone was attributed to reductions in transportation costs but some credit also went to an increase in customer demand stemming from deeper penetration in the Chicago market. By utilizing new routing software, Peapod was able to shift the delivery demand to specific times in order to force the capacity density needed to offset the delivery costs. Thus, it seems that with Ahold's financial backing Peapod was able to concentrate on reducing costs in the fulfillment and delivery areas. This indicated that in order to be successful in the online grocery home delivery channel participants need to have deep pockets in order to finance operations until the cost structure could be brought under control and a critical mass of customers can be reached. At this point, as Peapod demonstrated, it may be possible to make a profit in the online grocery home delivery channel. 


\section{General Summary}

During Peapod's formative years between 1989 and 1991, it functioned as a partnership. Specifically, it served as the delivery arm for the BAM grocers it was partnered with. During these initial years, the company opted to use an in-store fulfillment model. This allowed it to get to market quickly with the least amount of capital outlay but the scalability of this model was limited. Thus, once Peapod reached a certain number of orders, the fulfillment function became inefficient due to the strain it placed on the retail partner's store inventory.

In addition to the scalability problem, the in-store fulfillment model also generated a significant labor cost due primarily to the variable cost associated with the labor component. That is, for each market that Peapod entered it had to acquire the capacity to handle the fulfillment function. As a result, the fulfillment function became very costly for Peapod. To offset this cost, Peapod began to expand its operation to other markets hoping to reduce the impact of the fixed costs on its profit structure. However, the variable costs were more significant because for each market that Peapod entered it had to duplicate many of the functions required to provide home delivery of groceries.

Peapod’s revenue structure initially relied on income generated from core delivery fees. In the formative years the revenue was not sufficient to sustain operations so Peapod had to rely on investment capital to survive during the formative years. Hence, by the end of 1991 Peapod had a cost structure that was much larger than its revenue structure. However, Peapod's management felt that things would change if the company could expand operations to new markets. 
In 1992, Peapod attached a grocery bill percentage fee to its service in order to offset the delivery costs. Also during the period Peapod expanded its operation. To facilitate the expansion, the company had to improve its proprietary ordering software. At the time, Peapod internalized these cost by bringing the software development function in-house. In 1995 Peapod released Version 4.0 of its software and in 1996 the company developed a virtual store on the Internet. These software updates allowed the company to improve the service but they were costly to develop.

According to Peapod, the expansion was undertaken in order to spread the fixed costs over a large enough customer base in order to lower the impact of fixed costs on margins. The problem with this strategy was that (1) Peapod was not generating enough revenue to fuel its growth and (2) the variable costs associated with the in-store fulfillment functions were a more serious problem. This became evident in 1993 when Peapod expanded into the San Francisco market.

Also during the period between 1992 and 1996 Peapod increased the service level it provided to its customers. These services included allowing customers to have their prescription drugs picked up and delivered, accepting coupons from Safeway or product manufacturer, offering personalized shopping lists, and 90 minute deliver time windows. By providing these services Peapod was increasing its cost structure with the hope of attracting more customers to its base service. In fact, during 1995 and 1996 Peapod embarked on an advertising campaign designed to increase membership and repeat purchases. Thus, Peapod was looking to increase its revenue stream.

Peapod continued to expand its service during the period between 1997 and 1999. It was during this period that Peapod also began to make changes to its profit structure. 
Specifically, in order to reduce the employee labor cost associated with the fulfillment function, Peapod incorporated warerooms into its channel structure. This move alone reduced the labor cost by reducing the number of employees needed in the fulfillment area. Moreover, it reduced picking time which further reduced labor costs. Moreover, Peapod incorporated hand-held technology that allowed the pickers to compile customer orders quicker and with better accuracy which further increased the efficiency of the company's fulfillment operation. Finally, in an attempt to boost demand for the core service, Peapod began offering auxiliary services to the customer.

During 2000, Peapod continued to consolidate its in-store fulfillment operations into wareroom fulfillment centers. These measures were enacted to reduce the labor costs associated with the fulfillment function. However, before Peapod could enjoy the fruits of its labor, the company had to disclose that it was short on capital and might not be able to continue operations through the last quarter of 2000. This forced Peapod to look for possible buyers and prepare for possible liquidation. The Dutch grocery conglomerate, Royal Ahold, rescued Peapod by purchasing a 51 percent interest in the company and providing it with enough capital to continue operating through the end of the year.

Once Peapod became part of the Ahold family, the company continued to follow a moderate growth strategy but only expanded into markets where an Ahold subsidiary already had a presence. By becoming an Ahold subsidiary, Peapod received a supply and service agreement from them which gave Peapod access to local dedicated fulfillment space and inventory to stock the fulfillment centers. This allowed Peapod to capitalize on Ahold purchasing power and acquire inventory at a reduced rate. Since grocery costs 
were a large portion of Peapod's cost structure, reducing this cost helped improve Peapod's margins on grocery sales.

Once Peapod's financial future was secure, the company turned to efforts to increase the demand for its service. One way Peapod intended to accomplish this was to eliminate the delivery fees for certain markets. According to the company's research, reducing or eliminating delivery related fees increased the membership drives and renewal rates and reduced the cancellation rate. Peapod also began using different delivery options in order for the service to appeal to a broader market. Thus, as Peapod reduced its cost structure the company turned to increasing demand for its service. Peapod has always engaged in customer acquisition activities, but this became a more central focus once the financing and costs associated with the fulfillment and delivery functions were brought under control. This is what helped Peapod to turn a profit in the Chicago market.

\section{$\underline{\text { Conclusion }}$}

This case analysis was undertaken to determine whether an online grocer's success was a function of the business models it was using. To determine this, it was necessary to establish some measure of success. Three of the secondary research questions alluded to the notion that profitability may be one measure of success. In order to measure profitability it was necessary to determine the components underlying the revenue (research question 6) and cost (research question 5) structures of companies operating in the online channel. The goal of assessing the company's profit structure was to determine how that company's profit structure impacted the company's success/failure 
(research question 7). By using profitability as a measure of success, the impact that a company’s business model had on profit could be assessed. This was accomplished by analyzing secondary data sources concerning Peapod and by looking for information regarding the revenues and costs that the company incurred.

Based on this analysis, the profit structure for Peapod during the period from 1989 to 2006 was determined. Since Peapod underwent changes during this period, it was decided to group specific years together and analyzed the cost structure for each period. For the Peapod study four periods were established. These periods cover the years between 1989 to 1991, 1992 to 1996, 1997 to 1999, and 2000 to 2006. Tables 2, 4, 6, and 8 show the profit structure for Peapod during the four periods respectively. Due to the fact that published data was used, it was possible to have missed components of either the revenue or cost structures. However, it was believed that analyzing the public data would allow for a basic picture of the profit structure for Peapod, in particular, and other online grocers in general. To assess the degree of accuracy for the profit structure generated from published sources, Peapod's actual profit structure was determined from 10-K reports filed with the Securities and Exchange Commission (SEC).

Table 10 displays the correspondence between Peapod's profit structure generated from published sources and Peapod's actual profit structure based on 10-K filings for the four periods respectively. Based on the amount of overlap between these structures it 
Table 10

Peapod's Actual Profit Structure: 1989 - 2006

\begin{tabular}{|c|c|c|c|}
\hline Sources of Operating Capital & Front End Costs & Back End Costs & Performance Drivers \\
\hline $\begin{array}{l}\text { Investment Capital } \\
\text { (Investment Capital) } \\
\text { 1. Investment Capital (RC1) }\end{array}$ & $\begin{array}{l}\text { System Development and } \\
\text { Maintenance } \\
\text { (Order Taking Costs) } \\
\text { 1. Website Related } \\
\text { 1a. Design Cost }\end{array}$ & $\begin{array}{l}\text { Grocery Operations } \\
\text { (Capital Expenditures) } \\
\text { 2. Capital Expend. } \\
\text { 2a. Facilities }\end{array}$ & $\begin{array}{l}\text { Customer Patronage Drivers } \\
\text { 1. Number of Orders (PD3) } \\
\text { 2. Item per Order (PD13) } \\
\text { 3. Customer Level }\end{array}$ \\
\hline $\begin{array}{l}\text { Member and Retailer Services } \\
\text { (Delivery Revenue) }\end{array}$ & $\begin{array}{l}\text { In-house (CC1) } \\
\text { 1b. Maintenance Cost }\end{array}$ & $\begin{array}{l}\text { Leased (CC2) } \\
\text { 14. Delivery Fleet }\end{array}$ & $\begin{array}{l}\text { 3a. Number of Repeat Customers } \\
\text { (PD2) } \\
\text { 3b. Cancellation Rate (PD8) } \\
\text { 3c. Number of Membership }\end{array}$ \\
\hline $\begin{array}{l}\text { 1. Core Delivery Fee (RC4) } \\
\text { 2. Grocery Bill Percentage Fee } \\
\text { (RC5) }\end{array}$ & In-house (CC11) & $\begin{array}{l}\text { 14a. Company Owned (CC21) } \\
\text { 15. Fleet Maintenance (CC22) }\end{array}$ & $\begin{array}{l}\text { Renewals } \\
\text { 3d. Number of New Customers } \\
\text { (PD1) }\end{array}$ \\
\hline (Fees) & $\begin{array}{l}\text { Marketing and Selling Costs } \\
\text { (Customer Relationship Costs) } \\
\text { 7. Customer Awareness }\end{array}$ & $\begin{array}{l}\text { (Fulfillment Expenses) } \\
\text { 4. Picking Costs (F.V) }\end{array}$ & 4. Purchase Amount (PD10) \\
\hline 1. Installation/Packaging (RC2) & 7a. Done Alone (CC7) & 4a. Human Capital (CC4) & $\begin{array}{l}\text { Delivery Service Drivers } \\
\text { 5. Number of Orders Delivered }\end{array}$ \\
\hline 2. Subscription/Membership (RC3) & $\begin{array}{l}\text { 7b. Partnership (CC9) } \\
\text { 8. Customer Acquisition Costs }\end{array}$ & $\begin{array}{l}\text { 5. Packing/Assembly Costs (F,V) } \\
\text { 5a. Human Capital (CC5) }\end{array}$ & $\begin{array}{l}\text { (PD9) } \\
\text { 6. Number of Vehicles Used (PD15) }\end{array}$ \\
\hline $\begin{array}{l}\text { Interactive Marketing Services } \\
\text { (Commission) }\end{array}$ & $\begin{array}{l}\text { 8a. Done Alone (CC8) } \\
\text { 8b. Partnership (CC10) }\end{array}$ & $\begin{array}{l}\text { 6. Delivery Costs } \\
\text { 6a. Fuel Costs (CC6) }\end{array}$ & $\begin{array}{l}\text { (PD14) } \\
\text { 10. Delivery Truck Capacity (PD22) }\end{array}$ \\
\hline 1. Integrated Marketing & & $\begin{array}{l}\text { 6b. Delivery Personnel Costs } \\
\text { (CC17) }\end{array}$ & $\begin{array}{l}\text { 11. Routing and Scheduling Process } \\
\text { (PD17) }\end{array}$ \\
\hline
\end{tabular}

Table 10 (Cont'd) 
Peapod's Actual Profit Structure: 1989 - 2006

\section{Sources of Operating Capital \\ 1a. Advertising Service (RC7) \\ 1b. Promotional Service (RC8) \\ 1c. Research Service (RC9)}

(Website Revenue)

1. Direct Advertising Revenue

(RC10)

2. Indirect Advertising Revenue

(RC11)

\section{Grocery Sales}

(Inventory Sales)

1. Grocery Inventory Sales (RC12)

(CC26)

\section{Back End Costs}

13. Routing and Scheduling (CC20)

(Interactive Marketing Services)

General And Administrative

(General And Administrative)

10. General and Admin. (CC25)

11. Other Costs and Expenses

9. Auxiliary Service Level

9a. Delivery Related (CC12)

9b. Coupon Redemption (CC13)

Grocery Costs

(Inventory Expenses)

3. Inventory Acquisition Cost

3a. Purchased via Partner (CC3)

3b. Purchased via

Manuf./Wholesaler (CC23)

\section{Performance Drivers}

Operational Service Drivers

8. Fulfillment Performance

8a. Picking Speed (PD5)

8b. Number of Lines Picked (PD16)

8c. Picking Accuracy (PD6)

8d. Assembly Accuracy (PD7)

Customer Service Drivers

9. Auxiliary Services

9a. Number Using Delivery (PD11)

9b. Number Using Advertising (PD18)

9c. Number Using Promotional (PD19)

9d. Number Using Research (PD20) 
was reasonable to conclude that it was possible to determine the rudimentary profit structure for a company based on published information other than actual financial records. Having Peapod's actual profit structure resembling the profit structure generated from public sources provides the basis for assessing the financial complexity of other online grocers. Based on the profit structure generated from Peapod's analysis, it was assumed that the profit structure for other online grocery home delivery companies would be similar. Given that Peapod existed as a partnership and as the arm of a click-andmortar company, its profit structure should have been similar to companies that operate with similar business models under the partnership and hybrid categories. One can extrapolate and posit that the profit structure for pure-plays will be similar as well. This is based on the notion that when Peapod was developing a dedicated fulfillment system, the company was close to becoming a pure-play. Thus, since there were no major changes to the company's profit structure once Ahold acquired Peapod, it seems logical to assume that the profit structure of actual pure-plays would be similar to that of Peapod's.

Once Peapod's profit structure was assessed, the analysis turned to determining whether the business models the company used were the cause of its financial performance. When Peapod first started in 1989, it functioned as a partnership. The company served as the delivery arm for BAM grocers that contracted with Peapod to pick, pack, and deliver customer orders to their homes. During these initial years, the company opted to use an in-store fulfillment model. In this capacity Peapod was operating using model $6 \mathrm{~b}$ under the partnership category (see Appendix 1). This model allowed Peapod to get to market quickly with the least amount of capital outlay, but, it 
greatly curtailed the scalability of Peapod's operation. In addition, the in-store fulfillment model had a significant variable labor cost component associated with it. As a result, the fulfillment function became a major part of Peapod's cost structure. Moreover, since Peapod purchased its inventory directly from the shelves of its retail partners, the method of inventory acquisition became costly. That is, in order to attract customers to its service Peapod advertised the retail prices of its retail partner. Hence, when customers placed an order with Peapod they were charged the same prices that they would have had to pay had they gone to the store themselves. This method of inventory acquisition precluded Peapod from extracting any margins on the sale of grocery inventory.

During this period, Peapod's revenue stream consisted of subscription fees, packaging and installation fees, and core delivery fees. Further, the cash generated from financing activities was scarce because investors did not understand Peapod's business model. Given that Peapod had about 400 households in its customer base, it could not generate enough revenue to fund current operations. Thus, during the period between 1989 and 1991 Peapod's costs exceeded its revenues and the company operated at a loss. This provides support for the contention that Peapod's lack of success, at least in the formative years of development, may have been due to its business model. The model Peapod selected resulted in a profit structure with a small revenue component and a large cost component. To offset these costs, Peapod began to expand its operation to other markets hoping this would help to correct the imbalance in the company's profit structure.

During the period from 1992 to 1996 Peapod continued to operate as a partnership using the in-store fulfillment method and attended home delivery. As the company 
expanded its service into new markets, it was hoping to spread its fixed costs over a large enough customer base in order to reduce its impact on the company’s profit structure. The problem with Peapod's business model was that the variable costs had a greater impact on the profit structure then the fixed costs did. Hence, for each market that Peapod entered, the labor costs associated with the fulfillment function increased because Peapod was duplicating that function in multiple markets. In addition to the costs associated with the order fulfillment function, Peapod also incurred sizable costs connected to the company's software development and maintenance. During this time Peapod relied on proprietary software systems, which meant the company had to internalize the software development process in order to protect its intellectual property. Also during this period, Peapod began offering auxiliary services in an attempt to have the home delivery service appeal to a broader customer base. This indicated that customer demand for Peapod's service was not as robust as the company had hoped.

In 1992, in the face of a rising cost structure, Peapod added a grocery bill percentage fee for each delivery. This was designed to increase the company's revenue stream and offset some of its rising costs. However, as Figure 22 shows, this fee was not enough to totally offset the rising costs. The graph displays the relationship between Peapod's total revenue and total costs over this period. Based on the graph, it is clear that Peapod's costs were still outpacing its revenue. Only after cash from financing operations was added in was Peapod able to cover its total costs (see Figure 23). Thus, Peapod's business model was a primary cause of the high inventory acquisition costs and the increasing costs of fulfillment operations. The company's decision to internalize the software development process further increased the cost structure. To bring its costs 
under control, Peapod began looking for ways to reduce some of its costs components. To accomplish this, the company focused on aspects of the fulfillment and delivery functions.

During the period between 1997 and 1999 Peapod began to make changes to its fulfillment and delivery functions. By making changes to these functional areas, Peapod was actually changing its business model. Peapod's decision to focus on the fulfillment area was due to the impact that this area was having on the employee labor cost. To bring this cost under control, Peapod began using a wareroom fulfillment model. By switching fulfillment methods Peapod was able to consolidate many of the in-store locations allowing the company to reduce its labor costs by cutting the number of employees in the fulfillment area. Further, the company implemented new technology in the fulfillment area that increased the efficiency of the employees working in the picking function. By switching to wareroom fulfillment centers Peapod was using models 13a and $13 \mathrm{~b}$ under the partnership category.

In the delivery area, Peapod introduced new routing software that allowed it to assemble customer orders faster. This reduced the number of employees needed in the fulfillment area while at the same time increasing their productivity. In addition, in 1999, the company began purchasing inventory from wholesalers, which meant it was eligible for volume discounts. This allowed the company to extract a profit margin on some of the inventory that it sold, which helped to increase revenue. Further, Peapod continued to add auxiliary services such as a store pick-up option and unattended and third party delivery options. Although Peapod made significant changes to certain aspects of its business model, these changes were not enough to alter the profit structure. As Figure 39 
shows, even after improving the efficiency of the fulfillment and delivery functions, Peapod's costs still exceeded its revenues. There was a glimmer of hope when Peapod announced that it was headed toward profitability in the Chicago market. However, as a whole, the company was still unprofitable. Thus, from 1997 to 1999 it seems that the business models that Peapod was using were still adding significantly to the cost structure and were unable to generate the revenues necessary for the company to break even, let alone turn a profit.

During the early part of 2000, Peapod continued to consolidate its in-store fulfillment centers into dedicated wareroom fulfillment centers and announced plans to expand into the New York market. These plans were placed on hold once it became apparent that the company did not have enough cash to cover operations for the last quarter of the year. Although the company was using several different business models simultaneously, these efforts were not enough to rectify the imbalance between the revenue and cost structures. Hence, it seemed that Peapod was heading for insolvency. Before the company actually became insolvent, it was saved by Royal Ahold. This marked the point at which Peapod ceased operating under the partnership category and began operating under the hybrid category (see Appendix 3). At the time of the merger Peapod was using business models 7a, 7b, 14a, and 14b under the hybrid category.

The merger with Ahold provided Peapod with \$20 million in capital, which provided the company with the financial backing to stay solvent. The merger also provided Peapod with a supply and service agreement which allowed the company to leverage the purchasing power of Ahold, thereby reducing its inventory costs. Ahold also provided Peapod with the capital to purchase Streamline’s centralized dedicated 
fulfillment centers. This resulted in Peapod using models 20 and 21a under the hybrid category. By merging with Ahold, Peapod was able to eliminate delivery fees in certain markets. According to Peapod's research, reducing or eliminating these fees increased the yield on membership drives. The merger also changed Peapod's expansion strategy. Instead of Peapod expanding into markets of its choice, the company only expanded into markets where an Ahold subsidiary already had a presence. This helped to reduce the costs associated with brand building.

In March 2001, Peapod achieved its first operating profit in the Chicago market. This was possible due to reductions in transportation costs and increased customer demand. It seems that the merger with Ahold had produced positive results because before the merger Peapod was not profitable in any of its markets. Hence, it can be argued that the business models that the company used prior to the merger were plagued with high cost structures that could not be offset by the revenue being generated. Once Peapod merged with Ahold, it began to turn a profit in one of the markets it served. This would not have occurred had Ahold not provide Peapod with the necessary capital to stay solvent. After the merger, Peapod was operating under some of the same business models that it was before the merger. What changed was Peapod's classification from a partnership to a hybrid. That is, Peapod stopped being a stand alone business and became the delivery arm of a BAM grocer. The financial backing of Ahold allowed Peapod to improve efficiency and increase margins enabling the company to turn a profit in one of its markets. However, as a whole the company was still operating in the red. Whether or not the move towards profitability continued for Peapod is difficult to determine. After Peapod merged with Ahold, it was delisted and no further financial information for the 
company was provided. In its 2000 through 2003 annual reports, Ahold simply reported net sales for Peapod. After 2003 Ahold changed its reporting format and combined the financial information from its subsidiaries located geographically. This made determining Peapod’s financial data practically impossible.

Based on the information analyzed, it would seem that the business model(s) used by Peapod resulted in a profit structure that was heavily weighted towards the cost end. Figure 41 displays the relationship between Peapod's revenue and cost structures from 1992 to 2000. This represents the period for which financial data on Peapod were available. The graph clearly shows that over this nine year period Peapod's costs were greater than its revenue. Even using different business models was not enough to

Figure 41

Peapod’s Total revenue and Total Cost: 1992 - 1999

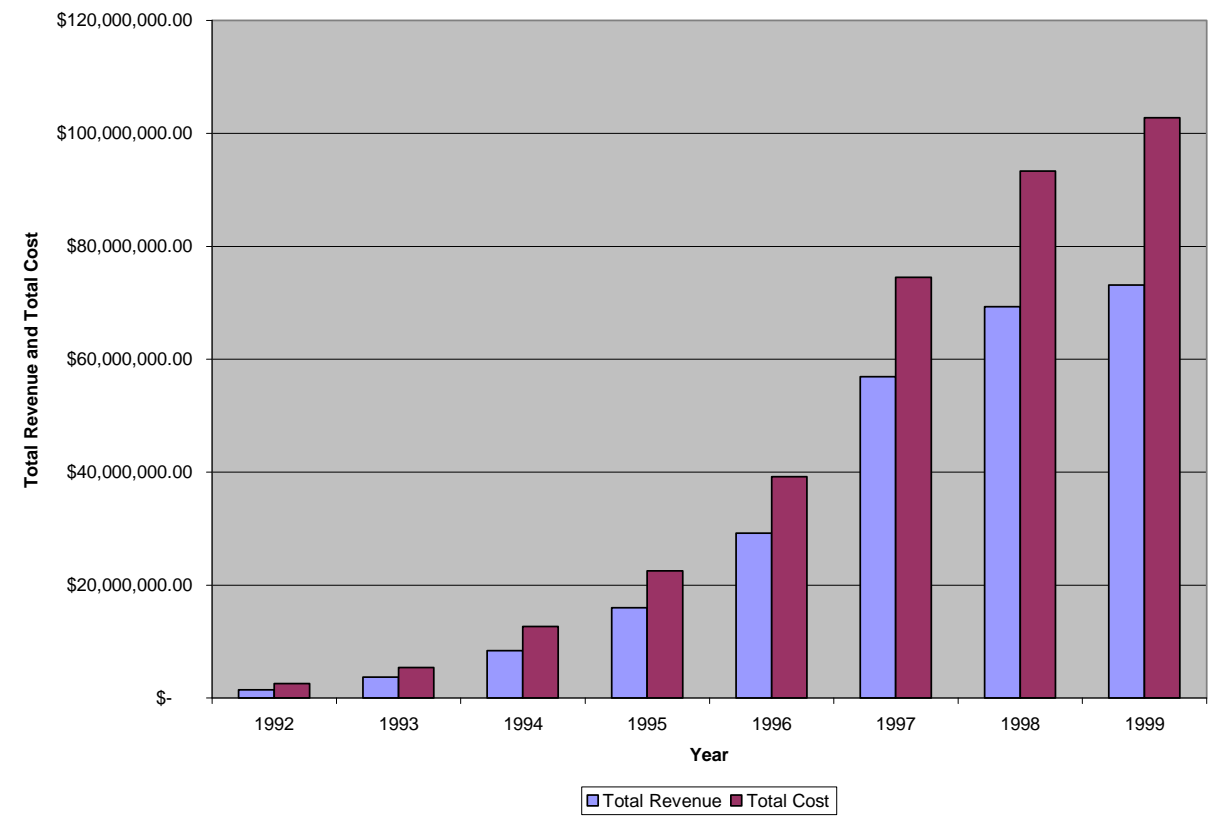


overcome the massive cost component. Thus, on the surface it looks as if the industry watchers were right when they concluded that the business models that online grocers were using were the main cause of their demise.

Although this conclusion emanates directly from the Peapod analysis, it seemed to simplistic to actually be the sole root cause of failure given the dynamics of the online grocery home delivery channel. Thus, in order to determine whether the Peapod results were truly reflective of the processes that led to the demise of many companies operating in the online channel, it was decided to survey financial analysts for their opinions. Financial analysts were selected due to their ability to peer inside of companies and better assess the causes of financial performance. They were in the best position to provide insight into why Peapod's, and other online grocers' financial performances were so dismal. According to the case based theory building process, the goal of the analysis is to develop a broader and deeper understanding of the phenomenon under study. This is done through an iterative process between data collection and data analysis. The idea is for the researcher to continue to collect information and analyze that information until redundancy sets in. Ultimately, the goal is to allow the research to guide the researcher from a general to a more specific focus so it becomes possible to generate hypotheses concerning the phenomenon. Thus, it is quite in line with the case based theory building process to collect additional data that would help to establish a deeper understanding of the root cause, or causes, of so many failures in the online grocery home delivery channel. 


\section{Verification of Peapod Results}

One central question of this research was whether the business models used by online grocers were the primary factor in their demise. Based on the analysis of Peapod, it appeared that the business models used were the cause of the company's demise due to the models' impact on the profit structure. However, was this the cases for other online grocers as well? Were there other factors that could explain the Peapod result?

To provide validity to the Peapod analysis, financial analysts familiar with the online grocery retail channel were contacted to get their assessment of the factor(s) that led to the demise of many online grocery retailers. Twenty-six brokerage firms were contacted and their grocery retail analysts were surveyed. After contacting approximately eight firms, it was learned that the passage of the Sarbanes-Oxley Act forced many brokerage firms to abandon certain aspects of their research departments and, therefore, they no longer had access to the information being sought. As a result, it was decided to begin contacting market research firms. A sample of 30 market research firms was selected and contacted in order to ascertain whether they employed any analysts who followed the online grocery channel. While contacting one of these market research firms, this researcher was informed that there was a website (www.quirks.com) dedicated to market research that listed market research companies and consulting firms according to industry focus. Using the website, a search was performed which resulted in 28 possible contacts. From these 28 company hits, 20 were selected bringing the total sample to 50 companies.

After contacting the 50 market research companies, only six provided information related to the online grocery channel. Four of the companies contacted provided 
additional information concerning other sources to review. These firms either forwarded the information to the researcher or they pointed to their websites as a source for the information. While searching one of the websites (www.RetailWire.com), the researcher found the names of eleven persons who served as panel discussants for online grocery topics. Most of these discussants were either self-employed retail consultants, or employed by retail consulting firms. All seemed to focus on the online grocery channel. Two of the market research firms actually had people employed who followed the online industry and these two people were also listed as panel discussants on this site. These two analysts were subsequently contacted and interviewed for their top-of-mind responses to the question - Why did/do online grocery retail companies fail? In addition, it was decided to look at the comments of the other panel discussants to see if they made reference to factors they believed explain the failure of many online grocers.

Based on the responses of these consultants, there were ten reasons given for the demise of many companies operating in the online grocery channel. One primary cause discussed by three of the analysts was the overstatement of demand for online grocery shopping. Many of the original forecasts concerning the size of the online grocery market stated that it would grow to anywhere from 15 to 30 percent of the yearly grocery retail business. According to one analyst, Peapod and Webvan both used the overstated demand figures to explain the profit potential of their business models. However, based on research conducted by Jupiter Media, online grocery shopping represented only about one percent of the total grocery shopping market. Thus, these analysts felt that the size of the market was overstated and that online grocery shopping was in essence a niche market. 
Three analysts also mentioned the business models used as a prime factor responsible for the demise of many online grocers. One analyst, commenting on various business models stated that "[t]he deliverable food business will have to reach out and create a profitable business model." This comment hinted at the idea that the business models that were in use at the time were not profitable. According to the Peapod analysis, a main reason for this was the cost structure these models produced. In fact, three analysts specifically cited operating costs as another factor contributing to the demise of many of the online grocers. They noted that the revenue generated from online sales was not great enough to offset the costs associated with running the online channel. These analysts felt that in order to become profitable online, grocers would need to find a way of reducing or eliminating significant areas of cost in their operations. In a similar vein, one of the analysts interviewed stated that transportation (i.e., delivery) costs, which were a significant portion of operating costs, were a prime reason for many online grocer failures. Together, these factors indicate that online grocers failed because the costs associated with operating in the online channel were greater than the revenue being generated.

Operating performance was cited by one analyst as a cause for online grocers' failures. This analyst stated that online grocery shopping “. . . is a service more than anything. ... It's equally about the execution as the food itself.” This indicated that the fulfillment and delivery operations were not running efficiently. In fact, one analyst specifically mentioned that service execution played a roll in the failure of many company initiatives in the online channel. As a result of the poor service execution, it was more a matter of keeping customers than it was in attracting them. Together, these 
factors culminated in some customers avoiding the service due to direct experience with it. Others may have avoided the service due to indirect experience with it stemming from word-of-mouth communication from customers who had tried the service.

One of the analysts interviewed also noted that product selection and infrastructure costs played a significant role in the demise of many online grocers. The analysts noted that many of the early adopters were dual income families looking for a different set of products than was being offered by the original pure-plays. Since these early pure-plays did not have the product assortment that the early adopters were looking for, these families either curtailed their use of the service or they ceased using the service. The analyst continued by noting that the infrastructure costs had usurped a significant portion of the operating capital of many online grocers. As a result, these companies were not able to generate enough revenue to recoup the investment costs associated with infrastructure development.

Delivery fees were mentioned by two analysts as a primary reason for the failure of many online grocers. These analysts indicated that consumers were not willing to pay more then 5 percent of the sales value for delivery service. Thus, the fees seemed to act as a barrier to trial for many customers. In addition, customer demand was noted by three of the research analysts as the primary reason for the lack of success for many companies operating in the online channel. According to these analysts, the online ordering and home delivery of groceries never caught on with the general grocery shopping public. Therefore, the online grocers were never able to generate the critical mass of customers necessary to become profitable. Lastly, one of the analysts interviewed commented that high population density and low car ownership were necessary for the online grocery 
channel to work. Thus, there were only certain markets that were viable for companies operating in the online grocery home delivery channel.

The main objective of this data collection stage was to determine if there was a consensus, among those who regularly follow the online grocery channel, concerning the factors that lead to the demise of many of the original online grocers. The primary research question posited that the business models they used were the main factor behind the demise of many company initiatives in the online channel. The results from the Peapod analysis provide support for this idea. However, according to analysts' comments, gathered from print and interview sources, there were ten factors that contributed to the demise of many online grocery retail operations. These factors include customer demand, service execution, operating performance, delivery fees, the business model, infrastructure cost, operating costs, delivery costs, product selection, and low population density.

Based on these analysts' responses, the general consensus seems to be that, in one form or another, the business models that these online grocers were using was one of the primary causes for their demise. Another reoccurring theme was that low customer demand was to blame for the demise of many of the online grocers. These conclusions are illustrated in Figure 42, which shows that many of the factors mentioned by analysts, were linked to the business model and to customer demand. Specifically, product selection, delivery costs, operating costs, and infrastructure costs represent specific areas associated with the business model. If one views the business model itself as a factor, then the business model accounts for five of the ten factors mentioned. These costs determine the cost structure associated with a particular business model. The selection of 
a particular business model determined the company's operating performance in the online channel. The company’s operating performance determined how well the company delivering its service.

The service component was directly linked to customer demand which in turn was impacted by delivery fees. Counting actual customer demand as a factor, there were four factors associated with customer demand. Service execution and delivery fees were directly linked to customer demand while operating performance and the business model were indirectly linked to customer demand. In summary, there is support for the Peapod results demonstrating that the business models employed were a key factor in the company's inability to generate profits in the online channel. However, based on reports and interviews with analysts, there seemed to be other factors that were equally responsible for the demise of these online grocers. 
Figure 42

Factors Mentioned by Retail Analyst

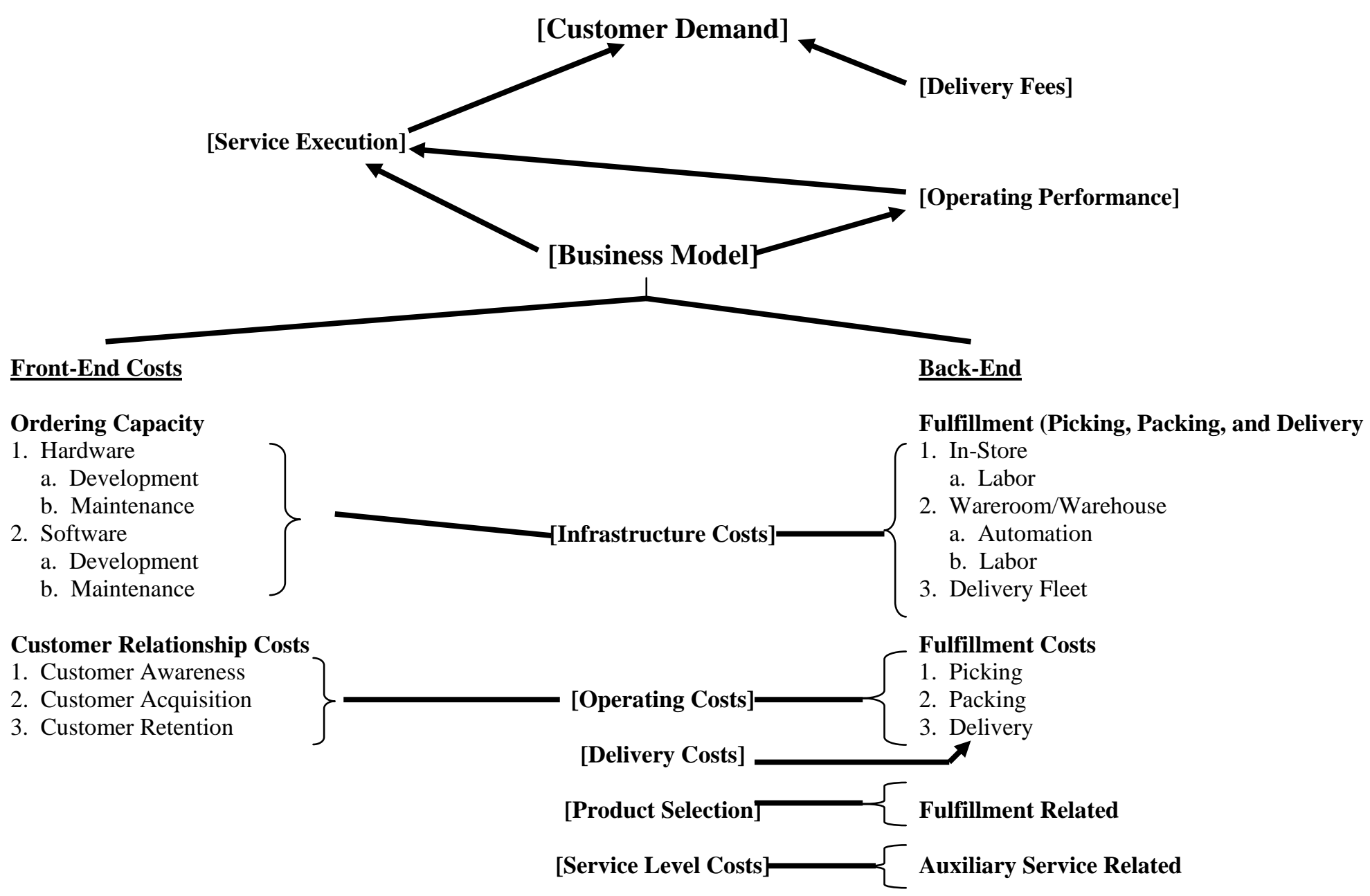




\section{Chapter VI}

\section{Case 2 - GroceryWorks}

\section{$\underline{\text { Case } 2 \text { Selection Process }}$}

When selecting cases for the theory building process, the cases should be selected in such a manner to either (1) allow for the prediction of similar results (i.e., a literal replication) or (2) produce contrary results but for predictable reasons (i.e., a theoretical replication). To determine if the initial conceptual framework, derived from the Peapod analysis was representative of the channel, a second company was selected for analysis. Finding a similar set of profit determinants for this company would satisfy the selection criteria for a literal replication. To determine which company would be selected as the second company for analysis, certain criteria had to be met. One criterion was that the company had to have commenced operations before the collapse of the online channel in 2000. The reason for this criterion was to increase the probability that the company was not the online division of a major retail grocer since most of these hybrid online grocers did not come into existence until after 2000. Thus, the profit structure for this company should be similar to that of Peapod during this period, since it too was not the online arm of a major BAM grocery retailer. A second criterion was that, at some point in the company's existence, it did become the online arm of a BAM grocery retailer. The reasoning for this second criterion was based on the fact that Peapod had been acquired by a major BAM grocery retailer and, thus, a comparison between it and the second company would be facilitated if the second company had also become the online division of a brick-and-mortar grocery retailer. Based on these criteria, GroceryWorks was selected as the second company to analyze. 


\section{Case 2 - Analysis}

The Peapod case served two basic purposes: (1) it demonstrated that publicly available information could be used to determine the basic components of an online grocer's profit structure; and (2) the case provided support for the notion that the business models that Peapod was using was were the main cause for the company's demise. However, once grocery retail analysts were interviewed, or their public statements were scrutinized, it became apparent that there were other factors, besides the business model, that may have accounted for the poor performance of companies operating in the online channel. With these factors in mind, GroceryWorks was analyzed to determine if they did indeed play a role in GroceryWorks situation or was it strictly the business model.

\section{Initial Profit Structure from January 1999 - March 2000}

GroceryWorks was founded in 1999 by Kelby Hagar on the idea that an online home delivery grocery store could compete with a traditional BAM grocery store on price and product offerings. During the year, GroceryWorks sold \$3 million of convertible promissory notes and stock warrants to ten investors in a private placement. The proceeds from this transaction were to be used for working capital, construction or leasing of plant facilities, salaries, fees and the purchase, renting or leasing of machinery and equipment.

In mid-November the company had problems processing customer orders. Visitors to the site were greeted with the message informing them that because of an overwhelming response to the online grocery store, GroceryWorks was unable to process their request to use the site at that moment. GroceryWorks acknowledged that it was 
adding more capacity to handle the extraordinary demand and intended for the site to be available in the next few days. The service failure was blamed on problems with the company server.

Profit Structure Analysis for GroceryWorks: January 1999 to March 2000.

Investment Capital

1. In GroceryWorks formative year, the company received investment capital from a private placement of its promissory notes and stock warrants. Using the Tables developed for Peapod, this was represented by the investment capital component 'investment capital' - IC(1) (see Table 11).

\section{Costs Components}

2. GroceryWorks used the proceeds of this private placement to acquire plant facilities and automation equipment. This cost was represented by the back-end capital cost components 'land' - CC(31), 'facilities company built' - CC(32), 'fulfillment (automation) equip. purchased' - CC(26), and 'fleet and equip. maintenance' - CC(28) (see Table 11).

3. In order to operate, GrocerWorks had to hire a corporate staff to deal with the day-to-day functions associated with running the business. These costs were represented by the front-end cost components 'general and admin.' - CC(17), and 'other costs and expenses' - CC(18) (see Table 11).

4. To take customer orders GroceryWork had to have a website (software) and the hardware to run it on. From the case information it was not clear if GroceryWorks used a third-party to design the website. Accordingly, it was assumed that this function was handled internally by the company. Thus, these costs were represented by the front-end cost components 'website design in-house' - CC(1), and 'website maintenance in-house’ - CC(11) (see Table 11). 
Table 11

GroceryWorks Profit Structure Components: January 1999 - March 2000

\section{Sources of Operating \\ Capital}

Investment Capital

1. Investment Capital (IC1)

Inventory Sales

2. Grocery Inventory Sales (RC12)

\section{Front End Costs}

Order Taking Costs

1. Website Related

1a. Design Cost In-house (CC1)

1b. Maintenance Cost

In-house (CC11)

Customer Relationship Costs

7. Customer Awareness

7a. Done Alone (CC7)

8. Customer Acquisition Cost 8a. Done Alone (CC8)

General And Administrative 10. General and Admin. (CC17)

11. Other Costs and Expenses (CC18)

\section{Back End Costs}

Capital Expenditures

18. Land (CC31)

19. Facilities

19a. Company Built (CC32)

17. Fulfillment Equipment

17b. Purchased CC(26)

14. Delivery Fleet

14a. Company Owned (CC27)

15. Fleet and Equipment Maintenance (CC28)

Inventory Expenses

3. Inventory Acquisition Cost

3a. Purchased via

manufacturer/wholesaler (CC23)

Fulfillment Expenses

4. Picking Costs (F,V)

4a. Human Capital (CC4)

5. Packing/Assembly Costs (F,V)

\section{Performance Drivers}

Customer Patronage Drivers

1. Number of Orders (PD3)

2. Item per Order (PD13)

3. Customer Level

3a. Number of Repeat Customers (PD2)

3d. Number of New Customers (PD1)

Delivery Service Drivers

5. Number of Orders Delivered (PD9)

6. Number of Vehicles Used (PD15)

7. Number of Delivery Attempts (PD14)

10. Delivery Truck Capacity (PD22)

11. Routing and Scheduling Process (PD17)

Operational Service Drivers

8. Fulfillment Performance

8a. Picking Speed (PD5) 
Table 11 (Cont'd)

GroceryWorks Profit Structure Components: January 1999 - March 2000

\section{Sources of Operating}

\section{Capital}

Front End Costs

\section{Back End Costs}

5a. Human Capital (CC5)

6. Delivery Costs

6a. Fuel Costs (CC6)

6b. Delivery Personnel Costs

(CC17)

13. Routing and Scheduling (CC20)

\section{Performance Drivers}

8b. Packing Speed (PD21)

8c. Number of Lines Picked (PD16)

8d. Picking Accuracy (PD6)

8e. Assembly Accuracy (PD7) 


\section{Performance Drivers}

5. The purchase of the automation equipment was designed to improve the performance and efficiency of the picking and packing personnel. This in turn helped to improve the efficiency of the fulfillment function. Thus, there were links between the back-end cost components 'fulfillment equipment (automation)' - CC(26) and the performance drivers 'picking speed' - PD(5) and 'packing speed' - PD(21) (see Figure 43).

6. The automation equipment also improved the accuracy of the picking and packing functions. Hence, there were links between the back-end cost component 'fulfillment equipment (automation)' - CC(26) and the performance drivers 'picking accuracy' - PD(6) and 'assembly accuracy' - PD(7) (see Figure 43).

7. Moreover, the automation also increased the number of lines that picking personnel could handle due to the configuration of the inventory. This was represented by the link between backend cost component 'fulfillment equipment (automation)' CC(26) and the performance driver 'number of lines picked' $\mathrm{PD}(16)$ (see Figure 43).

8. The improvements in efficiency stemmed from reductions in the costs associated with the picking and packing functions. Hence, the picking and packing costs were impacted by the interaction of the performance drivers 'number of lines picked' - PD(16), 'picking speed' - PD(5), and 'packing speed' $\mathrm{PD}(21)$ in conjunction with the corresponding back-end cost components 'picking costs human capital' - CC(4) and 'packing/assembly costs human capital' - CC(5) respectively (see Figure 43). (This relates only to those drivers that were affected by the use of automation).

In January 2000, Gary J. Fernandes, a former Electronic Data Systems Corp. executive, joined GroceryWorks as an investor and its chief executive officer. During the period, the company was able to secure $\$ 48.5$ million in venture capital. The venture capital team was composed of the Sprout Group, the venture capital affiliate of Donaldson, Lufkin \& Jenrette Inc., Enterprise Capital Partners, J.P. Morgan Investment 
Figure 43

GroceryWorks Back-End Cost Components and Performance Drivers: January 1999 - March 2000

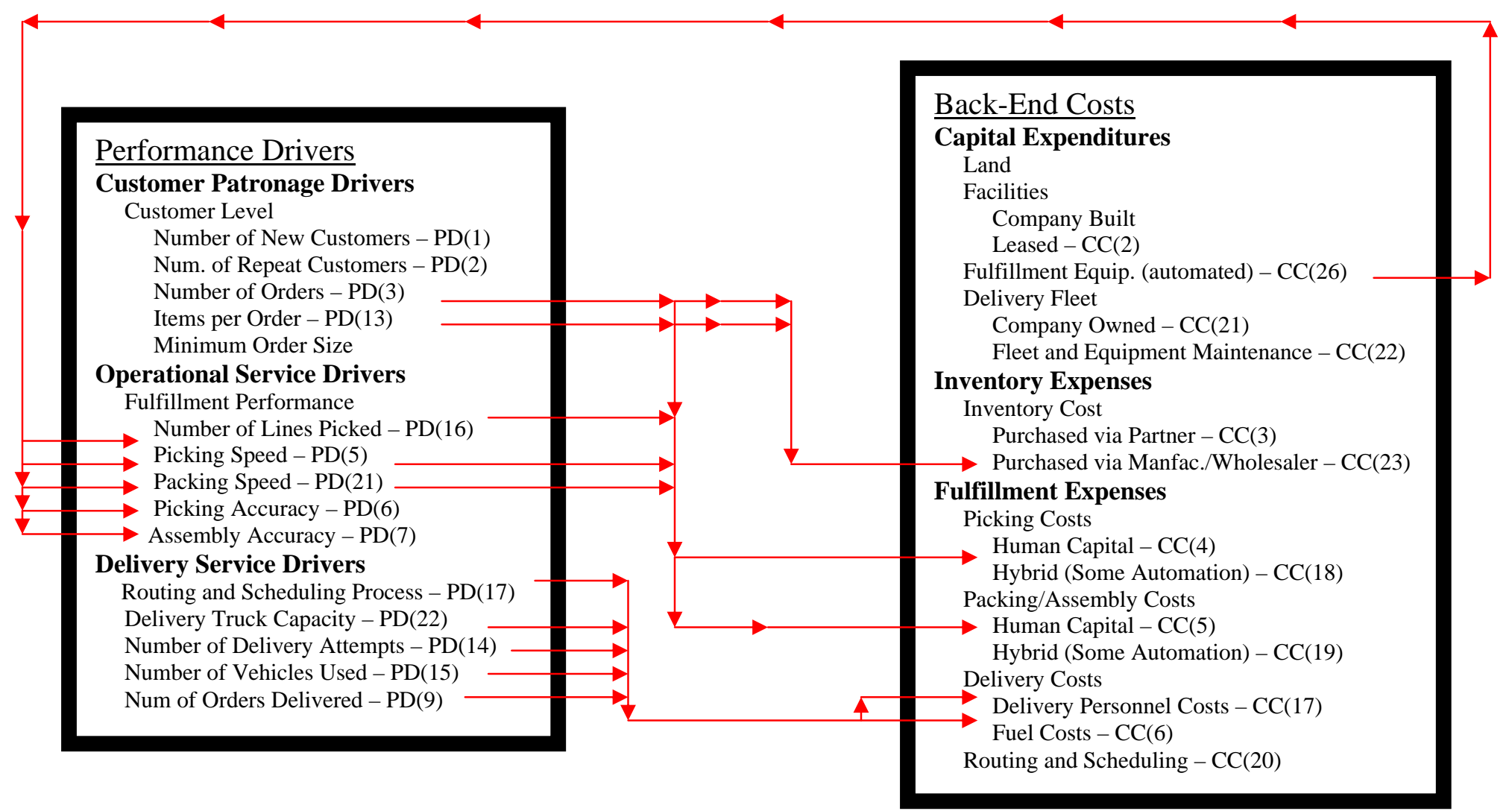


Bank, Blue Rock Capital Partners and a group of private investors led by Carl Wescott. The company planed to use the funds over the next two years to build 21 fulfillment centers in 11 new markets. Based on this statement, the company had a moderate growth strategy (see Table 12). The growth plan started with the expansion of service into the Fort Worth and Houston areas in May 2000. Specifically, the company opened a 100,000-square-foot warehouse in Grapevine, to serve customers in Tarrant County, and a 120,000-square-foot facility in Glenmont to serve the greater Houston area.

GroceryWorks' stated growth strategy indicated that there was a heavy fixed cost component associated with it.

Table 12

Other Mediating/Moderating Factors for GroceryWorks: January 1999 - March 2000

January 1999

- March 2000

Company Related Factors

Scalability (Picking Location)

High

Medium Dedicated

Warehouse $\mathrm{X}$

Large Dedicated Warehouse

Moderate

Wareroom (Hybrid)

Small Dedicated Warehouse

Low

In-Store

Method of Delivery

Store Pickup

Local Pickup

Home Delivery

$\mathrm{X}$ 
Table 12 (Cont'd)

Other Mediating/Moderating Factors for GroceryWorks: January 1999 - March 2000

January 1999

- March 2000

Company Rate of Expansion

Slow

Moderate

$\mathrm{X}$

Fast

Automation Level

High

Moderate

$\mathrm{X}$

Low

Employee/Management

Commitment

High

Moderate

Low

$\mathrm{X}$

\section{Market Structure Factors}

Connectivity

Internet Structure

High

Moderate

Low

Internet Penetration

High

Moderate

Low

Internet Access

High

Moderate

Low 
Table 12 (Cont'd)

Other Mediating/Moderating Factors for GroceryWorks: January 1999 - March 2000

Cost of Internet Service

High

Moderate

Low

Population Structure

Population Size

Population Density

Geographical Location

Continental

North America

$\mathrm{X}$

South America

Europe

Asia

Country

United States X

United Kingdom

Japan

County/Parish

Urban

$\mathrm{X}$

Suburban

$\mathrm{X}$

Rural

GroceryWorks’ first distribution center was located in Carrollton, a suburb of Dallas, Texas and opened in January 2000. The facility was 90,000 square feet and housed dry, refrigerated, and frozen groceries including meats, seafood, produce, and deli items. They also carried unique products such as fresh bread and chef-prepared meals. This indicated that GroceryWorks was using business model 20 under the pure-play category (see Appendix 2). What was unique about GroceryWorks’ distribution center 
was that it was a smaller, mid-sized distribution center that relied on low-tech

automation. By utilizing an automated distribution centers the scalability of

GroceryWorks’ operation was high and the automation level itself was moderate (see

Table 12).

The facility was designed by Cisco-Eagle, a materials handing company, to meet GroceryWorks' specifications of 24,000 orders a month or about a thousand orders per day. An average order consisted of about 4 large totes which where plastic rectangular bins used for assembling, storing, and transporting customer orders. Each order on average had between 35 and 50 items which equaled between 35,000 and 50,000 picks a day for the warehouse personnel. According to GroceryWorks, this could be accomplished by an employee picking between 175 to 250 items per hour. To achieve this picking rate the facility needed to be designed for efficiency.

\section{Investment Capital}

9. Early in January GroceryWorks received additional financing in the form of venture capital. This was represented by the investment capital component 'investment capital' - IC(1) (see Table 11).

\section{Costs Components}

10. The decision to open two stand alone central distribution centers also represented costs for GroceryWorks. This was accounted for by the back-end capital expenditure cost components 'land' - CC(31) and 'facilities company built' CC(32) (see Table 11).

11. In order to fulfill customer orders GroceryWorks had to have people employed in the picking, packing and delivery functions. The costs associated with these functions were represented by the back-end cost components 'picking costs 
human capital' - CC(4), 'packing/assembly costs human capital' - CC(5), 'delivery personnel cost' - CC(17), and 'delivery fuel costs’ - CC(6) (see Table 11).

\section{Performance Drivers}

12. The 'picking costs' - CC(4) and the 'packing and assembly costs' - CC(5) had both fixed and variable components. The fixed component emanated from the hiring and training of the employees and related directly to total cost through the frontend cost component 'general and admin.' - CC(17). For picking costs, the variable component represented the bulk of the cost and was based on how long it took employees to pick the items, how many orders the employee had to fill, the number of items for each order, and the number of items in inventory. Thus, the picking cost was determined by the performance drivers 'picking speed' - $\mathrm{PD}(5)$, 'number of orders' - $\mathrm{PD}(3)$, 'items per order' $-\mathrm{PD}(13)$, and 'number of lines picked' - $\mathrm{PD}(16)$ in conjunction with the cost component 'picking cost' - CC(4) (see Figure 43).

13. The bulk of the packing and assembly cost was variable in nature and was determined by the number of items in an order and the number of orders. Thus, the impact of picking and assembly costs on total costs will be determined by the performance drivers 'items per order' - $\mathrm{PD}(13)$, 'number of orders' - PD(3), 'packing speed' - $\mathrm{PD}(21)$, and 'number of lines picked' - $\mathrm{PD}(16)$ in conjunction with the cost component 'packing/assembly costs' - CC(5) (see Figure 43).

14. Given that the picking and assembly functions were handled by employees, these employees were susceptible to fatigue and tedium. As a result, their picking speed fluctuated. As the picking speed fluctuated, it was reasonable to assume that picking accuracy and assembly accuracy would fluctuate as well. Hence, the performance driver 'picking speed' - $\mathrm{PD}(5)$ impacted of the performance drivers 'picking accuracy' PD(6) and 'assembly accuracy' - PD(7) (see Figure 44). (Note: Due to the automation level, the impact of tedium on picking speed was reduced but not eliminated).

15. The fuel cost was a variable cost driven by the number of orders delivered, the number of vehicles used for delivery, the number of delivery attempts, the capacity of the delivery vehicle, and the routing and scheduling procedures. Thus, the 
fuel cost was determined by the performance drivers 'number of orders delivered' - PD(9), 'number of vehicles used' $\mathrm{PD}(15)$, 'number of delivery attempts' - PD(14), 'delivery truck capacity' - $\mathrm{PD}(22)$, and 'routing and scheduling process' - PD(17) in conjunction with the cost component 'fuel cost' CC(6) (see Figure 43). (As delivery activity increases the fuel cost should increase as well. However, this relationship may not be linear due to the fact that the company may gain efficiencies through routing and optimization processes).

16. The number of orders delivered was a function of the number of orders the company received. As a result there was a link between the customer patronage performance driver 'number of orders' - $\mathrm{PD}(3)$ and the delivery service performance driver 'number of orders delivered' - PD(9) (see Figure 44).

Figure 44

GroceryWorks Performance Drivers and Performance Drivers: January 1999 March 2000

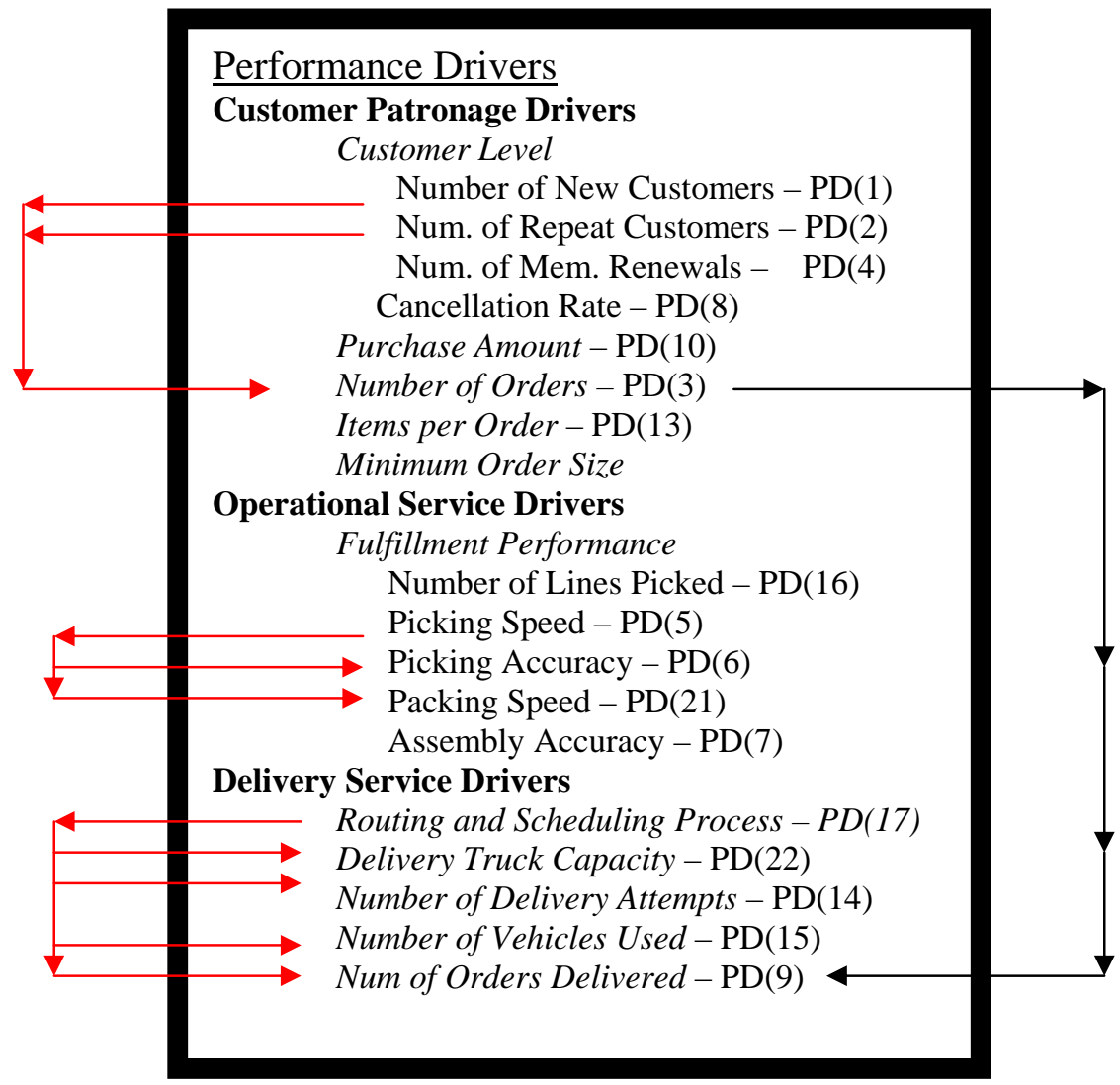


To achieve this efficiency, the actual facility used conveyors, flow racks, and stationary shelving as its central components. The way the system worked was that once a customer completed his/her order, the order processing software would convert the order into cubes and then calculate how many totes the order would need. Then a ticket for each tote was printed and attached to the totes. The totes were then entered into the system along gravity conveyors in a circular motion down each aisle. For refrigerated or frozen items, GroceryWorks used special totes equipped with linings filled with dry ice. This allowed the frozen and refrigerated goods to stay fresh for up to ten hours. Once all the picks for a certain aisle were complete the tote was moved to the next aisle by conveyor. When the totes were full, or the order was complete, they were manually pushed onto a power conveyor that moved them to the docking area.

To make deliveries from this distribution center, GroceryWorks relied on 50 trucks and several vans. According to Chuck Cans, then GroceryWorks director of transportation, the company wanted trucks that were easy to drive and did not require the driver to have a commercial driver's license (Farrar 2000). To power the trucks, GroceryWorks opted for the four speed automatic transmission over a standard five speed manual transmission citing that it was easier for drivers to use and it reduced the cost associated with repairing worn out clutches. The specially designed insulated bodies of the trucks were manufactured by Mickey Truck Bodies. To make their trucks suitable for temperature sensitive groceries, GroceryWorks approached Carrier, the air conditioning company, to assist them in upgrading their truck fleet with refrigeration units. According to Mr. Gans, the company was looking for a vendor that could assist them in solving their cold-chain concerns. Carrier provided GroceryWorks with recommendations concerning 
refrigeration equipment and upgrade possibilities. One of the main requirements for

GroceryWorks' refrigeration units was to keep their delivery trucks cargo area within the 50 to 60 degrees Fahrenheit range while operating year round in extremely hot climates.

Revenue Components

17. Once GroceryWorks acquired its inventory it then sold it to customers. This was represented by the revenue component 'grocery inventory sales' - RC(12) (see Table 11).

\section{Costs Components}

18. In order for GroceryWorks to provide its service, the company had to acquire the inventory from manufacturers and wholesalers. This was depicted by the back-end inventory acquisition cost component 'purchased via manufacturer/wholesaler' - CC(23) (see Table 11).

19. To make home deliveries GroceryWorks purchased a fleet of trucks and vans. This cost was represented by the back-end cost 'delivery fleet company owned' - CC(27) (see Table 11).

20. In order to deliver the customer's order, GroceryWorks had to have personnel employed in the delivery function. This was represented by the back-end cost component 'delivery personnel costs' - CC(17) (see Table 11).

21. While making deliveries, GroceryWorks incurred costs associated with fuel consumption. This was represented by the back-end cost component 'fuel costs' - CC(6) (see Table 11).

22. When GroceryWorks purchased its fleet of delivery vehicles, the company had to keep these vehicles in good operating condition. This required GroceryWorks to perform repair and maintenance work on the fleet. This was represented by the back-end cost component 'fleet and equipment maintenance' CC(28) (see Table 11).

\section{Performance Drivers}

23. The actual inventory cost was determined by the number of orders received and the number of items per order. Hence, the impact of inventory expense on total cost was determined by 
the performance drivers 'number of orders' - $\mathrm{PD}(3)$ and 'items per order' - PD(13) in conjunction with the back-end cost component 'inventory costs purchased via manuf./wholesaler' - CC(23) (see Figure 43).

24. The actual amount of revenue generated was determined by the number of orders received and the number of items per order. Thus, the impact of inventory sales on total revenue was determined by the performance drivers 'number of orders' $\mathrm{PD}(3)$ and 'items per order' - $\mathrm{PD}(13)$ in conjunction with revenue component 'grocery inventory sales' - RC(12) (see Figure 45).

25. The cost generated by the delivery function was determined by the number of orders delivered, the number of vehicles used, the number of delivery attempts, delivery truck capacity, and the routing process. Thus, delivery personnel costs and fuel costs were determined by the performance drivers 'routing and scheduling process' - $\mathrm{PD}(17)$, 'delivery truck capacity' $\mathrm{PD}(22)$, 'number of delivery attempts' - PD(14), 'number of vehicles used' - $\mathrm{PD}(15)$, and the 'number of orders delivered' - PD(9) in conjunction with the back-end cost components 'delivery personnel costs' - CC(17) and 'fuel costs' - CC(6) (see Figure 43).

For GroceryWorks to run its fulfillment operation, the company relied on a host of products from EXE Technologies. By utilizing these products, GroceryWorks was able to save at least twelve months of in-house development time and a significant amount of capital on software development. The package that EXE Technologies supplied for GroceryWorks was the EXceed eFulfillment System (eFS). This system provided GroceryWorks with virtual warehousing capabilities, which enabled the company to handle inventory that was not actually in the fulfillment center. That is, in order for GroceryWorks to offer meat, poultry, fish, and produce to its customers, the company had to enter into contracts with suppliers of those items and provide them with 
Figure 45

GroceryWorks Revenue Components and Performance Drivers: January 1999 - March 2000

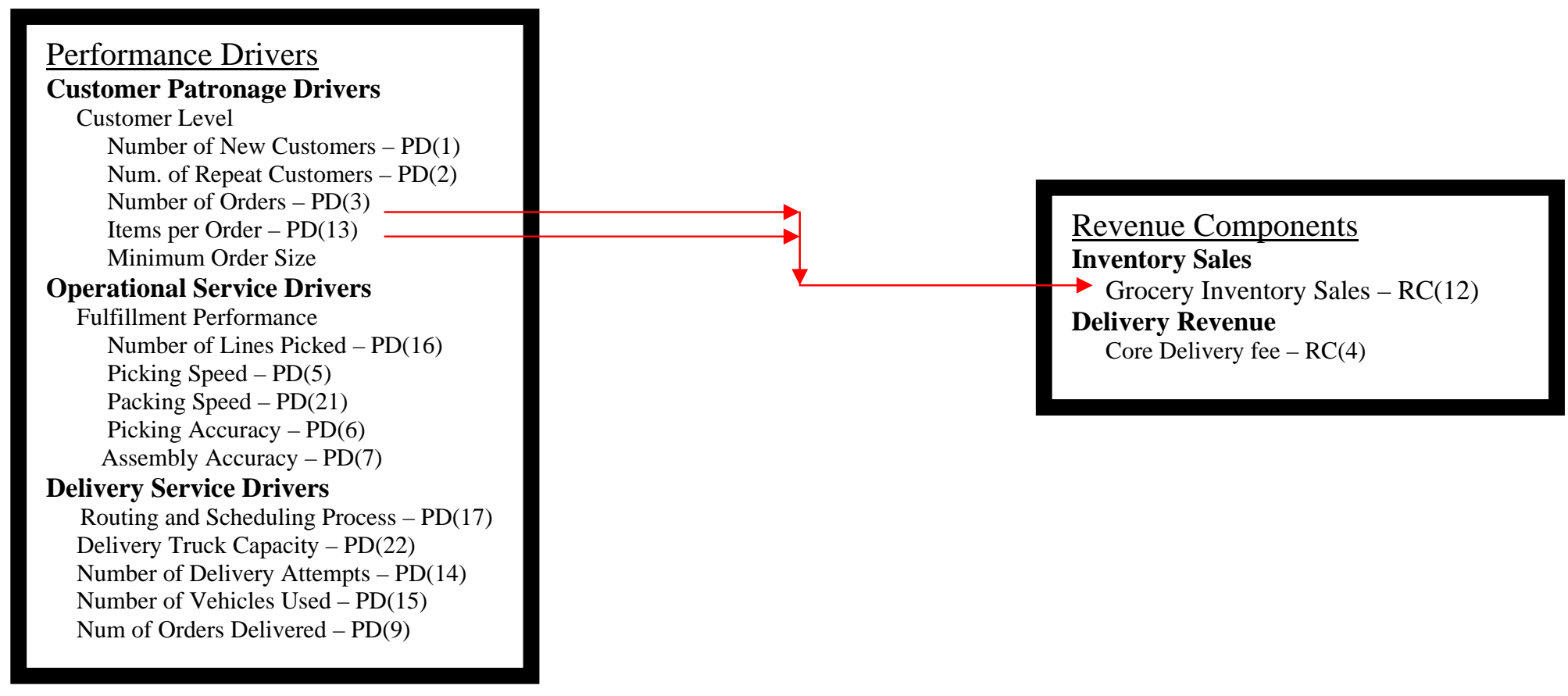


eFS capabilities. Thus, for certain items, the suppliers filled the orders and then shipped them to GroceryWorks. These shipments were facilitated by the eFS which linked GroceryWorks delivery system to the virtual system. As the delivery vehicles completed their delivery cycle, the eFS system transmitted information to the drivers instructing them to collect orders from the suppliers. This pickup phase amounted to a negligible increase in cost but resulted in a significant saving to the company.

Once GroceryWorks received the fresh items from its suppliers, it then combined them with the non-perishable items located in its fulfillment center to complete customer orders. The eFS system facilitated this cross-docking and consolidation (i.e., combining) process allowing the completion of customer orders to take place smoothly. This allowed GroceryWorks to minimize inventory and handling costs while simultaneously allowing it to offer a wider range of fresh products without running the risk of inventory spoilage.

In terms of actual delivery, the system works by linking GroceryWorks’ web site directly to the eFS system. Once an order was received, the software would send it to the suppliers of GroceryWorks’ ‘virtual inventory’ and to the fulfillment center itself. During this time the software would be continually interacting with RoadNet, the vehicle routing system developed by UPS. The RoadNet system allows GroceryWorks to group orders together within a neighborhood on a dynamic or sequential basis. While the customer was completing his/her order RoadNet calculated a series of different routes and then provided the customer with a set of choices for delivery time. These times corresponded to the times that GroceryWorks was planning on being in the neighborhood to deliver other customer orders. Thus, the customers were given a specific set of delivery times and was asked to select one of the predetermined times giving them the 
illusion of choosing their delivery time. Once a delivery time was selected, RoadNet transferred the order back to eFS with the routing information embedded in the order. Thus, by using third-party routing and scheduling software, GroceryWorks was able to optimize the delivery efficiency of their van and truck fleets. This in turn reduced the company's costs by increasing the efficiency of the fulfillment and delivery functions. Moreover, by relying on a third-party software provider, GroceryWorks was able to reduce the software development costs.

During this initial period, GroceryWorks also conducted its own customer awareness and acquisition (i.e., brand building) activities. The company used a combination of print, radio, newspaper and billboard (e.g., sides of trucks) advertising. Given GroceryWorks' size, this was a significant financial undertaking for the company. Further, the company provided its customers with a coupon redemption service allowing them to use manufacturer coupons. This allowed the service to appeal to a larger segment of the market.

In March, the company announced the hiring of a CEO, CFO, CMO, and a CIO (chief information officer) in order to solidify its management team. These executives included Dennis Andruskiewicz (CEO), Jeffrey Cushman (CFO), John Lauck (CMO) and Howard Weisberg (CIO) (Fox and Taylor 2000). The hiring of these individuals represented additional general and administrative costs for the company.

\section{Costs Components}

26. In order to coordinate fulfillment and delivery functions, GroceryWorks relied on third-party warehousing and logistics software. This cost was represented by the back-end cost component 'routing and scheduling' - CC(20) (see Table 11). 
27. In order to build the brand, GroceryWorks needed to communicate with its target market. To accomplish this, the company incurred costs associated with brand awareness and customer acquisition. These costs were represented by the front-end cost components 'customer awareness done alone' CC(7) and ''customer acquisition done alone' - CC(8) (see Table 11).

28. By hiring additional corporate officers, GroceryWorks incurred additional general and administrative costs. This was represented by the front-end cost components 'general and admin.' - CC(17) and 'other costs and expenses' - CC(18) (see Table 11).

\section{Performance Drivers}

29. The use of the third-party routing and scheduling software was designed to improve the efficiency of the delivery process. As a result, the performance driver 'routing and scheduling process' - PD(17) was linked to the performance drivers 'delivery truck capacity' - PD(22), 'number of delivery attempts' - PD(14), number of vehicles used' - PD(15), and 'number of orders delivered' - PD(9) (see Figure 44).

30. The branding activities resulted in an increase in membership and the number of orders. Hence, the customer relationship costs 'customer awareness done alone' - CC(7) and 'customer acquisition done alone' - CC(8) were linked to the customer patronage performance drivers 'number of new customers' $\mathrm{PD}(1)$ and 'number of repeat customers' - PD(2) (see Figure 46).

31. The increase in the number of new customers and the increase in repeat customer business results in an increase in the number of orders. Therefore, the customer patronage performance drivers 'number of new customers' - $\mathrm{PD}(1)$ and 'number of repeat customers' - $\mathrm{PD}(2)$ are linked to the customer patronage performance driver 'number of orders' - PD(3) (see Figure 44). 
Figure 46

GroceryWorks Front-End Costs and Performance Drivers: January 1999 - March 2000

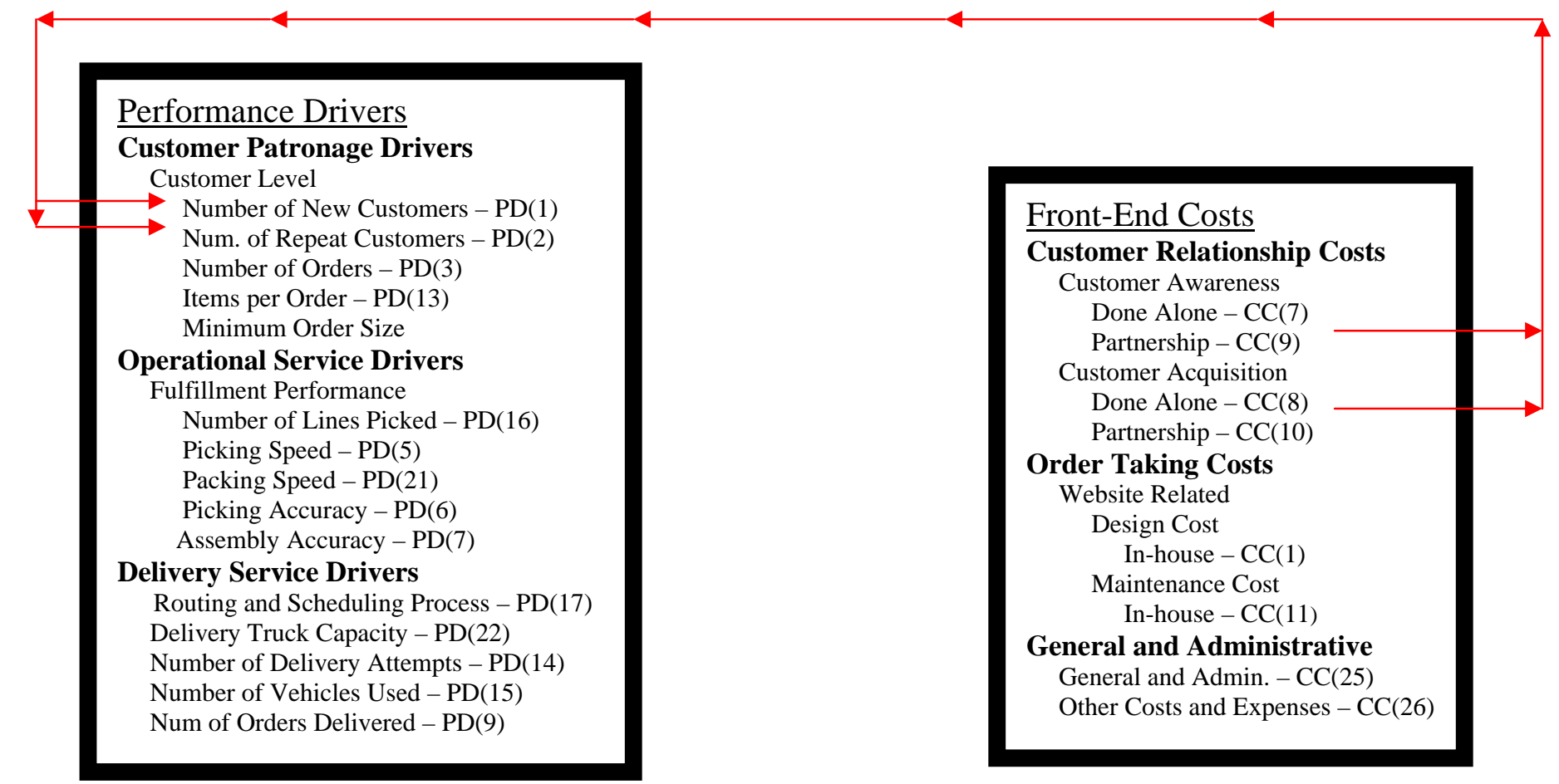




\section{Financial data}

Since GroceryWorks was a privately held company, no information concerning the company’s financial performance was available for the period from January 1999 through December 2006. Therefore, there is no financial analysis to present related to GroceryWorks’ performance.

Profit Structure Summary from January 1999 - March 2000

GroceryWorks’ profit structure during its formative years was burdened by a significant cost structure. A major portion of this cost was linked to the construction of an infrastructure necessary to conduct business (see Table 11). Specifically, the company purchase land, built fulfillment centers, purchase equipment, and bought a fleet of delivery vehicles. According to the grocery retail analysts, the development of costly infrastructure was a factor in the demise of many online grocery initiatives. Based on GroceryWorks infrastructure this may have been a factor in the company’s situation.

In order to begin service, GroceryWorks had to acquire inventory, which represented another significant cost for the company. According to grocery retail experts, the inventory represents the largest component of cost for a grocer. GroceryWorks purchased its inventory directly from the manufacturer or through wholesalers. Given that the company did not have significant sales during this period, it was unlikely that GroceryWorks could extract major quantity discount from these manufacturers and wholesalers. Therefore, the company’s profit margins were literally razor thin.

Once operations commenced, GroceryWorks incurred costs associated with the fulfillment operation. Specifically, the company incurred picking, packing/assembly, 
delivery, and fuel cost. These costs had both fixed and variable components. The fixed component was associated with the hiring and training of personnel while the variable component materialized as these employees performed their jobs. The variable component was more costly and represented the central portion of this cost. The use of automated equipment helped to reduce the impact that this cost had on the variable component of the labor cost.

In an effort to stimulate demand for its service, GroceryWorks incurred customer relationship costs. These costs were significant because the company was trying to generate selective demand for its service. In addition, GroceryWorks also had to design and develop a website and the accompanying ordering software. It was not clear from the case information whether or not this function was conducted internally; therefore, it was assumed it was. The expense associated with developing this software internally, stemmed from the hiring of computer personnel and the purchase of hardware. Lastly, GroceryWorks had the day-to-day general and administrative costs to deal with. The aggregation of these various costs components indicated that GroceryWorks had a significant cost structure.

GroceryWorks initially relied on working capital generated through stock sales to the general public and private placements from venture capitalists. The proceeds from these financing activities were used to finance the company's growth and infrastructure development. The other source of capital came from revenue generated from the sale of the grocery inventory. Given that GroceryWorks was in its formative years, it was not generating a significant amount of revenue from grocery sales. Therefore, during its 
initial years, the investment and venture capital were the main sources of GroceryWorks' operating capital.

During these formative years there were other mediating/moderating factors that may have affected GroceryWorks' profit structure. These factors were broadly grouped into company related factors and market structure related factors. The company related factors include scalability, method of delivery, company rate of expansion, automation level, and employee/management commitment (see Table 12). Scalability related to the extent to which the capacity for picking, packing, and assembling customer orders could be increased in a cost effective manner. For the purpose of this study, scalability was assessed from low to high. GroceryWorks' initial model was that of a pure-play and relied on a medium sized dedicated fulfillment center. This meant that the scalability of the fulfillment center was high. Going beyond the fulfillment centers capacity would result in inefficiency but the size of the fulfillment center could be expanded thereby increasing the scalability. Although the use of a dedicated fulfillment center signified high scalability, it was costly to the company in terms of the amount of time it took to build and the capital requirements necessary.

Another factor to take into consideration was the method of delivery. How the company chooses to deliver the customer's groceries had a significant bearing on the company's cost structure. In the formative years, attended home delivery was GroceryWorks' chosen method for delivery. In relation to the cost structure, this was one of the most costly methods for delivering groceries because it required the company to incur all the cost associated with transporting the groceries to the customer's home. It does, however, result in high customer satisfaction in terms of delivery options. 
Further, the company's rate of expansion was another factor to consider when analyzing the profit structure. In general, the faster the rate of expansion, the greater the impact on the company cost structure. This was due to the higher costs associated with acquiring facilities, inventory, delivery means, and the human capital necessary to conduct operations in multiple locations. Some of these operational expenses had significant fixed and variable components. The fixed expenses emanated from the development of an infrastructure and the hiring and training of fulfillment and delivery personnel. The variable expenses originated from the operational activities associated with the delivery service. Hence, based on the variable component of this model, as the number of customers increased the costs associated with servicing those customers would also increase. This in turn could make it difficult to break even. This situation would then be repeated for each market that the company entered. Thus, a fast growth rate may compound the problem resulting in an ever changing breakeven point which may require a longer time horizon. During this initial time period, GroceryWorks only operated in one market which meant that it had a slow rate of expansion. However, the company's stated expansion goals would indicate that it was following a moderate growth rate (see Table 12).

From the time of its founding, GroceryWorks relied on low-level automation in its fulfillment centers. As a result, the company was able to extract gains in efficiency from the picking and packing/assembly functions. However, by using an automated fulfillment system, the gains in efficiency were accompanied by an increase in the company's cost structure. Employee and management commitment was also important to the company's profitability and survival. In the formative years, GroceryWorks' 
management was dedicated to seeing the company survive and prosper. There did not seem to be any conflicting motives at work that may have caused the management to undermine the workings of the company.

The market structure factors include the level of connectivity, population structure, and geographical location. Connectivity was concerned with the ability of the online grocer's customers to access the Internet in order to place orders and communicate with the company. There are four subfactors associated with connectivity which include Internet structure, Internet penetration, Internet access, and cost of Internet Service. Internet structure relates to the Internet infrastructure present in an area, including the phone lines, fiber optics, and land lines (i.e., DSL). These sub-factors were assessed as low, medium, and high (see Table 12). It is unlikely that without a sizable group of potential customers with access to computers, that GroceryWorks would have been able to survive.

The population structure referred to the size and density of an area in terms of its population. This factor is directly related to the cost structure because the more dispersed the population the greater the cost associated with delivering the groceries to the consumers. This brings the geographical location into the discussion. The geographical location was assessed on several levels from the continental location to the county/parish that the company was operating in (see Table 12). Together the population structure and the geographical location interacted to determine the number of households within a specific market in general, and the number within the service area in particular. 


\section{Summary}

Although GroceryWorks seems to have accumulated a sizable cost structure, the company did so with the intention of saving capital in the short- and long-run. For instance, GroceryWorks’ decision to invest in a mid-sized fulfillment center demonstrates that the company had learned from the mistakes of Webvan and other pure-play online grocers that built large, expensive dedicated fulfillment centers. These smaller facilities were able to be expanded in stages as demand increased. As a result, construction and maintenance costs were kept low thus reducing the breakeven point. Moreover, the decision to invest in automated fulfillment equipment was an attempt to improve the performance, and, ultimately, the efficiency of the fulfillment function. That is, the automation improved the performance of the personnel in the picking and packing areas by helping to reduce the incidence of mispicking and product exclusion. The automation also allowed these personnel to perform their jobs faster and improved the overall efficiency of the fulfillment function. These gains in efficiency could only be fully realized if the facility was operating at, or near, full capacity. In GroceryWorks’ initial years, the company did not have the demand necessary to take advantage of the efficiencies generated from its fulfillment center. As a result, GroceryWorks’ fulfillment operation was operating inefficiently.

When GroceryWorks first began operations, the company had underestimated demand for its service. That is, in the initial days of operation the demand for GroceryWorks' service was high enough to cause the website to crash. This posed a customer service problem for the company which may have had an impact on customers' overall level of satisfaction with GroceryWorks service. According to the grocery retail 
analysts, the execution of the service is critical for winning customers over. Failure to satisfactorily deliver the service was listed as a factor in the failure of many online initiatives. The fact that GroceryWorks' site crashed may have led to some customers not using, or adopting, the service.

GroceryWorks' decision to use third-party routing and logistics software was an attempt to save capital. By using the eFS software, GroceryWorks did not have to incur the expenses associated with employing personnel necessary to develop the software internally. The software allowed GroceryWorks to expand its inventory selection to include meat, poultry, fish, and produce. Having a large selection of products should lead to higher customer satisfaction with the service. The software also allowed GroceryWorks to improve the efficiency of the routing and scheduling function which resulted in savings generated from the delivery area. Further, through the use of crossdocking and a virtual inventory, GroceryWorks was able to save capital due to reduced inventory holding costs.

Looking at GroceryWorks' formative years it was apparent that the company had a significant cost structure. However, many of these costs were incurred in order to gain efficiency in the fulfillment and delivery functions. The logic was that the gains in efficiency would translate into reductions in operating costs. Further, the decision to use third-party providers, cross-docking procedures, and the use of a virtual inventory demonstrated that GroceryWorks was trying to save capital and keep the cost structure down. However, looking at GroceryWorks' revenue components, it is unlikely, at least in the initial years, that the company was able to generate the revenue necessary to offset its cost. As a result, the company was operating at a loss. 
GroceryWorks Profit Structure for April 2000 - March 2001

On April 17, 2000, GroceryWorks and Safeway announced the formation of a strategic alliance. At the time GroceryWorks was a privately held online grocery home delivery company while Safeway was a Fortune 50 food and drug retailer with 1,663 stores (Fridman 2000). Based on the agreement, Safeway was to invest $\$ 30$ million for a 50 percent stake in GroceryWorks. As part of the deal, another $\$ 20$ million in capital was to be invested in the company by one or more unnamed parties (Wren 2000). In exchange for the capital infusion, a specially created Safeway subsidiary would receive preferred stock in GroceryWorks which would subsequently be converted into 50 percent of GroceryWorks fully diluted common stock.

Under the terms of the agreement, GroceryWorks became Safeway’s exclusive online grocery channel. From Safeway's vantage point, the company was able to implement its online (e-commerce) strategy quickly with a partner that was Internet savvy, utilizing a business model that was more promising than others currently in use. For GroceryWorks, the alliance gave them significant financial backing, inventory cost savings, advertising and promotional backing, the ability to leverage known national brands, and quick entry into top markets. The inventory cost savings were considered significant because the cost of inventory acquisition in the food business was about 75 percent of total expenses (Fridman 2000).

The deal allowed GroceryWorks to expand nationally much easier with less risk and better capitalization. This was because Safeway supermarkets were located in 12 of the top 25 U.S. grocery markets. Safeway owned several established grocery store brands including Vons, Dominick’s, Carr, Randalls and Tom Thumb. By partnering with 
Safeway, GroceryWorks was able to expand its product offerings because it was able to offer national brands as well as private label brands from Safeway's various subsidiary chains. In relation to advertising and promotion, the two companies were able to cobrand in local markets where Safeway would promote GroceryWorks Internet service in its advertising.

Through the co-branding agreement, the GroceryWorks name was affiliated with Safeway stores in northern California and the Baltimore-Washington area, Vons stores in the southern California area, Tom Thumb stores in the Fort Worth and Dallas markets, Dominick's stores in the Chicago market, and Randall's Food Markets in the market comprising Houston and other parts of Texas (Ghitelman 2000). The deal gave GroceryWorks an immediate boost in credibility for its online grocery service, but it came at the cost of sacrificing the company's independence. Nonetheless, this cobranding was significant to GroceryWorks because it allows the company to save money that otherwise would have gone to brand building. According to Steve Burd, Safeway president and chief executive officer, brand building activities represented 15 to 50 percent of sales for online grocers (Ghitelman 2000). In fact, GroceryWorks spent $\$ 4$ to $\$ 5$ million in advertising in its first six months and attained 52 percent awareness in the Dallas market. This was far below the 97 percent brand awareness enjoyed by Safeway's Tom Thumb store in the same market (Alaimo 2000). These results indicated to GroceryWorks executives that brand building and customer acquisitions were a significant part of the company's cost structure. According to Kelby Hagar, founder of GroceryWorks, "... we realized very early in our growth cycle ... that we could not keep up with the customer acquisition curve that was going to be demanded in the on-line 
business, nor did we believe any other pure-play could. We needed to partner with someone who had that brand awareness and that brand recognition to help lower customer acquisition dollars” (Alaimo 2000, p. 30).

At the time of the deal GroceryWorks was only operating in Dallas but had plans to implement the service in the Fort Worth and Houston markets. The partnership had the potential to accelerate GroceryWorks expansion into other markets as well. Moreover, according to Wren (2000), the alliance had the potential to become profitable in a short period of time because GroceryWorks would benefit from lower costs due to Safeway’s buying clout, merchandise, wholesale distribution channel, and advertising synergies. In addition, Safeway’s decision to invest in GroceryWorks was not done haphazardly. Safeway conducted a year long test to determine if it should develop its online channel internally but, based on the results the company decided against that decision. Given that investment capital was moving away from the stock market the opportunity arose for Safeway to buy an online division. By acquiring GroceryWorks, Safeway was able to pursue a faster and less expensive strategy for developing its online channel. Further, according to Debra Lambert, then corporate director of public affairs for Safeway, GroceryWorks had the best business model and the best cost structure. This was partially due to the fact that from an operating perspective, GroceryWorks took a more conservative slant towards online grocery shopping.

Unlike other online grocers that built large warehouse fulfillment centers of 300,000 square feet, GroceryWorks opted for smaller 90,000 square feet warehouse fulfillment centers. In addition, it used automation in its fulfillment centers instead of relying solely on human labor for order picking. This allowed the company to reduce the 
number of employees needed to run the fulfillment center which helped reduce the labor cost. Similarly, this also increased the order assembly efficiency which further reduced the labor expense. At the time, GroceryWorks had an estimated gross weekly volume of $\$ 294,000$, an average weekly order volume of 3,500, and an average order amount of \$84. During this period, sales were growing at about 9 percent a week. At that rate, GroceryWorks hoped to gain enough market share in order to offer its same-day, no-fee, attended and unattended service in at least 16 markets by the end of 2001. Hence, GroceryWorks was still pursuing a moderate rate of growth (see Table 13). Based on GroceryWorks merger with Safeway, and the company's decision to offer unattended delivery, the company was operating under the hybrid category using business models 20 and 21a (see Appendix 2).

Table 13

Other Mediating/Moderating Factors for GroceryWorks: April 2000 - March 2001

January 1999 - April 2000 -

March 2000 March 2001

Company Related Factors

Scalability (Picking Location)

High

Medium Dedicated Warehouse $\quad$ X $\quad$ X

Large Dedicated Warehouse

Moderate

Wareroom (Hybrid)

Small Dedicated Warehouse

Low

In-Store 
Table 13 (Cont'd)

Other Mediating/Moderating Factors for GroceryWorks: April 2000 - March 2001

January 1999 - April 2000 -

Method of Delivery

Store Pickup

March 2000 March 2001

Local Pickup

Home Delivery

Company Rate of Expansion

Slow

Moderate

X $\quad X$

Fast

Automation Level

High

Moderate

$\mathrm{X}$

X

Low

Employee/Management Commitment

High

X $\quad X$

Moderate

Low

\section{Market Structure Factors}

Connectivity

Internet Structure

High

Moderate

Low

Internet Penetration

High

Moderate

Low

Internet Access

High

Moderate

Low 
Table 13 (Cont'd)

Other Mediating/Moderating Factors for GroceryWorks: April 2000 - March 2001

$$
\text { January } 1999 \text { - } \quad \text { April } 2000 \text { - }
$$

March $2000 \quad$ March 2001

Cost of Internet Service

High

Moderate

Low

$\underline{\text { Population Structure }}$

Population Size

Population Density

Geographical Location

Continental

North America

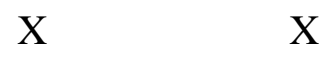

South America

Europe

Asia

Country

United States

X $\quad$ X

United Kingdom

Japan

County/Parish

Urban

Suburban

X X

Rural

$\mathrm{X} \quad \mathrm{X}$

By May, GroceryWorks and Safeway had begun operations in the Huston market.

Specifically, GroceryWorks teamed up with Safeway’s Randalls Food Markets and launched its home delivery service (Rutledge 2000). In the Huston area, GroceryWorks had already built a fulfillment center so there was no need to use a Safeway warehouse for fulfillment operation. Like the Dallas fulfillment center, the Houston site relied on 50 
trucks and several vans to make deliveries. However, the company noted that when new online markets were opened they would be serviced from fulfillment centers separate from Safeway stores and distribution facilities. According to Kelby Hagar, president and founder of GroceryWorks, “[W]e will only enter markets as we build the infrastructure to handle those processes" (Alaimo 2000, p.30). This seemed to guarantee that GroceryWorks would incur significant fixed costs associated with building the infrastructure to conduct operations.

Also during May, GroceryWorks announced a strategic partnership with Lincoln Property Company Commercial, Inc. to be its exclusive agent for locating and negotiating commercial real estate acquisitions in new markets. This arrangement gave Lincoln the authorization to research potential sites for the establishment of new fulfillment centers nation wide. According to the arrangement, Lincoln would gather background information on potential properties, research the demographics of the surrounding communities, make recommendations, and negotiate the sale or lease agreement when a decision had been made. Hiring Lincoln Property Company Commercial, Inc., to research the demographics of areas demonstrated that population characteristics were important to the company. This would seem to coincide with the statements by the grocery analysts concerning low population density as a factor in the demise of many online grocery initiatives.

In June the deal between Safeway and GroceryWorks was solidified with a subsidiary of Safeway giving GroceryWorks \$10 million and GroceryWorks signing a long-term product purchase agreement with Safeway in return for GroceryWorks preferred stock. The shares were convertible into 50 percent of GroceryWorks' fully 
diluted common stock. A Safeway subsidiary was then to funnel the remaining \$20 million to GroceryWorks at a later date.

Also during June, GroceryWorks decided to enhance its service in the Dallas area by brokering a delivery agreement with upscale apartment operator Post Properties. For those residents in Post's downtown apartments who did not have easy access to a nearby grocery store, they could order online from GroceryWorks and arrive home to a fullystocked refrigerator. Given that a refrigerator was basically the same as a reception box, this indicated that GroceryWorks was using business model 21b under the hybrid category (see Appendix 3). For Post Properties, the arrangement allowed it to offer an additional service to its tenants. For GroceryWorks, the arrangement marked the company's desire to move into the 'group delivery' business. The 'group delivery' business was more lucrative and cost-efficient than the single home delivery business. That is, it was more cost effective to make one delivery of many orders to one address, than to make a series of single deliveries to many addresses. These group deliveries could be made to multi-family housing complexes, an agreed upon location such as an employer parking lot (Tanner 2000) or other local pickup points. Thus, in order for the service to appeal to a broader market segment, and in an attempt to gain control over rising costs, GroceryWorks began to experiment with different business models. Also during this time period, GroceryWorks raised an additional \$5.84 million through a private placement of a combination of Series B preferred stock, common stock and warrants from three investors with the proceeds used to purchase equipment (Private Equity Weekly 2000). 
Profit Structure Analysis for GroceryWorks: April 2000 - March 2001

Investment Capital

32. As a result of the merger with Safeway, GroceryWorks received \$30 million in additional investment capital. This was represented by the investment capital component 'investment capital' - IC(1) (see Table 14).

33. GroceryWorks received an additional \$5.8 million in investment financing through a private placement. This was represented by the investment capital component 'investment capital' - IC(1) (see Table 14).

\section{Costs Components}

34. By merging with Safeway, GroceryWorks was able to acquire its inventory directly from them. This allowed GrocerWorks to leverage Safeway's buying power and acquire inventory at a reduced cost. Although this still represented a cost, it represents a smaller cost than GroceryWorks would have incurred had the company purchased the inventory direct from the manufacturers and wholesalers. This was represented by the back-end cost component 'inventory acquisition via parent company' - CC(29) (see Table 14).

35. The merger with Safeway allowed GroceryWorks to begin to conduct co-branding activities. This was represented by the front-end cost components 'customer awareness partnership' CC(9) and ‘customer acquisition partnership' - CC(10) (see Table 14). Although the co-branding activities represented costs, these costs were less than the cost associated with solo attempts by GroceryWorks at customer awareness and acquisition.

36. The $\$ 5.8$ million was used to buy equipment and was represented by the back-end cost component 'fulfillment (automation) equipment purchased' - CC(26) (see Table 14).

In an attempt to build brand awareness GroceryWorks teamed with Launch Partnership, which was a newly formed incubator, with the mission to offer brand 
Table 14

GroceryWorks Profit Structure Components: April 2000 - March 2001

\section{Sources of Operating \\ Capital}

Investment Capital

1. Investment Capital (IC1)

Inventory Sales

2. Grocery Inventory Sales (RC12)

Delivery Revenue

3. Core Delivery Fee (RC4)

\section{Front End Costs}

Order Taking Costs

1. Website Related

1a. Design Cost

In-house (CC1)

1b. Maintenance Cost

In-house (CC11)

Customer Relationship Costs

7. Customer Awareness

7a. Done Alone (CC7)

7b. Partnership (CC9)

8. Customer Acquisition Costs

8a. Done Alone (CC8)

8b. Partnership (CC10)

\section{Back End Costs}

Capital Expenditures

18. Land (CC31)

19. Facilities

19a. Company Built (CC32)

17. Fulfillment Equipment

17b. Purchased CC(26)

14. Delivery Fleet

14a. Company Owned (CC27)

15. Fleet and Equipment

Maintenance (CC28)

\section{Inventory Expenses}

3. Inventory Acquisition Cost

3a. Purchased via manufacturer/wholesaler (CC23)

3b. Purchased via Parent

Company (CC29)

\section{Performance Drivers}

Customer Patronage Drivers

1. Number of Orders (PD3)

2. Item per Order (PD13)

3. Customer Level

3a. Number of Repeat Customers (PD2)

3d. Number of New Customers (PD1)

Delivery Service Drivers

5. Number of Orders Delivered (PD9)

6. Number of Vehicles Used (PD15)

7. Number of Delivery Attempts

(PD14)

10. Delivery Truck Capacity (PD22)

11. Routing and Scheduling Process (PD17) 
Table 14 (Cont'd)

GroceryWorks Profit Structure Components: April 2000 - March 2001

\section{Sources of Operating}

\section{Capital}

\section{Front End Costs}

General And Administrative

10. General and Admin. (CC17)

11. Other Costs and Expenses

$$
\text { (CC18) }
$$

\section{Back End Costs}

Fulfillment Expenses

4. Picking Costs $(F, V)$

4a. Human Capital (CC4)

5. Packing/Assembly Costs (F,V)

5a. Human Capital (CC5)

6. Delivery Costs

6a. Fuel Costs (CC6)

6b. Delivery Personnel Costs (CC17)

13. Routing and Scheduling (CC20)

\section{Performance Drivers}

Operational Service Drivers

8. Fulfillment Performance

8a. Picking Speed (PD5)

8b. Packing Speed (PD21)

8c. Number of Lines Picked (PD16)

8d. Picking Accuracy (PD6)

8e. Assembly Accuracy (PD7) 
building and marketing advice to fledgling entrepreneurs seeking financing and growth opportunities. Launch Partnership, a division of Temerlin McClain, receives some money from clients upfront, but much of its compensation came in the form of stock since the budding companies tended not to have large advertising budgets. For GroceryWorks, Launch Partnership planned to embark on a television advertising campaign centered around the slogan "Looking at grocery shopping in a whole new way”. The spots were aired in July in the Chicago, Dallas, Houston, and Phoenix markets and were expanded to the San Francisco market. The commercials were run until the end of the year, and complemented the print and outdoor advertising that was already under way. Total cost for this advertising campaign was estimated to be between \$12 million and \$15 million (Chura 2000).

By July the deal between GroceryWorks and Safeway was finalized. In accordance with the terms of agreement, GroceryWorks received \$10 million in June and the other \$20 million during July. Safeway also recruited its longtime financial partner, Kohlberg Kravis Roberts, to contribute an additional \$20 million. This brought the total investment for July to $\$ 40$ million which helped finance GroceryWorks' expansion through the end of the year. In characterizing the deal, Kelby Hagar, GroceryWorks' president and founder, stated that he felt it was “. . . both necessary and crucial to get a strategic partner to boost [the company's] buying power and cut down on customeracquisition costs. We think we already have the delivery and picking model right." This indicated that GroceryWorks concentrated on the delivery side of the business first and then focused on customer acquisition. The statement acknowledges that the customer awareness and acquisition costs were a significant portion of the company's overall cost 
structure. Moreover, GroceryWorks realized that utilizing Safeway’s buying power would result in reduced inventory acquisition costs. This was an admission that the company was not generating enough revenue to finance its own operations.

By September, further details concerning the strategic alliance between GroceryWorks and Safeway surfaced. One particular aspect concerned co-branding initiatives that included the launch of a state-of-the-art website. The site was an enhanced version of GrocerWorks current site but with new capabilities. These new capabilities included easier and faster navigation, an online tutorial, a 'SaveCart' option, electronic coupons, downloadable recipes and new personal preference features. For the consumer, this translated into the convenience of shopping online for a large selection of items (e.g., meat, fish, produce, prepared meals, refrigerated and frozen foods), in-store prices and weekly specials, extra online specials, the ability to use the Randalls Remarkable Card, the acceptance of Manufacturers' coupons (online and traditional), the use of 'SmartList' (a feature that allows up to 250 of the customer's items purchased at Randalls to be automatically entered into the shopping cart), and an easy return policy. Participating customers could also earn Continental Airlines(R) OnePass(R) miles or American Airlines(R) AAdvantage(R) miles. The new co-branding initiative was available to Texas customers under the names GroceryWorks by Randalls and GroceryWorks by Tom Thumb. The co-branding alliance was extended into Austin, Texas in September under the name GroceryWorks by Randalls. With the expansion of service in the Texas market, GroceryWorks was following a moderate growth strategy (see Table 13). 
GroceryWorks also confirmed that it would enter other new markets where Safeway had a presence using the co-branding strategy. One market in particular was the Phoenix, Arizona market which the company planned to enter in October. The facility in the metro Phoenix market was to be a new 170,000-square-foot warehouse that would operate in a similar fashion as the company's other fulfillment facilities. Specifically, once an order was received it showed up on the computer at the fulfillment center where the items were then picked and placed on an intricate system of conveyors. These conveyors would then move the contents of the customers order to a location where the order was assembled and wheeled to one of the 50 waiting trucks that would then deliver the order to the customer's home. If no one was at home to accept the delivery, arrangements were made to have the order ready and waiting at the Safeway store closest to the customer's home. This pickup option was tested as a means to increase the service level and reduce delivery costs. If the store was considered a local pickup point, then GroceryWorks was using business model 16 under the hybrid category (see Appendix 3). Initially, the delivery service in Arizona was limited to the Chandler, Tempe, Mesa, Gilbert, Phoenix, Scottsdale, Glendale and Peoria markets. In these markets, the cobranding strategy stated Safeway.com powered by GroceryWorks.

When GroceryWorks was privately owned, there were no delivery fees for the service. However, once Safeway purchased a controlling interest, the company began to charge for delivery. This helped to offset some of the costs associated with the fulfillment and delivery functions. It also demonstrated that Safeway viewed the service as a convenience service. 


\section{Investment Capital}

37. During the month of July GroceryWorks received an additional $\$ 20$ million in investment financing. This was represented by the investment capital component 'investment capital' - IC(1) (see Table 14).

\section{Revenue Components}

38. Once Safeway purchased a controlling interest in GroceryWorks, Safeway changed the pricing structure to include a delivery fee. This was represented by the revenue component 'core delivery fees' - RC(4) (see Table 14).

\section{Costs Components}

39. By using Launch Partnership to help offset the costs associated with brand building activities, GroceryWorks incurred additional costs. These costs were represented by the front-end cost components ‘customer awareness partnership' - CC(9) and 'customer acquisition partnership' - CC(10) (see Table 14). Although the brand building activities done in conjunction with a partner represented a cost, it was less of a cost than GroceryWorks would incur if it were to conduct these brand building activities alone. These savings were on top of the savings that GroceryWorks gained when Safeway began cobranding with the company

40. The development of a new website represents a cost to the company. This cost was represented by the front-end cost components 'website design in-house' - CC(1), and 'website maintenance in-house' - CC(11) (see Table 14). Given that this cost was incurred in conjunction with Safeway, the actual amount was less than it would have been if GroceryWorks were to perform this function alone.

\section{Performance Drivers}

41. Conducting brand building activities in conjunction with its partners, was done in an attempt to increase demand for the service and to stimulate repeat purchase. Hence, there were links between the front-end cost components 'customer awareness partnership' - CC(9) and 'customer acquisition partnership' - CC(10) and the performance drivers 'number of 
new customers - PD(1) and 'number of repeat customers' $\mathrm{PD}(2)$ (see Figure 47).

42. Once GroceryWorks imposed a delivery fee system, the revenue stream increased. This new revenue component was determined by the number of orders the company delivers. As a result, there was a link between the delivery service performance driver 'number of orders delivered' - PD(9) and the revenue component 'core delivery fees' - CC(4) (see Figure 48).

According to Gary Fernandes, Chairman and Chief Executive Officer of GroceryWorks, the alliance with Safeway had proved to be extremely valuable. With Safeway's purchasing power, brand recognition, and focus on efficiency in accordance with GroceryWorks’ web merchandising expertise, and fulfillment and routing systems, the resulting business model seemed superior to all others in the market. Using this model the company had planed to enter the Chicago market in partnership with Dominicks, another subsidiary of Safeway. The venture went by the name Dominicks.com.

In March 2001, GroceryWorks encountered problems when shareholders allege that the online grocer was cash-strapped because of actions taken by Safeway, Inc. Specifically, minority stakeholders in GroceryWorks filed a \$180 million lawsuit against the majority stakeholders, including Safeway Inc., Accel-KKR Co. L.L.C., a California venture concern co-run by Accel Partners and the buyout firm Kohlberg Kravis Roberts, over what they call a conspiracy to damage GroceryWorks and pilfer its knowledge about the Internet grocery business (Habal and Bounds 2001). According to the suit, Safeway was not taking the necessary steps to keep GroceryWorks viable and, to do so, Safeway would need to infuse GroceryWorks with a substantial amount of working capital by 
Figure 47

GroceryWorks Front-End Costs and Performance Drivers: April 2000 - March 2001

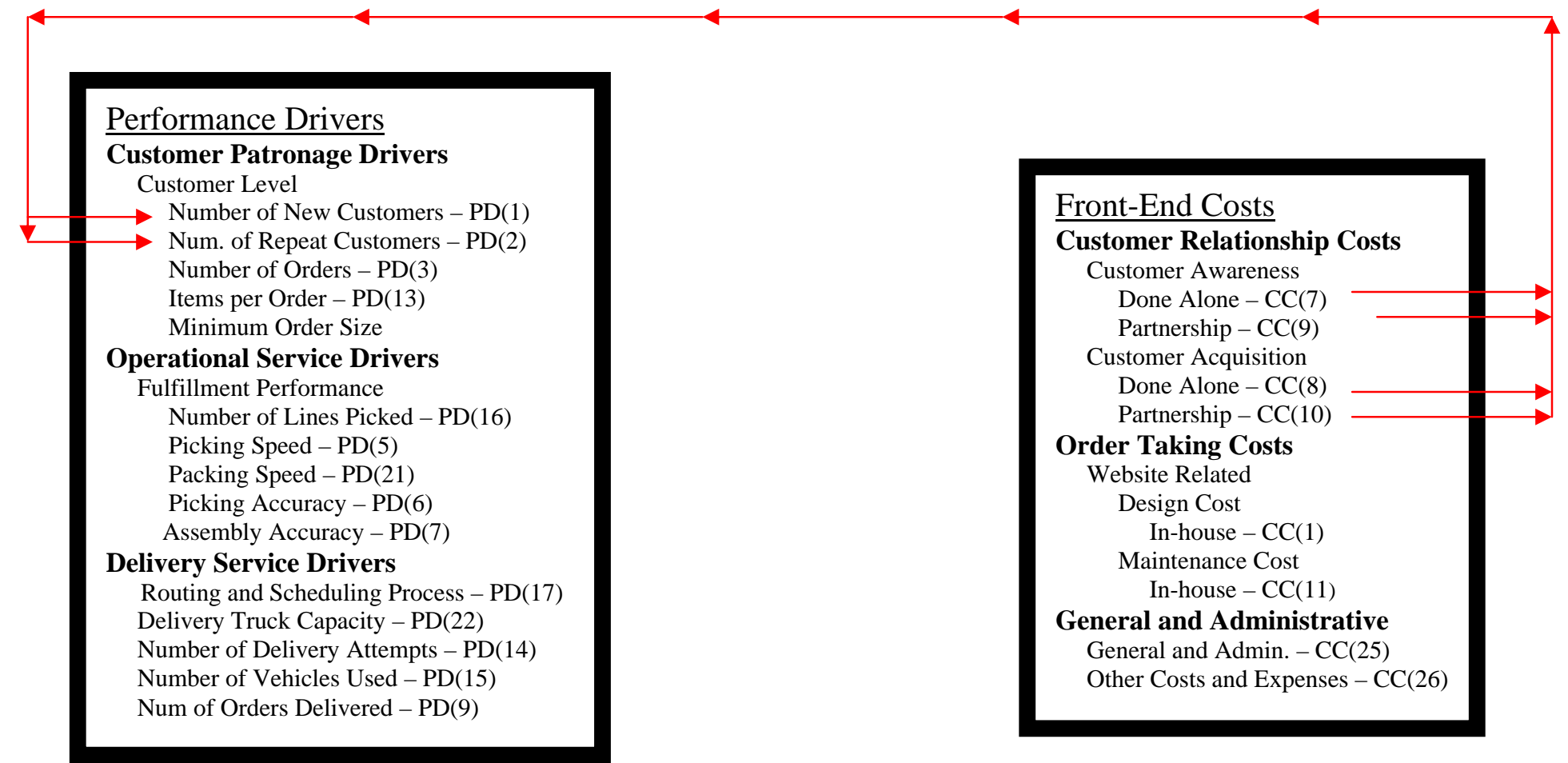


Figure 48

GroceryWorks Revenue Components and Performance Drivers: April 2000 - March 2001

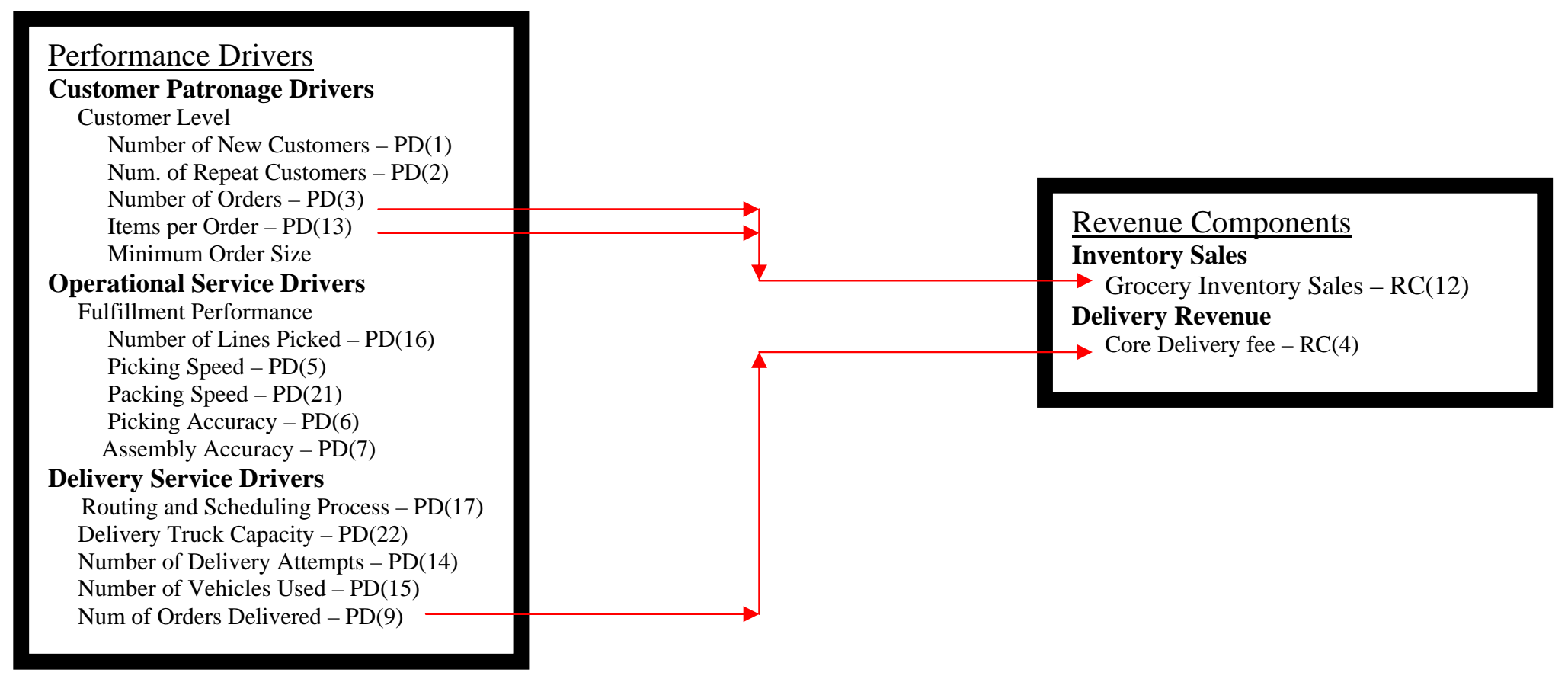


May. The complaint charged that Safeway brokered two partnership agreements with GroceryWorks with the stated goal to help the online grocer improve its business. However, instead of wanting to help the company, Safeway's real motive was to obtain GroceryWorks' proprietary knowledge of the online grocery channel. In the interim, Safeway was allowing GroceryWorks to deteriorate as a going concern by failing to infuse the company with much needed funding (Habal and Bounds 2001). Subsequently, as GroceryWorks continued to decline, Safeway would be in the best position to `pickoff' the remaining minority shareholders of GroceryWorks for little or no consideration (Zwiebach 2001).

Other claims in the document stated that the partnership between the two companies, signed June 5, 2000, called for them to co-brand in markets where they both operated, and to offer certain products, such as pharmaceuticals, flowers, videos and other items, on both the Safeway.com and GroceryWorks.com Web sites. Terms of the agreement called for GroceryWorks to purchase those items exclusively from Safeway, which was to sell them to GroceryWorks at cost. Other claims included overcharging for products, or providing GroceryWorks with goods that were out of date, discontinued or no longer marketed in Safeway stores; failing to give GroceryWorks preferential (or even equal) treatment with Safeway stores; selling certain items, such as floral products, directly to customers through the Randalls and Tom Thumb sites; failing to make GroceryWorks the lead in promotional and "loyalty" programs (Habal and Bounds 2001) and failing to implement the procedures for picking up on-line orders at Safeway stores (Zwiebach 2001). 
Profit Structure Summary from April 2000 - March 2001

Once GroceryWorks merged with Safeway the company continued to operate out of its dedicated fulfillment centers. At the time it was using both an attended and unattended reception method corresponding to models 20 and 21a under the hybrid category (see Appendix 3). In June 2000, GroceryWorks struck a deal with Post Properties to provide the upscale tenants of its downtown apartments with a grocery home delivery option. Since the refrigerator was similar to a reception box, GroceryWorks was using business model 21b under the hybrid category (see Appendix 3). In the Phoenix market, GroceryWorks tested a store pickup model. Specifically, once the delivery truck left the fulfillment center, it made two attempts to deliver the customer's order. If there was no one home on the second attempt, arrangements were made so the customer could pick up his/her order from the Safeway store nearest his/her home. In this situation, the store served as a default local pickup point corresponding to business model 16 under the hybrid category (see Appendix 3). Thus, during the time period between April 2000 and March 2001, GroceryWorks operated using four different business models. However, even by experimenting with different business models, and making changes to its revenue structure, GroceryWorks was unable to reduce its cost structure enough to keep the company from losing money.

Table 14 displays GroceryWorks back-end capital expenditure costs which were a significant portion of the total cost component. Since the company had a moderate growth strategy at the time, and a stated policy to build dedicated fulfillment centers for each market it entered, the fixed component increased each time the company entered a new market. For each market that GroceryWorks entered it needed to purchase land, 
build a facility, equip that facility, purchase a delivery fleet, and provide maintenance for that fleet. The cost associated with building and equipping the facility represented the bulk of these costs. Having such a large sunk cost made breaking even difficult for the company especially given its revenue structure.

For each market that GroceryWorks entered, it also had to hire and train personnel necessary for the picking, packing, and delivery functions. Although the automation equipment reduced the number of employees necessary for these functions, GroceryWorks still incurred general and administrative costs associated with filling these positions. The fuel and delivery personnel costs were also significant. However, the use of the routing and scheduling software helped to defray costs in this area by increasing efficiency. Hence, the capital costs associated with the purchase of the automation equipment was designed to reduce costs linked to the fulfillment function. Nonetheless, the costs associated with the picking, packing, and delivery functions were a significant portion of the cost structure.

The inventory procurement expenses decreased as a result of the merger with Safeway. Prior to the merger, GroceryWorks purchased its inventory directly from manufacturers and wholesalers. Since the company did not have the customer demand necessary to receive quantity discounts, GroceryWorks was forced to pay a higher price for inventory than other grocers. However, once the purchase agreement with Safeway was signed, GroceryWorks was able to procure its inventory from Safeway at a reduced cost. This helped the company to increase its profit margin on sales.

To stimulate demand for the service, GroceryWorks incurred customer relationship costs. Initially, GroceryWorks handled this function itself, but once it 
merged with Safeway, GroceryWorks used co-branding activities to help generate demand. By co-branding with Safeway, GroceryWorks was able to save a significant amount of capital that could be used in other areas of the operation. Further, by cobranding, the company received an immediate boost in brand awareness. This boost in awareness then helped to reduce the cost of customer acquisition. Although the cobranding activities helped to reduce the customer relationship costs, there was still a cost that GroceryWorks incurred for these activities.

The order taking costs were significant due to the proprietary nature of the system. The system needed to be custom designed for each of Safeway's subsidiaries to reflect that GroceryWorks was now the online division of that subsidiary. For some of these sites, several new features were incorporated which increased their sophistication as well as the costs associated with the sites design and maintenance. For instance, in Texas the GroceryWorks by Randalls site featured online store specials, electronic coupons, and frequent flyer miles. These efforts were undertaken to increase the appeal of the service to a wider market and they also had the effect of driving up the administrative costs. Lastly, as GroceryWorks expanded its market and implemented customer service programs, the general and administrative costs for the company increased.

During this period, GroceryWorks' revenue stream also improved. Specifically, due to the merger with Safeway, GroceryWorks was able to acquire inventory cheaper than it could on its own. This allowed the company to increase its profit margin on sales and thus increase revenue. In addition, GroceryWorks received revenue as a direct result of the imposition of a core delivery fee. The fee was enacted by Safeway to offset the costs associated with the delivery function. However, according to the grocery retail 
analysts, delivery fees were negatively correlated with customer acquisition and positively correlated with the service cancellation rate. Therefore, by enacting these fees GroceryWorks may have been curtailing its customer base. On the other hand, due to the co-branding activities, the company had access to Safeway's large customer base which lowered its customer acquisition costs. Therefore, it may have been possible to replace these customers at a fraction of the cost that it would have taken without the co-branding activities. Even if these customers were not replaced, perhaps the logic was that by imposing a delivery fee customers would buy more grocery products on each order and hence drive up the average dollar amount of an order. In this case the reduction in revenue caused by the decrease in the customer base could be offset by the increase in the average amount of a customer order. Another explanation may be that Safeway realized that GroceryWorks could not operate as a profit center and began to see the services as a value-added one. Nonetheless, the addition of increased profit margins and core delivery fees did improve the revenue structure of the company, but it was still not enough to offset the impact that the cost components were having on the profit structure. In fact, the majority of the capital used to finance the company's operations was coming from investment capital.

In terms of the other mediating/moderating variables, GroceryWorks made one significant change. Instead of using only the 'home delivery' method of delivery, the company also used the 'store pickup' and 'local pickup’ methods of delivery. Thus, GroceryWorks was utilizing all three methods of delivery in its online channel. In relation to the other variables, the construction of medium sized dedicated fulfillment centers meant the scalability of GroceryWorks' fulfillment function remained high. The 
company's growth rate remained moderate, employee/management commitment remained high, and the company continued to rely on a moderate level of automation in its fulfillment facility.

GroceryWorks’ decision to use Lincoln Property Company Commercial, Inc. as the company's exclusive agent for locating and negotiating commercial real estate acquisitions, demonstrated that the company took market structure factor seriously when determining where to expand the service. Specifically, once Lincoln located a potential property it gathered information on the demographics of the area. This seemed to indicate that the company took population characteristics seriously when considering market potential. Finally, there were no changes in the geographical locations that the company was operating from.

\section{Summary}

During the period between April 2000 and March 2001, GroceryWorks merged with Safeway and became Safeway's online grocery delivery service. This transformed GroceryWorks from a pure-play Internet grocer into a hybrid internet grocer. The merger provided GroceryWorks with several benefits. For example, the company received significant financial backing, reduced inventory procurement costs, reduced advertising and promotional activities through co-branding, reduced customer acquisition costs, and quick and less costly entry into top markets.

These benefits were needed because GroceryWorks' initial profit structure revealed that it was losing money due, in part, to the heavy fixed cost associated with infrastructure development. GroceryWorks' stated expansion policy did not help this 
situation. According to the company, as it expanded its service it would build the necessary infrastructure to conduct operations. These facilities were separate from Safeway facilities. Actual plans called for the company to build two new mid-sized fulfillment centers that were larger than the company’s current structure. Hence, in terms of GroceryWorks cost structure, the fixed component associated with infrastructure development was increasing noticeably with each new market that the company was entering. These fixed costs were to be expected given the business model that GroceryWorks had selected.

During the company's formative years, it was concerned with improving the efficiency of the fulfillment and delivery functions. As a result, GroceryWorks focused a significant amount of its capital and effort in this area. However, the cost structure became prohibitive causing the company to look for ways to reduce costs. One way was to begin co-branding with Safeway. By co-branding with Safeway, GroceryWorks was able to reduce the cost associate with brand building activities. This allowed the company to increase its brand awareness while at the same time reducing the cost of customer acquisition. In addition, by working with Launch Partnership, GroceryWorks was able to conduct an expanded advertising campaign at a fraction of the cost that it would have been able to had the company funded the advertising campaign itself.

GroceryWorks further demonstrated its focus on cost reduction through its continued reliance on automation. By utilizing automation in the fulfillment area, GroceryWorks was able to gain economies of scale in this area. Specifically, since the company had a stated policy of expanding into new markets by building the necessary infrastructure, there was going to be an increase in the costs associated with capital 
expenditures. However, by utilizing the automation equipment, GroceryWorks was hoping to benefit from the savings associated with reductions in the variable portion of the labor cost. That is, due to the efficiencies in the fulfillment area, as demand increased for the service the cost of fulfillment would be reduced. Whether or not GroceryWorks actually reached its target demand rate, the continued utilization of automation in the delivery area further demonstrated GroceryWorks' focus on cost reduction. The use of the eFS system allowed GroceryWorks to handle a virtual inventory (i.e., an inventory spread over several locations) and to have customer orders assembled properly. The system also allowed GroceryWorks to force the order capacity necessary to improve the efficiency of the delivery service. This in turn reduced the cost of delivery for the company.

Further cost savings came from reductions in the inventory procurement costs. Once GroceryWorks signed the service agreement with Safeway, the company was entitled to purchase its inventory through Safeway. Given the buying power of Safeway, it seems reasonable to assume that GroceryWorks inventory procurement costs were lower when the company purchased inventory from Safeway then when it purchased it directly from the manufacturers or wholesalers.

Another major concern of GroceryWorks during this period was increasing the demand for its delivery service. In an attempt to increase customer demand, GroceryWorks decided to increase the number of services that were available to the customer through its online channel. By offering more services, the company was hoping to increase customer trial and customer satisfaction which in turn would lead to more customer patronage. For instance, by acquiring its inventory through Safeway, 
GroceryWorks was able to increase the number of product lines that it carried.

According to conventional grocery retail thinking, having more inventory leads to better customer satisfaction. Thus, increasing the product assortment should have had a positive effect on overall customer satisfaction. Moreover, the deal with Post Properties, to deliver groceries to the apartments of upscale residents in downtown Dallas, demonstrated that GroceryWorks was interested in increasing demand while providing greater customer service. Likewise, the development of a website for the Dallas market that featured easier and faster navigation, an online tutorial, a 'SaveCart' option, electronic coupons, downloadable recipes and new personal preference features also demonstrated GroceryWorks' commitment to increasing customer service and ultimately customer demand. For the consumer, this translated into the convenience of shopping online for a large selection of items, in-store prices and weekly specials, extra online specials, the ability to use loyalty cards, acceptance of Manufacturers' coupons (online and traditional), and an easy return policy. According to grocery retail analysts, poor service was a primary factor in customer dissatisfaction and cancellations. Thus, indirectly by increasing the service level, GroceryWorks was attempting to expand the customer base by competing on a non-price attribute. This again highlights the fact that increasing customer demand for the service was a main focus.

\section{Profit Structure from April 2001 - December 2006}

Due to mounting financial problems, GroceryWorks announced that it would be shutting down its distribution centers in Grapevine and Houston, Texas. In the Houston 
area the shutdown resulted in the lay off of close to 50 corporate staffers and 80 delivery drivers. The company did not give a reason for the closing but indicated that the layoffs would be permanent. In light of these fulfillment center closings, the company stated that it would be using a store-based fulfillment models and would be delivering out of Randalls and Tom Thumb stores in the affected areas (Weir 2001). This represented a dramatic shift in GroceryWorks' fulfillment strategy. By switching to an in-store fulfillment model GroceryWorks was now operating under business models 1, 6b, 7b, and 7d under the hybrid category (see Appendix 3). GroceryWorks had been experimenting with the store-based picking model for three to four months in the Dallas area and had received favorable results prompting an additional test in the Austin market. That test also proved successful and the decision was made to convert all GroceryWorks' operations to store-based fulfillment models (Alaimo 2001). The company mentioned that it would sublease the two warehouse facilities and auction off the equipment.

According to Gary Fernandes, chairman and chief executive officer, GroceryWorks was out of the centralized fulfillment center business. Fernandes noted that the affiliation with Safeway allowed this option to be considered. He stressed that it was less expensive to operate using a store based method because there were minimal capital costs involved. In setting up a fulfillment center the cost could easily reach between $\$ 10$ million and \$12 million each. To cover all the expenses for these facilities it takes a high utilization rate (Alaimo 2001; Weir 2001). On the other hand, the storebased picking model requires minimal per store cost which reduces the breakeven point, and subsequently makes achieving that milestone easier. As a result, using the storebased picking model, one can enter a market and use between five and 20 stores to 
service that market. This method facilitates getting to breakeven quicker, with less risk, then is possible using the dedicated fulfillment center model. Fernandes also mentioned that the store-based model was more efficient, due to the fact that the stores were closer to the customers' homes. Hence, delivery productivity would be higher because there would be less unproductive time on the road before the first customer delivery was made (Alaimo 2001; Weir 2001).

The in-store picking model also has its own set of problems. For one, it is inefficient due to an increase in the level of mispicking that occurs. According to the grocery retail analyst, poor service execution was a prime factor in the demise of many online grocery store initiatives. Thus, this model has the potential to alienate some customers resulting in reduced use, or perhaps termination, of service.

GroceryWorks’ decision to abandon the dedicated fulfillment models resulted in the company cutting several costs. For one, when entering new markets, GroceryWorks relied on Safeway to provide the necessary facilities for conducting operations. Since GroceryWorks was no longer using dedicated fulfillment centers it did not needed to purchase land, lease or construct facilities, or equip any facilities. Further, the costs associated with operating the facility and equipment on a daily basis were also alleviated. Moreover, GroceryWorks was also able to save capital by reducing the general and administrative costs.

Although GroceryWorks’ decision to close its dedicated fulfillment centers and use an in-store fulfillment model saved the company capital in certain areas, it also required the company to incur certain cost in other areas. The bulk of this increase was associated with an increase in labor costs. This occurred because for each in-store 
fulfillment location that GroceryWorks used, the company had to have personnel there to pick, pack and deliver the customer orders. Since this function was being duplicated in several locations the labor expenses quickly began to climb.

The fulfillment conversion did not come without a price. For one, changes to the software were need. Specifically, the order taking software and the website needed to be updated so that when customers logged on they would be steered to the right store's webpage based on their Zip code. In addition, the routing software needed to be changed so that a customer's order would be directed to a store in the neighborhood in which that customer lived. Scheduling deliveries now took place on a local level as opposed to being centrally coordinated. Further, there was the actual in-store picking that needed to be considered. New hardware and software were needed, as was a support staff at each in-store fulfillment location. Lastly, the delivery fleet needed to be expanded to accommodate an increase in local deliveries.

Profit Structure Analysis for GroceryWorks: April 2001 to December 2006.

\section{Costs Components}

43. GroceryWorks' decision to close all of its dedicated fulfillment centers resulted in cost savings for the company. Specifically, there were no longer any costs associated with acquiring land and paying taxes on it, leasing or building facilities, and no more costs associated with the purchase and repair of automation equipment. These cost eliminations were represented by the removal of the back-end cost components 'land' - CC(21), 'facilities company built' - CC(25), and 'fulfillment equipment purchased' - CC(30) (see Table 15). (*Removed due to closing of dedicated fulfillment centers).

44. The expenses associated with maintaining the automation equipment was represented by the back-end cost component 'fleet and equipment maintenance' - CC(28). Once 
GroceryWorks switched to the in-sore fulfillment model, there were no longer any costs associated with repairing the automation equipment. However, there were still fleet maintenance costs (see Table 15).

45. In order to facilitate order picking and packing from decentralized locations, GroceryWorks had to make changes to its ordering software. This was represent by the front-end costs 'website related design in-house' - CC(1), and 'website related maintenance in-house' - CC(11) (see Table 15).

46. To coordinate deliveries from the various store locations, GroceryWorks had to augment its routing and scheduling software. This cost was represented by the back-end cost component 'routing and scheduling' - CC(20) (see Table 15). Since GroceryWorks continued to use the eFS system, the company was still receiving the benefits in efficiency that the system produced.

47. To facilitate making deliveries from multiple store locations, GroceryWorks had to increase the size of its delivery fleet. This expense was represented by the back-end cost component 'delivery fleet company owned' - CC(21). Further, in order to keep the fleet in good operating condition GroceryWorks incurred costs associated with fleet maintenance. This was represent by the back-end cost component 'fleet and equipment maintenance' - CC(28) (see Table 15).

\section{Performance Drivers}

48. By abandoning the centralized automated fulfillment model for the local in-store fulfillment model the company was sacrificing efficiency for cost reductions. Specifically, by switching fulfillment models GroceryWorks was sacrificing the improvements in the number of lines that could be picked, picking speed, picking accuracy, packing speed, packing accuracy, and assembly accuracy. As a result, there were links between the back-end cost components 'picking costs' $\mathrm{CC}(4)$, and the performance drivers 'picking speed' - $\mathrm{PD}(5)$ and 'picking accuracy' - PD(6) (see Figure 49). This represented a decrease in these drivers due to the change in GroceryWorks business model. 
49. There were also links between the back-end cost component 'packing/assembly cost' - CC(5) and the performance drivers 'packing speed' - PD(21) and 'assembly accuracy' - PD(7) (see Figure 49). These links represented decreases in these drivers due to the change in GroceryWorks business model.

50. Once GroceryWorks switched to an in-store picking model, the picking and packing cost increased. The picking and packing costs both had fixed and variable components. The fixed component stemmed from the general and administrative costs associated with hiring and training the personnel. For the picking costs, the variable component represented the bulk of this cost and was based on how long it took the employees to pick the items, how many orders the employees need to fill, the number of items needed for each order, and the number of items in inventory. Hence, the picking cost were determined by the performance drivers 'picking speed' - $\mathrm{PD}(5)$, 'number of orders' - $\mathrm{PD}(3)$, 'items per order' - $\mathrm{PD}(13)$, and 'number of lines picked' - $\mathrm{PD}(16)$ in conjunction with the back-end cost component 'picking cost' - CC(4) (see Figure 49).

51. For the packing and assembly cost, the bulk of this cost was variable in nature and was determined by the number of items in an order, the number of orders, and the packing speed. Therefore, the impact of packing and assembly costs on total costs was determined by the performance drivers 'items per order' - PD(13), 'number of orders' - $\mathrm{PD}(3)$, 'number of lines picked' - PD(16) and 'packing speed' - PD(21) in conjunction with the cost component 'picking/assembly costs' - CC(5) (see Figure 49).

In relation to service, GroceryWorks would be relying on Safeway to have in stock the products that customers order. With a central distribution center keeping track of the inventory was much easier because only the picking personnel were removing product from the shelf. With a store-based model, the picking personnel, as well as the stores regular patrons, are removing products from the shelves. This increased level of demand on the store's inventory could lead to frequent stockouts. This was a 
Table 15

GroceryWorks Profit Structure Components: April 2001 - December 2006

\section{Sources of Operating \\ Capital}

Investment Capital

1. Investment Capital (IC1)

Inventory Sales

2. Grocery Inventory Sales (RC12)

Delivery Revenue

3. Core Delivery Fee (RC4)

\section{Front End Costs}

Order Taking Costs

1. Website Related

1a. Design Cost

In-house (CC1)

1b. Maintenance Cost

In-house (CC11)

Customer Relationship Costs

7. Customer Awareness

7a. Done Alone (CC7)

7b. Partnership (CC9)

8. Customer Acquisition Costs

8a. Done Alone (CC8)

8b. Partnership (CC10)

\section{Back End Costs}

Capital Expenditures

* 18. Land (CC31)

* 19. Facilities

19a. Company Built (CC32)

* 17. Fulfillment Equipment

17b. Purchased CC(26)

14. Delivery Fleet

14a. Company Owned (CC21)

15. Fleet and Equipment

Maintenance (CC28)

Inventory Expenses

3. Inventory Acquisition Cost

3a. Purchased via

manufacturer/wholesaler (CC23)

3b. Purchased via Parent

Company (CC29)

\section{Performance Drivers}

Customer Patronage Drivers

1. Number of Orders (PD3)

2. Item per Order (PD13)

3. Customer Level

3a. Number of Repeat Customers (PD2)

3d. Number of New Customers (PD1)

Delivery Service Drivers

5. Number of Orders Delivered (PD9)

6. Number of Vehicles Used (PD15)

7. Number of Delivery Attempts (PD14)

10. Delivery Truck Capacity (PD22)

11. Routing and Scheduling Process (PD17) 
Table 15 (Cont'd)

GroceryWorks Profit Structure Components: April 2001 - December 2006

\section{Sources of Operating}

Capital

\section{Front End Costs}

General And Administrative

10. General and Admin. (CC17)

11. Other Costs and Expenses

(CC18)

\section{Back End Costs}

Fulfillment Expenses

4. Picking Costs $(\mathrm{F}, \mathrm{V})$

4a. Human Capital (CC4)

4b. Hybrid (Some Automation) (CC18)

5. Packing/Assembly Costs (F,V)

5a. Human Capital (CC5)

5b. Hybrid (Some Automation) (CC19)

6. Delivery Costs

6a. Fuel Costs (CC6)

6b. Delivery Personnel Costs (CC17)

13. Routing and Scheduling (CC20)

\section{Performance Drivers}

Operational Service Drivers

8. Fulfillment Performance
8a. Picking Speed (PD5)
8b. Packing Speed (PD21)
8c. Number of Lines Picked
8d. Picking Accuracy (PD6)
8e. Assembly Accuracy (PD7) (PD16) 
Figure 49

GroceryWorks Back-End Cost Components and Performance Drivers: April 2001 - December 2006

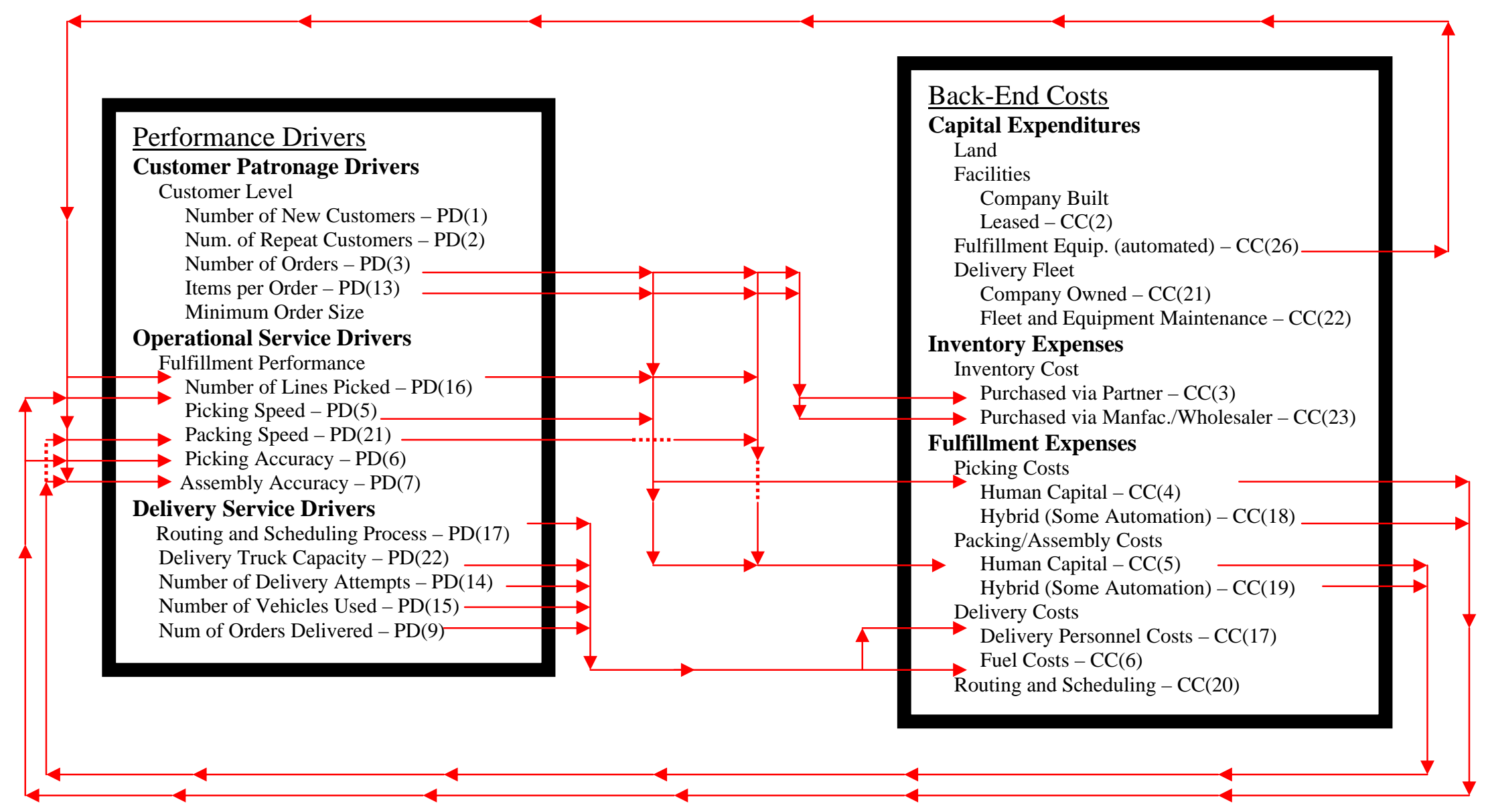


documented primary problem with the in-store picking method with the frequency as high as 8 to 15 percent of items. This had a direct bearing on customer satisfaction which in turn may have had an effect on the customer retention rate. The substitution for outof-stock products may also become a problem because some customers would not want any substitution for their product selection while others may be willing to only substitute the same brand but a different size, while still yet others may only be willing to substitute a different brand for the same out-of-stock product. On the positive side, the store-based model allowed for a larger selection of products than the central fulfillment center did. In the central fulfillment center there are about 11,000 SKU's while in a large metropolitan supermarket there can be anywhere from 30,000 to 35,000 SKU's.

In June, GroceryWorks underwent another round of financing receiving \$35 million in cash and other assets. Part of the financing came from Tesco, a U.K. food retailer, in the amount of $\$ 22$ million for which Tesco received 35 percent of GroceryWorks' voting equity. The terms of the deal called for Safeway to adopt Tesco's online grocery business model. This investment was Tesco's plan to export its online grocery business model to the U.S. GroceryWorks and Safeway had already decided to move to a store-based fulfillment model but it would have taken some time for the company to work out the technology and operating procedures necessary for that model. Therefore, instead of taking 18 to 24 months to build the infrastructure and design the necessary systems, GroceryWorks decided to license Tesco’s store-based technology, which Tesco had practically perfected over the six years it had been operating in the online channel. Specifically, GroceryWorks installed Tesco's in-store technology, which 
enabled orders to be downloaded on a shopping cart computer screen that then directed the picker to each item in the store. This aided the picking process and allowed orders to be completed more efficiently. Tesco executives noted that they believed that the alliance between Safeway and Tesco would make GroceryWorks profitable the following year.

Whether or not GroceryWorks would be profitable in a year or two was open to debate. Analysts observe that Tesco's success probably had more to do with its market than with its model. There are many differences between the U.K. and U.S. markets. The U.S. market has more individuals with Internet access, which benefits Safeway and other U.S. grocers wanting to develop online channels. However, in the U.K., Tesco and other U.K. grocers benefits from a much higher population density, with over eight times the number of people per square mile compared with the U.S (Jacobson 2001). Further, gas prices are higher in the U.K. than in the U.S. and there are fewer cars in the U.K. than in the U.S. making home delivery more cost efficient for persons in the U.K. Thus, whether home delivery can work in sprawling American suburbs was still open to question.

In January 2002, GroceryWorks launched its online shopping service in the Portland, Oregon area. According to company officials, Portland was selected because the area ranked as one of the nation's most Internet-accessible. In fact, Portland had consistently ranked as one of the most wired cities in the United States, with nearly 70 percent of households connected to the Internet. GroceryWorks' service was available in 70 zip codes encompassing the Portland and Vancouver, Washington areas. When shoppers logged on to the Web site, they were able to order nearly all of the items 
available in Safeway owned stores. Once an order was placed, it was hand picked by 'personal shoppers' operating from one of five local stores. Each product was removed from the shelf and scanned using a hand held computerized unit. If the personal shopper picked the wrong item from the shelf the scanner system would beep allowing the personal shopper to correct a picking error before the customer's order was set for delivery. If a product that the customer ordered was not in stock, the personal shopper consulted a substitution list, compiled by the customer, and made a substitution for the out-of-stock item (Adamy 2002). If the customer indicated that no substitute was possible, the particular item in question was excluded from the order. Once the proper item had been selected, the computer updated the customer's shopping list by removing that product from the list. Using this method, filling the average order took approximately 51 minutes. Once picked, the groceries were then bagged, placed in totes, and put into delivery vans designed with separate compartments for room temperature, chilled, and frozen goods. Drivers then delivered the orders to the customer's home the day after the order was placed. For this service, GroceryWorks charged customers $\$ 9.95$. In February 2002, GroceryWorks began offering its online grocery service to shoppers in select zip codes in the Sacramento, California area while in March, GroceryWorks began delivering orders to the San Jose, California market. The service offered was the same as that offered in the Portland market. By expanding into these new markets, GroceryWorks demonstrated that it was still following a moderate growth strategy (see Table 14). In May, GroceryWorks named Gary Rocheleau as the new president. Rocheleau was previously vice president of marketing operations for the Vons 
division. He replaced Frisby who rejoined Safeway as president of its Randalls division in Texas.

Table 16

Other Mediating/Moderating Factors for GroceryWorks: April 2001 - December 2006

January 1999 April 2000 - April 2001 -

- March 2000 March 2001 December 2006

Company Related Factors

Scalability (Picking Location)

High

Medium Dedicated

$\mathrm{X}$

$\mathrm{X}$

Large Dedicated Warehouse

Moderate

Wareroom (Hybrid)

Small Dedicated Warehouse

Low

In-Store

X

Method of Delivery

Store Pickup

Local Pickup

Home Delivery

X

$\mathrm{X}$

$\mathrm{X}$

$\mathrm{X}$

$\mathrm{X}$

$\mathrm{X}$

$\mathrm{X}$

Company Rate of Expansion

Slow

Moderate

X

X

X

Fast

Automation Level

High

Moderate

X

X

Low

X 
Table 16 (Cont'd)

Other Mediating/Moderating Factors for GroceryWorks: April 2001 - December 2006

January 1999 April 2000 - April 2001 -

- March 2000 March 2001 December 2006

Employee/Management

Commitment

High

$\mathrm{X}$

$\mathrm{X}$

$\mathrm{X}$

Moderate

Low

Market Structure Factors

Connectivity

Internet Structure

High

Moderate

Low

Internet Penetration

High

Moderate

Low

Internet Access

High

Moderate

Low

Cost of Internet Service

High

Moderate

Low

Population Structure

Population Size

Population Density 
Table 16 (Cont'd)

Other Mediating/Moderating Factors for GroceryWorks: April 2001 - December 2006

January 1999 April 2000 - April 2001 -

- March 2000 March 2001 December 2006

Geographical Location

Continental

North America

$\mathrm{X}$

$\mathrm{X}$

$\mathrm{X}$

South America

Europe

Asia

Country

United States

X

X

$\mathrm{X}$

United Kingdom

Japan

County/Parish

Urban

Suburban

Rural

$\begin{array}{lll}X & X & X \\ X & X & X\end{array}$

In August 2002, GroceryWorks began service in the San Diego, California market through its Vons subsidiary. For the service, GroceryWorks usually charged $\$ 9.95$ for delivery but dropped its fee to $\$ 4.95$ for a 30 day period. This was done to generate customer trials and repeat purchase for the service. According to the grocery retail analysts, consumers would refrain from using the service if the delivery fee exceeds $\$ 10$ or about five percent of the total grocery bill. Unlike in other markets, however, Vons did not have an option for customers to order online and pick-up their groceries at the store. Company officials stated that the store pickup option was not offered because there was very little customer interest. 


\section{Investment Capital}

52. GroceryWorks received an additional \$35 million in investment capital. This was represented by the investment capital component 'investment capital' - IC(1) (see Table 15).

\section{Costs Components}

53. In order to utilizing the Tesco business model, GroceryWorks had to purchase Tesco's store-based technology. This was represented by the back-end cost component 'fulfillment equipment purchased’ - CC(30) (see Table 15).

54. Once Tesco became a partner in GroceryWorks, the website was redesigned to accommodate the new fulfillment technology. This resulted in additional costs for GroceryWorks which were represented by the front-end cost components 'website design in-house' - CC(1) and 'website maintenance in-house' - CC(11) (see Table 15).

55. The adoption of Tesco's store-based technology was designed to help increase the efficiency of the picking and packing personnel. The technology represented low-level automation and was intended to increase the speed at which the picking and packing personnel performed their jobs. By improving the efficiency of the fulfillment area, GroceryWorks was indirectly reducing the cost structure associated with that area. This was represented by the back-end cost components 'picking costs human capital' - CC(4), 'picking costs hybrid some automation' - CC(18), 'packing/assembly costs human capital' - CC(5), and 'packing/assembly costs hybrid some automation' - CC(19). The use of Tesco's technology reduced the actual labor cost associated with the picking and packing personnel. However, there were still some costs associated with using this low-level technology (see Table 15).

56. Expansion into the Portland and Washington markets required GroceryWorks to hire fulfillment and delivery personnel. This was represented by the 'picking costs human capital' - CC(4), 'picking costs hybrid' - CC(18), 'packing/assembly costs human capital' - CC(5), 'packing/assembly hybrid' - CC(19), 'delivery costs personnel” - CC(17), and 'fuel costs' - CC(6) (see Table 15). 


\section{Performance Drivers}

57. The use of Tesco's store-based low-level technology improved the performance of the picking and packing personnel. This was represented by the links between the back-end cost component 'picking costs hybrid some automation' - CC(18) and the performance drivers 'picking speed' - PD(5) and picking accuracy' - $\mathrm{PD}(6)$. Further, there were also links between the back-end cost component 'packing/assembly costs hybrid some automation' - CC(19) and the performance drivers 'packing speed' - PD(21) and 'assembly accuracy' PD (7) (see Figure 49).

58. By lowering the delivery fees, GroceryWorks was attempting to simulate demand for its delivery service. Thus, there were links between the revenue component 'core delivery fees' $\mathrm{RC}(4)$ and the performance drivers 'number of new customer' - PD(1) and 'number of repeat customers' - PD(2) (see Figure $50)$.

In January 2003, GroceryWorks expanded its online grocery order and delivery service into the Las Vegas area in conjunction with Vons. This new venture was titled Vons.com. Aside from the standard services that GroceryWorks offered its customers, Vons.com included a new Nutrition Center feature that was full of helpful information about product ingredients, tips on how to add more fruits and vegetables to the family's diet, and recipes to easily create meals using healthy ingredients. According to Tom Keller, president of Vons, the center ". . . offers ideas and answers, and our site helps them put those ideas into practice by allowing parents to add products directly to their online shopping baskets. It's a definite benefit for busy parents." (PR Newswire, Jan 13, 2003). Vons website also allowed shoppers to communicate their preferences for the size and ripeness of produce to the personal shopper at Vons.com. No other online grocery service in Las Vegas allowed customers to communicate with their in-store shopper, 
Figure 50

GroceryWorks Revenue Components and Performance Drivers: April 2001 - December 2006

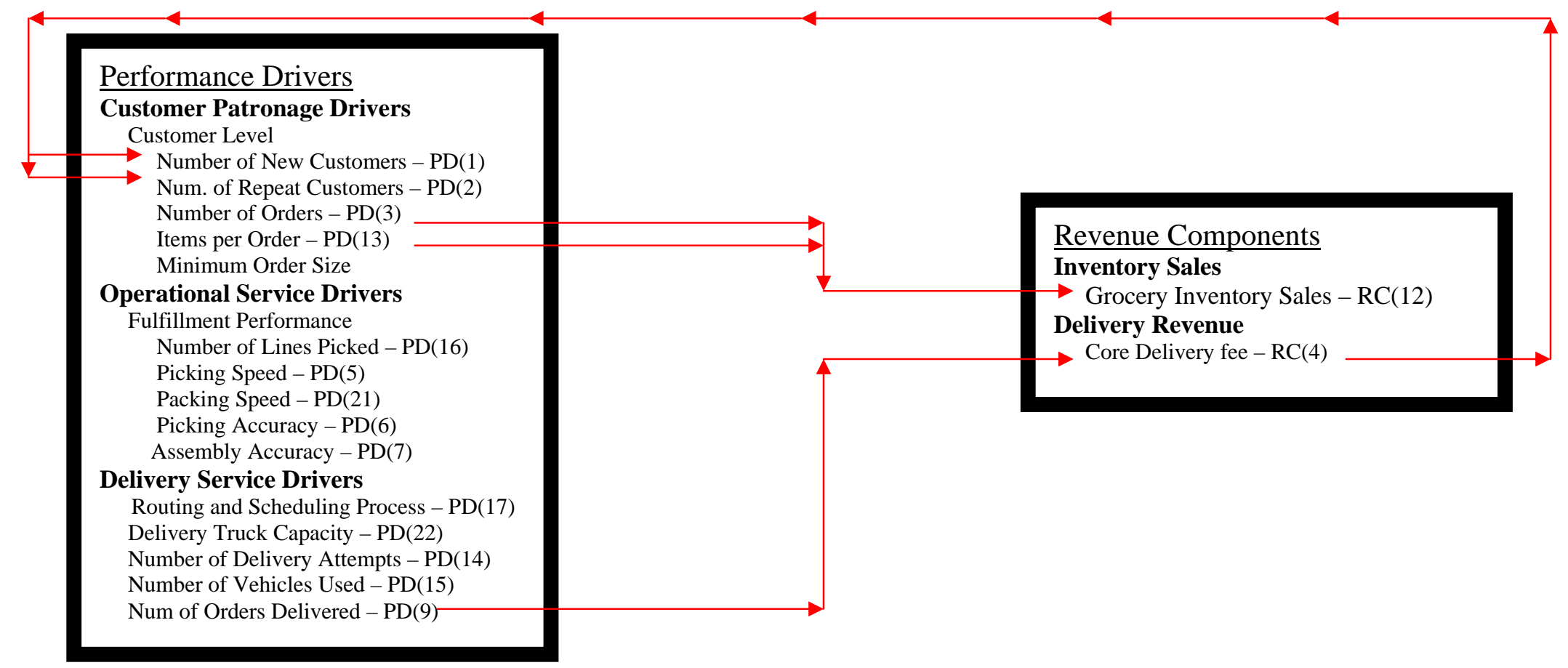


which allowed Vons to differentiate its service. In addition, Vons.com offered customers the 'My Favorites' grocery list builder, which helped new online customers compete their first shopping list. Specifically, the service instantly presented the customer with a categorized list of as many as 300 products that the shopper recently purchased using a Vons Club Card at a Vons store. This way, customers were reminded of their favorite brands and package sizes. Moreover, as an additional service incentive, customers received all Vons Club Card discounts. Vons service costs $\$ 4.95$ for orders totaling $\$ 150$ and higher or $\$ 9.95$ for orders under $\$ 150$. There was no minimum order size and VONS.com offered the entire range of products found on the shelves of nearby Vons store.

In mid September 2003, GroceryWorks announced it was launching a new program, designed to encourage customer trial that would entail offering 10 shopping sprees of $\$ 100$ each to customers whose names were selected at random. According to Mark Marymee, spokesman for GroceryWorks.com, the company “... wanted to test a new way to get customers to register" (Hamstra 2003). For those customers who had registered for GroceryWorks service but had not actually placed their first order, GroceryWorks planned to use the customer's e-mail address to offer them $\$ 10$ off on the first shopping trip. According to Marymee, from the customer's perspective, this equals free delivery. For those customers who ordered for the first time, Safeway typically followed up with an e-mail promotion touting a \$5 discount on the next visit (Hamstra 2003). These actions demonstrated that GroceryWorks was attempting to increase its 
customer base. Granted, the company was losing money on these particular transactions, but the goal was to generate enough customer patronage to offset these marketing costs.

The online grocery market was once predicted to be $\$ 10.8$ billion in 2002 . By 2002 it had reached an estimated \$1 billion in sales. According to Jupiter Research, this amount was expected to grow to $\$ 5.4$ billion by 2007 . With the potential size of the online grocery market, one would think more companies would have viewed the online channel as a profit center. However, according to insider information, Vons viewed the services as a way to strengthen its existing brands and keep shoppers happy, rather than as profit center (Knight Ridder/Tribune Business News, Feb 9, 2003). This demonstrated that Safeway considered the online channel as a niche market and those in that market had to pay for the service. This helped to reduce the costs associated with the fulfillment and delivery functions. In discussing the current state of the online grocery channel, Ms. Overby of Forrester Research noted that in 2003 online grocery shopping expectations were more in perspective. Gone were the over inflated sales projections of the past. According to Ms. Overby, the online channel is now viewed as “. . . a niche offering that's part of a larger basket" (Knight Ridder/Tribune Business News, Nov 2, 2003). Some major chains also see it as a way to differentiate themselves from other grocers in their area.

In December 2003, Safeway.com allowed customers to purchase holiday gift cards from 21 major retailers, including Nordstrom, Circuit City, and, Bed, Bath \& Beyond, and have them sent to recipients across America. Customers could also purchase Safeway gift cards redeemable inside Safeway, Vons, Pavilions, Randalls, Tom Thumb, Dominicks, Genuardis and Carrs stores. According to Mitch Rhodes, president 
of Safeway.com, "This is a great way for busy people to take care of both grocery shopping and holiday gift giving at the same time. We can mail the gift cards to the customer so they can hand them out, or ship directly to recipients anywhere in the United States.” There was a $\$ 2.50$ service charge for each address that the customer wanted a card sent (PR Newswire, Dec 4, 2003). The addition of this service demonstrated that Safeway.com/Groceryworks.com were increasing the service level in order to appeal to a broader market.

In February 2004, Safeway announced it would be opening a new Vons.com store in Henderson, Nevada for picking customer orders. Once the store was opened, Safeway added 27 new ZIP codes to its service area in greater Las Vegas. According to Mitchell Rhodes, president of Vons.com., "We've expanded our coverage area by more than 75 percent in order to serve an even larger segment of the growing Las Vegas market... Our newest pick store in Henderson is a great addition and allows us to not only broaden our service area and open new delivery slots, but also shorten drive times and improve on-time delivery. That's critical for consumers." (PR Newswire, Feb 13, 2004). In the Las Vegas area, there was a minimum order size of $\$ 50$ and it cost $\$ 4.95$ for delivery of orders exceeding $\$ 150$ or $\$ 9.95$ for orders under $\$ 150$. Vons.com offered the entire range of products found on the shelves of a nearby Vons store at the same prices. To get the service operational, GroceryWorks expanded the delivery fleet to include an additional 75 trucks.

In March 2006, GroceryWorks chief marketing officer at the time, Brian Cornell, stated that the company was in the process of reviewing its partnership with Tesco. The review was sparked by Tesco's announcement that it was considering opening a 
convenience store chain in the U.S. Tesco officials commented that the move was preliminary and had a considerable way to go before it constituted a major concern for Safeway. Nonetheless, it meant that Safeway and Tesco would soon be in direct competition in many of the markets that the two companies were currently partners in. As a result, the two companies decided that it was best that each go its separate way.

Profit Structure Summary from April 2001 - December 2006

Between April 2001 and December 2006, GroceryWorks underwent a significant change in its fulfillment area. During this period, the company decided to abandon the centralized fulfillment model and switch to an in-store fulfillment model. In this situation, GroceryWorks was relying on Safeway to provide all the necessary resources for establishing operations in various markets. Although the company did not provide any details concerning the shift in focus it was most likely done in an attempt to reduce the cost components associated with operating a dedicated fulfillment center model.

Table 11 displays the profit structure of GroceryWorks. As the table demonstrates, GroceryWorks' cost structure was a substantial portion of the company's profit structure. The majority of these costs were associated with capital expenditures. These costs included the purchase of land, the building of facilities, equipping the facility, and performing the delivery function. What made these costs prohibitive was that they needed to be carried out in each market that GroceryWorks entered. The construction of the fulfillment facility alone cost anywhere from $\$ 10$ million to $\$ 12$ million. Given the moderate growth strategy that GroceryWorks was pursuing, it was obvious that these fixed costs were overrepresented in the company's profit structure. 
However, once GroceryWorks made the decision to abandon the dedicated fulfillment center model, the company was able to alleviate the impact of these costs.

As Table 15 displays, once GroceryWorks switched to the in-store fulfillment model its profit structure changed. As the table indicates, GroceryWorks was able to eliminate the costs associated with the purchase of land, the construction of facilities, and the equipping of the facilities. However, the change in the fulfillment strategy did require GroceryWorks to expand its delivery fleet in order to have the delivery capacity at each store serving as a fulfillment point. Even though there were increases to the number of vehicles in the fleet, switching to an in-store fulfillment model allowed GroceryWorks to save a significant amount of capital on infrastructure development. This had the effect of reducing the company's breakeven point, making it possible to reach profitability sooner.

The change in fulfillment strategy also required GroceryWorks to incur additional costs in the picking and packing areas. These costs materialized because for each in-store fulfillment location, GroceryWorks needed to have personnel employed in the picking and packing areas. These costs had both fixed and variable components. The fixed component stemmed from the increase in the general and administrative expenses associated with hiring and training the picking and packing personnel. The variable component materialized as the picking and packing personnel were performing their functions. Thus, as the order volume increases more employee time was necessary to pick and pack customer orders. This process was carried out at each in-store fulfillment location. Hence, due to the labor intensive nature of the in-store picking model, GroceryWorks' labor costs increased. 
Once GroceryWorks decided on an in-store fulfillment model, the company made changes to the order taking software. These changes were necessary in order to direct the customer's order to the proper fulfillment location. This resulted in an increase in the costs component associated with the re-design and maintenance of the website. In addition, for GroceryWorks to staff each in-store locations with pickers, packers, and delivery drivers, the company first had to hire and train these individuals. These hiring and training costs were part of the general and administrative expenses. Thus, by changing its fulfillment strategy to an in-store model, GroceryWorks was increasing its general and administrative expenses. Finally, there were no changes to the customer relationship costs and the inventory expenses as a result of switching to the in-store fulfillment model.

In relation to the other mediating/moderating variables, GroceryWorks made two significant changes (see Table 14). The first was a change in scalability. By switching to an in-store fulfillment model, GroceryWorks' operation was now confined to selected stores. The space capacity for these stores was fixed so as demand increased inefficiency would set in due to store congestion and an increased turnover rate. The second change concerned the automation level. By switching to an in-store model, GroceryWorks had to forego the use of automation in the fulfillment centers. Instead, the company had to rely on the low level picking automation that Tesco supplied. Although it improved the picking speed and accuracy, these increases in efficiency were far below those gained by the use of the fulfillment center automation. In terms of the method of delivery, GroceryWorks continued to use all three methods of delivery. The company continued to 
follow a moderate growth strategy, and employee/management commitment remained high. There were also no changes in the variable concerning geographical location.

\section{Summary}

The period between April 2001 and December 2006, begins with GroceryWorks deciding to abandon the dedicated fulfillment center model for an in-store fulfillment model. This decision by the company was not done haphazardly. In fact, GroceryWorks had researched and experimented with the in-store model for three to four months before deciding to make the change. However, GroceryWorks’ public announcement came via the abrupt closing of the company's two dedicated fulfillment centers. Although the company did not indicate why it was closing the fulfillment centers, it was likely due to the steep costs associated with building and maintaining the infrastructure necessary to operate them.

By closing its dedicated fulfillment centers, GroceryWorks was able to save money since the company no longer had to purchase land or build and equip facilities. According to Gary Fernandes, chairman and chief executive officer, the in-store fulfillment method was less expensive to operate because there were minimal capital costs involved. To make the dedicated fulfillment model work, there needed to be a high volume of business in order to cover the operating costs. It seemed that indirectly Mr. Fernandes was acknowledging that customer demand was not high enough for the company to benefit from the economies of scale resulting from the use of dedicated fulfillment centers. Hence, besides the costs associated with the fulfillment center, the decision to abandon the dedicated fulfillment model may have been based on demand 
projections. If the demand for GroceryWorks service was projected to increase, then it was simply a matter of continuing to fund current operations until demand reached a point where the economies of scale began to set in. Perhaps GroceryWorks conducted demand projections for its service and realized that the demand was not projected to reach a level high enough to justify continuing to use a dedicated automated fulfillment model.

Once Safeway abandoned the dedicated fulfillment center model, the company announced that it was teaming with Tesco, a U.K. grocery retail chain, to help with GroceryWorks' operation. According to the deal, GroceryWorks had to agree to adopt the Tesco's online grocery business model. This entailed Tesco providing GroceryWorks with cutting-edge technology and the operational expertise necessary to get the store-based fulfillment model to work. It would seem that this strategic move was designed to further reduce GroceryWorks’ cost structure. Although GroceryWorks had decided to switch to an in-store picking model, the company had not determined what technology it was going to use nor how the system was actually going to function. Instead of taking 18 to 24 months to develop these technologies and operating procedures, which would have been quite costly for the company, GroceryWorks decided to simply lease the technology from Tesco.

There were some benefits associated with switching to an in-store fulfillment model. For one, the store-picking model did not require a large financial commitment up front. Therefore, the order volume necessary to cover operating costs in a particular market was lower which improved the company's chances of reaching breakeven. Second, the store-based picking model had less risk associated with it because the 
infrastructure was already in place. The majority of capital costs associated with the instore picking model were tied to the purchase of in-store fulfillment equipment and the purchase of a delivery fleet. There were no capital costs associated with infrastructure development because the fulfillment facility was the store itself. As a result, the risk associated with entering new markets was greatly reduced under the in-store picking model. Further, according to GroceryWorks' CEO, the in-store picking model was more efficient because the stores were closer to the customers' home. Hence, the delivery productivity was higher because there was less unproductive time on the road before the first delivery was made. Moreover, by changing to an in-store picking model, GroceryWorks was able to offer its customers a wider selection of products. This was because the number of lines carried in GroceryWorks fulfillment centers average around 11,000 while in a large Safeway grocery store there were between 30,000 and 35,000 products in inventory.

There were also some problems associated with the in-store fulfillment model. For example, the fulfillment method was inefficient because it increased the occurrence of mispicking and order incompleteness. This then led to reduced customer satisfaction, which could manifest as customer cancellations. In addition, this fulfillment method also had a considerable number of variable costs associated with it. As discussed above, the employee labor costs rose under this fulfillment method because GroceryWorks had to duplicate certain functions at each store based fulfillment point.

During this period, GroceryWorks continued to focus on customer service and increasing demand for the service. For instance, allowing customers to request what type of product substitutions they wanted was an effort to boost the service level. In the Las 
Vegas market, GroceryWorks was working to improve the service by improving the rate of on-time delivery. According to the grocery retail analyst, lack of operating performance and poor service execution were major factors in the demise of some online grocery initiatives. The use of Tesco's hand-held technology was designed to improve the picking and packing accuracy. The more accurate and complete customer orders were, the higher their overall satisfaction with the service. This demonstrated that GroceryWorks was focused on enhancing its service for its customers. Finally, by offering customers \$10 off their first order and offering customers who had ordered once, a five dollar discount on their next order, GroceryWorks was trying to increase the demand for its service. By offering these discounts the company was signaling that it was confident that consumers would enjoy the service. This was also a sign that customer demand was a primary focus for GroceryWorks.

\section{General Summary}

During GroceryWorks’ first year, the company focused on establishing an infrastructure for conducting operations. This entailed purchasing land, building and equipping a fulfillment center, and purchasing a delivery fleet. As a result, these capital expenditures were a significant portion of the overall cost structure. This was expected since the business model that GroceryWorks choose relied on the development of dedicated central fulfillment centers. By utilizing a dedicated fulfillment center model, GroceryWorks focused on economies of scales in two areas. One was the fulfillment center and the other was the delivery function. 
To improve the efficiency of the fulfillment center GroceryWorks installed automated equipment. This allowed the company to reduce both the fixed and variable portions of the labor expense. In terms of the variable portion, automation allowed the company to improve the speed at which a customer's order could be picked and packaged for delivery. This helped reduce the time that an employee was on the clock, which resulted in direct savings for the company. In relation to the fixed portion of the labor cost, automation reduced the number of picking and packing personnel needed which also resulted in direct savings for the company. Although the automation helped to reduce costs in the fulfillment area, the company still incurred some labor costs associated with the picking, packing, and delivery functions.

The other area that GroceryWorks concentrated on was the delivery area. By using third-party routing and scheduling software, GroceryWorks was able to save capital in two distinct ways. First, the use of third party software meant the company did not have to acquire the core competencies necessary to develop these systems in house from scratch. Secondly, the system allowed GroceryWorks to schedule deliveries more efficiently by allowing the number of orders delivered to a specific location to be maximized. By using its routing and scheduling system GroceryWorks was able to force the order density necessary to make a route more profitable. Hence, from the beginning it seems that GroceryWorks was focused on creating an infrastructure that would allow the company to gain economies of scale as the operation expanded. This would seem to indicate that GroceryWorks was expecting a level of demand, high enough to capitalize on the economies of scales generated via the automated fulfillment center. However, during the company's first year of operation, there was insufficient demand to offset the 
impact that the cost components were having on the profit structure. This could be expected since the company had only been in operation for a little over a year.

Once GroceryWorks had the necessary infrastructure in place, the company turned its focus to brand building activities. GroceryWorks' first attempt at building brand awareness involved print, radio, newspaper, and billboard advertising. Whether or not the company’s advertising campaign was successful at generating customer trial cannot be assessed from the case information. However, what could be gleaned was that the demand for the service did not reach a level high enough to offset the cost structure that the company had accumulated. What GroceryWorks learned was that generating selective demand for its service was difficult and very costly for the company. On top of these costs, GroceryWorks also incurred costs linked to the development of the company website and ordering software, and the general and administrative costs necessary to conduct operations on a day-to-day basis. Once all these costs were combined, GroceryWorks’ cost structure become prohibitive.

Looking at GroceryWorks' revenue structure, it was apparent why the company was losing money. Initially GroceryWorks only relied on the markup on inventory to generate revenue. The company purchased its inventory from manufacturers and wholesalers and these purchases represented another significant cost for the company. Given GroceryWorks’ size it was unlikely that the company could have extracted quantity discounts from the manufacturers and wholesalers. As a result, in order to stay competitive, the company needed to offer its inventory at a competitive price. Given the thin profit margins that most BAM grocers operate with, it was unlikely that GroceryWorks had a large enough margin on sales to offset the impact that the cost 
components were having on the company's profit structure. As a result, GroceryWorks had to rely on investment capital to finance operations. However, during this period investment capital for online initiatives was drying up and many pure-play online grocers were beginning to feel the pinch.

During the period between April 2000 and March 2001, the realities of GroceryWorks' business model became apparent. Utilizing a dedicated fulfillment center model, the company had accumulated a significant cost structure. A large portion of this cost was associated with the establishment of the infrastructure necessary to conduct operations. Based on GroceryWorks' revenue structure it was improbable that the company was ever going to generate enough revenue to break even. Faced with a mounting cost structure, and a relatively weak revenue structure, GroceryWorks looked for a source of investment capital in order to keep the company operational. The company found just such a benefactor in the grocery retail giant Safeway, which agreed to purchase a controlling interest in GroceryWorks. What is interesting to note is that it only took a year and a half for GroceryWorks to accumulate a cost structure so prohibitive that it almost forced the company out of business. This would seem to support the grocery analysts statements that the development of costly infrastructure was a prime factor in the demise of many online grocery failures.

Once Safeway took a controlling interest in GroceryWorks, it provided GroceryWorks with the capital necessary to expand its grocery delivery service into a new market. This expansion required the company to incur additional capital expenditures such as buying land, building a facility, equipping that facility, and purchasing a delivery fleet. According to GroceryWorks' stated growth objectives, the 
company intended to expand into 16 markets. Although this stated growth rate was moderate, it carried an expensive price tag. By expanding into a second market GroceryWorks added more capital expenditures to the cost structure. The expansion also resulted in costs associated with changing the website and order taking software to represent the Safeway subsidiary GroceryWorks was affiliated with in a particular market. Moreover, by expanding into a new market, GroceryWorks also increased its general and administrative costs. A significant proportion of this cost was linked to the hiring and training of picking, packing, and delivery personnel. Thus, the expansion had the effect of increasing the cost structure of the company, which increased the breakeven point, and ultimately prolonged the time horizon for the company to turn a profit.

For both Safeway and GroceryWorks, the decision to merge was a cost saving one. For Safeway, the merger allowed the company to acquire an online channel immediately, saving the company money and 18 to 24 months in development time. The deal gave GroceryWorks access to significant financial backing, reduced inventory procurement costs, reduced advertising and promotion costs, reduced customer acquisition costs, and quick and less costly entry into new markets. The inventory savings alone were significant because they related directly to the revenue component. That is, once GroceryWorks signed the purchase agreement with Safeway, the company was able to purchase inventory from Safeway at cost. Given Safeway's size and buying strength, it was able to extract quantity discounts from the manufacturers and wholesalers. Thus, by purchasing its inventory from Safeway, GroceryWorks was able to increase its margins on sales which in turn increased the revenue stream for the company. 
The cost savings associated with co-branding activities were also significant to GroceryWorks. According to Kelby Hagar, founder of GroceryWorks, ". . . we realized very early in our growth cycle ... that we could not keep up with the customer acquisition curve that was going to be demanded in the on-line business, nor did we believe any other pure-play could. We needed to partner with someone who had that brand awareness and the brand recognition to help lower customer acquisition dollars” (Alaimo 2000, p. 30). This statement clearly demonstrated that brand building activities were extremely costly for GroceryWorks. The statement also hints at the notion that brand building activities may have been a barrier to the success of many pure-play online grocers. In its original market GroceryWorks spent $\$ 4$ to $\$ 5$ million in advertising during the first six months and only attained a 52 percent awareness rate. Safeway on the other hand, had a 97 percent awareness rate in the same market. Through co-branding, GroceryWorks was able to gain a boost in brand awareness that translated into reduced customer acquisition costs. However, there is no evidence that the increase in brand awareness translated into an increase in customer trial (i.e., customer demand).

In an attempt to improve the financial performance of GroceryWorks, once Safeway took a controlling interest in the company it immediately imposed a core delivery fee on each delivery. This was a direct attempt to offset some of the costs associated with the fulfillment and delivery functions. Hence, during the period between April 2000 and March 2001 GroceryWorks concentrated on expanding its operations, reducing costs, increasing demand for the service, and improving its revenue structure. Nonetheless, during this time period the company was still losing money. 
By April 2001, GroceryWorks had decided to abandon the dedicated central fulfillment model and switched to an in-store fulfillment model. This decision provided support for the notion that the brand building activities, that GroceryWorks undertook, did not produce the desired increase in customer trial and repeat patronage. Specifically, had there been a significant increase in customer trial and repeat purchase behavior, it would have then just been a matter of time until a critical mass of customers was reached and the profit structure for the company improved. Because this did not happen, it indicated that the cost structure was still prohibitive resulting in an operating loss for the company.

What may have happened was that initially GroceryWorks over estimated demand. Based on this inflated demand projection, the company reasoned that it could capitalize on the demand level by creating economies of scale. To gain these economies of scale GroceryWorks decided that an automated fulfillment center and an improved routing and delivery function would produce the desired results. This resulted in a business model that required a heavy up-front capital expenditure cost. When the projected level of demand did not materialized the heavy fixed cost component caused the company to operate at a loss. When Safeway took a controlling interest in GroceryWorks, it allowed GroceryWorks to initially continue to operate using the dedicated central fulfillment model. Once Safeway became intricately involved in GroceryWorks' operation, Safeway’s demand projections, along with its understanding of the grocery retail business, indicated that demand for the service was not expected to reach a level high enough to justify the continued use of dedicated central fulfillment centers. As a result, Safeway changed GroceryWorks' business model from a dedicated 
central fulfillment model to an in-store picking model. It seemed that customer demand was a major factor associated with GroceryWorks’ decision to switch its business model.

The decision to abandon the dedicated central fulfillment model was based on the need for GroceryWorks to improve its cost structure. By switching business models, GroceryWorks was able to eliminate the costs linked to the purchase of land and the building and equipping of facilities. The elimination of these cost alone substantially improved the fixed cost structure for GroceryWorks. Nonetheless, the change in fulfillment strategy also had cost involved. For example, with an in-store fulfillment model, GroceryWorks needed to have picking, packing, and delivery personnel at each in-store fulfillment location. This resulted in an increase in the fixed and variable components of the labor cost. Increases to the fixed portion of the labor costs were attributable to the hiring and training of these personnel. This resulted in an increase in the general and administrative expenses. The majority of the labor expense was associated with the variable component and was directly linked to the order volume. As the number of orders increases this cost increased as well. The use of Tesco's low level automation resulted in GroceryWorks receiving some economies of scale, but these were not as significant as those gained via the automated fulfillment center. GroceryWorks also incurred additional costs associated with changing its fulfillment strategy. For each store-based fulfillment center, GroceryWorks had to purchase delivery vehicles. In addition, there were also costs associated with upgrading the website and order-taking software.

The decision by Tesco to take a minority interest in GroceryWork was based on a deal between Tesco and Safeway. At the time Tesco was looking to export it online 
grocery home delivery technology while Safeway was looking to save capital while improving GroceryWorks’ performance. The two companies struck a deal that called for Tesco to receive a minority interest in GroceryWorks in exchange for access to Tesco's in-store picking technology and operating procedures. This was a prudent move on Safeway’s part because Tesco was one of the U.K.'s largest grocery retailers that happened to have, by many accounts, the only successful large scale online grocery delivery operation. Tesco began its grocery home delivery service using the in-store fulfillment model and became profitable using that same model. As a result, it looked as if GroceryWorks had a chance at breaking even and perhaps becoming profitable.

Whether or not GroceryWork became profitable is open to debate. According to insiders close to Safeway's subsidiary Vons, upper management viewed the online channel as a value added service. This suggests that Safeway had changed the strategic focus of its online channel from a profit center to a value added service. If the service happened to make a profit in certain market this was a benefit for the company. It would have been good to know whether or not Tesco's technology and operational procedures actually turned GroceryWorks' situation around. But, without financial information or a public confirmation by GroceryWorks’ management, its profitability remains a mystery. 


\section{Chapter VII}

Case 3 - Tesco

\section{Case 3 Selection Process}

In the case based theory building process, case selection is fundamental in helping to derive functional relationships between the constructs associated with the underlying phenomenon. Cases should be selected in such a manner as to either (1) allow for the prediction of similar results (i.e., a literal replication) or (2) produce contrary results but for predictable reasons (i.e., theoretical replication). The decision to select GroceryWorks as the second case for comparison represented a literal replication comparing a partnership that became a hybrid and a pure-play that became a hybrid. Through the use of public information, the profit structure for GroceryWorks was found to be similar to that of Peapod with neither company achieving financial success.

The selection of the third case extended the analysis theoretically. The third company was selected in order to produced contrary results but for predictable reasons. Towards this end Tesco was selected as the third online grocer for analysis. The decision to select Tesco was to provide a comparison between the hybrid modes. Since both Peapod and GroceryWorks became hybrids, comparing them to Tesco, a hybrid from the start, should provide valuable information concerning why Tesco was so successful while Peapod and GroceryWorks struggled to break even. What is presented next is an analysis of Tesco’s profit structure. 


\section{Case 3 - Analysis}

Initial Profit Structure Components: January 1995 to December 1996

In the U.K., when the idea of home delivery of groceries was introduced, many felt that it could replace 10 to 20 percent of the $£ 80$ billion market. Those in the logistics area did not feel it would replace traditional grocery retail stores but it could function as an added service to consumers. Given that the service was new, no one knew what type of business model would work in the U.K. market. One of the primary participants in this new channel was Tesco, one of the U.K.’s largest grocery retail chains.

In 1995, Tesco started its home shopping services by first delivering wines to customers. Through an agreement with CompuServe, Tesco offered 90 of its privatelabel wines from around the world. Through the CompuServe system, the customer was able to select a wine based on the particular occasion. Under the agreement, CompuServe was responsible for taking the customer's order and then sending it electronically to Tesco. Tesco then sent the order electronically to its warehouse, where the wine was selected, picked up by a courier and delivered to the customer. This process took approximately fourteen days from the time the order was place to the time the consumer took possession of the wine (Tesco, Sainsbury launch online shopping, 1995). Based on this arrangement Tesco was using business model 18 under the hybrid category (see Appendix 3).

At the time, proliferation of the Internet was not that extensive and the consumer direct home shopping channel had not taken root. In addition, the supermarkets did not 
have the logistical capability to deliver a wide range of goods. Further, the majority of shoppers in the U.K. were female while the majority of PC owners were middle class males. Hence, the majority of U.K. grocery shoppers did not possess the means to participate in the online consumer direct channel. Given the current stage of the online channels development in the U.K., it was not profitable for Tesco to offer a wide range of goods for computer home shopping.

Initial Profit Structure Analysis for Tesco: January 1995 to December 1996

Revenue Components

1. Tesco received revenue on the sale of the wine inventory. This was represented by the revenue component 'grocery inventory sales' - RC(12) (see Table 17).

\section{Cost Components}

3. In order to have the wine delivered to the customer, Tesco had to incur order receiving costs and general and administrative costs. This was represented by the front-end cost components 'electronic medium designed in-house' - CC(30), 'general and admin - CC(17), and 'other costs and expenses' - CC(18) (see Table 17). There were no delivery costs since delivery was handled by a third-party logistics provider.

4. The wine that Tesco delivered had to be purchased from the manufacturers and wholesalers. This was represented by the inventory expense component 'grocery inventory purchased via manufacturer and wholesaler’ - CC(23) (see Table 17).

5. In order to have inventory on hand, Tesco incurred inventory handling costs and storage costs. This was represented by the back-end cost component 'storage and handling cost' - CC(31) (see Table 17).

6. In order to compile customer orders, Tesco had to have personnel at the warehouse to pick and pack/assemble the orders. These costs were represented by the back-end cost 
Table 17

Tesco’s Profit Structure Components: January 1995 - December 1996

\section{Sources of Operating Capital \\ Delivery Revenue \\ 1. Core Delivery Fee (RC4) \\ Inventory Sales \\ 1. Grocery Inventory Sales (RC12)}

\section{Front End Costs}

Order Taking Costs

1. Website Related

1a. Design Cost

In-house (CC1)

Third-Party (CC33)

1b. Maintenance Cost

In-house (CC11)

2. Electronic Medium 2a. In-House (CC30)

\section{Customer Relationship Costs}

7. Customer Awareness

7a. Done Alone (CC7)

8. Customer Acquisition Costs

8a. Done Alone (CC8)

\section{Back End Costs}

Capital Expenditures

1. Store Conversion (CC34)

2. Delivery Fleet

2a. Company Owned (CC21)

3. Fleet Maintenance (CC22)

\section{Inventory Expenses}

4. Grocery Inventory Acquisition

Cost

4a. Purchased via

Manuf./Wholesaler (CC23)

5. Storage and Handling Costs

(CC31)

\section{Operational Service Drivers}

9a. Picking Speed (PD5)

9b. Number of Lines Picked

(PD16) ice Drivers

5. Number of Orders Delivered (PD9)

6. Number of Vehicles Used (PD15)

7. Number of Delivery Attempts

8. Delivery Truck Capacity (PD22)

12. Routing and Scheduling Process

(PD17)

Table 17 (Cont'd) 
Tesco’s Profit Structure Components: January 1995 - December 1996

\section{Sources of Operating}

\section{Capital}

\section{Front End Costs}

General And Administrative

10. General and Admin. (CC17)

11. Other Costs and Expenses

(CC18)

\section{Back End Costs}

Fulfillment Expenses

6. Picking Costs $(\mathrm{F}, \mathrm{V})$

6a. Human Capital (CC4)

7. Packing/Assembly Costs (F,V)

7a. Human Capital (CC5)

8. Delivery Costs

6a. Fuel Costs (CC6)

6b. Delivery Personnel Costs (CC17)

\section{Performance Drivers}

Operational Service Drivers

(Cont'd)

9d. Picking Accuracy (PD6)

9e. Assembly Accuracy (PD7) 
components 'picking costs human capital' - CC(4), and packing/assembly costs human capital’ - CC(5) (see Table 17).

\section{Performance Drivers}

7. Tesco's inventory expense was determined by aspects of the customer demand level. Hence there were links between the performance drivers 'number of orders' - $\mathrm{PD}(3)$, 'items per order' - $\mathrm{PD}(13)$ and the back-end cost component 'inventory purchased via manufacturer and wholesaler' - CC(23) (see Figure 51).

8. The impact of picking and packing/assembly costs on total cost was determined by the number of different items in inventory, the speed of the personnel selecting the inventory, and the rate at which the order could be assembled for delivery. These relationships were represented by the links between the performance drivers 'number of lines picked' - $\mathrm{PD}(16)$, 'picking speed' - $\mathrm{PD}(5)$, 'packing speed' - $\mathrm{PD}(21)$ and the back-end cost components 'picking costs human capital' CC(4) and 'packing/assembly cost human capital' - CC(5) (see Figure 51).

In early 1996, Tesco began conducting a home delivery service trial for 150 pensioners in the London borough of Ealing. The trial was conducted in conjunction with social services which had sub-contracted help from Tesco. Participants (customers) in the trial could order from a catalog of 2500 products, by phone or by post, and have them delivered. The idea was to test the viability and economics of the home shopping and delivery channel (Lee 1996a). The trial phase was necessary in order to provide Tesco with information before the company committed itself to a full national roll-out. According to Ken Towle, project leader at the time, if the concept could work with the elderly then it could work with other groups as well (Lee 1996a). Tesco realized that 
Figure 51

Tesco’s Back-End Cost Components and Performance Drivers: January 1995 - December 1996

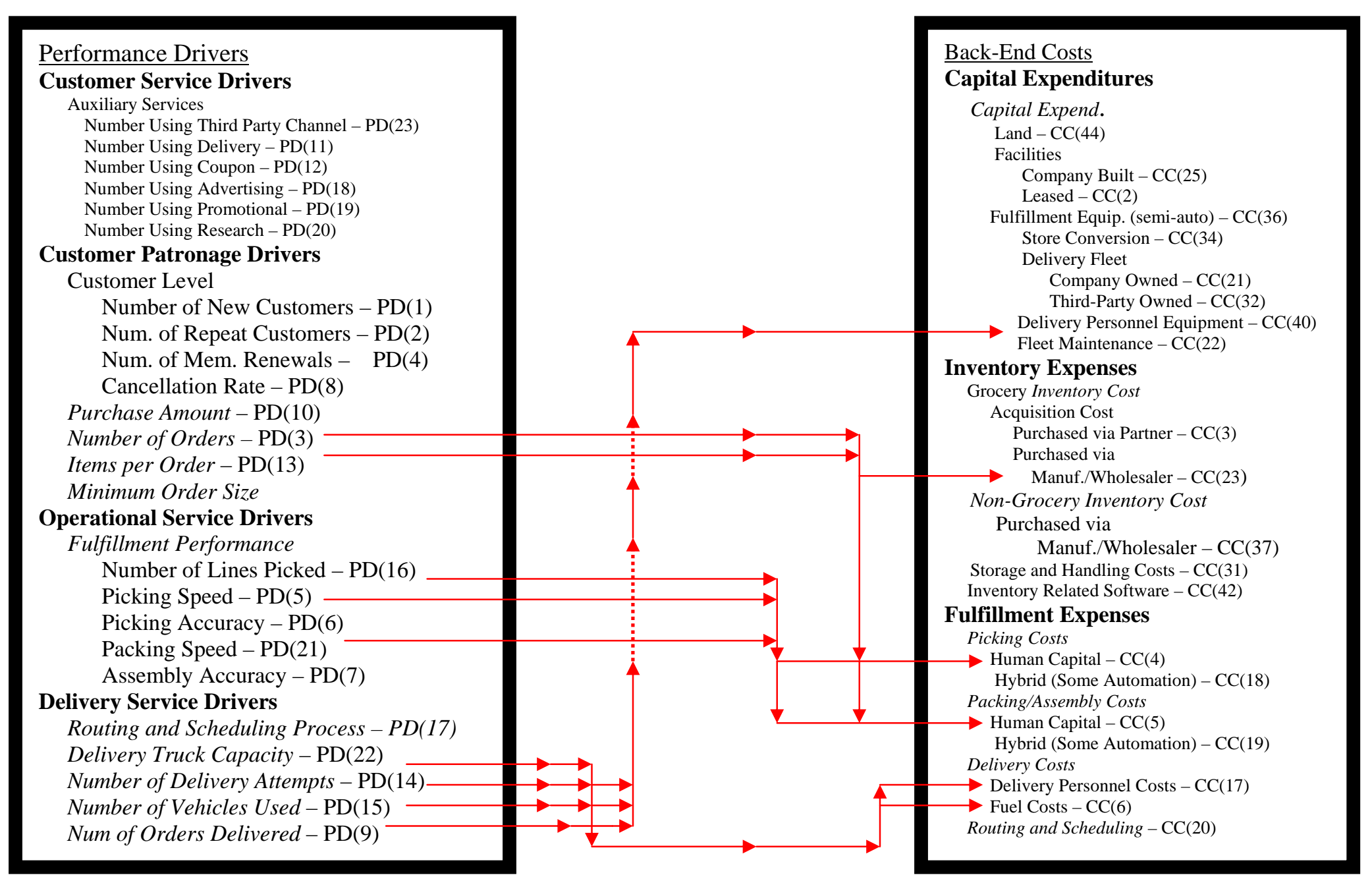


home delivery was going to be part of the retail landscape and the company needed to be part of that landscape. Like other Internet shopping ventures, it was believed that this service would lose money, but the company considered the service important to its longterm strategy.

In terms of delivery infrastructure, there were several distribution services in the U.K. that could deliver regular packaged, chilled, or frozen groceries. At the time Tesco was considering third-party delivery for its service. In relation to the fulfillment function, Tesco began with a store-based fulfillment model, because for a nominal cost the company could convert sections of a current store, or an entire store, into a fulfillment center (Lee 1996a).

With limited success from this initial foray, Tesco cautiously progressed into the online waters by outfitting a single store in Osterley, England. The store was equipped to accept orders by phone, fax, or a crude website. Once the customers completed their order, they could pay for it by credit card. To actually place an order, customers in the test area had to install the software provided by Tesco. According to those who used the trial version software, it was difficult to use because it contained no illustrations of the products and, when searching for a product, the search tool would sometimes bring up completely irrelevant items. Based on Tesco's decision to test the grocery home delivery channel by equipping a single store, the company was operating using business model $6 \mathrm{a}$ under the hybrid category (see Appendix 3). (It is not clear if the company used its own delivery fleet or a third-party delivery service. As a result, it is assumed that Tesco used its own vehicles to make deliveries). 
When it came to developing its own website, Tesco also took it slow. Initially the site did not reflect the image of the store and customer first impressions were generally unfavorable (Field 1996). In August, Tesco enhanced its webpage with help from the BIT Group’s Interactive Development Division. The new webpage incorporated an additional feature called the Tesco Recipe Collection Online which was a collection of recipes and wine ideas from the retailer's monthly in-store magazine. Customers indicated that with the inclusion of the new features, the website was more reflective of the company.

By September Tesco’s home delivery program had expanded to include more residents of Ealing. Sources said the trial was initially being limited to a small number of people in order for the company to develop a level of expertise before considering expansion. The main problem with the service was that after placing an order, it sometimes took several days for it to arrive. In order to promote their new service, Tesco used flyers or leaflets place in the mailboxes of consumers in the service area. This was a rather inexpensive way to promote a new service (O’Connor 1998). For this service Tesco charged a $£ 5$ pounds sterling delivery charge.

\section{Revenue Components}

2. To have their orders delivered to their homes, the customer had to pay $£ 5$ pounds sterling. This was represented by the revenue component 'core delivery fee' - RC(4) (see Table 17).

\section{Cost Components}

9. In order to make delivers to the pensioners, Tesco had to purchase a delivery fleet. This was represented by the backend cost component 'delivery fleet company owned' - CC(21) (see Table 17). 
10. Once Tesco began making deliveries the company incurred additional costs associated with delivery personnel and fuel. These costs were represented by the back-end fulfillment expenses 'delivery personnel costs' - CC(17), and 'fuel costs' - CC(6) (see Table 17).

11. The development of a crude website for order taking represented an additional cost to the company. This was represented by the front-end cost components 'website design in-house' - CC(1), and 'website maintenance in-house' CC(11) (see Table 17).

12. Tesco’s decision to allow BIT Group’s Interactive Development Division to redesign its webpage caused the company to incur an additional cost. This cost was depicted by the front-end cost component 'website design third-party' CC(33). Moreover, in order to keep the website functioning, Tesco also incurred costs associated with website maintenance. This cost was represented by the front-end cost component 'website maintenance in-house' - CC(11) (see Table 17).

13. In order to stimulate demand for the service, Tesco incurred customer relationship costs. These costs were represented by the front-end cost components 'customer awareness done alone' - CC(7), and 'customer acquisition done alone' - CC(8) (see Table 17). (The method used for these activities was inexpensive. Hence there was a cost saving component associated with this expense).

14. By the end of 1996, Tesco was operating its grocery home delivery service out of 2 locations. This required that these stores be upgraded to accommodate the service. This cost was represented by the back-end capital expenditure component 'store conversion' - CC(34) (see Table 17).

15. Further, in order to provide the service, there had to be picking, packing, and delivery personnel at each location. This was represented by the back-end fulfillment expense components 'picking costs human capital' - CC(4), 'packing/assembly costs human capital' - CC(5), 'delivery personnel costs' CC(17), and 'fuel costs' - CC(6) (see Table 17).

16. To store the orders before they were loaded for delivery required Tesco to incur storage and handling costs. This cost 
was represented by the back-end inventory expense component 'storage and handling costs' - CC(31) (see Table 17).

17. As the number of deliveries increased, there was naturally an increase in fleet utilization resulting in repair and maintenance costs. This cost was represented by the back-end capital expenditure cost component 'fleet maintenance' - CC(22) (see Table 17).

18. In order to perform the day to day operations of the online channel Tesco incurred general and administrative costs. This was represented by the front-end general and administrative components 'general and administrative' - CC(17), and 'other costs and expenses’ - CC(18) (see Table 17).

\section{Performance Drivers}

19. The delivery personnel costs and the fuel costs were determined by the number of vehicles used, the number of delivery attempts, and delivery truck capacity. Hence, there were links between the performance drivers 'delivery truck capacity' - PD(22), 'number of delivery attempts' - PD(14), 'number of vehicles used' - PD(15), and the back-end cost components 'delivery personnel costs' - CC(17) and 'fuel costs’ - CC(6) (see Figure 51).

20. Tesco's decision to revamp its website was done to appeal to the customer. Therefore, website design and maintenance expenses were undertaken to improve the customer interface. Thus, one of the websites functions was to stimulate primary and repeat demand for the service. Hence, there were links between the front-end order taking cost components 'website design in-house'- CC(1), 'website design third-party' CC(33), 'website maintenance in-house' - CC(11) and the customer patronage performance drivers 'number of new customers' - PD(1) and 'number of repeat customers' - $\mathrm{PD}(2)$ (see Figure 52).

21. The decision to use customer relationship activities represented an attempt by the company to stimulate demand for their 
Figure 52

Tesco’s Front-End Cost Components and Performance Drivers: January 1995 - December 1996

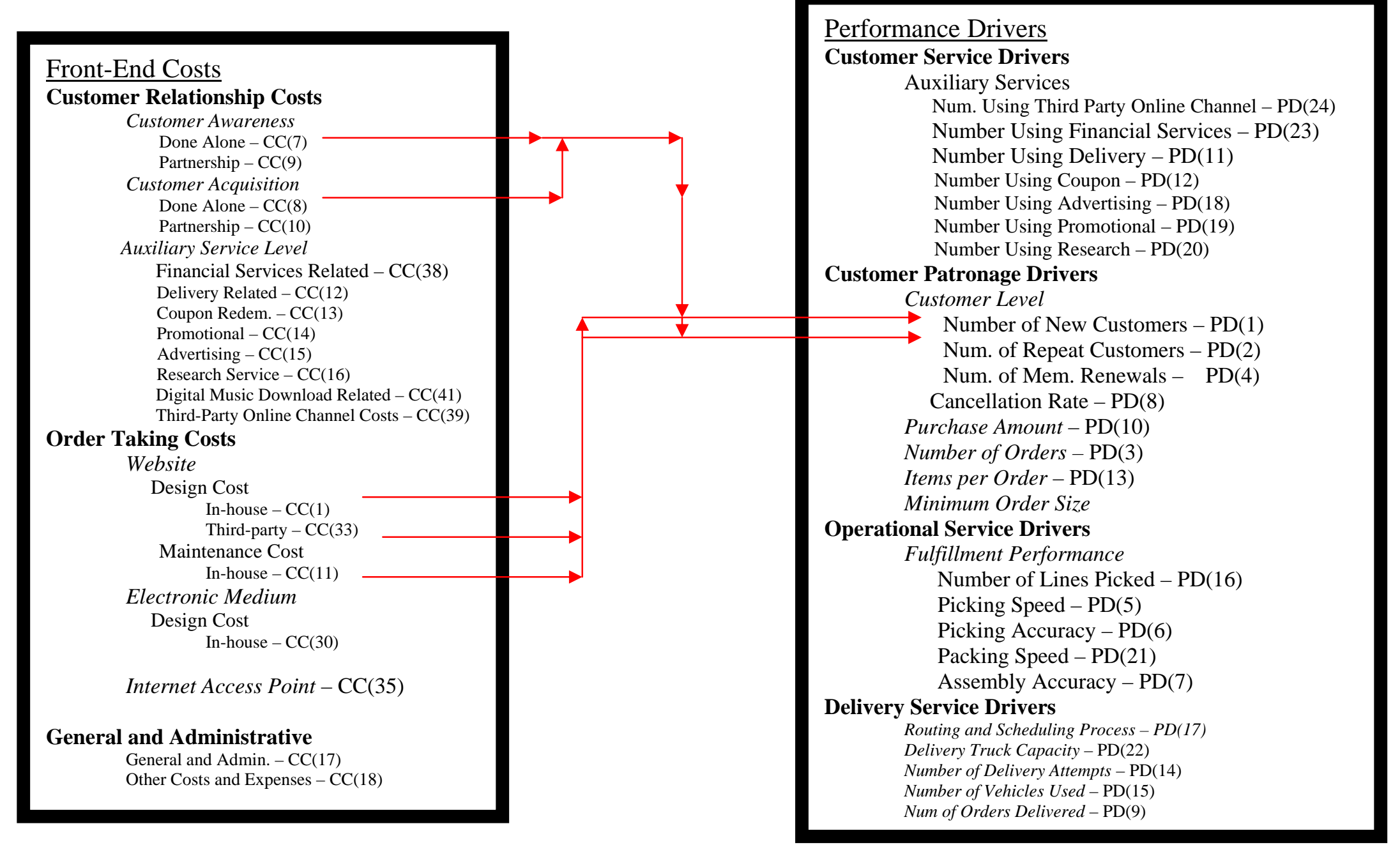


service. Thus, there were links between the front-end costs components ‘customer awareness done alone' - CC(7), 'customer acquisition done alone' - CC(8), and the performance drivers 'number of new customers' - PD(1) and 'number of repeat customers' - PD(2) (see Figure 52).

22. The fleet maintenance cost was driven by the number of orders delivered, the number of vehicles used, and the number of delivery attempts. These relationships were represented by the links between the delivery service performance drivers 'number of delivery attempts' - PD(14), 'number of vehicles used' - PD(15), 'number of orders delivered' - PD(9) and the back-end capital expenditure component 'fleet maintenance' CC(22) (see Figure 51).

23. The revenue from grocery inventory sales was driven by the number of orders, the number of items per order, and the number of product lines picked from. This was represented by the links between the customer patronage performance drivers 'number of orders' - PD(3), 'items per order' - PD(13), the operational performance driver 'number of line picked' $\mathrm{PD}(16)$ and the inventory sales revenue component 'grocery inventory sales' - RC(12) (see Figure 53).

24. The revenue generated by the delivery fees was driven by the number of orders delivered. This was represented by the link between the delivery service performance driver 'number of orders delivered' - PD(19) and the delivery revenue component 'core delivery fees' - RC(4) (see Figure 53).

25. Given that the picking function was performed by humans, one could expect that under certain conditions tedium would set in. As this occurs, one would expect the picking speed to vary which would affect the level of mispicks and thus the accuracy of the customers order. This was represented by the links between the fulfillment performance driver 'picking speed' $\mathrm{PD}(5)$ and the other fulfillment performance drivers 'picking accuracy' - PD(6) and ‘assembly accuracy' - PD(7) (see Figure 54).

26. In terms of customer patronage, the number of new and repeat customers determines the number of orders and the number of items per order. This was represented by the links between the customer patronage performance drivers 'number of new customers' - PD(1), 'number of repeat customers' - PD(2) and 
Figure 53

Tesco’s Performance Drivers and Revenue Components: January 1995 - December 1996

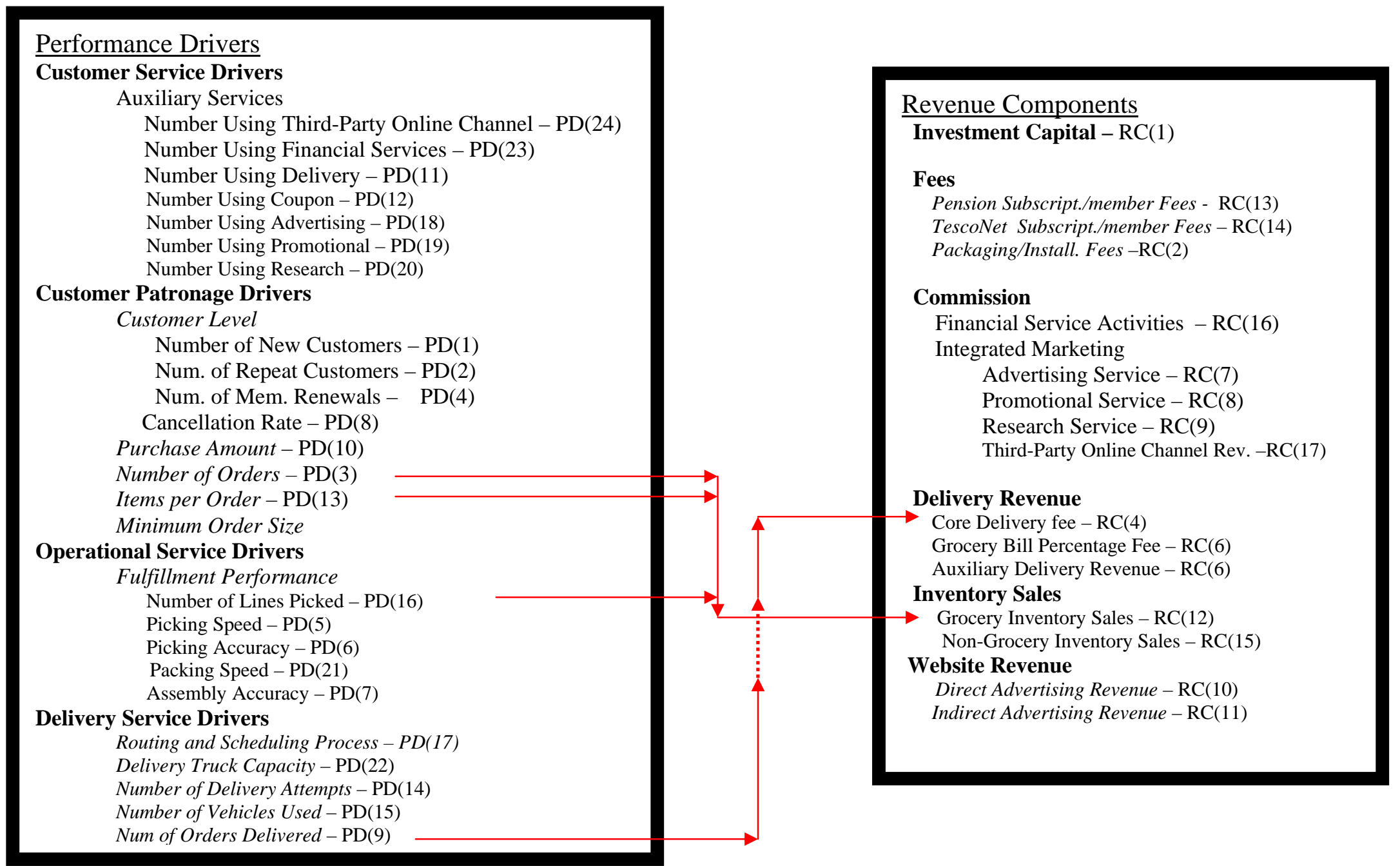


Figure 54

Tesco’s Performance Drivers and Performance Drivers: January 1995 - December 1996

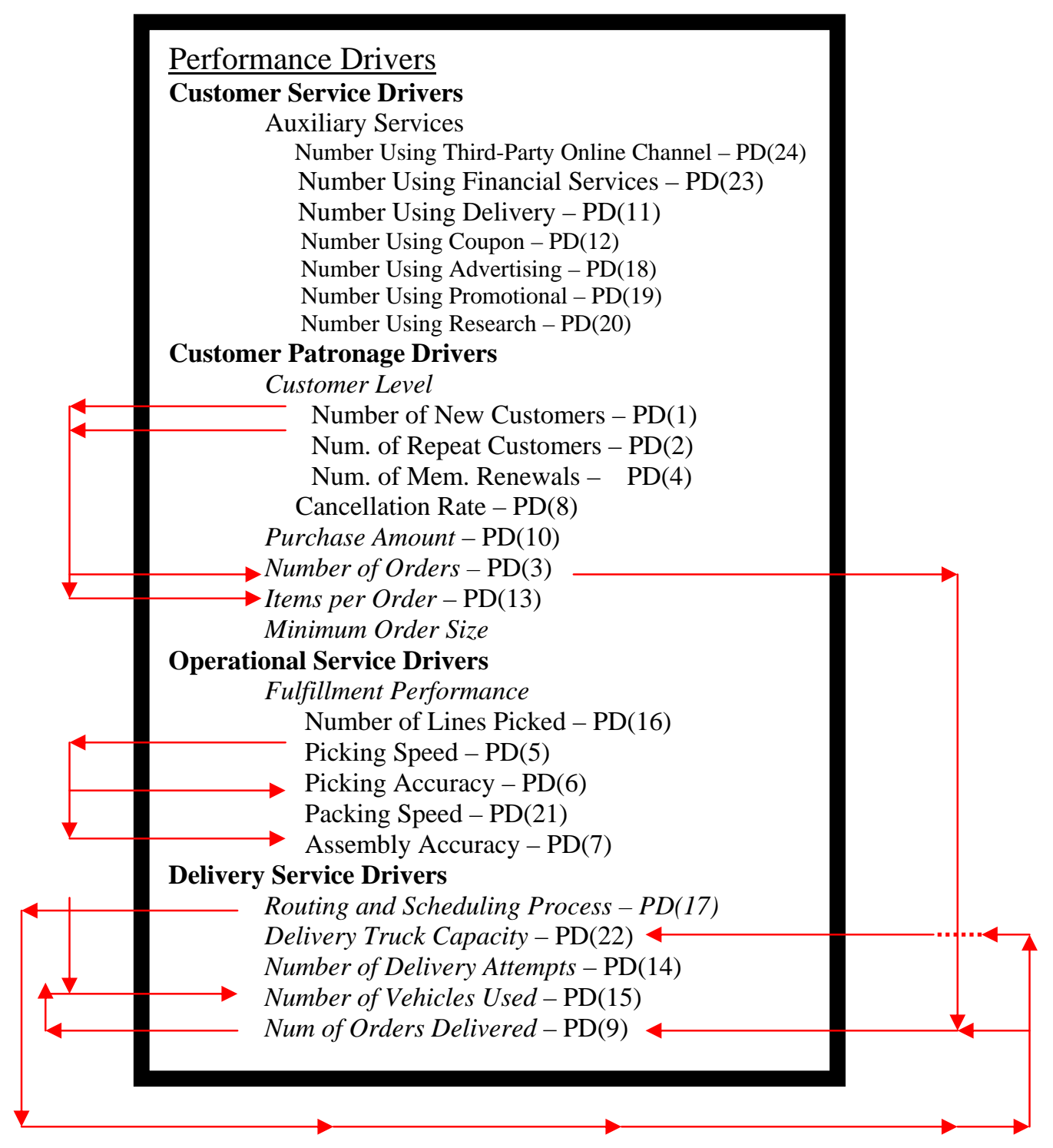


the other customer performance drivers 'number of orders' $\mathrm{PD}(3)$ and 'items per order' - PD(13) (see Figure 54).

27. The number of orders delivered was determined by the number of orders and the routing and scheduling process. This was represented by the links between the customer patronage performance drivers ' number of orders' - PD(3) and 'routing and scheduling process' - PD(17), and delivery service performance driver 'number of orders delivered' - PD(9) (see Figure 54).

28. The number of vehicles used for deliveries was determined by the number of orders needing to be delivered and the routing and scheduling process. This was represented by the link between the delivery service performance driver 'number of orders delivered' - PD(9), 'routing and scheduling process' $\mathrm{PD}(17)$, and the other delivery service performance driver 'number of vehicles used' - PD(15) (see Figure 54).

Profit Structure Summary from January 1995 - December 1996

Tesco’s partnership with CompuServe provided the company with the opportunity to begin developing its order taking capacity. This was evident by the capital the company spent on the website and order taking capabilities (see Table 17). Tesco’s initial website design proved to be sub-standard for its consumers so the company hired BIT Group for assistance in developing the website. Given that Tesco focused on the website from the beginning, it would seem that the customer interface was a critical component. This indicated that Tesco was dedicated to being customer focused in the online channel just as the company was in its BAM store operations. Given the terms of the partnership Tesco served as a content provider for CompuServe.

In addition to the lessons learned in the order taking area, the partnership with CompuServe also provided Tesco with the root requirements necessary to run a consumer 
direct channel from a fulfillment perspective. This was evident by the rudimentary costs the company incurred while filling wine orders through the CompuServe partnership. The costs associated with picking and packaging the wines provided the company with valuable information concerning the cost structure of the fulfillment function.

To develop its delivery capabilities, Tesco initially chose a third-party logistics provider to deliver its wines to customers. However, once Tesco began testing the online channel, through the Ealing pensioner test, the company began accumulating information necessary to develop its own delivery capabilities. Once Tesco expanded its operation to the Osterley, England location, the company was plunged into the delivery function.

Acquiring grocery inventory to sell online was no problem for Tesco because in the stores that were operating the online channel, the inventory was beginning picked off the retail shelf. However, providing space for customer orders within the store resulted in storage and handing costs. To provide these staging areas Tesco needed to convert areas in the 22 stores which represented a capital expenditure. The decision to begin home delivery also resulted in costs associated with purchasing the fleet and providing maintenance for it (see Table 17).

The decision by Tesco to use flyers and leaflets to establish brand awareness, represented a low intensity brand awareness and customer acquisition tactics (see Table 17). Since Tesco already had high name recognition within the U.K., utilizing this low intensity approach saved the company money on advertising. This indicated that Tesco was relying on its brand equity to promote the new service. Lastly, the general and administrative support necessary to coordinate and run the online operation resulted in 
additional costs for Tesco. Each time that Tesco's online network expanded the general and administrative costs increased as well.

In the initial stages, Tesco's online revenue stream was restricted to core delivery revenue and grocery inventory sales. As a result, the cost structure was greater than the revenue structure which resulted in an operating loss for the company. However, at this stage, Tesco still viewed the online channel as a value added component of the company's current service and not as a profit center.

During the formative years there were other mediating/moderating variables to take into consideration that may have affected Tesco's profit structure. These factors were broadly grouped into company related factors and market structure related factors. The company related factors include scalability, method of delivery, company rate of expansion, automation level, and employee/management commitment (see Table 18). Scalability relates to the extent to which the capacity for picking, packing, and assembling customer orders could be increased in a cost effective manner. For the purpose of this study, the different methods for picking, packing, and assembly were assessed based on the extent of their scalability ranging from low to high. Tesco's initial model was a hybrid one that relied on an in-store fulfillment process. This represented low level scalability but also represented a low cost approach to developing an online channel.

Another factor that needed to be considered was the method of delivery. How Tesco chose to deliver the customer's order had a significant bearing on the company's cost structure. In the company's formative years, attended home delivery was the chosen 
Table 18

Other Mediating/Moderating Factors for Tesco: January 1995 - December 1996

January 1995 -

December 1996

\section{Company Related Factors}

Scalability (Picking Location)

High

Medium Dedicated

Warehouse

Large Dedicated Warehouse

Moderate

Wareroom (Hybrid)

Small Dedicated Warehouse

Low

In-Store

$\mathrm{X}$

Method of Delivery

Store Pickup

Local Pickup

Home Delivery

X

Company Rate of Expansion

Slow

X

Moderate

Fast

Automation Level

High

Moderate

Low

X

Employee/Management

Commitment

High

X

Moderate

Low 
Table 18 (Cont'd)

Other Mediating/Moderating Factors for Tesco: January 1995 - December 1996

January 1995 -

December 1996

Market Structure Factors

Connectivity

Internet Structure

High

Moderate

Low

$\mathrm{X}$

Internet Penetration

High

Moderate

Low

X

Internet Access

High

Moderate

Low

X

Cost of Internet Service

High

Moderate

X

Low

Population Structure

Population Size

Large

Population Density

High

Geographical Location

Continental

North America

South America

Europe

X

Asia 
Table 18 (Cont'd)

Other Mediating/Moderating Factors for Tesco: January 1995 - December 1996

January 1995 -

December 1996

\section{Country}

United States

United Kingdom

$\mathrm{X}$

Japan

County/Parish

Urban

$\mathrm{X}$

Suburban

Rural

method for delivery. In relation to the cost structure, this was one of the most costly methods for delivering groceries because it required the company to incur most, if not all, the cost associated with transporting the groceries to the customer's home. It did, however, result in high customer satisfaction.

The company's expansion rate was another factor to consider when analyzing the company's profit structure. In general, the faster the rate of expansion, the greater the impact on the company cost structure. This resulted from the higher costs associated with acquiring facilities, inventory, delivery means, and the human capital necessary to conduct operations in multiple locations. Since Tesco used an in-store fulfillment function, expansion resulted in increases in the equipment, inventory, and labor costs. Some of these operational expenses had significant fixed and variable components. The fixed expenses emanated from the development of an infrastructure and the hiring and training of fulfillment and delivery personnel. The variable expenses originated from the operational activities associated with the delivery service. Hence, based on the variable 
component of this model, as the number of customers increased the costs associated with servicing those customer also increased. As a result, it may prove difficult to break even. This situation would then be repeated for each market that the company entered. Thus, a fast growth rate would compound the problem resulting in a continually changing (i.e., higher) breakeven point which would result in a longer time horizon for the company to make a profit. During this initial time period, Tesco operated out of a limited number of stores which meant that it had a slow rate of expansion. However, the company's stated expansion goals indicated that it was following a moderate to fast rate of expansion (see Table 18).

When Tesco decided to enter the consumer direct channel it relied on low level automation for performing the fulfillment functions. This resulted in an inflated labor cost component. Tesco felt that these costs were justified when compared to the costs of building and equipping a dedicated fulfillment center. Employee and management commitment was also important to Tesco's profitability and survival. Initially, Tesco's management and employees seemed dedicated to seeing the online channel survive and prosper. There did not seem to be any conflicting motives at work that may have caused management to undermine the online initiative so the management and employee commitment levels were high (see Table 18).

The market structure factors included the level of connectivity, population structure, and geographical location. Connectivity was concerned with the ability of the online grocer's customers to access the Internet in order to place orders and communicate with the company. There were four subfactors associated with connectivity which include Internet structure, Internet penetration, Internet access, and cost of Internet 
service. Internet structure relates to the Internet infrastructure present in an area, including the phone lines, fiber optics, and land lines (i.e., DSL). These sub-factors are assessed as low, medium, and high (see Table 18).

In 1995, the U.K. Internet infrastructure was relatively low. There were few persons with computers, and even fewer with Internet access. This was indicative of a low Internet penetration rate. Internet services, at the time, were restricted to a few companies so the Internet access level was also low. For customers in the U.K. market, Internet connections were expensive. This may have served as a barrier to Internet adoption rates. Nonetheless, the cost of Internet service was high in the U.K. market (see Table 18).

Population structure refers to the size and density of an area in terms of the population. This factor was directly related to the cost structure because the more dispersed the population the greater the costs associated with delivering groceries to consumers. Assessing the population structure brings the geographical location into the discussion. The geographical location was assessed on several levels from the continent to the county/parish that the company operated in. Together the population structure and the geographical location interacted to determine the number of households within a specific market in general, and the number within the company's service area in particular. In the U.K., the population size is large given the land mass. In the urban areas the population density is higher than that in the U.S. urban centers which represented an advantage for U.K. online grocers. In reference to the geographical location, Tesco was located in Europe, and specifically in the U.K. The company's grocery home delivery service initially started in the urban areas (see Table 18). 


\section{Summary}

Tesco’s partnership with CompuServe represented the company’s initial forge into the consumer direct channel. The partnership called for Tesco to provide private label wines to CompuServe customers. In this capacity Tesco was serving as a content provider for another retailer. This gave Tesco some basic experience in the order taking area and allowed the company to glimpse the labor requirements necessary to fulfill customer orders. The main problem with the service was that it was relatively slow, taking on average fourteen days for the customers to receive their order. However, given the limited level of Internet penetration, this was a forward looking move by Tesco.

Tesco’s first real push into the consumer direct channel came in the form of a partnership between Tesco and the social service division. The initial trial was limited to pensioners in the Ealing borough of London. The test allowed pensioners to order items by phone or by mail from a catalog featuring 2500 products. Most of the initial participants were older individuals, some of whom had trouble getting to a physical store. For Tesco and the social services agency, these pensioners were a good test market.

With limited success in the initial test, Tesco decided to expand the test to a second store located in Osterley, England. To conduct these operations, Tesco converted these stores to receive orders by phone, fax, or a crude website. This represented a low cost, low risk strategy for entering the online channel, demonstrating that Tesco was in a cautionary mode when it came to getting involved in the online channel. Initially, Tesco viewed the online channel as a value added service to its customers as opposed to a profit center. 
From the beginning, ordering and delivery was a problem. The ordering software was error prone, sometimes queuing up the wrong product after a product query. In terms of delivery, the fourteen day time windows seemed excessive. In order for the service to become acceptable to the general public Tesco needed to make improvements to these areas. To improve its order taking function, Tesco looked to the BIT Group for assistance. The change was prompted by customer feedback indicating that Tesco was customer focused where the online component was concerned. What is interesting to note is that Tesco charged a delivery fee from the beginning. This indicated that, with the limited success it was having, Tesco was viewing the online channel as a value added component of its service.

By the end of 1996, Tesco had expanded its service to include a network of two stores. This required upgrading these stores to receive order information, developing instore picking, packing, and assembly procedures, and developing delivery protocols. It was during this period that Tesco was developing its business model. Initially Tesco used business model 13a under the hybrid category (see Appendix 3). As the company expanded its online channel, costs began to increase giving Tesco an understanding of the requirements necessary to expand its model.

Tesco’s Profit Structure from January 1997 to December 1998

1997

In February, Tesco increased the service that it offered through Tesco Direct by offering a stand alone catalogue aimed at new mothers. The catalog was designed to 
complement the BabyClub loyalty program launched in January. The program was designed to guide expectant women through the various stages of pregnancy and the first year of the new born's life, while at the same time increasing the soon-to-be mothers' awareness of Tesco's range of baby products. Included in the issues was information dedicated to precise stages of pregnancy detailing ideas for food, drink, skincare, toiletries, baby bath products and even toys. All these products were stocked by Tesco and those customers who were part of Tesco's loyalty program were awarded moneysaving vouchers for purchases.

Also during this period, Tesco entered into talks with the Bank Group, comprised of The Royal Bank of Scotland (RBS), Direct Line, and Scottish Widows to develop and launch a financial venture. Tesco was already offering its customers a high-interest deposit account card, known as the ClubCard Plus, through its financial partner NatWest. This card was designed as a budgeting account to help customers identify what they were spending on food. It also provided them with the opportunity to put money in an interestearning account (Retail Banker International, 1997). Tesco’s proposed venture was more ambitious and looked to offer a wider range of financial products to its customers from credit cards to insurance.

Based on the scope of Tesco's proposal, NatWest could not provide Tesco with these services because it conflicted with NatWest's own core business. At the time NatWest had about 20 percent of the U.K. personal banking market whereas the Royal Bank of Scotland had around 5 percent. If successful, Tesco's plan would push the company past its supermarket rivals in terms of providing financial services. Tesco's Internal research revealed that customers would be happy to own and use a credit card 
from the supermarket - particularly if they could get ClubCard (i.e., loyalty) points based on how much they spent on their card. Based on this research, Tesco planned to offer a credit card as the first financial product. However, for each new product under consideration, Tesco planned to carry out customer research to ensure that it could offer the service to its customers more economically than other institutions. The joint venture was equally owned by Tesco and RBS. Tesco brought its 9 million loyalty card customer base to the venture while RBS brought its vast knowledge of financial services retailing. Tesco explicitly noted that it would not sell its ClubCard information to RBS, but would market products and services designed specifically for these customers. Tesco had a cost advantage here because the company had lower customer acquisition cost in comparison to the banks. As a result, a partnership between Tesco and RBS had the potential to produce an increased return on equity for both companies. This venture put Tesco in a position to launch a range of financial products designed to meet its customers' needs. This again demonstrated Tesco’s focus on customer service.

In April, Tesco expanded its online service in the U.K. to Hammersmith, Sutton, Romford, Leeds, and the Lea Valley. The decision to increase the service area was based on the success of the first wave of stores outfitted for online grocery home delivery. These were so successful that it put the company's website in the top ten most popular websites in the U.K. (Gold 1997). When Tesco first launched its online service, users visited the site just to look, but after a while they were visiting the site to shop. According to Jon Higgins, information technology (IT) manager at Tesco, 80 percent of those who used the service returned to use it again (Gold 1997). 
The Tesco web service was based on clusters of Dell servers. The servers were powerful enough to allow the company to add additional stores without reducing overall performance. The technology used to manage the online service was based on Dell PowerEdge 2100 servers, running Windows NT, and the Microsoft Merchant server application. The offline portion of Tesco's service was managed on a Dell PowerEdge server running SQL Servers and Microsoft Back Office (Gold 1997). Customers could interact with the system in two ways: online or offline. The offline method proved to be the most popular due to the high cost associated with using Internet services in the U.K. (Gold 1997). Customers could use the software to prepare any number of shopping lists on their PC and then simply send their selected lists, or items, to Tesco over the Internet. Customers then had the option of paying for their groceries on account or by credit card via a secure transaction over the Internet (Gold 1997). In order to handle the site traffic, Tesco turned to BTnet’s Direct Plus to provide a reliable system capable of handling multiple customer orders efficiently. The system provided the company with a high speed reliable permanent link capable of handling large volumes of Internet traffic.

By September, online sales were so successful that Tesco began planning a national rollout. This was evident by the decision to extend the grocery home delivery service to twelve additional stores. This move demonstrated that Tesco felt it could make money from its home delivery services. According to a company insider, Tesco was already showing a profit with the limited trial it was conducting (Lee 1997a). During the rollout phase, one of Tesco's primary concerns was how to improve the picking function. According to Ian O'Reilly, Tesco's IT director, "One of the key drivers of home shopping in terms of profitability is pick-up productivity. One of the ways we can get better pick- 
up productivity is through simple, semi-automated picking. Tesco's goal was to allow customers to submit their orders over the Internet and have that order go untouched by human hands all the way down to the picking trolley," (Paton 1997). Further, according to property services director Mike Raycraft, Tesco Direct could relocate out of individual stores to a stand alone site (Paton 1997). This demonstrates that Tesco was customer focused and it was seriously considering switching to a dedicated fulfillment strategy.

Profit Structure Analysis from January 1997 to December 1998

Revenue Components

29. Tesco's decision to offer its customers financial services represented an additional revenue source for the company. This was represented by the commission revenue component 'financial services activities' - RC(16) (see Table 19).

30. Tesco continued to receive revenue from its core delivery fee and grocery inventory sales. This was represented by the revenue components 'core delivery fee'- RC(4), and 'grocery inventory sales' - RC(12) (see Table 19).

\section{Cost Components}

31. The decision by Tesco to offer a catalog to new and expectant mothers represents a customer awareness cost for the company. Allowing those who were members of Tesco's loyalty program to receive vouchers for products purchased represented a customer acquisition cost for the company. These relationships were represented by the 'customer awareness done alone' CC(7), and 'customer acquisition done alone' - CC(8) (see Table 19).

32. Tesco's decision to offer its customers financial services represented an additional cost for the company. This cost was represented by the front-end auxiliary service cost component 'financial related services' - CC(38) (see Table 19). 
Table 19

Tesco’s Profit Structure Components: January 1997 - December 1998

\begin{tabular}{l} 
Sources of Operating Capital \\
\hline Fees \\
3. Pension Subscription/Membership \\
Fees (RC13) \\
4. TescoNet \\
Subscription/Membership Fees \\
(RC14) \\
5. Packaging/Installation Fees (RC2) \\
Commission \\
2. Financial Service Activities \\
(RC16)
\end{tabular}

\section{Delivery Revenue}

1. Core Delivery Fee (RC4)

\section{Inventory Sales}

1. Grocery Inventory Sales (RC12)

6. Non-Grocery Inventory Sales (RC15)

\section{Back End Costs} Order Taking Costs

1. Website Related

1a. Design Cost

$$
\begin{aligned}
& \text { In-house (CC1) } \\
& \text { Third-Party (CC33) }
\end{aligned}
$$

1b. Maintenance Cost

In-house (CC11)

\section{Electronic Medium Cost}

$$
\begin{aligned}
& \text { 2a. In-House (CC30) } \\
& \text { 3. Internet Access Point } \\
& \text { (CC35) }
\end{aligned}
$$

\section{Customer Relationship Costs}

7. Customer Awareness

7a. Done Alone (CC7)

\section{Capital Expenditures}

9. Fulfillment Equipment (semi-

automatic) (CC36)

1. Store Conversion (CC34)

2. Delivery Fleet

2a. Company Owned (CC21)

3. Fleet Maintenance (CC22)

\section{Inventory Expenses}

4. Grocery Inventory Acquisition

Cost

4a. Purchased via

Manuf./Wholesaler (CC23)

10. Non-Grocery Inventory

Acquisition Cost

10a. Purchased via

Manuf./Wholesaler (CC37)

5. Storage and Handling Costs (CC31)

11. Inventory Related Software (CC42)
Performance Drivers

Customer Service Drivers

11b. Number Using Financial Services (PD23)

\section{Customer Patronage Drivers}

1. Number of Orders (PD3)

2. Item per Order (PD13)

3. Customer Level

3a. Number of Repeat Customers (PD2)

3b. Number of New Customers

(PD1)

\section{Delivery Service Drivers}

5. Number of Orders Delivered (PD9)

6. Number of Vehicles Used (PD15)

7. Number of Delivery Attempts

(PD14)

8. Delivery Truck Capacity (PD22)

12. Routing and Scheduling Process

(PD17) 
Table 19 (Cont'd)

Tesco’s Profit Structure Components: January 1997 - December 1998

\section{Sources of Operating} Capital

\section{Front End Costs}

8. Customer Acquisition Costs

8a. Done Alone (CC8)

12a. Financial Services Related (CC38)

\section{General And Administrative}

10. General and Admin. (CC17)

11. Other Costs and Expenses (CC18)

\section{Back End Costs}

Fulfillment Expenses

6. Picking Costs (F,V)
6a. Human Capital (CC4)
6b. Hybrid (Some Automation)

(CC18)

7. Packing/Assembly Costs (F,V)

7a. Human Capital (CC5)

7b. Hybrid (Some Automation) (CC19)

8. Delivery Costs

6a. Fuel Costs (CC6)

6b. Delivery Personnel Costs

(CC17)

\section{Performance Drivers}

\section{Operational Service Drivers}

9a. Picking Speed (PD5)

9b. Number of Lines Picked (PD16)

9d. Picking Accuracy (PD6)

9e. Assembly Accuracy (PD7) 
33. The decision by Tesco to expand its service to five new markets and twelve new stores resulted in Tesco incurring additional cost associated with capital expenditures, inventory expenses, fulfillment expenses, and general and administrative costs. The capital expenditure costs were represented by the back-end cost component 'store conversion' - CC(34), 'delivery fleet company owned' - CC(21), and 'fleet maintenance' - CC(22). The inventory related costs were represent by the inventory expense components 'grocery inventory purchased via manuf./wholesaler' - CC(23), and 'storage and handling' - CC(31). The fulfillment related costs were represented by the back-end fulfillment expense components 'picking costs human capital' - CC(4), 'packing/assembly costs human capital' - CC(5), 'delivery personnel costs' - CC(17), and 'fuel costs' - CC(6). The increase in costs associated with general and administrative functions were represented by the front-end cost components 'general and administrative' - CC(17) and 'other costs and expenses’ - CC(18) (see Table 19).

34. The purchase and installation of the servers and software that Tesco used to power its website represented additional costs for the company. The purchase of the servers and software was represented by the front-end cost component 'website design third-party' - CC(33). The costs associated with website development and maintenance were represented by the links between front-end cost components 'website design in-house' - CC(1), and 'website maintenance in-house' - CC(11) (see Table 19).

35. In order for Tesco's website to serve as a portal to the Internet, the company had to rent a high-speed permanent line from BTnet. This cost was represented by the front-end cost component 'Internet access point' - CC(35) (see Table 19).

36. As the number of deliveries increased, Tesco incurred additional fuel costs. This was represented by the back-end cost component 'fuel cost' - CC(6) (see Table 19).

37. As the number of deliveries increased so did the fleet maintenance costs. This was represented by the back-end capital cost component 'fleet maintenance' - CC(22) (see Table 19). 


\section{Performance Drivers}

38. The catalog was targeted to new and expecting mothers to increase the customer patronage level thus increasing the number of orders and possibly the purchase amount. These relationships were represented by the links between the frontend cost components 'customer awareness done alone' CC(7), and 'customer acquisition done alone' - CC(8), and the performance drivers 'number of new customers' - PD(1), and 'number of repeat customers' - PD(2) (see Figure 55).

39. The costs spent to develop the financial services area was directly related to the number of customers using the service. This was represented by the link between the front-end auxiliary service cost component 'financial services related' CC(38) and the customer service performance driver 'number using financial services' - PD(23) (see Figure 55).

40. Given that the picking and assembly functions were handled by employees, these employees were susceptible to fatigue and tedium. As a result, their picking speed will fluctuate. As the picking speed fluctuated, it was reasonable to assume that picking accuracy and assembly accuracy would also fluctuate. Hence, the performance driver 'picking speed' -PD(5) has an impact of the performance drivers 'picking accuracy' - PD(6) and ‘assembly accuracy’ - PD(7) (see Figure 56).

41. The number of orders that Tesco received was based on the number of new customers trying the service and the number of repeat customers using the service. As the number of new and repeat customers increased, the number of orders increased. This relationship was represented by the links between the performance drivers 'number of new customers' - PD(1), number of repeat customers - $\mathrm{PD}(2)$ and the performance drivers 'number of orders' - PD(3) and 'items per order' PD(13) (see Figure 56).

42. Given the number of deliveries that Tesco was making, the fleet maintenance costs increased. This was represented by the links between the delivery service performance driver 'number of delivery attempts' - PD(14), 'number of vehicles used' $\mathrm{PD}(15)$, 'number of orders delivered' - PD(9), and the backend capital expenditure cost 'fleet maintenance' - CC(22) (see Figure 57). 
Figure 55

Tesco’s Front-End Cost Components and Performance Drivers: January 1997 - December 1998

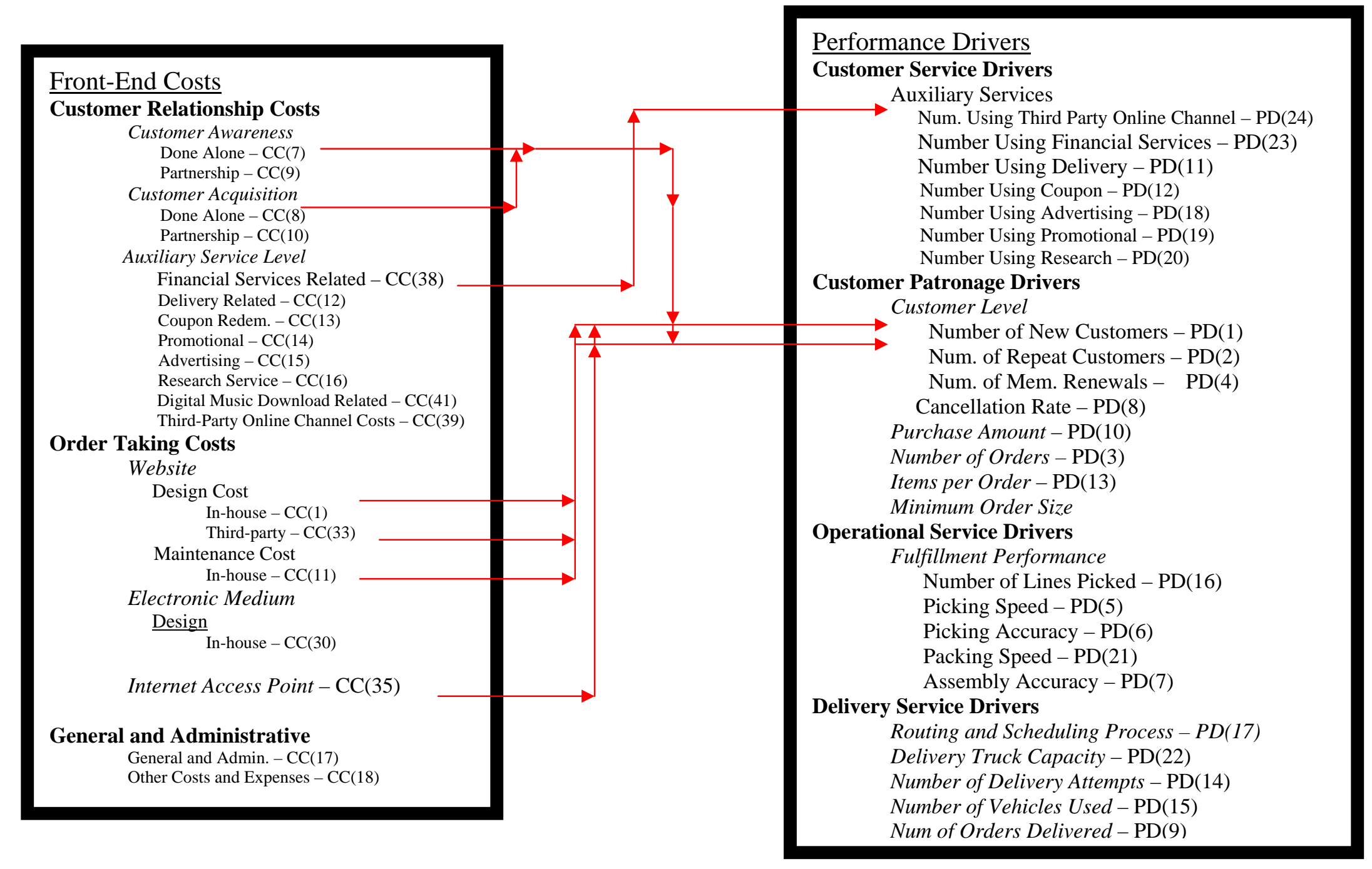


Figure 56

Tesco’s Performance Drivers and Performance Drivers: January 1997 - December 1998

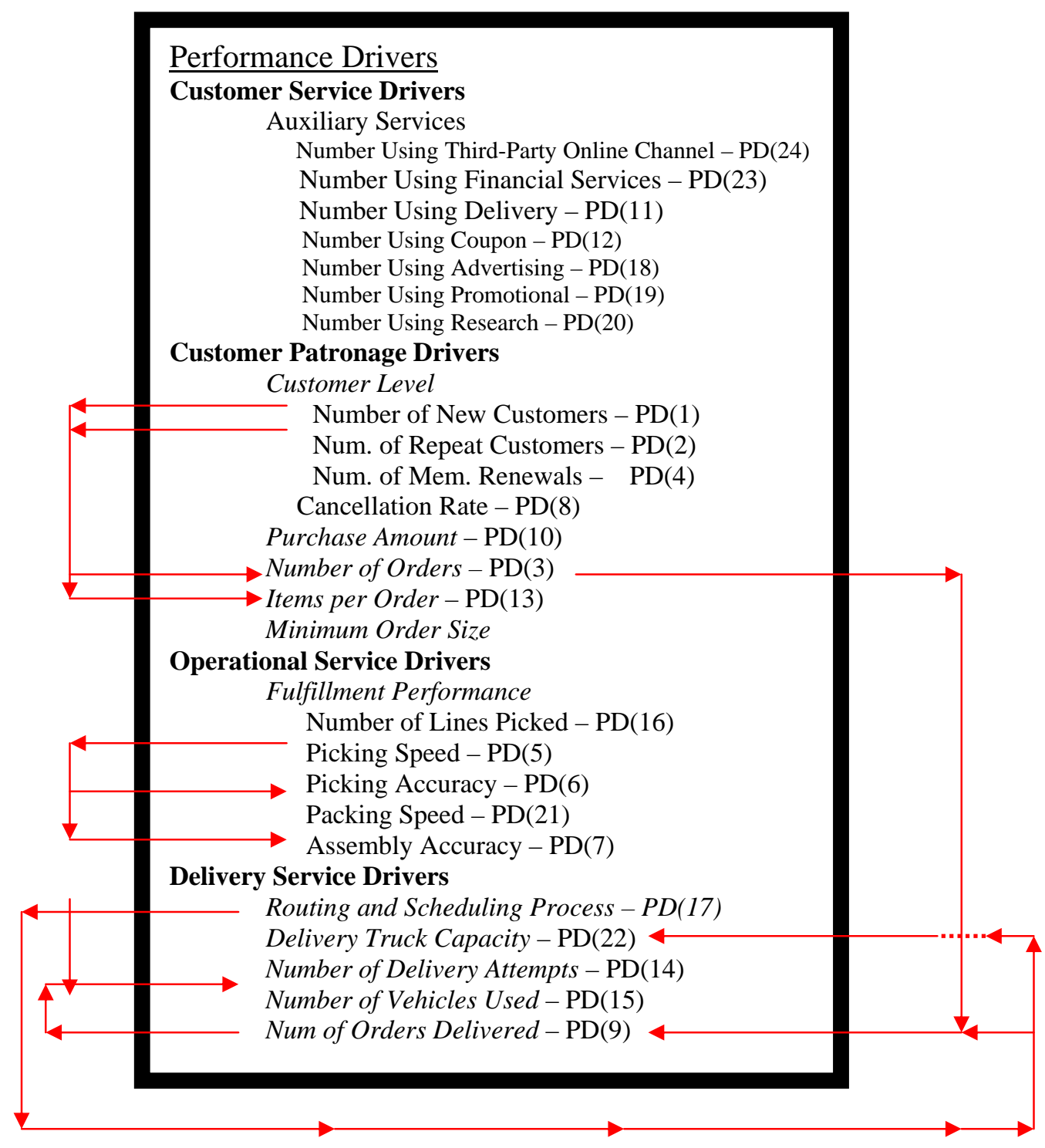


Figure 57

Tesco’s Back-End Cost Components and Performance Drivers: January 1997 - December 1998

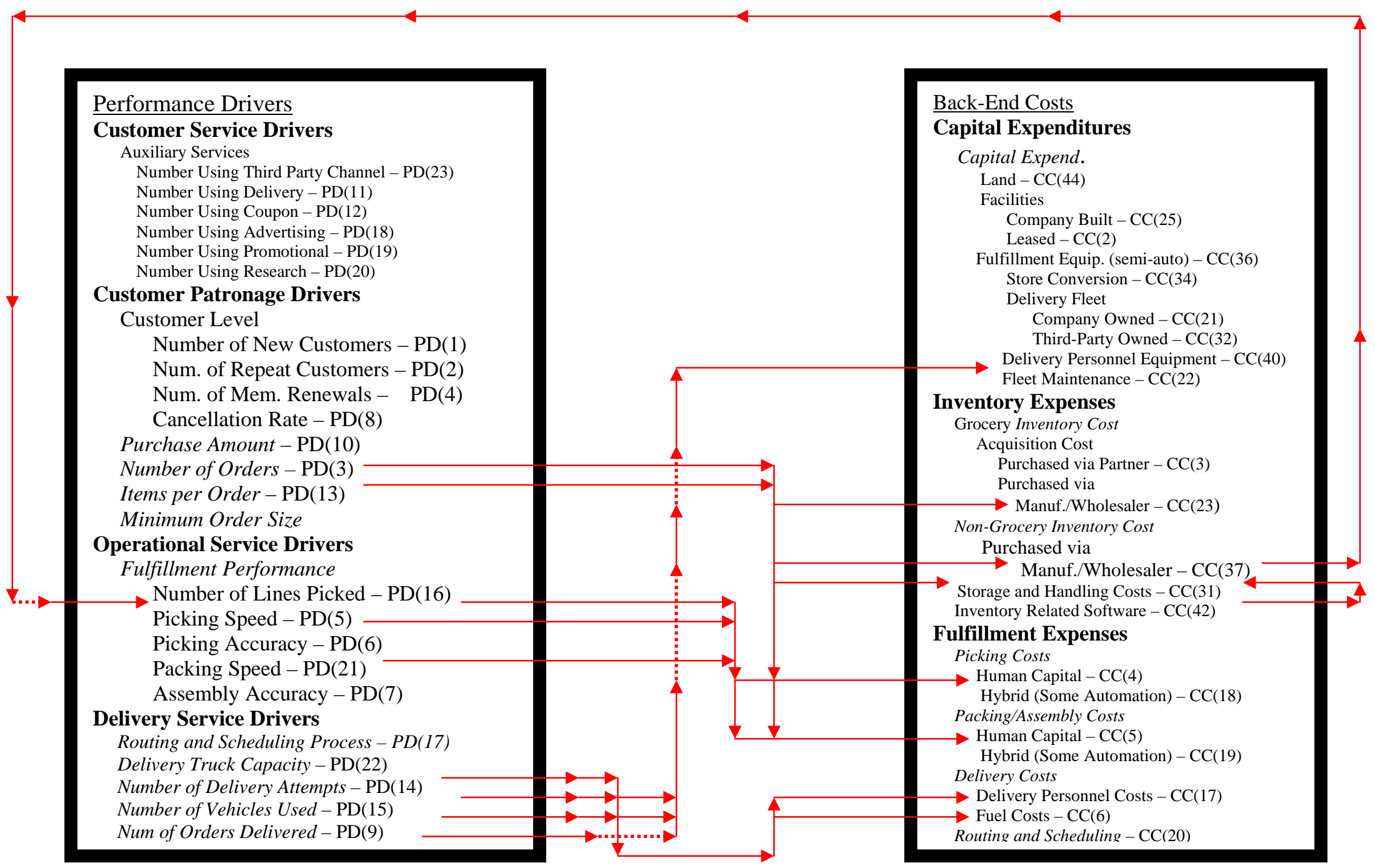


According to Fletcher Research's U.K. Internet Survey, many of Britain's largest companies were not using the Internet effectively. Only 35\% of sites surveyed generated revenue by selling product or carrying ads while 35\% were simply online ads with no opportunity to buy. Tesco's site was different in that it allowed customers, in certain areas, to order groceries over the Internet. However, the site was rather simplistic in appearance and restrictive in use because only those using Microsoft's Internet Explorer browser could view the site. Thus, Tesco’s use of the Internet was more proactive making the company's website more sophisticated than rival grocery retailers.

During this same period, Tesco was considering moving from a store base picking method to a warehouse fulfillment method. The main concern was the cost associated with constructing the facility. Although the company was considering this option, it was still very focused on getting the delivery function straight. In fact, Paul Arnold, a consultant for Tesco, noted that getting the order right, was more important than “...whether there is a flashy front-end ordering system” (O’Connor 1998). Arnold pointed out that he expected technology to be extremely important in Tesco's operation especially in the use of electronic pick lists and in-store radio-frequency technology.

During this period Tesco expanded its store offerings to include non-food items. In the process the company updated 50 stores to carry the non-food items which, in some cases, could take up half a store. The bulk of the non-food merchandise was in the area of adult clothing, children's and baby products, healthcare and home entertainment.

In June, Tesco launched a flexible personal pension plan in a joint venture with Scottish Widows. The plan was initially offered in 20 stores but was to be expanded 
nationally at a later date. It was designed as a low cost product to attract people who had not made any provisions for their retirement. From Tesco’s point of view, this was a way of demonstrating its long term commitment to its customers. The cost of the plan was \$30 per month and allowed for telephone advice on pensions planning, payment protection, a money back guarantee and 1,000 Tesco ClubCard points with each plan (Precision Marketing 1998).

In July, Tesco made the decision to become an Internet Service Provider (ISP). This allowed Tesco to provide its customers with a less expensive alternative to Internet access and to position itself for the future. It had the added benefit of enabling those customers, wishing to use the online shopping service, to do so at a reduced cost. The service, TescoNet, was priced at 9 pounds a month and could be purchased from a local store. The ISP initiative was being touted as a value added service to its customers but given the price that Tesco was charging, it initially made money because it was priced as one of the cheapest ISPs in the U.K. (Binnur 1998). Again this demonstrated Tesco’s commitment to customer service (Network Briefing 1998). To activate the service, customers had to purchase the CD-ROM containing the TescoNet software for 50 pounds which was converted into ClubCard points. The user inserted the CD-ROM into their computer, and loaded the software on to their PCs (Binnur 1998). They then provided their credit card information and their ClubCard details, if applicable. ClubCard holders received points which were transferable into money-off vouchers when they used the service. Once they signed up, users received five e-mail addresses and 5Mb of disk space to create personal web sites. British Telecommunications provided the back end 
technology for TescoNet, which prevented a confrontation with the Telecommunication companies (Network Briefing 1998).

In October Tesco announced that it had adopted Unipower System's ShoppingMagic eCommerce suite for its next-generation home shopping system. The ShoppingMagic tools took a middle of the road approach that took into consideration the speed and reliability problems of the Internet. Before making this decision, Tesco engaged in extensive research on the customers using its online service. The new software gave Tesco the ability to expand the services it was offering and allowed the company to experiment with new ways of recruiting and keeping customers. For the customers, the new system gave them the benefit of a high speed connection and simplified store navigation which meant that they spent less time online (M2 Presswire 1998). Further, the program remembered the customer's favorite items the very first time an order was processed and generated a shopping list automatically. Customers could then access this list each time they logged onto the system which reduced the time it took to complete shopping sessions. For Tesco, the new shopping software allowed the company to capture more detailed information on each customer's buying patterns each time they submitted an order. The software was available for free download from www.tesco.co.uk by all customers with a standard home PC operating on a Windows95 platform and an Internet connection. It was also packaged with the recently launched TescoNet ISP software. According to Paul Arnold, who at the time was a senior business consultant at Tesco Direct, "[O]ur two main aims for the new Tesco Home Shopper were to give our customers the fastest, most easy-to-use store available, and to fully integrate the electronic commerce supply chain with our existing channels” (M2 Presswire 1998). 
During October, Tesco invested in new inventory control software designed to help control waste and manage its stock more effectively.

During November, Tesco invested in new equipment and upgraded a store for testing that equipment. Using the new software products, the new facility received customer orders and uploaded them to the new intelligent shopping carts. Once the orders were complete the intelligent shopping cart was used to pass the order off directly to a new hi-tech delivery van. These changes were put into place to improve efficiency and ultimately customer service (Kemeny 1998).

\section{Revenue Components}

43. Tesco's decision to offer non-grocery items resulted in a new revenue source. This was represented by the revenue component 'non-grocery inventory sales' - RC(15) (see Table 19).

44. To enroll in the pension plan, customers had to pay $\$ 30$ per month. This represented a source of revenue for the company and was represented by the revenue component 'pension subscription/membership fees’ - RC(13) (see Table 19).

45. To register for TescoNet the customers had to pay a one time $\$ 50$ fee for the CD-ROM with the necessary software. This fee was convertible into Tesco ClubCard points. This was represented by the revenue component 'packaging/installation fee' - RC(2) (see Table 19).

46. To activate and use the TescoNet service, customers had to pay a \$9 dollar monthly fee for the service. This was represented by the revenue component 'TescoNet subscription/membership fee’ - RC(14) (see Table 19). 


\section{Cost Components}

47. Tesco's decision to expand its service and store offerings resulted in the company incurring additional costs in the area of store conversion and inventory procurement. This was represented by the back-end cost components 'store conversion' - CC(34), 'non-grocery inventory purchased via manufacturer/wholesaler' - CC(37), and 'storage and handling costs' - CC(31) (see Table 19).

48. Each time that Tesco expanded its operation, the company incurred additional general and administrative costs. Some of these costs stemmed from the fixed portion of the labor expense. These expenses were associated with the hiring and training of picking, packing, and delivery personnel as well as other costs associated with operating the online division. These costs were represented by the front-end cost components 'general and administrative' - CC(17), and 'other costs and expenses’ - CC(18) (see Table 19).

49. The decision to offer a personal pension plan resulted in an increase in the auxiliary services and general and administrative costs. The majority of these costs was bore by Scottish Widows. This was represented by the front-end auxiliary services component 'financial services related' CC(38), and the front-end general and administrative components 'general and administrative' - CC(17), and 'other costs and expenses' - CC(18) (see Table 19).

50. To offer its customers ISP service, Tesco had to incur additional Internet access costs. In addition, the company incurred additional general and administrative costs necessary to run the ISP service. These costs were represented by frontend order taking cost component 'Internet access point' CC(35) (see Table 19).

51. Tesco's decision to use the ShoppingMagic eCommerce suite to help improve the order taking function represented another cost for the company. This cost was represented by the frontend cost components 'website design third-party' - CC(33), 'website design in-house' - CC(1), and 'website maintenance in-house' - CC(30) (see Table 19). (The decision to use this third-party software represented a cost saving for the company). 
52. The decision to invest in new inventory control software resulted in Tesco incurring an additional cost. This was represented by the inventory expense component 'inventory related software' - CC(42) (see Table 19).

53. Tesco's decision to invest in, and test, new equipment represented additional costs for the company. To test the new equipment the company had to upgrade a store. This cost was represented by the back-end cost components 'store conversion' - CC(34), and 'fulfillment equip. (semi-auto)' CC(36). Once the new equipment was functional, there was a cost associated with its operation and maintenance. These costs were represented by the back-end cost components 'picking costs hybrid (some automation)' - CC(18), and 'packing/assembly costs hybrid (some automation)' - CC(19) (see Table 19).

54. The opening of a new fulfillment store equipped with semiautomated fulfillment equipment resulted in an increase in the general and administrative costs for Tesco. These costs were represented by the front-end cost components 'general and administrative' - CC(17), and 'other costs and expenses' CC(18) (see Table 19).

55. For each new store-based fulfillment center that Tesco opened, the labor expense increased. This was represented by the backend cost components 'picking costs human capital' - CC(4), 'delivery personnel costs' - CC(17), and 'packing/assembly costs human capital' - CC(5) (see Table 19).

56. Each time that Tesco expanded its service, the company had to purchase additional delivery vehicles. This cost was depicted by the back-end cost component 'delivery fleet company owned' - CC(21) (see Table 19).

57. With the expansion of service, Tesco was covering a greater territorial area. This increased the fuel cost. This was represented by the back-end cost component 'fuel costs' CC(6) (see Table 19).

\section{Performance Drivers}

58. As Tesco's service expanded the costs associated with fleet maintenance, inventory procurement, inventory handling, and 
fulfillment activities also increased. The fleet maintenance costs were driven by the number of delivery attempts, the number of vehicles used, and the number of orders delivered. This was represented by the links between the delivery service performance drivers 'number of delivery attempts' - PD(14), 'number of vehicles used' - $\mathrm{PD}(15)$, 'number of orders delivered' - $\mathrm{PD}(9)$, and the back-end capital expenditure expense 'fleet maintenance' - CC(22) (see Figure 57). Inventory procurement costs were driven by the number of orders received and the number of items per order. This was represented by the links between the customer patronage performance diver 'number of orders' - PD(3) and 'items per order' - $\mathrm{PD}(13)$ and the back-end inventory expense components 'grocery inventory costs' - CC(23), 'non-grocery inventory costs' - CC(37), and 'storage and handling costs' CC(31) (see Figure 57). Fulfillment expenses were driven by operational performance drivers. This was represented by the links between the operational service performance drivers 'number of lines picked' - PD(16), 'picking speed' - PD(5), 'packing speed'- PD(21), and the back-end fulfillment cost components 'picking costs human capital' - CC(4), packing costs human capital' - CC(5) (see Figure 57). Delivery expenses were driven by delivery performance drivers. This was represented by the link between delivery service performance drivers 'delivery truck capacity' - $\mathrm{PD}(22)$, 'number of delivery attempts' - PD(14), 'number of vehicles used' - PD(15), and the back-end fulfillment delivery expenses 'delivery personnel costs' - CC(17), and 'fuel cost' - CC(6) (see Figure 57).

59. Tesco's decision to invest in a high speed Internet portal was an attempt to increase customer patronage. This was represented by the front-end cost component 'Internet access point' - CC(35) and the performance drivers 'number of new customers' - $\mathrm{PD}(1)$ and 'number of repeat customers' - $\mathrm{PD}(2)$ (see Figure 55).

60. The new ordering software allowed Tesco to experiment with new ways to recruit and retain customers. This was represented by the links between the front-end cost components 'website design in-house' - CC(1), 'website design third-party' - CC(33), 'website maintenance in house' - CC(11), and the performance drivers 'number of new customers' - PD(1) and 'number of repeat customers' - PD(2) (see Figure 55). 
61. Non-grocery inventory sales were driven by the customer patronage drivers. This was represented by the links between the customer patronage drivers 'number of orders' - PD(3), 'items per order' - $\mathrm{PD}(13)$ and the inventory revenue component 'non-grocery inventory sales' - RC(15) (see Figure 58).

62. Revenue from the financial services was determined by the number of individuals using the service. This was represented by the links between the auxiliary service performance driver 'number using financial services' - PD(23) and the commission revenue component 'financial services activities' $\mathrm{RC}(16)$ and the fee revenue component 'pension subscription/membership fees’ - RC(13) (see Figure 58).

63. The use of the inventory related software was to improve the storage and handling function. These changes were made to improve the stockout rate. This was represented by the link between the back-end cost components 'inventory related software' - CC(42) and 'storage and handling costs' - CC(31) (see Figure 57).

64. Tesco's decision to invest in new software and hardware was done to improve the efficiency of the fulfillment function. This was represented by the links between the back-end capital expenditure component 'fulfillment equipment (semi-auto)' CC(36) and the fulfillment performance drivers 'number of lines picked' - PD(16), 'picking speed' - PD(5), 'picking accuracy' - PD(6), 'packing speed' - PD(21), and 'assembly accuracy' - PD(7) (see Figure 57).

65. By adding non-grocery products to their inventory, Tesco increased the number of lines it was carrying. This was represented by the link between the back-end inventory expense 'non-grocery inventory purchased via manuf./wholesaler' - CC(37) and the fulfillment performance driver 'number of lines picked' - PD(16) (see Figure 57).

Profit Structure Summary from January 1997 - December 1998

During the period between 1997 through 1998, Tesco’s profit structure did not change very much but the actual costs began to increase as the company expanded its 
Figure 58

Tesco’s Performance Drivers and Revenue Components: January 1997 - December 1998

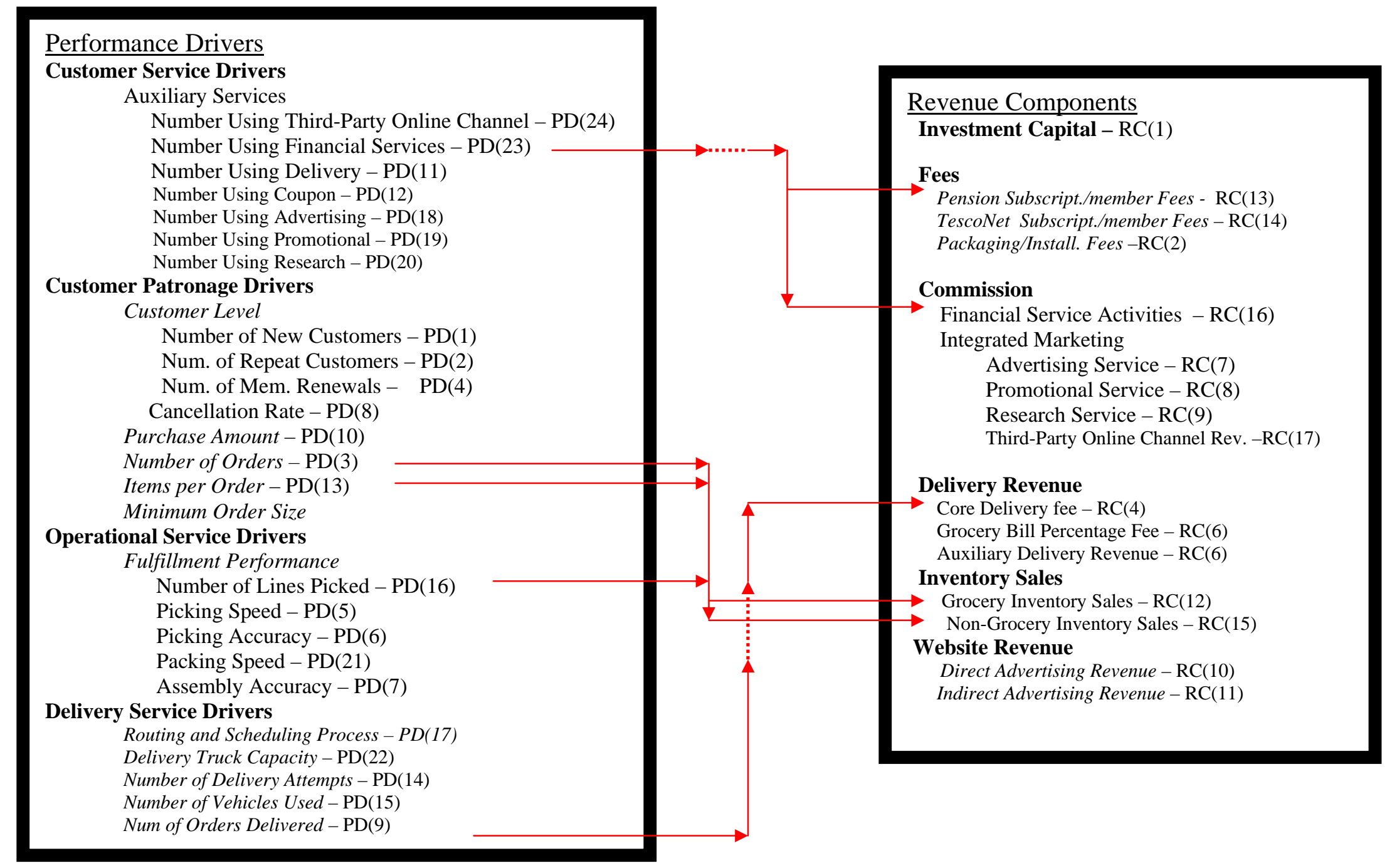


service (see Table 19). Capital expenditures in the areas of store conversion, purchase of a delivery fleet, and the maintenance cost for the fleet were increasing. At each new location Tesco incurred inventory storage and handling costs stemming from preparing customer orders for delivery. Further, at each new location the company had to hire picking, packing, and delivery personnel, which drove up the labor costs. Moreover, given the increase in demand and the expanded service area the fuel cost increased as well.

On the front-end side, the company was still spending capital on developing its order taking and order routing capacity. Each time Tesco added a new location the server had to be updated to reflect this addition. Likewise, as the company added new products and services, it had to add new web pages to the site which meant changing the website. Customer relationship costs were kept low due to the synergies gained through cobranding with the parent company. Lastly, general and administrative costs increased as Tesco expanded the service to new locations.

From a revenue perspective, Tesco continued generating revenue through core delivery fees and grocery inventory sales. The decision to offer financial services resulted in additional revenue components. One stemmed from the banking activities that Tesco was involved in and the other stemmed from monthly fees associated with the pension fund. By providing these financial services Tesco was able to collect commissions and fees. Also, the fee Tesco was charging its customers for Internet access provided the company with another revenue source. The sale of non-grocery items represented yet another revenue component for Tesco. What is interesting is that insiders were reporting that Tesco’s online operation was already showing signs of becoming 
profitable. Thus, it would seem that Tesco's low cost, low risk business model was paying off.

In terms of the other mediating/moderating variables, Tesco did not make any major changes during this period. In terms of the scalability, Tesco continued to use the low scalability in-store fulfillment method. In terms of the method of delivery Tesco continued to rely on home delivery. The company's rate of expansion increased to moderate as a result of Tesco's stated expansion goals. The automation level and employee and management commitment to the service did not change (see Table 20).

In relation to the market structure factors, the Internet structure, penetration, and access levels remained the same while the cost of Internet service was declining due in large part to efforts by Tesco. Population size and density remained unchanged as did the geographical location variables (see Table 20).

Table 20

Other Mediating/Moderating Factors for Tesco: January 1997 - December 1998

$$
\text { January } 1995 \text { - } \quad \text { January } 1997 \text { - }
$$

December 1996 December 1998

\section{Company Related Factors}

Scalability (Picking Location)

High

Medium Dedicated

Warehouse

Large Dedicated Warehouse

Moderate

Wareroom (Hybrid)

Small Dedicated Warehouse

Low

In-Store

X

X 
Table 20 (Cont'd)

Other Mediating/Moderating Factors for Tesco: January 1997 - December 1998

January 1995 - J January 1997 -

December 1996 December 1998

Method of Delivery

Store Pickup

Local Pickup

Home Delivery

$\mathrm{X} \quad \mathrm{X}$

Company Rate of Expansion

Slow

$\mathrm{X}$

Moderate

$\mathrm{X}$

Fast

Automation Level

High

Moderate

Low

$\mathrm{X}$

$\mathrm{X}$

Employee/Management

Commitment

High

$\mathrm{X}$

$\mathrm{X}$

Moderate

Low

Market Structure Factors

Connectivity

Internet Structure

High

Moderate

Low

X

X

Internet Penetration

High

Moderate

Low

X

X 
Table 20 (Cont'd)

Other Mediating/Moderating Factors for Tesco: January 1997 - December 1998

$\begin{array}{ll}\text { January } 1995 \text { - } & \text { January } 1997 \text { - } \\ \text { December } 1996 & \text { December } 1998\end{array}$

Internet Access

High

Moderate

Low

$\mathrm{X}$

$\mathrm{X}$

Cost of Internet Service

\author{
High \\ Moderate \\ Low
}

Population Structure

Population Size

Population Density

Geographical Location

Continental

North America

South America

Europe

Asia

Country

United States

United Kingdom

Japan

County/Parish

Urban

Suburban

Rural
$\mathrm{X}$

X

$\begin{array}{lc}\text { Large } & \text { Large } \\ \text { High } & \text { High }\end{array}$

X

X

$\mathrm{X}$

X

X

X 


\section{Summary}

During the 1997 through 1998 period Tesco continued to stay customer focused and continued to develop new products for its customers. For instance, the company launched the BabyClub loyalty program which provided soon to be mothers with valuable information concerning the proper nutrition and care for their babies before and after birth. To entice these soon to be mothers into purchasing baby products from Tesco, the company tied online purchases to the ClubCard by offering points and vouchers. Further, Tesco’s decision to offer its customers deposit accounts, credit cards, and insurance highlighted the company’s strategy of superior customer service. Moreover, it reinforced Tesco’s commitment to providing its customers with products and services priced below what was being offered at other retail outlets. The decision to allow customers the option of compiling their orders offline and then logging in to send them to Tesco further demonstrated the company’s customer focus. Lastly, Tesco’s decision to become a low cost ISP further demonstrates the company's focus on customer service.

Although Tesco had a customer focus, this strategy was also designed to help boost the profits of the company. Specifically, by focusing on the customers and providing them with products/services that they needed/wanted, Tesco was trying to increase the brand loyalty of its customers. To do this the company used ClubCard tieins, which allowed customers to gain ClubCard points with their online purchases. This provided them with an incentive to shop at Tesco. According to the company's internal research, consumers were willing to use financial products offered by Tesco as long as the customers could receive ClubCard points. This indicated that cost savings in one area 
could drive purchase behavior in another area. This seems to be what Tesco was relying on when it decided to become a low cost ISP. By providing a savings to customers and allowing them access to the Internet, Tesco was hoping to be rewarded with an online purchase. Thus, Tesco’s strategy was to leverage its ClubCard customer base and provide those customers with lower cost products/services. For these services Tesco charged a fee. As long as the fees for these services exceeded the cost of providing the services, Tesco was gaining an incremental revenue source.

Due to the popularity of the online grocery service, Tesco decided to expand its online grocery delivery network to five new boroughs. The popularity of Tesco's website put it in the top ten most popular U.K. sites. It is the contention here that the popularity of the website drove Tesco's push to include more content on the site. The objective was to have the consumer stay on Tesco’s website thus increasing the probability of a sale. Similarly, opening twelve new locations demonstrated the company’s commitment to developing the online channel. By the end of 1997, Tesco’s online grocery home delivery service was doing so well that the company began formulating plans for a national roll-out. With the limited trial that Tesco was running, the company was already showing signs of becoming profitable. At this point Tesco viewed the online channel as a true profit center.

In developing its online channel, Tesco also paid attention to its cost structure by trying to reduce costs whenever possible. This is evident by the decision to use thirdparty software to run its online division. This allowed the company to save money on software development and testing and provided it with a flexible customer interface system. Their decision to use third party software demonstrated the company's 
confidence in the technology on the market and showed that it did not view the software as a critical strategic advantage for them. Further, the company saved money on development and maintenance by using readily available commercial products. In addition to saving money, these software systems were incorporated to improve certain problems that were plaguing the fulfillment function. The main problem concerned out of stock items which resulted in products being excluded from customer orders. Improving this function became a major priority for Tesco. In addition, the investment in the new semi-automatic equipment increased the number of lines the picking personnel could handle, which in turn improved the picking speed, packing/assembly speed, and improved the assembly accuracy.

During this period, Tesco was considering moving from a store based to a warehouse fulfillment model. It realized the efficiency that could be gained using a fulfillment center but the costs were problematic with breakeven concerns at the center. This indicates that current customer demand may not have been high enough to justify the use of a warehouse model.

\section{Tesco’s Profit Structure from January 1999 to December 2004} 1999

In January, Tesco made the decision to adopt new technology developed by Unipower, the makers of the ShoppingMagic software that the company was currently using. The new feature, called ScanMagic, allowed Tesco's customers the option of using either a PalmPilot with a bar code scanner or a new innovative scanner called InfoScan, to scan the barcodes of products in their home and then add them automatically 
to their Internet shopping lists (M2 Presswire Jan 21 1999). They could then order replacement products by simply plugging their organizers into a PC with an Internet connection running Tesco’s online software (Goodwin 1999). Tesco believed the devices would broaden the appeal of Internet shopping by making it easier for customers to compile shopping lists since they could avoid having to go through the entire 20,000 products in order to complete the list. The scanner was pocket sized so it could be used away in the home. The Palm Pilot Scanner also had a touch screen personal organizer with diary, address book and calculator functions. The InfoScan device did not have these features and was designed to be used mainly in the kitchen. This service was available only to customers within a five-mile radius of 12 select stores (Goodwin 1999).

In February, Tesco began offering its ISP service for free to all its customers having a loyalty ClubCard. Customers could connect to the Internet using a free telephone number but were charged a premium to contact the helpline. The actual connections and much of the technical support for the service was provided by BT (Electronic Times (Online) 1999). Also during the month, Tesco announced a partnership with Excite to provide Tesco's free ISP Web site with specially formatted channel content and Internet search capabilities. Using Excite's expertise in aggregating the best of the web, Tesco's customers were able to take advantage of news, sports, weather, lifestyle, money and investing information all within the TescoNet environment. The service also included entertainment and chat-room channels. According to Helen Bridgett, a spokesperson for Tesco, customers “. . . come to Tesco's web site because they trust the brand to deliver quality. Excite shares our commitment to serving up the best web experience for the customer” (M2 Presswire, February 15 1999). 
In March, in an effort to increase the efficiency of its home-shopping operations, Tesco began testing new in-store picking technology that used a cart-mounted computer, which interfaced with another computer in the store that contained the customer orders (Sciacca 1999). When a customer's order was received, it was downloaded into the portable computer. An employee then put the computer in the cart and followed an electronic picking list. The computer would then provide an optimized picking sequence. Once products were picked from the shelf, their barcodes were scanned into the portable unit and the items were placed in the cart. The new carts allowed the employees to pick four orders at a time and were designed to help reduce mispicks, ensure order accuracy and increase employee picking speed (Sciacca 1999).

By April, Tesco had announced that it planned to expand its fledgling Internet home-delivery service. Terry Leahy, Tesco's chief executive officer, commented that the Tesco Direct service would be rolled out to 100 stores throughout South East and Central England. The expansion time table amounted to, on average, five stores a week being added to the service area. The expansion created 1500 jobs and required heavy investments in computers and a delivery fleet. At the time, Tesco claimed to already have 200,000 subscribers to its free subscription Internet service, and the number was increasing by 10,000 customers a week (Computergram International, April 15, 1999). In July, in an attempt to boost revenue, Tesco selected e-Space, a specialist in Internet advertising, to handle all their online advertising sales. Tesco also made the decision to allow its savings account customers to bank online by launching its personal finance services on the Web. The service allowed customers to check their balances and organize direct debits and gave them access to application forms for Tesco's other 
personal finance services, which included pensions, insurance, Visa cards, ISAs and personal loans. Rather than going into shops, customers could apply by filling in the form on their PCs, which could be printed off and signed. According to Mark Wakeley, IT projects manager for Tesco Personal Finance, “... the offer was a way of adding value to Tesco services ... It provides another channel for people to use our business and is a good way of showing all of our products in one medium” (Gregory 1999).

Tesco’s online advertising was a way for the company to gain extra revenue by allowing those paying for the advertising to receive detailed information on the effectiveness of their ads. For example, Stella, Heineken and Murphy's ran `click-to-buy' ads and studied the results in terms of category penetration and how sales of one product affected those of another (New Media Age, August 26, 1999). Another advertising partner, Whitbread, received detailed reports assessing the effectiveness of its campaign in terms of the amount of product sold and how that related to the type, timing and positioning of its banner ads. To aid in these analyses, new terms such as SCR (Sale to Click Ratio) and SIR (Sale to Impression Ratio) were developed to help evaluate how the banner ads affected online shopping patterns and to help determine if there was a difference between online and in-store shoppers in terms of particular products and pack sizes (New Media Age, August 26, 1999). These tests netted some results, but the market for online grocery sales was not large enough to attract a significant level of advertising revenue from the large consume goods companies. Even as Tesco was expanding its service to 100 stores, there were only about 200,000 of its 14 million ClubCard customers shopping online. Before a substantial number of these 14 million ClubCard users could 
be reached, there would need to be higher Internet penetration among the general population (New Media Age, August 26, 1999).

By August, Tesco had expanded its service to 37 stores and planned to complete the expansion to 100 stores by February 2000. However, the expansion efforts were hindered when hundreds of online shoppers had their grocery deliveries delayed for more than a week following a series of glitches. The problem was restricted to existing customers who had downloaded and installed an incomplete version of the new ordering software. Customers that had recently signed up for the service were not affected. During September, Tesco's rival claimed to be the ultimate in one stop bargain shopping. Tesco's response was a commitment to increase its non-food offerings via the Internet. The company claimed it would begin selling an extensive range of electronic goods, books, CDs, homecare, and clothes on a revamped Internet site. The company also hinted at the possibility of selling a line of cars. Tesco's chief executive officer, Terry Leahy stated, "The company wants to be as strong in non food as it is in food." According to industry analyst, non food items accounted for $15 \%$ of Tesco sales.

In October, to increase brand awareness and trial, Tesco launched a multi-million dollar billboard, newspaper and radio campaign highlighting the expansion of its Tesco Direct online home-shopping service and to promote its use. The campaign featured ads on 230 billboards and 348 cross platform panels in London's tube stations that complemented the radio ads. It also included direct mailing, in store PoS, Internet advertising and even a 3D billboard (Grocer, October 23, 1999). According to Nick Laffan, e-commerce marketing planner at Tesco Direct, "The core campaign message is 
that the Tesco Direct service is a time saving device of benefit to a high percentage of our customers" (Grocer, October 23, 1999).

Tesco's online banking service was due to go live in November and was called Tesco On-Line Banking and offered products including instant access savings, insurance packages, personal loans and pensions. Once the service was offered nationwide, all Tesco's instant access savings account holders would be able to transfer money between Tesco accounts and other banks, view and print statements, and pay online orders (Grocer, October 23, 1999). Also during October, Paul Arnold, home-shopping business consultant for Tesco, at the FMI IT Leadership Forum sponsored by the Food Marketing Institute in Washington, stated that Tesco planed to tap into its existing customer base and its existing retail technologies to build its online business. According to Arnold, "We want to build a powerful presence on-line, and we found that we can leverage a lot of our legacy systems, such as our loyalty program” (Zimmermann 1999). With the ClubCard loyalty program, card holders could shop at the store or online. In discussing Tesco's business model, Arnold noted, “In Tesco's home-shopping model, order picking is done at the store level ... [because] ... [f] ulfillment from the stores, rather than the warehouse, is the most pragmatic approach for us at the moment” (Zimmermann 1999). The company was considering picking from a central distribution point but Arnold noted that to do so required a lot of throughput. Also, given the slow transportation systems in London, it would be difficult to meet the two-hour delivery window (Summerour 1999). He also pointed out that Tesco made strides in improving the accuracy and efficiency of in-store picking by introducing scanner technology that allowed pickers to scan the items as they assembled the customer's order. Improvements in the picking area were needed 
because in the beginning, Tesco had a significant number of 'mispicks'. After the improvements, products were selected from the shelf, scanned, and if a product did not match the product on the customer's list, the system displayed a warning message. As a result of this new system, picking accuracy improved (Summerour 1999). Tesco also improved the speed and accuracy for completing orders by reducing the level of order handing (Zimmermann 1999). According to Tesco, once the order was picked it was put directly in the van by the picker, eliminating the need to inventory the order in the store and reducing the possibility that the order could be misplaced. By linking its online operation with its offline BAM operation, Tesco was able to leverage the labor and inventory management costs. According to Arnold, accurate inventory data are critical to the success of Tesco's online operation (Zimmermann 1999).

Tesco’s Profit Structure Analysis from January 1999 to December 2004

Revenue Components

1. Tesco's decision to offer its ClubCard holders free Internet access was a removal of a revenue source. This was represented by the removal of the revenue component 'TescoNet subscription/membership fees’ - RC(14) (see Table 21). (* represents the removal of this component)

2. Tesco's decision to allow e-Space to handle its online advertising sales represented indirect advertising revenue. This was represented by the revenue component 'indirect advertising revenue' - RC(11) (see Table 21).

3. The decision by Tesco to offer integrated marketing services to the consumer goods manufacturers represented an additional revenue source for the company. This was represented by the commission revenue component 'integrated marketing research services' RC(9) (see Table 21). 
Table 21

Tesco’s Profit Structure Components: January 1999 - December 2004

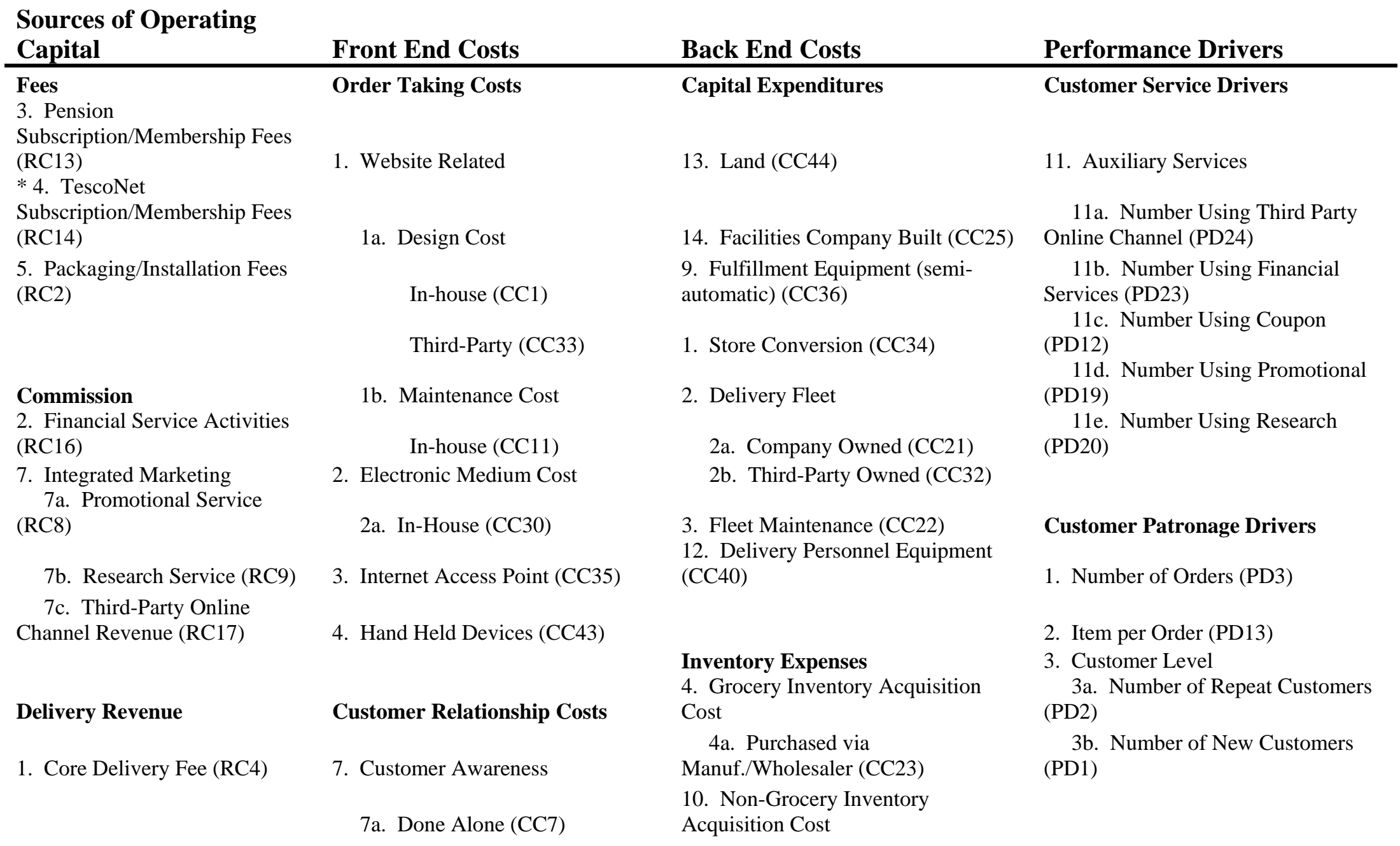


Table 21 (Cont'd)

Tesco’s Profit Structure Components: January 1999 - December 2004

\section{Sources of Operating Capital \\ Inventory Sales \\ 1. Grocery Inventory Sales \\ (RC12) \\ 6. Non-Grocery Inventory Sales (RC15)}

\section{Website Revenue}

8. Indirect Advertising Revenue

(RC11)

\section{Front End Costs}

8. Customer Acquisition Costs

8a. Done Alone (CC8)

12. Auxiliary Service Level

12a. Financial Services Related (CC38)

12b. Coupon Redemption (CC13)

12c. Promotional (CC14)

12d. Research Service (CC16)

12e. Third-Party Online Channel Costs (CC39)

\section{General And Administrative}

10. General and Admin. (CC17)

11. Other Costs and Expenses (CC18)

\section{Back End Costs}

10a. Purchased via

Manuf./Wholesaler (CC37)

5. Storage and Handling Costs

(CC31)

11. Inventory Related Software

(CC42)

\section{Fulfillment Expenses}

6. Picking Costs (F,V)

6a. Human Capital (CC4)

6b. Hybrid (Some Automation)

(CC18)

7. Packing/Assembly Costs (F,V)

7a. Human Capital (CC5)

7b. Hybrid (Some Automation) (CC19)

8. Delivery Costs

6a. Fuel Costs (CC6)

6b. Delivery Personnel Costs

\section{Performance Drivers}

\section{Delivery Service Drivers}

5. Number of Orders Delivered (PD9)

6. Number of Vehicles Used (PD15)

7. Number of Delivery Attempts

(PD14)

8. Delivery Truck Capacity (PD22)

12. Routing and Scheduling Process

(PD17)

\section{Operational Service Drivers}

9. Fulfillment Performance

9a. Picking Speed (PD5)

9b. Number of Lines Picked (PD16)

9c. Packing Speed (PD21)

9d. Picking Accuracy (PD6)

9e. Assembly Accuracy (PD7) 
4. Once Tesco began offering banking services, the company added a new revenue source based on the commission from those services. This was represented by the revenue component 'financial services activities' - RC(16) (see Table 21).

\section{Cost Components}

5. The development and use of the ScanMagic hardware and software represented another cost for Tesco. This was represented by the front-end order taking cost component 'hand-held devices' CC(43) (see Table 21).

6. By offering its ClubCard holder's free Internet access, Tesco was increasing the general and administrative costs necessary to keep the service operational. This was represented by the front-end cost components 'general and administrative' - CC(17), 'other costs and expenses' - CC(18), and 'Internet access point' - CC(35) (see Table 21).

7. Tesco's decision to expand its service to more customers resulted in several costs. To actually expand the service, Tesco had to convert several stores and purchase and install the semi-automated equipment. This was represented by the back-end cost components 'store conversion' - CC(34), and 'fulfillment equipment (semiauto) - CC(36). The expansion also required a massive investment in computers. This was represented by the front-end cost components 'website design in-house' - CC(1), 'website design third-party' - CC(33), and 'website maintenance in-house' CC(11). Tesco's expansion also resulted in an increase in the fulfillment expenses. These increases were represented by the back-end cost components 'picking cost human capital' - CC(4), 'picking costs hybrid (some automation)' - CC(18), 'packing/assembly costs human capital' - CC(5), 'packing/assembly costs hybrid (some automation)' - CC(19), 'delivery personnel costs' - CC(17), and 'fuel costs' - CC(6). Lastly, the delivery fleet had to be expanded. This cost was represented by the back-end cost component 'delivery fleet company owned’ - CC(21) (see Table 21).

8. As a result of the expansion decision, Tesco increased its general and administrative expenses. This was represented by the frontend cost components 'general and administrative' - CC(17), and 'other costs and expenses' - CC(18) (see Table 21). 
9. Tesco's decision to match the non-grocery inventory selection of its rival resulted in additional costs for the company in the areas of non-grocery inventory costs, inventory holding costs, and store conversion costs. These costs were represented by the back-end cost components 'non-grocery inventory purchased via manuf./wholesalers' - CC(37), 'storage and holding costs' CC(31), and 'store conversion costs' - CC(34). To add the nongrocery inventory items to the website, and to update the order taking software to handle the new inventory, Tesco had to update the order taking software. This was represented by the front-end cost components 'website design in-house' - CC(1), and 'website maintenance in-house' - CC(11) (see Table 21).

10. Tesco's decision to launch a multi-million dollar ad campaign resulted in the company acquiring additional costs. This was represented by the front-end cost components 'customer awareness done alone' - CC(7), and 'customer acquisition done alone' CC(8) (see Table 21).

11. Tesco's decision to offer integrated marketing services to consumer goods manufacturers represented another cost for the company. This was represented by the front-end auxiliary cost components 'research service' - CC(16) (see Table 21).

12. The inclusion of the new banking activities required Tesco to incur additional costs in the general and administrative area. This was represented by the front-end cost components 'general and administrative' - CC(17), and 'other costs and expenses' - CC(18) (see Table 21).

\section{Performance Drivers}

13. The combination of the ecommerce software and the new equipment was designed to improve the efficiency of the fulfillment function. This was represented by the links between the front-end cost components 'website design in-house' - CC(1), 'website design third-party' - CC(33), 'website maintenance in house' - CC(30), and the performance drivers 'number of lines picked' - PD(16), 'picking speed' - PD(5), 'picking accuracy' $\mathrm{PD}(6)$, 'packing speed' - PD(21), and 'assembly accuracy' PD(7) (see Figure 59). This was also represented by the links between the back-end cost component 'fulfillment equipment (semi-auto) - CC(36) and the performance drivers 'number of lines picked' - PD(16), 'picking speed' - PD(5), 'picking accuracy' - 
PD(6), 'packing speed' - PD(21), and 'assembly accuracy' $\mathrm{PD}(7)$ (see Figure 60).

14. The number of orders and the number of items per order are determined by the number of new and repeat customers. This was represented by the links between the customer patronage performance drivers 'number of new customer' - PD(1), 'number of repeat customers' - $\mathrm{PD}(2)$ and the other customer patronage drivers 'number of orders' - $\mathrm{PD}(3)$ and 'items per order' - $\mathrm{PD}(13)$ (see Figure 61).

15. The non-grocery inventory cost was determined by the number of orders and the number of items per order. This was represented by the links between the performance drivers 'number of orders' $\mathrm{PD}(3)$, 'items per order' - $\mathrm{PD}(13)$ and the back-end cost component 'non-grocery inventory purchased via manuf./wholesaler' - CC(37) (see Figure 60).

16. By adding non-grocery items to its inventory, Tesco increased the number of lines it was carrying. This was represented by the link between the back-end cost component 'non-grocery inventory purchased via manuf,/wholesaler' - CC(37) and the performance driver 'number of lines picked' - PD(16) (see Figure 60).

17. By offering free Internet service, Tesco was attempting to boost customer patronage. This was represented by the links between the front-end cost component 'Internet access point' - CC(35) and the performance drivers 'number of new customers' - $\mathrm{PD}(1)$ and 'number of repeat customers’ - PD(2) (see Figure 59).

18. Tesco's decision to launch a multi-million dollar ad campaign was designed to increase the awareness and usage of the online home delivery service. This was depicted by the link between the frontend cost component 'customer awareness done alone - CC(7), 'customer acquisition done alone' - CC(8) and the performance drivers 'number of new customers' - $\mathrm{PD}(1)$ and 'number of repeat customers' - PD(2) (see Figure 59).

2000

In January, Tesco reported that it would expand the number of stores offering home shopping from 100 to 300 while simultaneously broadening its online offerings of 
Figure 59

Tesco’s Front-End Cost Components and Performance Drivers: January 1999 - December 2004

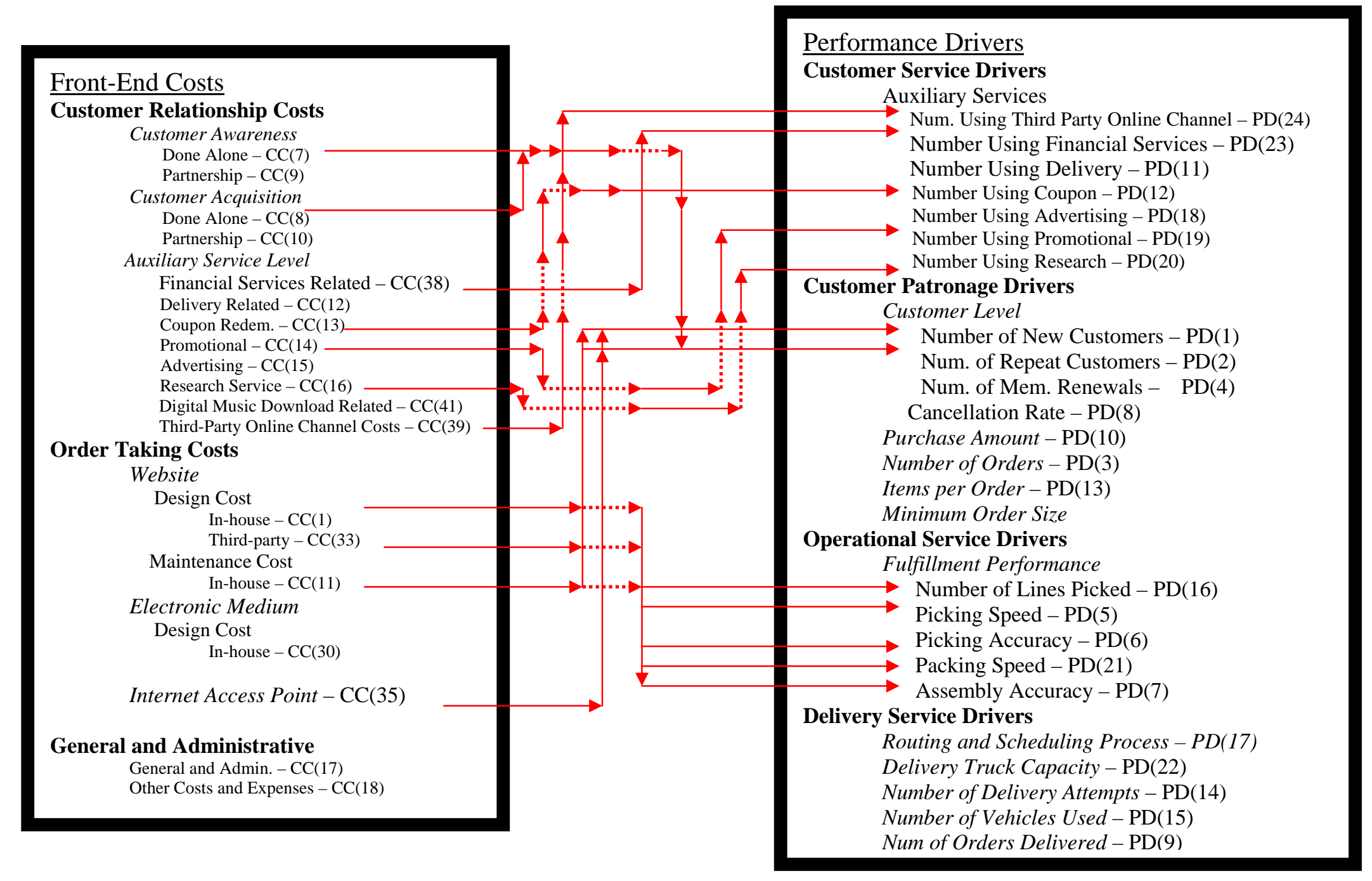


Figure 60

Tesco’s Back-End Cost Components and Performance Drivers: January 1999 - December 2004

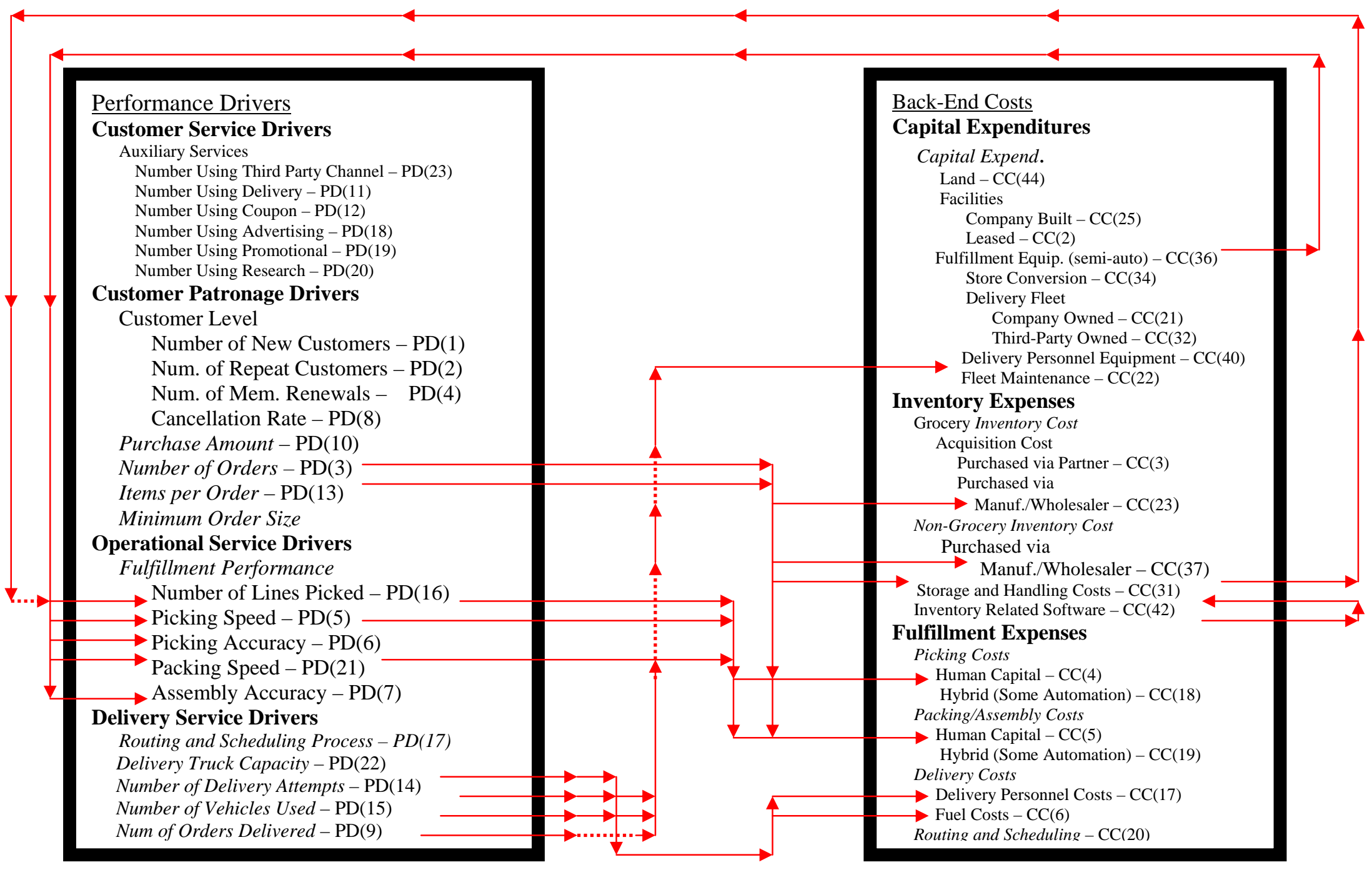


Figure 61

Tesco’s Performance Drivers and Performance Drivers

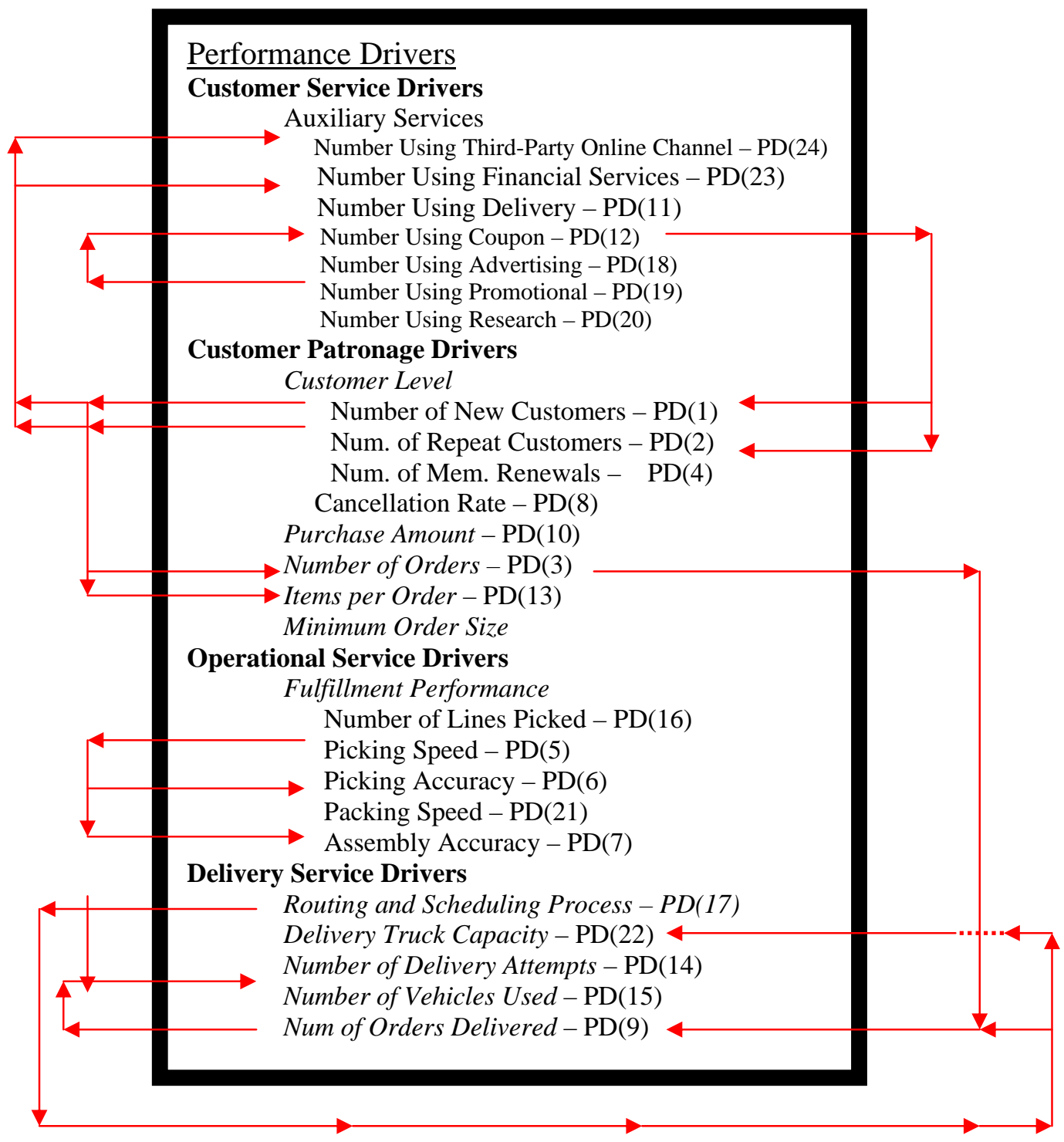


nonfood items like books, clothes, furniture, and banking services (Cowell 2000). Once the expansion was complete, $90 \%$ of the U.K. population would be able to order their groceries online from Tesco.

During February, Tesco decided to enhance its online service by listing product labeling information. The enhanced service offered customers extra product information such as lists of ingredients, nutritional advice and usage tips (Super Marketing, February 4, 2000). In addition, Tesco was working to provide customers with a search engine that would enable them to search for products that were salt free or fat free. Jon Higgins, Tesco's e-commerce development manager, was also working with manufacturers to provide product photographs. According to Higgins, "Customers have always said they want to see what they were buying” (Super Marketing, February 4, 2000).

Helen Bridgett, head of marketing for Tesco Direct, was careful in her choice of words when discussing Tesco Direct’s profitability stating “On a cost-per-order basis the service does make a contribution, and it doesn't lose money” (New Media Age, February 17, 2000, p.28). In terms of cannibalization she responded saying "As an industry we have to get over this fear of cannibalization, because if we're really customer-driven, we have to be there for them when they want us" (New Media Age, February 17, 2000, p. 28). According to Clive Vaughan, director of consultancy at Retail Intelligence, the short term profitability of Tesco was not the problem. The problem was getting the groceries to the customer on time. According to Vaughan, “. . . There's going to be a lot of peak loading because most people will want their goods delivered in the early evening” (New Media Age, February 17, 2000, p. 28). He went on to state, “The mechanics of ordering online are also problematic because using a Web site with the whole inventory listed is 
like going to a supermarket and having to take the goods you want from closed cardboard boxes. There are a lot of visual prompts in a real shop, and until VR can be used, that will be missing online. Even then, you won't see the actual item you're buying” (New Media Age, February 17, 2000, p. 28). On this comment Bridgett defended Tesco's presentation method stating that "We've talked to our customers ever since we launched and the main thing that we've learned is that a graphics-rich environment is completely wrong, because people want to do their shopping quickly. So our mantra here is speed” (New Media Age, February 17, 2000, p. 28).

Clive Vaughan also pointed out the possible service level problems with Tesco's in-store model. The low cost, low investment in-store picking strategy could be problematic in the future because conflicts may arise between shoppers and store picking personnel over products on the shelves (New Media Age, February 17, 2000, p. 28). Tesco's Helen Bridgett agreed that logistics were at the heart of the matter, but noted that most of the warehouse facilities Tesco toured manage about 5000 to 8000 lines. Tesco's strategy was to carry 20,000 products because the company felt that customers wanted to buy all their shopping items online (New Media Age, February 17, 2000, p. 28). She also noted that the current level of customer volume, did not justify building an expensive distribution facility. She conceded, that volume could increase to the point where a separate picking warehouse facility would be necessary and could be operated in parallel with a store-based approach (New Media Age, February 17, 2000, p. 28).

Gary Sergeant, grocery director at Tesco, admitted that the idea of picking from a warehouse was something Tesco Direct might have to consider in the near future. But, as it currently stood, the in-store route was the best way to build the business initially. He 
stated, "Ultimately it is going to be more productive to pick in a warehouse, but no one knows or has worked out what size that warehouse should or needs to be” (Hawkes 2000, p. 8). During this same time period, Tesco announced it was launching a new wave of Internet advertising using a series of banner advertisements. This campaign was part of Tesco Direct's decision to increase its marketing effort, and followed the distribution of 60,000 'Wish You Were Here' postcards earlier in the month to users who had registered with the service but had not yet placed an order (Hawkes 2000).

In a move to solidify its lead in the online area, and to compete with Amazon.com, Tesco partnered with entertainment e-commerce distributor Startle to offer Tesco Direct customers access to Startle's database of 200,000 music and 30,000 videos and DVD titles. According to a Tesco spokesperson, the Web represented unlimited opportunity for the brand to diversify. According to the deal, Startle delivered the CDs and DVD/Videos to a Tesco distribution center, with a next day guarantee if the item was in stock.

In April, Tesco announced that it would be consolidating its three main Internet arms - Tesco Online (the company's corporate site), Tesco Direct (the company’s home shopping service), and Tesco.Net (the company's Internet service provider) into a single unit titled Tesco.com (Buxton 2000). According to company officials, the primary purpose for this was to give the e-commerce business more flexibility. It had its own management structure and budget used primarily to expand its non-food product offering. In addition, the budget was also used to further the national roll-out, to develop new technology and software, and to cover staffing costs. To head up this new venture Tesco 
assembled a management team consisting of John Browett (CEO), Carolyn Bradley (COO), and David Clements as marketing controller replacing Helen Bridget.

In May, Tesco announced it would be exporting its Tesco Direct home-shopping arm to Ireland. According to Tim Mason, chairman of Tesco.com, the company wanted to expand the grocery home-shopping business either through introducing Tesco Direct to countries where Tesco already conducted operations or through third-party joint ventures with other retailers. Based on extensive research, Tesco contemplated expanding the home shopping service into Ireland and South Korea (Hawkes and Gregory 2000).

According to Marcus Bokkerink, vice president for Boston Consulting Group, London, the key to Tesco's success was its store-based fulfillment strategy. Based on this strategy, orders were received, picked and delivered from the local store closest to the customer; thus, allowing the consumer full access to the total range of products the store had (Springer 2000). Further, the in-store model was faster to rollout and, if volume increased substantially, Tesco could build dedicated warehouses at a later date (Springer 2000). What was even more telling about Bokkerink's statement was that $90 \%$ of TescoDirect users were repeat customers (Springer 2000). Matthew Nordan, senior analyst at Forrester Research, stated that by the end of 2000 Tesco would have reached scale for the in-store picking model and would have to convert to a warehouse based system. He pointed out that "[t]hirteen per cent of orders are filled incorrectly and Tesco itself admits that the most accuracy it can achieve through in-store picking is getting mistakes down to one in 10" (Coslett 2000). Thus, the current model had the potential to lead to customer dissatisfaction due to a high mispicking rate. 
In October, Tesco added electronic goods to its online store in an effort to expand sales of higher-margin goods. The initial offerings included washing machines, refrigerators and DVD players. John Browett, head of Tesco.com, stated that the company was starting with a complement of products similar to those found in an electronic superstore. To compete against established electronic retailers, Tesco planned to match or undercut competitors' prices and offer free delivery. According to Browett, this was possible because Tesco was a trusted brand and it offered lower prices and extended warranty plans. He went on to note that Tesco.com should benefit from the high site traffic. According to company officials, the company was on track to secure a 6\% share of the non-food U.K. market. This was another example of Tesco extending its brand into non-grocery related areas. With the decision to offer electronics, Tesco's product assortment increased. The original online grocery offerings were expanded to include over 1 million book titles in the online Bookstore, videos and CDs in the online Entertainment store, products for the home through the Home catalog, and items for babies and toddlers through the Baby and Toddler catalog (MMR, October 2, 2000).

Also in October, Tesco discussed re-engineering the infrastructure responsible for its Internet shopping service. The changes were needed in order to keep pace with the rapid growth of the service. In the span of one year, Tesco.com had seen the number of grocery orders increase from 15,000 to 60,000 a week which pushed its current servers almost to their limits. According to the company, the growth in order volume put the company on track to become profitable for the first time by the end of financial year 2000 (Goodwin 2000). The redesigned infrastructure was part of a larger project designed to move Tesco.com's databases to the XML system. This doubled the company's order 
processing capacity and improved customer access times. (In 2000, Tesco.com had about 80 Fujitsu and IBM Windows 2000/NT servers) (Goodwin 2000). According to Mike McNamara, Tesco.com's chief technology officer, customer access times had been a major customer service problem for the company. The first stage of the redesign was completed in July and gave Tesco the ability to switch in new servers as the number of online orders increased (Goodwin 2000). So, when customer orders reached a certain level, these customers would be transferred seamlessly to other servers brought online. Tesco.com planned to develop its system further by rewriting the system software around the XML data standard. This would allow Tesco.com's IT department to add new shopping services to the site with a minimum of extra programming. To further increase customer service, the company planned to use Net Perception's software to provide a more personalized service to its customers. The software was designed to individually analyze customers' buying habits and draw their attention to goods or offers they may be interested in. Further, Tesco planed to extend its use of XML to allow individual customers to have a personalized website that would reflect their specific interests (Goodwin 2000).

Further, Tesco Direct began running a pilot scheme offering shoppers the choice of picking up their groceries from a store close to their work rather than having them delivered at home. This meant that Tesco was using business model 1 under the hybrid category (see Appendix 3). To improve its service offering in the home-shopping arm, Tesco began testing online e-ClubCard point redemption (Hawkes, March 17, 2000). Other new services included Express Shopping, which was a search engine that retrieved the price and name of every brand of a product. Customers also received a personalized 
recipe book (Hawkes March 17, 2000) with an option to automatically add ingredients to a shopping list (Bruce 2000). At the same time that these new services were being introduced, Carolyn Bradley, chief operating officer of Tesco.com was revealing that customers had received poor service. According to Bradley, "We have had problems, there have been unacceptable waits for delivery slots, availability problems, and the system has sometimes been down for up to two hours" (Hawkes March 17, 2000). Thus, although Tesco’s home delivery service was doing well, there were still significant customer service problems to contend with.

\section{Revenue Components}

19. Tesco's decision to offer its customers entertainment content represented another revenue source for the company. This was represented by the commission revenue component 'third-party online channel revenue' - RC(17) (see Table 21).

\section{Cost Components}

20. Tesco's decision to significantly expand its service from 100 to 300 stores resulted in the company incurring major new costs. Expanding the service required Tesco to purchase the semiautomated fulfillment equipment, engage in store conversion, increase the delivery fleet, and expand the fulfillment function. These costs were represented by the back-end cost components 'fulfillment equipment (semi-auto)' - CC(36), 'store conversion' CC(34), and 'delivery fleet company owned' - CC(21). The expansion also required Tesco to increase its non-grocery inventory purchasing and holding costs. These costs were represented by the back-end cost components 'non-grocery inventory purchased via manuf./wholesalers' - CC(37), and 'storage and handling costs' - CC(31). Finally, the expansion resulted in an increase in the fulfillment area functions of picking, packing, and delivery. These costs were represented by the backend cost components 'picking costs human capital' - CC(4), 'picking cost hybrid (some automation)' - CC(18), packing costs human capital' - CC(5), 'packing costs hybrid (some automation) 
- CC(19), 'delivery personnel costs' - CC(17), and 'fuel cost' CC(6) (see Table 21).

21. The decision to have product labeling information listed on the website resulted in additional order taking costs. This was represented by the front-end cost components 'website design inhouse' - CC(1), 'website design third-part' - CC(33), and 'website design maintenance in-house’ - CC(11) (see Table 21).

22. Tesco’s partnership with Startle to provide its customers with the ability to purchase entertainment content online represented an additional cost to the company. This was represented by the frontend auxiliary service component 'third-party online channel cost' CC(39), the order taking costs 'website design in house' - CC(1), 'website design third-party' - CC(33), and 'website maintenance in-house' - CC(11) (see Table 21).

23. The decision to add electronic goods to the inventory required the company to increase the inventory costs, holding costs, website related costs, and general and administrative costs. These costs were represented by the back-end inventory cost components 'nongrocery inventory purchased via manful./wholesaler' - CC(37), and 'storage and handling costs' - CC(31). These costs were also depicted by the front-end order taking cost components 'website design in-house' - CC(1), 'website design third-part' - CC(33), 'website maintenance in-house' - CC(11), the general and administrative cost components 'general and administrative' CC(17), and 'other costs and expenses' - CC(18) (see Table 21).

24. Tesco launched a new Internet advertising campaign which resulted in an increase in customer relationship costs. This was represented by the links between the front-end cost components 'customer acquisition done alone' - CC(7), and 'customer awareness done alone’ - CC(8) (see Table 21).

25. Tesco's decision to revamp the order taking infrastructure resulted in costs associated with the purchase of new hardware and software. This was represented by the front-end cost components 'website design in-house' - CC(1), 'website design third-party' CC(33), and 'website maintenance in-house' - CC(30) (see Table 21).

\section{Performance Drivers}

26. The decision to expand the service from 100 to 300 stores meant increasing the inventory turnover for the company. This was 
represented by the links between the customer patronage performance drivers 'number of orders' - $\mathrm{PD}(3)$, 'items per order' - $\mathrm{PD}(13)$ and the back-end inventory expense components 'grocery inventory purchased via manuf./wholesaler' - CC(23) and non-grocery inventory purchased via manuf./wholesaler' - CC(37) (see Figure 60).

27. The increase in service also had an impact on the fulfillment expenses as well. The delivery related costs were driven by the delivery service performance drivers 'delivery truck capacity' PD(22), 'number of delivery attempts' - PD(14), 'number of vehicles used' - PD(15), and the back-end fulfillment expenses 'delivery personnel costs' - CC(17) and 'fuel costs' - CC(6) (see Figure 60). The picking and packing related costs were driven by the customer patronage performance drivers 'number of orders' $\mathrm{PD}(3)$, 'items per order' - $\mathrm{PD}(13)$, the fulfillment performance drivers 'number of lines picked' - PD(16), 'picking speed' $\mathrm{PD}(5)$, 'packing speed' - $\mathrm{PD}(21)$ and the fulfillment expense components 'picking costs human capital' - CC(4), and 'packing/assembly costs' - CC(5) (see Figure 60).

28. In order to offer its customers CD/DVD online purchasing, Tesco entered into an arrangement with Startle. From this third party arrangement, Tesco received revenue. What drove the revenue component was the number of customers using the service. This was depicted by the link between the front-end customer relationship costs ‘third-party online channel costs' - CC(39), 'customer awareness done alone' - CC(7), 'customer acquisition done alone' - $\mathrm{CC}(8)$ and the customer service performance driver 'number using third-party online channel' PD(24) (see Figure 59).

29. The revenue generated from the third party online channel was determined by the number of persons utilizing the service. This was represented by the link between the customer service performance driver 'number using third-party online channel' $\mathrm{PD}(24)$ and the commission revenue component 'third-party online channel revenue' - RC(17) (see Figure 62).

30. Utilizing Internet advertising was done to increase certain customer patronage drivers. This was demonstrated by the links between the front-end cost components 'customer acquisition done alone' - CC(7), 'customer awareness done alone' - CC(8) and the customer patronage performance drivers 'number of new customers' - PD(1) and 'number of repeat customers' - $\mathrm{PD}(2)$ (see Figure 59). 
Figure 62

Tesco’s Performance Drivers and Revenue Components: January 1999 - December 2004

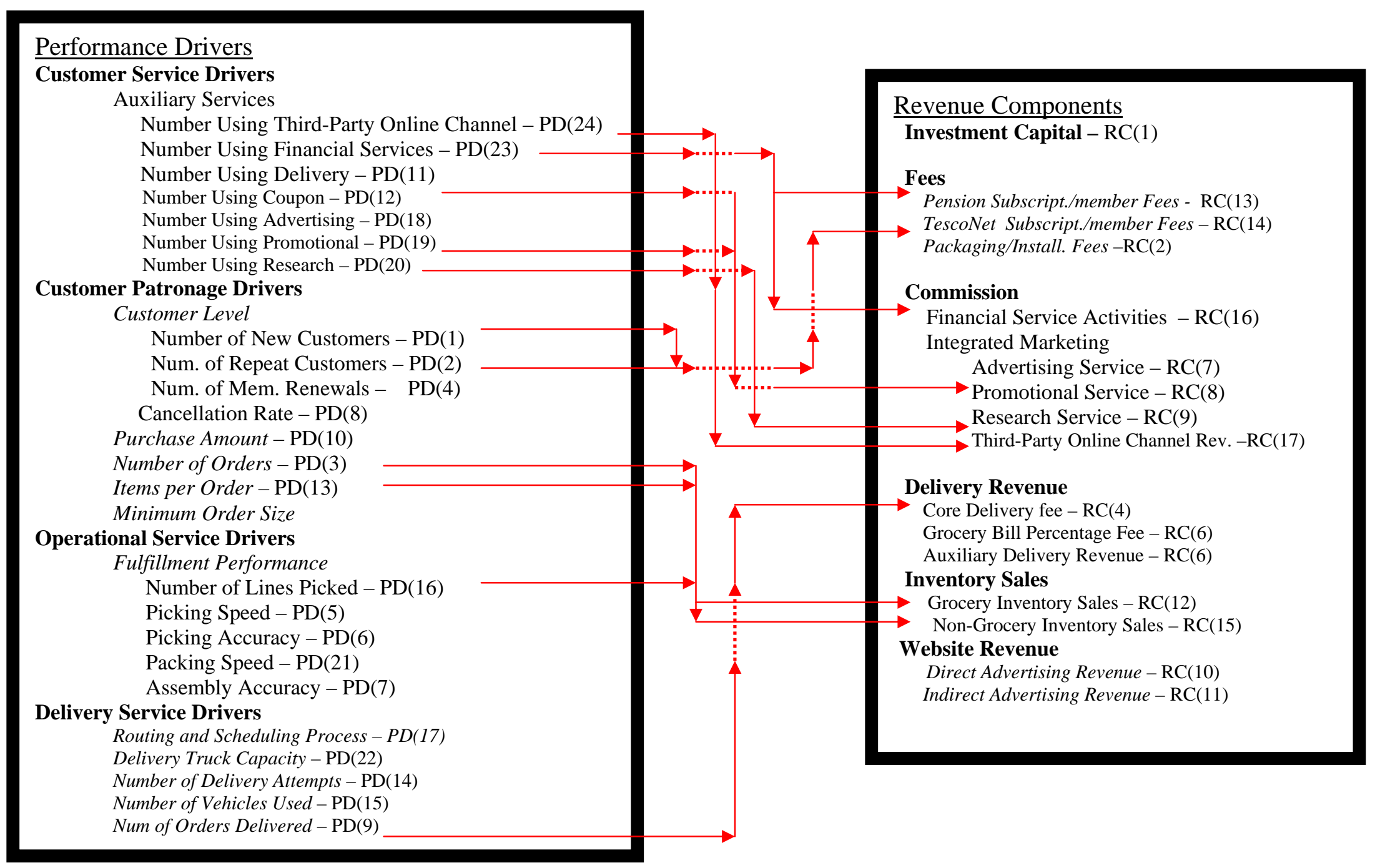


According to company officials, Tesco’s grocery home delivery business was already making a profit. However, the broader Tesco.com division was not doing as well. This was due to the continual addition of new product categories such as electronic goods, financial services, mother/baby goods, clothes, and home entertainment equipment. "The reason we report losses is that we put in all the start-up losses for all the other e-commerce initiatives that we have. But the grocery business is profitable. It is not the same as store profitability, ... [but our plans are] ... to have profit margins that are the same as, if not higher than, the stores," said John Browett, chief executive of Tesco.com (Cosslett, January 25, 2000).

The growth and profitability of Tesco’s grocery home delivery service had come with some tension. Specifically, the relationship between Tesco.com and the stores at the heart of the operation had always been a tenuous one. The greatest source of the tension concerned the issue of cannibalization. The fear was that e-commerce success was the result of cannibalization from BAM store sales. According to Browett, "[h]alf our sales on the Internet are new to Tesco, so half are cannibalized. That is a really exceptional performance” (Cosslett, January 25, 2000). Apparently, Tesco’s top management was less concerned about the cannibalization issue and more concerned about providing customers with an alternative channel. According to Browett, "We always knew that this was a device to increase market share. It is a new service, it adds value to customers and enables us to access customers we could not otherwise get to” (Cosslett, January 25, 2000). 
One main cost component for online grocers is associated with hardware and software development and maintenance. Therefore, for companies that choose to internalize this component, they must bear a significant cost burden. Tesco’s stance on the issue was different than most companies. According to Browett, "The way we do our IT is we have a core group of people who work on key projects, but we then outsource quite a lot of tasks such as code writing to contractors, consultants and even the Tesco IT department. When you are developing the business, you need different skills at different times. There is no way we could go out and hire a snapshot of all the people we need because we know it will change in six months' time” (Cosslett, January 25, 2000). Browett noted that most of the $£ 35$ million of capital expenditures invested in Tesco.com during 2000 was in the IT area (Cosslett, January 25, 2000).

During January, Tesco divulged that it was making 65,000 deliveries a week from its loyal customer base of 250,000. According to Carolyn Bradley, chief operating officer, the profile of a Tesco online customer was changing as a result of the popularity of the home delivery service. The early adopters of the online service were the 'yuppie' upscale customers but trends indicated that the working class was beginning to use the services more. Due to the shifting customer profile, Carolyn Bradley noted that it may be possible to mass market the service.

During February, Tesco revealed that it was contemplating selling customer profiles from its ClubCard database. The decision was made after Tesco acquired a 53 percent share in the marketing consultancy agency Dunnhumby (Kleinman 2001). The two companies were not strangers. Tesco has worked with Dunnhumby since the launch of the ClubCard scheme in 1995. The new Tesco subsidiary was known as Dunnhumby 
Retail. Specifically, Tesco was talking to consumer food manufacturers about selling consumer data from the new subsidiary. The data would allow brand manufacturers access to detailed information about anonymous consumer buying habits, and allow these companies to develop more sophisticated marketing initiatives for their brands (Kleinman 2001). According to Tim Mason, Tesco’s marketing director, “We can now combine Dunnhumby's analytical expertise and ClubCard data to give companies the best consumer understanding in the marketplace" (Kleinman 2001). In 2001 Tesco had about 14 million ClubCard holders, which accounted for ten million households. According to Tesco, the partnership with Dumbhumby would give the company a significant new revenue stream.

During April, Tesco made it known that it was looking to expand its online grocery format to the United States. Company officials believed that the success that Tesco had in the U.K. could be duplicated and even surpassed in the United States. The company noted that for the past six months it had been actively seeking a partner in the U.S. in order to establish an online joint venture. At the time of the announcement, Tesco.com had already launched an online grocery venture in the Republic of Ireland, and planned to be operating out of 16 stores there by May. Tesco was also looking to expand into Korea due to their high Internet penetration rate (Alaimo 2001). Gary Sargeant, Tesco.com's director of international operations, conceded that the United States grocery market was the big target for Tesco's store-based system. At the time, according to Sargeant, Tesco was “... looking for a joint venture with another retailer who has a brand and has the infrastructure, [and] the store network .... We will bring the knowledge of how to implement this inter-store network, as well as all the software 
and hardware that goes along with the picking solution." Tesco’s representatives noted that the company was not looking just to outsource its system, but was interested in being involved in the operational side as well (Alaimo 2001). According to Sargeant, "We want to be a retailer with the other retailer. We don't just want to be a provider of software. We are a retail company." He further noted, "[w]e are looking for a stake of $30 \%$ to $40 \%$ to $50 \%, \ldots$. . So we are not only bringing capability, but we are bringing capital as well” (Alaimo 2001). Sargeant stated that he would like to start the venture with a large U.S. retailer, but would be willing to work with a smaller one.

In relation to startup costs, the Tesco system was inexpensive to roll out in comparison to the investments made by some 'pure-play’ Internet grocers. Sargeant believed that the economics for the store-based model were more favorable in the U.S. because the inventory assortment would be the key to order size and profits (Alaimo 2001). He specifically stated, Typically, a U.S. supermarket has 5,000 to 10,000 more SKUs than a U.K. supermarket ... and that will improve your basket size. Profitability increases with the range [of products] offered. We believe a full range is fundamental, and absolutely key to success in this market" (Alaimo 2001). He went on to point out that margins are comparable if not better in the U.S., labor costs are lower, picking productivity is greater, vehicle costs are lower, and consumer demand, because the U.S. has more two-income households, should be higher. Sargeant also pointed out "There is demand for grocery home shopping in the U.S. Choosing the right business model is critical. Store-based fulfillment wins hands down” (Alaimo 2001). Tesco shoppers who regularly bought on the Internet became more loyal than ClubCard holders and spent more money in the store where their goods were picked. According to Paul Arnold, 
Tesco.com's head of computer systems, online basket size, on average, increased in proportion to the larger number of products offered. "People who bought online more than three times were more loyal than ClubCard holders." (Grocer, April 7, 2001).

In order to use the Tesco online shopping services, customers had to have a Tesco ClubCard. This allowed Tesco to tie users of its online shopping service to the store that they regularly shop at, and made that particular store responsible for receiving, processing, and fulfilling the customers' orders. John Browett, chief executive officer of Tesco.com, said, “[t]ying each online customer to one particular store has made the logistics and economics of receiving, processing, filling and distributing orders work for us" (MMR, May 28, 2001).

In June, Tesco announced that it would spend \$22 million for a 35 percent stake in Safeway's recently acquired online grocery division known as GroceryWorks. Under the venture, GroceryWorks would re-launch its website under the Safeway brand name, and move to an in-store fulfillment model using Safeway's network of 1,747 stores covering the U.S. and Western Canada (Gold 2001). The deal combined Tesco's experience in developing Internet sites and the systems necessary to run a store-based grocery home shopping service with Safeway's quality operations, procurement strength, well-recognized brands, and knowledge of the U.S. market. Besides the capital investment, Tesco installed a clone of its front and back office systems at the GroceryWorks operation. Prior to Tesco’s involvement, GroceryWorks used a warehouse fulfillment model to fill customer orders. Jonathan Church, a spokesperson for Tesco, noted that GroceryWorks would “. . . be moving away from the warehouse fulfillment approach and over to our model of store picking," (Gold 2001). Safeway was 
already moving towards a store based picking model but realized it could set one up much quicker and more cost effectively by teaming up with Tesco, which had already cracked the technology behind it. From an operational perspective, the store-based model was a better model for a slow-growth business like groceries because it has a lower break-even point. The question was whether this system would work in the United States, which is a large, sprawling country, with a population density less than that in the U.K. By moving to a store fulfillment system, Tesco expected the U.S. Safeway online grocery service to be profitable by the end of next year (Gold 2001).

In July, Tesco announced a deal with Microsoft that allowed Tesco.com to be accessed on Pocket PC-based handheld devices and smartphones. This was done in order to provide an additional channel for Tesco.com to attract customers. In September, Tesco announced that it was going to introduce separate home pages for its website that would cater to the varying levels of experience of different online customer segments. The move was designed to increase the shopping frequency of new and occasional customers (Alaimo 2001b). For first time users, Tesco.com did not want to overwhelm them or to get them to make additional purchases. For these customers Tesco simply wanted to communicate that the site was easy to use and give them the experience of buying something online. According to Paul Arnold, Tesco.com's development architect, "The objective with a brand new customer is to get them to the checkout screen as quickly as possible, with a mechanism that is as simple as possible” (Alaimo 2001b). With the more advanced customers, Tesco increased the sensory appeal of the page and encouraged the customer to do more complex maneuvers or transactions. With the experienced customer, Tesco presented them with the full webpage where they were free to work with 
all the functions (Alaimo 2001b). This again indicated Tesco's focus on customer

service. The impetus behind the new Web page format stemmed from a general shift in marketing strategy from customer personalization to segmentation of customer groups.

The goal was to create groups of customers with similar needs, preferences and behavior.

These groups needed to be large enough to be useful to marketing, but small enough to allow for subtle differences in behavior to be noticed (Alaimo 2001b).

\section{Revenue Components}

31. The decision by Tesco to sell anonymous customer information to consumer goods manufacturers provided Tesco with an additional revenue source. This was represented by the integrated marketing revenue component 'research service' - RC(9) (see Table 21).

\section{Cost Components}

32. The decision by Tesco.com to internalize the central portion of its IT department and outsource a majority of its IT work, allowed the company to save money in the IT area. This was represented by the front-end order taking cost components 'website design inhouse' - CC(1), 'website design third-party' - CC(33), and 'website maintenance in-house' - CC(11) (see Table 21).

33. Tesco's decision to invest 35 million into Tesco.com's IT infrastructure represented a major cost for the company. This was represented by the front-end order taking cost components 'website design in-house' - CC(1), 'website maintenance in-house' CC(11), and the back-end capital cost component 'fulfillment equip. (semi-auto)' - CC(36) (see Table 21).

34. The decision by Tesco to provide research information from its online ClubCard holders was another cost for the company. These costs stemmed from providing the service itself and the general and administrative costs associated with overseeing the service. These costs were represented by the front-end auxiliary service cost component 'research service' - CC(16), the general and administrative cost components 'general and admin.' - CC(17) and 'other cost and expenses' - CC(18) (see Table 21). 
35. Tesco's decision to partner with Microsoft to provide Tesco.com customers with Pocket PC based access to the Tesco website, represented another cost for Tesco.com. This was represented by the front-end order taking cost components 'website design inhouse' - CC(1), 'website design third-party' - CC(33), and 'website maintenance in-house' - CC(11) (see Table 21).

36. The decision to present the customer with a webpage based on their usage rate resulted in order taking costs. This was represented by the front-end order taking cost components 'website design in-house' - CC(1), 'website design third-party' - CC(33), and 'website maintenance in-house' - CC(11) (see Table 21).

\section{Performance Drivers}

37. Improving the Tesco.com in-house IT division and outsourcing much of the IT work was designed to improve the website. Improving the website was designed to enhance customer interaction with the site. This in turn helped stimulate customer acquisition by reducing the amount of time it took the customer to place their first order. In addition, this also improved repeat purchase due to the positive experience from interacting with the site. These relationships were represented by the links between the front-end order taking cost components 'website design in-house' - CC(1), 'website design third-party' - CC(33), 'website maintenance in-house' - CC(11) and the customer patronage performance drivers 'number of new customers - PD(1) and 'number of repeat customers' - $\mathrm{PD}(2)$ (see Figure 59).

38. The improvement to the IT department was also designed to improve the fulfillment function by upgrading stores to have a network that could communicate with the smart shopping carts. This was represented by the links between the front-end order taking cost components 'website design in-house' - CC(1), 'website design third-party' - CC(33), 'website maintenance inhouse' - CC(11) and the operational service performance drivers 'number of lines picked' - PD(16), 'picking speed' - PD(5), 'picking accuracy' - $\mathrm{PD}(6)$, 'packing speed' - $\mathrm{PD}(21)$, and 'assembly accuracy’ - PD(7) (see Figure 59).

39. The decision by Tesco to partner with Microsoft to provide consumers with Pocket PC based access to the Tesco.com website was to increase customer access. In addition, it also provided an alternative channel for customers already using the service. Thus, there were links between the front end order taking cost 
components 'website design in-house' - CC(1), 'website design third-party' - CC(33), 'website maintenance in-house' - CC(11) and the customer patronage performance drivers 'number of new customers' - PD(1) and 'number of repeat customers' - PD(2) (see Figure 59).

40. The decision by Tesco to create different websites based on usage behavior was designed to increase the frequency of use by new and occasional customers. This was represented by the links between the front-end order taking cost components 'website design inhouse' - CC(1), 'website design third-party' - CC(33), 'website maintenance in-house' - CC(11) and the customer patronage performance drivers 'number of new customers' - PD(1) and 'number of repeat customers’ - PD(2) (see Figure 59).

2002

Although Tesco had been given the title of the U.K.'s largest online grocer, there was still the question of costs. Many analysts note that Tesco.com's grocery unit was not making large sums of money, which prompted many analysts to ask why Tesco continued with the offer. What was driving Tesco's online push was market share. Because the company did not regard online retailing as a way of cannibalizing store sales, but as a way of growing market share, Tesco believed that the benefit of acquiring new customers was worth the delivery and picking costs. Thus, it seemed that Tesco viewed the online channel as a value added component to its service offering that also served as a profit center (Gregory 2002). Besides providing the company with a value added channel, Tesco used its ClubCard, in conjunction with its online channel, to better target customers. Specifically, using information collected through its ClubCard, Tesco planned to send targeted, personalized e-mails to customers. The basis or criteria for segmenting may have been the aisle, lifestyle, life stage, region, or basket of goods. According to Kanaiya Parekh, grocery project manager at Tesco.com, "We'll know 
exactly who the e-mail has gone to and we'll know exactly who buys product on line so we can see how effective the marketing campaign has been" (Gregory 2002, p. 37). If this promotional tactic proved successful, the company planned to try e-coupons. Using e-coupons the manufacturer of consumer goods products would send customers a targeted e-mail with a coupon attachment encouraging shoppers to visit the site and redeem the offer. If a shopper decided to redeem the coupon by inputting the coupon number at the checkout, the customer would received the price reduction, and both the retailer and supplier would know exactly who had redeemed the offer (Gregory 2002). According to company sources, Unilever was to be the first company to test the e-mail promotion by sending out four to six different e-mails in March.

Tesco.com also began offering high-end retail products online by developing a channel called Marketplace. The site offered products from more than 100 merchants including fashion brands Charles Tyrwhitt, Franchetti Bond and Denner Cashmere and home furnishing suppliers such as Cucina and Whittard of Chelsea. According to Roy Perticucci, business development director at Tesco.com, "This is part of Tesco's overall strategy to be as strong in non-grocery items as it is in grocery sales." To promote the site, Tesco.com used an e-mail marketing campaign. Marketplace was managed and hosted by e-commerce specialist Altura International. The deal between the two companies called for Tesco.com to receive a split of Altura International's sales commission on each of the products sold on its site (Revolution, February 20, 2002).

In March, Tesco decided to export its online shopping service to a third overseas market. The new service, known as Homeplus, conducted business from a store near Seoul, South Korea. This location was selected because it had a high Internet penetration 
rate (over 70\%) and a high population density. This demonstrated that the company was pursuing an international presence. The launch followed successful penetration into Ireland and the U.S. Based on research conducted by The Grocer, Tesco consistently outperformed the competition in terms of speed of website access, the ease with which an order could be completed, availability, and delivery reliability. However, stockouts and substitutions continued to be a problem for the company.

In April, Tesco reported that its online grocery segment and its financial services segment were profitable. In 2001 the financial services business was Tesco's fastest growing business unit. Profit for the company increased from $£ 6$ million to $£ 40$ million in 2002. The division had more than 2.5 million customer accounts, more than one million credit card holders and 500,000 vehicle insurance customers. During this time, the non-food segment was the second fastest growing business for Tesco with home entertainment sales up 80 percent over 2001 (Grocer, April 13, 2002). These claims of profitability excluded the start-up costs associated with the purchase of a minority interest in GroceryWorks, a subsidiary of the U.S. grocery giant Safeway. Many analysts believed that a significant proportion of the company's success was attributable to the brand building activities (i.e., customer acquisition, retention, and loyalty programs) that Tesco used (Campaign, April 19, 2002).

In an attempt to boost revenue and smooth demand, Tesco began charging more for its Friday night time slot. According to Carolyn Bradley, chief operating officer at Tesco.com, the Friday night slots were very popular for the customer, but, depending on the precise time, these delivery slots were expensive to cover due to the peak-traffic times. To cover the costs of delivery during these peak times, Tesco required customers 
to pay a variable charge anywhere from $£ 3.99$ to $£ 6.49$ (The Independent, April 24, 2002). Also in April, Tesco decided to use a tiered pricing strategy in order to alleviate delivery demand during peak hours. Specifically, Tesco customers in Hertfordshire and Essex were given the options of three price tiers such that deliveries before midday cost $£ 3.99$, deliveries between noon and 5:00 pm cost the usual £5, and deliveries during the peak time cost $£ 6.49$. Company officials noted that this price scheme would be applied to all of Tesco's service areas. Apparently, the new pricing scheme was designed to take the pressure off the fulfillment personnel by spreading the workload across the entire day (Bruce 2002).

In May, Tesco revamped its financial services website in order to make it more visually compatible with the main Tesco site. The new site revolved around a new search engine designed to speed up the search for insurance products. The decision to redesign the financial website was based on customer research that suggested that they preferred the simple layout of the Tesco.com site that had the navigation bars on the top left hand side as opposed to the financial sites current layout that had navigation buttons spread throughout the page (Financial Net News, May 6, 2002). (This demonstrates that Tesco was focused on improving customer value by increasing customer service).

In July, grocery retail analysts reported that Tesco was suffering from availability (i.e., stocking) problems. According to the reports, Tesco's in-store fulfillment model had accelerated store inventory turnover. Apparently, the scale of the operation had placed a heavy demand on in-store inventory. However, these same retail analysts felt that Tesco was in no worse shape than any of its rivals when it came to the problem of stockouts. Thus, this was a wide spread problem within the online channel (Hunt 2002). 
According to company spokespersons, Tesco was in the process of improving its availability problem.

In September, Tesco initiated a customer acquisition campaign designed to illustrate the ease of using Tesco.com. It highlighted Tesco's belief that by persuading consumers to try the service, they would remain loyal to it. The campaign was launched as an attempt to attract customers from other chains in the hopes of increasing market share. To prompt customers, Tesco sent a mailing to them which included a voucher offering a discount on a customer's first online order.

\section{Revenue Components}

41. Offering the e-mail promotional service to Unilever represented a revenue source for the company. This was represented by the revenue commission component 'promotional service' - RC(8) (see Table 21).

42. By launching the MarketPlace website, Tesco.com gained a new revenue source. This was represented by the revenue commission component 'third-party online channel revenue' - RC(17) (see Table 21).

43. By charging more for its Friday night deliveries, and by changing its pricing strategy in general, Tesco increased the revenue being generated from the core delivery fees. This was represented by the delivery revenue component 'core delivery fee' - RC(4) (see Table 21).

\section{Cost Components}

44. Tesco's decision to target customers with e-coupons represented another cost to the company. The cost was associated with providing the service itself and the administrative cost associated with overseeing it. These costs were represented by the front-end auxiliary service cost component ‘coupon redemption' - CC(13), the front-end general administrative cost components 'general and 
admin.' - CC(17), and 'other costs and expenses' - CC(18) (see Table 21).

45. The decision to provide a promotional service to consumer goods manufacturers based on ClubCard data represented a cost to the company in terms of the service itself and the general and administrative cost needed to oversee it. This was represented by the front-end auxiliary service cost component 'promotional' CC(14), and the front-end general administrative costs 'general and admin.' - CC(17) and 'other costs and expenses' - CC(18) (see Table 21).

46. Tesco's decision to launch the online website Marketplace to sell high-end retail products, by lending the Tesco brand name, represented certain costs to the company. One cost was associated with the development and maintenance of the website while another stemmed from the general and administrative costs associated with overseeing the venture. These costs were represented by the front-end auxiliary service cost component 'third-party online channel costs' - CC(39), and the front-end general and administrative cost components 'general and admin.' CC(17), and 'other costs and expenses' - CC(18) (see Table 21).

47. Tesco's decision to revamp its financial services website resulted in the company incurring additional costs. These costs stemmed from the design and maintenance of the web page and were represented by the front-end order taking cost components 'website design in-house' - CC(1), 'website design third-party' - CC(33), and 'website maintenance in-house' - CC(11) (see Table 21).

48. The decision by Tesco to launch a web based campaign resulted in the company incurring customer relationship costs. This was represented by the front-end cost components 'customer awareness done alone' - CC(7), and 'customer acquisition done alone' CC(8) (see Table 21).

\section{Performance Drivers}

49. The decision to provide the consumer goods manufacturers with a research and e-mail promotional service created an additional revenue source. Several manufacturers would need to subscribe to these services in order for them to be profitable. Nonetheless, this was represented by the links between the front-end auxiliary service cost components 'promotional' - CC(14), and 'research 
service' - CC(16) and the customer service performance drivers 'number using promotional' $\mathrm{PD}(19)$ and the 'number using research' - PD(20) respectively (see Figure 59).

50. Tesco's decision to use its own ClubCard data to target customers with e-mail coupons was designed to simulate the number of customers using the service. This was represented by the link between the front-end auxiliary service cost component 'coupon redemption' - CC(13) and the customer service performance driver 'number using coupon' - PD(12) (see Figure 59).

51. The customer service performance driver 'number using coupon' $\mathrm{PD}(12)$ was directly related to the customer patronage performance drivers 'number of new customers' - $\mathrm{PD}(1)$ and 'number of repeat customers'- PD(2) (see Figure 61).

52. The number of consumer goods manufacturing companies that used the e-mail promotional service had an impact on the number of customers redeeming coupons. This was represented by the link between the customer service performance driver 'number using promotional' - $\mathrm{PD}(19)$ and the customer service performance driver 'number using coupon' - PD(12) (see Figure 61).

53. The number of customers ordering from Tesco.com had a direct impact on the number of orders delivered and the number of vehicles used. This was represented by the link between the customer patronage performance driver 'number of orders' $\mathrm{PD}(3)$ and the delivery service performance driver 'number of orders delivered' - PD(9) (see Figure 61).

54. The more consumer goods manufacturers that use the research and promotional services the more profit Tesco.com received. These relationship were represented by the links between the customer service performance drivers ‘number using research' - $\mathrm{PD}(20)$, 'number using promotional' - $\mathrm{PD}(19)$ and the revenue commission components 'research service' - RC(9) and 'promotional service' $\mathrm{PD}(8)$ respectively (see Figure 62).

55. The more brand licensing agreements that Tesco engaged in the more revenue that the company generated. This was represented by the link between the customer service auxiliary performance driver 'number using third-party online channel services' - $\mathrm{PD}(23)$ and the commission revenue component 'third-party online channel revenue' - RC(17) (see Figure 62). 
In early January 2003, Tesco made the decision to offer its customers a low cost phone service. This was another attempt by Tesco to continue moving into the household services area. According to sources, Tesco entered into deals with the cable and wireless company, Servista, to provide the primary service and the customer management company, Vertex, to provide billing support. One of the benefits of the service was that it used new technology known as carrier pre-selection, which did not require callers to remember PIN numbers or to install any new equipment in their homes (EuropeMedia, Jan 27, 2003; The Guardian Jan 28, 2003).

In February, Tesco entered into an agreement with Marriott Hotels to offer ClubCard points to members of Marriott's loyalty program. This agreement built on Tesco's partnership with Air Miles. The program allowed members of Marriott's loyalty program to earn ClubCard points on stays at any of Marriott's 2300 global hotels. These points were then redeemable as Marriott loyalty points or ClubCard points or converted to Air Miles. The ClubCard points could then be used at Tesco stores, gas stations, or Tesco.com (Marketing February 27, 2003).

In March, Tesco began selling cut-price musical instruments on its Tesco.com site. Specifically, the company slashed the price of top-quality guitars, drum kits and keyboards. Initially, Tesco sold 37 different types of guitars, three basses, five drum kits and eight keyboards from manufacturers such as Fender and Yamaha (The Express on Sunday March 16, 2003; Daily Star, March 16, 2003). Initially these products were offered only on Tesco.com but the retailer had plans to bring these products into its BAM retail shops. 
In May, Tesco announced that the Tesco.com unit had achieved profitability. According to company insiders, Tesco.com's success was due to its innovative use of web services and its current XML technology. According to Jon Higgins, head of ecommerce development at Tesco.com, "Using existing strengths, such as IT infrastructure, was one of the most important factors behind our success. The investment we have made over the years on IT is pitiful when you compare it to the return on investment we have gained" (Computer Weekly, May 27, 2003, p8). By using the XML system, Tesco could plug in various modules without compromising the integrity of the software. According to Tesco the winning strategy required the company to begin slowly using existing systems to gain efficiencies.

By September, Tesco announced that sales for the Tesco.com division were up 30 percent over the previous year. This resulted in profits of £11million in the first half of 2003. According to Tesco, the growth in sales and profits were largely due to the growth in non-food sales. In October The Grocer reported the results of its annual mystery shopping research. According to the report none of the U.K. grocers were able to deliver the exact items ordered by The Grocer. These results highlighted that availability (i.e., inventory stock levels) was still a major problem for online grocery home delivery in the U.K. The problem manifested itself in the picking and packing functions by increasing the rate of substitutions and exclusions (Grocer, Oct 25, 2003).

In order to increase customer demand for its service, Tesco.com began a direct mailing campaign in November aimed at getting young couples to use Tesco's service. To generate the mailing list, Tesco used its ClubCard database to target 150,000 professional couples aged 30 to 35 who did not have children. According to Tesco, this 
segment was targeted because the company believed that it would benefit the most from Tesco’s delivery service due that segment's busy lifestyles. The mailing actually served two purposes. One was to raise awareness of the website and the other was to entice customers to try, or continue to use, the home delivery service. Inside the mailings was a step-by-step guide on using the site and included details concerning Tesco's personal shopper service and delivery information (Marketing, Nov 6, 2003). In addition, during December, Tesco created an online promotional campaign to build sales for its nongrocery products division. The 'Christmas Wish List' campaign, offered customers the chance to win $£ 1000$ worth of products and create a 'present wish lists', which could be e-mailed to friends or family (Marketing, Dec 4, 2003).

\section{Revenue Components}

56. Tesco’s decision to enter into a partnership with Servista and Vertex was to provide Tesco.com with another revenue source. Its deal with Marriott was also designed to generate additional revenue. These revenue sources were represented by the revenue commission component 'third-party online channel revenue' RC(17) (see Table 21).

57. By selling cut-priced musical instruments on the Tesco.com website, Tesco was generating another non-grocery revenue source. This was represented by the inventory sales revenue component 'non-grocery inventory sales' - RC(15) (see Table 21).

\section{Cost Components}

58. Tesco’s decision to enter into agreements with Servista and Vertex, to offer its customers low cost phone service, resulted in a cost for the company in the form of third-party online channel costs. Further, Tesco's agreement with Marriott to allow customers to gain ClubCard point based on the amount of money spent in Marriott lodgings also represented a cost for the company. These 
costs were represented by the customer relationship cost component 'third-party online channel costs' - CC(39) (see Table 21).

59. Offering these services also required Tesco to incur costs associated with overseeing the services. This was represented by the front-end general and administrative cost component 'general and admin.' - CC(17), and 'other costs and expenses' - CC(18) (see Table 21).

60. Tesco's decision to offer cut-priced musical instruments resulted in additional costs for the company in the form of inventory acquisition costs, inventory holding costs, and website design and maintenance costs. The inventory acquisition and holding costs were represented by the back-end inventory cost components 'nongrocery inventory purchased via manuf./wholesaler’ - CC(37), 'grocery storage and handling costs' - CC(27), and 'storage and handling costs' - CC(31) (see Table 21).

61. The website design and maintenance costs were represented by the front-end order taking cost components 'website design in-house' - CC(1), 'website design third-party - CC(33), and 'website maintenance in-house' - CC(11) (see Table 21).

62. Increasing the number of lines carried by the store resulted in increased general and administrative costs associated with coordinating activities. This was represented by the front-end general and administrative cost components 'general and admin.' CC(17), and 'other costs and expenses' - CC(18) (see Table 21).

63. The decision to launch direct marketing and promotional campaigns to increase demand for the service represented additional costs for the company in the form of customer relationship and auxiliary service costs. These costs were represented by the front-end customer relationship cost components 'customer awareness done alone' - CC(7), 'customer acquisition done alone' - CC(8), and 'auxiliary service promotional’ - CC(14) (see Table 21).

\section{Performance Drivers}

64. Tesco’s decision to offer its customers low cost phone services and ClubCard points for stays at Marriott lodgings represented the 
addition of content to Tesco's website from third party providers. The costs associated with providing this content drove the third party online channel. This was represented by the link between the front-end customer relationship cost component 'third-party online channel cost' - CC(39) and the customer service driver 'number using third-party channel' - PD(24) (see Figure 59).

65. The amount of revenue generated through the third-party online channel depended on the number of customers using the service. This was represented by the link between the customer service performance driver 'number using third-party online channel' $\mathrm{PD}(24)$ and the commission revenue component 'third-party online channel revenue' - RC(17) (see Figure 62).

66. The inventory costs were driven by the number of orders and the number of items per order. These were represented by the links between the customer patronage performance drivers 'number of orders' - PD(3), 'items per order' - $\mathrm{PD}(13)$ and the back-end inventory expense components 'grocery inventory purchased via manuf./wholesaler' - CC(23), 'non-grocery inventory purchased via manuf./wholesaler' - CC(37), and 'storage and handling costs' - CC(31) (see Figure 60).

67. Upgrades and enhancements to the website had two purposes. One was to drive customer awareness and acquisitions while the other was to improve certain aspects of the fulfillment function. The customer awareness and acquisition function was represented by the links between the order taking costs components 'website design in-house' - CC(1), 'website design third-party - CC(33), 'website maintenance in-house' - CC(11) and the customer patronage performance drivers 'number of new customers' - $\mathrm{PD}(1)$ and 'number of repeat customers' - PD(2) (see Figure 59). The improvements to the fulfillment function were based on the interaction between the computer network and the low automation cart technology. This was represented by the links between the order taking costs components 'website design in-house' - CC(1), 'website design third-party - CC(33), 'website maintenance inhouse' - CC(11) and the operational service performance drivers 'number of lines picked' - PD(16), 'picking speed' - PD(5), 'picking accuracy' - PD(6), 'packing speed' - $\mathrm{PD}(21)$, and 'assembly accuracy’ - PD(7) (see Figure 59).

68. The decision to launch a direct marketing campaign was designed to increase customer awareness and acquisition. This was represented by the links between the front-end customer 
relationship cost components 'customer awareness done alone' CC(7), 'customer acquisition done alone' - CC(8) and the customer patronage performance drivers 'number of new customers' - PD(1) and 'number of repeat customers' - PD(2) (see Figure 59).

2004

During April, Tesco announced it was entering the DVD movie rental market with its own online DVD offering. The service became active in March and allowed visitors to the site to rent movies from the 15,000 titles Tesco had in inventory. The site was actually run by Video Island, an online DVD download service. Subscribers to the service were able to rent an unlimited number of DVDs for a flat-rate monthly fee and had the chance to earn ClubCard points. According to Laura Wade-Gery, Tesco.com's chief executive, "DVDs-by-post has revolutionized the way people watch film in the US and we're confident by moving into the market that we can do the same in the U.K.” (Revolution, April 21, 2004, p.4). Once consumers enrolled in the service, they were prompted to compile a 'wish-list' of movies from the catalogue of titles. This ensured that the customers were always sent a movie title that they wanted. Further, customers could keep a film for as long as they liked, which eliminated the cost of late fees. This should have helped to increase overall satisfaction with the service. During this same period, Tesco.com reported a profit of $£ 28$ million, up from $£ 12$ million the previous year. This demonstrated that Tesco’s online home delivery service was making a contribution to overall company profits. This clearly put Tesco in the lead in terms of sales. In fact, the online division achieved sales of $£ 577$ million, up 29\% over 2003.

The phenomenal growth of Tesco’s online channel caused many analyst and industry watchers to question the mechanics behind the company's success. According 
to some, a primary advantage of the online channel was that it enabled Tesco to extend its range of non-food products beyond what the company was able to physically stock even in its largest superstores. For example, Tesco's in-store book selection only had about 120 bestselling titles while their online division had two million titles to choose from (Davies 2004). Over the previous two years, Tesco's non-food product sales had been increasing significantly. The key to this increase was the efficient use of its supply chain. Initially many of the non-food products Tesco sold online were products that the retailer already had experience with selling in its stores. Hence, Tesco understood the supply chain issues associated with those products. For those non-food products that Tesco did not have experience in selling, the company partnered with companies that specialized in those areas. For example, the handling and delivery of electronic products was performed by the catalog company Grattan. Similar agreements were made with Lastminute.com for its travel offers, Video Island for DVD rentals, and O2 for its mobile telephones. This model also extended to financial services where Tesco had a joint venture with Royal Bank of Scotland for banking and insurance services (Davies 2004). By partnering with companies that had the expertise in delivering specific types of products/services, Tesco was able to use a variety of supply chains to get product to the customer in the most efficient manner. Several analysts were quick to point out that Tesco did not sell any of the more problematic product categories such as clothing due to the return issues involved. In discussing Tesco’s non-food product selection, Laura Wade-Gery, chief executive of Tesco.com in 2004, noted that it was “. . . about finding the right categories to go with next where we can add value and it makes economic sense ... Sequencing is the challenge so we don't launch on too many fronts at once" (Davies 
2004, p. 39). Given the tremendous growth in the non-food sector, many analysts suggested that non-food sales were an essential component of Tesco's success online. However, Wade-Gery argued that Tesco's success was not driven by non-food product sales and that Tesco “ . . . made a profit of 28 million [pounds sterling] ... online when non-food was still young" (Davies 2004, p. 38).

In early June, Tesco announced that it was offering legal services in the form of a self-help law channel. Specifically, the company had partnered with Law Pack, a legal publisher, to offer legal books, kits, and software under the Tesco.com brand. The channel allowed customers to download information and forms related to a range of legal issues including wills, personal injury claims, pensions, property sales and an online legal jargon reference. The price of the service was comparable to that offered by Law Pack (New Media Age, June 3, 2004). Tesco's goal in providing the service was to provide basic legal services to the masses of people who were not currently using such services. Tesco viewed the inclusion of the legal services as a natural extension of the financial services that the company was already offering. This indicated that part of Tesco's strategy was to leverage its brand equity by licensing products under the Tesco brand.

Also during July, Tesco introduced an online brand that acted as an umbrella for the company's growing range of non-grocery products and services. The new brand, labeled Tesco Home (www.tesco-home.com) brought together 23 of Tesco's offerings which included home shopping, vehicle insurance, telecoms and utilities. The new site allowed users to navigate through the rooms of an interactive house to see where and how Tesco could offer valuable products and services to them. For instance, if the customer entered the hallway of the cartoon house and clicked on the suitcase, he/she would be 
provided with information on travel insurance. If a customer were to enter the lounge he/she could click on a piggy bank and receive information on Tesco Personal Finance while clicking on the mobile phone icon provided the customer with details concerning Tesco Mobile. Tesco’s goal was to use the site for a range of promotional activities. This was the first time the company had tried to cross-sell its products and services in this way (Marketing, July 14, 2004).

Tesco did not come to the decision to use a cartoon style house to represent serious content haphazardly. The decision to try to put a little entertainment into the personal finance area was based on the results of research Tesco conducted which found that customers reacted well to a company trying to add a sense of fun in selling products normally seen as boring (Hargrave 2004). According to Mike Dear, online marketing manager for Tesco Personal Finance, "[w]e believe we're now seeing the early adopters of the web being joined by people more used to interacting with game machines or TV, so they're open to being entertained. They may think the house looks a little strange at first, but we believe there will be a strong element willing to have a look at what's behind the rooms and the items in the house” (Hargrave 2004, p 20). The site also allowed Tesco to track customers as they move around the site. By providing their ClubCard number when they entered the site, Tesco could track the progress of customers as they progressed through the house to see what they were looking at.

During the month of July, Tesco also announced that it had signed a licensing deal with eDiets.com to acquire the rights to eDiets.com's technology. Subscribers to the e-mail based service were offered one of 19 personalized meal plans, a fitness program, newsletters, access to support groups, and a mentor program. Tesco augmented the 
service by allowing dieters to have the products contained in their personal meal plans delivered to their door once a week. For this service, Tesco charged customers £12.99. In September, Tesco began selling a BT-based 512 Kbps permanent Internet connection for £19.97 a month which complemented the dial-up service Tesco was already offering customers. At that price Tesco's broadband service was the cheapest, unlimited, full 512k speed service in the U.K. For the monthly fee, Tesco paid for the BT connection and provided the customer with a DSL modem. Tesco noted it was confident that it would attract thousands of users for its online service (The Online Reporter, Sept 6, 2004). Also during the month, Tesco.com announced that profits had increased by 95 percent to $£ 15$ million on sales of $£ 307$ million. Profits for the company’s financial services business increased to $£ 84$ million during the first half of 2004, of which Tesco's share was $£ 42$ million. At the time Tesco had 4.6 million customer accounts, of which 1.6 million were credit cards and 1.4 million were motor insurance policies.

In November, Tesco began offering a digital music downloading service similar to Napster. At the time of the announcement, Tesco controlled 15 percent of chart CD sales and had plans to gain a similar market share in the digital music download channel. The service worked by allowing customers access to more than 500,000 tracks that could be purchased for a flat rate of 79 pence while albums sold for $£ 7.99$. These tracks or albums could be downloaded directly to the customer's PCs or mobile audio playing devices. These files could then be copied onto blank CDs (Reece 2004). The service was actually run by Cable \& Wireless, one of Tesco's existing telecom partner, but it was powered by the German digital music provider 24/7 MusicShop. The network underlying Tesco’s music downloading service was capable of remembering what an individual 
customer had purchased in the past and allowed the customer to restore their music catalogue up to three times. For the consumer this was a benefit of the service. To complement the service, Tesco began selling digital music players on its website.

During December, Tesco made changes to its picking function by upgrading the picking carts. To accomplish this Tesco hired mobile computing specialist Xperience Group to supply 300 of Tesco's stores with the new technology. According to the multimillion pound contract, Xperience would provide Tesco with 5000 'pre-imaged' Xybernaut Atigo wireless flat panel display computers, along with a full set of support services. When attached to the shopping cart, the computers displayed the customer's shopping list allowing the picking personnel to improve their picking speed. Mike Yorwerth, Head of Operations and Infrastructure, noted that “... [o]ur pickers like it because it is fast, compatible with existing systems, and has a clear, bright screen display. From an IT point of view it suits our needs perfectly in that it is tough, intelligent technology, which can easily be integrated” (Wireless News, Dec 7, 2004).

The way the system worked was that once a customer completed his/her order, it was logged on to Tesco's central server network and then relayed to the store nearest the postal code provided by the customer. Once an order had been downloaded to the selected store's local server, it was then split into logical picking groups. These groups were then recombined in a particular order and then downloaded to the computers mounted on the picking carts. The system allowed for the picking personnel to fill multiple orders simultaneously. It guided the picking personnel through the store to the items on the list. The barcode reader attached to the picking cart allowed the picking personnel to scan picked items into the system and then progress to the next product on 
the list. Once the list was completed the trolley could be returned to the back of the store ready for the order to be delivered (M2 Presswire, Dec 7, 2004).

During the period between 2002 and 2003, Tesco was plagued by stockouts on its store shelves which resulted in products having to be substituted or excluded from customer orders. According to grocery retail analysts, Tesco.com needed to improve its stockout and substitution levels. The analysts note that Tesco.com's in-store pickers were discovering stockout levels as high as 10 percent. Based on these results, Sir Terry Leahy, Tesco's chief executive, vowed that Tesco would be number one in product availability, and towards that end he began making changes to the product replenishment area. An analysis of The Grocer's monthly Stockwatch data from November 2003 to November 2004 shows Tesco was superior to rivals in availability of promoted lines across 12 categories and just behind its rivals for normal lines. According to The Grocer, their Stockwatch monitor was more stringent than other similar measures because it measured products at risk of going out of stock during busy trading times. The term 'at risk' was defined as items with less than $10 \%$ of stock left on the shelf during peak periods. The statistic showed that Tesco had 13.6 percent of the tracked products at risk which was far below its rivals which had 17 and 17.7 percent of the tracked products at risk of a stockout. Hence, Tesco's replenishment strategy had actually improved the availability of products on the shelves.

\section{Revenue Components}

69. Tesco's decision to offer its customers a website dedicated to DVD rental was another revenue source for the company. This was 
represented by the revenue commission component 'third-party online channel revenue' - RC(17) (see Table 21).

70. Tesco’s decision to offer legal services under its Tesco.com website represented an additional revenue source for the company. This revenue source was represented by the commission revenue component 'third-party online channel services' - RC(17) (see Table 21).

71. Tesco’s partnership with eDiets.com also provided the company with an additional revenue source. This was represented by the revenue commission component 'third-party online channel service’ - RC(17) (see Table 21).

72. The decision to offer BT $512 \mathrm{Kbps}$ permanent Internet connections to its customers for a monthly fee represented another revenue source for Tesco. This revenue source was represented by the revenue fee component 'tesco.net subscription/membership fee' RC(14) (see Table 21). (Note: This revenue component had been previously removed once Tesco began offering its Internet connection for free. However, the company's broadband service was not free).

73. Tesco’s digital music download service represented an additional revenue source for the company. This was represented by the revenue commission component 'third-party online channel revenue’ - RC(17) (see Table 21).

\section{Cost Components}

74. The decision by Tesco to design a website that allowed its customers to rent DVDs represented another cost for the company. This was represented by the front-end order taking cost components 'website design in-house' - CC(1), 'website design third-party' - CC(33), 'website maintenance in-house’ - CC(11), and the auxiliary service component 'third-party online channel costs' - CC(39) (see Table 21).

75. The decision to offer legal services through the Tesco.com site represented a cost for Tesco. This cost was represented by the front-end customer relationship cost 'third-party online channel costs' - CC(39) (see Table 21). 
76. The development of the Tesco Home website represented additional costs for Tesco. These costs were represented by the front-end order taking cost components 'website design in-house' - CC(1), 'website design third-party' - CC(33), and 'website maintenance in-house’ - CC(11) (see Table 21).

77. Tesco's licensing deal with eDiets.com represented an additional cost to the company. This cost was represented by the front-end customer relationship cost 'third-party online channel cost' CC(39) (see Table 21).

78. Tesco's decision to partner with BT to deliver $512 \mathrm{Kbps}$ permanent Internet connections to its customers represented another cost for the company. This was represented by the front-end order taking cost component 'Internet access point' - CC(35) (see Table 21).

79. The decision by Tesco to offer its customers a digital music download service required the company to incur additional costs. These costs were represented by the front-end auxiliary service cost component 'third-party online channel costs' - CC(41) and the order taking cost components 'website design in-house' CC(1), 'website design third-party' - CC(33), and 'website maintenance in-house' - CC(11) (see Table 21).

80. By offering customers the opportunity to purchase digital music players on the Tesco.com site, the company incurred additional costs. These costs were represented by the back-end inventory expenses of 'non-grocery inventory purchased via manuf./wholesaler' - CC(37), and 'storage and handling costs' CC(31) (see Table 21).

81. The decision by Tesco to upgrade its picking carts represented a capital expenditure cost for the company. This was represented by the back-end capital expenditure cost 'fulfillment equipment (semi-auto)’ - CC(36) (see Table 21).

Performance Drivers

82. Tesco's decision to offer its customers a low cost DVD movie rental service represented the addition of content to Tesco's website from third party providers. The costs associated with providing the content helped drive the third party online channel. This was represented by the link between the front-end customer relationship cost component 'third-party online channel cost' - 
CC(39) and the customer service driver 'number using third-party channel' - PD(24) (see Figure 59).

83. The decision to offer legal services at a low cost represented the addition of content to Tesco's website from third party providers. The costs associated with providing this content helped drive the third party online channel. This was represented by the link between the front-end customer relationship cost component 'third-party online channel cost' - CC(39) and the customer service driver 'number using third-party channel' - PD(24) (see Figure 59).

84. Tesco’s decision to offer its customers access to third-party provider content from eDiets.com, represented the addition of more content to Tesco's website. This was represented by the links between the front-end customer relationship cost component 'third-party online channel cost' - CC(39) and the customer service driver 'number using third-party channel' - PD(24) (see Figure 59).

85. The decision by Tesco to offer its customers a digital music download service represented additional content from third party providers. This was represented by the link between the front-end customer relationship cost component 'third-party online channel cost' - CC(39) and the customer service driver 'number using third-party channel' - PD(24) (see Figure 59).

86. The revenue being generated by the content on the third-party online channel was based on the number of individuals using the channel. This was represented by the link between the customer service performance driver 'number using third-party online channel' - PD(24) and the commission revenue component 'thirdparty online channel revenue' - RC(17) (see Figure 62).

87. The number of individuals using the financial and third-party online channels was determined by the number of new and repeat customers. This was represented by the links between the customer patronage performance drivers 'number of new customers' - PD(1), 'number of repeat customers' - PD(2) and the customer service performance drivers 'number using financial services' - PD(23) and 'number using third-party channel' PD(24) (see Figure 61).

88. Customer awareness and customer acquisition costs are directly related to the number of customers using the financial services and 
the number of customers using the third-party online channel. This was represented by the links between the front-end customer relationship cost components 'customer awareness done alone' CC(7), 'customer acquisition done alone' - CC(8) and the customer service performance drivers 'number using third party online channel' - $\mathrm{PD}(24)$ and 'number using financial services' PD(23) (see Figure 59).

89. TescoNet's subscription fees were driven by the number of new and repeat customers using the service. This was represented by the link between the fee revenue component 'TescoNet subscription/membership fees' - RC(14) and the customer patronage performance drivers 'number of new customers' - $\mathrm{PD}(1)$ and 'number of repeat customer' - PD(2) (see Figure 62).

Profit Structure Summary from January 1999 - December 2004

During the period between 1999 through 2004, Tesco’s profit structure changed.

In 1999 Tesco decided to expand its operation to 100 stores and in 2000 the company made the decision to increase the network to include 300 stores. Each time that Tesco expanded the number of stores in its grocery home delivery network, the company incurred significant costs. For instance, capital expenditure costs, in the form of store conversion costs, were incurred to prepare each stores in the network to receive and deliver orders. Providing picking and packing personnel with specialized carts required further expenditures in the fulfillment equipment area. In order for Tesco to provide the delivery service to its customers, the company had to expand its delivery fleet. Once Tesco began making deliveries, normal wear and tear on the vehicles required that they be serviced, which resulted in fleet maintenance costs.

As Tesco's service grew, it added non-grocery products to its offering. This meant that Tesco had to have a structure in place to accommodate the purchasing, storage and handling of both grocery and non-grocery inventory. As the online service expanded 
Tesco's grocery sales increased resulting in an increase in the grocery inventory cost component. The addition of non-grocery items to Tesco's stores and website proved to be very popular. As a result, the costs associated with acquisition of the non-grocery items increased as well. As the sale of grocery and non-grocery product lines increased, Tesco incurred additional costs associated with the storage and handling of these products before they were delivered. With the increase in grocery sales, Tesco began to run into stockout problems. The inclusion of inventory related software was to improve the inventory replenishment and availability problem, but it too came with a cost.

Each time that Tesco expanded its operation, it also incurred significant costs associated with the fulfillment function. These costs were associated with the picking, packing, and delivery areas. Tesco's use of an in-store, labor intensive fulfillment model resulted in high labor costs. In addition, the costs associated with the delivery function also represented a significant portion of the total cost. Just as the picking and packing functions needed to be duplicated at each location the delivery function also needed duplication. Moreover, there were also costs associated with operating the low level automation equipment which further increased Tesco's costs.

Expanding Tesco's service also meant that the company had to expand its order taking capabilities. This required making changes to the website to reflect the inclusion of new stores in the network. Moreover, each time that Tesco added a new product category or a new service, the website needed to be changed to reflect these new products and services. Further, in order to keep the website running, there were costs associated with its maintenance. Tesco's decision to serve as an ISP required that the company 
acquire an Internet access point from BT. This represented another order taking expense for Tesco.

In order for Tesco to generate customer awareness and trial, the company conducted advertising and promotional campaigns in the off- and online domains. For online grocers, this is one of the most significant expenses but it is necessary to drive service usage. Another aspect of Tesco’s customer relationship expenditures revolved around providing auxiliary services to its business and consumer markets. For the business segment Tesco provided a coupon redemption service, a promotional campaign service, and an integrated research service. These costs were incurred in order to generate revenue streams from the consumer goods manufacturing companies. For the consumer market, Tesco provided several financial services and access to its non-grocery related content provided by third party retailers. These costs were incurred in order to drive the traffic on Tesco’s website and to provide the company with alternative revenue sources. As a result of providing and administering these new products and services, Tesco’s general and administrative fees increased. Given the scale of the company's online grocery and non-grocery operations, the general and administrative fees were a significant portion of its costs.

During the 1999 through 2004 period, Tesco added several new revenue sources. The decision to offer the consumer goods manufacturers’ promotional and research services provided Tesco with two new integrated marketing revenue sources. Tesco’s primary new revenue source came from its third-party online channel which provided the company’s ClubCard holders with access to content provided by third-party retailers. Lastly, given the amount of traffic that Tesco’s website was generating, the company 
began advertising on it. This allowed the company to generate indirect advertising revenue. The company also continued to generate revenue from inventory sales, core delivery fees, pension fees, and financial services.

In relation to the other mediating/moderating factors, Tesco underwent changes in some of these factors. In terms of the company related factors, scalability remained the same while the method of delivery was expanded to include a store pick-up option (see Table 22). The company's rate of expansion moved from moderate to fast as it expanded the store network of the online channel from 100 to 300 stores. The automation level moved from low to moderate as the company introduced new picking technology that combined in-store routing techniques to guide picking personnel. Employee commitment seemed to remain high for the service but there was a drop in management support due primarily to the cannibalization of in-store sales.

In terms of the market structure factors, Internet structure, penetration, and access increased, spurred by the general increase in demand for Internet use. Price competition at the ISP level had driven the cost of Internet service down to the point where the cost level was moderate compared to that in the U.S. In relation to the geographical location factors, Tesco's expansion to 300 stores represented a 90 percent coverage rate for the U.K. market. This meant that Tesco was covering urban, suburban, and rural communities. Other than this there were no other changes to the geographical factors (see Table 22). 
Table 22

Other Mediating/Moderating Factors for Tesco: January 1999 - December 2004

Jan. 1995 -

Dec. 1996

Company Related Factors

Scalability (Picking Location)

High

Medium Dedicated

Warehouse

Large Dedicated

Warehouse

Moderate

Wareroom (Hybrid)

Small Dedicated

Warehouse

Low

In-Store

Method of Delivery

Store Pickup

Local Pickup

Home Delivery

Company Rate of Expansion

Slow

Moderate

Fast

Automation Level

High

Moderate

Low

Employee/Management

Commitment

High

Moderate

Low
Jan. 1997 - Jan. 1999 -

Dec. 1998 Dec. 2004
$\mathrm{X}$

X

$\mathrm{X}$

$\mathrm{X}$

$\begin{array}{lll}\text { X } & \text { X }\end{array}$

$\mathrm{X}$

X

$\mathrm{X}$

$\mathrm{X}$

X

X

X

X 
Table 22 (Cont'd)

Other Mediating/Moderating Factors for Tesco: January 1999 - December 2004

Jan. 1995 - Jan. 1997 - Jan. 1999 -

Dec. 1996 Dec. 1998 Dec. 2004

Market Structure Factors

Connectivity

Internet Structure

High

Moderate

Low

$\mathrm{X} \quad \mathrm{X}$

Internet Penetration

High

Moderate

X $\quad$ X

Low

$\mathrm{X}$

Internet Access

High

Moderate

X $\quad \mathrm{X}$

X

Low

$\mathrm{X}$

Cost of Internet Service

High
Moderate
Low

Population Structure

Population Size

Population Density

Geographical Location

Continental

North America

South America

Europe

Asia
$\mathrm{X}$

X $\quad X$

Large Large Large

High High High

$\mathrm{X}$

X

$\mathrm{X}$ 
Table 22 (Cont'd)

Other Mediating/Moderating Factors for Tesco: January 1999 - December 2004

Jan. 1995 - Jan. 1997 - Jan. 1999 -

Dec. 1996 Dec. 1998 Dec. 2004

Country

United States

United Kingdom

$\mathrm{X}$

$\mathrm{X}$

$\mathrm{X}$

Japan

County/Parish

Urban

$\mathrm{X}$

X

X

Suburban

Rural

$\mathrm{X}$

$\mathrm{X}$

\section{Summary}

During the 1999 through 2004 period, Tesco remained customer focused by developing and providing new products and services to its customers. In 1999 the company launched an advertising campaign designed to stimulate customer trial by promoting the grocery home delivery service as a time saving one. In 2000, Tesco began to offer its customers an in-store grocery pick-up service for online orders, free delivery for non-grocery items, and began testing the viability of e-ClubCard point redemption. To promote these services the company used targeted advertising and banner ads. In 2002, the company again used targeted e-coupons to promote its services further demonstrating the company’s customer focus. Based on customer feedback, Tesco redesigned its financial services website in order to make shopping for financial products easier. Finally, in 2004 Tesco developed an umbrella online brand to bring all of its online services under one roof. The design of the site featured a cartoon house and 
according to customer input, they did not mind a humorous approach to selling 'boring' products.

Given the popularity of Tesco's online service, in 1999 the company decided to expand the service network to include 100 stores. By 2000, Tesco was making plans to expand the service network to 300 stores, which would give its online grocery home shopping service national coverage. By this point Tesco had come to the decision that an in-store fulfillment model was more cost effective than the construction of a dedicated fulfillment center. As a result of Tesco's service expansion and the increase in demand, the company had to re-engineer the online website due to the strain it was placing on system resources. By moving the online system to Tesco’s XML system, the company was able to gain the flexibility it needed to continue its growth.

While expanding its online grocery network, Tesco was still focused on saving money and improving efficiency whenever possible. For example, during 1999 the company continued to make improvements to its fulfillment area with the intention of reducing the incidence of mispicks and product exclusions from customer orders. In addition, the installation of new in-store picking technology improved the number of orders that could be picked, ensured order accuracy, increased employee picking speed, and reduced the number of mispicks. According to analysts and The Grocer’s mystery online shoppers, the fulfillment function was still problematic for Tesco. In 2004 Tesco invested in new picking technology from Xperience that further improved the number of orders that could be picked, ensured order accuracy, increased employee picking speed, and reduced the number of mispicks. By outsourcing much of the IT work and 
developing in-store picking technology, Tesco demonstrated it was trying to save money while at the same time upgrading its processes.

What drove Tesco's success during this period was the enormous amount of website traffic that the company generated. The traffic was generated by the inclusion of new products and services that were either directly provided by Tesco or provided by third-party retailers. In terms of new products, in 1999 Tesco developed handheld scanners for its customers that allowed them to scan items and compile a shopping list without having to look through Tesco's grocery inventory catalog. Further, the company began offering a wide variety of non-food products at competitive prices. This was part of Tesco's stated strategy which was to be as strong in non-grocery sales as it was in grocery sales online. In 2000, Tesco added consumer electronic to its product offering while in 2003 it added name brand musical instruments. In terms of new services, in 1999 Tesco began offering new banking services that allowed customers to check their accounts online and, through its banking relationships, allowed them to transfer money between other member banks. Free Internet access was another service Tesco was offering its customers. This decision served two purposes. One was to continue the customer focus strategy and the other was to generate revenue. In order to allow its customers access to content on the Internet, Tesco partnered with Excite to provide the extra website content. It was this decision that opened the door for Tesco to become a content provider by providing the company with sales data for non-grocery items and services. Tesco also began offering consumer goods manufacturers a research service that allowed them to study customer responses to ads that the manufacturers were running. 
In 2000, Tesco partnered with Startle, an entertainment e-commerce distributor of music and video, to provide its customers with CD and DVD sales opportunities. It also created a search engine called Express Shopper that retrieved the prices and names of every brand in a product category. The company also provided its customers with product label information and created a search engine that could sort the labeling information based on key words or ingredients. In 2001, Tesco offered consumer goods companies access to detailed information on the buying habits of an anonymous group of online shoppers. Also during this period Tesco made a deal with Microsoft to allow pocket PC users access to Tesco's website. Further, the company developed separate web pages for novice and experienced users of its service. In 2002, the company developed a website called Marketplace for selling high-end retail products that complemented the apparel that Tesco was already selling.

In 2003, Tesco added a new low cost wireless phone service for its customers and, in a deal with Marriott, allowed its ClubCard holders to gain points on stays at any of Marriott's 2300 global locations. This was a tie-in to the travel service it was already offering. In 2004, the company offered its customers a $512 \mathrm{Kbps}$ permanent Internet connection which was priced lower than competitor offerings. This demonstrated Tesco's commitment to offering customers low cost quality products. Tesco also began offering its customers the opportunity to rent DVDs. Since customers could keep the movie for an extended period this virtually eliminating late fees. In June, Tesco partnered with Law Pack, a legal publisher, to offer books, kits, and software through a law channel on its website. Tesco viewed this as a natural extension of its financial services. To further drive its content, Tesco offered its customers access to eDiets.com 
and then augmented the service by allowing customers the opportunity to have the products from their eDiets.com meal plan delivered to their homes. Finally, in November the company began offering its customers a digital music download service. Tesco was already offering its customers the opportunity to purchase CDs and DVDs online so this was a natural extension for them. At the time Tesco controlled 15 percent of the chart CD sales.

Hence, during the period between 1999 and 2004 Tesco seemed to be concerned with expanding its service to provide national coverage. By expanding the coverage nationally, the company was indirectly admitting that its online grocery home delivery service was doing well and the company viewed the channel as a profit center. This was demonstrated by Tesco's concern with increasing the number of new products in its nongrocery section while also increasing the content that it provided to its customers via the third-party online channel. These new products and services that Tesco was offering were designed to increase the amount of traffic that the site generated. To gain access to Tesco's website, however, customers needed to have a loyalty ClubCard. This allowed the company to track customers while they were on the site. By tying ClubCard points to purchases in-store or online, customers could redeem their point in the form of vouchers which in essence served as product discounts. By continually seeking customer feedback, Tesco was able to add the content to its website that customers wanted, which in turn reinforced the brand loyalty. Thus, Tesco's website was evolving into more than an online grocery home delivery service that delivered a few non-grocery items. It was evolving into an online content portal for which the grocery home delivery service was but one component. This is evident by the fact that the majority of Tesco's costs went to 
either increasing content for its website or to customer patronage activities such as targeted e-mails and direct mail vouchers designed to stimulate online traffic.

\section{Profit Structure Components: January 2005 to December 2006}

2005

In May, Tesco made a major online strategy shift by announcing that it planned to invest millions in a dedicated central automated fulfillment center in London. This move was prompted by Tesco's rival, Waitrose/Ocado, when it began to outsell Tesco in London. Most retail analyst noted that having a warehouse dedicated to online shopping was more efficient than picking products off the shelf, but that efficiency could only be reached with a high utilization rate. According to Laura Wade-Gery, chief executive of Tesco.com, the company's vast online customer base meant that a dedicated warehouse had become cost-efficient (Daily Mail (London), May 1, 2005).

2006

In February Tesco opened its first dedicated fulfillment center for grocery products in Croydon, south London. What was unique about the fulfillment center was that it looked like a warehouse on the outside but inside it was set up just like one of Tesco’s supermarkets. According to Andrew Higginson, finance director, since Tesco’s model relied on in-store picking, creating the fulfillment center in a supermarket format was essential. This indicated that the investment in its IT and low level shopping cart technology took precedent over the prospect of increasing efficiency by switching to an automated fulfillment center. According to Sir Terry Leahy, Tesco's chief executive, this 
format would only be used in a few key locations around the country (Barnes 2006). Tesco's decision to invest in a dedicated fulfillment center represented the use of business model 20 under the hybrid category (see Appendix 3). In addition to Tesco.com's grocery business, the company had a thriving non-food segment. The company had been developing the non-food network over the previous year and built a non-food only warehouse in Daventry, Northamptonshire. Tesco's decision to invest in a non-food fulfillment center highlighted the company's commitment to growing the nonfood segment of its business (Barnes 2006). One of the reasons that Tesco began focusing on the non-food sector was that sales in the online grocery sector had remained at about 5 percent over the previous three years.

In July Tesco entered the online clothing market by upgraded its website to allow customers to purchase children's clothing. This decision was part of Tesco's aim to build market share for the Tesco.com brand and boost its position in the clothing market. Before the upgrade, customers could only see the products online but had to go to select Tesco stores to actually buy them. A company spokesperson indicated Tesco's decision to sell clothes online was a trial phase and, if successful, Tesco would expand the program to include the rest of its clothing lines (Marketing, July 5, 2006 p12).

During the month of August, ComScore Networks, an Internet data tracking company, reported that Tesco was generating four times the online orders of its closest competitor. The company stated that Tesco.com had gained $66 \%$ of online grocery orders in the U.K., which amounted to, on average, about 30,000 orders per day. The report went on to note that while Tesco.com had generated sales of nearly £1 billion 
during 2005, online grocery sales were only £38.3 million, which accounted for a small proportion of the total revenues.

In February, Tesco opened its dedicated fulfillment center in Croydon and needed to provide the personnel with more advanced technology. Specifically, Tesco.com was testing a handheld device that combined satellite navigation, order processing, and mobile phone capabilities into one unit. This device made it possible for the delivery driver to do away with all the paperwork associated with delivering a customer's order. The devices were able to record the exact latitude and longitude of the delivery vans which was subsequently used to plot a precise path to a customer's home using an onscreen map. The process began with a driver downloading all the customer orders he/she was to deliver, to the handheld device. The download also included product substitution and exclusion information for each customer's order. Once the order lists were downloaded and the van was loaded, the handheld device would be placed in a mounted sleeve that allowed the delivery driver to see a map displaying the route to the first delivery. Once the delivery drivers made a delivery, the wireless system would upload the information to the main computer where the map to the customer's house was stored. This allowed different drivers to work different routes without sacrificing delivery efficiency and punctuality. The uploaded information also allowed Tesco to make improvements to its delivery routes and delivery time tables. These devices were being tested by the company as a way to increase the efficiency of the delivery function. There were also cost savings associated with reducing the number of hardware devices needed. According to Jon Higgins, Tesco’s IT director, drivers at the Croydon 
fulfillment center “ . . . are required to deliver across south London. It is impossible to know the whole area, so a navigation tool was needed” (Friedlos 2006, p3).

In August Tesco launched a new online non-food home shopping service called Tesco Direct. The site offered over 8,000 products including beds, sofas, kitchenware, electrical appliances, cameras, bikes, and golf clubs. The decision to enter the non-food online delivery sector was based on the company's belief that it had found a gap in the current market offerings. Based on Tesco's research, consumers revealed they experienced deep dissatisfaction with current services. The research showed that $63 \%$ of people had had to wait a day or more for a single, small item to be delivered, and 36\% complained about having to have had to wait weeks for a furniture order. To appeal to this market, Tesco’s service was promising customers next-day delivery on regular items purchased through the service and a two hour time slots for making deliveries. For furniture, however, there was a five to ten day wait but this wait was shorter than the ones offered by Tesco’s rivals (Europe Intelligence Wire, August 30, 2006). Once Tesco decided to launch the Tesco Direct site, the decision was made to outsource the delivery to TNT Logistics UK instead of trying to handle this function in-house. To make deliveries, TNT utilized dedicated Tesco Direct vehicles, as well as its own multi-user fleet, which was already equipped to handle furniture delivery. The logistics operation was housed at Tesco's new 38,000-square-meter National Distribution Center at Crewe, England. TNT managed the distribution center and the six home delivery platforms from Glasgow, Scotland to Exeter. Estimates projected that at least 200 TNT personnel would be need initially with more personnel added as sales volumes increased (The Journal of Commerce Online, Sept 6, 2006). 
During October, Tesco made the decision to offer computer software to its customers. This put the company head to head with Microsoft in the lucrative software market. The company launched Tesco-branded software in 100 stores with products including software for offices, security suites, personal finance, CD/DVD-burning, and photo-editing. These products retailed for less than $£ 20$ which undercut rival prices substantially (e.g., Microsoft Office was selling for as much as £300). To make the software available to its customers, Tesco launched a new website called TescoSoftware.com which also offered customer support functions. To acquire its own branded software, the company partnered with Formjet Innovation, a firm that specialized in acquiring territorial rights to alternative software products, and acquired the distribution rights to certain software products. Daniel Cook, Tesco's software buyer, pointed out that "Customers can access a wide range of good-quality computer hardware at amazing prices, but when it comes to software there is little choice and the prices are high. Our [offering] changes this" (Sunday Telegraph (London, England), Oct 1, 2006). Graham O'Reilly, director at Formjet Innovations noted "It's part of our strategy to let Tesco promote these items as their own brand of software. When the support comes in at our end, we will in essence, be working for Tesco” (Snowden 2006). O'Reilly went on to state "Quite a lot of development has gone into producing this software for Tesco .... The software has been specifically developed for [them]; the feature set, look and feel has been agreed based upon Tesco's customer base” (Snowden 2006). Hence, it seemed that the Formjet software was, in essence, being repackaged specifically for Tesco. Based on this arrangement, Tesco was actually serving at the marketing department for Formjet Innovation's new software (Snowden 2006). 
In November, the Grocer conducted its periodic test of online grocery shopping. The test was conducted by having mystery shoppers order a specific 33 items to be delivered. According to the mystery shopper using Tesco.com, the site was easy to access and navigate. Nonetheless, when it was necessary to select a time slot, Tesco.com was unable to offer next-day delivery and could only offer a time slot two days after the order had been placed. When it came time for the delivery Tesco was very punctual arriving well within the time period. The mystery shopper described the delivery personnel as helpful and extremely polite (Walker 2006a). However, this is where the pleasantries ended. When the mystery shopper unpacked the order it was incomplete with two substitutions, as well as various out of stocks (i.e., missing products) and an assortment of un-ordered or unwanted items. According to The Grocer the problem of substitutions had been problematic in the past, and while the online retailer had improved, in terms of the items they select for substitutions, the sheer number of switches still disappointed the mystery shopper. The mystery shopper indicated that the substituted items were more expensive than the original products ordered and that the shopper was charged the higher prices of the substituted items (Walker 2006a).

This finding suggested that Tesco.com's replenishment program was incapable of keeping up with demand, which was demonstrated by the level of stockouts. As a result, the picking function was plagued by incomplete orders in the form of substitutions or product exclusions. The fact that Tesco invested in 'smart carts', that allowed the picking personnel to scan products before they were placed in the cart, indicated that tedium, or time restrictions placed on the picking personnel may have played a major role in the level of inaccuracies in customer orders. That is, the carts were designed so that picking 
personnel could scan the bar codes of the selected item and have the computer verify a match between the product selected by the picking personnel and the product requested by the customer. The system was designed to indicate instances of a mismatch. Thus, the probability of an unordered or unwanted item being included in the customers order was close to zero. Therefore, it seemed that the picking personnel were circumventing the system either due to time pressure or fatigue. Grocery industry analysts noted that these findings were disturbing for the online channel. Tim Denison, a member of the KPMG/SPSL Retail Think Tank, noted that service execution was the cornerstone of sound retailing. Specifically he stated "Despite the acceptance of Internet retailing as a mainstream channel, the fundamentals of retailing remain unchanged. The technology aspect comes behind getting the traditional retailing basics right. . . People expect to receive the same or higher levels of service that they receive in store. That's not occurring [online]" (Walker 2006b).

Tesco’s Profit Structure Analysis from January 2005 to December 2006

\section{Revenue Components}

90. The development of the website for selling children clothes represented another revenue source for Tesco.com. This was represented by the inventory revenue component 'non-grocery inventory sales' - RC(15) (see Table 23).

91. The development of the Tesco Direct website provided Tesco with another revenue source. This was represented by the inventory revenue component 'non-grocery inventory sales' - RC(15) (see Table 23).

92. The development of a website for selling computer software presented Tesco with another revenue source. This was represented by the commission revenue component 'third-party online channel revenue’ - RC(17) (see Table 23). 
Table 23

Tesco’s Profit Structure Components: January 2005 - December 2006

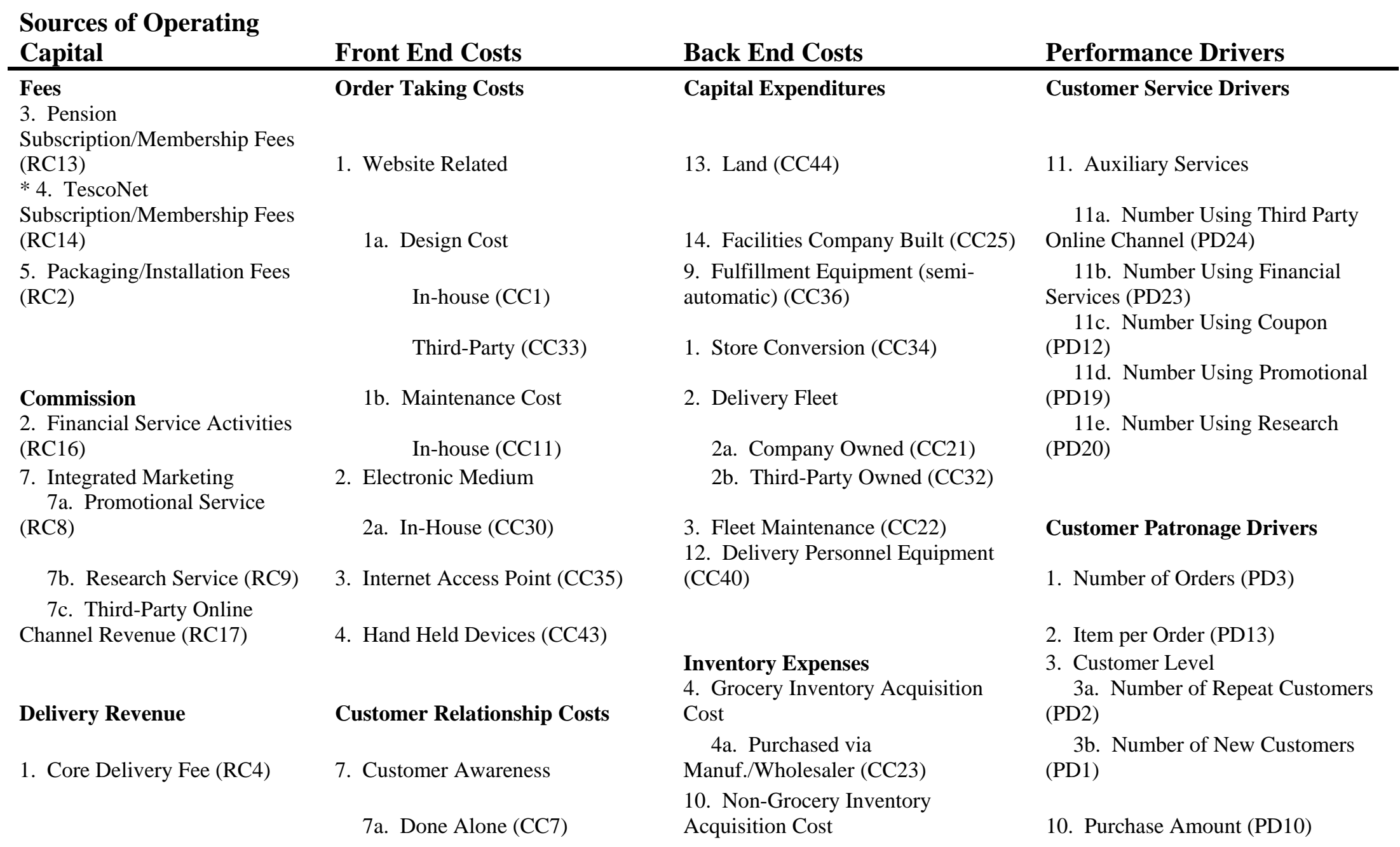


Table 23 (Cont'd)

Tesco’s Profit Structure Components: January 2005 - December 2006

\section{Sources of Operating \\ Capital}

Inventory Sales

1. Grocery Inventory Sales

(RC12)

6. Non-Grocery Inventory Sales

(RC15)

\section{Website Revenue}

8. Indirect Advertising Revenue

(RC11)

\section{Front End Costs}

8. Customer Acquisition Costs

8a. Done Alone (CC8)

12. Auxiliary Service Level

12a. Financial Services Related (CC38)

12b. Coupon Redemption (CC13)

12c. Promotional (CC14)

12d. Research Service (CC16)

12e. Third-Party Online Channel Costs (CC39)

\section{General And Administrative}

10. General and Admin. (CC17)

11. Other Costs and Expenses

(CC18)

\section{Back End Costs}

10a. Purchased via

Manuf./Wholesaler (CC37)

5. Storage and Handling Costs

(CC31)

11. Inventory Related Software

(CC42)

\section{Fulfillment Expenses}

6. Picking Costs (F,V)

6a. Human Capital (CC4)

6b. Hybrid (Some Automation)

(CC18)

7. Packing/Assembly Costs (F,V)

7a. Human Capital (CC5)

7b. Hybrid (Some Automation)

(CC19)

8. Delivery Costs

6a. Fuel Costs (CC6)

6b. Delivery Personnel Costs (CC17)

\section{Performance Drivers}

\section{Delivery Service Drivers}

5. Number of Orders Delivered (PD9)

6. Number of Vehicles Used (PD15)

7. Number of Delivery Attempts

(PD14)

8. Delivery Truck Capacity (PD22)

12. Routing and Scheduling Process

(PD17)

\section{Operational Service Drivers}

9. Fulfillment Performance

9a. Picking Speed (PD5)

9b. Number of Lines Picked (PD16)

9c. Packing Speed (PD21)

9d. Picking Accuracy (PD6)

9e. Assembly Accuracy (PD7) 


\section{Cost Components}

93. Tesco's decision to construct a dedicated central semi-automated fulfillment center represented a significant number of costs for the company. These costs were represented by the capital expenditure costs 'land' - CC(21), 'facilities company built' - CC(25), 'fulfillment equipment (semi-auto)' - CC(36), 'delivery fleet company owned' - CC(21), and 'fleet maintenance' - CC(22) (see Table 23).

94. Tesco's decision to invest in dedicated fulfillment centers for the non-food division resulted in significant costs for the company. These costs were represented by the back-end capital expenditure components 'land' - CC(21), 'facilities company built' - CC(25), 'fulfillment equipment (semi-auto)' - CC(36), 'delivery fleet company owned' - CC(21), and 'fleet maintenance' - CC(22) (see Table 23).

95. For the grocery fulfillment center in Croydon, Tesco also incurred costs associated with the fulfillment function. These costs were represented by the back-end fulfillment expense components 'picking costs human capital' - CC(4), 'picking costs hybrid (some automation)' - CC(18), 'packing/assembly costs human capital' CC(5), 'packing/assembly costs (some automation)' - CC(19), 'delivery personnel cost' - CC(17), and 'fuel costs' - CC(6) (see Table 23).

96. The decision by Tesco to begin selling clothes on the Tesco.com site required the company to add content to its website. This cost was represented by the front-end order taking cost components 'website design in-house' - CC(1), 'website design third-party' CC(33), and 'website maintenance in-house' - CC(30) (see Table 23).

97. The development of new equipment designed to improve efficiency for the delivery function represented another cost for the company. This was represented by the back-end capital expenditure component 'delivery personnel equipment' - CC(40) (see Table 23).

98. The decision by Tesco to develop its new online service known as Tesco Direct required Tesco to develop a website and procure and store inventory. These costs were represented by the front-end order taking cost components 'website design in-house' - CC(1), 'website design third-party' - CC(33), 'maintenance in-house' - 
CC(30), the inventory expenses 'non-grocery inventory purchased via manuf./wholesaler' - CC(37), and 'storage and handling costs' - CC(31) (see Table 23).

99. The decision by Tesco to outsource the non-food product deliveries represented a cost for the company since it would need to buy delivery vehicles and pay a third-party logistics provider. The decision also represented a cost savings in the delivery area since Tesco did not need to build a non-food delivery channel itself. These costs were represented by the back-end capital expenditure components 'delivery fleet company owned' CC(21), and 'delivery fleet third-party owned' - CC(32) (see Table 23).

100. The decision by Tesco to begin selling computer software on the Tesco.com site required Tesco to develop the TescoSoftware.com website. This cost was represented by the front-end order taking cost components 'website design in-house' - CC(1), 'website design third-party' - CC(33), 'website maintenance in-house' - CC(30), the auxiliary cost component 'third-party online channel costs' - CC(39), the general and administrative cost components 'general and administrative' CC(17), and ‘other costs and expenses’ - CC(18) (see Table 23).

\section{Performance Drivers}

101. By constructing a dedicated fulfillment center that was not open to the public, there were no customers inside. The reduction in store traffic improved the picking speed, picking accuracy, packing speed, and assembly accuracy. In addition, by removing certain in-store displays and the majority of cash registers, Tesco was able to increase floor space and thus carry more product lines. These relationships were depicted by the links between the backend capital cost component 'facilities company built' - CC(25) and the operational service performance drivers 'picking speed' $\mathrm{PD}(5)$, 'picking accuracy' - PD(6), 'packing speed' - PD(21), 'assembly accuracy' - PD(7), and 'number of lines picked' PD(16) (see Figure 63).

102. The cost associated with fleet maintenance was determined by the delivery truck capacity, number of delivery attempts, and the number of vehicles used. This was represented by the links between the delivery services performance drivers 'delivery truck capacity’ - PD(22), ‘number of delivery attempts’ - PD(14), 
Figure 63

Tesco’s Back-End Cost Components and Performance Drivers: January 2005 - December 2006

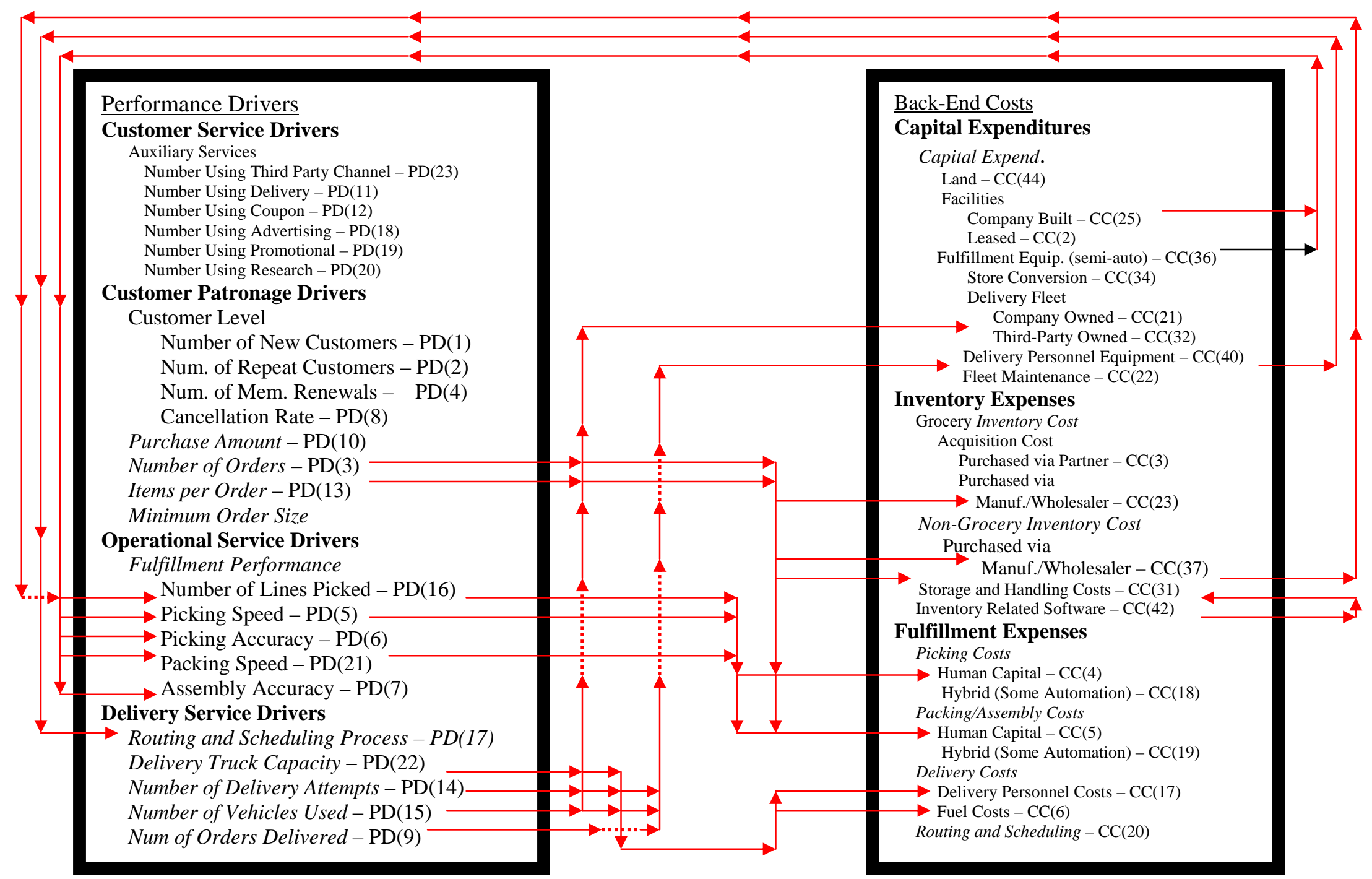


'number of vehicles used' - PD(15) and the back-end capital expenditure cost 'fleet maintenance' -CC(22) (see Figure 63).

103. The delivery personnel and the fuel costs were determined by the number of vehicles used, number of delivery attempts, and delivery truck capacity. This was represented by the links between the 'delivery truck capacity' - $\mathrm{PD}(22)$, 'number of delivery attempts' - PD(14), 'number of vehicles used' - PD(15) and the back-end fulfillment expenses 'delivery personnel costs' - CC(17) and 'fuel costs' - CC(6) (see Figure 63).

104. The decision to begin selling clothes on its website was done to stimulate customer patronage behavior. This was represented by the links between the front-end order taking cost components 'website design in-house' - CC(1), 'website design third-party' - CC(33), 'website maintenance in-house' - CC(11) and the customer patronage performance drivers 'number of new customers' - PD(1) and 'number of repeat customers' - $\mathrm{PD}(2)$ (see Figure 64).

105. Non-grocery inventory sales were determined by the number of orders, number of items per order, and the number of lines being picked. These relationships were depicted by the links between the customer patronage performance drivers 'number of orders' - $\mathrm{PD}(3)$, 'items per order' - $\mathrm{PD}(13)$ and the inventory sales revenue component 'non-grocery inventory sales' - RC(15) (see Figure 65).

106. The delivery personnel equipment was designed to improve certain aspects of the routing and scheduling process. This was represented by the link between the back-end capital expenditure component 'delivery personnel equipment' - CC(40) and the delivery service performance driver 'routing and scheduling process’ - PD(17) (see Figure 63).

107. The routing and scheduling process had an impact on the delivery truck capacity, and the number of orders delivered. These relationships were represented by the links between the delivery service performance driver 'routing and scheduling process' $\mathrm{PD}(17)$ and the other delivery service performance drivers 'delivery truck capacity' - $\mathrm{PD}(22)$ and 'number of orders delivered’ - PD(9) (see Figure 66).

108. Storage and handling costs were determined by the number of orders and the number of items per order. These relationships 
Figure 64

Tesco’s Front-End Cost Components and Performance Drivers: January 2005 - December 2006

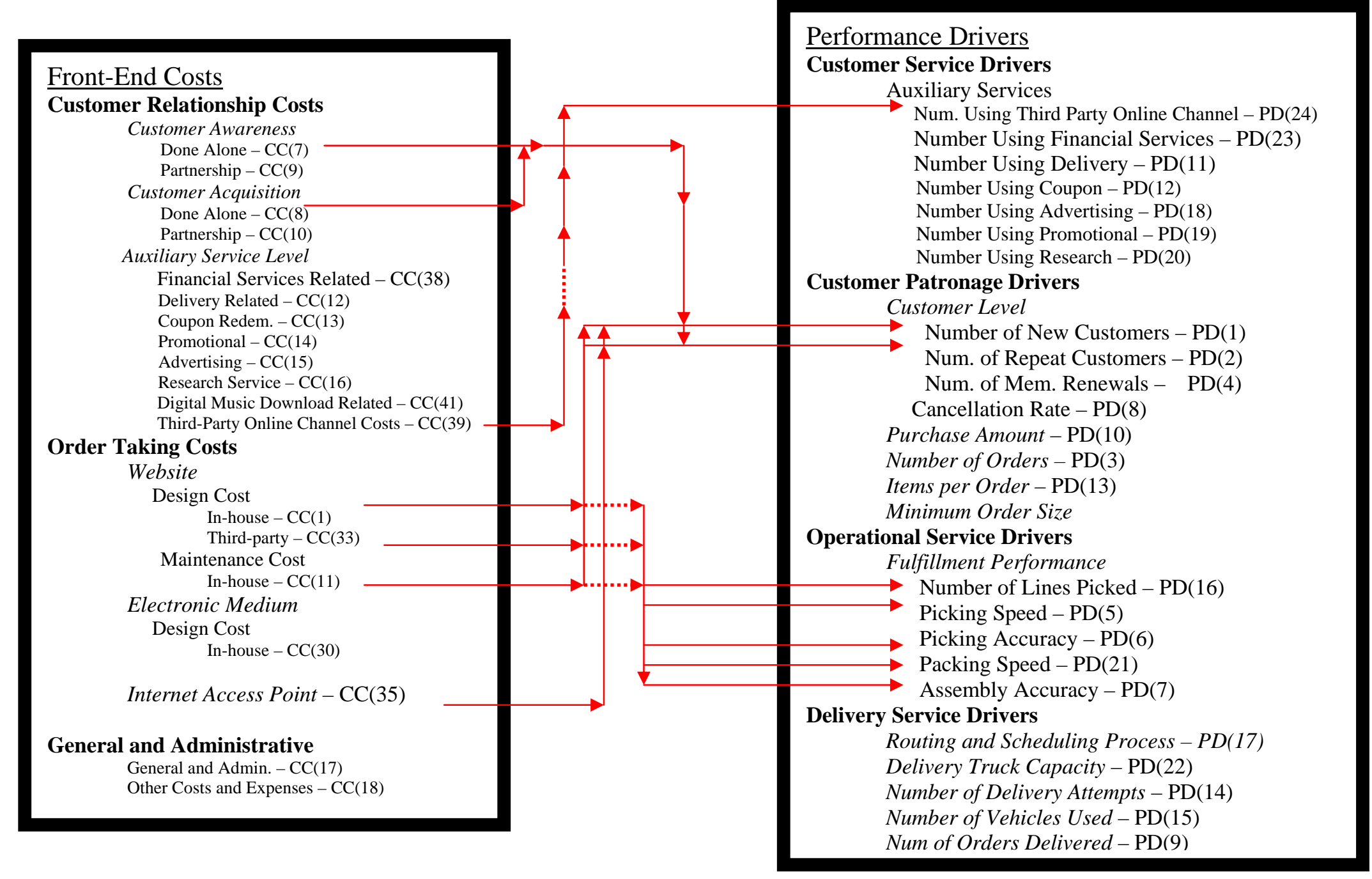


Figure 65

Tesco’s Performance Drivers and Revenue Components: January 2005 - December 2006

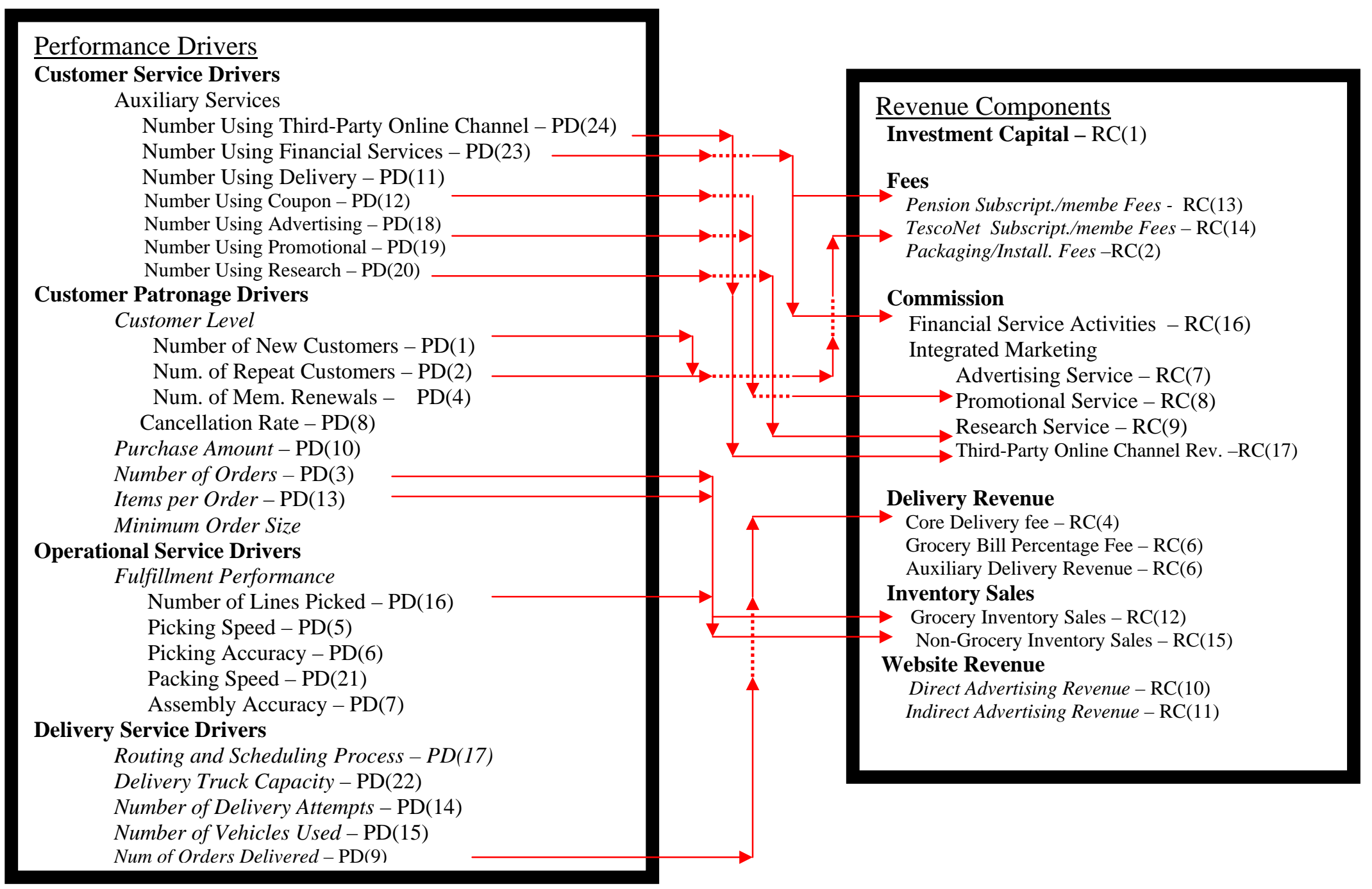


Figure 66

Tesco’s Performance Drivers and Performance Drivers: January 2005 - December 2006

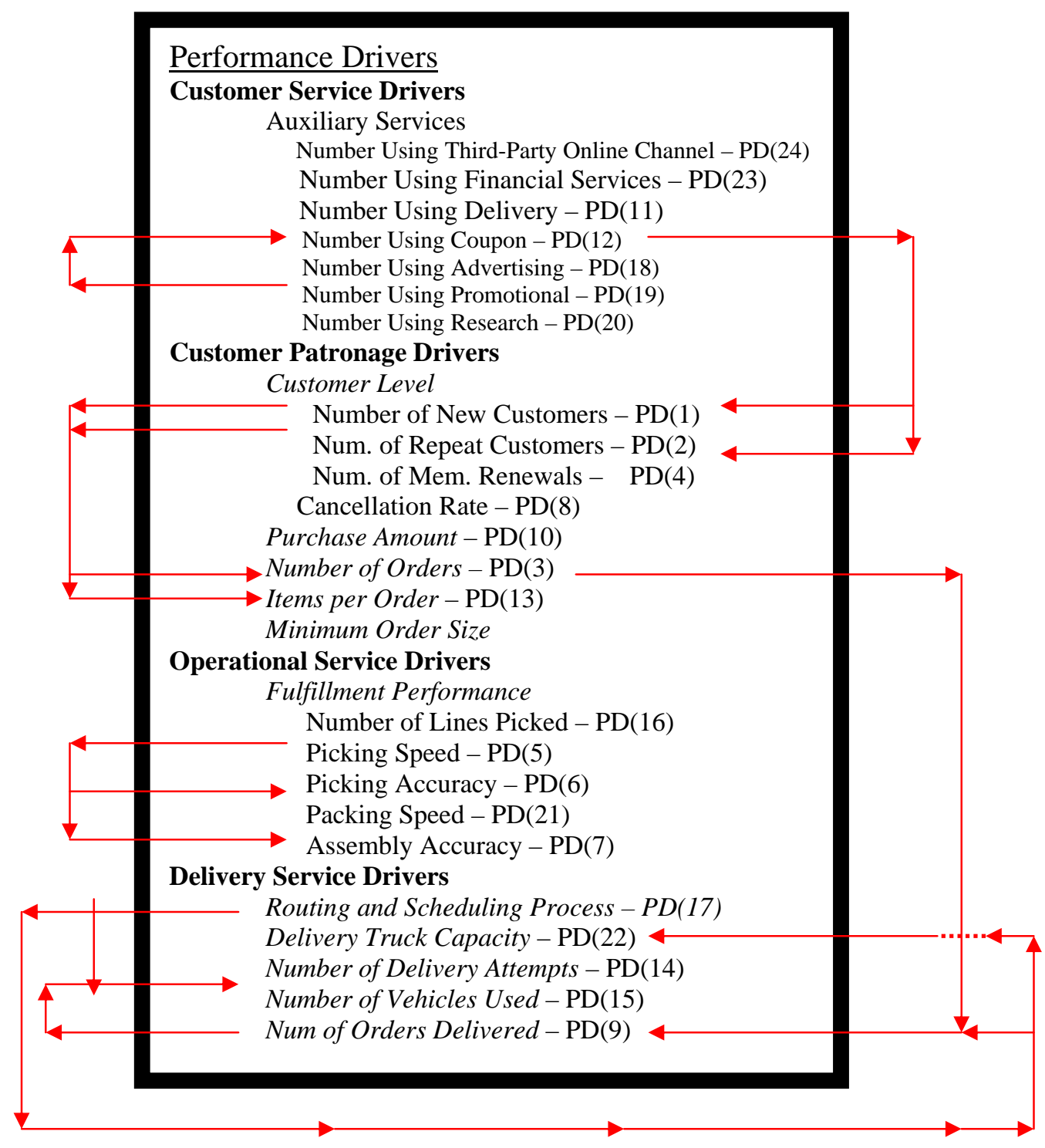


were depicted by the links between the customer patronage performance drivers 'number of orders' - $\mathrm{PD}(3)$, and 'items per order' - $\mathrm{PD}(13)$, and the back-end inventory expense component 'storage and handling costs' - CC(31) (see Figure 63).

109. The costs associated with non-grocery third-party delivery was driven by the delivery truck capacity, number of delivery attempts, the number of vehicles used, the number of orders, and the amount of items to deliver. These relationships were represented by the links between the customer patronage performance drivers 'number of orders' - $\mathrm{PD}(3)$, 'items per order' - $\mathrm{PD}(13)$, the delivery service performance drivers 'delivery truck capacity' - PD(22), 'number of delivery attempts' - PD(14), 'number of vehicles used' - PD(15), and the back-end capital expenditure component 'delivery fleet third-party owned' CC(32) (see Figure 63).

110. The revenue produced from the third-party online channel was determined by the number of customers using that channel. This was represented by the link between the customer service auxiliary performance driver 'number using third-party online channel' - PD(24) and the revenue component 'third-party online channel revenue' RC(17) (see Figure 65).

Profit Structure Summary from January 2005 to December 2006

Tesco's profit structure during the period between 2005 and 2006 is practically identical to the profit structure during the period between 1999 and 2004. The only major differences in expenditures were the inclusion of capital costs associate with the purchase of land, the building of a dedicated fulfillment center, the development of delivery personnel equipment, and the costs associated with third-party logistics and delivery. In terms of its revenue stream, selling clothes, computers, and other non-grocery items through its website provide Tesco with additional revenue sources. Other than these changes, there were no other changes to the profit structure. 
In terms of the other mediating/moderating factors, the decision to construct a dedicated fulfillment center represented a change in scalability from low to moderate (see Table 24). The methods of delivery remained the same while the rate of expansion subsided to a slow rate as Tesco looked to expand the service to other counties. The automation level remained the same and the employee and management commitment levels remained unchanged. In terms of the market structure factors there were not changes (see Table 24).

Table 24

Other Mediating/Moderating Factors for Tesco: January 2005 - December 2006

$\begin{array}{llll}\text { January } & \text { January } & \text { January } & \text { January } \\ 1995- & 1997- & 1999- & 2005- \\ \text { December } & \text { December } & \text { December } & \text { December } \\ 1996 & 1998 & 2004 & 2006\end{array}$

Company Related Factors

Scalability (Picking

Location)

High

Medium Dedicated

Warehouse

Large Dedicated

Warehouse

Moderate

Wareroom (Hybrid)

Small Dedicated

Warehouse

X

Low

In-Store

X

X

X

X

Method of Delivery

Store Pickup

$\begin{array}{llll} & & X & X \\ X & X & X & X\end{array}$

Home Delivery

(n)


Table 24 (Cont'd)

Other Mediating/Moderating Factors for Tesco: January 2005 - December 2006

Company Rate of

$\begin{array}{cccc}\text { January } & \text { January } & \text { January } & \text { January } \\ 1995- & 1997- & 1999- & 2005- \\ \text { December } & \text { December } & \text { December } & \text { December } \\ 1996 & 1998 & 2004 & 2006\end{array}$

Expansion

Slow

Moderate

$\mathrm{X}$

$\mathrm{X}$

Fast

$\mathrm{X}$

$\mathrm{X}$

Automation Level

Low

$\mathrm{X}$

X

Moderate

$\mathrm{X}$

X

High

Employee/Management

Commitment

High

Moderate

X

X

Low

Market Structure Factors

Connectivity

Internet Structure

High

Moderate

Low

X

X

X

Internet Penetration

High

Moderate

$\mathrm{X}$

X

X

Low

X

$\mathrm{X}$

Internet Access

High

Moderate

Low

X

X

$\mathrm{X}$

X 
Table 24 (Cont'd)

Other Mediating/Moderating Factors for Tesco: January 2005 - December 2006

$\begin{array}{cccc}\text { January } & \text { January } & \text { January } & \text { January } \\ 1995- & 1997- & 1999- & 2005- \\ \text { December } & \text { December } & \text { December } & \text { December } \\ 1996 & 1998 & 2004 & 2006\end{array}$

Cost of Internet Service

High

Moderate

Low

$\mathrm{X}$

Population Structure

Population Size

Population Density

Large Large Large Large

High High High High

Geographical Location

Continental

North America

South America

Europe

X

$\mathrm{X}$

$\mathrm{X}$

$\mathrm{X}$

Asia

Country

United States

United Kingdom

Japan

X

X

X

X

County/Parish

Urban

Suburban

X

Rural

$\begin{array}{lll}X & X & X \\ & X & X \\ & X & X\end{array}$

\section{Summary}

During the period between 2005 and 2006, Tesco continued to demonstrate its

customer focus. In 2006 the company added a website for purchasing children's clothes which was done to help increase the company’s share in the clothing market. In addition, 
the decision to launch the Tesco Direct site was another attempt to gain market share in the non-grocery market by offering customers over 8,000 items including beds, sofas, kitchenware, electrical appliances, cameras, and bikes. Moreover, in October, Tesco began selling computer software on its website which included products such as software for offices, security suites, personal finance, CD/DVD-burning, and photo-editing. By keeping the price of these products under $£ 20$ while comparable products were selling for as much as $£ 300$, Tesco again demonstrated its customer focus and commitment to providing its customers with low priced quality products and services.

Also during this period Tesco continued to make upgrades to its fulfillment and delivery functions. In terms of the delivery function, Tesco developed handheld devices for its delivery personnel which allowed them access to digital maps and GPS positioning. This also had the benefit of improving the routing and scheduling processes. By improving these processes, Tesco improved the overall efficiency of the fulfillment and delivery functions. The decision to outsource the non-grocery delivery function to TNT Logistics represented a cost saving measure because Tesco did not bring this function in-house. Even though Tesco was making progress in improving its fulfillment function, the availability and mispicking problems still plagued the company. Several mystery shoppers continually gave Tesco high marks for the courteousness and punctuality of its delivery personnel but gave the company poor marks when it came to mispicks, substitutions, and product exclusions from orders. This finding suggested that Tesco.com’s replenishment program could not keep up with demand. 


\section{General Summary}

During the period between 1995 and 1996, Tesco was concerned with determining whether or not the consumer direct channel would be right for its business. The company’s initial foray into the channel was in the form of a partnership with CompuServe to deliver wines. Under the agreement, CompuServe would take the customer's wine order and then forward it electronically to Tesco. Tesco would then forward it electronically to its warehouse, where the wine would be selected, packaged, and picked up by courier and delivered to the customer. These initial tests provided Tesco with valuable information concerning order taking requirements and parts of the fulfillment requirements, as well as an understanding of the administrative requirements necessary to keep the channel operational.

Tesco’s first attempt at delivery in the consumer direct channel came in the form of a partnership with social services. Specifically, in early 1996 Tesco conducted home delivery service trials for 150 pensioners in Ealing. The pensioners were provided with a catalog of 2500 products to order from by phone or by post. The idea was to test the viability and economics of the home shopping and delivery channel and provide Tesco with vital information before the company committed itself to a full national roll-out. The company seemed to view the development of the online channel as an important part of its long-term strategy. Thus, at this point Tesco viewed the online channel as a value added component to its service as opposed to a stand alone profit center. It was during these initial tests that Tesco experimented with the in-store fulfillment model. By September Tesco’s home delivery program had expanded to include more residents of Ealing. Sources said the trial was initially being limited to a small number of people in 
order for the company to develop a level of expertise before considering expansion. The company had plans to expand the store network to 37 stores and then to 100 stores by the end of February of the following year.

With the information that Tesco was receiving from its initial online test, the company made the decision to expand the service. Cautiously, the company outfitted a store in Osterley that was equipped to accept orders by phone, fax, or a crude website. In order for customers to place their orders, they needed to install a program that gave then access to the list of products they could choose from. However, those who used the software noted that it was difficult to use because it contained no illustrations of the products, and, when searching for a specific product, the search tool would sometimes bring up completely irrelevant items.

Based on the performance of Tesco’s initial website, it seems that Tesco was taking it slow in its approach to the online consumer direct channel. To help correct these problems with its website, the company contracted with BIT Group’s Interactive Development Division to help make the website more customer friendly. By focusing on the customer interface, Tesco demonstrated that it had a customer focus from the start. Customers indicated that with the redesign of the website, it was more reflective of the company. This indicated that Tesco’s customers were accustomed to the company’s customer focus strategy. Lastly, the company took a very inexpensive way to promote its new service by using flyers or leaflets placed in the mailboxes of consumers in the service area.

For the period between 1997 and 1998, Tesco continued to operate cautiously in the online consumer direct channel. Results from the initial tests the company conducted 
were so successful that it put Tesco’s website in the top ten most popular websites in the U.K. Thus, from the first set of stores outfitted for online grocery home delivery Tesco was already reaping some benefits, and according to a company insider, the online home delivery service was already showing a profit. As a result, in April, Tesco announced that it was expanding its online service in the U.K. to Hammersmith, Sutton, Romford, Leeds, and the Lea Valley. By September, online sales were so successful that Tesco decided to extend the test to another twelve stores and began contemplating a national rollout. The decision to expand the service demonstrated that Tesco believed that it could make a profit from its home delivery services (Lee 1997a).

During this period Tesco remained customer focused and introduced new products and services to its customers. For example, in February, Tesco offered new and expectant mothers a stand alone catalogue designed to provide them with information concerning precise stages of pregnancy and detailing ideas for food, drink, skincare, toiletries, and baby bath products. The catalogue was designed to complement the BabyClub loyalty program that was launched in January. Also during this period, Tesco entered into talks with the Bank Group, which was comprised of The Royal Bank of Scotland (RBS), Direct Line, and Scottish Widows in order to develop and launch a set of financial products for its customers. Tesco's research revealed that customers would be happy to own and use a credit card from the supermarket especially if they could accumulate ClubCard points based on their spending amounts. Based on this research the company launched its own credit card which was the first in a series of financial products it was considering. 
In 1998 Tesco began to expand its store offerings to include non-food items. Initially this test was conducted in 50 stores that were updated to carry these items. Initially the bulk of the non-food merchandise was limited to adult clothing, children's and baby products, healthcare, and home entertainment. Building on the success of its credit card products Tesco launched a flexible personal pension plan in a joint venture with Scottish Widows. It was designed as a low cost product to attract people who had not made any provisions for their retirement. Further, in order to provide its customers with a less expensive alternative to Internet access Tesco made the decision to become an Internet Service Provider (ISP). Tesco publicized the initiative as a value added service to its customers but, given the price that Tesco was charging, its web service was one of the cheapest ISPs in the U.K. Given this competitive advantage, Tesco's Internet service made a profit from the beginning. The decision by Tesco to introduce these new products and services to its customers, demonstrated that the company placed a high value on customer service.

As Tesco’s service expanded, it was necessary to expand the order taking capacity. To do so, Tesco adopted Unipower System's ShoppingMagic eCommerce suite. Tesco chose the software package because it took a middle of the road approach by taking both speed and reliability into consideration. The software gave Tesco the ability to expand its services and begin experimenting with new ways of recruiting customers. In addition, it allowed Tesco to capture more detailed information on each customer's buying patterns every time he/she submitted an order. For the customers, the new system gave them the benefit of a high speed connection and helped simplify the navigation through the stores inventory which meant the customers spent less time online. 
Just as Tesco was customer focused in developing new products and services, the company was equally concerned with the fulfillment functions. As Tesco expanded its service range, one of the company’s primary concerns was with how to improve the picking function. One solution was to move from a store based picking model to a warehouse fulfillment model. However, one of the main concerns with this idea was the cost associated with constructing the facility. Although the company was considering this in 1998, it was still very focused on getting the delivery function straight. This prompted Tesco to invest in and test a new shopping cart designed to improve efficiency in the picking area. The new equipment was designed to work with an in-store picking model. Using the new software and hardware, customer orders were received and uploaded to the new intelligent shopping carts and once the orders had been filled, the intelligent shopping cart was used to pass them off directly to a new hi-tech delivery van. This demonstrated that Tesco was continually concerned with the fulfillment function. During the period between 1999 and 2004 Tesco’s strategy was to leverage its ClubCard database to better target customers with a variety of products and services. Specifically, Tesco began using a segmentation approach on its ClubCard data to find segments that were then targeted with promotional information. Thus, part of the company’s strategy involved data mining in its ClubCard database. Another aspect of Tesco’s strategy during this period was to expand its content offering on its website and continue to generate heavy site traffic. The goal was to continue to add content to its website while at the same time continuing to stimulate demand for the service by offering ClubCard point tie-ins and targeted e-mail vouchers. 
At the beginning of 1999 Tesco's management contemplated using a warehouse model but the company was content using an in-store model for the moment. Once the decision to expand the operation from 100 to 300 stores was made, it was clear that Tesco was going to continue using an in-store fulfillment model and the company viewed the service as a profit center. According to Tesco the in-store method was the best for building the business initially.

By 2001, it was reported that Tesco’s online grocery home delivery service was already showing a profit. By 2003 it was confirmed that the Tesco.com unit was indeed profitable with sales for the company increasing 30 percent over 2002 levels. Tesco admitted that the majority of this sales growth was in non-food sales which indicated that Tesco’s strategy of providing its customers with low priced quality content was paying off for the company. Many analysts commented that Tesco's success was due to its lowcost, low risk business model.

In terms of its delivery function, Tesco was superior to its rivals when it came to punctuality and delivery personnel courteousness. However, the picking and packing functions were still problematic for the company which was evident by the level of stockouts which resulted in substitutions and product exclusions from customer orders. There was also some tension concerning cannibalization for the store managers who operated stores that were part of the online network. However, management was more concerned with acquiring market share than it was with issues of store cannibalization.

From 2005 through 2006 Tesco continued to remain customer focused. This customer focus drove many of the new products and services that the company developed. For example, Tesco's introduction of low cost clothing proved to be so 
successful, that the company created a website designed to sell clothing online. This was a push by Tesco to acquire more market share in the apparel channel. By focusing on providing quality clothing at a low price, and allowing customers to gain ClubCard points for their purchases, Tesco was strengthening customer brand loyalty. Tesco's decision to launch the Tesco Direct website for selling non-grocery items further demonstrated Tesco’s strategy to be as dominant online in non-grocery sales as the company was in grocery sales. Launching a site to sell computer software at deeply discounted prices further demonstrated the company's strategy to remain customer focused by providing quality products at low prices. In addition, it also demonstrated the company's focus on providing products in areas that it felt it could gain significant market share.

One of Tesco's main problems concerned the fulfillment function and according to company spokespersons, Tesco was resolved to improving these areas. Based on published reports by mystery shoppers, Tesco’s delivery personnel were given high marks for their courteousness and punctuality. However, the company continued to receive poor ratings when it came to product substitutions, product mispicks, and product exclusions. These were symptoms of a much wider problem concerning in-store stockouts and picking function problems. The in-store stockout problem was an indication that the online grocery operation was having a significant impact on the inventory turnover rates. Tesco's replenishment function was unable to keep up with this turnover rate which caused the fulfillment problems to continue. To resolve this, Tesco had to either alleviate the demand strain on the stores or increase the replenishment rate. It seemed that Tesco's in-store fulfillment function had reached scale and it was time to make changes to the fulfillment model. 
In relation to the delivery area, once Tesco began to make deliveries from its dedicated grocery fulfillment center, it was necessary to upgrade its delivery personnel equipment to improve driver punctuality and to improve the routing and scheduling process. Since the service area covered by the dedicated fulfillment center was wider than that covered by any particular store, it was necessary to give the delivery personnel equipment that would help them navigate the streets of neighborhoods. Moreover, to improve the delivery function for its non-grocery items, Tesco partnered with TNT Logistics, which was a third-party logistics provider. This represented a strategic move to reduce the cost structure by outsourcing a portion of the logistics requirements. In addition, since TNT was already proficient in delivering non-grocery items, it was possible for Tesco to incorporate TNT's service into its delivery channel without the customers noticing the integration.

In the end, based on market share data, the primary advantage that Tesco gained from the development of its grocery home delivery channel was the creation of a portal website that allowed the company to sell more non-food products than the store had in stock. The development of this website also provided the company with a residual effect by increasing the number of customers using the company's online grocery home delivery service. For the previous four years this is how Tesco had been increasing its online sales while the sales in the grocery home delivery area had been stagnant. This does not mean that the grocery home delivery service was not making a profit, it simple indicates that it may have temporarily reached a ceiling. Tesco's internal analysis had shown that the fourth time a shopper used Tesco.com was the point at which that customer become committed, but heavy marketing was need to help move initial 
adopters. This explains why the majority of costs, either directly related to providing coupons or vouchers, or related to price discounts associated with ClubCard point redemption, had gone to generate customer trial and repeat purchases. 


\section{Chapter VIII}

\section{Between Case Analysis}

With the completion of the within case analyses of the profit structures for Peapod, GroceryWorks, and Tesco, it was possible to look across these companies to assess what had been learned. Recall that the original impetus for this research centered around two observations. The first was that many of the pure-plays and partnership business models had not been very successful. After the 2000 dot.com collapse many of the original pure-plays and partnerships failed out right, merged with other pure-plays, or were acquired by brick-and-mortar grocers looking to establish their own online channels. Given the severity of the online grocery channel collapse, many grocery industry analysts and watchers questioned the viability of the pure-play and partnership business models for the grocery retail industry. The question was - were these analysts and industry watchers correct in their prognosis?

The second observation concerned the rise and decline of the hybrid online grocery home delivery models in the wake of the dot.com correction. Once the pureplays and partnerships failed, there was a void in the online grocery channel. This was filled by brick-and-mortar retailers looking to establish operations in the online grocery channel. However, it was not long before many of these hybrid online initiatives met a similar fate as their pure-play and partnership counterparts. Again, industry analysts and watchers commented that the business models were the root cause of the hybrid model failures. The question raised again was - were these analysts and industry watchers correct in their prognosis? 
It is possible that in both cases the business models had nothing to do with the success/failure of these companies. It may be that structural factors associated with the online channel itself may have had more to do with the demise of many online initiatives. Further, it is equally plausible that neither the business models nor the channel structural factors were the cause of company success/failure and it was actually some other factor, or combination of factors, that was responsible.

To date there had not been a systematic analysis to determine whether or not the business models were the primary cause for the success/failure of many online initiatives. Through case analyses, this study looked into whether or not the specific business models used by companies operating in the online grocery home delivery channel, were the root cause of their success/failure. In order to conduct this analysis, it was necessary to provide an operative definition for success. For the purpose of this study, success was defined as a company being profitable. This allowed assessing the companies based on their profit structure components and the relationships among these components.

Presented next are the synopses of the business models used by the three companies selected for this study. Included in each synopsis is a discussion of that model's dynamics that focuses on the relationship between the key performance drivers and the costs and revenue components they influence. This analysis demonstrated that although these companies used different business models, there was a basic structure that was roughly the same for all models. Also included in the synopsis is a discussion concerning the appropriateness of the models that the companies were using and a discussion of the specific operationaliztion of these models by the selected companies. 


\section{Business Model Synopses}

\section{Case 1: Peapod}

Based on Peapod's original business strategy, the company served as the delivery component for a traditional brick-and-mortar grocer, which required it to use an in-store fulfillment method. This arrangement between Peapod and the BAM grocer constituted a partnership. According to the model delineations presented in chapter four, there were thirteen possible models under the Partnership structural category that relied on in-store fulfillment (see Appendix 1). One required no delivery (Model 1), three relied on a local pickup point to make the transaction (Models 2, 3a, and 3b), three relied on a third-party logistics provider to make deliveries (Models 4, 5a, and 5b), three required the brick-andmortar grocer to make deliveries (Models 6a, 7a, and 7c), and three relied on the online grocer to make the deliveries (6b, 7b, and 7d). Since Peapod's business strategy was to be in the grocery delivery business the company was restricted to those business models that relied on the online grocer to make deliveries. Based on the three possible models, Peapod chose to begin operations using Model 6b under the Partnership category.

Given Peapod's stated business objectives, the selection of this particular business model represented one of the least expensive ways for a company to enter the online channel. With this model, the online grocer did not have to extend or establish an inventory procurement channel. The model called for Peapod to forge a partnership with an established brick-and-mortar grocery retailer. There were several ways that this model could have been operationalized. Based on the tenents of the model, and in accordance with the terms of the partnership, Peapod took orders from the BAM's customers, filled those orders from the BAM's shelves, packed the orders for transport, and delivered them 
to waiting customers. According to the terms of the partnership, Peapod had to purchase the grocery inventory from the brick-and-mortar grocer at retail price and was reimbursed by the customer when the delivery was made.

Given the level of competitive pricing in the grocery industry, Peapod could not realistically raise its prices on the grocery inventory and expect people to patronize the service. As a result, the company was forced to sell the grocery inventory at cost which made it impossible to generate any significant margins on sales. Due to the shallow income stream generated from the core delivery fees, Peapod had to rely on investment capital to fund business operations. For online grocers using these partnership models, it is necessary that they have access to a substantial amount of capital, on a recurring basis, over an extended period of time. This capital is necessary not only for financing business operations, but also for funding customer relationship activities necessary to drive new and repeat business. To gain a level of brand recognition necessary to sustain a high utilization rate for the delivery service, Peapod spent a lot of capital on brand building activities. According to the case information, these customer relationship costs were prohibitive to the point where it was necessary to co-brand with the BAM grocer. Thus, as the case demonstrated, brand building activities represented a significant portion of Peapod's financial expenditures.

It was also necessary for Peapod to generate additional revenue sources. According to the company's own research, delivery fees were negatively correlated with customer trials and positively correlated with the cancellation rate. Therefore, to keep current customers and acquire new ones, Peapod kept the delivery fees as low as possible. 
This put a strain on the revenue structure causing the company to seek alternative revenue sources. These sources initially came in the form of subscription and membership fees. During the period between 1992 and 1996 Peapod continued using business model 6b hoping to generate enough customers to make the service profitable. During the period the company expanded its service geographically in order to demonstrate to investors that the model was expandable. Prior to the expansion Peapod was already suffering from a significant imbalance in its profit structure. The expansion only exacerbated the imbalance forcing Peapod to continue relying on investment capital to fund business operations.

During the period between 1997 and 1999, Peapod utilized different business models searching for a combination that would allow the company to make a profit. Peapod also began attacking its cost structure looking for ways to reduce costs either directly through the elimination of specific cost components or indirectly through improvements in efficiency. To help improve Peapod's efficiency, one of its BAM grocery retail partners established warerooms for the company. The warerooms allowed Peapod to utilize business models that were designed around local dedicated fulfillment models. Moreover, Peapod began acquiring some of its grocery inventory directly from the manufacturers and wholesalers. This improved Peapod's revenue stream by allowing the company to gain margins on the sale of inventory. Thus, during this period Peapod began to move in the direction of becoming a pure-play but its cost structure remained a problem.

To generate more customer trials, and thus more revenue, Peapod developed new products and services for both the consumer and business markets. For the consumer 
market Peapod offered a coupon redemption service and an auxiliary delivery service which complemented its core delivery service. For the business market, Peapod developed integrated advertising, promotional, and research services. The case data indicate that these auxiliary services did not provide Peapod with any significant revenue but they did demonstrate the urgent need by the company to generate additional revenue sources. Also during this period, Peapod imposed a percentage fee on the customer's grocery bill. Since Peapod could not gain any margins from markups on products purchased from the BAM grocer, charging customers a fee based on the purchase amount was the next best way to generate revenue from the sale of inventory. By charging customers an additional fee, however, Peapod was working counter to its own customer acquisition efforts. This indicated that there was pressure on Peapod to generate more revenue.

During the period from 2000 to 2006 Peapod purchased a dedicated fulfillment center for delivering customer orders. This purchase positioned Peapod to become a pure-play by providing a key component for the development of its own inventory procurement channel. However, during this period, Peapod's investment capital receded and the company was forced to accept a buyout offer from Ahold. Once Ahold purchased a controlling interest in Peapod, the company ceased operating as a partnership and began operating as a hybrid. At the time of the acquisition, Peapod was operating using two different fulfillment strategies. One centered on a wareroom fulfillment model while the other was designed around a dedicated fulfillment center model. Given the two fulfillment strategies, Peapod operated using several business models. 
As a hybrid, Peapod was able to shed significant portions of its cost structure. For example, as a subsidiary of Ahold, Peapod no longer had to finance brand building activities since it could capitalize on the equity of all of Ahold's brands. In addition, inventory sourcing was no longer a problem since Peapod bought directly from its parent company at cost. The absorption of these costs by Ahold placed Peapod in a better financial position. This was evident by the fact that in certain markets Peapod's operation began to show a profit.

\section{Peapod's Model Dynamics}

Initially, Peapod's business model became operational once the company began incurring customer relationship costs associated with soliciting initial customer trial and repeat purchases. Specifically, the front-end customer relationship cost components ‘customer awareness done alone’ and ‘customer acquisition done alone’ were responsible for driving the customer patronage performance drivers 'number of new customers' and 'number of repeat customers' (see Figure 67). Since these key components drove other central performance drivers they were critical to the success of Peapod's business model. That is, the customer patronage performance drivers 'number of new customers' and 'number of repeat customers' drove the other customer patronage performance driver 'number of orders' (see Figure 68). The customer patronage performance driver 'number of orders' then drove the delivery service performance driver 'number of orders delivered' (see Figure 68).

The customer patronage performance driver 'number of orders' then drove the back-end inventory expense component 'inventory purchased via partner' and the 
Figure 67

Peapod's Front-End Cost Components and Performance Drivers

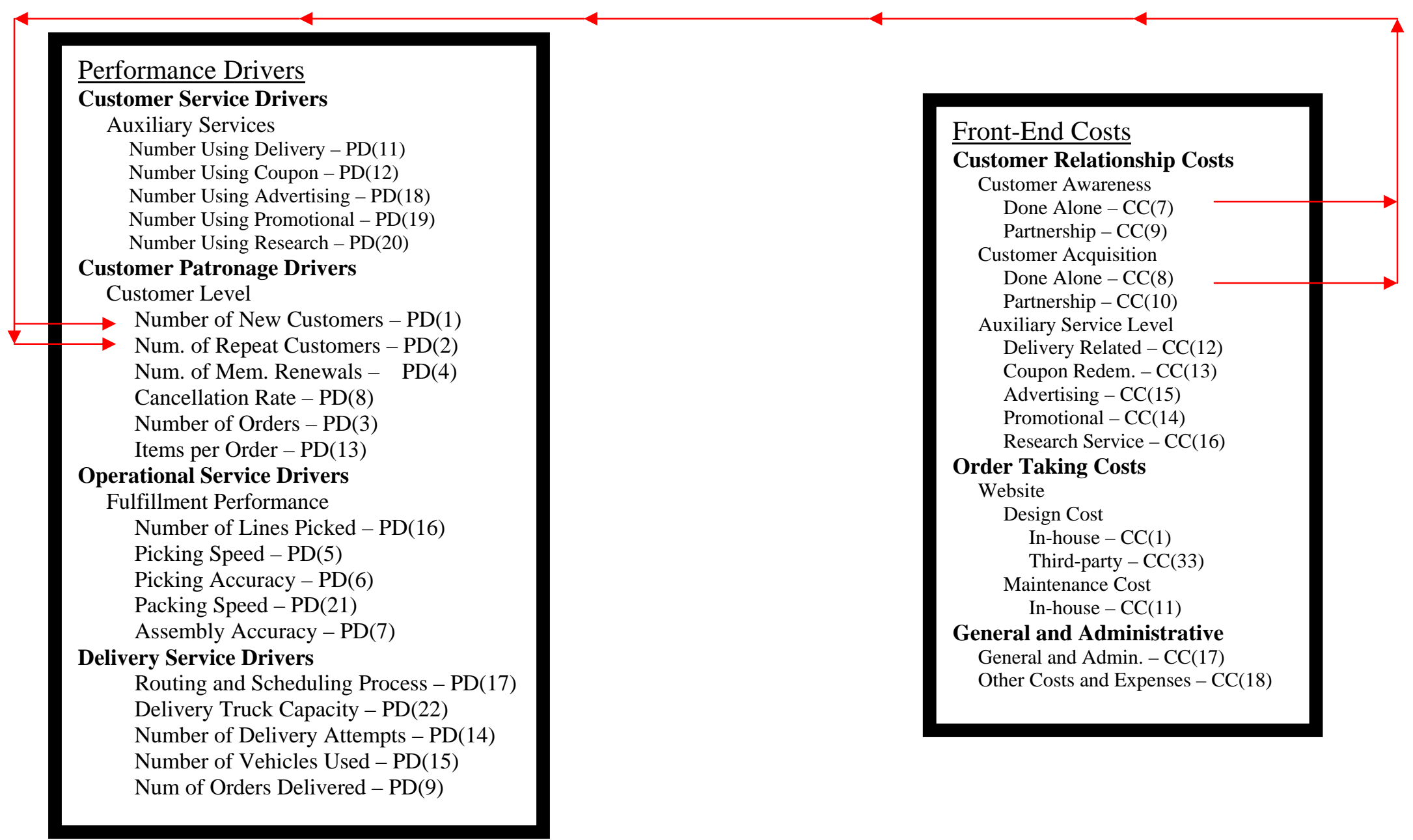


Figure 68

Peapod's Performance Drivers and Performance Drivers

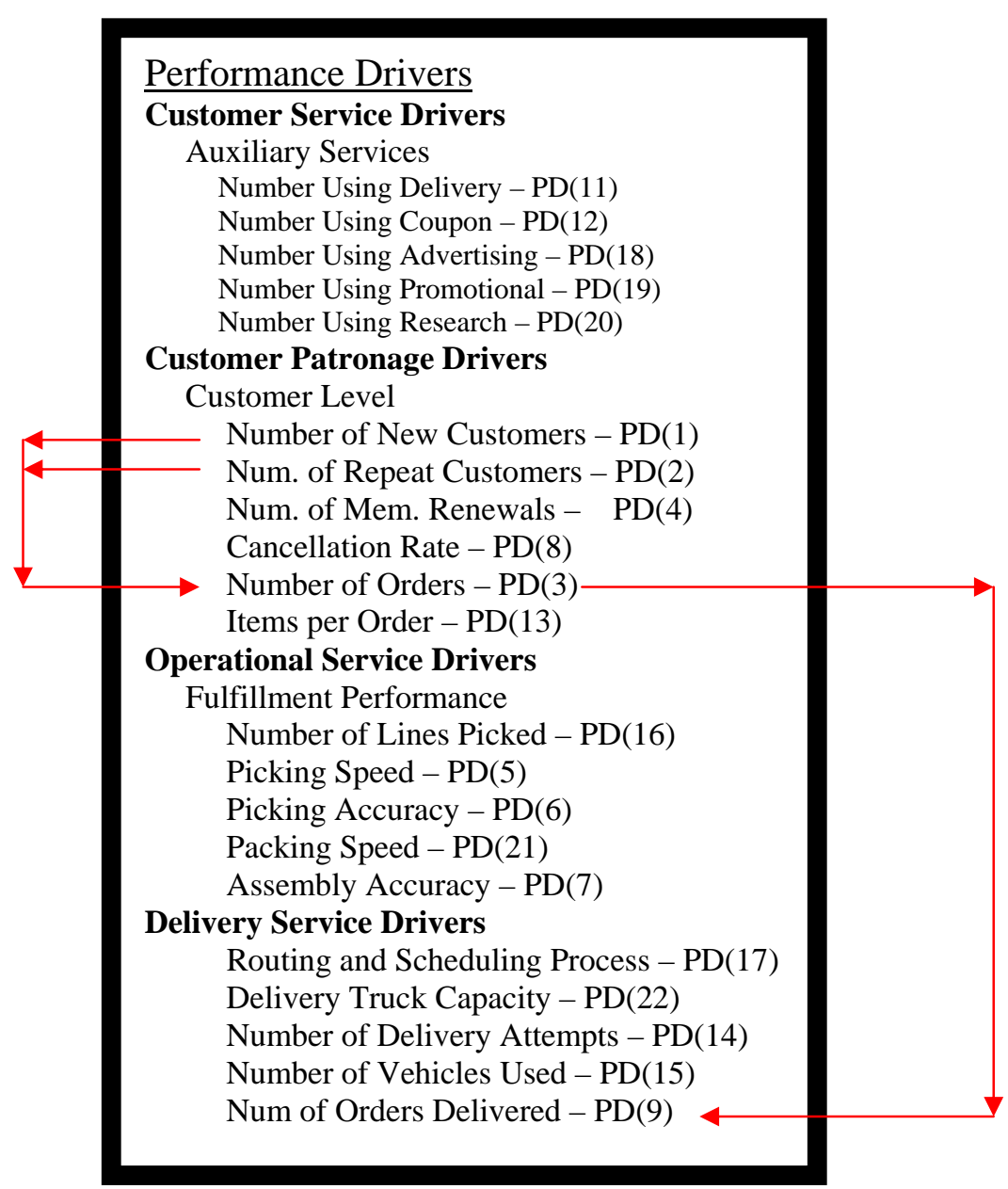


Figure 69

Peapod's Back-End Cost Components and Performance Drivers

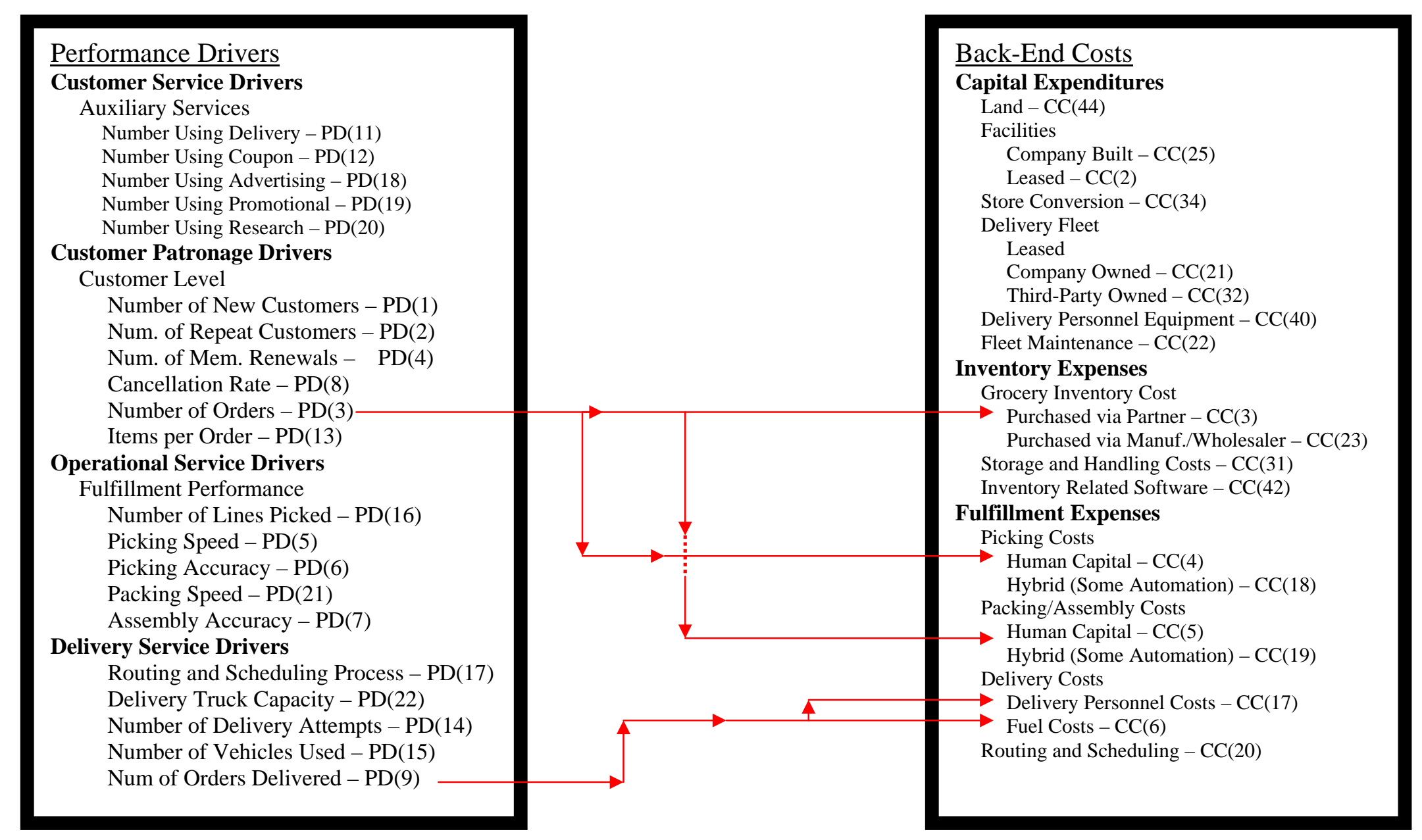


Figure 70

Peapod's Revenue Components and Performance Drivers

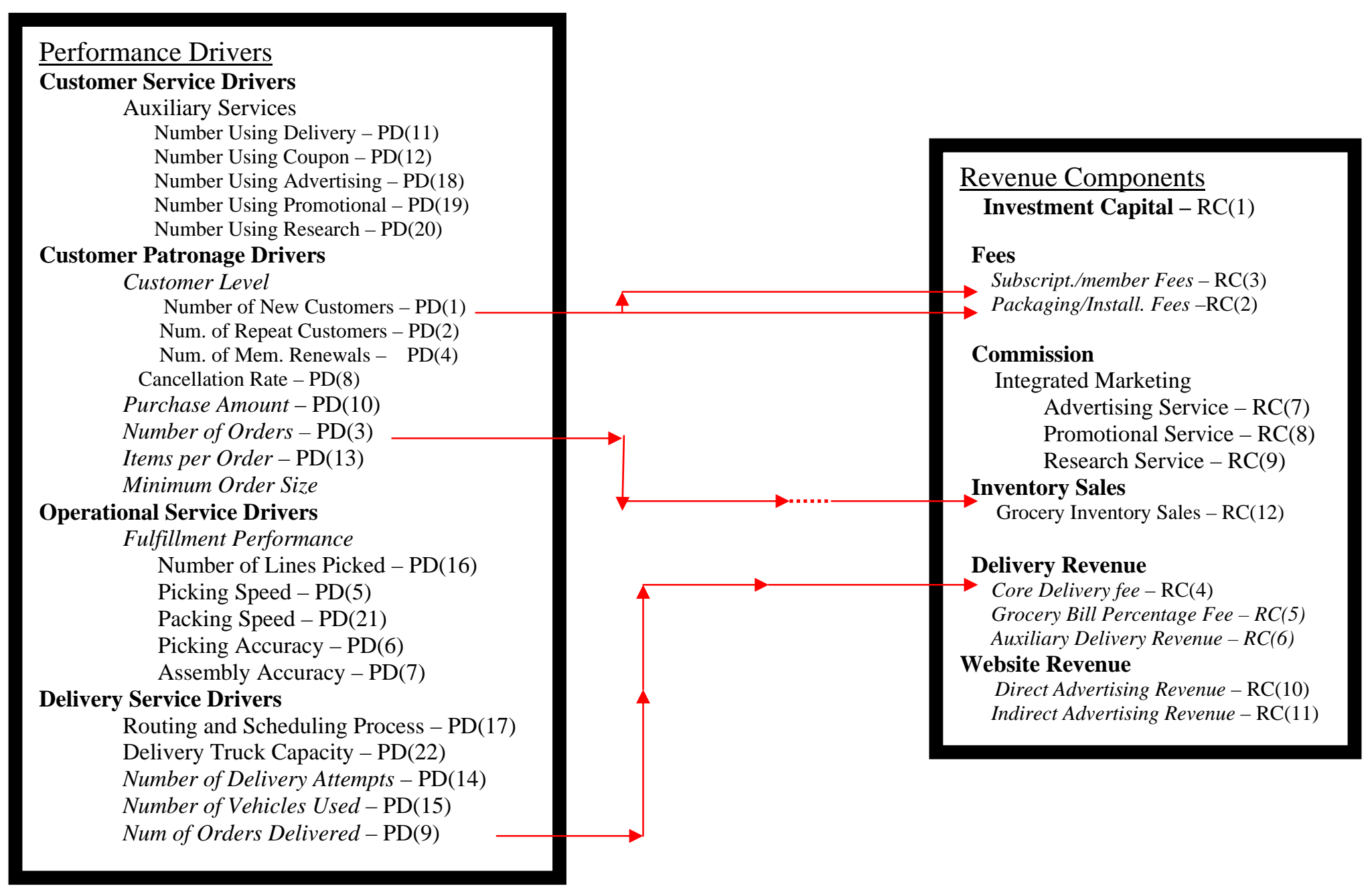


fulfillment expenses components 'picking cost human capital', and 'packing/assembly costs human capital' (see Figure 69). The delivery service performance driver 'number of orders delivered' then helped to drive the back-end costs associated with 'fuel cost' and 'delivery personnel costs'(see Figure 69). In relation to the revenue components, the customer patronage performance driver 'number of new customers' helped to drive the revenue fee components 'subscription/membership fees' and 'packaging/installation fees' (see Figure 70). Since Peapod purchased its inventory at retail prices, there were no actual margins on these sales. However, these sales still existed as a revenue source. Thus, the customer patronage performance driver 'number of orders' drove the inventory revenue component 'grocery inventory sales' (see Figure 70). Finally, the delivery service performance driver 'number of orders delivered' drove the delivery revenue component ‘core delivery fee’ (see Figure 70).

Looking at Peapod's business model dynamics revealed how critical customer acquisition and retention activities were. The number of new customers was a key driver of the revenue component 'subscription and membership fees'. It was also a key driver for the performance driver 'number of orders' which in turn drove the revenue component 'grocery inventory sales'. The 'number of orders' also drove the 'number of orders delivered' which in turn drove 'core delivery fee'. The 'number of orders' also drove the fulfillment and inventory costs. Based on this initial model, customer patronage activities were critical because they drove the 'number of new and repeat customers', which were the nucleus of the model. Thus, it was clear that customer acquisition and retention activities were vital to Peapod's survival. 
During the period between 1992 and 1996, Peapod expanded its model to new geographical locations. In the process the company also expanded its cost structure, which was already dwarfing the revenue structure. As a result, the company included new revenue components. In order to offer these new revenue components Peapod had to incur the initial costs for establishing the service and the recurring costs associated with keeping the service operational. The company was hoping to gain a positive margin over the cost of providing these services. By increasing its revenue components, Peapod was able to add a percentage fee based on the customer's aggregate grocery bill. This allowed Peapod to collect a delivery fee and a percentage fee based on the total purchase amount. Thus, the customer patronage performance driver 'number of orders' was a primary driver for the revenue delivery component 'grocery bill percentage fee’ (see Figure 70). The other revenue components were all driven by the number of customers using the service. Hence, the revenue being generated from these services was being indirectly stimulated by the number of new and repeat customers.

During this period, the market for auxiliary services was not providing Peapod with a significant amount of revenue. As a result, Peapod was still relying on revenue generated from the delivery function. However, the cost structure associated with Peapod's operation was greater than the revenue being generated which meant that Peapod had to rely on investment capital to continue financing business operations. This demonstrated that Peapod had not reached a critical mass of customers sufficient to sustain its operations. Moreover, this further demonstrated how vital customer acquisition and retention activities were for Peapod. 
Between 1997 and 1999, Peapod began operating out of specially designed warerooms in order to improve efficiency and indirectly reduce costs. During this period the company began moving away from the Partnership structural category and towards the Pure-Play structural category. This was evident by the company's decision to source some of its inventory directly from manufacturers and wholesalers. Other than the change to the inventory sourcing, there were no other major costs related to the dynamics of Peapod's model.

Throughout this period, Peapod's model was still anchored to the number of new and repeat customers. Since the company had not reached a critical mass of customers, the cost structure continued to far outpacing the revenue structure. As a result, Peapod had to continue relying on investment capital to finance business operations. The company continued to make changes to the fulfillment side of its operation in order to increase efficiency and indirectly reduce costs.

During the period between 2000 and 2006 Peapod moved a step closer to becoming a pure-play when it purchased a dedicated fulfillment center. This put the company in the final stages of completing its inventory procurement channel. However, this came with significant additional capital expenditures. Specifically, once Peapod began operations out of the dedicated fulfillment center, the company utilized business models specifically designed for dedicated fulfillment operations. Other then the inclusion of the new fulfillment facility there were no other changes to the model dynamics. Also during this time period investment capital evaporated and the company could no longer sustain business operations. Peapod was rescued from certain 
bankruptcy by Ahold when it purchased a controlling interest. At that point Peapod was no longer a partnership and was instantly placed in the Hybrid category.

\section{Comments Concerning the Model}

For a stand alone company operating in the grocery retail industry, business Model $6 \mathrm{~b}$ is a suitable one. The model permits the company to enter the online channel with a minimum amount of capital expenditures. Utilizing the brand equity of the BAM grocer allows the online grocer to increase its brand awareness and recognition in the markets. In addition, this model allows the online grocer access to a large inventory and the ability to co-brand, which reduces the customer acquisition costs. Thus, Partnership Model $6 \mathrm{~b}$ allows the online grocer to gain a number of benefits that would be very costly if the online grocer attempted to provide them for itself.

However, Peapod's operationalization of Model 6b does not seem suitable for a company in the grocery retail industry. This criticism is due primarily to Peapod's inability to extract any margins on the sale of grocery inventory. This made it difficult to generate enough revenue to cover the overall cost structure. The revenue being generated from the core delivery fees was not enough to offset the actual cost of delivery, not to mention the other costs associated with running the business. As a result, Peapod's costs increased substantially. This required the company to rely on investment capital to finance business operations. Thus, Peapod's inability to cover its costs can be linked to: 1) the company's inability to gain any margins from the sale of grocery inventory, and 2) the company's inability to generate a critical mass of customers large enough to sustain operations internally. 
Improving on Peapod's operationalization would require negotiating some sort of price reduction with the BAM grocer in order to allow Peapod to generate some level of margins on inventory sales. Moreover, Peapod would need to conceptualize a way to increase the service utilization rate. This could be done with deeper penetration in the BAM grocer's customer base or it could be done by partnering with multiple BAM grocers in the same market. In this scenario it might be possible for Peapod to generate the customer base necessary to sustain operations internally and make a profit.

As it currently stands, it seems that there are two basic ways that this model could be used in the grocery industry. For one, it could be used strictly as an online grocery channel. This would require that the online grocer have access to a substantial reserve of capital that would be needed for brand building and promotional activities. This reserve would need to be large enough to allow the online grocer the time necessary to gain a critical mass of customers, at which point it should begin to turn a profit. This capitalization requirement is a significant barrier for companies to overcome. Secondly, this model could be used to establish a customer portal allowing the customer access to grocery and non-grocery products through the online channel. This would allow a company to drive traffic to the website while at the same time providing additional revenue sources.

Based on Peapod's performance, and the general tenents of the Partnership category, it does not seem that partnership models are stable models over the long run. It seems that both parties have a specific agenda and once that agenda has been met by either, that company will initiate a termination of the partnership. These relationships seem more like a convenience for both parties while they learn critical aspects of their 
business partner's practices. Either the BAM grocery retailer will gain enough experience with online retailing to sever ties with the online grocer and begin its own online operation; or the online grocer will reach a point where it has learned the essentials of grocery retail and sales are strong enough to break away from the BAM grocer and establish its own pure-play operation. Either way, it does not seem that partnership models are stable over the long run.

\section{Case 2: GroceryWorks}

Based on GroceryWorks’ original model, the company was organized as a pureplay using a dedicated fulfillment strategy. Based on the model delineations in Appendix 2, there were ten possible models from which GroceryWorks could choose to operate under. One required no delivery (Model 15), three relied on a local pickup points to make the transaction (Models 16, 17a, and 17b), three relied on a third-party logistics providers to make deliveries (Models 18, 19a, and 19b), and three required the brick-andmortar grocer to make deliveries (Models 20, 21a, and 21c). Given GroceryWorks’ desire to provide the delivery service in-house, there were only three models to choose from (Models 20, 21a, and 21b). Of these three models the easiest and least expansive one to operationalize was Model 20, which was the one GroceryWorks chose. Using this organizational format and fulfillment method, GroceryWorks was attempting to develop its own inventory procurement channel, which was part of the company strategy from the beginning. Based on GroceryWorks' model, the company took customer orders, filled those orders from its inventory, packaged them for delivery, and then delivered them to customers' homes. However, GroceryWorks’ decision to operationalize Model 20 
required the company to incur a significant level of costs. These included capital expenditures for facilities, inventory expenses related to stocking and replenishment, fulfillment expenses, development of order taking capacity, customer relationship costs, and general and administrative costs.

Initially, GroceryWorks' revenue structure was quite simple. Since the company did not charge a delivery fee, the only means of revenue and operating capital stemmed from the margins on grocery inventory sales and investment capital. GroceryWorks was able to compete with other grocers because it could charge similar prices. Based on the company's strategy, as sales grew the profit from the company's margin on sales would cover more of the costs associated with running the business. By not charging a delivery fee GroceryWorks removed a barrier for customer trials. This meant that in order for the company to survive, it needed to generate a critical mass of customers. This would generate revenue from sales and, based on quantity discounts from manufacturers and wholesalers, increase the margin on inventory sales. However, until that critical mass of customers was reached, GroceryWorks had to rely on investment capital to finance company operations.

GroceryWorks' reliance on investment capital almost forced the company into bankruptcy. That is, before GroceryWorks could establish itself as a viable pure-play online grocery retailer, its investment funding receded and the company was forced to sell a controlling interest to Safeway. Once Safeway took control, it allowed GroceryWorks to continue using a dedicated fulfillment model. What changed about GroceryWorks' model was that the customer relationship, order fulfillment, and inventory expenses were now being subsidized by Safeway. This allowed GroceryWorks 
to concentrate on promotional activities necessary to stimulate customer trials and repeat purchases. Moreover, in an attempt to generate additional revenue, GroceryWorks began to charge a core delivery fee. This was an indication that Safeway viewed the online channel as a value added service component as opposed to a profit center.

During the period between 2000 and 2006, Safeway allowed GroceryWorks to continue to operate from its dedicated fulfillment centers. During this time Safeway was in talks with Tesco concerning Tesco becoming a minority partner in GroceryWorks. Once Safeway and Tesco worked out the terms of agreement, Safeway immediately switched GroceryWorks from a dedicated fulfillment model to an in-store fulfillment model. The change allowed GroceryWorks to shed the costs associated with operating the dedicated fulfillment facilities. This move alone saved GroceryWorks a significant amount of money. Even after making this change, the relationships among the key performance drivers and the revenue and cost components were still intact.

\section{GroceryWorks Model Dynamics}

During the period between 1999 and 2000, GroceryWorks’ business model became operational once the company began incurring customer relationship costs. Specifically, the front-end customer relationship cost components 'customer awareness done alone' and 'customer acquisition done alone' were responsible for driving the customer patronage performance drivers 'number of new customers' and 'number of repeat customers' (see Figure 71). The customer patronage performance drivers 'number of new customers' and 'number of repeat customers' then drove the other customer patronage performance driver 'number of orders' (see Figure 72). The customer 
Figure 71

GroceryWorks Front-End Costs and Performance Drivers

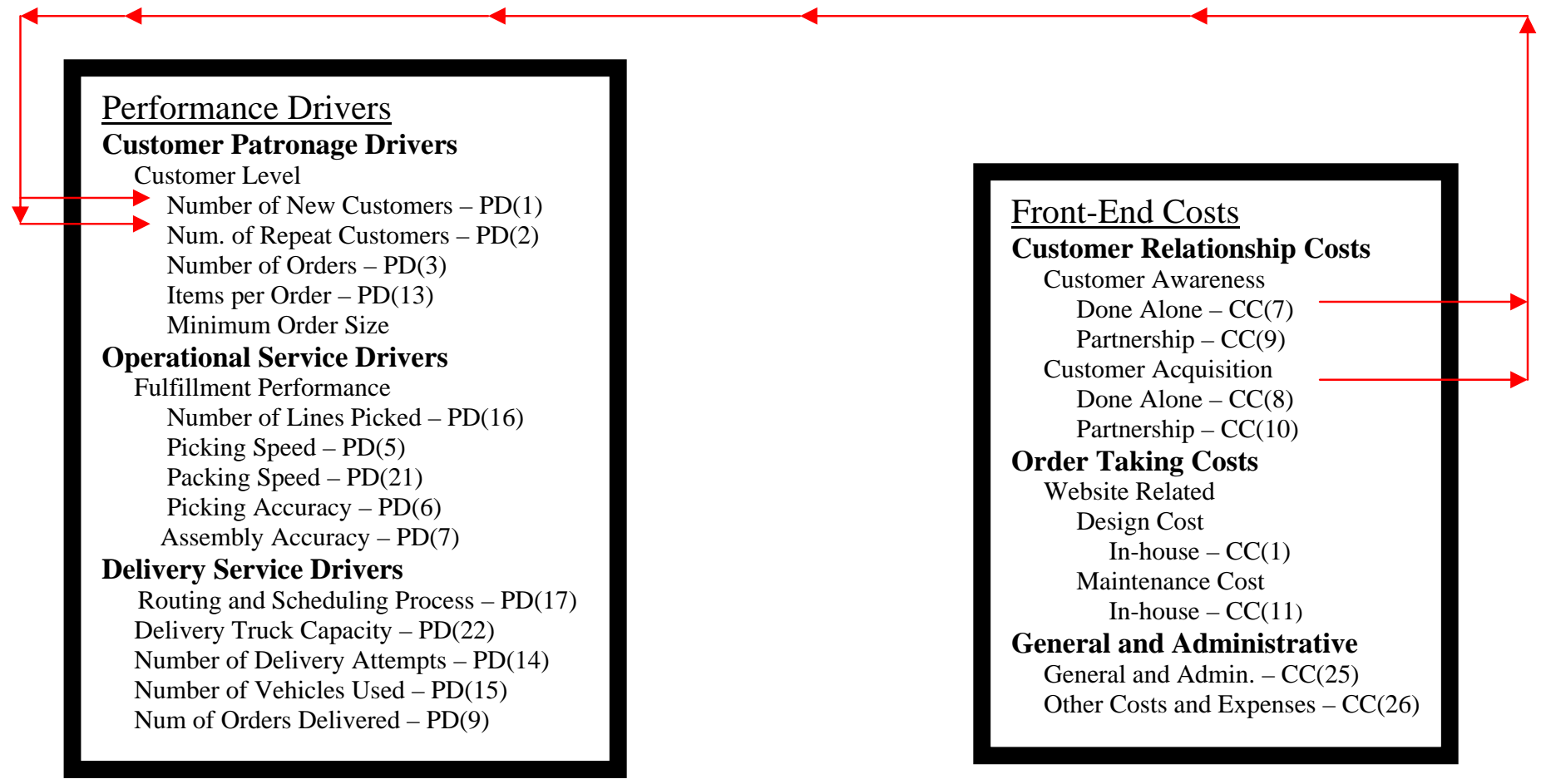


Figure 72

GroceryWorks Performance Drivers and Performance Drivers

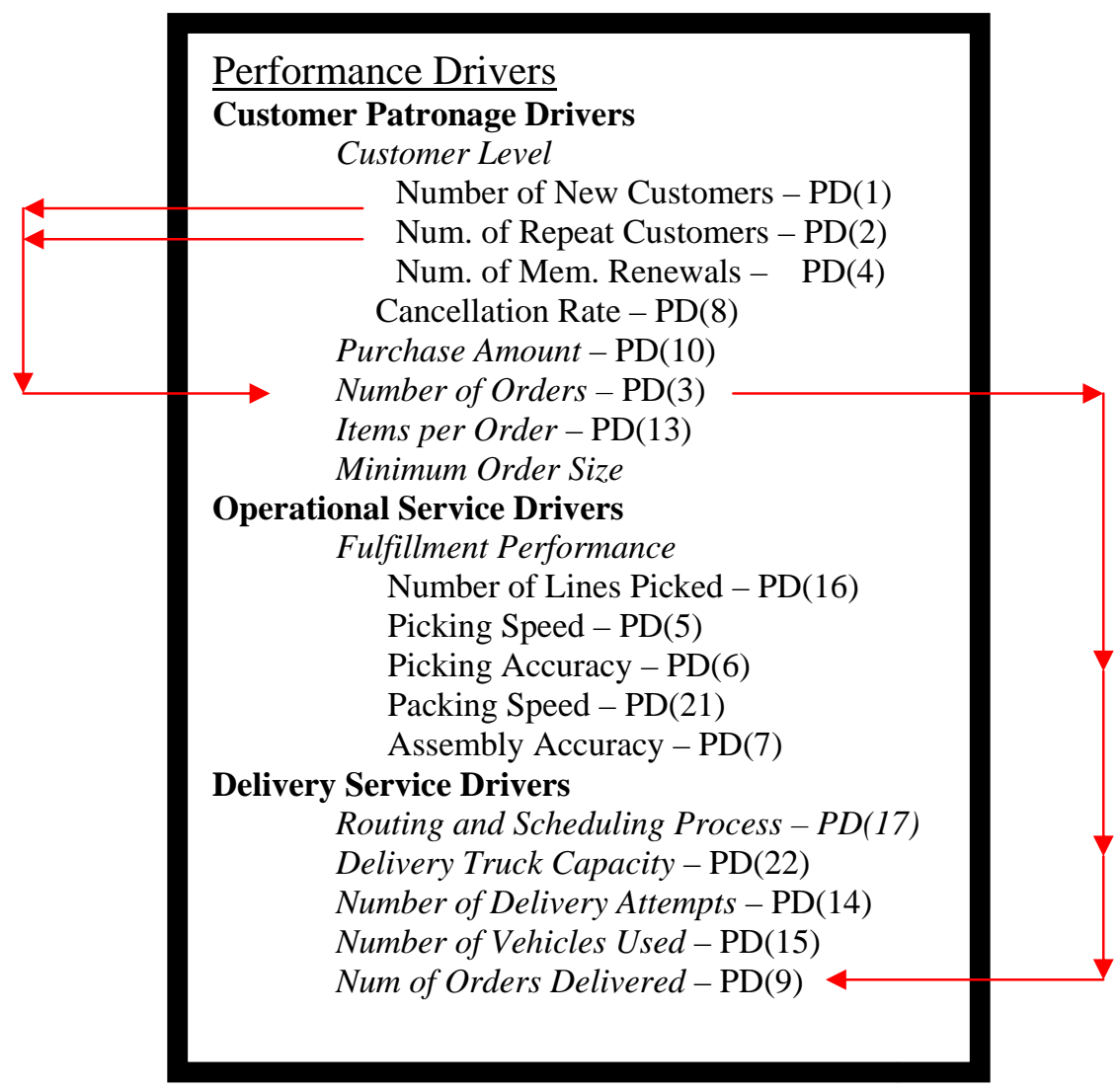


Figure 73

GroceryWorks Back-End Cost Components and Performance Drivers

$$
\begin{aligned}
& \text { Performance Drivers } \\
& \text { Customer Patronage Drivers } \\
& \text { Customer Level } \\
& \text { Number of New Customers - PD(1) } \\
& \text { Num. of Repeat Customers - PD(2) } \\
& \text { Number of Orders - PD(3) } \\
& \text { Items per Order - PD(13) } \\
& \text { Minimum Order Size } \\
& \text { Operational Service Drivers } \\
& \text { Fulfillment Performance } \\
& \text { Number of Lines Picked - PD(16) } \\
& \text { Picking Speed - PD(5) } \\
& \text { Packing Speed - PD(21) } \\
& \text { Picking Accuracy - PD(6) } \\
& \text { Assembly Accuracy - PD(7) } \\
& \text { Delivery Service Drivers } \\
& \text { Routing and Scheduling Process - PD(17) } \\
& \text { Delivery Truck Capacity - PD(22) } \\
& \text { Number of Delivery Attempts - PD(14) } \\
& \text { Number of Vehicles Used - PD(15) } \\
& \text { Num of Orders Delivered - PD(9) }
\end{aligned}
$$

$\underline{\text { Back-End Costs }}$

Capital Expenditures

Land

Facilities

Company Built

Leased - CC(2)

Fulfillment Equip. (automated) - CC(26)

Delivery Fleet

Company Owned - CC(21)

Fleet and Equipment Maintenance - CC(22)

Inventory Expenses

Inventory Cost

Purchased via Partner - CC(3)

Purchased via Manfac./Wholesaler - CC(23)

Fulfillment Expenses

Picking Costs

Human Capital - CC(4)

Hybrid (Some Automation) - CC(18)

Packing/Assembly Costs

Human Capital - CC(5)

Hybrid (Some Automation) - CC(19)

Delivery Costs

Delivery Personnel Costs - CC(17)

Fuel Costs - CC(6)

Routing and Scheduling - CC(20) 
Figure 74

GroceryWorks Revenue Components and Performance Drivers

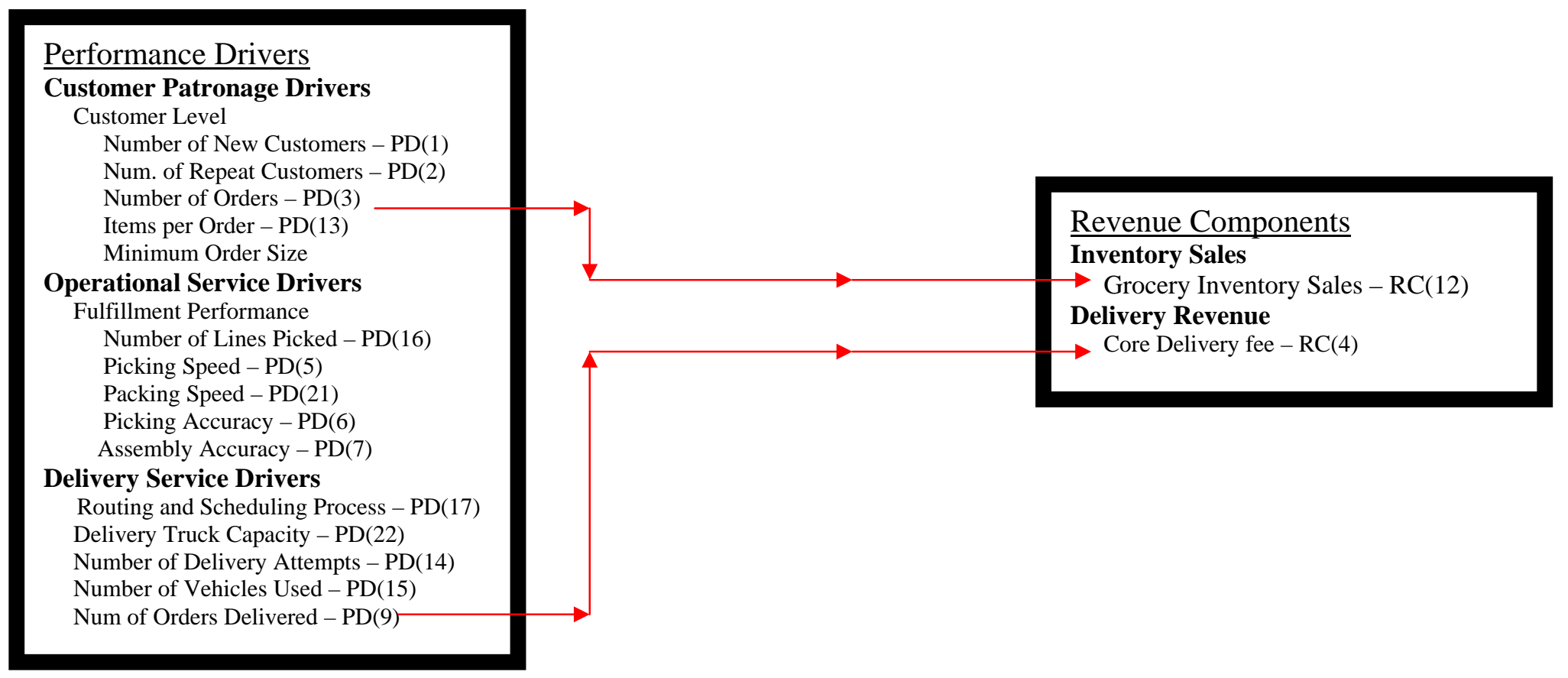


patronage performance driver 'number of orders' then drove the delivery service performance driver 'number of orders delivered' (see Figure 72).

The customer patronage performance driver 'number of orders' was also the primary driver for the back-end inventory expense 'inventory purchased via parent company' and the back-end fulfillment related costs 'picking human capital' and 'packing/assembly human capital' (see Figure 73). The customer patronage performance driver 'number of orders delivered' also helped to drive the back-end costs associated with 'fuel cost' and 'delivery personnel costs'. From a revenue perspective, the customer patronage performance driver 'number of orders' was a primary driver for the revenue component 'grocery inventory sales' while the delivery service driver 'number of orders delivered' was a primary driver for the delivery revenue component 'core delivery fees' (see Figure 74).

GroceryWorks' business model showed how critical customer acquisition and retention activities were. The 'number of new customers' was a key driver for the revenue component 'grocery inventory sales' while the 'number of orders delivered' was a key driver for core delivery fees. The 'number of customers' was also a key driver for the other performance driver 'number of orders' which in turn drove the fulfillment and inventory costs. Thus, at the heart of these relationships were the customer patronage drivers associated with the number of new and repeat customers. This demonstrated that customer acquisition and retention activities were vital to GroceryWorks’ survival.

During the period between 2000 and 2001, GroceryWorks was unable to secure additional investment revenue and sold a controlling interest in the company to Safeway. At that point, GroceryWorks ceased operating under the Pure-Play category and began 
operation under the Hybrid category. Other than this change, GroceryWorks’ profit structure remained the same. Even with the change in structural category, the primary relationships between the performance drives and the cost and revenue components remained the same. Thus, the model was being driven by the number of new and repeat customers.

During the 2001 through 2006 period, GroceryWorks abandoned the dedicated fulfillment model and replaced it with an in-store fulfillment model. This changed the specific business models that GroceryWorks was operating under. Specifically, GroceryWorks implemented Tesco’s in-store picking strategy and switched to models that were based on that fulfillment method. Even though GroceryWorks changed its fulfillment method, the primary relationships among the performance drivers and the cost and revenue components remained the same. Thus, the success of GroceryWorks model was dependent on the 'number of new and repeat customers' using the service. Hence, promotional activities were critical to GroceryWorks’ success.

\section{Comments Concerning the Model}

For a stand alone company operating in the grocery retail industry, Model 20 is a very expensive model to develop. It requires that the online grocer have a sizable amount of capital to dedicate to the establishment of a distribution channel and virtual storefront. For companies using these pure-play models, it is necessary that they have access to a substantial amount of capital, on a recurring basis, over an extended period of time. This capital is necessary not only for financing business operations, but also for funding capital expenditures necessary to acquire operating facilities, the relationship activities 
necessary to drive new and repeat business, and the order taking costs necessary to provide the customer with an interface. In order to obtain brand recognition levels high enough to gain a critical mass of customers, companies using these models need to spend a lot of capital on brand building activities. Building demand to this critical level may take several years so companies should be prepared to be in the channel for several years before they make a profit.

GroceryWorks’ actual operationalization of Model 20 under the Pure-Play category seemed suitable due to the model's ability to provide margins on grocery sales and its ability to generate higher margins as quantity discounts on inventory sales volume increased. However, GroceryWorks' low capitalization rate was a primary barrier to the company being able to sustain its operation. Although GroceryWorks’ cost structure was streamlined, it did not have the capital necessary to finance its operations until a critical mass of customers could be reached. As a result, once investment capital evaporated, the company was unable to sustain operations. Since GroceryWorks did not stay in the PurePlay category for long, it was difficult to determine if the initial model the company was operating under could have ever been profitable. For this same reason, it is difficult to determine how the model could have been improved. On the surface, this seemed to be a suitable model for companies in the online grocery home delivery channel as long as these companies realize that it may take a substantial amount of capital and several years before they break even. 


\section{Case 3: Tesco}

Based on Tesco’s original business strategy, the company chose to enter the online channel using an in-store fulfillment model under the Hybrid category (see Appendix 3). According to the model delineations presented in chapter four, there were thirteen possible models that relied on in-store fulfillment. One required no delivery (Model 1), three relied on a local pickup point to complete the transaction (Models 2, 3a, and 3b), three relied on a third-party logistics provider to make deliveries (Models 4, 5a, and 5b), three required the brick-and-mortar grocer to make deliveries (Models 6a, 7a, and 7c), and three relied on the online grocer to make the deliveries (6b, 7b, and 7d).

Since Tesco’s business strategy called for the company to deliver groceries to the customer, the company was restricted to those business models that relied on the grocer itself making the deliveries. Based on the three possible models, Tesco chose to begin operations using Model 6a under the Hybrid category. There were several ways that this model could have been operationalized. Based on Tesco's stated business objectives, its operationalization represented one of the least expensive ways for a company to enter the online channel because it did not require establishing an inventory procurement channel. Based on the model, Tesco took customer orders and filled those orders from the shelves of its stores, packed the orders for transport, and then delivered them to waiting customers. Since Tesco was an established BAM grocery retailer, there were several areas where the company was able to gain synergies. For instance, customer relationship and inventory procurement costs were significantly reduced for Tesco’s online division. This left the company with costs associated with prompting customer trial and repeat purchase behavior. Further, as an established grocery retailer, Tesco was able to charge 
the same prices online as it did in its stores. This made it possible to eliminate a possible price barrier to customer trial.

From a revenue perspective, Tesco had several revenue components but the central ones were core delivery fees and inventory sales. Initially these revenue components were not sufficient to offset the costs of Tesco's online operation. As a result, in the formative years Tesco had to rely on infusions of capital into its online division. In order for Tesco to operate using the hybrid model it had to be willing to invest a substantial amount of capital, on a recurring basis, over an extended period of time. This capital was used to some extent for financing the business operations, but also for funding customer relationship activities necessary to drive new and repeat business. Because Tesco enjoyed strong brand awareness and recognition, there was no need to spend large amounts of capital on brand building activities. What was necessary for Tesco was to stimulate customer trials and repeat purchases.

During the period between 1997 and 1998, Tesco expanded its service area and the online grocery operation began showing signs of becoming profitable. The company began developing new products for its customers that provided alternative revenue sources. Given Tesco’s early success with its online channel, the company decided that it was best not to change the business model. During the 1999 through 2004 period, Tesco continued using the same model and announced that the online grocery division was profitable. During this period Tesco began selling non-grocery items and developed a portal for selling non-grocery items from other retailers. By selling non-grocery items on its own site, and helping to sell non-grocery items through the third-party online channel, the traffic and sales volume for Tesco's online channel increased dramatically. In fact, 
the third-party online channel was a major revenue source for Tesco. During the 2005 through 2006 period, Tesco constructed a dedicated fulfillment center for grocery delivery. Thus, it was evident that in certain areas Tesco's model had reached scale for the in-store fulfillment method. Other than that there were no other changes to Tesco's operation.

\section{Tesco’s Model Dynamics}

During the period between 1995 and 1996, Tesco’s model became operational once the company began incurring order taking and customer relationship costs. Specifically, the front-end customer relationship costs 'customer awareness done alone' and 'customer acquisition done alone' were responsible for the generation of the performance drivers 'number of new customers' and 'number of repeat customers' (see Figure 75). The customer patronage performance drivers 'number of new customers' and 'number of repeat customers' then drove the other customer patronage performance drivers 'number of orders’ and 'items per order’ (see Figure 76). These two customer patronage performance drivers also drove the customer service performance driver 'number using third-party online channel' and 'number using financial services'. In turn, the customer patronage performance drivers 'number of orders' drove the delivery service performance driver 'number of orders delivered' (see Figure 76).

In relation to the cost structure, the customer patronage performance driver 'number of orders' was one of the primary drivers for back-end inventory acquisition expenses and the picking and packing fulfillment costs. The customer patronage 
Figure 75

Tesco’s Front-End Cost Components and Performance Drivers

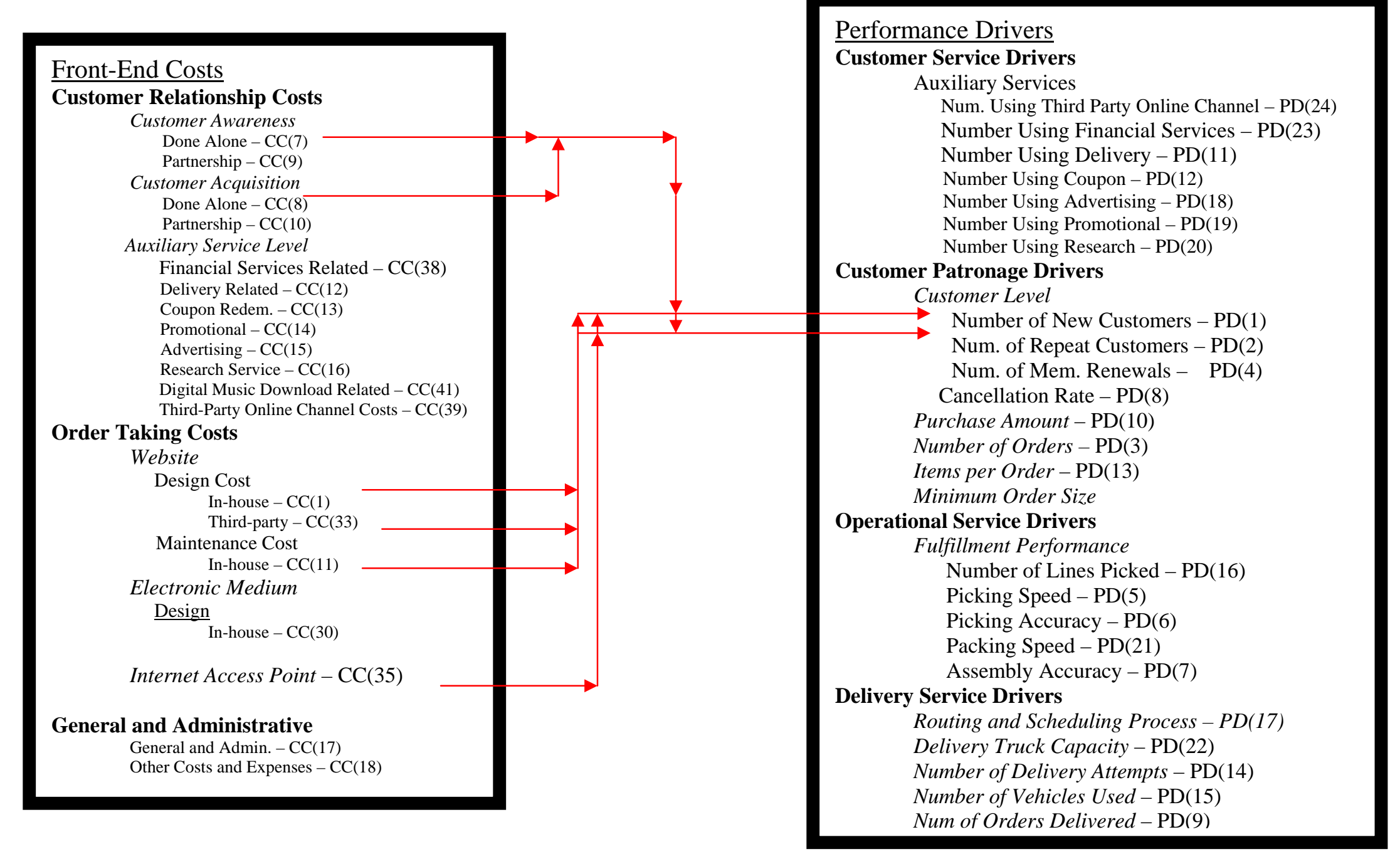


Figure 76

Tesco's Performance Drivers and Performance Drivers

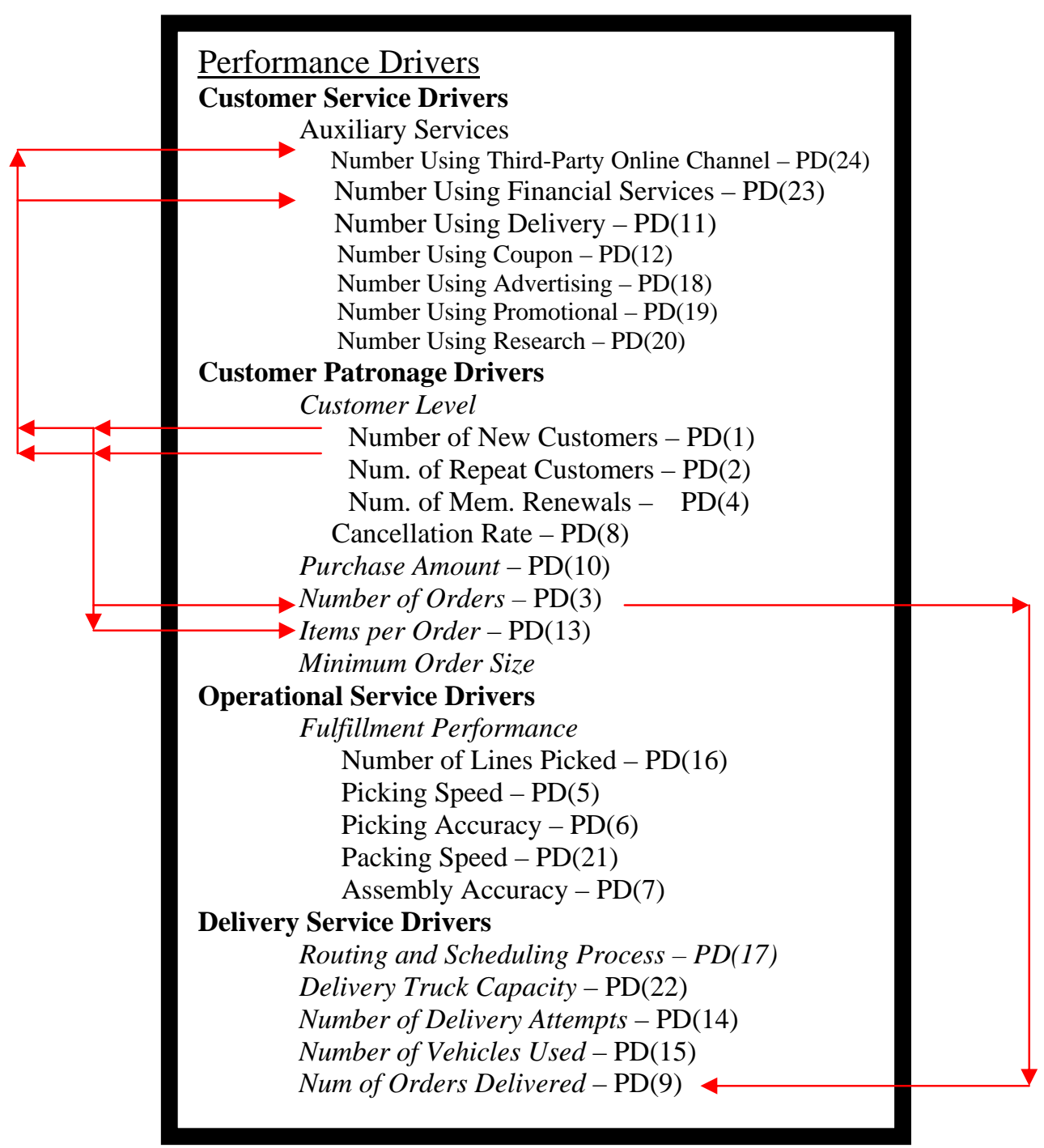


Figure 77

Tesco’s Backend Cost Components and Performance Drivers

\begin{tabular}{|c|c|c|}
\hline $\begin{array}{l}\text { Performance Drivers } \\
\text { Customer Service Drivers } \\
\text { Auxiliary Services } \\
\text { Number Using Third Party Channel - PD(23) } \\
\text { Number Using Delivery - PD(11) } \\
\text { Number Using Coupon - PD(12) } \\
\text { Number Using Advertising - PD(18) } \\
\text { Number Using Promotional - PD(19) } \\
\text { Number Using Research - PD(20) } \\
\text { Customer Patronage Drivers } \\
\text { Customer Level } \\
\text { Number of New Customers - PD(1) } \\
\text { Num. of Repeat Customers - PD(2) } \\
\text { Num. of Mem. Renewals - PD(4) } \\
\text { Cancellation Rate - PD(8) } \\
\text { Purchase Amount - PD(10) } \\
\text { Number of Orders - PD(3) } \\
\text { Items per Order - PD(13) } \\
\text { Minimum Order Size } \\
\text { Operational Service Drivers } \\
\text { Fulfillment Performance } \\
\text { Number of Lines Picked - PD(16) } \\
\text { Picking Speed - PD(5) } \\
\text { Picking Accuracy - PD(6) } \\
\text { Packing Speed - PD(21) } \\
\text { Assembly Accuracy - PD(7) } \\
\text { Delivery Service Drivers } \\
\text { Routing and Scheduling Process - PD(17) } \\
\text { Delivery Truck Capacity - PD(22) } \\
\text { Number of Delivery Attempts - PD(14) } \\
\text { Number of Vehicles Used - PD(15) } \\
\text { Num of Orders Delivered - PD(9) }\end{array}$ & 4 & $\begin{array}{l}\text { Back-End Costs } \\
\text { Capital Expenditures } \\
\text { Capital Expend. } \\
\text { Land - CC(44) } \\
\text { Facilities } \\
\text { Company Built - CC(25) } \\
\text { Leased - CC(2) } \\
\text { Fulfillment Equip. (semi-auto) - CC(36) } \\
\text { Store Conversion - CC(34) } \\
\text { Delivery Fleet } \\
\text { Company Owned - CC(21) } \\
\text { Third-Party Owned - CC(32) } \\
\text { Delivery Personnel Equipment -CC(40) } \\
\text { Fleet Maintenance - CC(22) } \\
\text { Inventory Expenses } \\
\text { Grocery Inventory Cost } \\
\text { Acquisition Cost } \\
\text { Purchased via Partner - CC(3) } \\
\text { Purchased via } \\
\longrightarrow \text { Manuf./Wholesaler - CC(23) } \\
\text { Non-Grocery Inventory Cost } \\
\text { Purchased via } \\
\text { Manuf./Wholesaler - CC(37) } \\
\text { Storage and Handling Costs - CC(31) } \\
\text { Inventory Related Software - CC(42) } \\
\text { Fulfillment Expenses } \\
\text { Picking Costs } \\
\longrightarrow \text { Human Capital - CC(4) } \\
\text { Hybrid (Some Automation) - CC(18) } \\
\text { Packing/Assembly Costs } \\
\longrightarrow \text { Human Capital - CC(5) } \\
\text { Hybrid (Some Automation) - CC(19) } \\
\text { Delivery Costs } \\
\longrightarrow \text { Delivery Personnel Costs - CC(17) } \\
\longrightarrow \text { Fuel Costs - CC(6) } \\
\text { Routing and Scheduling - CC(20) }\end{array}$ \\
\hline
\end{tabular}


Figure 78

Tesco’s Performance Drivers and Revenue Components

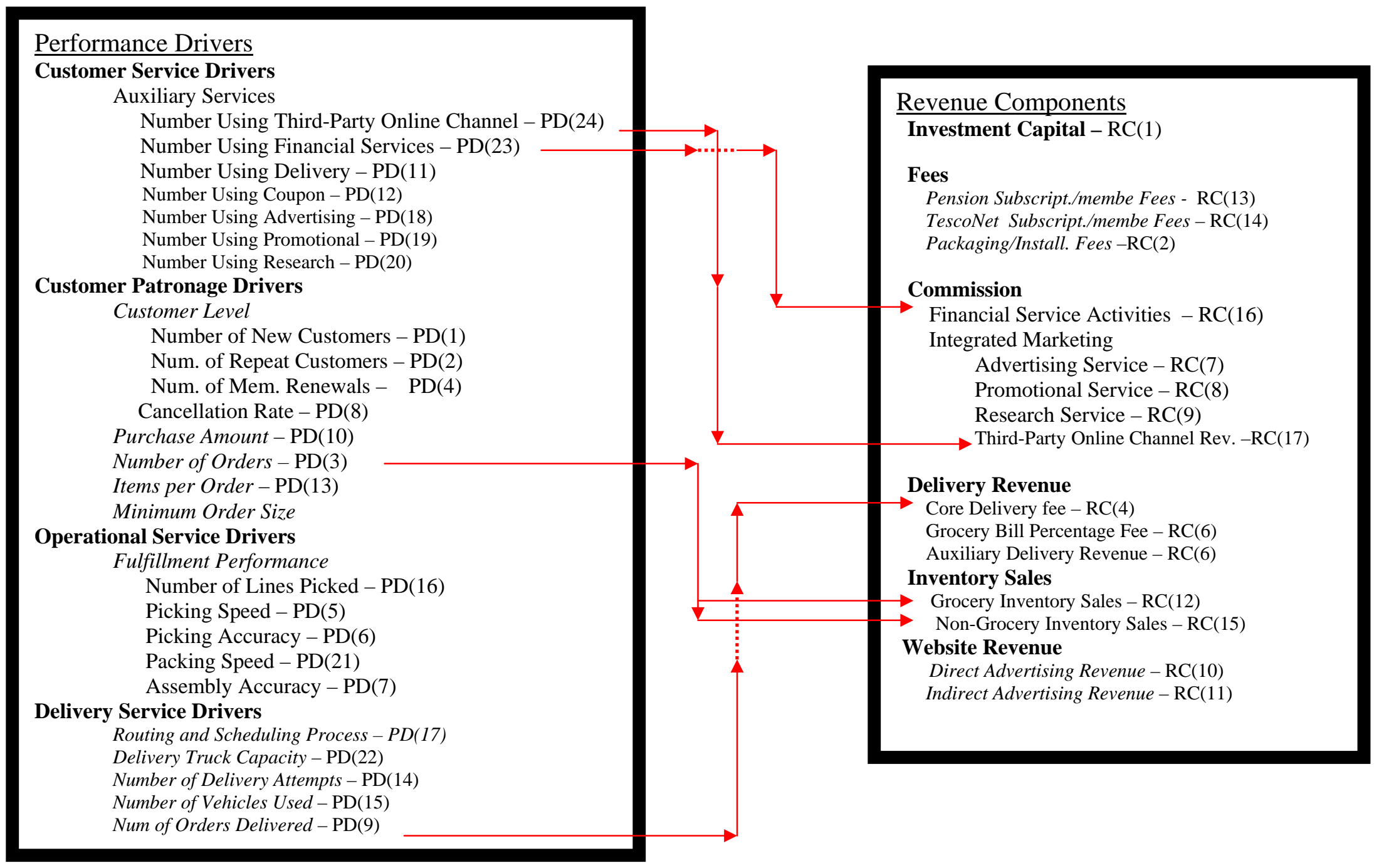


performance driver 'number of orders delivered' also helped to drive the back-end costs associated with 'fuel cost' and 'delivery personnel costs' (see Figure 77). In terms of revenue, the customer patronage performance drivers 'number of orders' was a primary driver for the revenue component 'grocery inventory sales' and 'non-grocery inventory sales' while the delivery service performance driver 'number of orders delivered', was a primary driver of the delivery revenue component ‘core delivery fees’ (see Figure 78). The customer service performance driver 'number using third-party online channel' drove the revenue component 'third-party online channel revenue' while the other customer service performance driver 'number using financial service' drove the commission revenue component ‘financial services activities’ (see Figure 78).

Tesco's business model shows how critical customer acquisition and retention activities were. The number of new and repeat customers was a key driver of the performance driver 'number of orders' which in turn was a primary driver of the revenue components 'grocery inventory sales' and 'non-grocery inventory sales'. The 'number of orders' was also a primary performance driver for the 'number of orders delivered' which in turn was a primary driver of the revenue component 'core delivery fees'. The 'number of orders' was also a primary driver for the back-end inventory expenses. Given that all of these drivers were based on the number of new and repeat customers, it is clear that customer acquisition and retention activities were vital to Tesco's entire operation.

\section{Comments Concerning the Model}

For a BAM grocer operating in the online grocery home delivery channel, Model 6a seemed extremely suitable. The model allows the BAM grocery retailer to capitalize 
on synergies between its online and offline operations. Specifically, the hybrid models allow the BAM grocer to use its current network of stores to fill customer orders. This requires little in terms of capital expenditures for facilities, which keeps the cost structure low. In addition, the online component also benefited from lower advertising costs, which helped to reduce the costs associated with brand building activities. This allowed the online division to spend its budget on promotional activities designed to stimulate customer trials for the service. Further, the online division also benefits from the purchasing power of the parent company. The ability of the parent company to gain quantity discounts from the product manufacturers and wholesalers allows the online division to extract greater margins, thus increasing its revenues. These models do have drawbacks in that they are very labor intensive, require a large investment in a delivery fleet, and require the duplication of functions in several locations. Hence, the variable cost structure associated with this type of fulfillment model can become quite expensive.

Tesco's operationalization of Model 6a seemed suitable because it allowed the company to take advantage of all the benefits that the model offered in terms of synergies. That is, it allowed Tesco to avoid certain costs and marginalize others, which helped the company keep the cost structure low. For example, there was no need to construct costly dedicated fulfillment centers since Tesco’s stores could serve that purpose. Inventory procurement costs were low since Tesco's online division could source inventory directly from Tesco which meant that the online division could gain the same, if not higher, margin on inventory sales. Tesco’s main costs were associated with developing the online order taking capacity, acquiring and operating a delivery fleet, and the general and administrative costs necessary to run the operation. 


\section{Between Case Analysis Comparisons}

Now that the in-depth case analyses are complete, and the various model dynamics have been discussed and commented on, it was possible to take a look across these cases to determine what factors were responsible for the success/failure of companies operating in the online grocery home delivery channel. The first of the two central research questions sought to determine the factors responsible for the success/failure of many online grocers prior to the 2000 dot.com collapse. The other question sought to determine the factors responsible for the success/failure of many online grocers in the wake of the 2000 dot.com collapse.

Answering the first research question requires comparisons of the profit structure of companies prior to the 2000 dot.com collapse. Based on the cases analyzed in this study, there were several between case comparisons that could have been conducted. For example, one could compare Peapod as a partnership with GroceryWorks as a pure-play or compare GroceryWorks as a pure-play and Tesco as a hybrid. Although these twoway comparisons would provide valuable information concerning the factors responsible for the success/failure of online grocers operating under the different structural categories, the very fact that these companies were operating under different categories introduces confounding elements into the analysis. This observation by no means diminishes the importance of the comparisons across the different structural categories, but simply points out that it is more difficult to isolate the root factor(s) for company success/failure if the analysis initially begins as a between category analysis. Given that the goal of the case analysis process is to help guide theory development, it seemed much more prudent to first make comparisons for the success/failure factor(s) within a specific 
structural category. Thus, the best starting point for this analysis would be to find an instance, or instances, where comparisons can be made within a specific structural category.

Given the cases that were analyzed in this study, it was possible to conduct just such a comparison. That is, in their current forms, Peapod, GroceryWorks, and Tesco all operate under the hybrid structural category. As the case data show, each of these three companies was at a different stage in terms of becoming profitable. Specifically, GroceryWorks had not turned an operating profit in any of the markets that it was operating in while Peapod had only begun to turn an operating profit in a few of the markets that it was operating in. Tesco, on the other hand, was showing an actual profit for its entire operation. By comparing the cost, revenue, and performance driver components for these three companies, it seemed possible to gain an understanding of what was driving profitability (i.e., company success/failure).

\section{Rules for Making Model Comparisons}

In order to prevent haphazard comparisons of models between and within structural categories, it was necessary to establish a set of rules to guide the process. These rules then served as the basis on which comparisons could be made. If these criteria were not met the comparison should not be considered valid. These rules were as follows:

Rule 1: The models between companies within a structural category can be compared during the years pertaining to the initial formation of each company's online channel presence even if the periods in question are dissimilar in terms of the date range. 
Rule 1 concerns comparisons between models within a structural category during the formative years of each company's development, which entails a period between one and four years. During this period it is assumed that all companies in the comparison would have gone through the initial problems associated with establishing a business but would not have begun making significant changes to their business model. This allows the assessment of the actual configuration that a company chooses once it decides to operationalize a specific model. Thus, the comparison assesses the performance of a theoretical model and its specific manifestation (see Figure 79).

Figure 79

Graphical Representation of Rule 1

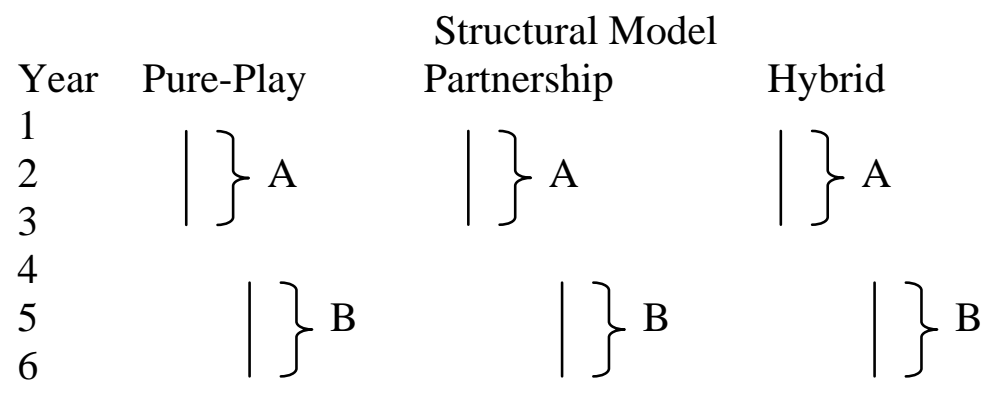

A = Initial setup and formative years of operation for company A.

$\mathrm{B}=$ Initial setup and formative years of operation for company B.

Rule 2: The models between companies across categories can be compared during the years pertaining to the initial formation of each company's online channel presence even if the periods in question are dissimilar in terms of the date ranges.

Rule 2 concerns comparisons between models across categories during the formative years of each company's development which entails a period between one and four years. During this period it is assumed that all companies in the comparison would 
have gone through the initial problems associated with establishing a business but would not have begun making changes to their business model. This allows the assessment of the actual configuration that a company chooses once it decides to operationalize a specific model. Thus, the comparison assesses the performance of the theoretical structural category and its specific manifestation.

Figure 80

Graphical Representation of Rule 2

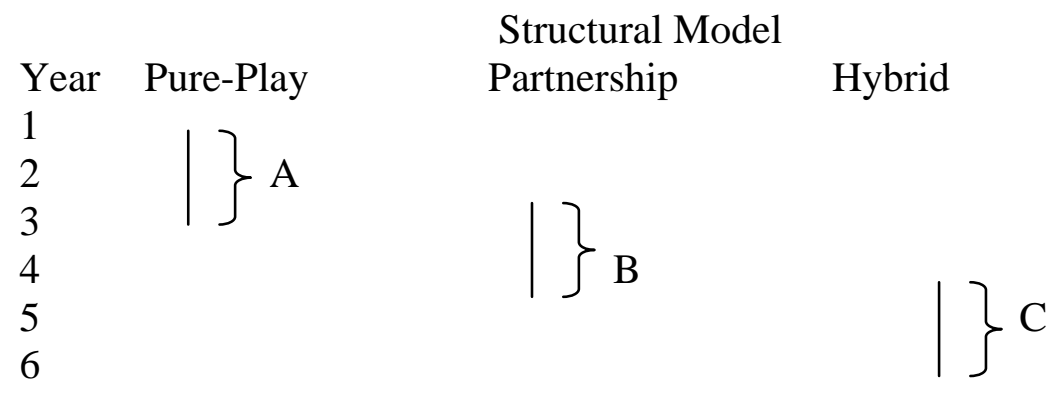

A = Initial setup and formative years of operation for company A.
$B=$ Initial setup and formative years of operation for company B.
C = Initial setup and formative years of operation for company C.

Rule 3: All other comparisons must be based on the following sub-rules:

a. For each comparison, there must be similarity in the time period (i.e., date range) over which the companies are to be compared. This does not need to be isomorphic but the ranges must be in close proximity.

b. The comparison must take place between the companies at relatively similar points in each company's stage of evolution (i.e., development). As going concerns the companies must be compared at roughly the same stage in their development.

Rule 3 ensure that company comparisons are not made between a company in its formative years and a company that was a going concern. In this case there would be an extreme imbalance between the revenue structures which would affect profitability. Rule 3 also guards against comparisons within and between structural categories for 
companies operating during vastly different chronological time periods. Comparisons between companies in close proximity to one another in terms of chronological time periods can be made.

Based on these rules there were several comparisons that could be made between the three companies in this study. These comparisons could be used to examine the profit structure for the same business models within a category, different business

Figure 81

Graphical Representation of Rule 3

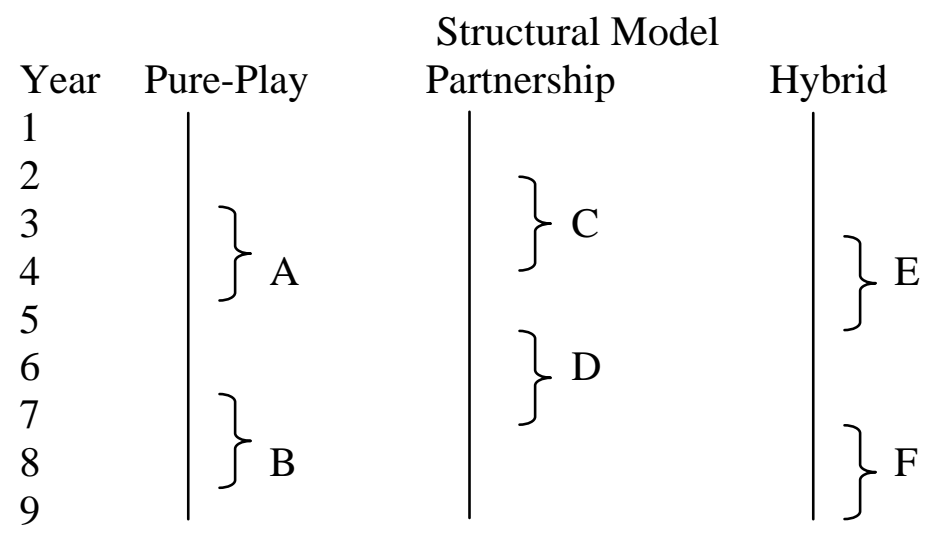

A, B = Operating range for comparison of an ongoing online Pure-Play. $\mathrm{C}, \mathrm{D}=$ Operating range for comparison of an ongoing online Partnership. $\mathrm{E}, \mathrm{F}=$ Operating range for comparison of an ongoing online Hybrid. Comparisons: A - C, C - E, A - E, B - D, D - F, B - F, A - D, D - E

models within a category, the same business models across different categories, and different business models across different categories. However, based on the above discussion, it seemed prudent to begin the analysis at a point where all three companies were operating within the same structural category. This occurs during the period between 2002 and 2006 when Peapod, GroceryWorks, and Tesco were all operating under the Hybrid structural category. Assessing the profit structure for these companies during this period allowed for the isolation of the success factors within a single category. 
From this analysis it was then possible to make between category analysis to determine if specific within structural category success/failure factors are generalizable across structural categories.

\section{$\underline{\text { Profit Structure Analysis Between Peapod, GroceryWorks, and Tesco }}$}

\section{Profit Structure Alignment}

Before the profit structure analysis among the three companies could proceed, the final profit structures for each company needed to be cleaned up to reflect current realities. Based on the final structure of Peapod, there were certain revenue components that needed to be removed. These components were part of the revenue and capitalization structures during a time when the company operated under different structural categories. Once the company became the online division of a major grocery retailer, these revenue and capital components were no longer needed. For example, once Peapod became a hybrid, there was no need for the company to solicit investment capital. In addition, given the open environment of the Internet, and the competitive nature of the grocery industry, Peapod was no longer able to charge an installation/packaging fee, a subscription/membership fee, or a grocery bill percentage fee. Moreover, due to the lack of demand for the integrated marketing services and auxiliary delivery services, Peapod ceased offering these services and thus received no further revenue. In addition, once Peapod became a subsidiary of Ahold, there was no longer a need to spend capital for leasing facilities, customer relationship costs were no longer done in partnership with the BAM grocer, and the inventory was no longer purchased directly from manufacturers and wholesalers. As a result, these cost components were removed (see Table 25). 
Based on GroceryWorks' final profit structure, there were also certain revenue components that needed to be removed. Like Peapod, once GroceryWorks became a hybrid it was no longer necessary to solicit investment capital. In addition, once the company changed to an in-store fulfillment method there was no need to spend money on capital expenditures (e.g., buying land, building facilities, and equipping those facilities) (see Table 26).

Based on the final profit structures for Tesco, 'electronic medium in-house' could be removed. This component was part of the cost structure during a time when Internet access was not as prevalent. Once Tesco began using the Internet as the primary access point, there was no longer a need for this order taking cost (see Table 27).

\section{Discussion of Online Model Levels}

Taking the above exclusions into account, there were some common revenue components between Peapod, GroceryWorks, and Tesco (see Table 28). These included the inventory sales component 'grocery inventory sales' and the delivery component 'core delivery fees'. Since these were the only revenue components that these companies had in common, this represented the core revenue structure for hybrid models. There were no revenue sources that were exclusive to the Hybrid structural category. However, there were some revenue components that were unique to Peapod and Tesco that resulted from the specific way in which these companies chose to operationalize their models (see Table 28). For Peapod, these revenue components included website revenue from direct and indirect advertising. For Tesco, these revenue components included fees from 
Table 25

Peapod's Profit Structure Components

\section{Sources of Operating Capital}

Investment Capital

(Investment Capital)

1. Investment Capital (RC1)

Member and Retailer Services

(Delivery Revenue)

1. Core Delivery Fee (RC4)

2. Grocery Bill Percentage Fee (RC5)

3. Auxiliary Delivery Revenue (RC6)

\section{(Fees)}

1. Installation/Packaging (RC2)

2. Subscription/Membership (RC3)

Interactive Marketing Services (Commission)

\section{Front End Costs}

System Development and

Maintenance

(Order Taking Costs)

1. Website Related

1a. Design Cost

$$
\text { In-house (CC1) }
$$

1b. Maintenance Cost

In-house (CC11)

Marketing and Selling Costs

(Customer Relationship Costs)

7. Customer Awareness

7a. Done Alone (CC7)

7b. Partnership (CC9)

8. Customer Acquisition Costs

8a. Done Alone (CC8)

8b. Partnership (CC10)
1. Integrated Marketing

Table 25(Cont'd)
Back End Costs

Performance Drivers

Grocery Operations

(Capital Expenditures)

2. Capital Expend.

2a. Facilities

Leased (CC2)

14. Delivery Flee

14a. Company Owned (CC21)

15. Fleet Maintenance (CC22)

(Fulfillment Expenses)

4. Picking Costs $(\mathrm{F}, \mathrm{V})$

4a. Human Capital (CC4)

5. Packing/Assembly Costs (F,V) 5a. Human Capital (CC5)

6. Delivery Costs

6a. Fuel Costs (CC6)

6b. Delivery Personnel Costs (CC17)
Customer Patronage Drivers

1. Number of Orders (PD3)

2. Item per Order (PD13)

3. Customer Level

3a. Number of Repeat Customers (PD2)

3b. Cancellation Rate (PD8)

3c. Number of Membership

Renewals

3d. Number of New Customers (PD1)

4. Purchase Amount (PD10)

Delivery Service Drivers

5. Number of Orders Delivered (PD9)

6. Number of Vehicles Used (PD15)

7. Number of Delivery Attempts

(PD14)

10. Delivery Truck Capacity (PD22)

11. Routing and Scheduling Process (PD17) 
Peapod's Profit Structure Components

\section{Sources of Operating \\ Capital}

1a. Advertising Service (RC7)

1b. Promotional Service (RC8)

1c. Research Service (RC9)

(Website Revenue)

1. Direct Advertising Revenue

(RC10)

2. Indirect Advertising Revenue

(RC11)

Grocery Sales

(Inventory Sales)

1. Grocery Inventory Sales

(RC12)

\section{Front End Costs}

(Interactive Marketing Services)

General And Administrative (General And Administrative)

10. General and Admin. (CC25)

11. Other Costs and Expenses (CC26)

(Inventory Expenses)

3. Inventory Acquisition Cost 3a. Purchased via Partner

(CC3)

3b. Purchased via

Manuf./Wholesaler (CC23)

\section{Performance Drivers}

Operational Service Drivers

8. Fulfillment Performance

8a. Picking Speed (PD5)

8b. Number of Lines Picked (PD16)

8c. Picking Accuracy (PD6)

8d. Assembly Accuracy (PD7)

Customer Service Drivers

9. Auxiliary Services

9a. Number Using Delivery (PD11)

9b. Number Using Advertising (PD18)

9c. Number Using Promotional (PD19)

9d. Number Using Research (PD20) 
Table 26

GroceryWorks' Profit Structure Components

\section{Sources of Operating \\ Capital}

Investment Capital

1. Investment Capital (IC1)

Inventory Sales

2. Grocery Inventory Sales (RC12)

Delivery Revenue

3. Core Delivery Fee (RC4)

\section{Front End Costs}

Order Taking Costs

1. Website Related

1a. Design Cost In-house (CC1)

1b. Maintenance Cost

In-house (CC11)

Customer Relationship Costs

7. Customer Awareness

7a. Done Alone (CC7)

7b. Partnership (CC9)

8. Customer Acquisition Costs

8a. Done Alone (CC8)

8b. Partnership (CC10)

\section{Back End Costs}

Capital Expenditures

* 18. Land (CC31)

* 19. Facilities

19a. Company Built (CC32)

* 17. Fulfillment Equipment

17b. Purchased CC(26)

14. Delivery Fleet

14a. Company Owned (CC21)

15. Fleet and Equipment

Maintenance (CC28)

Inventory Expenses

3. Inventory Acquisition Cost 3a. Purchased via manufacturer/wholesaler (CC23)

3b. Purchased via Parent Company (CC29)

\section{Performance Drivers}

Customer Patronage Drivers

1. Number of Orders (PD3)

2. Item per Order (PD13)

3. Customer Level

3a. Number of Repeat Customers (PD2)

3d. Number of New Customers (PD1)

Delivery Service Drivers

5. Number of Orders Delivered (PD9)

6. Number of Vehicles Used (PD15) 7. Number of Delivery Attempts (PD14)

10. Delivery Truck Capacity (PD22) 11. Routing and Scheduling Process (PD17) 
Table 26 (Cont'd)

GroceryWorks’ Profit Structure Components

\section{Sources of Operating Capital Front End Costs}

General And Administrative

10. General and Admin. (CC17)

11. Other Costs and Expenses

(CC18)

\section{Back End Costs}

Fulfillment Expenses

4. Picking Costs $(\mathrm{F}, \mathrm{V})$

4a. Human Capital (CC4)

4b. Hybrid (Some Automation) (CC18)

5. Packing/Assembly Costs (F,V)

5a. Human Capital (CC5)

5b. Hybrid (Some Automation) (CC19)

6. Delivery Costs

6a. Fuel Costs (CC6)

6b. Delivery Personnel Costs (CC17)

13. Routing and Scheduling (CC20)

\section{Performance Drivers}

Operational Service Drivers

8. Fulfillment Performance

8a. Picking Speed (PD5)

8b. Packing Speed (PD21)

8c. Number of Lines Picked (PD16)

8d. Picking Accuracy (PD6)

8e. Assembly Accuracy (PD7) 
pension subscription/membership fees, TescoNet subscription/membership fees, and packaging/installation fees. Tesco's revenue components also include commissions from financial service activities, integrated marketing promotional and research services, and third-party online channel revenue. In addition, Tesco received revenue from its website through indirect advertising, and through the sale of non-grocery inventory. Thus, for Tesco, the operationalization of its model called for the inclusion of several additional revenue sources (see Table 28).

Taking the cost component exclusions into account, there were some common cost components among Peapod, GroceryWorks, and Tesco (see Table 29). In terms of front-end cost components, the order taking components 'website design in-house' and 'website maintenance in-house' were common to all three companies business models. In addition, the general and administrative components 'general and administrative' and 'other costs and expenses' were also common to all three companies. Although these components represent the only ones that were common to all three models they did not represent the base components necessary to operate in the online channel. To establish this basic set of front-end costs required the inclusion of a means of soliciting customer trials. The reason for the initial exclusion as a common component results from the manner in which GroceryWorks became a hybrid. Specifically, Peapod was the wholly owned subsidiary of Ahold and as such served as Ahold's online division. Similarly, Tesco also had a wholly owned online channel division. Both of these companies conducted customer awareness and acquisition activities for their online divisions. GroceryWorks, on the other hand, was not a fully owned subsidiary of Safeway. As a result, it had to enter into agreements concerning co-branding activities. Based on this 
Table 27

Tesco’s Profit Structure Components

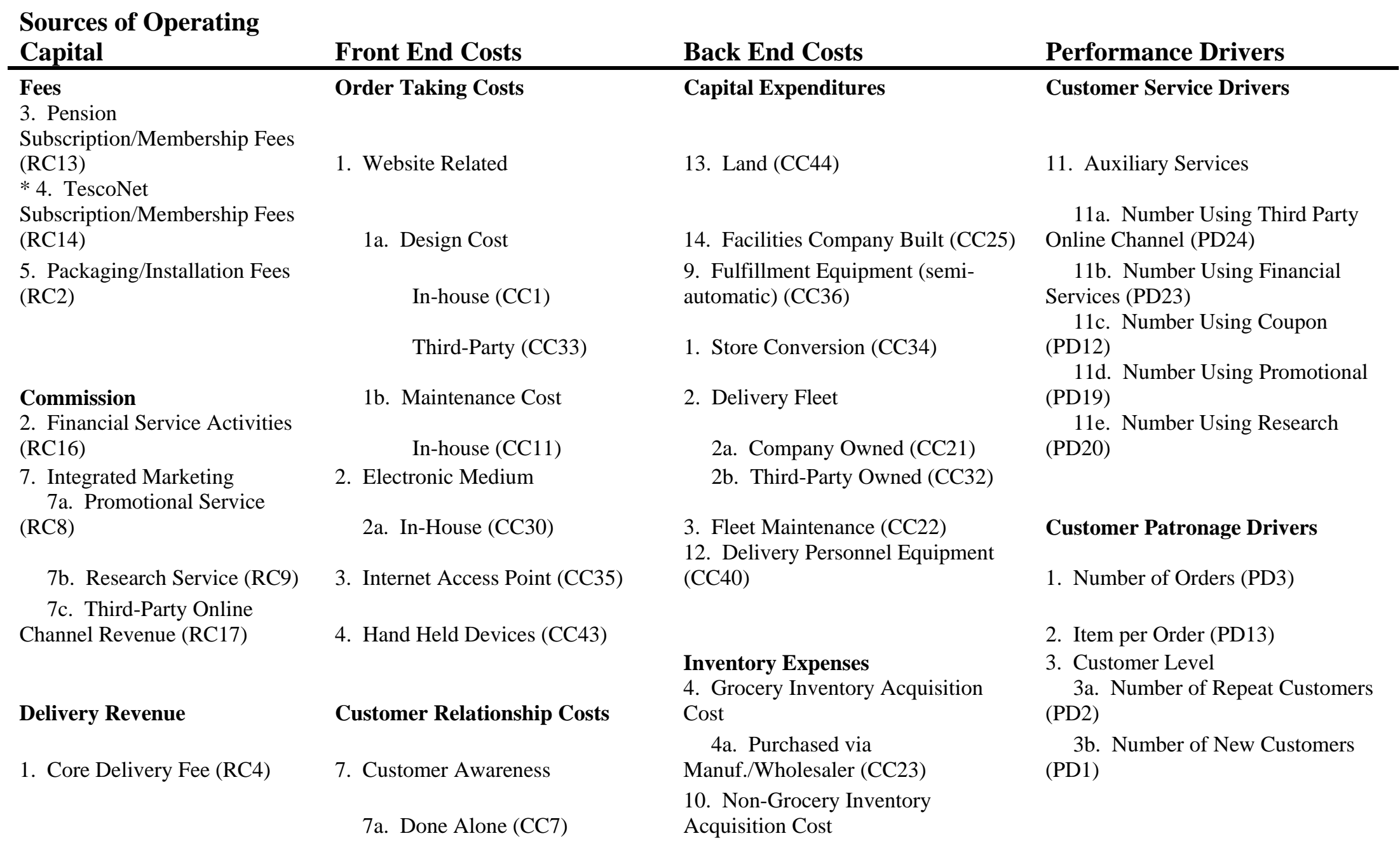


Table 27 (Cont'd)

Tesco’s Profit Structure Components

\section{Sources of Operating Capital}

Inventory Sales

1. Grocery Inventory Sales

(RC12)

6. Non-Grocery Inventory Sales (RC15)

\section{Website Revenue}

8. Indirect Advertising Revenue (RC11)

\section{Front End Costs}

8. Customer Acquisition Costs

8a. Done Alone (CC8)

12. Auxiliary Service Level

12a. Financial Services Related (CC38)

12b. Coupon Redemption (CC13)

12c. Promotional (CC14)

12d. Research Service (CC16)

12e. Third-Party Online Channel Costs (CC39)

\section{General And Administrative}

10. General and Admin. (CC17) 11. Other Costs and Expenses (CC18)

\section{Back End Costs}

10a. Purchased via

Manuf./Wholesaler (CC37)

5. Storage and Handling Costs

(CC31)

11. Inventory Related Software

(CC42)

\section{Fulfillment Expenses}

6. Picking Costs (F,V)

6a. Human Capital (CC4)

6b. Hybrid (Some Automation) (CC18)

7. Packing/Assembly Costs (F,V)

7a. Human Capital (CC5)

7b. Hybrid (Some Automation) (CC19)

\section{Delivery Costs}

6a. Fuel Costs (CC6)

6b. Delivery Personnel Costs (CC17)

\section{Performance Drivers}

\section{Delivery Service Drivers}

5. Number of Orders Delivered (PD9)

6. Number of Vehicles Used (PD15)

7. Number of Delivery Attempts

(PD14)

8. Delivery Truck Capacity (PD22)

12. Routing and Scheduling Process

(PD17)

\section{Operational Service Drivers}

9. Fulfillment Performance

9a. Picking Speed (PD5)

9b. Number of Lines Picked (PD16)

9c. Packing Speed (PD21)

9d. Picking Accuracy (PD6)

9e. Assembly Accuracy (PD7) 
Table 28

Common and Idiosyncratic Revenue Components for Peapod, GroceryWorks, and Tesco

\section{Sources of Operating Capital}

Common Revenue Components

Core Delivery Fee

Grocery Inventory Sales

Idiosyncratic Components Based on Structural Categories

Idiosyncratic Components Based on Model Operationalization

Peapod

Website Revenue

1. Direct Advertising Revenue

2. Indirect Advertising Revenue

$\underline{\text { Tesco }}$

Fees

Pension Subscription/Membership Fees (RC13)

TescoNet Subscription/Membership Fees (RC14)

Packaging/Installation Fees (RC2)

Commission

Financial Services Activities

Integrated Marketing

Promotional Service

Research Service

Third-Part Online Channel Revenue

Website Revenue

Indirect Advertising Revenue

Inventory Sales

Non-Grocery Inventory Sales 
reasoning, GroceryWorks did not meet the standard of a true hybrid model. Nonetheless, GroceryWorks' relationship with Safeway qualifies it as a hybrid model just not a pure form of the model. Hence, conducting customer relationship costs in-house seems to be a necessary but insufficient requirement for distinguishing a true hybrid. Based on this reasoning, the customer relationship activities done alone by the parent company or done through an agreement between the parent company and its subsidiary, also constitute common front-end cost components (see Table 29).

There were also front-end cost components that were unique to each company's specific operationalization of the hybrid model (see Table 29). For Peapod, this was the auxiliary service component ‘coupon redemption’. It seemed that Peapod felt that providing this service would help to make it more appealing to its target market. Because GroceryWorks was not a true hybrid, it had to enter into agreements with Safeway concerning customer relationship (i.e., co-branding) activities. As a result, this became a particularity of GroceryWorks’ hybrid model. However, based on the discussion concerning the common set of front-end costs, customer acquisition and awareness activities, whether done alone or with the partner, are part of the common set of front-end cost components. Hence, this cost was reclassified under common components (see Table 29). In Tesco’s case, there were several front-end costs that were specific to its model. For one, Tesco allowed certain aspects of its website design to be handled by third-parties. More importantly, Tesco incurred several auxiliary service costs targeted at both the consumer and business markets. The coupon redemption costs were designed to provide the customer with a value added service while the financial services, and the third-party online channel cost where designed to generate revenue for Tesco. 
Table 29

Common and Idiosyncratic Front-End Costs Components for Peapod, GroceryWorks, and Tesco

\author{
Front End Costs Components \\ Common Front-End Cost Components \\ Order Taking Costs \\ Website Related \\ Design \\ In-house \\ Website Related \\ Maintenance \\ In-house \\ Customer Awareness \\ Done Alone \\ Partnership \\ Customer Acquisition \\ Done Alone \\ Partnership
}

General And Administrative

General and Admin.

Other Costs and Expenses

Idiosyncratic Components Based on Structural Categories

Idiosyncratic Components Based on Model Operationalization

$\underline{\text { Tesco }}$

Order Taking Costs

Website Related

Design Third-Party

Internet Access Point

Hand Held Devices

Auxiliary Service Level

Financial Services Related

Coupon Redemption

Promotional

Research Service 
Table 29 (Cont'd)

Common and Idiosyncratic Front-End Costs Components for Peapod, GroceryWorks, and Tesco

\section{Idiosyncratic Components Based on Model Operationalization}

$\underline{\text { Tesco }}$

Auxiliary Service Level (Cont'd)

Third-Party Online Channel Costs

$\underline{\text { Peapod }}$

Auxiliary Service Level

Coupon Redemption

Similarly, the promotional and research services were designed to provide the consumer goods manufacturers with services for which Tesco charged a fee. Thus, most of Tesco’s auxiliary costs were incurred to provide the company with additional revenue sources. In addition to the common revenue and front-end cost components, there were also common back-end components between the three companies in the areas of capital expenditures and fulfillment expenses (see Table 30). The common capital expenditure components were 'delivery fleet company owned' and 'fleet maintenance' while the common fulfillment expense components included 'picking human capital', packing/assembly human capital', 'fuel costs', and 'delivery personnel costs'. Although these back-end costs were common across all three companies, they did not represent the most basic set of back-end cost components necessary to operate in the online channel. To establish this basic set of components required the inclusion of a means of inventory procurement. Given the online companies analyzed in this study, their inventories were either acquired through an agreement from the parent company or direct from the manufacturer/wholesaler. It would seem that from an operational perspective, the 
difference between a hybrid online grocer that sources inventory from the parent company and one that sources inventory from the manufacture/wholesaler boils down to paperwork and semantics. Granted, there may be some quantity discounts that accrue to the parent company but in terms of the actual sourcing activity, there is no difference. As a hybrid, sourcing from the parent is an indirect way of sourcing from the manufacture/wholesaler especially if the parent company sells the online unit the inventory at cost. Based on this reasoning, inventory expenses were considered to be a common back-end component whether it was sourced directly from the manufacture/wholesaler or from the parent company. The inclusion of the inventory components completes the common back-end cost components for the hybrid model (see Table 30).

There were also back-end costs associated with the particular structural category that a company was operating under (see Table 30). For example, given Tesco's decision to use an in-store fulfillment model the company incured capital expenses associated with store conversion. Moreover, based on Tesco's stated strategic decision to make nongrocery retailing a significant portion of its business, the company had to incur the costs associated with establishing a non-grocery inventory channel. Since Tesco already had the retail floor space, the establishment of a non-grocery inventory channel was based on the company's ability to procure non-grocery inventory. Moving this inventory through the channel required the company to incur storage and handling costs. Since GroceryWorks was using Tesco's in-store fulfillment model, it too incurred storage and handling costs. 
Table 30

Common and Idiosyncratic Back-End Cost Components for Peapod, GroceryWorks, and Tesco

\section{Back End Costs}

Common Front-End Cost Components

Capital Expenditures:

Delivery Fleet

Company Owned

Fleet Maintenance

Inventory Expense:

Grocery Inventory Purchased via Manufacturer / Wholesaler

Grocery Inventory Purchased via Parent Company

Fulfillment Expenses:

Picking Human Capital

Packing/Assembly Human Capital

Fuel

Delivery Personnel

Idiosyncratic Components Based on Structural Categories

$\underline{\text { Tesco }}$

Capital Expenditures

Store Conversion

Inventory Expense

Non-Grocery Inventory Purchased via Manufacturer / Wholesaler

Storage and Handling Costs

Idiosyncratic Components Based on Structural Categories (Cont'd)

GroceryWorks

Inventory Expense

Storage and Handling Costs 
Table 30 (Cont'd)

Common and Idiosyncratic Back-End Cost Components for Peapod, GroceryWorks, and Tesco

Idiosyncratic Components Based on Model Operationalization

$\underline{\text { Tesco }}$

Capital Expenditures

Facilities Leased

Delivery Personnel Equipment

Fulfillment Equipment (Semi-Automatic)

Facilities Company Built

Land

Delivery Fleet Third Party

Inventory Expense

Inventory Related Software

Fulfillment Expense

Hybrid Picking (some-automation)

Hybrid Packing/Assembly (some-automation)

GroceryWorks

Capital Expenditures

Equipment Maintenance

Fulfillment (Automation) Equipment Purchased

Facilities Company Built

Land

Fulfillment Expense

Routing and Scheduling

Peapod

Capital Expenditures

Facilities Leased 
Table 30 (Cont'd)

Common and Idiosyncratic Back-End Cost Components for Peapod, GroceryWorks, and Tesco

Idiosyncratic Components Based on Model Operationalization

(Cont'd)

$\underline{\text { Peapod }}$

Fulfillment Expense

Hybrid Picking (some-automation)

Hybrid Packing/Assembly (some-automation)

Routing and Scheduling

There were also back-end costs that were unique to a specific company's operationalization of a model (see Table 30). For GroceryWorks, these costs were associated with capital expenditures and fulfillment expenses. The capital expenditures were related to equipment maintenance, company built facilities, land purchases, and fulfillment (automation) equipment. The fulfillment related expenses were associated with routing and scheduling processes. For Peapod, the unique back-end costs were related to capital expenditures and fulfillment expenses. The capital expenditures concerned the company's leased facilities while the fulfillment expenses concerned the use of low-level automated equipment for the picking and packing/assembly functions, and routing and scheduling software for improving the delivery functions’ efficiency. Lastly, for Tesco, these unique back-end costs were associated with capital expenditures, inventory expenses, and fulfillment expenses. In terms of capital expenditures, these expenses included facilities leased, delivery personnel equipment, fulfillment equipment, company built facilities, land, and the use of a third-party delivery fleet. The inventory expenses included the costs associated with the inventory related software. The 
fulfillment expenses were associated with the cost of operating the low-level automated equipment (e.g., smart carts).

Based on this analysis of the profit structures for Peapod, GroceryWorks, and Tesco, there are three levels at which to classify an online grocery home delivery channel business model. The first level is the 'Core Online Grocery Channel Model'. It represents the fundamental cost and revenue components that a company must have in order to operate in the online grocery home delivery channel (see Figure 82). The next model level is the 'Structural Online Grocery Channel Model'. This represents the model that exists as a result of the strategic decision by a company to operate under a specific structural category (e.g., Pure-Play, Partnership, and Hybrid). The final model level was the 'Augmented Online Grocery Channel Model’. This model represents the incorporation of unique revenue and cost components onto either the core model or the structural model. This model represents the actual configuration that a specific company chooses to operate with in the online grocery channel.

\section{Core Model Analysis}

From the above discussion concerning the three levels of an online grocery home delivery model, it seems logical to begin the comparison at the most rudimentary level the core. As Figure 82 demonstrates, the core represents the base model upon which all other model incarnations rely. This made it the most logical place to begin the analysis. Differences between company performances at this stage may be seen as possible reasons or factors that may explain the success/failure of those companies in the online channel. However, if these differences prove to be insufficient to explain the success/failure of 
Figure 82

Online Grocery Channel Model Levels

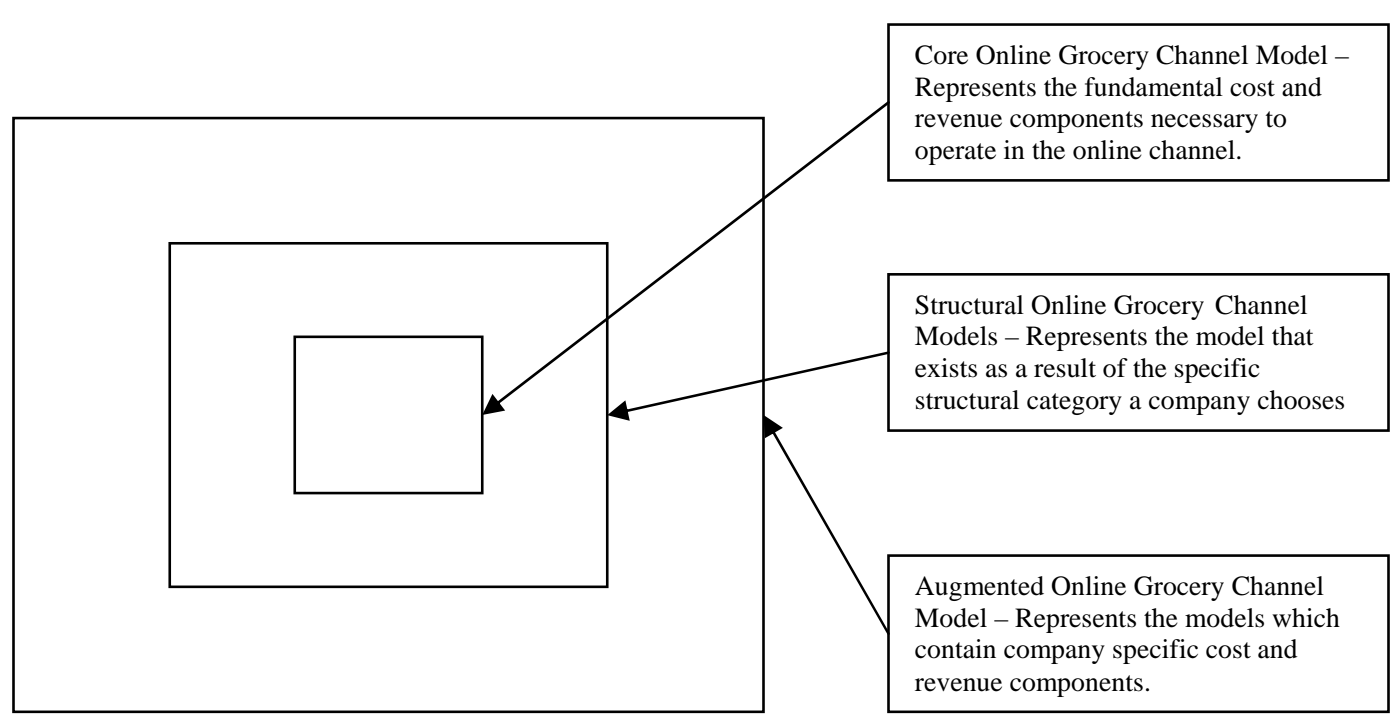

companies, then the analysis should progress to the structural level. Again the objective is to isolate those factors that are different between the companies. Any major differences at this level may be considered possible candidates for explaining the success/failure of companies in the online channel. If these factors prove to be insufficient for explaining the success/failure of the companies in the online channel, then the analysis should proceed to the augmented level. At this level the idiosyncrasies of the specific models should be able to explain the variations in company profitability. If these factors fail to provide an explanation for the success/failure of the companies in the online channel, then the analysis should turn to market related factors.

Figure 83 displays the core model, including performance driver components, for companies operating under a hybrid category in the online grocery home delivery channel. The model's dynamics began with the decision by an online grocer to solicit 
customer trials and repeat purchases (i.e., engage in customer relationship activities). These solicitation efforts gave rise to the customer patronage performance drivers 'number of new customers' and 'number of repeat customers' These customer patronage performance drivers then drove the other customer service performance driver 'number of orders'. The 'number of orders' then drove the delivery service performance driver 'number of orders delivered' (see Figure 83).

From a back-end cost perspective, the customer patronage performance driver 'number of orders' was a primary driver for the inventory expense components ‘inventory purchased via partner’ and ‘inventory purchased via manufacturers/wholesalers'. The customer patronage performance driver 'number of orders' also drove the fulfillment expenses components 'picking cost human capital', and 'packing/assembly costs human capital'. Moreover, the delivery performance driver ‘number of orders delivered’ was a primary driver for the back-end delivery cost components 'delivery personnel costs' and 'fuel costs' (see Figure 83). From a revenue perspective, the 'number of orders delivered' served as a primary driver for the delivery revenue component 'core delivery fee' while the customer patronage performance driver 'number of orders', was a primary driver for the revenue component 'grocery inventory sales’ (see Figure 83).

Based on this core model, it was clear that the key drivers were the number of new and repeat customers. In order to generate these performance drivers, the online grocer had to engage in customer relationship activities. This indicated that the customer awareness and acquisition activities were a central factor initially for companies entering the online channel. Given that the cost and revenue components were driven by the same 
Figure 83

Core Online Grocery Home Delivery Model

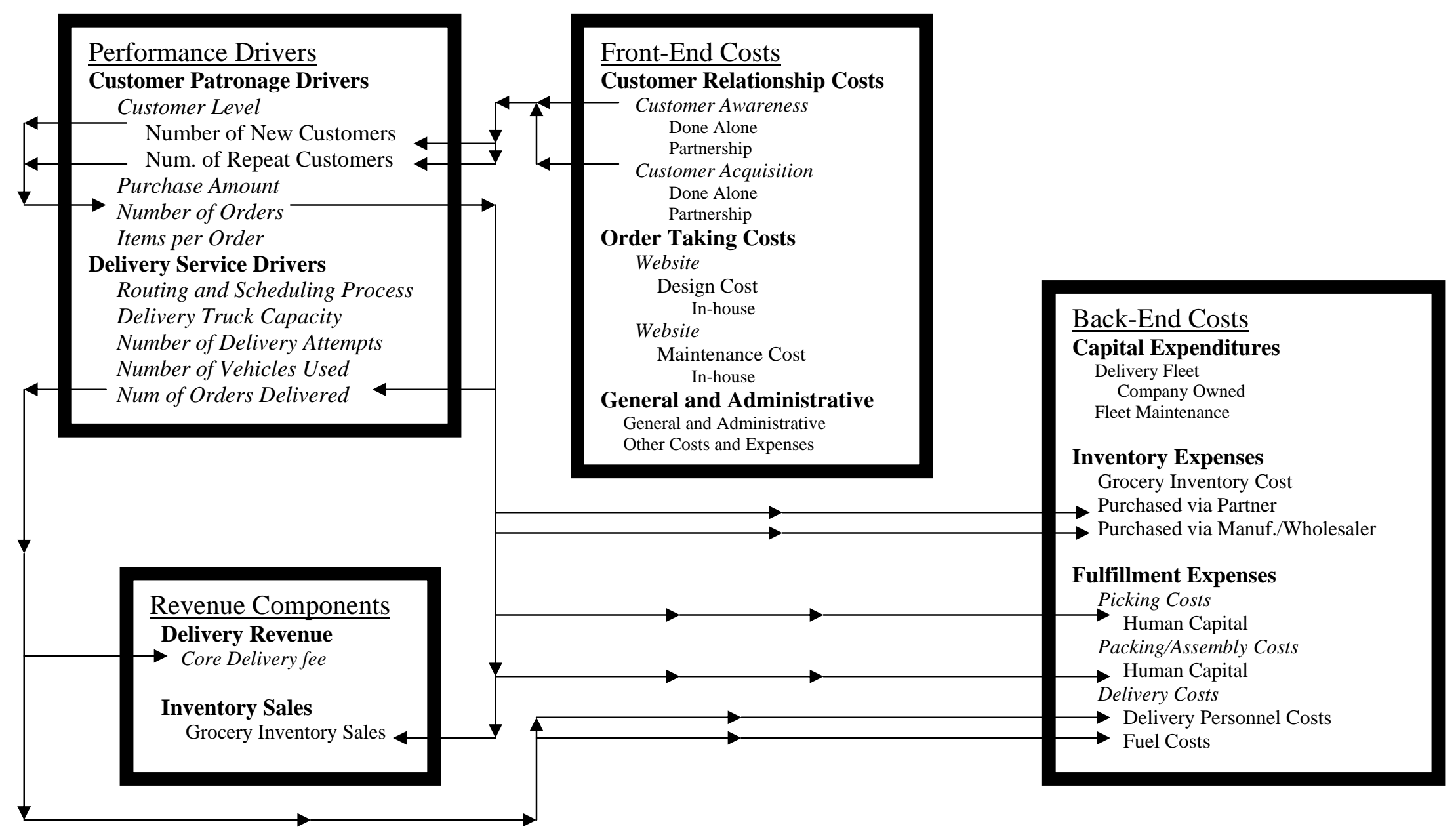


performance drivers, company profit was determined by the difference between revenue and costs components. Based on general economic theory, the fixed costs per unit decrease as the number of units produced increases. Hence, the margin between revenue and cost should increase as the fixed cost component is spread over more units. Applying this rationale to the grocery home delivery channel indicates that as the number of deliveries increases, the fixed cost for any single delivery declines and the profit for that delivery increases. Thus, the faster that an online grocer generates a critical mass of customers, the sooner that grocer begins reducing the fixed cost component. As sales increase, the higher margin allows the grocer to earn more revenue thus reducing the time to breakeven. The faster that the online grocer reaches breakeven, the faster the online grocer will become profitable. In essence, those grocers that are able to generate enough customer trials and repeat purchases should be profitable while those companies that are unable to generate enough customer trials and repeat purchases should not be profitable. Holding to this logic, what is presented next is a discussion of each company's efforts to stimulate customer trial and repeat purchase.

\section{Peapod}

During the period between 1989 and 1991 Peapod was in its formative years and did not have a substantial advertising and promotional budget. To compensate the company relied on a low-cost, low-tech approach by placing flyers on phone poles and bulletin boards in an effort to drive brand awareness and prompt customer trial. This effort proved inefficient and the company began co-branding with its BAM grocery retail partner. During the period Peapod was losing money indicating that it had not reached a 
critical mass of customers to drive the core model. This should have been expected given the company's age.

During the 1992 through 1996 period, with the help of its BAM grocery retail partner, Peapod initiated a radio and newspaper advertising campaign. The company reported that membership increased by $63 \%$ from 4,600 to 12,500 and order volume increased 76\% from 70,300 to 124,100. This demonstrated that customer relationship costs were one of the primary catalysts for generating customer patronage drivers. Since no figures concerning the cancellation rate were given, the actual net increase in membership, due to promotional activities, could not be determined. Even though the advertising was able to increase the membership and order volume, Peapod continued to lose money indicating that the company still had not reached a critical mass of customers to drive the core model.

From 1997 through 1999 Peapod continued to conduct co-branding activities with its BAM grocery retail partner. Although the company continued to see benefits in terms of increased membership and order volume from these co-branding activities, it was still losing money. During the 2000 through 2006 period, Peapod was purchased by Royal Ahold. Once Ahold acquired Peapod, the company began conducting co-branding activities through Ahold's subsidiaries. One of the stated goals for Peapod in the Chicago market was deeper penetration, which usually is associated with heavier marketing and sales promotion. These co-branding activities were successful in increasing awareness, membership, and order volume to the point where Peapod was turning a profit in a few of the markets that it was operating in. Granted, some of this increase was attributable to the reduced cost structure that Peapod benefited from as a 
result of being annexed by Ahold. Nonetheless, it seemed that the customer awareness and acquisition efforts made it possible for Peapod to begin generating a critical mass of customers necessary to drive the core model and become profitable in some markets.

What is interesting is that other than the desire to shop for groceries online or search for recipes and healthy eating ideas, neither Peapod's nor any of Ahold's subsidiaries offered customers any other incentives to stay on their websites. That is, customers who logged onto Peapod's website were there exclusively to shop for groceries. For those consumers who were not exclusively interested in purchasing groceries online, there were no other activities or offerings to keep them on, and/or draw them to, the website. As a result, the website was unable to generate the traffic necessary to stimulate additional customer trials. Furthermore, based on the case information, at no point did Peapod ever tie the in-store loyalty programs offered through Ahold's various subsidiaries to online purchases. Moreover, there was no opportunity to collect loyalty points for online purchases made on other retailers' websites accessed through Peapod's website. This also prevented Peapod from generating additional revenue from other retailers' based on the amount of traffic that the company could direct to those other retailers' sites. Hence, referring to Figure 83, Peapod was never able to generate enough customers to make the core model profitable. In fact, it took roughly thirteen years in the market that Peapod originally started in for the company to begin to show signs of profitability. Many analysts noted that it was the efficiencies that Peapod gained as an Ahold subsidiary, and not any significant increase in demand, that allowed the company to move towards profitability. As of December 2006 Peapod was profitable in some of the markets that it served but overall the company was still unprofitable. 


\section{GroceryWorks}

During the period between 1999 and 2000 GroceryWorks was in its formative years of development. During this period, the company conducted its own customer awareness and acquisition (i.e., brand building) activities using a combination of print, radio, newspaper and billboard advertising. These activities were successful in increasing brand awareness, but they were unsuccessful at prompting a substantial number of customer trials. As a result, GroceryWorks was unable to reach a critical mass of customers necessary to generate the core model. Given the company's age this was understandable.

During the period between 2000 and 2001, Safeway purchased a controlling interest in GroceryWorks. This allowed the company to conduct co-branding activities with Safeway subsidiaries, which increased brand awareness for the company. Also during this period, GroceryWorks teamed with Launch Partnership to conduct a television advertising campaign. This was the most aggressive advertising that GroceryWorks had conducted to this point in time. The spots ran for several months and had the effect of increasing GroceryWorks’ brand awareness and customer trials. However, these increases in customer trials and repeat purchases were not enough to overcome the cost components.

In an attempt to improve GroceryWorks’ virtual facade, Safeway upgraded the GroceryWorks’ website to resemble Safeway’s site. The upgrade allowed customer access to health related information through a wellness page and it also allowed customers access to non-grocery content such as patio and outdoor furniture and accessories. Other than these features, however, there were no other offerings to 
stimulate website traffic. As a result, there was no opportunity to collect loyalty points for online purchases made on other retailers' websites accessed through GroceryWorks' website. This prevented the company from generating additional revenue from other retailers based on the level of traffic the company could direct towards those other retailers. From 2001 through 2006 GroceryWorks expanded its service area and continued to co-brand with Safeway subsidiaries. However, even though these efforts were having some success, the company was still not profitable. This indicated that, even with all the co-branding activities, GroceryWorks was still unable to produce a critical mass of customers necessary to generate the core model.

Tesco

During the period between 1995 and 1996, Tesco's online initiative was in its initial years of development. The company offered its service on a very limited basis and advertised using flyers and leaflets placed in the mailboxes of prospective customers. This was a very low-cost method of advertising the service. Nonetheless, during this period, Tesco was not profitable.

During the period between 1997 and 1998 Tesco was using in-store promotions and co-branding activities to increase the awareness of the service. Given the low level of Internet penetration in the U.K., Internet initiatives were a novelty. Thus, many people were coming to Tesco's website just to look around, but soon they were coming to the website to purchase groceries. In fact, once Tesco began selling groceries over the Internet the service was so successful that it put Tesco's website in the top ten most popular websites in the U.K. Tesco ability to generate a sizable amount of website traffic 
indicated that the company may have benefited from a sort of first mover advantage, or at least first group or set advantage. As a result, Tesco was showing signs of becoming profitable, which prompted the company to make plans for a national rollout. This indicated that the company was able to generate the critical mass of customers necessary to power the core model. Once the core model was generating enough customer trials and repeat purchases to sustain itself internally, it was possible for Tesco to build on that model. From that point forward, increasing the number of customer trials and repeat purchases would only add to Tesco's profitability.

During this period Tesco did exactly that by adding more content to its website which helped to drive additional traffic to the site. Assuming that the probability of making an online grocery sale is higher for customers already on the site, attracting additional traffic has the residual effect of increasing grocery sales. This is demonstrated by the links between the front-end order taking costs 'website design in-house' and 'website maintenance in-house' and the customer patronage performance drivers 'number of new customers' and 'number of repeat customers' (see Figure 84) (The lines are dashed to indicate that this source of customer trials and repeat purchases stemmed from the residual number generated by customers who did not come specifically to the site to purchase groceries).

In 1998 Tesco decided to become an ISP and was able to make a profit on the service because it was the low cost provider. In order to use the service customers had to have a Tesco ClubCard. This allowed Tesco to tie the use of its Internet service to its loyalty program. Since ClubCard points could be applied to online purchases, Tesco was in essence reducing the cost of delivery by allowing the points to be applied to grocery 
purchases online. Thus, by tying its loyalty program to its online channel, Tesco was able to stimulate additional traffic on its site. In essence Tesco was paying people to shop. It took four years from the time Tesco began its online initiative for the company to show signs of profitability.

During the period between 1999 and 2004 Tesco continued to advertise its grocery home delivery service through co-branding efforts. In February 1999 Tesco announced that it was offering its ISP service for free to all its customers who had a loyalty ClubCard. Immediately after that Tesco announced a partnership with Excite to provide Tesco's free ISP website with specially formatted channel content and Internet search capabilities. This gave Tesco's customers access to news, sport, weather, lifestyle, money, and investment information within the TescoNet environment. At this point, Tesco’s model advanced past the core model. Once the core model was generating enough customer trials and repeat purchases to sustain itself internally, Tesco capitalized on this by opening up new revenue sources in the form of new products and services. To continue driving new and repeat customer trials, the company launched a multi-million pound sterling billboard, newspaper and radio campaign that highlighted the expansion of its online home-shopping service and promoted its use. The advertising campaign was more aggressive because it needed to drive the augmented model. Thus, it seems that Tesco's success was due to its ability to generate a critical mass of customers necessary to drive the core model. 
Figure 84

Core Online Grocery Home Delivery Model with Website Generated Demand

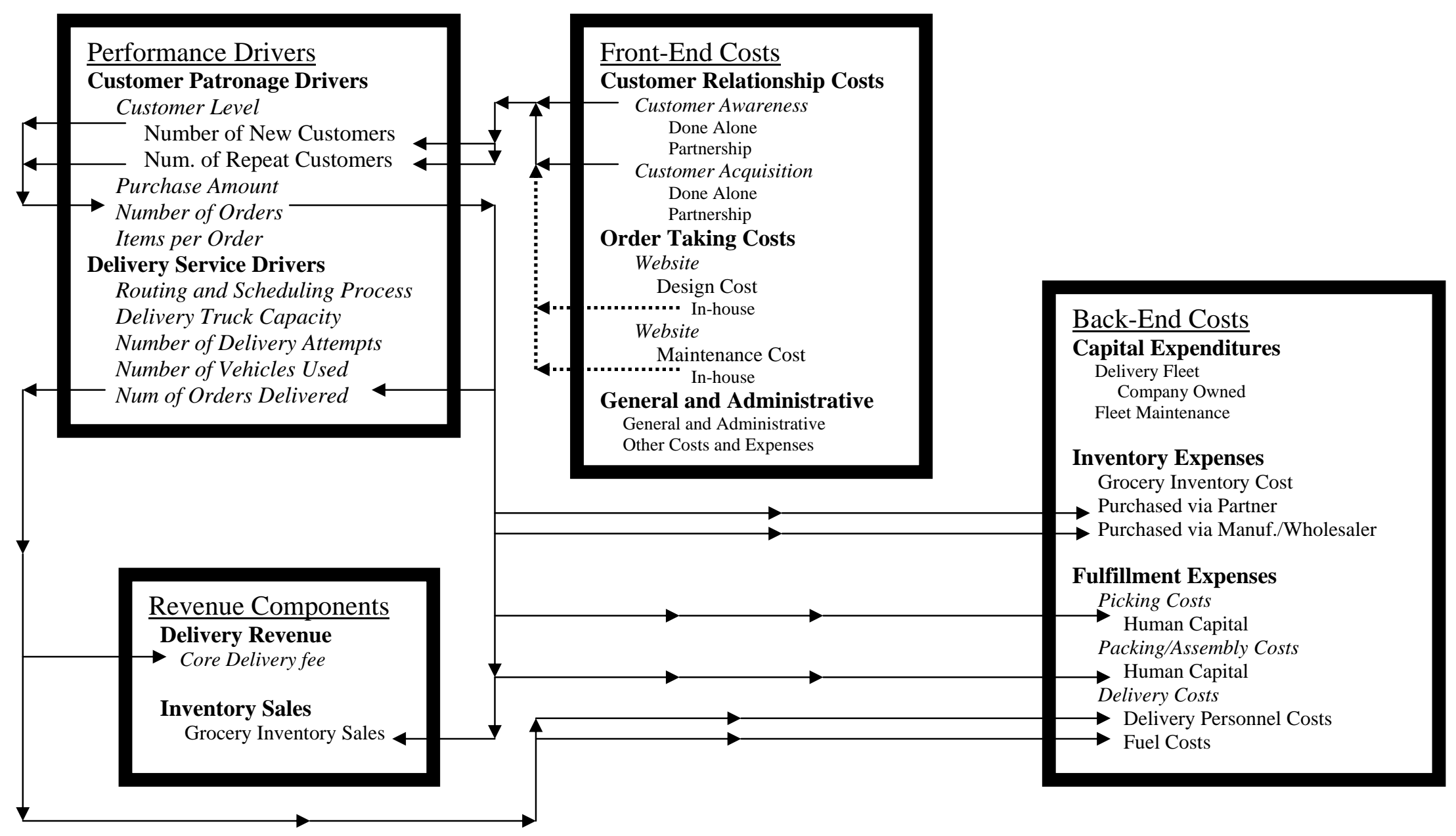




\section{Other Mediating/Moderating Variables}

At this point in the discussion, the case has been made that the success/failure of the online grocers was primarily due to the customer relationship activities (i.e., advertising, promotions, and loyalty programs) that companies undertook. However, this analysis would be incomplete without discussing the impact that the other mediating and moderating factors may have had on the success/failure of companies operating in the online grocery home delivery channel. Based on Rule 2 and Rule 3, a comparison between the mediating and moderating factors for the companies in this study was undertaken. The goal of the comparison was to determine if there were any significant changes in these factors from a company’s inception to the year 2006. Major changes during this time period could indicate that the factor(s) in question may have had an effect on the success/failure of online grocers.

In reference to the company related factors, scalability for Tesco followed the path from an in-store fulfillment model, with low scalability, to a model with a moderate to high level of scalability (see Table 31). In contrast, Peapod began with an in-store fulfillment model and then acquired the capacity necessary to move to a dedicated fulfillment model. However, once Ahold acquired Peapod, it changed Peapod's fulfillment method back to an in-store method. GroceryWorks, on the other hand, followed the path from a dedicated fulfillment center model to an in-store fulfillment model. Given the cost structures of GroceryWorks and Peapod while the two companies were supporting dedicated fulfillment models, it seemed that both companies imploded. Referring back to the discussion on the three levels of the online grocery channel model, it would seem that during the time when both companies were supporting dedicated 
fulfillment, neither company's core model was able to generate a critical mass of customers large enough to support the augmented structure. As a result, both companies had to shed excess costs in an attempt to strip down to a structure that their core models could support. Thus, the development of scalability capacity may be a factor that can explain the success/failure of online grocers. By building medium/large dedicated fulfillment centers Peapod and GroceryWorks may have inadvertently usurped precious capital that could have been used in other functional areas to help sustain and grow each company.

Looking at the method of delivery, all three companies began using attended home delivery and ended using this method (see Table 31). All three also ended using the store-pickup method with GroceryWorks also experimenting with the local pickup method. Given the similarities between the companies on this factor, it was unlikely that it was responsible for the success/failure of online grocers. In relation to the company rate of expansion, GroceryWorks had a moderate rate of growth at the beginning and end of the period. Peapod started slow and ended with a moderate rate of growth while Tesco started with a slow rate of growth and ended the same way. However, a closer look at Tesco's expansion rate reveals that at one point the company's rate of expansion was high and once the company expanded its service area to a certain size (i.e., 95 percent coverage in the U.K.) it scaled back its growth rate. This observation lends support to the initial contention that the success/failure of online grocers was primarily due to the customer relationship activities that drove customer trial. According to the discussion concerning the three levels of the online model, once the core model was powered up, it could support the other two levels of the model. So once its core model was generating a 
Table 31

Other Mediating/Moderating Factors for Peapod, GroceryWorks, and Tesco

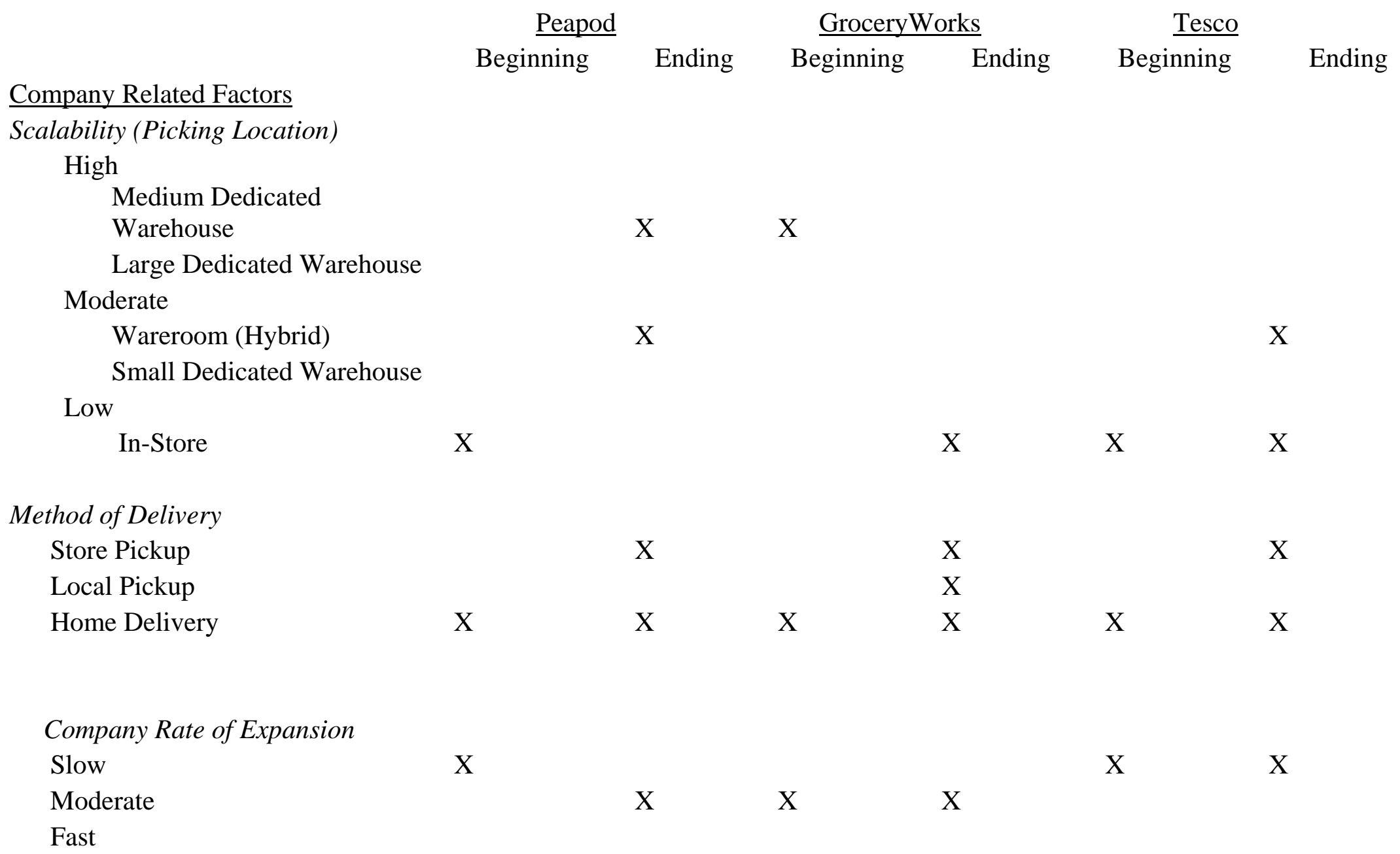


Table 31 (Cont'd)

Other Mediating/Moderating Factors for Peapod, GroceryWorks, and Tesco

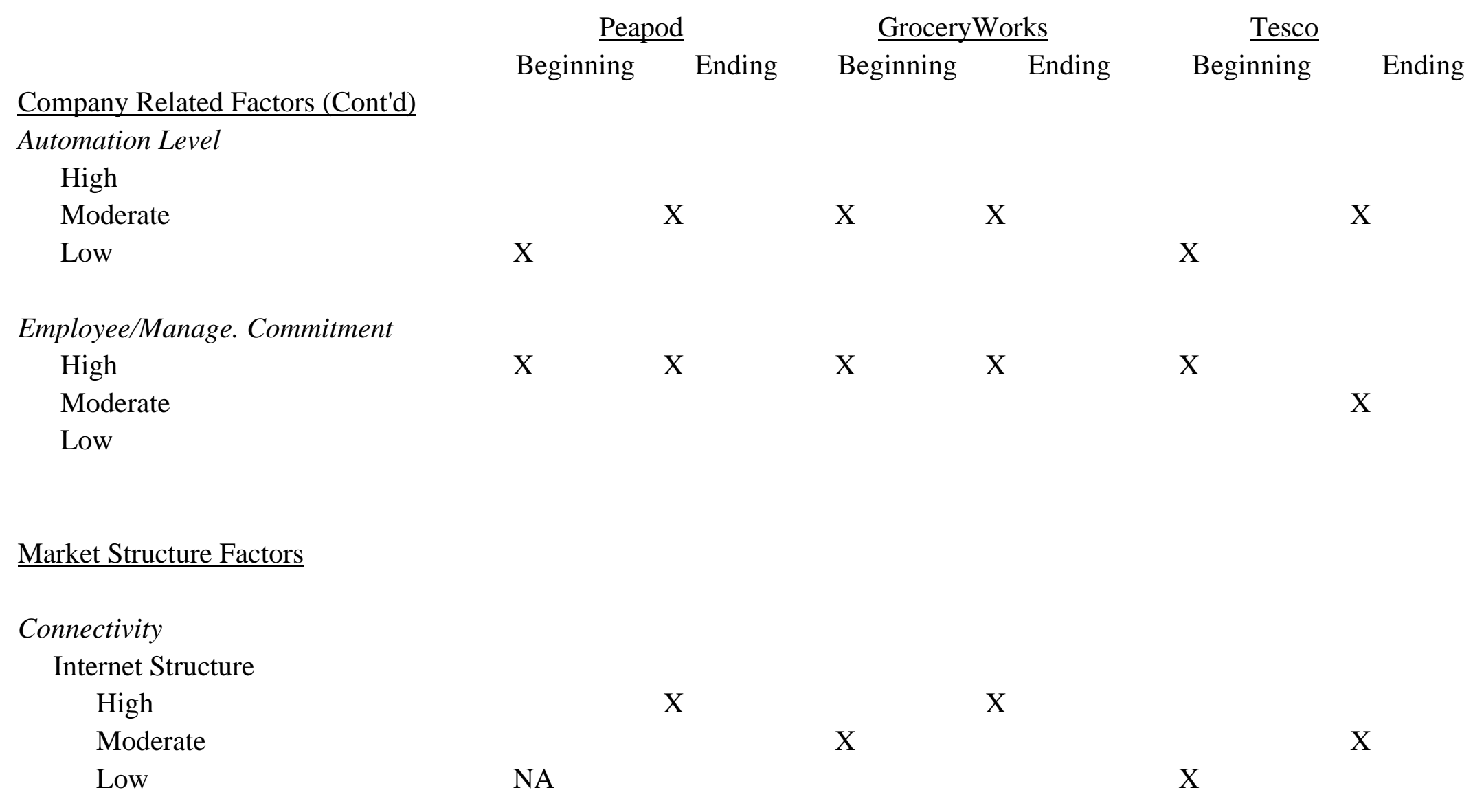


Table 31 (Cont'd)

Other Mediating/Moderating Factors for Peapod, GroceryWorks, and Tesco

\begin{tabular}{|c|c|c|c|c|c|c|}
\hline \multirow[b]{2}{*}{ Market Structure Factors } & \multicolumn{2}{|c|}{ Peapod } & \multicolumn{2}{|c|}{ GroceryWorks } & \multicolumn{2}{|l|}{$\underline{\text { Tesco }}$} \\
\hline & Beginning & Ending & Beginning & Ending & Beginning & Ending \\
\hline \multicolumn{7}{|l|}{ Internet Penetration } \\
\hline High & & $\mathrm{X}$ & & $\mathrm{X}$ & & \\
\hline Moderate & & & $\mathrm{X}$ & & & $\mathrm{X}$ \\
\hline Low & NA & & & & $X$ & \\
\hline \multicolumn{7}{|l|}{ Internet Access } \\
\hline High & & $\mathrm{X}$ & & $\mathrm{X}$ & & \\
\hline Moderate & & & $X$ & & & $X$ \\
\hline Low & NA & & & & $X$ & \\
\hline \multicolumn{7}{|l|}{ Cost of Internet Service } \\
\hline High & & $X$ & & & $\mathrm{X}$ & \\
\hline Moderate & & & $X$ & & & $\mathrm{X}$ \\
\hline Low & NA & & & $X$ & & \\
\hline \multicolumn{7}{|l|}{ Population Structure } \\
\hline Population Size & MODERATE & MODERATE & MODERATE & MODERATE & SMALL & SMALL \\
\hline Population Density & MODERATE & MODERATE & MODERATE & MODERATE & HIGH & HIGH \\
\hline
\end{tabular}


Table 31 (Cont'd)

Other Mediating/Moderating Factors for Peapod, GroceryWorks, and Tesco

\begin{tabular}{|c|c|c|c|c|c|c|}
\hline \multirow[b]{2}{*}{ Market Structure Factors } & \multicolumn{2}{|c|}{ Peapod } & \multicolumn{2}{|c|}{ GroceryWorks } & \multicolumn{2}{|c|}{$\underline{\text { Tesco }}$} \\
\hline & Beginning & Ending & Beginning & Ending & Beginning & Ending \\
\hline \multicolumn{7}{|l|}{ Geographical Location } \\
\hline \multicolumn{7}{|l|}{ Continental } \\
\hline North America & $\mathrm{X}$ & $\mathrm{X}$ & $\mathrm{X}$ & $\mathrm{X}$ & & \\
\hline \multicolumn{7}{|l|}{ South America } \\
\hline Europe & & & & & $\mathrm{X}$ & $\mathrm{X}$ \\
\hline \multicolumn{7}{|l|}{ Asia } \\
\hline \multicolumn{7}{|l|}{ Country } \\
\hline United States & $\mathrm{X}$ & $\mathrm{X}$ & $\mathrm{X}$ & $\mathrm{X}$ & & \\
\hline $\begin{array}{l}\text { United Kingdom } \\
\text { Japan }\end{array}$ & & & & & $\mathrm{x}$ & $\mathrm{x}$ \\
\hline \multicolumn{7}{|l|}{ County/Parish } \\
\hline Urban & $\mathrm{X}$ & $\mathrm{X}$ & $\mathrm{X}$ & $\mathrm{X}$ & & $\mathrm{X}$ \\
\hline Suburban & & $\mathrm{X}$ & $\mathrm{X}$ & $\mathrm{X}$ & & $\mathrm{X}$ \\
\hline Rural & & & & & & $\mathrm{X}$ \\
\hline
\end{tabular}


critical mass of customers, Tesco was able to expand the augmented model and grow to a 95 percent coverage area and then cut back on growth. As a result of this disparity, the rate of expansion may be a factor that can explain the success/failure of online grocers.

In terms of the automation level, Peapod and Tesco started with a low level of automation and then moved to a moderate level of automation (see Table 31). GroceryWorks started with a moderate level of automation and ended with a low level of automation. Given the similarities between the three companies on this factor, it was unlikely that it was a primary factor for explaining the success/failure of online grocers. However, once the core model was functioning properly, the addition of automation could help to reduce costs and thus improve profits. Therefore, this factor is tentatively included as a possible factor for explaining the success/failure of online grocers. The last company related factor was employee/management commitment to the online initiative. This factor was relatively constant over the stated time periods so it is unlikely that this factor played a role in determining the success/failure of online grocers. Based on the five company related factors, scalability, rate of expansion, and the automation level were potential candidates for helping to explain the success/failure of online grocers.

Concerning the market structure factors, connectivity for Peapod and GroceryWorks was basically the same since both companies operated in the U.S. market. However, for Tesco, all four of these factors improved as the rate of Internet adoption improved in the U.K. It should be noted that Tesco had the good fortune to be one of the U.K.'s earliest ISPs. As a result, it is possible that Tesco gained some type of first mover advantage. Once Tesco applied the right advertising and promotional activities, its core model was able to generate the necessary critical mass of customers. As a result, 
connectivity issues should be viewed as possible factors in explaining the success/failure of online grocers. It is doubtful that these factors will be the primary ones but they may provide some level of explanation.

For both GroceryWorks and Peapod, the general population size was moderate while for Tesco it was small. However, in relation to the population density, Tesco operated in a market with a high density rate (in some cases six times as high) while GroceryWorks and Peapod operated in markets with moderate to low population densities. Due to this imbalance, the population structure factors can be considered as possible candidates for explaining the success/failure of online grocers. Likewise, since Peapod and GroceryWorks were marginally to slightly profitable U.S. online grocers respectively, while Tesco was a profitable online U.K. grocer, geographical location, for continent and country, must be considered a primary factor for explaining the success/failure of online grocers. Thus, all the market structure related factors were possible candidates for explaining why some online grocers have been profitable while others have not.

\section{Hypotheses}

The original impetus for this research was to assess if there was support for the notion that the demise of many online grocers, before and after the 2000 dot.com collapse, was due to the business model(s) these grocery retailers were utilizing. Towards this end, three online grocers were analyzed. Each grocer's structural configuration was representative of one of the three basic online grocer formations. The within case analyses seemed to reveal that the business models utilized by each company 
may have had a significant role in the success/failure of that online grocer. However, a three-way cross-case analysis revealed an alternative explanation. Based on this analysis, it was the customer relationship activities (i.e., advertising, promotions, and loyalty program tie-ins) that were the real drivers for the success/failure of online grocers.

Based on a review of the literature, and discussions with grocery industry analysts, there were other possible factors that may have contributed to the success/failure of online grocers. These other mediating/moderating factors fell into the two broad categories of: (1) company related factors and (2) market related factors. The five company related factors were scalability, method of delivery, company rate of expansion, automation level, and employee/management commitment. Of these five factors, only scalability, rate of expansion, and the automation level were considered possible candidates for explaining the success/failure of online grocers.

The three market structure factors were connectivity, population structure, and geographical location. Connectivity had four sub-components which included Internet structure, Internet penetration, Internet access, and cost of Internet service. Population structure had two sub-components consisting of size and density. The two main geographical sub-categories were continental and country of operation. None of the market structure variable could be ruled out as possible factors for explaining the success/failure of online grocers.

Based on this analysis, the following hypotheses are posited:

H1: The business model(s) utilized by online grocers were the primary cause of their success/failure. 
H2: Customer relationship activities were the primary cause of the success/failure of online grocers.

H3: In relation to the company related factors:

3A: Model scalability level is related to the success/failure of online grocers.

3B: The company rate of expansion is related to the success/failure of online grocers.

3C: The level of automation is related to the success/failure of online grocers.

H4: In relation to the market related factors:

4A: Internet structure is related to the success/failure of online grocers.

4B: Internet penetration is related to the success/failure of online grocers.

4C: Internet access is related to the success/failure of online grocers.

4D: Cost of Internet service is related to the success/failure of online grocers.

H5: In relation to population structure:

5A: Population size is related to the success/failure of online grocers.

5B: Population density is related to the success/failure of online grocers.

H6: In relation to geographic location:

6A: Continental factors are related to the success/failure of online grocers.

6B: The specific country that an online grocer operates in is related to the success failure of that online grocer. 
H7: Online grocery home delivery business models have three main levels (the core, the structural, and the augmented).

H8: In order for an online grocer to be profitable the core business model must be functioning properly.

H9: Tesco’s success in the online channel was due to the company gaining a first mover advantage in the U.K. market.

\section{$\underline{\text { Conclusion }}$}

This dissertation sought to examine the circumstances surrounding the success/failure of many online grocery home delivery companies before and after the 2000 dot.com collapse. Before the collapse, the majority of online grocers were organized as either pure-plays or partnerships. None of these partnerships or pure-plays were successful before the dot.com collapse, and once the collapse occurred they were either forced into bankruptcy, reorganization, or merger talks with established BAM grocers. Many analysts and industry watchers commented that it was the business model(s) that these companies were using that caused them to be unsuccessful in the channel.

After the dot.com collapse there was a void in the online channel that was filled by the BAM grocers. Based on their structure these grocers were able to use a different set of business models to operate in the online channel. However, these BAM online initiatives encountered a similar fate as their pure-play and partnership counterparts they could not make the channel profitable for themselves. Again, the analysts and 
industry watchers commented that it was the business models that these companies were using that caused them to be unsuccessful in the channel.

Although these analysts and industry watchers have provided sound reasoning for their opinions, it is possible that there were other factors that may have been the root cause(s) of the success/failure of online grocers. Along this line of reasoning, this dissertation sought to determine whether or not there may have been other factors responsible for the demise of many online grocers. To conduct the analysis, a case based theory building methodology was utilized because it allowed for an exploratory investigation into the factors surrounding the demise of companies operating in the online channel. Given the relative immaturity of the channel, this method provided a mechanism for: (1) exploring the issues concerning the various business models used by companies operating in the channel, (2) determining whether or not these companies were operating successfully, and (3) articulating the key performance drivers affecting company success/failure. The overall objective of the analysis was to develop a set of testable hypotheses concerning the topic under investigation.

Before the case data were collected and analyzed, a method for delineating the various online grocers was articulated. The case analysis data then provided support for the model classifications. Analysis of the case data for Peapod and GroceryWorks revealed that they both had excessive cost structures that dwarfed their revenue structures. Year after year the imbalance increased to the point where each company had to enter into merger talks in order to survive. Tesco, on the other hand, was a profitable U.K. online grocer that utilized a model built around the retailer's current assets. In this regard, Tesco was able to keep costs low and after four year it was generating a profit. 
Thus, on the surface it did seem that the business models that these companies had selected were the primary cause of their success/failure.

However, once the cross case analysis was conducted, a new line of reasoning emerged. Looking across the three cases allowed for the observation that there were common components to the models that the three companies were using. These common components constituted the 'core model'. Further analysis revealed that there were commonalities also associated with the structural categories (i.e., Pure-Play, Partnership, and Hybrid). The model at this level was termed the 'structural model'. Finally, there were differences between company models that were specific to each company. The model at this level was termed the 'augmented model'. Since these models are hierarchical, it was posited that the core model must be functioning properly in order to support the other models.

An articulation of the core model dynamics demonstrated that the core model was dependent on the performance drivers - number of new and repeat customers. However, these performance drivers initiated from the customer relationship activities (i.e., advertising, promotional, and loyalty programs tie-ins). Thus, in order for the core model to work, an online grocer must generate a critical mass of customers. An examination of the customer relationship activities for Peapod, GroceryWorks, and Tesco, revealed that Tesco was the only company able to put together a successful mix of customer relationship activities to generate the critical mass of customers at the core model level. The case data raised the specter that it was Tesco’s advertising and promotional tie-ins that resulted in the critical mass of customers. Thus, this provided an alternative 
explanation concerning why certain companies are successful in the online grocery home delivery channel and others are not.

In addition to assessing the business models utilized by the three companies selected for this study, this research also examined other factors that may have contributed to the success/failure of online grocers. These included company related factors and market related factors. The company related factors were scalability, method of delivery, company rate of expansion, automation level, and employee/management commitment. The cross-case comparisons revealed that there were differences between the companies in terms of scalability, rate of expansion, and automation level. Therefore, these factors were included as possible factors affecting the success/failure of online grocers.

The market structure factors included connectivity, population structure, and geographical location. Connectivity was concerned with Internet structure, penetration rate, access rate, and cost of service. Population structure concerned population size and density while geographical factors assessed the location of each company's main markets. Comparisons across the market structure factors were between the U.S. companies Peapod and GroceryWorks and the U.K. company, Tesco. Results revealed that there were differences between these companies based on all the market structure factors. As a result, these factors were also deemed possible candidates for explaining the success/failure of online grocery home delivery companies. From these analyses, several hypotheses were generated. 


\section{Limitations and Future Research}

The primary limitation to this study is that it consisted of a series of case analyses and, as such, is subject to alternative explanations of the case data. The re- or alternative interpretation could result in the development of a different set of testable hypotheses. Another limitation is that a significant factor, or set of factors, associated with the success/failure of online grocers may have not been included in the analysis. As a result, the resulting picture of the phenomenon in question would be incomplete. Lastly, although this dissertation looked at three cases, several more need to be prepared and analyzed before a definitive answer concerning the causes of online grocer success/failure can be articulated.

The result of this case based theory development process has been the development of 9 main hypotheses. A primary emphasis for future research should be to test these hypotheses. The primary tests of interest should be to determine whether the business model or the customer relationship activities account for more variation in the factor used to measure online grocer success/failure. In addition the three cases analyzed in the study allow for several two-way comparisons between pure-plays, partnerships, and hybrids. In addition, there are other within structural category comparisons that can be made. Finally, the development of more case analyses is needed. These analyses will help to provide a deeper and broader body of literature concerning online retail in general and online grocery retail in particular. 


\section{LIST OF REFERENCES}

Adamy, Janet (2002, March 14). Safeway’s Online Sales Rely On Stores. Contra Costa Times, p. c01.

Alaimo, Dan (2000, October 9). Council of Logistics Management Conference; GroceryWorks Expansion Hinges on Logistics. Supermarket News, p. 30.

Alaimo, Dan (2001, May 14). GroceryWorks Closes DCS, Shifts to Store Fulfillment. Supermarket News, p. 23.

Alaimo, Dan (2001, April 2). Tesco Eyes U.S. Market For Online Grocery Venture. Supermarket News, p. 36.

Alaimo, Dan (2001b, September 10). Tesco.com Home Pages Draw Higher Shopping. Supermarket News, p. 39.

Albertsons Plans Online Grocery Orders for Dallas-Fort Worth, Texas, Area (2003, November 2). Knight Ridder/Tribune Business News. Retrieved from Galenet (http://www.galenet.com).

Alexis, Marcus (1962). The Changing Consumer Market: 1935-1959. Journal of Marketing, 26 (1), 42-46.

Allen, Eric and Jerry Fjermestad (2001). E-Commerce marketing strategies: an integrated framework and case analysis. Logistics Information Management, 14 (1/2), 14-23.

Amato-McCoy, Deena (1997, February 24). Providers Use Different Way to Score Home Shopping Goal. Supermarket News, 47 (8), 61.

Anderson, Paul F. (1986). On Method in Consumer Research: A Critical Relativist Perspective. Journal of Consumer Research, 13 (2), 155

Arnould, Eric J. (2001). Ethnography, Export Marketing Policy, and Economic Development in Niger. Journal of Public Policy \& Marketing, 20 (2), 151-169.

Ashill, Nicholas, Mark Frederikson and John Davies (2003). Strategic Marketing Planning: A Grounded Investigation. European Journal of Marketing, 37 (3/4), 430-460.

Balto, David A. (2001). Supermarket Merger Enforcement. Journal of Public Policy \& Marketing, 20 (1), 38-50. 
Barnes, Rachel (2006, April 29). Concept store to boost online grocery service ... Tesco looks to fresh engines as growth slows. The Grocer, 229 (7752), p8.

Beckman, Theodore and Herman C. Nolen (1976). The Chain Store Problem: A Critical Analysis. New York: Arno Press.

Berghman, Liselore, Paul Matthyssens and Koen Vandenbempt (2006). Building Competences for New Customer Value Creation: An Exploratory Study. Industrial Marketing Management, 35 (8), 961-973.

Blair, Adam (1997). NetGrocer bid for national home delivery uses Internet. Supermarket News, 47 (32), 53.

Bode, Matthias (2005), “’Now That’s What I Call Music!” An Interpretive Approach to Music in Advertising”, Advances in Consumer Research, 33, 580-585.

Bond, Patti (1998, March 14). Area Online Grocers Fail to Connect with Shoppers. The Atlanta Journal and Constitution, p 01H.

Brady, John and Ian Davis (1993). Marketing’s Mid-Life Crisis. The McKinsey Quarterly, 2, 17-28.

British Grocer Tesco Tries to Succeed Where Others Have Failed (2001, August 2). The Dallas Morning News. Retrieved from Galenet Database.

Broadband Added to Grocery Shopping Lists (2004, September 6). The Online Reporter. Retrieved from InfoTrac.

Bruce, Anne. (2000) Tesco woos online shoppers, The Grocer, 223 (7474), 4.

Bruce, Anne (2002). Tesco.com hikes up charge for trial area peak-time deliveries; 'it is tantamount to putting the supermarket prices up on Friday evenings. The Grocer, 225 (7551), 10.

Bunker, Matthew (2000). A Preliminary Analysis of Consumer Behavior in Monopolistic Situations Using Grounded Theory Methodology. American Marketing Conference Proceedings, 11, 4.

Buxton, Philip (2000, April 13). Tesco Picks Chief for Net Operation. Marketing Week, 5.

Campbell, Ann Melissa and Martin W. P. Savelsbergh (2005). Decision Support for Consumer Direct Grocery Initiatives. Transportation Science, 39 (3), 313-328. 
Cassady, Ralph, Jr., and Wylie L. Jones (1949). The Los Angeles Wholesale Grocery Structure: 1920-1946: A Case Study. Journal of Marketing, 14 (2), 169-177.

Catterall, Miriam (1998). Academics, Practitioners and Qualitative Market Research. Qualitative Market Research, 1 (2), 69.

Chamis, Eleni (1999). Streamline response surpasses expectations. Washington Business Journal, 18 (25), 30.

Chandler, Michele (2006, July 12). Albertsons to abandon online home delivery: Observers Say Service Lost Money. Knight Ridder/Tribune Business, p. 1.

Chen, Stephen (2003). The Real Value of 'e-Business Models'. Business Horizons, November-December, 27-33.

Cherrier, Helene (2004). Becoming Sensitive to Ethical Consumption Behavior: Narratives of Survival in an Uncertain and Unpredictable World. Advances in Consumer Research, 32, 600-604.

Chura, Hillary (2000). Temerlin’s incubator launches campaign; July rollout for $\$ 30$ mil account's first TV effort. Advertising Age, 71, 31.

Copacino, William C (1996, March). Logistics and the world of "virtual retailing. Logistics Management, 35 (3), 101.

Coslett, Gareth (2000, June 30). Tesco Direct to outgrow in-store picking. Super Marketing, 3.

Cosslett, Gareth. (2001, January 25). Battle of the e-grocers, Computer Weekly, p65. Retrieved June 11, 2006, from InfoTrac OneFile via Thomson Gale.

Cowell, Alan (2000, January 20). World Business Briefing: Europe; Tesco Plans to Expand. The New York Times, p. 4(L).

Cross, Richard (1996). From Distribution Chain to Communication Channel. Direct Marketing, 59 (2), 16-20.

Crown, Judith (1993, March 1). Computer Grocery Shopper Branching Out. Crain's Chicago Business, 26.

David, Fed R. (2003). Strategic Management Case Writing: Suggestions After 20 Years of Experience. S.A.M. Advanced Management Journal, 68 (3), 36-43. 
Davies, Glynn (2004). The online challenge: as Tesco's online sales of non-food items storm ahead, Glynn Davies finds out why they are so successful and how other multiples are trying to compete. The Grocer, 227 (7653), 37(3).

de Koster, Rene B. M. (2002), "Distribution Structures for Food Home Shopping. International Journal of Physical Distribution \& Logistics Management, 32 (5), 362-381.

de Ruyter, Ko and Norbert Scholl (1998). Positioning Qualitative Market Research: Reflections from Theory and Practice. Qualitative Market Research, 1 (1), 7-14.

Deutsch, Tracey (1999). From “Wild animal stores” to Women’s Sphere: Supermarkets and the Politics of Mass Consumption, 193001950. Business and Economic History, 28 (1), 143-153.

Dorgan, Tim (1996). Online Shopping: What's in it for the retailer?. Progressive Grocer, 75 (11), 67-68.

Edgecliffe-Johnson, Andrew (2001, February 16). Ahold and Online Grocers Like Two Peas in a Pod. The Financial Times, p. 30.

Eisenhardt, Kathleen M. (1989). Building Theories from Case Study Research. The Academy of Management Review, 14(4), 532-550.

Engle, Nathanael H. (1949). Chain Store Distribution VS. Independent Wholesaling. Journal of Marketing, 14 (2), 241-252.

Excite: Excite Dishes Up Aisles More Choice for Tesco's Free ISP Users (1999, February 15). M2 Presswire, Retrieved from Galenet.

Farrar, Foss (2000). GroceryWorks Offers Vast Inventory from Safeway. Refrigerated Transporter, 38 (5), 24-28.

Field, Christopher (1996). Shop Flaws. Computer Weekly, June (20), 39.

Financial fastest growing (2002, April 13). The Grocer, 225 (7549), 14.

FMCG: The sector that came in from the cold; The virtual shopping aisles of TescoDirect are a hotbed of brand activity, argues Neil Morgan (1999, August 26). New Media Age, Retrieved from Galenet.

Fox, Bruce (1994). For Peapod, Fulfillment is Key to Success; On-line service takes total control of orders. Chain Store Age Executive with Shopping Center Age, 70 (10), 33. 
Fox, Valerie and Lisa Y. Taylor (2000). GroceryWorks Moves Up. Dallas Business Journal, 23 (29), 50.

Frankel, Robert, Thamas J. Goldsby, and Judith M. Whipple (2002). Grocery Industry Collaboration in the Wake of ECR. International Journal of Logistics Management, 13 (1), 57-72.

Frees, John W. (1997). Peapod Changes Pricing Option to Add Customers. Business First-Columbus, 14 (3), 13.

Friedman, Jeff (2000). Welcome to the E-Volution. Progressive Grocer, 79 (4), S3.

Fridman, Sherman (2000, April 17). Safeway Goes E-Marketing With GroceryWorks. Newsbytes PM, Retrieved from Galenet.

Fridman, Sherman (2000, April 21). Safeway Goes E-marketing With GroceryWorks. Newsbytes, Retrieved from Galenet.

Friedlos, Dave (2006, August 24). Mobile delivers for Tesco.com. Computing, 3.

Garry, Michael (2002, October 7). Peapod Generates New Sales for Ahold. Supermarket News, 57.

Geiger, Susi and Darach Turley (2003). Grounded Theory in Sales Research: An Investigation of Salespeople's Client relationships. The Journal of Business \& Industrial Marketing, 18 (6/7), 580-594.

Ghitelman, David (2000, May 8). Safeway Works. Supermarket News. 55.

Giblen, Gary M. (2000). Will grocery e-tailers eat supermarkets' lunch?. Grocery Headquarters, 66 (2), 89.

Gillespie, Cailein and Alison Morrison (2001). Commercial Hospitality Consumption as a Live Marketing Communication System. International Journal of Contemporary Hospitality Management, 13 (4/5), 183-188.

Girod, Stéphane J. G. (2005). The Human Resource Management Practice of Retail Branding. International Journal of Retail \& Distribution Management, 33 (6/7), $514-530$.

Gold, Steve (1997, April 9). Tesco Grocery Delivery Via Web A Top UK Site. Newsbytes. Retrieved May 30, 2006, from InfoTrac OneFile via Thomson Gale.

Gold, Steven (2001, June 25). Tesco Invests In Safeway’s GroceryWorks. Newsbytes. retrieved from Galenet. 
Golicic, Susan L., Donna F. Davis, Teresa M. McCarthy, and John T. Mentzer (2002). The Impact of e-Commerce on Supply Chain Relationships. International Journal of Physical Distribution and Logistics Management, 32 (9/10), 851-871.

Goodwin, Bill (1999, January 28). Tesco to Offer Grocery Scanning at Home. Computer Weekly, 16.

Goodwin, Bill (2000, October 5). Tesco rebuilds for e-boom. Computer Weekly, 3. Retrieved June 11, 2006, from InfoTrac OneFile via Thomson Gale.

Goodway, Nick (1999, August 29). Grocery Deliveries Fail Internet Shoppers after Upgrade Glitches. Knight Ridder/Tribune Business News. Retrieved from Galenet.

Gould, Stephen J. (1995), "Sexualized Aspects of Consumer Behavior: An Empirical Investigation of Consumer Lovemaps”, Psychology \& Marketing, 12 (5), 395414.

Goulding, Christina (1998). Grounded Theory: The Missing Methodology on the Interpretivist Agenda. Qualitative Market Research, 1 (1), 50.

Goulding, Christina (2005). Grounded Theory, Ethnography, and Phenomenology. European Journal of Marketing, 39 (3/4), 294-308.

Greer, Jim (1999). Peapod Signs McLane in Online Grocery Game. Houston Business Journal, Exclusive Reports. Http://www.bizjournals.com/houston/ stories/1999/11/15/story2.html

Gregory, Helen (1999, July 16). Tesco Set to Launch Banking on the Web. Super Marketing, p. 3.

Gregory, Helen (2002). Dotcom Driver. The Grocer, 225 (7541), 36-38.

Gummesson, Evert (2003). All Research is Interpretive. The Journal of Business \& Industrial Marketing, 18 (6/7), 482-492.

Habal, Hala and Jeff Bounds (2001). Shareholders of Dallas online grocer hungry for action from Safeway. Houston Business Journal, 31 (44), 4.

Hackley, Christopher (1998). Social Constructionism and Research in Marketing and Advertising. Qualitative Market Research, 1 (3), 125-131.

Halkias , Maria (2000, January 7). Dallas-Area Online Grocery Firm Names New CEO. Knight Ridder/Tribune Business News. Retrieved from Galenet. 
Hall, James (2004, July 25). Tesco watches the pounds and signs deal with eDiets. Sunday Telegraph (London, England). Retrieved from InfoTrac.

Hall, James (2006, October 1). Tesco takes on Microsoft in battle for software market. Sunday Telegraph (London, England), Retrieved from InfoTrac.

Hamstra, Mark (2003, October 13). E-GROCERS MODIFY PROMOTIONS TO ENCOURAGE TRIAL. Supermarket News, 10.

Hanover, Dan (1998). Peapod Explores Produce’s Pull. Chain Store Age, 74 (9), 194.

Harvey, Michael and Malcolm Evans (2001). Decoding Competitive Propositions: A Semiotic Alternative to Traditional Advertising Research. International Journal of Market Research, 43 (2), p. 171-187.

Hargrave, Sean (2004, July 22). Feel at home with insurance: Tesco Personal Finance is trying to bring a little fun to the process of buying insurance products. Is it too much to hope it could lead to greater cross-selling too?. New Media Age, 20-21.

Harrington, Sian (2003, October 25). Online blighted by service. The Grocer, 226 (7627), p 4(2).

Harrington, Sian (2005, January 8). Flying off the shelves (if it's there): Tesco has improved but availability is still causing headaches for suppliers and retailers. The Grocer, 228 (7686), 38-39.

Harrison, Tina, and Kathryn Waite (2005). Critical Factors Affecting Intermediary Web Site Adoption: Understanding How to Extend e-Participation. The Journal of Business \& Industrial Marketing, 20 (4/5), 187-199.

Hausman, Angela and Diana L. Haytko (2003). Cross-Border Supply Chain Relationships: Interpretive Research of Maquiladora Realized Strategy. The Journal of Business \& Industrial Marketing, 18 (6/7), 545-563.

Hawkes, Steve (2000, March 17). Tesco Direct figures exceed expectations. Super Marketing, 8. Retrieved June 11, 2006, from InfoTrac OneFile via Thomson Gale.

Hawkes, Steve and Helen Gregory (2000, May 12). Tesco exports home shopping to Ireland. Super Marketing, p. 2.

Hawkes, Steve (2000, Oct 6). Tesco trials formats for deliveries arid points redemption. Super Marketing, p 3. Retrieved June 11, 2006, from InfoTrac OneFile via Thomson Gale. 
Hays, Tom, Pinar Keskinocak and Virginia Malcome de Lopez (2004). Strategies and Challenges of Internet Grocery Retailing Logistics. In J. Geunes, E. Akcali, P.M. Pardalos, H. E. Romeijn, and Z. J. Shen (Eds.), Applications of Supply Chain Management and E-Commerce Research in Industry (pp. 1-36). Kluwer Academic Publishers, Dordrecht, The Netherlands.

Hedges, A. (1985). Group Interviews. In R. Walker, (Ed.), Applied Qualitative Research. Aldershot: Gower.

Helet, Miguel (2001). Online Groceries Just Won’t Die. The Industry Standard, 4 (18), 38.

Hobson, Katherine (2000). Investors Shuck Peapod as 'First-Mover Advantage' Proves Illusory. TheStreet.com. Http://www.thestreet.com/_aol/stocks/retail/902064.html.

Howell, Debbie (2000). The Grocer With A Business Plan That Delivers. DSN Retailing Today, 39 (9), 117.

Hunt, Julian (2002, July 27). New Tesco team tackles availability headaches: Tesco puts 'a lot more focus' on out of stocks as home shopping spotlights the problem. The Grocer, 225 (7564), 4.

Hunt, Shelby D. (1990). Truth in Marketing Theory and Research. Journal of Marketing, 54 (3), 1.

Internet: Tesco to Become ISP - Will Target in Store Customers (1998, July 6). Network Briefing. Retrieved from Galenet.

Jacobson, Greg (2001). Drama in On-Line Food Retailing. MMR, 18 (10), 1.

Jardine, Alexandra (2000, March 23). Tesco Direct loses Chief to Greenfingers. Marketing, 2.

Kamarainen, Vesa (2001). The reception box impact on home delivery efficiency in the e-grocery Business. International Journal of Physical Distribution \& Logistics Management, 31 (6), 414-426.

Kamarainen, Vesa (2003). The impact of Investments on e-Grocery Logistics Operations. D.Sc.(Tech.) dissertation. Teknillinen Korkeakoulu (Helsinki) (Finland), Finland.

Kaufman, Phil (1988, September). Nontraditional Retailers are challenging Traditional Grocery Stores. Food Review, 21 (3), 31-33. 
Keh, Hean Tat and Elain Shieh (2001). Online Grocery Retailing: Success Factors and Potential Pitfalls. Business Horizons, 44 (4), 73.

Kelsey, Dick (2000, March 16). Sick Peapod CEO Leaves, Investors Yank \$120 Mil. Newbytes. Retriever from Galenet.

Kelsey, Dick (2000b, March 20). Ailing Online Grocer Peapod Sued 03/20/00. Newsbytes PM. Retrieved from Galenet.

Kemeny, Lucinda (1998, November 9). Tesco Bags Net Ordering Trolleys. Precision Marketing, p. 1.

Kleinman, Mark (2001, February 8). Tesco to offer profiles of Clubcard customers. Marketing, 8, 3.

Leading the world in shopping from home; With several years' experience of online grocery selling behind it, Tesco is way ahead of its competitors, who are only just getting to grips with home delivery. But that doesn't mean it hasn't some way yet to go, as Richard Simpson discovers (2000, February 28), New Media Age, 28.

Lee, Julian (1996, March 7). Tesco Tries Out Home Shopping with Pensioners. Marketing, 1.

Lee, Julian (1996, March 14). A checkout on your doorstep. Marketing, 13.

Lerner, Jill (2002). Peapod sees Profit on its Grocery List. The Boston Business Journal, 22 (33), 1.

----- (1996, March 28). A Checkout on Your Doorstep. Marketing, 13.

----- (1996, September 12). Tesco Pioneers Home-Delivery Service by Van. Marketing. 1.

----- (1997, September 25). Tesco Extends Home Shop. Marketing, 13.

Lewis, Len (1996). Shopping the Net. Progressive Grocer, 75 (9), 35-40.

Liebeck, Laura (1996a). It's the right time for food retailers to log on. Discount Store News, 35 (19), F45.

Liebeck, Laura (1997). NetGrocer Now Open for Business. Discount Store News, 36 (16), 3.

Liebeck, Laura (1998). Peapod Goes National. Discount Store News, 37 (16), 4. 
Lincoln, Yvonna S. and Egon G. Guba (1994). Naturalistic Inquiry. Beverly Hills, California: Sage Publications.

Mallalieu, Lynnea and Kay M. Palan (2006), “How Good A Shopper Am I? Conceptualizing Teenage Girls’ Perceived Shopping Competence. Academy of Marketing Sciences Review, 5, 1.

Martyka, Jim (2000). National web grocer will enter local market. Citybusiness, 17 (50), 1.

Massingill, Teena (1999, May 20). Online Grocers on Road to Deliver in California's Bay Area. Knight Ridder/Tribune Business News.

Mayo, James M (1993). The American Grocery Store : The Business Evolution of an Architectural Space. Westport, Connecticut: Greenwood Press.

McAlexander, James, John W. Schouten, and Harold F. Koening (2002). Building Brand Community. Journal of Marketing, 66 (1), p. 38-54.

Meredith, Jack (1998). Building Operations Management Theory Through Case and Field Research. Journal of Operations Management, 16 (4), 441-455.

Merrefield, David (2001, February 26). Peapod Presents a Challenge to Ahold; The Case for a Worldwide Retailer to Succeed in the Online Environment. Supermarket News, 2.

Miles, Matthew B. and A. Michael Huberman (1994). Qualitative Data Analysis: An Expanded Sourcebook. Thousand Oaks, California: Sage.

Morganosky, Michelle A. (1997). Format Change in US Grocery Retailing. International Journal of Retail \& Distribution Management, 25 (6), 211-218.

Morganosky, Michelle A. and Brenda J Cude (2000). Consumer Response to Online Grocery Shopping. International Journal of Retail \& Distribution Management, 28 (1), 1.

Morganosky, Michelle A and Brenda J Cude (2002). Consumer demand for online food retailing: Is it really a supply side issue?. International Journal of Retail \& Distribution Management, 30 (10), 451-459.

NEW MEDIA: Spotlight On - Tesco.com. Tesco.com leads the way with completely integrated thinking. Tesco.com uses its existing data on customers to best effect (2002, April 19). Campaign, p.14. 
Noble, Charles H. and Michael P. Mokwa (1999). Implementing Marketing Strategies: Developing and Testing a Managerial Theory. Journal of Marketing, 63 (4), 5773.

Ogawara, Sachiko, Jason C H Chen and Quan Zhang (2003). Internet Grocery Business in Japan: Current Business Models and Future Trends. Industrial Management \& Data Systems, 103 (8/9), 727-735.

O'connor, Robert (1998). Europe Trails U.S. in Web Grocery Shopping. Chain Store Age, 74 (6), 70-72.

Online Builds Loyal Shoppers (2001, April 7). The Grocer, 224 (7498), 4. Retrieved from Galenet database.

O’Shaughnessy, John and Morris Holbrook (1988). Understanding Consumer Behaviour: The Linguistic Turn in Marketing Research. Journal of the Market Research Society, 30 (2), 197.

Online Grocery Stores Re-Emerge with More Conservative Business Model (2003, February 9). Knight Ridder/Tribune Business News. Retrieved from Galenet database.

Park, Kristen and John L. Park (2000). The Decision to Enter Consumer Direct Initiatives by Supermarket Companies. Food Industry Management Program, Cornell University.

Paton, Nic (1997, December 5). Tesco Focuses on Delivery ... and Recruits to Cope with Demand. Super Marketing, 4. Retrieved from Galenet.

Patton, Michael Quinn (1990). Qualitative Evaluation and Research Methods. Newbury Park, California: Sage Publications.

Peapod. (1997). S-1 General Form for Registration of Securities Under the Securities Act of 1933. Retrieved from U.S. Securities and Exchange Commission (http://www.sec.gov).

Peapod. (1997). 10-K Annual Report. Retrieved from U.S. Securities and Exchange Commission (http://www.sec.gov).

Peapod. (1999). 10-Q Quarterly Report. Retrieved from U.S. Securities and Exchange Commission (http://www.sec.gov).

Peapod. (2000). 10-K Annual Report. Retrieved from U.S. Securities and Exchange Commission (http://www.sec.gov). 
Peapod. (2001). 10-K Annual Report. Retrieved from U.S. Securities and Exchange Commission (http://www.sec.gov).

Perry, Chad (1998). Processes of a Case Study Methodology for Postgraduate Research in Marketing. European Journal of Marketing, 32 (9/10), 785.

Pop down to Tesco and grab a guitar! (2003, March 16). Daily Star (London, England), 51.

Prinella’s Mouse. (1999, October 23). The Grocer, p. 8.

Punakivi, Mikko, Hannu Yrjola and Jan Holmstrom (2001). Solving the last mile issue: Reception box or delivery box?. International Journal of Physical Distribution \& Logistics Management, 31 (6), 427.

Purpura, Linda (1997, October 13). Peapod Shifts its Fulfillment to Dedicated Picking Site. Supermarket News, 69.

Reece, Damian (2004, January 14). Now it's Napster-style music service to go with fruit and veg. The Independent (London, England), 21.

Reidy, Chris (2000, March 10). Quincy, Mass.-Based Grocery to Open Online Service in Connecticut. Tribune Business News. Retrieved from Galenet.

Retail News: Tesco website to sell kids' school clothes (2006, July 5). Marketing, 12.

Rewick, C. J. (1998). Profits must start clicking for Peapod. Crain's Chicago Business, 21 (19), p. 3 (2).

Riedman, Patricia (1997). Peapod Readies for Web with Revised Service. Advertising Age, 68 (35), 35.

Riedman, Patricia (1997b). New Peapod Software Delivers Web-Based Ads to Shoppers. Crain's Chicago Business, 20 (42), 51.

Riege, Andreas (2003). Validity And Reliability Tests in Case Study Research: A Literature Review with "Hands-On Applications for Each Research Phase". Qualitative Market Research, 6 (2), 75-86.

Romano, C (1989). Research Strategies for Small Business: a Case Study. International Small Business Journal, 7 (4), 35-43.

Rowland, P. (2001). Home Delivery - the story so far. e-logistics magazine, 14 (October), 12-13. 
Rutledge, Tanya (2000). Guess who's coming with dinner?. Houston Business Journal, 30 (53), 4A.

Ryant, Carl G. (1973). The South and the Movement Against Chain Stores. The Journal of Southern History, 39 (2), 207-222.

Saccomano, Ann (1998). Groceries Online. Traffic World, 253 (13), 32.

Safeway.com Introduces Holiday Gift Cards Online; Along with Groceries, Customers Can Add Nordstrom, Blockbuster, Red Lobster Cards to Cyber-Shopping Baskets (2003, December 4). PR Newswire. Retrieved from Galenet database.

Salomon Smith Barney. (January 13, 1998). Peapod, Inc. Retrieved from http://infotrac.galegroup.com.

Schmidt, Ruth A. and Elke A. Pioch (2005). Community Pharmacies Under Pressure Can Branding Help?. International Journal of Retail \& Distribution Management, 33 (6/7), 494.

Schouten, John W. and James H. McAlexander (1995). Subcultures of Consumption: An Ethnography of New Bikers. Journal of Consumer Research, 22 (1), p. 43-61.

Sciacca, Patrick (1999b, February 15). Peapod weighs Scaling Up Fulfillment Center. Supermarket News, 22.

Sciacca, Patrick (1999c, March 8). Peapod's DC Launch Confirms Strategy. Supermarket News, 31.

Sciacca, Patrick (1999, March 29). Tesco Tests New In-Store Picking For Home Shopping. Supermarket News, 19.

Seth, Andrew and Geoffrey Randall (2000). The Grocers: The Rise and Rise of the Supermarket Chains. London: Kogan Page.

Sherry, John F and Eduardo G. Camargo (1987). "May Your Life Be Marvelous:” English Language Labeling and the Semiotics of Japanese Promotion”. Journal of Consumer Research, 14 (2), 174-188.

Sherry, John F. (1990). A Sociocultural Analysis of a Midwestern American Flea Market. Journal of Consumer Research, 17 (1), p. 13 -30.

Shoham, Aviv (2004). Flow Experiences and Image Making: An Online Chat-Room Ethnography. Psychology \& Marketing, 21 (10), 855-882. 
Shook, Carrie (1998). Annual Report on American Industry: Food Distributors. Forbes, 161 (1), 160(4).

Silcock, E., G.P. Clarke, D.B. Clarke, and N. Wrigley (1999). Grocery Provisions in the USA: room for expansion?. International Journal of Retail \& Distribution Management, 27 (1), 8.

Snowden, Scott (2006, October 16). Is software success in store for Tesco? Computer Reseller News, 47.

Springer, Jon (2000, June 26). Tesco Store-Based Internet Model Urged for U.S.. Supermarket News, 21.

Springer, Jon (2000, May 8). STREAMLINE KEEPING IT SIMPLE. Supermarket News. p. 44.

Springer, Jon (2000, July 31). Safeway Completes 50\% Stake in GroceryWorks. Supermarket News, 15.

Stake, R. E. (1994). Case Studies. In Norman K. Denzin, and Yvonna S. Lincoln (Eds.), Handbook of qualitative research. Thousand Oaks, Calif.: Sage Publications.

Stoffle, Richard W. (1972). Whither the Country Store?. Ethnohistory, 19 (1), 63-72.

Summerour, Fenny (1999). What Makes Brits Click. Progressive Grocer, 78 (12), 97-98.

Tanner, Lisa (2000). GroceryWorks adds downtown delivery. Dallas Business Journal, 23 (44), p.13.

Tesco adds non-grocery offer online (2002, February 20). Revolution, p. 3.

Tesco Launches Joint Venture with RBS (1997, February 24). Retail Banker International. Retrieved from Galenet (http://www.galenet.com)

Tesco’s Big Test (1997, February 24). Retail Banker International. Retrieved from Galenet.

Tesco Clubcard answers Nectar with Marriott tie (2003, February 27). Marketing, p. 3.

Tesco develops Christmas 'wish list' online offer (2003, December 4). Marketing, p. 8.

Tesco Direct selects TNT Logistics (2006, September 6). The Journal of Commerce Online. Retrieved form Galenet.

Tesco Direct to offer more info (2000, February 4). Super Marketing, p. 13. 
Tesco enters the telecom business (2003, January 27). EuropeMedia. Retrieved from Galenet.

Tesco Flexible Pension with Scottish Widows (1998, June 8), Precision Marketing, p2 (1). Retrirved from Galenet (http://www.galenet.com)

Tesco gains $66 \%$ of UK's online grocery orders (2006, August 23). Internet Business News. Retrieved from Galenet.

Tesco Gives Net Access Away (1999, February 8), Electronic Times (Online), p. 12.

Tesco goes to town in online war (2005, May 1). Daily Mail (London). Retrieved from Galenet.

Tesco launches new non-food home shopping service (2006, August 30). Europe Intelligence Wire. Retrieved from Galenet.

Tesco looks to speed up personal finance site (2002, May 6). Financial Net News, p. 2.

Tesco, Sainsbury launch online shopping (1995, June 5). Supermarket News 45 (23), p10. Retrieved from Galenet.

Tesco set to offer online law service (2004, June 3). New Media Age, p. 3.

Tesco Supermarkets Fulfill Internet Orders (2000). MMR, 17 (18), p. 44.

Tesco Telecom on the way (2003, January). The Guardian (London, England), p. 24.

Tesco to unite services under Home web brand (2004, July 14). Marketing, p. 6.

Tesco tunes into next pop idols (2003, March 16). The Express on Sunday (London, England), p. 1.

Tesco.com aims at young professionals (2003, November 6). Marketing. p. 10.

Tesco.com Connects With Xperience for 'Smart' Shopping Carts (2004, December 7). Wireless News. Retrieved from Galenet.

Tesco.com decides to keep IT in-house (2004). Europe Intelligence Wire. Retrieved from Galenet.

Tesco.com enters DVD rental market (2004, April 2004). Revolution, p. 4.

Tesco.com reveals the secret of web success (2003, May 27). Computer Weekly, p. 8. 
Tesco.com to charge more for Friday delivery (2002, April 24). The Independent (London, England), p. 20.

The World's First Profitable Grocery E-Tailer (2001, May 28), MMR, 18 (8), p.63.

Thomas, Daniel (2002, December 12). Tesco online sales break [pounds sterling]10m-aweek barrier. Computer Weekly, p. 12.

Thomas, Jane Boyd and Cara Lee Okleshen Peters (2006). The Underground Mall. International Journal of Retail \& Distribution Management, 34 (2/3), 106.

Thompson, Craig J., Howard R. Pollio and William B. Locander (1994). The Spoken and Unspoken: A Hermeneutic Approach to Understanding the Cultural Viewpoints That Underlie Consumers' Expressed Meanings. Journal of Consumer Research, 21 (3), 432-452.

Tyler, Katherine, David McGirr, and Edmund Stanley (1998). Contextualising: Technology, Relationships and Time in a Financial Services Virtual Organization. The Service Industries Journal, 18 (3), 70-89.

Unipower Systems: Unipower Systems Continues the Revolution in e-commerce! (1999, January 21). M2 Presswire. Retrieved from Galenet.

Unipower System: Tesco Direct Announce ShoppingMagic to Power the Next Generation Tesco Home Shopper (1998, October 2). M2 Presswire. Retrieved from GaleNet.

Vons.com Expands Las Vegas Service With Additional Store in Henderson; Online Grocery Service Now Covers 62 ZIP Codes in Greater Las Vegas (2004, February 13). PR Newswire. Retrieved from Galenet database.

Voss, Chris, Nikos Tsikriktsis and Mark Frohlich (2002). Case Research in Operations Management. International Journal of Operations \& Production Management, 22 (2), 195-219.

Wacker, John G. (1998). A Definition of Theory: Research Guidelines for Different Theory-Building Research Methods in Operations Management. Journal of Operations Management, 16, 361-385.

Walker, Gaelle (2006a). Oh what a tangled web we weaved: the five online retailers' systems were a joy to use. And their drivers were delightful. But that was where the fun stopped ... The Grocer, 229 (7780), 26-27. 
Wallace, David J. (1994). Logging on for a loaf of bread: food fight looming as grocery stores take their wares online. Advertising Age, 65 (43), p. 20.

Wallendorf, Melanie and Merrie Brucks (1993). Introspection in Consumer Research: Implementation and Implications., Journal of Consumer Research, 20 (3), p. 339.

Weischedel, Birgit, Sheelagh Matear and Kenneth R. Deans (2005). A Qualitative Approach to Investigating Online Strategic Decision Making. Qualitative Market Research, 8 (1), 61-76.

Weir, Tom (2001). Choosing How to Pick. Supermarket Business, 56 (6), 16.

We'll be as strong in non-food as in food (1999, September 25). The Grocer, p. 8.

William Blair and Company. (October 3, 1997a). Peapod, Inc., Basic Report. Retrieved from http://infotrac.galegroup.com.

William Blair and Company. (1997b). Peapod, Inc. (No. 3305319). Retrieved from http://infotrac.galegroup.com.

William Blair and Company. (1997c). Peapod, Inc. (No. 3323720). Retrieved from http://infotrac.galegroup.com.

Winner in the Online Sales Category; Peapod; It's the Delivery Stupid (2004, March 1). Supermarket News, p 60. Retrieved from Galenet.

Woods, Bob (1999, November 8). Peapod Stock Plunges Despite “We’ve Got Cash” Claim. Newsbytes. Retrieved from Galenet.

Woodside, Arch G. and Elizabeth J. Wilson (2003). Case Study Research Methods for Theory Building. The Journal of Business \& Industrial Marketing, 18 (6/7), 493508.

Wren, Worth, Jr. (2000, April 17). Supermarkets Teams with Web Site to Spawn Online Grocery. Knight Ridder/Tribune Business News. Retrieved from Galenet.

Wright, John (1958). A Brief Marketing History of the Jewel Tea Company. Journal of Marketing, 22 (1), 367-376.

Wrigley, Neil (2001). The Consolidation Wave in U. S. Food Retailing: A European Perspective. Agribusiness, 17 (4), p. 489-513.

Xperience... nets multi-million pound deal with Tesco.com (2004, December 7). M2 Presswire. Retrieved for Galenet. 
Yin, Robert K. (1994). Case study research: design and methods. Thousand Oaks : Sage Publications

Yrjölä, Hannu (2001). Physical Distribution Considerations for Electronic Grocery Shopping. International Journal of Physical Distribution \& Logistics Management, 31 (10), 746-761.

Yrjölä, Hannu (2003). Supply Chain Considerations for Electronic Grocery Shopping. doctoral dissertation, University of Technology (Espoo, Finland).

Zimmermann, Kim Ann (1999, October 25). Tesco To Use Retail Base To Build On-Line Success. Supermarket News, p. 23.

Zimmerman, Max Mandell (1955). The super market: A Revolution in Distribution. New York: McGraw-Hill.

Zwiebach, Elliot (2001, March 19). GroceryWorks Shareholders Seek Damages From Safeway. Supermarket News, p. 1.

Zwiebach, Elliot (2001b, April 16). Peapod's Progress; The Internet Grocer Says it will Use its Partnership with Majority Stockholder Ahold to Become Profitable Within Two Years. Supermarket News, p. 1. 


\section{APPENDICES}

\section{APPENDIX 1}

Online Grocery Store Business Models: Partnerships

Model 1: $\quad$ Picking from Local Store Shelf $\rightarrow$ Consumer Picks up Groceries from Local Store

Model 2: $\quad$ Picking from Local Store Shelf $\rightarrow$ Consumer Picks up Groceries from Local Pickup Point $\rightarrow$ Attended

Model 3a: Picking from Local Store shelf $\rightarrow$ Consumer Picks up Groceries from Local Pickup Point $\rightarrow$ Unattended $\rightarrow$ Delivery Box

Model 3b: Picking from Local Store Shelf $\rightarrow$ Consumer Picks up Groceries from Local Pickup Point $\rightarrow$ Unattended $\rightarrow$ Reception Box

Model 4: $\quad$ Picking from Local Store Shelf $\rightarrow$ Groceries Delivered by Third Party $\rightarrow$ Attended

Model 5a: Picking from Local Store Shelf $\rightarrow$ Groceries Delivered by a Third Party $\rightarrow$ Unattended $\rightarrow$ Reception Box

Model 5b: Picking from Local Store Shelf $\rightarrow$ Groceries Delivered by a Third Party $\rightarrow$ Unattended $\rightarrow$ Delivery Box

Model 6a: Picking from Local Store Shelf $\rightarrow$ Groceries are Delivered to the Customers Home by Grocer $\rightarrow$ Attended

Model 6b: Picking from Local Store Shelf $\rightarrow$ Groceries are Delivered to the Customers Home by Online Grocer $\rightarrow$ Attended

Model 7a: Picking from Local Store shelf $\rightarrow$ Groceries are Delivered to the Customers Home by Grocer $\rightarrow$ Unattended $\rightarrow$ Delivery Box

Model 7b: Picking from Local Store shelf $\rightarrow$ Groceries are Delivered to the Customers Home by Online Grocer $\rightarrow$ Unattended $\rightarrow$ Delivery Box

Model 7c: Picking from Local Store Shelf $\rightarrow$ Groceries are Delivered to the Customers Home by Grocer $\rightarrow$ Unattended $\rightarrow$ Reception Box

Model 7d: Picking from Local Store Shelf $\rightarrow$ Groceries are Delivered to the Customers Home by Online Grocer $\rightarrow$ Unattended $\rightarrow$ Reception Box 
Model 8: $\quad$ Picking from Local Fulfillment Center $\rightarrow$ Consumer Picks up Groceries from Local Store

Model 9: $\quad$ Picking from Local Fulfillment Center $\rightarrow$ Consumer Picks up Groceries from Local Pickup Point $\rightarrow$ Attended

Model 10a: Picking from Local Fulfillment Center $\rightarrow$ Consumer Picks up Groceries from Local Pickup Point $\rightarrow$ Unattended $\rightarrow$ Delivery Box

Model 10b: Picking from Local Fulfillment Center $\rightarrow$ Consumer Picks up Groceries from Local Pickup Point $\rightarrow$ Unattended $\rightarrow$ Reception Box

Model 11: Picking from Local Fulfillment Center $\rightarrow$ Groceries are Delivered by a Third Party $\rightarrow$ Attended

Model 12a: Picking from Local Fulfillment Center $\rightarrow$ Groceries are Delivered by a Third Party $\rightarrow$ Unattended $\rightarrow$ Delivery Box

Model 12b: Picking from Local Fulfillment Center $\rightarrow$ Groceries are Delivered by a Third Party $\rightarrow$ Unattended $\rightarrow$ Reception Box

Model 13a: Picking from Local Fulfillment Center $\rightarrow$ Groceries are Delivered to the Customers Home by Grocer $\rightarrow$ Attended

Model 13b: Picking from Local Fulfillment Center $\rightarrow$ Groceries are Delivered to the Customers Home by Online Grocer $\rightarrow$ Attended

Model 14a: Picking from Local Fulfillment Center $\rightarrow$ Groceries are Delivered to the Customers Home by Grocer $\rightarrow$ Unattended $\rightarrow$ Delivery Box

Model 14b: Picking from Local Fulfillment Center $\rightarrow$ Groceries are Delivered to the Customers Home by Online Grocer $\rightarrow$ Unattended $\rightarrow$ Delivery Box

Model 14c: Picking from Local Fulfillment Center $\rightarrow$ Groceries are Delivered to the Customers Home by Grocer $\rightarrow$ Unattended $\rightarrow$ Reception Box

Model 14d: Picking from Local Fulfillment Center $\rightarrow$ Groceries are Delivered to the Customers Home by Online Grocer $\rightarrow$ Unattended $\rightarrow$ Reception Box

Model 15: $\quad$ Picking from a Central/Regional Dedicated Distribution Center $\rightarrow$ Consumer Picks up Groceries from Distribution Center

Model 16: Picking from a Central/Regional Dedicated Distribution Center $\rightarrow$ Consumer Picks up Groceries from Local Pickup Point $\rightarrow$ Attended 
Model 17a: Picking from a Central/Regional Dedicated Distribution Center $\rightarrow$ Consumer Picks up Groceries from Local Pickup Point $\rightarrow$ Unattended $\rightarrow$ Delivery Box

Model 17b: Picking from a Central/Regional Dedicated Distribution Center $\rightarrow$ Consumer Picks up Groceries from Local Pickup Point $\rightarrow$ Unattended $\rightarrow$ Reception Box

Model 18: Picking from a Central/Regional Dedicated Distribution Center $\rightarrow$ Groceries are Delivered by a Third Party $\rightarrow$ Attended

Model 19a: Picking from a Central/Regional Dedicated Distribution Center $\rightarrow$ Groceries are Delivered by a Third Party $\rightarrow$ Unattended $\rightarrow$ Delivery Box

Model 19b: Picking from a Central/Regional Dedicated Distribution Center $\rightarrow$ Groceries are Delivered by a Third Party $\rightarrow$ Unattended $\rightarrow$ Reception Box

Model 20: Picking from a Central/Regional Dedicated Distribution Center $\rightarrow$ Groceries are Delivered to the Customers Home by Grocer $\rightarrow$ Attended

Model 21a: Picking from a Central/Regional Dedicated Distribution Center $\rightarrow$ Groceries are Delivered to the Customers Home by Grocer $\rightarrow$ Unattended $\rightarrow$ Delivery Box

Model 21b: Picking from a Central/Regional Dedicated Distribution Center $\rightarrow$ Groceries are Delivered to the Customers Home by Grocer $\rightarrow$ Unattended $\rightarrow$ Reception Box 
APPENDIX 2

Online Grocery Store Business Models: Pure-Play

Model 1: $\quad$ Picking from Local Store Shelf $\rightarrow$ Consumer Picks up Groceries from Local Store

Model 2: $\quad$ Picking from Local Store Shelf $\rightarrow$ Consumer Picks up Groceries from Local Pickup Point $\rightarrow$ Attended

Model 3a: Picking from Local Store shelf $\rightarrow$ Consumer Picks up Groceries from Local Pickup Point $\rightarrow$ Unattended $\rightarrow$ Delivery Box

Model 3b: Picking from Local Store Shelf $\rightarrow$ Consumer Picks up Groceries from Local Pickup Point $\rightarrow$ Unattended $\rightarrow$ Reception Box

Model 4: $\quad$ Picking from Local Store Shelf $\rightarrow$ Groceries Delivered by Third Party $\rightarrow$ Attended

Model 5a: Picking from Local Store Shelf $\rightarrow$ Groceries Delivered by a Third Party $\rightarrow$ Unattended $\rightarrow$ Reception Box

Model 5b: Picking from Local Store Shelf $\rightarrow$ Groceries Delivered by a Third Party $\rightarrow$ Unattended $\rightarrow$ Delivery Box

Model 6a: Picking from Local Store Shelf $\rightarrow$ Groceries are Delivered to the Customers Home by Grocer $\rightarrow$ Attended

Model 6b: Picking from Local Store Shelf $\rightarrow$ Groceries are Delivered to the Customers Home by Online Grocer $\rightarrow$ Attended

Model 7a: Picking from Local Store shelf $\rightarrow$ Groceries are Delivered to the Customers Home by Grocer $\rightarrow$ Unattended $\rightarrow$ Delivery Box

Model 7b: Picking from Local Store shelf $\rightarrow$ Groceries are Delivered to the Customers Home by Online Grocer $\rightarrow$ Unattended $\rightarrow$ Delivery Box

Model 7c: Picking from Local Store Shelf $\rightarrow$ Groceries are Delivered to the Customers Home by Grocer $\rightarrow$ Unattended $\rightarrow$ Reception Box

Model 7d: Picking from Local Store Shelf $\rightarrow$ Groceries are Delivered to the Customers Home by Online Grocer $\rightarrow$ Unattended $\rightarrow$ Reception Box

Model 8: $\quad$ Picking from Local Fulfillment Center $\rightarrow$ Consumer Picks up Groceries from Local Store 
Model 9: $\quad$ Picking from Local Fulfillment Center $\rightarrow$ Consumer Picks up Groceries from Local Pickup Point $\rightarrow$ Attended

Model 10a: Picking from Local Fulfillment Center $\rightarrow$ Consumer Picks up Groceries from Local Pickup Point $\rightarrow$ Unattended $\rightarrow$ Delivery Box

Model 10b: Picking from Local Fulfillment Center $\rightarrow$ Consumer Picks up Groceries from Local Pickup Point $\rightarrow$ Unattended $\rightarrow$ Reception Box

Model 11: Picking from Local Fulfillment Center $\rightarrow$ Groceries are Delivered by a Third Party $\rightarrow$ Attended

Model 12a: Picking from Local Fulfillment Center $\rightarrow$ Groceries are Delivered by a Third Party $\rightarrow$ Unattended $\rightarrow$ Delivery Box

Model 12b: Picking from Local Fulfillment Center $\rightarrow$ Groceries are Delivered by a Third Party $\rightarrow$ Unattended $\rightarrow$ Reception Box

Model 13a: Picking from Local Fulfillment Center $\rightarrow$ Groceries are Delivered to the Customers Home by Grocer $\rightarrow$ Attended

Model 13b: Picking from Local Fulfillment Center $\rightarrow$ Groceries are Delivered to the Customers Home by Online Grocer $\rightarrow$ Attended

Model 14a: Picking from Local Fulfillment Center $\rightarrow$ Groceries are Delivered to the Customers Home by Grocer $\rightarrow$ Unattended $\rightarrow$ Delivery Box

Model 14b: Picking from Local Fulfillment Center $\rightarrow$ Groceries are Delivered to the Customers Home by Online Grocer $\rightarrow$ Unattended $\rightarrow$ Delivery Box

Model 14c: Picking from Local Fulfillment Center $\rightarrow$ Groceries are Delivered to the Customers Home by Grocer $\rightarrow$ Unattended $\rightarrow$ Reception Box

Model 14d: Picking from Local Fulfillment Center $\rightarrow$ Groceries are Delivered to the Customers Home by Online Grocer $\rightarrow$ Unattended $\rightarrow$ Reception Box

Model 15: Picking from a Central/Regional Dedicated Distribution Center $\rightarrow$ Consumer Picks up Groceries from Distribution Center

Model 16: Picking from a Central/Regional Dedicated Distribution Center $\rightarrow$ Consumer Picks up Groceries from Local Pickup Point $\rightarrow$ Attended

Model 17a: Picking from a Central/Regional Dedicated Distribution Center $\rightarrow$ Consumer Picks up Groceries from Local Pickup Point $\rightarrow$ Unattended $\rightarrow$ Delivery Box 
Model 17b: Picking from a Central/Regional Dedicated Distribution Center $\rightarrow$ Consumer Picks up Groceries from Local Pickup Point $\rightarrow$ Unattended $\rightarrow$ Reception Box

Model 18: $\quad$ Picking from a Central/Regional Dedicated Distribution Center $\rightarrow$ Groceries are Delivered by a Third Party $\rightarrow$ Attended

Model 19a: Picking from a Central/Regional Dedicated Distribution Center $\rightarrow$ Groceries are Delivered by a Third Party $\rightarrow$ Unattended $\rightarrow$ Delivery Box

Model 19b: Picking from a Central/Regional Dedicated Distribution Center $\rightarrow$ Groceries are Delivered by a Third Party $\rightarrow$ Unattended $\rightarrow$ Reception Box

Model 20: Picking from a Central/Regional Dedicated Distribution Center $\rightarrow$ Groceries are Delivered to the Customers Home by Grocer $\rightarrow$ Attended

Model 21a: Picking from a Central/Regional Dedicated Distribution Center $\rightarrow$ Groceries are Delivered to the Customers Home by Grocer $\rightarrow$ Unattended $\rightarrow$ Delivery Box

Model 21b: Picking from a Central/Regional Dedicated Distribution Center $\rightarrow$ Groceries are Delivered to the Customers Home by Grocer $\rightarrow$ Unattended $\rightarrow$ Reception Box 
APPENDIX 3

Online Grocery Store Business Models: Hybrid

Model 1: $\quad$ Picking from Local Store Shelf $\rightarrow$ Consumer Picks up Groceries from Local Store

Model 2: $\quad$ Picking from Local Store Shelf $\rightarrow$ Consumer Picks up Groceries from Local Pickup Point $\rightarrow$ Attended

Model 3a: Picking from Local Store shelf $\rightarrow$ Consumer Picks up Groceries from Local Pickup Point $\rightarrow$ Unattended $\rightarrow$ Delivery Box

Model 3b: Picking from Local Store Shelf $\rightarrow$ Consumer Picks up Groceries from Local Pickup Point $\rightarrow$ Unattended $\rightarrow$ Reception Box

Model 4: $\quad$ Picking from Local Store Shelf $\rightarrow$ Groceries Delivered by Third Party $\rightarrow$ Attended

Model 5a: Picking from Local Store Shelf $\rightarrow$ Groceries Delivered by a Third Party $\rightarrow$ Unattended $\rightarrow$ Reception Box

Model 5b: Picking from Local Store Shelf $\rightarrow$ Groceries Delivered by a Third Party $\rightarrow$ Unattended $\rightarrow$ Delivery Box

Model 6a: Picking from Local Store Shelf $\rightarrow$ Groceries are Delivered to the Customers Home by Grocer $\rightarrow$ Attended

Model 6b: Picking from Local Store Shelf $\rightarrow$ Groceries are Delivered to the Customers Home by Online Grocer $\rightarrow$ Attended

Model 7a: Picking from Local Store shelf $\rightarrow$ Groceries are Delivered to the Customers Home by Grocer $\rightarrow$ Unattended $\rightarrow$ Delivery Box

Model 7b: Picking from Local Store shelf $\rightarrow$ Groceries are Delivered to the Customers Home by Online Grocer $\rightarrow$ Unattended $\rightarrow$ Delivery Box

Model 7c: Picking from Local Store Shelf $\rightarrow$ Groceries are Delivered to the Customers Home by Grocer $\rightarrow$ Unattended $\rightarrow$ Reception Box

Model 7d: Picking from Local Store Shelf $\rightarrow$ Groceries are Delivered to the Customers Home by Online Grocer $\rightarrow$ Unattended $\rightarrow$ Reception Box

Model 8: $\quad$ Picking from Local Fulfillment Center $\rightarrow$ Consumer Picks up Groceries from Local Store 
Model 9: $\quad$ Picking from Local Fulfillment Center $\rightarrow$ Consumer Picks up Groceries from Local Pickup Point $\rightarrow$ Attended

Model 10a: Picking from Local Fulfillment Center $\rightarrow$ Consumer Picks up Groceries from Local Pickup Point $\rightarrow$ Unattended $\rightarrow$ Delivery Box

Model 10b: Picking from Local Fulfillment Center $\rightarrow$ Consumer Picks up Groceries from Local Pickup Point $\rightarrow$ Unattended $\rightarrow$ Reception Box

Model 11: Picking from Local Fulfillment Center $\rightarrow$ Groceries are Delivered by a Third Party $\rightarrow$ Attended

Model 12a: Picking from Local Fulfillment Center $\rightarrow$ Groceries are Delivered by a Third Party $\rightarrow$ Unattended $\rightarrow$ Delivery Box

Model 12b: Picking from Local Fulfillment Center $\rightarrow$ Groceries are Delivered by a Third Party $\rightarrow$ Unattended $\rightarrow$ Reception Box

Model 13a: Picking from Local Fulfillment Center $\rightarrow$ Groceries are Delivered to the Customers Home by Grocer $\rightarrow$ Attended

Model 13b: Picking from Local Fulfillment Center $\rightarrow$ Groceries are Delivered to the Customers Home by Online Grocer $\rightarrow$ Attended

Model 14a: Picking from Local Fulfillment Center $\rightarrow$ Groceries are Delivered to the Customers Home by Grocer $\rightarrow$ Unattended $\rightarrow$ Delivery Box

Model 14b: Picking from Local Fulfillment Center $\rightarrow$ Groceries are Delivered to the Customers Home by Online Grocer $\rightarrow$ Unattended $\rightarrow$ Delivery Box

Model 14c: Picking from Local Fulfillment Center $\rightarrow$ Groceries are Delivered to the Customers Home by Grocer $\rightarrow$ Unattended $\rightarrow$ Reception Box

Model 14d: Picking from Local Fulfillment Center $\rightarrow$ Groceries are Delivered to the Customers Home by Online Grocer $\rightarrow$ Unattended $\rightarrow$ Reception Box

Model 15: Picking from a Central/Regional Dedicated Distribution Center $\rightarrow$ Consumer Picks up Groceries from Distribution Center

Model 16: Picking from a Central/Regional Dedicated Distribution Center $\rightarrow$ Consumer Picks up Groceries from Local Pickup Point $\rightarrow$ Attended 
Model 17a: Picking from a Central/Regional Dedicated Distribution Center $\rightarrow$ Consumer Picks up Groceries from Local Pickup Point $\rightarrow$ Unattended $\rightarrow$ Delivery Box

Model 17b: Picking from a Central/Regional Dedicated Distribution Center $\rightarrow$ Consumer Picks up Groceries from Local Pickup Point $\rightarrow$ Unattended $\rightarrow$ Reception Box

Model 18: Picking from a Central/Regional Dedicated Distribution Center $\rightarrow$ Groceries are Delivered by a Third Party $\rightarrow$ Attended

Model 19a: Picking from a Central/Regional Dedicated Distribution Center $\rightarrow$ Groceries are Delivered by a Third Party $\rightarrow$ Unattended $\rightarrow$ Delivery Box

Model 19b: Picking from a Central/Regional Dedicated Distribution Center $\rightarrow$ Groceries are Delivered by a Third Party $\rightarrow$ Unattended $\rightarrow$ Reception Box

Model 20: Picking from a Central/Regional Dedicated Distribution Center $\rightarrow$ Groceries are Delivered to the Customers Home by Grocer $\rightarrow$ Attended

Model 21a: Picking from a Central/Regional Dedicated Distribution Center $\rightarrow$ Groceries are Delivered to the Customers Home by Grocer $\rightarrow$ Unattended $\rightarrow$ Delivery Box

Model 21b: Picking from a Central/Regional Dedicated Distribution Center $\rightarrow$ Groceries are Delivered to the Customers Home by Grocer $\rightarrow$ Unattended $\rightarrow$ Reception Box 
VITA

WILLIAM DAVID LUCKY, JR.

Born, Scottsdale, Arizona

1990

B.S., Finance Jackson State University Jackson, Mississippi

1992

M.B.A

Florida International University

Miami, Florida

$1993-1994$

Graduate Student Association

Florida International University

$1995-1999$

Adjunct Professor

Division of Marketing and Business

Environment,

Florida International University

$1998-2001$

Adjunct Professor of Marketing Division of Business Administration, Florida Memorial College

$2000-2001$

Counselor, Summer Youth Training and Employment Program, Florida International University Miami, Florida

$2001-2008$

Assistant Professor of Marketing School of Business

Florida Memorial University

Miami, Florida

2008

Doctoral candidate in Business

Administration

Florida International University

Miami, Florida

Papers Presented at Professional Meetings:

2006 Presenter, William D. Lucky, Jr., M.B.A., Does Nonconscious and Conscious Affect Combine Additively or Multiplicatively?, with Barnett 
A. Greenberg, Ph.D. American Marketing Association, Winter Educators Conference, Conference Proceedings, 17, p. 234.

2000 Presenter, William D. Lucky, Jr., M.B.A., The Identification of Factors that Facilitate Academic Success of Students from African Descent in American Schools, Colleges and Other Institutions of Higher Education, with Luretha F. Lucky, Ed.D. African American Success Foundation's Success Summit, March, 2000 South Florida Education Center, Davie, Florida

1999 Presenter, William D. Lucky, Jr., M.B.A., The Attitudes of Non-Disabled Consumers of Businesses Toward Employees with Disabilities, at the YAI National Institute for People with Disabilities, $20^{\text {th }}$ Annual International Conference on MR/DD, New Horizons in Developmental Disabilities, April 26-30, 1999, New York, N.Y. 